\title{
U.S. Nuclear Power Plant \\ Operating Cost and \\ Experience Summaries
}

Manuscript Completed: October 1997

Date Published: February 1998

Prepared by

W. E. Kohn, R. L. Reid, V. S. White

Oak Ridge National Laboratory

Managed by Lockheed Martin Energy Research Corporation

Oak Ridge, TN 37831-8038

R. C. Brady, NRC Project Manager

Prepared for

Division of Reactor Program Management

Office of Nuclear Reactor Regulation

U.S. Nuclear Regulatory Commission

Washington, DC 20555-0001

NRC Job Code J2436

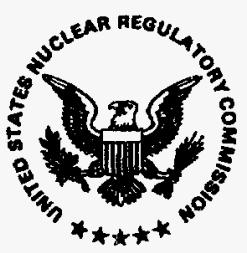




\section{DISCLAIMER}

This report was prepared as an account of work sponsored by an agency of the United States Government. Neither the United States Government nor any agency thereof, nor any of their employees, makes any warranty, express or implied, or assumes any legal liability or responsibility for the accuracy, completeness, or usefulness of any information, apparatus, product, or process disclosed, or represents that its use would not infringe privately owned rights. Reference herein to any specific commercial product, process, or service by trade name, trademark, manufacturer, or otherwise does not necessarily constitute or imply its endorsement, recommendation, or favoring by the United States Government or any agency thereof. The views and opinions of authors expressed herein do not necessarily state or reflect those of the United States Government or any agency thereof. 


\section{DISCLAIMER}

Portions of this document may be illegible electronic image products. Images are produced from the best available original document. 


\begin{abstract}
NUREG/CR-6577, U.S. Nuclear Power Plant Operating Cost and Experience Summaries, has been prepared to provide historical operating cost and experience information on U.S. commercial nuclear power plants. Costs incurred after initial construction are characterized as annual production costs, representing fuel and plant operating and maintenance expenses, and capital expenditures related to facility additions/modifications which are included in the plant capital asset base. As discussed in the report, annual data for these two cost categories were obtained from publicly available reports and must be accepted as having different degrees of accuracy and completeness. Treatment of inconclusive and incomplete data is discussed.

As an aid to understanding the fluctuations in the cost histories, operations summaries for each nuclear unit are provided. The intent of these summaries is to identify important operating events; refueling, major maintenance, and other significant outages; operating milestones; and significant licensing or enforcement actions. Information used in the summaries is condensed from annual operating reports submitted by the licensees, plant histories contained in Nuclear Power Experience, trade press articles, and the Nuclear Regulatory Commission (NRC) web site (www.nrc.gov)
\end{abstract}





\section{Contents}

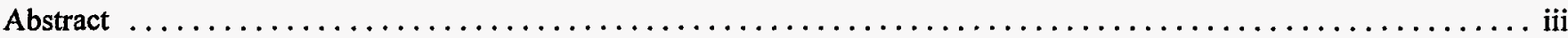

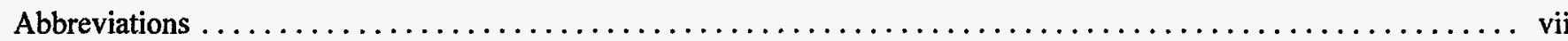

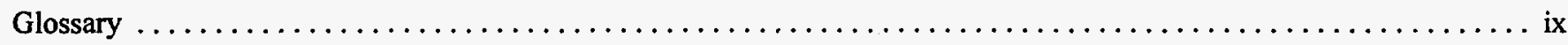

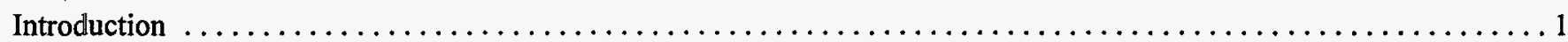

Operating Cost and Experience Summaries

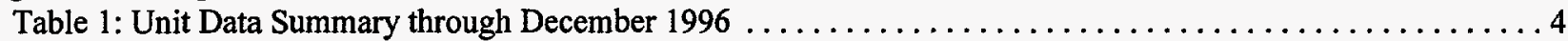

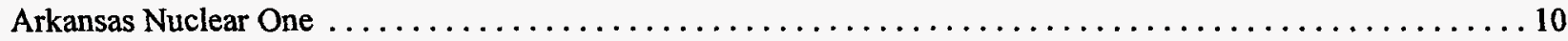

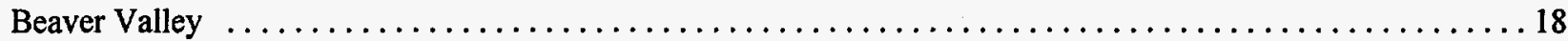

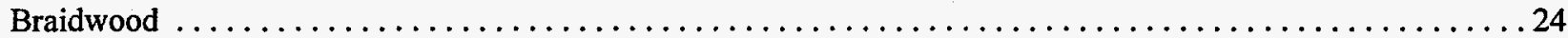

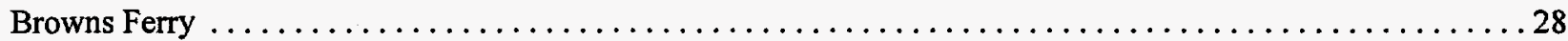

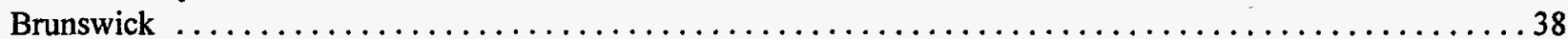

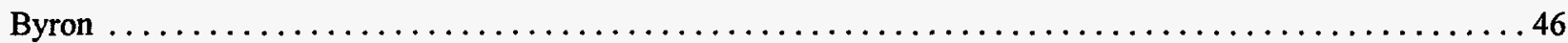

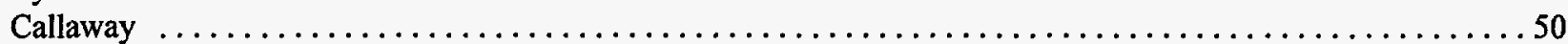

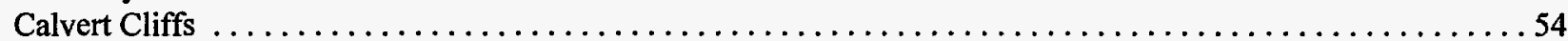

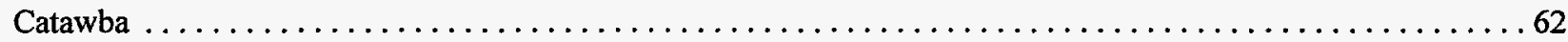

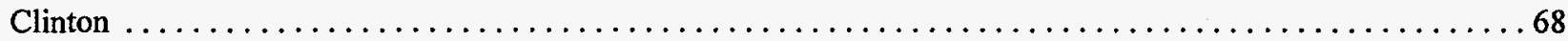

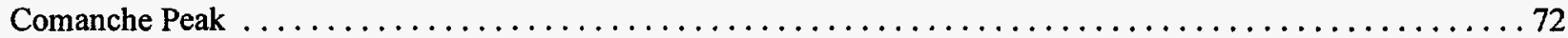

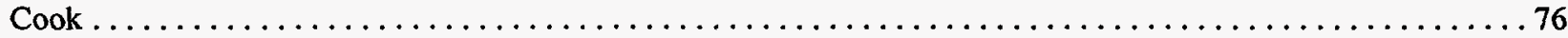

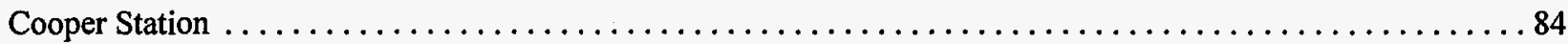

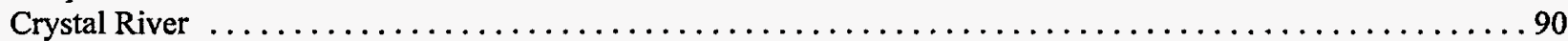

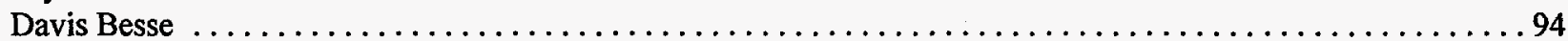

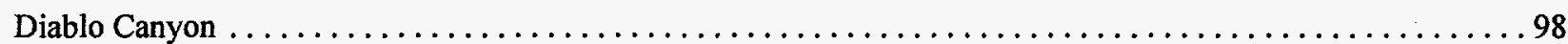

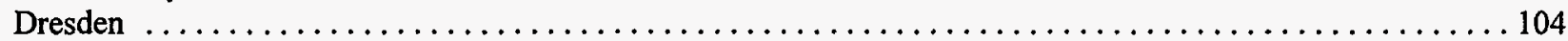

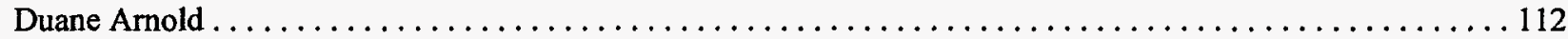

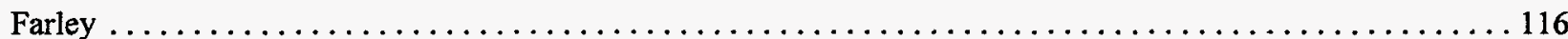

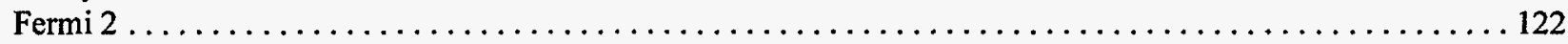

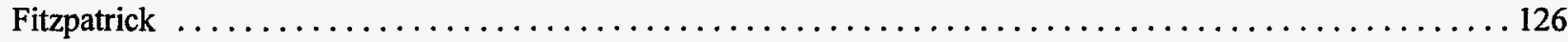

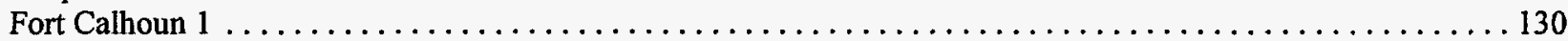

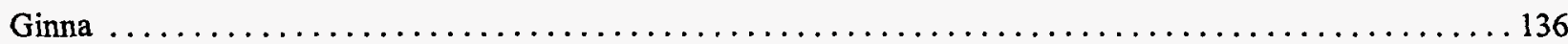

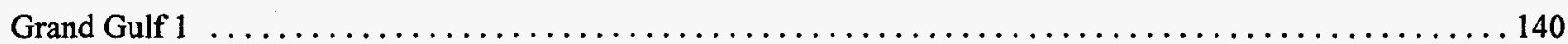

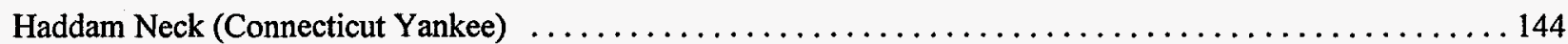

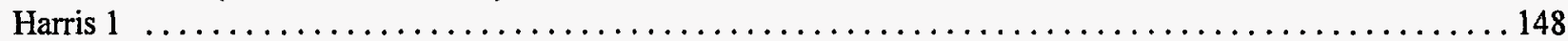

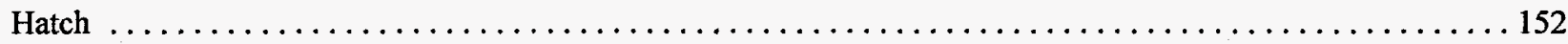

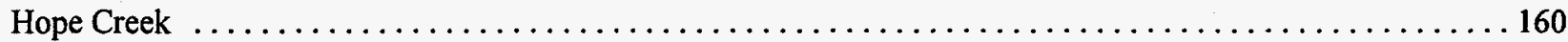

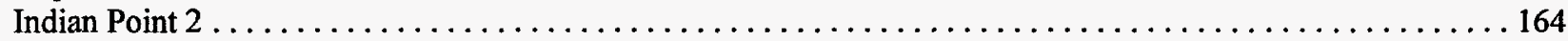

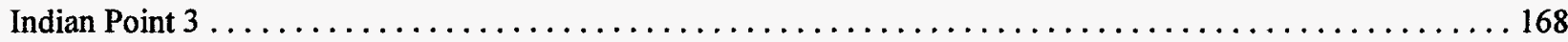

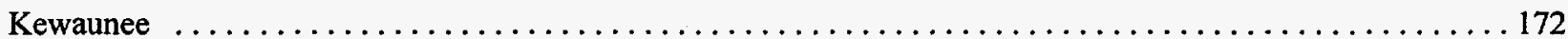

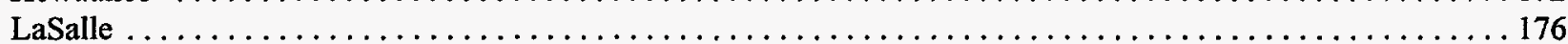

Limerick ......................................................... 182

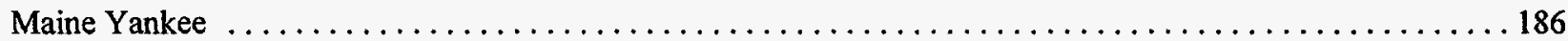

McGuire ....................................................... 190

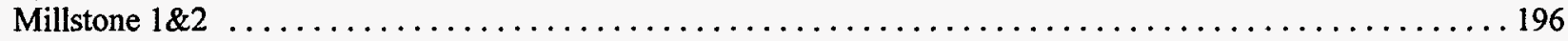

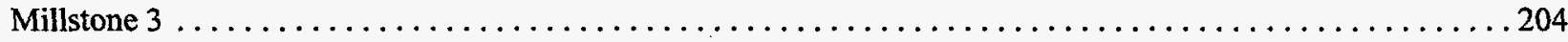

Monticello ........................................................... 208

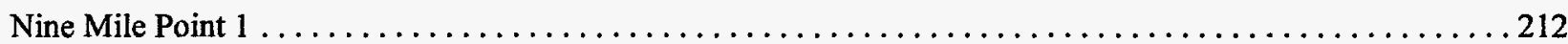

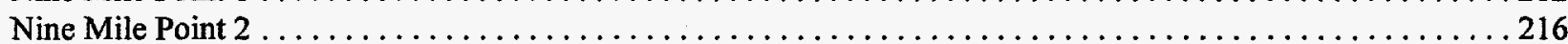

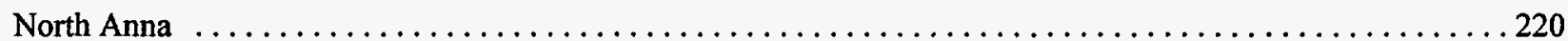




\section{Contents (Continued)}

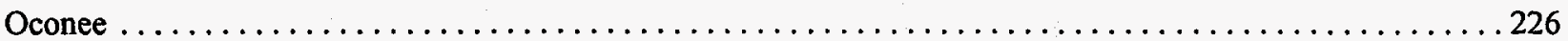

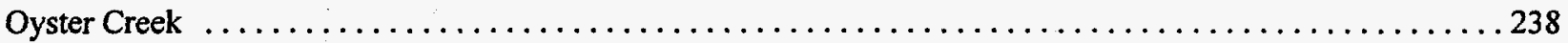

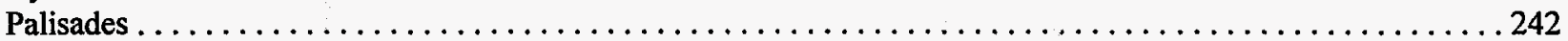

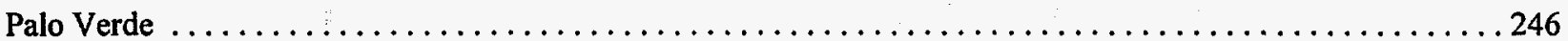

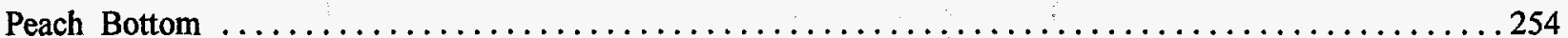

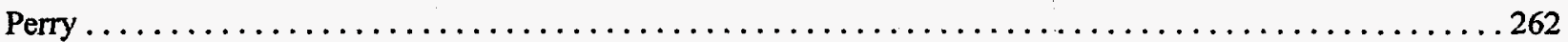

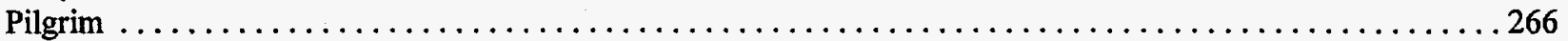

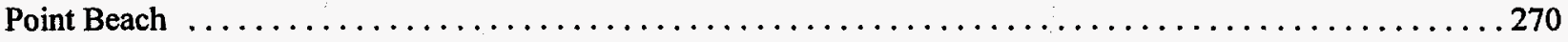

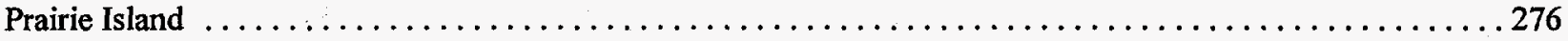

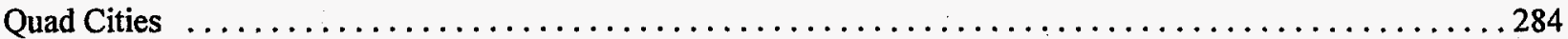

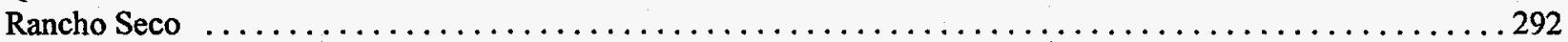

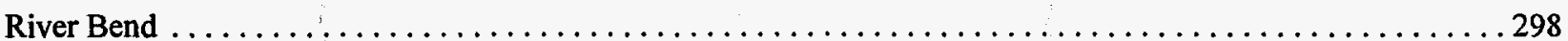

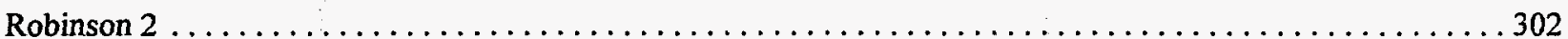

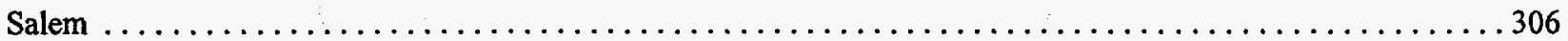

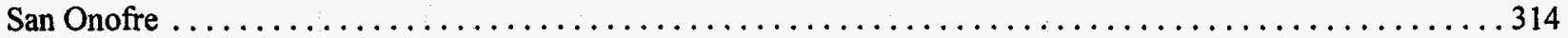

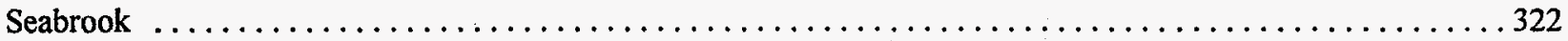

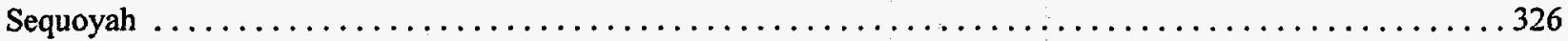

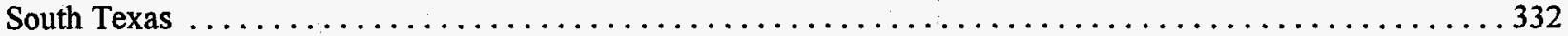

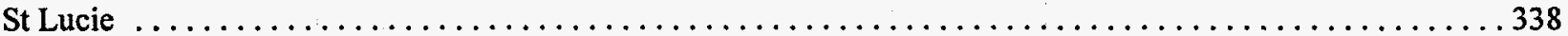

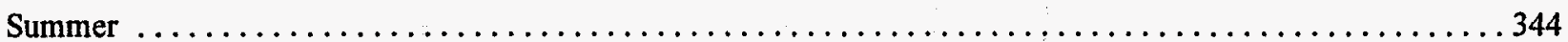

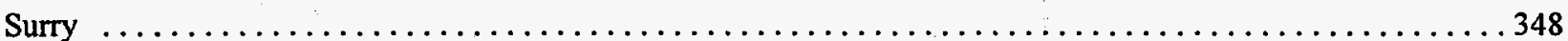

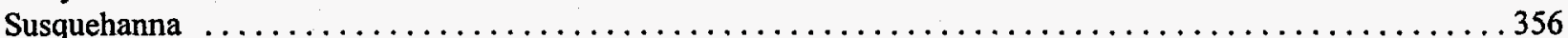

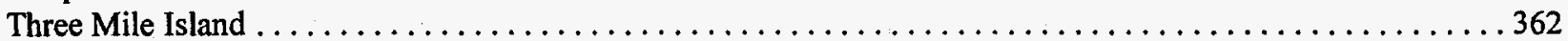

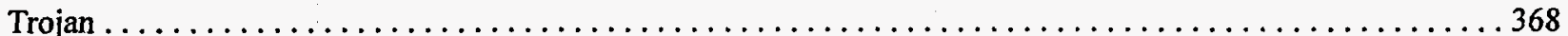

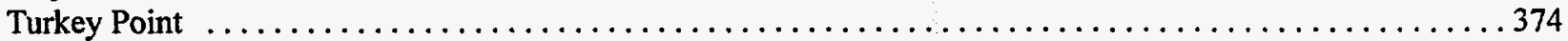

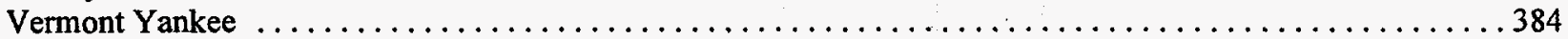

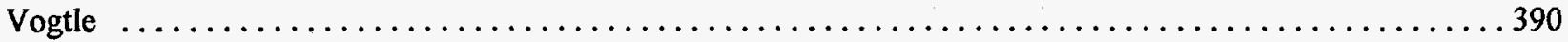

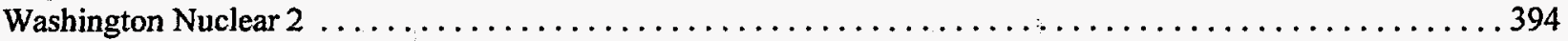

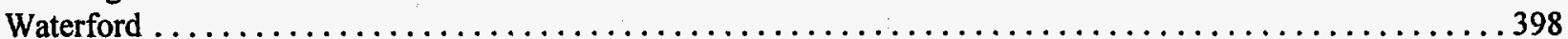

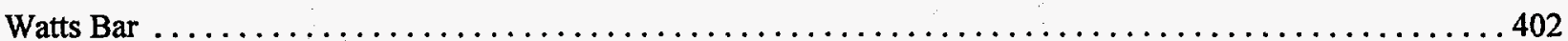

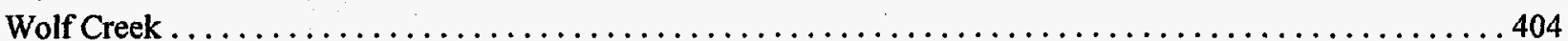

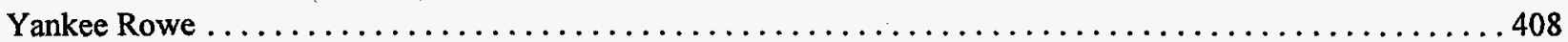

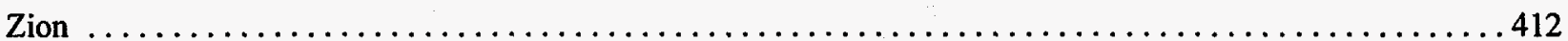




\section{Abbreviations}

$\mathrm{A} / \mathrm{E} \quad$ architect/engineer

ACRS Advisory Committee on Reactor Safeguards

ADS automatic depressurization system

ADV atmospheric discharge valve

AEC Atomic Energy Commission

AFW auxiliary feedwater

AIT Augmented Inspection Team

APRM average power range monitor

ASLAB Atomic Safety and Licensing Appeals Board

ASLB Atomic Safety and Licensing Board

ASME American Society of Mechanical Engineers

ATWS anticipated transient without scram

B\&W Babcock and Wilcox Company

BAST boric acid storage tank

BIT boron injection tank

BOP balance of plant

BPA Bonneville Power Administration

BWR boiling-water reactor

$\mathrm{CE}$ Combustion Engineering

CEA control element assembly

CEDM control element drive mechanism

CFCU containment fan cooling units

CP construction permit

CRD control rod drive

CRDM control rod drive mechanism

CS

CST

CVCS chemical and volume control system

$\mathrm{CW}$

DC

DEH

DET

DG

DOE

ECCS

ECT

EDG

EFW

EHC

EIA

EMI

EPA

EQ

ESF

ESW

FA

FCV

FEMA Federal Emergency Management Agency

FERC Federal Energy Regulatory Commission

FP fire protection

FSAR Final Safety Analysis Report
FW feedwater

FWCI feedwater core injection

GE General Electric Company

GPU General Public Utilities

HAZ heat affected zone

HCU hydraulic control unit

HEPA high efficiency particulate air

HFA relay model from GE

HP high pressure

HHSI high head safety injection

HPCI high pressure coolant injection

HPCS high pressure core spray

HPSI high pressure safety injection

HVAC heating, ventilation and air conditioning

HX heat exchanger

I\&C instrumentation and control

IAEA International Atomic Energy Agency

ICS integrated control system

IE(B) Inspection \& Enforcement (Branch)

IGSC intergranular stress corrosion

ILRT Integrated Leak Rate Test

INEEL Idaho National Engineering and Environmental Laboratory

INPO Institute for Nuclear Power Operations

IRM intermediate range monitor

ISFSI independent spent fuel storage installation

ISI Inservice Inspection

IST Inservice Test

LCO limiting condition for operation

LER licensee event report

LLRT local leak rate test

LOSP loss of off-site power

LP low pressure

LPCI low pressure coolant injection

LPRM local power range monitor

LPSI low pressure safety injection

LPSW low pressure service water

LWR light water reactor

MCC motor control center

MDC maximum dependable capacity

MFW main feedwater

MG motor-generator

MOV motor-operated valve

MS main steam

MSIV main steam isolation valve

MSL main steam line

MSR moisture separator reheater

MSRV main steam relief valve

MSSV main steam safety valve

MVA megavolt amperes

MWe megawatts electrical 


\section{Abbreviations (Continued)}

MWh

MWt

NNI

NPSH

NRC

NSSS

OL

ORNL

OSART

PASS

PM

PORV

psia

psig

PUC

PWR

QA

QC

RCCA

$\mathrm{RCIC}$

RCP

RCS

RG

RHR

RM

RPI

RPS

RPV

RTB

RTD

RV

RWCU

RWST

SAE

SALP

SAT

SBGT

SBLC

SCC

SDV

SEP

SFP

SG

SGTS

SI

SIAS

SJAE

SPDS

SRM

SRV megawatt-hours

megawatts thermal

non-nuclear instrumentation

net positive suction head

Nuclear Regulatory Commission

nuclear steam supply system

Operating License

Oak Ridge National Laboratory

Operational Safety and Review Team

post-accident sampling system

preventive maintenance

power operated relief valve

pounds per square inch absolute

pounds per square inch gauge

Public Utility Commission

pressurized water reactor

quality assurance

quality control

rod control cluster assembly

reactor core isolation cooling

reactor coolant pump

reactor coolant system

Regulatory Guide

residual heat removal

radiation monitor

rod position indicator

reactor protection system

reactor pressure vessel

reactor trip breaker

resistance temperature device

reactor vessel

reactor water clean up (system)

reactor water storage tank

site area emergency

Systematic Assessment of Licensee

Performance

station auxiliary transformer

standby gas treatment

standby liquid control

stress corrosion cracking

scram discharge volume

Systematic Evaluation Program

spent fuel pool

steam generator

standby gas treatment system

safety injection

safety injection actuation system

steam jet air ejector

safety parameter display system

source range monitor

safety relief valve
SSPS solid state protection system

SW service water

SWS service water system

TIP traversing in-core probe

TMI Three Mile Island

TMI-2 Three Mile Island Unit 2

TS Technical Specification

TSV turbine stop valve

TVA Tennessee Valley Authority

UE unusual event

UHI upper head injection

UPS uninterruptible power supply

USQ unreviewed safety question

UV under-voltage

W Westinghouse 


\section{Glossary}

Nameplate Rating

MDC

MDC Net MWe

Unit Available Hours

Cumulative Unit

Availability Factor

Net Electrical Energy Generated

Cumulative Capacity Factor

(MDC Net)

Cumulative Forced Outage Hours

Cumulative

Forced Outage Rate

Appendix R

(to 10CFR50)
The nameplate power designation (Gross MWe) of the generator in MVA times the nameplate rating power factor of the generator. The nameplate rating of the generator may not be indicative of the maximum or dependable capacity, since other items of equipment with a lesser rating (e.g., turbine capacity) may limit unit output.

Maximum Dependable Capacity

MDC Gross output less the normal station service loads

The total clock hours in the report period during which the unit operated on-line or was capable of such operation.

\section{Unit Available Hours x 100}

Lifetime Period Hours

Gross electrical output of the unit measured at the output terminals of the turbine generator during the report period minus the normal station service electrical energy utilization.

\section{Net Electrical Energy Generated x 100}

Lifetime Hours x MDC Net

The total clock hours since the date of the start of the power ascension test phase of the unit that the unit was unavailable due to forced outages. A forced outage is one required to be initiated no later than the weekend following discovery of an offnormal condition. The forced outage rate is calculated from the date of commercial operation.

$\frac{\text { Cumulative Forced Outage Hours x } 100}{\text { Cum. Unit Service Hours + Forced Outage Hours }}$

Fire Protection Program for Nuclear Power Facilities Operating Prior to January 1, 1979 


\section{Introduction}

This report is the result of a review performed by the Oak Ridge National Laboratory (ORNL) of historical operating cost and experience information on U.S. commercial nuclear power plants. The work was sponsored by the U.S. Nuclear Regulatory Commission's (NRC) Office of Nuclear Reactor Regulation's Generic Issues and Environmental Projects Branch and provides an update to the operating cost and experience information prepared for and submitted to the NRC in March 1995.

This report summarizes costs and operating experience for all operational U.S. nuclear plants with the exception of Big Rock Point, a $67 \mathrm{MWe}$ boiling water reactor (BWR), which is omitted due to insufficient operating experience documentation. Also included are data for six nuclear units which have ceased operations. United States nuclear plants detailed in this report are shown in Table 1 which contains unit summary information through December 1996. In the cost and experience section of this report, graphs of historical annual production costs (i.e., operations, maintenance, and fuel costs) and capital additions costs are presented followed by a unit-by-unit operating experience summary. In the majority of cases, cost data are only available on a total plant (rather than unit) basis. Only in a few cases, where each unit has a substantially different ownership arrangement, are cost data available on a unit-by-unit basis. Where possible, unit-by-unit cost histories have been provided. The production and capital addition costs represent the annual total dollar amounts expended for the named site whether it is a single or multiple plant representation. In addition, the costs incurred by all owners are included for each subject site.

The sources of cost data for the plots are the Federal Energy Regulatory Commission (FERC) Form 1 for private utility companies and the Energy Information Administration (EIA) Form 412 for public utilities. Data are supplied by the utilities annually on these forms and were obtained in computerized databases from the Utility Data Institute. It should be noted that capital additions costs reported in the utility filings are based on the current total capitalized value for the plant. The change in the capital value reported from one year to the next is the only source of publicly available data that can be analyzed to determine capital additions. There are, however, limits to the accuracy of this approach. Reports of total capital value include all adjustments to the capital base, including any decommissioning or capital write-offs, and as such, the annual capital additions represent net values of both additions and reductions in the capital asset base. As a result, the change in capital value for some years is a negative value. For the purposes of this report, years with negative capital change are shown as zero capital additions cost. Owing also to this net reporting, capital additions are not possible to discern in a year in which a new unit is placed into service at a multiunit site that is reported on a total plant basis. Finally, some utilities have sold part of their capital asset base to others in a sale/lease arrangement. In some cases, the reduced capital asset value that is reported precludes determining a true capital additions cost. In each of these scenarios, the capital additions cost has been shown on the charts as a zero value.

The nuclear power plant operating experience summaries contained in this document were prepared from several sources. The unit data summary was extracted from the monthly operating reports compiled by the Idaho National Engineering and Environmental Laboratory (INEEL) and is current through December 1996. The operating histories are compiled from a number of sources: Nuclear Power Experience, the monthly operating reports submitted to the NRC by the licensees, trade press articles, and the NRC web site (www.nrc.gov). The intent of these summaries is to identify important operating events; refueling, major maintenance, and other significant outages; operating milestones; and significant licensing or enforcement actions. A significant outage is defined as an outage that represents approximately one percent annual availability factor lost. As can be noted on the summaries for different units, the end point of the time period covered in the operating histories varies depending upon the availability of information. In addition, it should be recognized that these histories may be incomplete due to the lack of readily available historical operating experience information.

Comments on the operating cost and experience information in this report should be submitted to Mr. Robert Wood, Office of Nuclear Reactor Regulation, U.S. NRC, Washington, D.C. 20555. 



\section{U.S. NUCLEAR POWER PLANT \\ COST AND EXPERIENCE SUMMARIES}


TABLE 1: UNIT DATA SUMMARY THROUGH DECEMBER 1996

\begin{tabular}{|c|c|c|c|c|c|c|c|c|c|c|}
\hline $\begin{array}{l}\text { Docket } \\
\text { No. }\end{array}$ & Plant Name & $\begin{array}{l}\text { Nameplate } \\
\text { Rating } \\
\text { (MWe) }\end{array}$ & $\begin{array}{l}\text { MDC } \\
\text { Net }\end{array}$ & $\begin{array}{c}\text { Cumulative } \\
\text { Availability } \\
\text { Factor }\end{array}$ & $\begin{array}{l}\text { Cumulative } \\
\text { Capacity } \\
\text { Factor } \\
\text { (MDC Net) }\end{array}$ & $\begin{array}{c}\text { Cumulative } \\
\text { Forced } \\
\text { Outage Rate }\end{array}$ & $\begin{array}{l}\text { Construction } \\
\text { Permit Date }\end{array}$ & $\begin{array}{l}\text { Operating } \\
\text { License Date }\end{array}$ & $\begin{array}{c}\text { Commercial } \\
\text { Operation } \\
\text { Date }\end{array}$ & $\begin{array}{c}\text { License } \\
\text { Expiration } \\
\text { Date }\end{array}$ \\
\hline 313 & ARKANSAS NUCLEAR ONE 1 & 903 & 836 & 74.0 & 65.5 & 9.9 & $12 / 06 / 68$ & $05 / 21 / 74$ & $12 / 19 / 74$ & 2014 \\
\hline 368 & ARKANSAS NUCLEAR ONE 2 & 943 & 858 & 77.1 & 75.3 & 10.1 & $12 / 06 / 72$ & $09 / 01 / 78$ & $03 / 26 / 80$ & 2018 \\
\hline 334 & BEAVER VALLEY 1 & 923 & 810 & 67.2 & 61.5 & 15.0 & $06 / 26 / 70$ & $07 / 02 / 76$ & $10 / 01 / 76$ & 2016 \\
\hline 412 & BEAVER VALLEY 2 & 923 & 820 & 84.1 & 78.2 & 4.3 & $05 / 03 / 74$ & $08 / 14 / 87$ & $11 / 17 / 87$ & 2027 \\
\hline 155 & BIG ROCK POINT & 75 & 67 & 71.8 & 62.4 & 7.8 & $05 / 31 / 60$ & $08 / 30 / 62$ & $03 / 29 / 63$ & 2000 \\
\hline 456 & BRAIDWOOD 1 & 1175 & 1120 & 77.5 & 71.0 & 7.6 & $12 / 31 / 75$ & $07 / 02 / 87$ & $07 / 29 / 88$ & 2026 \\
\hline 457 & BRAIDWOOD 2 & 1175 & 1120 & 83.9 & 76.5 & 4.7 & $12 / 31 / 75$ & $05 / 20 / 88$ & $10 / 17 / 88$ & 2027 \\
\hline 259 & BROWNS FERRY $1^{\prime}$ & 1152 & 1065 & 60.9 & 52.8 & 25.6 & $05 / 10 / 67$ & $12 / 20 / 73$ & $08 / 01 / 74$ & 2013 \\
\hline 260 & BROWNS FERRY 2 & 1152 & 1065 & 69.0 & 61.8 & 15.2 & $05 / 10 / 67$ & $08 / 02 / 74$ & $03 / 01 / 75$ & 2014 \\
\hline 296 & BROWNS FERRY 3 & 1152 & 1065 & 64.5 & 58.6 & 18.8 & $07 / 31 / 68$ & $08 / 18 / 76$ & $03 / 01 / 77$ & 2016 \\
\hline 325 & BRUNSWICK 1 & 867 & 767 & 61.6 & 55.3 & 13.4 & $02 / 07 / 70$ & $11 / 12 / 76$ & $03 / 18 / 77$ & 2016 \\
\hline 324 & BRUNSWICK 2 & 867 & 754 & 62.1 & 53.4 & 10.7 & $02 / 07 / 70$ & $12 / 27 / 74$ & $11 / 03 / 75$ & 2014 \\
\hline 454 & BYRON 1 & 1175 & 1105 & 81.9 & 73.0 & 2.2 & $12 / 31 / 75$ & $02 / 14 / 85$ & $09 / 16 / 85$ & 2024 \\
\hline 455 & BYRON 2 & 1175 & 1105 & 86.3 & 76.4 & 2.5 & $12 / 31 / 75$ & $01 / 30 / 87$ & $08 / 21 / 87$ & 2026 \\
\hline 483 & CALLAWAY & 1236 & 1125 & 86.8 & 84.9 & 2.3 & $04 / 16 / 76$ & $10 / 18 / 84$ & $12 / 19 / 84$ & 2024 \\
\hline 317 & CALVERT CLIFFS 1 & 918 & 835 & 70.9 & 69.1 & 8.7 & 07/07/69 & $07 / 31 / 74$ & $05 / 08 / 75$ & 2014 \\
\hline 318 & CALVERT CLIFFS 2 & 918 & 840 & 74.0 & 71.6 & 5.5 & $07 / 07 / 69$ & $11 / 30 / 76$ & $04 / 01 / 77$ & 2016 \\
\hline 413 & CATAWBA 1 & 1305 & 1129 & 76.2 & 73.0 & 7.9 & $08 / 07 / 75$ & $01 / 17 / 85$ & $06 / 29 / 85$ & 2024 \\
\hline 414 & CATAWBA 2 & 1305 & 1129 & 78.4 & 75.0 & 8.8 & $08 / 07 / 75$ & $05 / 15 / 86$ & $08 / 19 / 86$ & 2026 \\
\hline 461 & CLINTON & 985 & 930 & 71.9 & 65.6 & 9.1 & $02 / 24 / 76$ & $04 / 17 / 87$ & $11 / 24 / 87$ & 2026 \\
\hline
\end{tabular}


TABLE 1: UNIT DATA SUMMARY THROUGH DECEMBER 1996

\begin{tabular}{|c|c|c|c|c|c|c|c|c|c|c|}
\hline $\begin{array}{c}\text { Docket } \\
\text { No. }\end{array}$ & Plant Name & $\begin{array}{c}\text { Nameplate } \\
\text { Rating } \\
\text { (MWe) }\end{array}$ & $\begin{array}{c}\text { MDC } \\
\text { Net }\end{array}$ & $\begin{array}{c}\text { Cumulative } \\
\text { Availability } \\
\text { Factor }\end{array}$ & \begin{tabular}{|c|} 
Cumulative \\
Capacity \\
Factor \\
(MDC Net) \\
\end{tabular} & $\begin{array}{l}\text { Cumulative } \\
\text { Forced } \\
\text { Outage Rate }\end{array}$ & $\begin{array}{l}\text { Construction } \\
\text { Permit Date }\end{array}$ & $\begin{array}{c}\text { Operating } \\
\text { License Date }\end{array}$ & $\begin{array}{l}\text { Commercial } \\
\text { Operation } \\
\text { Date }\end{array}$ & $\begin{array}{c}\text { License } \\
\text { Expiration } \\
\text { Date }\end{array}$ \\
\hline 445 & COMANCHE PEAK 1 & 1161 & 1150 & 81.2 & 72.9 & 4.8 & $12 / 19 / 74$ & $04 / 17 / 90$ & $08 / 13 / 90$ & 2030 \\
\hline 446 & COMANCHE PEAK 2 & 1161 & 1150 & 81.0 & 73.3 & 7.5 & $12 / 19 / 74$ & $04 / 06 / 93$ & $08 / 03 / 93$ & 2033 \\
\hline 315 & COOK 1 & 1152 & 1000 & 74.9 & 68.8 & 5.9 & $03 / 25 / 69$ & $10 / 25 / 74$ & $08 / 28 / 75$ & 2014 \\
\hline 316 & COOK 2 & 1133 & 1060 & 67.5 & 62.2 & 14.2 & $03 / 25 / 69$ & $12 / 23 / 77$ & $07 / 01 / 78$ & 2017 \\
\hline 298 & COOPER STATION & 836 & 764 & 73.7 & 63.4 & 8.0 & $06 / 04 / 68$ & $01 / 18 / 74$ & $07 / 01 / 74$ & 2014 \\
\hline 302 & CRYSTAL RIVER 3 & 890 & 818 & 66.4 & 62.3 & 17.0 & $09 / 25 / 68$ & $01 / 28 / 77$ & $03 / 13 / 77$ & 2016 \\
\hline 346 & DAVIS-BESSE & 925 & 873 & 65.4 & 58.9 & 17.2 & $03 / 24 / 71$ & $04 / 22 / 77$ & $07 / 31 / 78$ & 2017 \\
\hline 275 & DIABLO CANYON 1 & 1137 & 1073 & 84.0 & 79.7 & 3.4 & $04 / 23 / 68$ & $11 / 02 / 84$ & $05 / 07 / 85$ & 2021 \\
\hline 323 & DIABLO CANYON 2 & 1164 & 1087 & 85.2 & 81.7 & 3.9 & $12 / 09 / 70$ & $08 / 26 / 85$ & $03 / 13 / 86$ & 2025 \\
\hline 237 & DRESDEN 2 & 840 & 772 & 68.8 & 55.7 & 14.2 & $01 / 10 / 66$ & $12 / 22 / 69$ & $06 / 09 / 70$ & 2006 \\
\hline 249 & DRESDEN 3 & 840 & 773 & 67.2 & 55.2 & 14.9 & $10 / 14 / 66$ & $03 / 02 / 71$ & $11 / 16 / 71$ & 2011 \\
\hline 331 & DUANE ARNOLD & 566 & 520 & 74.4 & 69.6 & 10.3 & $06 / 22 / 70$ & $02 / 22 / 74$ & $02 / 01 / 75$ & 2014 \\
\hline 348 & FARLEY 1 & 860 & 812 & 79.7 & 77.2 & 5.6 & $08 / 16 / 72$ & $06 / 25 / 77$ & $12 / 01 / 77$ & 2017 \\
\hline 364 & FARLEY 2 & 860 & 822 & 84.6 & 81.7 & 3.7 & $08 / 16 / 72$ & $03 / 31 / 81$ & $07 / 30 / 81$ & 2021 \\
\hline 341 & FERMI 2 & 1179 & 1085 & 65.7 & 59.7 & 21.5 & $09 / 26 / 72$ & $07 / 15 / 85$ & $01 / 23 / 88$ & 2025 \\
\hline 333 & FITZPATRICK & 883 & 762 & 68.5 & 65.0 & 11.7 & $05 / 20 / 70$ & $10 / 17 / 74$ & $07 / 28 / 75$ & 2014 \\
\hline 285 & FORT CALHOUN 1 & 502 & 478 & 77.9 & 70.9 & 4.0 & $06 / 07 / 68$ & $08 / 09 / 73$ & $09 / 26 / 73$ & 2013 \\
\hline 244 & GINNA & 517 & 470 & 78.7 & 75.9 & 5.7 & $04 / 25 / 66$ & $09 / 19 / 69$ & $07 / 01 / 70$ & 2009 \\
\hline 416 & GRAND GULF 1 & 1373 & 1179 & 81.1 & 72.5 & 6.3 & $09 / 04 / 74$ & $11 / 01 / 84$ & 07/01/85 & 2022 \\
\hline 213 & HADDAM NECK 1 '? & 600 & 360 & 76.3. & 73.4 & 68 & $05 \% 26 \% 64$. & 0630767 & $01101 \% 68$ & 2007 \\
\hline
\end{tabular}


TABLE 1: UNIT DATA SUMMARY THROUGH DECEMBER 1996

\begin{tabular}{|c|c|c|c|c|c|c|c|c|c|c|}
\hline $\begin{array}{l}\text { Docket } \\
\text { No. }\end{array}$ & Plant Name & $\begin{array}{c}\text { Nameplate } \\
\text { Rating } \\
\text { (MWe) }\end{array}$ & $\begin{array}{c}\text { MDC } \\
\text { Net }\end{array}$ & $\begin{array}{c}\text { Cumulative } \\
\text { Availability } \\
\text { Factor }\end{array}$ & $\begin{array}{l}\text { Cumulative } \\
\text { Capacity } \\
\text { Factor } \\
\text { (MDC Net) }\end{array}$ & $\begin{array}{c}\text { Cumulative } \\
\text { Forced } \\
\text { Outage Rate }\end{array}$ & $\begin{array}{l}\text { Construction } \\
\text { Permit Date }\end{array}$ & $\begin{array}{l}\text { Operating } \\
\text { License Date }\end{array}$ & $\begin{array}{l}\text { Commercial } \\
\text { Operation } \\
\text { Date }\end{array}$ & $\begin{array}{c}\text { License } \\
\text { Expiration } \\
\text { Date }\end{array}$ \\
\hline 400 & HARRIS 1 & 951 & 860 & 83.2 & 80.4 & 3.3 & $01 / 27 / 78$ & $01 / 12 / 87$ & $05 / 02 / 87$ & 2026 \\
\hline 321 & HATCH 1 & 850 & 805 & 74.4 & 69.0 & 10.2 & $09 / 30 / 69$ & $10 / 13 / 74$ & $12 / 31 / 75$ & 2014 \\
\hline 366 & HATCH 2 & 850 & 809 & 76.0 & 65.8 & 6.5 & $12 / 27 / 72$ & $06 / 13 / 78$ & $09 / 05 / 79$ & 2018 \\
\hline 354 & HOPE CREEK & 1170 & 1031 & 82.5 & 81.0 & 4.8 & $11 / 04 / 74$ & $07 / 25 / 86$ & $12 / 20 / 86$ & 2026 \\
\hline 247 & INDIAN POINT 2 & 1013 & 951 & 70.5 & 65.9 & 6.1 & $10 / 14 / 66$ & $09 / 28 / 73$ & $08 / 01 / 74$ & 2013 \\
\hline 286 & INDIAN POINT 3 & 1013 & 965 & 54.7 & 49.7 & 29.5 & $08 / 13 / 69$ & $04 / 05 / 76$ & $08 / 30 / 76$ & 2015 \\
\hline 305 & KEWAUNEE & 560 & 511 & 84.4 & 82.6 & 2.0 & $08 / 06 / 68$ & $12 / 21 / 73$ & $06 / 16 / 74$ & 2013 \\
\hline 373 & LASALLE 1 & 1146 & 1036 & 67.4 & 62.4 & 9.2 & $09 / 10 / 73$ & $08 / 13 / 82$ & $01 / 01 / 84$ & 2022 \\
\hline 374 & LASALLE 2 & 1146 & 1036 & 71.0 & 66.8 & 10.0 & $09 / 10 / 73$ & $03 / 23 / 84$ & $10 / 19 / 84$ & 2023 \\
\hline 352 & LIMERICK 1 & 1160 & 1105 & 82.3 & 75.9 & 4.2 & $06 / 19 / 74$ & $08 / 08 / 85$ & $02 / 01 / 86$ & 2024 \\
\hline 353 & LIMERICK 2 & 1162 & 1115 & 89.8 & 85.8 & 3.6 & $06 / 19 / 74$ & $08 / 25 / 89$ & $01 / 08 / 90$ & 2029 \\
\hline 309 & MANE YANKEE & 920 & 860 & 75.1 & 69.7 & 8.5 & $10 / 21 / 68$ & $10 / 20 / 72$ & $12 / 28 / 72$ & 2008 \\
\hline 369 & MCGUIRE 1 & 1305 & 1129 & 72.2 & 65.2 & 12.7 & $02 / 23 / 73$ & $07 / 08 / 81$ & $12 / 01 / 81$ & 2021 \\
\hline 370 & MCGUIRE 2 & 1305 & 1129 & 77.6 & 74.8 & 7.2 & $02 / 23 / 73$ & $05 / 27 / 83$ & $03 / 01 / 84$ & 2023 \\
\hline 245 & MILLSTONE 1 & 662 & 641 & 72.9 & 67.8 & 15.7 & $05 / 19 / 66$ & $10 / 26 / 70$ & $03 / 01 / 71$ & 2010 \\
\hline 336 & MILLSTONE 2 & 909 & 873 & 63.5 & 60.0 & 19.3 & $12 / 11 / 70$ & $09 / 30 / 75$ & $12 / 26 / 75$ & 2015 \\
\hline 423 & MILLSTONE 3 & 1253 & 1137 & 70.3 & 66.8 & 20.5 & $08 / 09 / 74$ & $01 / 31 / 86$ & $04 / 23 / 86$ & 2025 \\
\hline 263 & MONTICELLO & 577 & 544 & 80.6 & 75.6 & 3.4 & $06 / 19 / 67$ & $09 / 08 / 70$ & $06 / 30 / 71$ & 2010 \\
\hline 220 & NINE MILE POINT 1 & 642 & 565 & 66.2 & 60.1 & 22.4 & $04 / 12 / 65$ & $12 / 26 / 74$ & $12 / 01 / 69$ & 2009 \\
\hline 410 & NINE MILE POINT 2 & 1214 & 1105 & 70.6 & 67.2 & 13.1 & $06 / 24 / 74$ & $07 / 02 / 87$ & $03 / 11 / 88$ & 2026 \\
\hline
\end{tabular}




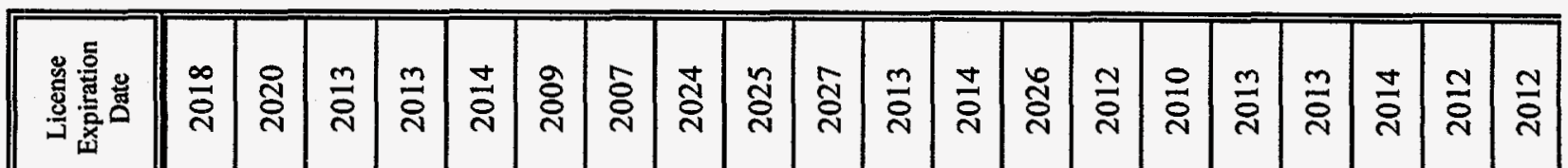

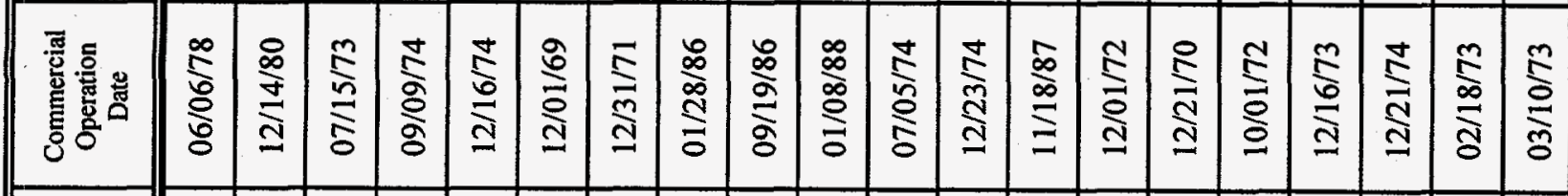

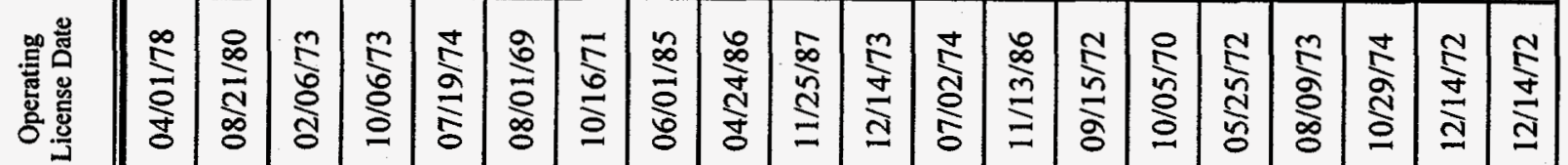

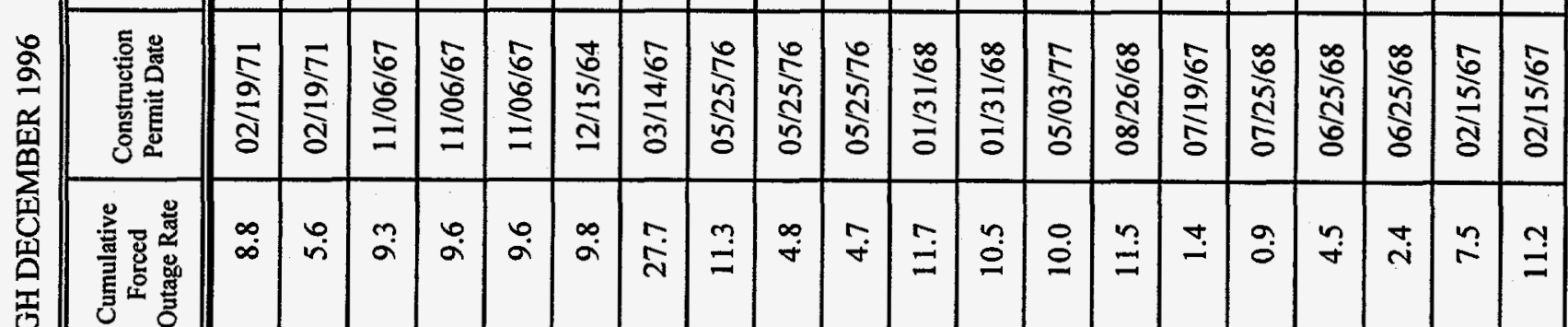

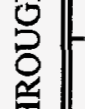
F

䓪

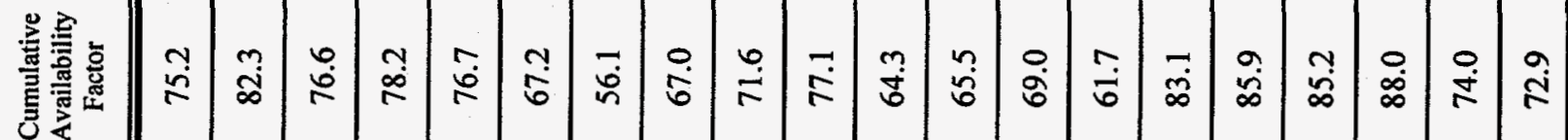
菅

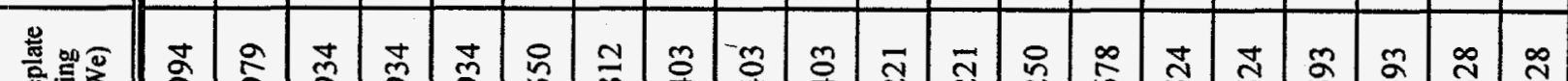

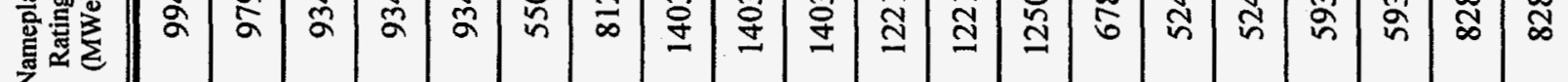

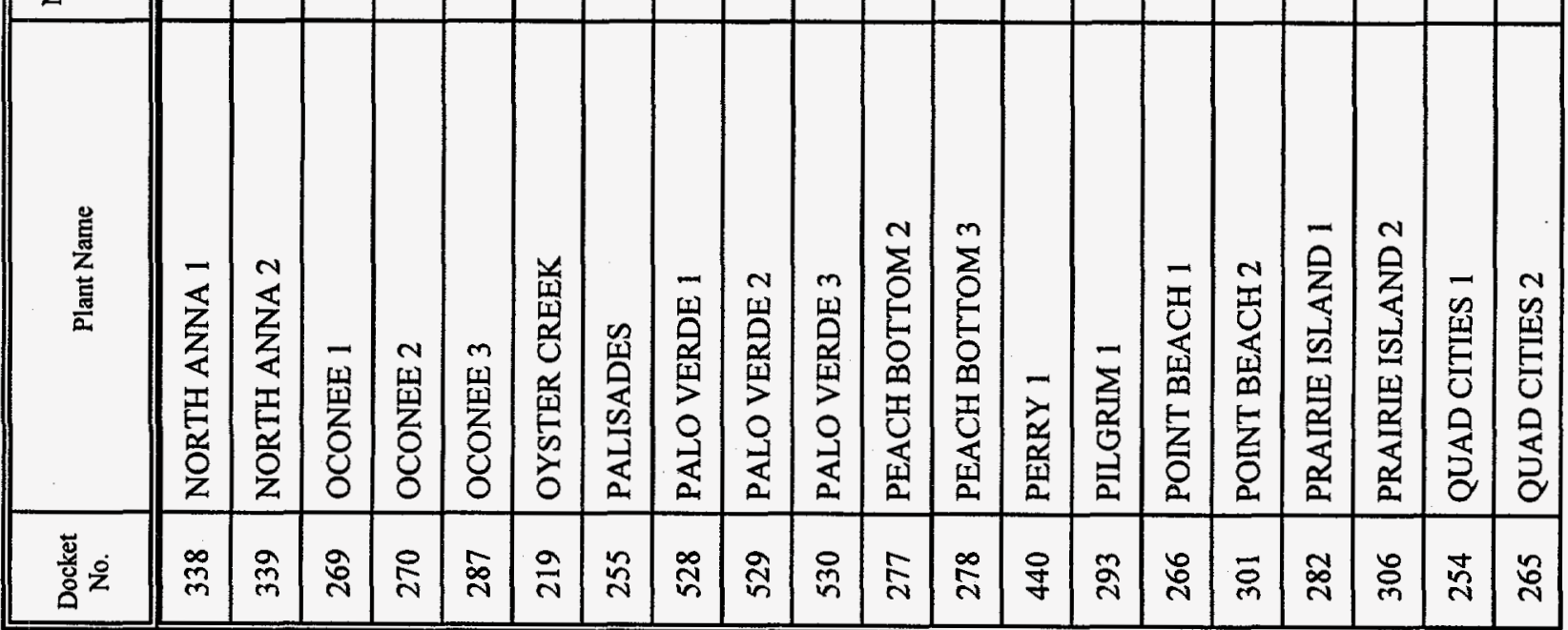


TABLE 1: UNIT DATA SUMMARY THROUGH DECEMBER 1996

\begin{tabular}{|c|c|c|c|c|c|c|c|c|c|c|}
\hline $\begin{array}{l}\text { Docket } \\
\text { No. }\end{array}$ & Plant Name & $\begin{array}{c}\text { Nameplate } \\
\text { Rating } \\
(\mathrm{MWe})\end{array}$ & $\begin{array}{c}\mathrm{MDC} \\
\mathrm{Net}\end{array}$ & $\begin{array}{c}\text { Cumulative } \\
\text { Availability } \\
\text { Factor }\end{array}$ & $\begin{array}{l}\text { Cumulative } \\
\text { Capacity } \\
\text { Factor } \\
\text { (MDC Net) }\end{array}$ & $\begin{array}{c}\text { Cumulative } \\
\text { Forced } \\
\text { Outage Rate }\end{array}$ & $\begin{array}{l}\text { Construction } \\
\text { Permit Date }\end{array}$ & $\begin{array}{c}\text { Operating } \\
\text { License Date }\end{array}$ & $\begin{array}{c}\text { Commercial } \\
\text { Operation } \\
\text { Date }\end{array}$ & $\begin{array}{c}\text { License } \\
\text { Expiration } \\
\text { Date }\end{array}$ \\
\hline 312 & RANCHO SECO? & 963 & 873 & 47.4 & $37 \%$ & 42.7 & $10 / 1168$ & $08 / 1674$ & $04 / 7 \% 5$ & 2008 \\
\hline 458 & RIVER BEND 1 & 936 & 936 & 72.6 & 68.0 & 11.8 & $03 / 25 / 77$ & $11 / 20 / 85$ & $06 / 16 / 86$ & 2025 \\
\hline 261 & ROBINSON 2 & 739 & 683 & 70.4 & 65.4 & 14.0 & $04 / 13 / 67$ & $09 / 23 / 70$ & $03 / 07 / 71$ & 2010 \\
\hline 272 & SALEM 1 & 1170 & 1106 & 58.7 & 53.0 & 26.3 & $09 / 25 / 68$ & $12 / 01 / 76$ & $06 / 30 / 77$ & 2016 \\
\hline 311 & SALEM 2 & 1170 & 1106 & 56.4 & 50.6 & 30.2 & $09 / 25 / 68$ & $05 / 20 / 81$ & $10 / 13 / 81$ & 2020 \\
\hline 206 & SAN ONOIRE I? & 456 & 436 . & 577 & 52.4 & 17.9 & $03102 / 64$ & $03 / 27167$ & $01,01 \% 68$ & 2007 \\
\hline 361 & SAN ONOFRE 2 & 1127 & 1070 & 76.6 & 75.4 & 4.8 & $10 / 18 / 73$ & $09 / 07 / 82$ & $08 / 08 / 83$ & 2013 \\
\hline 362 & SAN ONOFRE 3 & 1127 & 1080 & 79.2 & 76.0 & 4.7 & $10 / 18 / 73$ & $11 / 15 / 82$ & $04 / 01 / 84$ & 2013 \\
\hline 443 & SEABROOK 1 & 1197 & 1158 & 82.3 & 79.7 & 5.5 & $07 / 07 / 76$ & $05 / 26 / 89$ & $08 / 19 / 90$ & 2026 \\
\hline 327 & SEQUOYAH 1 & 1221 & 1117 & 55.6 & 52.9 & 32.1 & $05 / 27 / 70$ & $09 / 17 / 80$ & $07 / 01 / 81$ & 2020 \\
\hline 328 & SEQUOYAH 2 & 1221 & 1117 & 60.7 & 56.5 & 31.3 & $05 / 27 / 70$ & $09 / 15 / 81$ & $06 / 01 / 82$ & 2021 \\
\hline 498 & SOUTH TEXAS 1 & 1311 & 1251 & 67.0 & 64.0 & 22.9 & $12 / 22 / 75$ & $03 / 22 / 88$ & $08 / 25 / 88$ & 2027 \\
\hline 499 & SOUTH TEXAS 2 & 1311 & 1251 & 68.4 & 65.5 & 22.3 & $12 / 22 / 75$ & $03 / 28 / 89$ & $06 / 19 / 89$ & 2028 \\
\hline 335 & ST LUCIE 1 & 850 & 839 & 77.0 & 74.1 & 5.1 & $07 / 01 / 70$ & $03 / 01 / 76$ & $12 / 21 / 76$ & 2016 \\
\hline 389 & ST LUCIE 2 & 850 & 839 & 83.3 & 80.9 & 6.3 & $05 / 02 / 77$ & $06 / 10 / 83$ & $08 / 08 / 83$ & 2023 \\
\hline 395 & SUMMER & 900 & 885 & 80.4 & 78.1 & 4.2 & $03 / 21 / 73$ & $11 / 12 / 82$ & $01 / 01 / 84$ & 2022 \\
\hline 280 & SURRY I & 848 & 781 & 70.4 & 64.5 & 15.2 & $06 / 25 / 68$ & $05 / 25 / 72$ & $12 / 22 / 72$ & 2012 \\
\hline 281 & SURRY 2 & 848 & 781 & 68.0 & 63.7 & 12.5 & $06 / 25 / 68$ & $01 / 29 / 73$ & $05 / 01 / 73$ & 2013 \\
\hline 387 & SUSQUEHANNA 1 & 1165 & 1090 & 77.6 & 74.0 & 6.7 & $11 / 02 / 73$ & $11 / 12 / 82$ & $06 / 08 / 83$ & 2022 \\
\hline 388 & SUSQUEHANNA 2 & 1168 & 1094 & 83.3 & 80.6 & 5.0 & $11 / 02 / 73$ & $06 / 27 / 84$ & $02 / 12 / 85$ & 2024 \\
\hline
\end{tabular}


TABLE 1: UNIT DATA SUMMARY THROUGH DECEMBER 1996

\begin{tabular}{|c|c|c|c|c|c|c|c|c|c|c|}
\hline $\begin{array}{c}\text { Docket } \\
\text { No. }\end{array}$ & Plant Name & $\begin{array}{c}\text { Nameplate } \\
\text { Rating } \\
\text { (MWe) }\end{array}$ & $\begin{array}{c}\text { MDC } \\
\text { Net }\end{array}$ & $\begin{array}{c}\text { Cumulative } \\
\text { Availability } \\
\text { Factor }\end{array}$ & $\begin{array}{l}\text { Cumulative } \\
\text { Capacity } \\
\text { Factor } \\
\text { (MDC Net) } \\
\end{array}$ & $\begin{array}{c}\text { Cumulative } \\
\text { Forced } \\
\text { Outage Rate }\end{array}$ & $\begin{array}{l}\text { Construction } \\
\text { Permit Date }\end{array}$ & $\begin{array}{l}\text { Operating } \\
\text { License Date }\end{array}$ & $\begin{array}{c}\text { Commercial } \\
\text { Operation } \\
\text { Date }\end{array}$ & $\begin{array}{c}\text { License } \\
\text { Expiration } \\
\text { Date }\end{array}$ \\
\hline 289 & THREE MILE ISLAND 1 & 872 & 786 & 59.8 & 59.2 & 34.1 & $05 / 18 / 68$ & $04 / 19 / 74$ & $09 / 02 / 74$ & 2014 \\
\hline 320 & 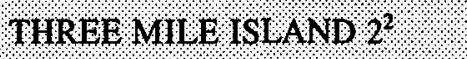 & 871 & 808 & 00 & 0,0 & 0,0 & $1104 \% 9$ & $02108 \% 8$ & 1230178 & 2009 \\
\hline 344 & TROIAN & 1216 & 1095 & 61.2 & 84.2. & $13 \%$ & 0210817 & 11217 & $05 / 20176$ & 2011 \\
\hline 250 & TURKEY POINT 3 & 760 & 666 & 68.0 & 62.4 & 10.3 & $04 / 27 / 67$ & $07 / 19 / 72$ & $12 / 14 / 72$ & 2012 \\
\hline 251 & TURKEY POINT 4 & 760 & 666 & 67.3 & 62.1 & 9.9 & $04 / 27 / 67$ & $04 / 10 / 73$ & $09 / 07 / 73$ & 2013 \\
\hline 271 & VERMONT YANKEE & 540 & 510 & 81.3 & 76.0 & 4.8 & $12 / 11 / 67$ & $02 / 28 / 72$ & $11 / 30 / 72$ & 2012 \\
\hline 424 & VOGTLE 1 & 1215 & 1162 & 86.3 & 84.3 & 4.5 & $06 / 28 / 74$ & $03 / 16 / 87$ & $06 / 01 / 87$ & 2027 \\
\hline 397 & WASHINGTON NUCLEAR 2 & 1199 & 1107 & 71.0 & 60.9 & 10.4 & $03 / 19 / 73$ & $04 / 13 / 84$ & $12 / 13 / 84$ & 2023 \\
\hline 382 & WATERFORD 3 & 1200 & 1075 & 84.3 & 82.8 & 3.7 & $11 / 14 / 74$ & $03 / 16 / 85$ & $09 / 24 / 85$ & 2024 \\
\hline 390 & WATTS BAR 1 & 1275 & 1117 & 91.4 & 89.1 & 0.2 & $01 / 23 / 73$ & $02 / 07 / 96$ & $5 / 27 / 96$ & 2035 \\
\hline 482 & WOLF CREEK 1 & 1236 & 1163 & 81.4 & 79.3 & 3.8 & $05 / 31 / 77$ & $06 / 04 / 85$ & $09 / 03 / 85$ & 2025 \\
\hline 29 & YANKEEROWI' & 185 & 167 & $17 \%$ & 737 & 4.9 & $11045 \%$ & $06 / 23 \%$ & 0710161 & 2000 \\
\hline 295 & ZION 1 & 1085 & 1040 & 66.2 & 58.4 & 15.9 & $12 / 26 / 68$ & $10 / 19 / 73$ & $12 / 31 / 73$ & 2013 \\
\hline 304 & ZION 2 & 1085 & 1040 & 69.2 & 61.1 & 13.2 & $12 / 26 / 68$ & $11 / 14 / 73$ & $09 / 17 / 74$ & 2013 \\
\hline
\end{tabular}

Note: ${ }^{1}$ Browns Ferry 1 no longer calculates cumulative data. Cumulative data are through August 1994.

${ }^{2}$ Unit is permanently shut down. Cumulative data are through the unit's effective shutdown date. 
ARKANSAS NUCLEAR ONE

PRODUCTION COST and CAPITAL ADDITIONS (1996 Dollars)

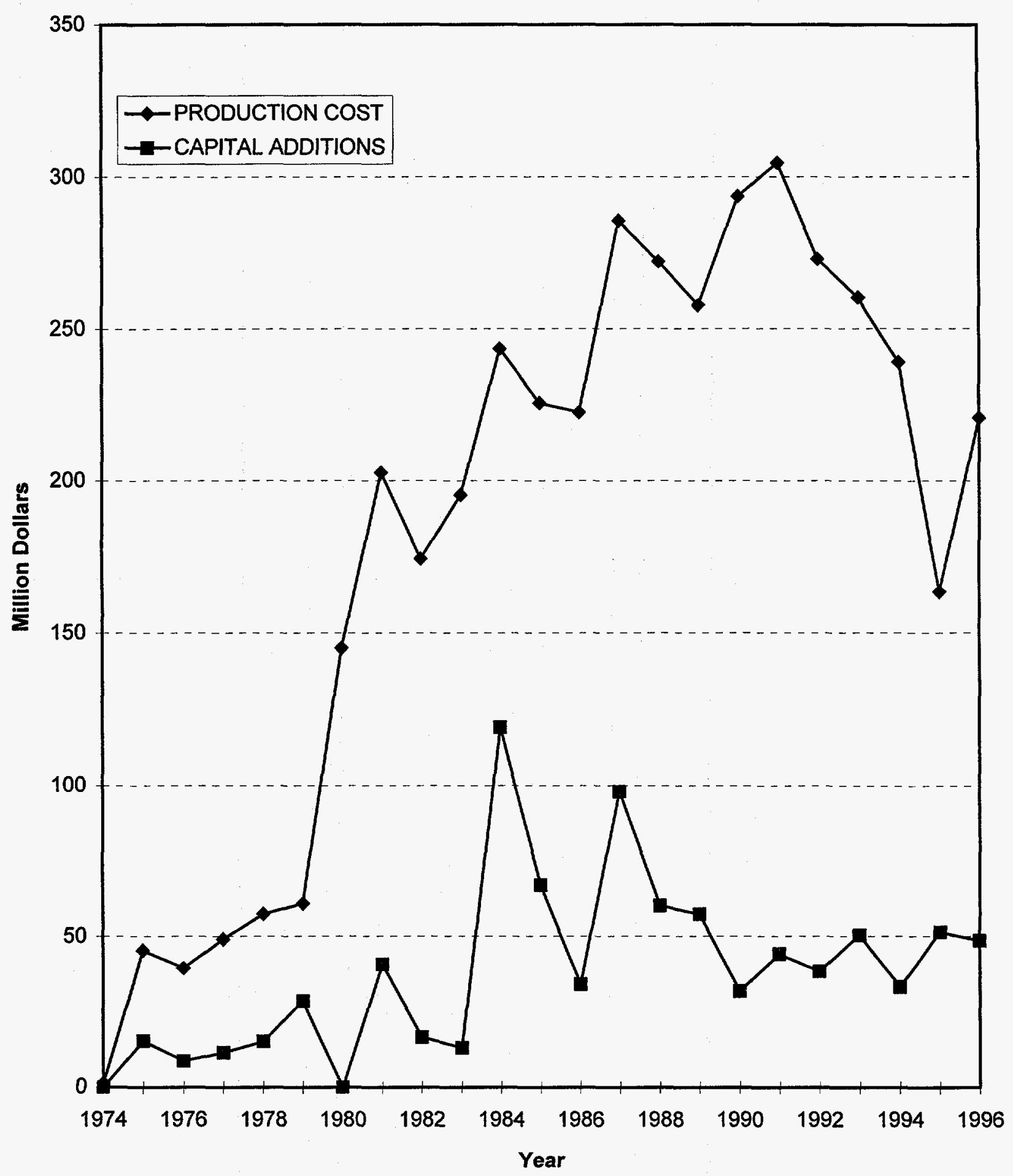




\title{
NUCLEAR POWER PLANT OPERATING EXPERIENCE SUMMARY
}

\author{
Unit data summary through December 1996
}

Unit: ARKANSAS NUCLEAR ONE 1

Location: POPE COUNTY, ARKANSAS

Owner: ENTERGY OPERATIONS

Type: BABCOCK \& WILCOX PWR

Construction Permit: 12/06/68

Operating License: $05 / 21 / 74$

Commercial Oper. Date: 12/19/74
Nameplate Rating: 903 MWe

MDC Net MWe: $836 \mathrm{MWe}$

Cumul. Avail. Factor: $\mathbf{7 4 . 0}$

Cumul. Cap. Factor (MDC Net): 65.5

Cumul. Forced Outage Rate: 9.9

3-Year Avg. Cap. Factor (MDC Net): 88.5

License Expiration: 2014

OPERATING HISTORY (To December 1996)

Date

Oct - Nov 1974

Dec 1974

Mar - Apr 1975

Oct - Nov 1975

Dec 1975 - Jan 1976

Mar 1976

Aug - Sep 1976

Dec 1976

Jan - Mar 1977

Nov - Dec 1977

Jan - Mar 1978

Apr 1978

Dec 1978 - Feb 1979

\section{Comment}

Two separate shutdowns, totaling about 4 weeks, were necessary for repairs on RCS drain line leaks.

Full power was achieved, and final testing was completed. The unit ended the year in an outage to repair a steam line leak.

The unit experienced a $61 / 2$-week maintenance outage.

The unit was shut down for 17 days to perform CRD changeout and other maintenance.

The unit shut down after a control rod failed to withdraw following a CRDM ratchet trip. During unit startup another CRDM was damaged as a result of a rachet trip. Repair outages totaled about 4 weeks.

A CRD stator failure and reactor specimen holder tube failures forced a repair outage. Fuel and reactor internals were removed to find loose parts that fell to the bottom of the vessel.

RCP failures caused two shutdowns totaling 37 days.

Secondary system problems required a power reduction to $93 \%$.

The unit was shut down for refueling and maintenance. Major work included SG inspection, CRDM stator replacement, and LP turbine inspection and repair.

There was a 15-day shutdown due to cooling fan problems at a reactor building.

Power was reduced to $50 \%$ until the unit was shut down for refueling and maintenance. Major work included SG inspection and tube plugging, and maintenance on RCPs, relief valves, CRD stators, and service water pumps.

Turbine lube oil leakage and blade damage forced an outage of 21 days.

Turbine vibration caused by blade failure required an outage for rotor replacement. The outage was used to adjust SG downcomer plates and complete various ISIs. 
Mar - Jun 1979

Jul - Aug 1979

Oct - Nov 1979

Dec 1979 - Feb 1980

Apr - May 1980

May - Jun 1980

Jul - Aug 1980

Sep 1980

Dec 1980

Jan - Mar 1981

Jul - Aug 1981

Mar 1982

Mar - May 1982

May - Jun 1982

Aug 1982

Nov 1982 - May 1983

Mar 1983

Jun - Jul 1983
The unit was shut down for a refueling and maintenance outage. The outage was extended pending resolution of generic safety concerns associated with the TMI-2 accident. During restart, the unit was returned to cold shutdown because of procedure deficiencies relating to emergency FW operation.

The unit entered a 22-day outage to resolve main turbine bearing vibration and review design of main steam snubbers. A pipe support inspection project was also conducted.

The unit was shut down to modify in-core temperature detection devices and restore vital power supply to an EFW pump.

An outage was necessary for TMI-related modifications. One LP turbine was modified to correct rotor cracking problems.

After a unit trip from LOSP caused by a tornado, the plant operated at reduced power for about 12 days until shutdown to accomplish HP turbine seal repairs, Crystal River 3 modifications, and repair of LP turbine/condenser expansion joint.

A RCP seal failure resulted in a 42,000 gallon spill to the reactor building basement. The unit went to cold shutdown to complete cleanup and rebuild RCP seals.

An outage was required to repair SG tube leakage and cracked studs on the SG manway.

Another 23-day outage was necessary for SG tube leak repair.

Unit power was restricted to about $75 \%$ due to excessive seal leakage on one RCP.

The unit was shut down for a refueling outage.

The unit had two separate outages - one to repair leaking manway covers on one SG (9 days) and a second to repair a loose diode heat sink on the main generator ( 9 days). The RCP seals were also replaced during the second outage.

Installation of an on-line PASS was completed.

After 208 days of operation, the unit had an outage of 44 days to replace the FW nozzles of one SG.

An outage of 16 days was necessary to conduct SG inspection and tube plugging.

An outage of 13 days was necessary to restore lost indication for both FW pumps after a scram and to replace a failed CRDM stator.

The unit entered a refueling outage early due to RCP seal leakage. SG inspection revealed 45 and 86 defective tubes, respectively, in each component. Other major items included 10year ISI, electrical testing, RCP flywheel inspection, and EFW pump turbine replacement. Unit failed to restart because of main turbine bearing failure. The outage was extended for other maintenance items including inspection of upper core barrel support bolts, safety evaluation of a failed CRD trip breaker, $\mathrm{RCP}$ seal repairs, and main generator $\mathrm{H}_{2}$ leak repair. Total outage time was about 201 days for the period.

The NRC assessed a $\$ 20,000$ fine for alleged violation concerning plugged ports on reactor building pressure transmitters.

Two outages occurred to repair the main generator exciter and plug 32 defective tubes in one SG. Both outages totaled 33 days. 
Mar - Apr 1984

Oct 1984

Oct 1984 -Jan 1985

Jan - Feb 1985

Jan 1986

Sep - Dec 1986

Jun 1987

Jul 1987

Oct - Nov 1987

Mar 1988

Aug - Dec 1988

Jan - Mar 1989

Mar 1989

May 1989

Nov - Dec 1989

$\operatorname{Jan} 1990$
A maintenance outage was needed for inspection of SGs to follow up on degradation found in 1983 inspection. Other work included implementation of RTB shunt trip devices, key lock switches for purge valves, $125 \mathrm{-V}$ battery modification, snubber inspections, installation of level taps on SGs.

The NRC imposed a fine of $\$ 20,000$ for alleged failure to apply controls for the procurement and installation of safety-related fasteners.

The unit entered a refueling and maintenance outage. The unit became the first $B \& W$ unit to install sleeves in SG tubes. Dynamic water shocking and $\mathrm{N}_{2}$ burst techniques were used to clean tube support plate orifices.

An outage lasting 21 days occurred following a high RCS pressure scram for SG level problems. RCP seals were repaired during the outage.

An 18-day outage occurred for DG repairs.

A refueling and maintenance outage included these major items: 10-year ISI of RCS components, SG inspection and cleaning, and I\&C modifications. Total outage time was 118 days.

The NRC imposed a $\$ 50,000$ fine for alleged violations occurring during installation of check valves in the EFW pump turbine steam lines and a $\$ 25,000$ fine for an alleged violation regarding a set point set too high on a pressurizer safety valve.

The NRC proposed a fine of $\$ 75,000$ for alleged security violations. One violation involved several cases of inadequate vital area barriers. The other violation involved two instances in which guards were found sleeping.

The unit was shut down for scheduled midcycle maintenance outage for 28 days.

The NRC proposed a fine of $\$ 100,000$ for alleged failure to take corrective action for the long-standing problem of high containment temperature during unit operation.

The unit was shut down for refueling and RCP seal leak. Major items involved replacement of LP turbine rotors and two MSR tube bundles, replacement of a number of secondary piping components, and overhaul of RCPs and SGs. The NRC required resolution of several safety issues before restart.

A 69-day outage occurred due to various equipment problems. HPSI system modifications were necessary prior to restart; power was limited to $50 \%$ because of injection line break analysis uncertainties.

The NRC proposed a fine of $\$ 25,000$ for two alleged radiation overexposure incidents in November 1987.

The unit was shut down because of a leak in RCS cold leg drain line. The outage lasted for 18 days. The NRC assessed a fine of $\$ 175,000$ for two alleged violations involving failure to ensure operability of EFW pump during heatup, improper reassembly of RCS valves, and inadequate control of safety-related equipment. Another fine of $\$ 75,000$ for alleged $\mathrm{EQ}$ program inadequacies was also imposed.

The unit was shut down for 27 days for scheduled maintenance; power was limited to $42 \%$ for 3 days because of FW control problems.

The NRC proposed a fine of $\$ 75,000$ for alleged violations involving wiring discrepancies in a control room panels. 
Mar 1990

Jun 1990

Oct 1990 - Jan 1991

Jan 1991

Feb 1991

Apr 1991

Feb - May 1992

Sep - Oct 1993

Apr 1994

Feb - Mar 1995

Apr 1995

May 1996

Sep 1996

Sep - Oct 1996
The NRC order imposing a fine of $\$ 75,000$ for alleged EQ program inadequacies cited in May 1989 was reduced to $\$ 50,000$ because of prompt corrective action by the utility.

The Securities and Exchange Commission approved the consolidation of operations management for both Arkansas 1 \& 2, Grand Gulf, and Waterford 3 under Entergy Operations, Inc.

The ninth refueling and maintenance outage lasted 97 days. The SG and the SW systems were chemically cleaned, and a reactor building chiller and air handling unit were added during the shutdown.

A 10-day outage occurred after a winding fault in the generator exciter rotor caused a main generator/reactor trip.

The NRC proposed a fine of $\$ 50,000$ for an alleged violation regarding design of the control room emergency ventilation system.

A 14-day planned maintenance outage was needed to complete deferred modifications from the previous refueling outage.

The tenth refueling and maintenance outage lasted 71 days. In addition to the refueling, the following activities were also performed: LP turbine overhaul, a RCP motor overhauled, CRDM flange gaskets replaced, plant computer replaced, $20 \%$ ECT for both SGs, dp testing of MOVs, ILRT, and ultrasonic testing and reconstitution of fuel.

The eleventh refueling and maintenance outage lasted 43 days.

The unit was shut down for $\mathbf{4}$ days after a lightning strike caused a main steam isolation.

The twelfth refueling and maintenance outage lasted 46 days.

Two reactor scrams caused 4 days of downtime.

The unit was shut down for 6 days following a reactor scram due to a short in one of reactor feed pumps control circuitry.

The NRC proposed and the licensee paid a $\$ 50,000$ fine for maintenance personnel failing to follow procedures, which resulted in a main steam safety valve sticking open.

The thirteenth refueling and maintenance outage lasted 33 days. During plant heatup, oilsoaked SG insulation ignited and forced the unit to shutdown for another 8 days. 


\section{NUCLEAR POWER PLANT OPERATING EXPERIENCE SUMMARY}

Unit data summary through December 1996

Unit: ARKANSAS NUCLEAR ONE 2

Location: POPE COUNTY, ARKANSAS

Nameplate Rating: 943 MWe

Owner: ENTERGY OPERATIONS

MDC Net MWe: $858 \mathrm{MWe}$

Type: COMBUSTION ENGINEERING PWR

Cumul. Avail. Factor: $\mathbf{7 7 . 1}$

Construction Permit: 12/06/72

Cumul. Cap. Factor (MDC Net): 75.3

Operating License: 09/01/78

Cumul. Forced Outage Rate: 10.1

Commercial Oper. Date: 03/26/80

3-Year Avg. Cap. Factor (MDC Net): 86.3

License Expiration: 2018

OPERATING HISTORY (To December 1996)

Date

Feb - Mar 1979

Mar - May 1979

Sep 1979

Oct - Dec 1979

Jan - Mar 1980

Apr - May 1980

Sep 1980

Dec 1980

Mar - Jul 1981

Sep - Oct 1981

Jan 1982

Apr 1982

May 1982

Aug - Nov 1982

Jan 1983

\section{Comment}

The unit was shut down for required modifications to all four RCPs. During $20 \%$ power testing it had been discovered that one RCP could not be rotated by hand.

Numerous problems with Lonergan safety valves prompted their replacement with Crosby valves. Testing of the new valves was delayed because of an RCP seal failure.

A unit shutdown was necessary to repair several condenser tube leaks and cracks in the condenser false floor.

A loss of instrument air resulted in a manual reactor trip. The unit remained shut down for a scheduled outage to inspect reactor internals and replace a DG. Physics and power ascension testing resumed after unit restart.

The unit was shut down for TMI modifications. During DG testing, the rotor shaft sheared and was returned to the manufacturer (Fairbanks-Morse) for repair.

Weather caused an LOSP and transmission line damage. The unit was cooled down during repair activities. It was restarted and operated at reduced power before complete repairs were made.

The unit was shut down to clean and test all SW coolers after inadequate flow to a reactor building cooler was discovered.

A 12-day outage was required to repair a cracked charging pump suction line.

The unit was shut down for a maintenance and refueling outage.

The unit was shut down to repair failed expansion joint in an FW heater extraction line.

Several RCS RTDs failed a response time test and caused a unit outage of 15 days.

A leak in the SG blowdown piping resulted in a 14-day repair outage.

The FW regulating valve problems caused two outages totaling 10 days.

The unit was shut down early for refueling due to RCS leakage at a SG primary manway. During fuel inspections, decreased shoulder gap clearances were found on some FAs, indicating problems with the $\mathrm{CE}$ calculation models for predicting fuel pin growth.

The unit entered a 24-day outage to repair leaking tubes in a shutdown heat exchanger. 
Mar 1983

Sep 1983

Oct $1983-$ Feb 1984

Jul - Sep 1984

Mar - May 1985

Sep - Oct 1985

Dec 1985

Jun - Sep 1986

Apr - May 1987

Jul 1987

Oct - Nov 1987

Feb - May 1988

Aug 1988

Apr - May 1989

Jun - Jul 1989

Sep - Nov 1989

Jul 1990

Feb - Apr 1991
The NRC proposed a $\$ 5000$ fine for alleged false statements by the utility regarding the completion of required testing in March 1980.

Five of 60 cells in one $125-\mathrm{V}$ DC battery were found below the required value, but due to a personnel error, the battery was not declared inoperable until 4 days later. The NRC found that the battery should have been declared inoperable after three previous surveillance tests. A fine of $\$ 40,000$ was proposed for the alleged violations.

The utility was shut down for a refueling and maintenance outage. A flange leak of the reactor vessel caused the outage to be extended.

Two outages, totaling 15 days, occurred because of operational problems. First the unit was manually tripped after an operator inadvertently caused an inverter transfer. Secondly, the unit was placed in cold shutdown after a CEA dropped. In both cases, routine maintenance work was also performed.

The unit was shut down for refueling and maintenance.

The unit underwent three shutdowns and four power reductions because of a number of operating problems - RCP seal leakage, extraction steam line expansion joint leaks, FW regulating valve problems, condenser leaks, and a leak in an FW heater required repairs.

The unit was taken off-line for about 10 days to replace two FW heater expansion joints.

The unit entered a refueling and maintenance outage. After return to power, a reactor scram occurred because set points on two pressurizer code safety valves were set too low and a level control valve for the MSR had been incorrectly reassembled.

The unit was shut down for 33 days to repair a leak in a pressurizer heater element sleeve penetration. In addition, a damaged area of the pressurizer vessel was found.

The unit was shut down for 10 days to repair a pressurizer heater weld leak previously repaired during the last forced outage.

Condenser tube leakage problems caused three separate power reductions during this operating period.

The unit was shut down about 100 days for refueling and maintenance. Work items included MOV actuator replacement per IEB 85-03, LP turbine rotor replacement, SW system upgrades, pressurizer spray isolation modifications, CST connection work, station battery charger replacement, pressurizer heater replacement, and control room instrumentation upgrades.

The unit was shut down for 15 days after it was manually tripped because of an RCP sensing line failure.

The unit tripped following an HP extraction line rupture. The outage lasted 19 days.

The unit went off-line for 10 days to correct excessive RCS leakage caused by the wrong type flange connection for a reactor vessel head vent valve.

The seventh refueling and maintenance lasted 57 days. Work included SG inspection and sludge lancing, turbine generator overhaul, LP turbine rotor replacement, and SW system pipe modification.

An outage of 9 days was required to replace leaking pressurizer SRVs.

The eighth refueling and maintenance outage lasted 56 days. The SW system was upgraded, and a new AFW pump was installed. 
Mar 1992

Sep - Oct 1992

May 1993

Mar - Apr 1994

Jan 1995

Sep - Nov 1995

Nov 1996
A 54-day outage was caused by increased primary-to-secondary leakage.

The ninth refueling and maintenance outage lasted 45 days. Major maintenance activities included main low-pressure and FW pump turbine inspections, ECT and sludge lancing of both SGs, SG A FW nozzle replacement, and RCP A motor replacement.

A 16-day SG outage showed cracking near the top of the tubesheet, but the condition was not as severe as in the past.

The tenth refueling and maintenance outage lasted 44 days.

The unit was shut down for steam generator inspection. During the subsequent heatup, an RCP seal required replacement. Total downtime was 18 days.

The eleventh refueling and maintenance outage was performed. Following the 55-day refueling outage, a number of equipment problems added an additional 12 days before the unit was returned to service.

The unit was shut down for 31 days due to primary-to-secondary leakage. 
BEAVER VALLEY

PRODUCTION COST and CAPITAL ADDITIONS (1996 Dollars)

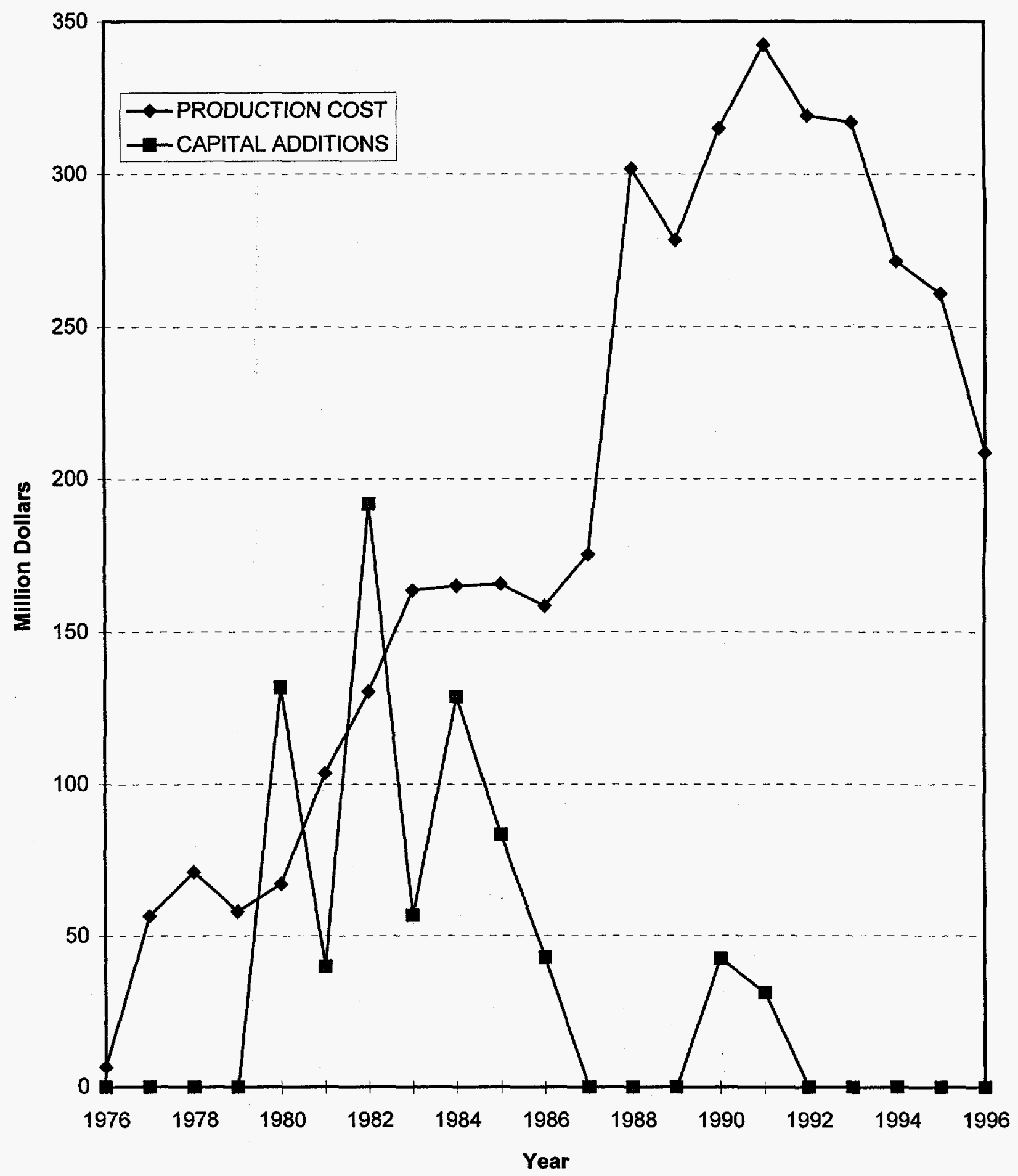




\section{NUCLEAR POWER PLANT OPERATING EXPERIENCE SUMMARY}

Unit data summary through December 1996

Unit: BEAVER VALLEY 1

Location: BEAVER COUNTY, PENNSYLVANIA

Nameplate Rating: $923 \mathrm{MWe}$

Owner: DUQUESNE LIGHT CO.

MDC Net MWe: 810 MWe

Type: WESTINGHOUSE PWR

Cumul. Avail. Factor: $\mathbf{6 7 . 2}$

Construction Permit: 06/26/70

Cumul. Cap. Factor (MDC Net): 61.5

Operating License: 07/02/76

Cumul. Forced Outage Rate: 15.0

Commercial Oper. Date: 10/01/76

3-Year Avg. Cap. Factor (MDC Net): 78.1

License Expiration: 2016

OPERATING HISTORY (To December 1996)

Date

1976

Jun 1976

Jul 1976

Aug 1976

Nov - Dec 1976

Jan 1977

Jun 1977

Aug - Oct 1977

Nov 1977

Apr - Jun 1978

Jul - Dec 1978

Jan 1979

Mar - Aug 1979

\section{Comment}

Plant completion was delayed more than 3 years to add natural draft cooling towers to the circulating water system. Additional delays were caused by lack of qualified welders, changes in licensing requirements, and plant design changes.

The plant was shut down on two occasions for unscheduled maintenance - once for 13 days and once for 9 days. The second outage cause was a leak from an RHR system transmitter hose that released about 5300 gallons of primary water to the containment.

Repair of leaky condenser tubes and other maintenance caused a 17-day shutdown.

The FW pump problems and other testing and maintenance caused almost 17 days of outage time on two separate shutdowns.

The FW water hammer damage and associated piping problems forced a 6-week outage.

Another FW hammer incident resulted in a 2-month shutdown for repairs and piping modifications.

A 12-day maintenance outage was needed for repairs on the MSRs, DGs and FW pumps.

A 2-month major maintenance outage included work on the main steam trip valves, MSRs, generator hydrogen ducts, RCP seals, SI pumps, and cooling tower pumps. A few days after startup, another shutdown of 3 days was needed to repair an RCS fill valve that allowed about 8500 gallons of primary water to leak to containment.

A forced outage of 11 days was required for repairs to generator hydrogen cooling ducts.

A 8-week shutdown was needed for inspection of LPSI pumps, outside recirculation spray pumps, and other maintenance.

The unit was shut down after an explosion and fire in the main transformer. The transformer was replaced. Additional maintenance included turbine/generator overhaul, containment leak testing, SG inspection, and modifications to SI system pipe supports.

A trip from the main steam stop valve closure and a subsequent SI forced a 15-day outage.

The NRC ordered a unit shutdown to resolve deficiencies in pipe support analysis code. New spent fuel racks were installed, and cracked FW pipes were repaired during the outage. 
Dec 1979 - Jan 1981

Feb 1981

Jul 1981

Dec 1981 - Jul 1982

Aug - Sep 1982

Mar 1983

Jun - Sep 1983

Oct 1984 - Jan 1985

Apr 1985

May - Aug 1986

Dec 1986

Apr - May 1987

Dec 1987 - Mar 1988

Sep - Dec 1989

May 1990

Jul 1990

Jan - Feb 1991

Apr - Jul 1991
The unit was shut down for refueling and major maintenance. A number of plant systems were modified. Power was limited on startup to about $60 \%$ until repairs were completed to the second FW pump.

A 54-day outage was forced by an RCS leak on a cracked weld in an instrument line.

The unit was shut down for about 14 days to repair a pressurizer relief tank rupture disk and make other plant modifications.

The plant entered a refueling and maintenance outage about 1 week early because of a plant trip from loss of instrument air. Major work during the outage included TMI modifications, installation of reactor head vent system, and replacement of the pressurizer relief valves and RCP seals. RCP seal problems delayed return to full power for about 1 month.

The SG tube repairs forced a 14-day outage.

The unit achieved its highest monthly thermal output and electrical output to date.

The unit was shut down for refueling and maintenance outage. Major items included SG inspection and tube plugging, RCP and RHR seal work, snubber seal replacement, and CRDM guide tube split pin replacement.

The unit was shut down for refueling and maintenance outage. Major items included 10-year ISI, SG and RCP inspection, FW heater replacement, main generator rework, and condenser retubing.

The unit was shut down for 9 days to repair leaky pressurizer manway. The NRC assessed a $\$ 50,000$ fine for alleged failure to maintain containment integrity for 3 days in late December 1984.

The unit was shut down for refueling and maintenance outage. Major items included additional 10-year ISI, SG inspection and repair, and overhaul of a number of plant pumps and valves. Total outage time was 94 days.

The NRC granted a license amendment to change the start of the 40-year plant operating license from construction permit date to operating permit date for a gain of about 6 years.

The plant was shut down for about 29 days to make modifications to the control room. An additional 8 days of outage time was forced by RCP motor repairs.

The seventh refueling and maintenance outage lasted 61 days. Major items included modifications to RPV baffle and RHR valves, snubber rework, SG tube plugging, and testing of MOVs.

The unit was shut down for refueling and maintenance outage. Major items included SG channel head decontamination, main generator overhaul, RCP motor overhaul, MSL ISI, and large bore snubber testing. Total outage time was 116 days.

The utility reported that plant personnel had set a new company record of 3.6 million work hours without a lost-time accident.

The plant was shut down for 12 days to repair control rod position indicator.

The unit was shut down for 16 days to repair an RCS isolation valve and main turbine lube oil pump.

The eighth refueling and maintenance outage lasted 79 days. Major items included SG inspection and repair, plant computer replacement, MSR tube bundle replacement, 10-year ISI work, and additional testing and maintenance of a number of plant systems. 
Apr 1991

Sep 1991

Oct 1991

Oct 1991

Oct 1991

Oct 1992

Mar - Jun 1993

Oct - Nov 1993

Jan 1994

May 1994

Jun - Jul 1994

Jul 1994

Jan - Mar 1995

Aug 1995

Dec 1995

Mar - May 1996

Aug 1996
Plant owners filed suit against $\underline{W}$ alleging misrepresentation of SG life expectancy.

A 7-day outage to plug the recirculation spray pump B HX tubes was conducted.

$\mathrm{NRC}$ proposed a $\$ 25,000$ fine for two alleged violations concerning the ISI program for piping welds and failure to take adequate corrective action.

The plant reached 15 years of operation.

An outage of 38 days occurred to repair river water pumps and clean the recirculation spray HXs. Additional work included RCP C motor repairs and AFW test and repairs.

A motor stator ground fault caused an RCP trip. The outage to repair it took 24 days.

The ninth refueling and maintenance outage lasted 83 days. Major work included replacing one-third of the flux thimble guide tubes, a main turbine governor valve, the fuel transfer system, one-half the recirculation spray HXs, a containment instrument air compressor, a plant process computer, and partial tube sleeving on all three SGs. Major inspections were conducted on an RCP motor, the secondary side on one SG, the bearings of the main FW pumps, both DGs, $100 \%$ eddy current testing on all three SGs, safety system MOV testing, and the cooling tower. Also, an LP turbine was overhauled, and station blackout modifications were performed.

The unit was shut down to repair leakage from a cold isolation vent valve. The outage was continued to repair an RCP motor and to perform MOV inspections. Total outage time was 35 days.

The unit was shut down for 10 days to clean debris from the recirculation spray heat exchangers.

A leak on a river water supply line to a diesel generator required 13 days to repair.

A fault in the main transformer resulted in a main generator/reactor trip. Replacement of the transformer took 37 days.

A main generator/reactor trip resulted from a flashover of a high-voltage bushing after the transformer fire protection deluge system activated. Repairs lasted 14 days.

The tenth refueling and maintenance outage lasted 63 days.

The plant was shut down for 9 days to repair a RCS pressure boundary leak.

The replacement of expansion joints in the river water system required a 1-week outage.

The eleventh refueling and maintenance outage lasted 50 days.

A 4-day outage was taken to perform modifications to various containment penetrations. Later in the month, a 2-week outage was necessary to repair the motor lube oil cooler on one of the RCPs. 


\title{
NUCLEAR POWER PLANT OPERATING EXPERIENCE SUMMARY
}

\author{
Unit data summary through December 1996
}

Unit: BEAVER VALLEY 2

Location: BEAVER COUNTY, PENNSYLVANIA

Owner: DUQUESNE LIGHT CO.

Type: WESTINGHOUSE PWR

Construction Permit: 05/03/74

Operating License: 08/14/87

Commercial Oper. Date: 11/17/87
Nameplate Rating: 923 MWe

MDC Net MWe: 820 MWe

Cumul. Avail. Factor: 84.1

Cumul. Cap. Factor (MDC Net): $\mathbf{7 8 . 2}$

Cumul. Forced Outage Rate: $\mathbf{4 . 3}$

3-Year Avg. Cap. Factor (MDC Net): 82.7

License Expiration: 2027

OPERATING HISTORY (To December 1996)

Date

Sep 1987

Oct - Nov 1987

Jan - Feb 1988

Mar - May 1989

Jun 1989

Sep - Nov 1990

Apr 1991

Mar - May 1992

Jun 1992

Sep - Dec 1993

Jun 1994

Mar - May 1995

Aug - Dec 1996

\section{Comment}

A 14-day outage performed to repair the pressurizer SRV.

Leakage of RCS valves caused a 3-day outage in October and an 11-day outage in November.

The plant was shut down for repairs to a leaking pressurizer manway. A plant alert was declared during the outage because of a sustained loss of some control room annunciators from a fire in a remote alarm panel.

The first refueling and maintenance outage lasted 85 days. The unit had achieved a capacity factor of $80 \%$ for the first 16 months of operation. Major outage work included SG inspection; turbine and main generator overhaul; inspection of DGs, cooling towers, and main condenser, LLRT; and snubber inspections.

The unit was shut down for about 22 days to repair SG primary-to-secondary leakage.

The second refueling and maintenance outage lasted 79 days. Major work included RV testing, turbine repairs, RCP seal inspection, 10-year ISI, and DG inspection.

Plant owners filed suit against $\underline{W}$ alleging misrepresentation of SG life expectancy.

The third refueling and maintenance outage lasted 59 days. Major work included replacement of tube bundles in all four MSRs and main FW and AFW inspection/overhaul. Major inspections were conducted on all three SGs (ECT), both DGs, flux thimbles (ECT), and the HP turbine. Tests of relief and safety system MOVs were also performed.

The NRC proposed and the utility paid a $\$ 75,000$ fine for allegedly using the wrong wire configuration for relays in electrical equipment, specifically the DG load sequencer relays.

The fourth refueling and maintenance outage lasted 78 days.

After the unit scrammed due to an electrical fault, the plant was shut down for 12 days to repair auxiliary feedwater check valves, which had excessive leak rates.

The fifth refueling and maintenance outage lasted 46 days.

The sixth refueling and maintenance outage lasted 107 days. The outage was extended by 62 days to perform relay replacements in MCCs, repair seals on both RHR pumps, and repair reactor head vent valves. 
This Page Intentionally Left Blank 
BRAIDWOOD

PRODUCTION COST and CAPITAL ADDITIONS

(1996 Dollars)

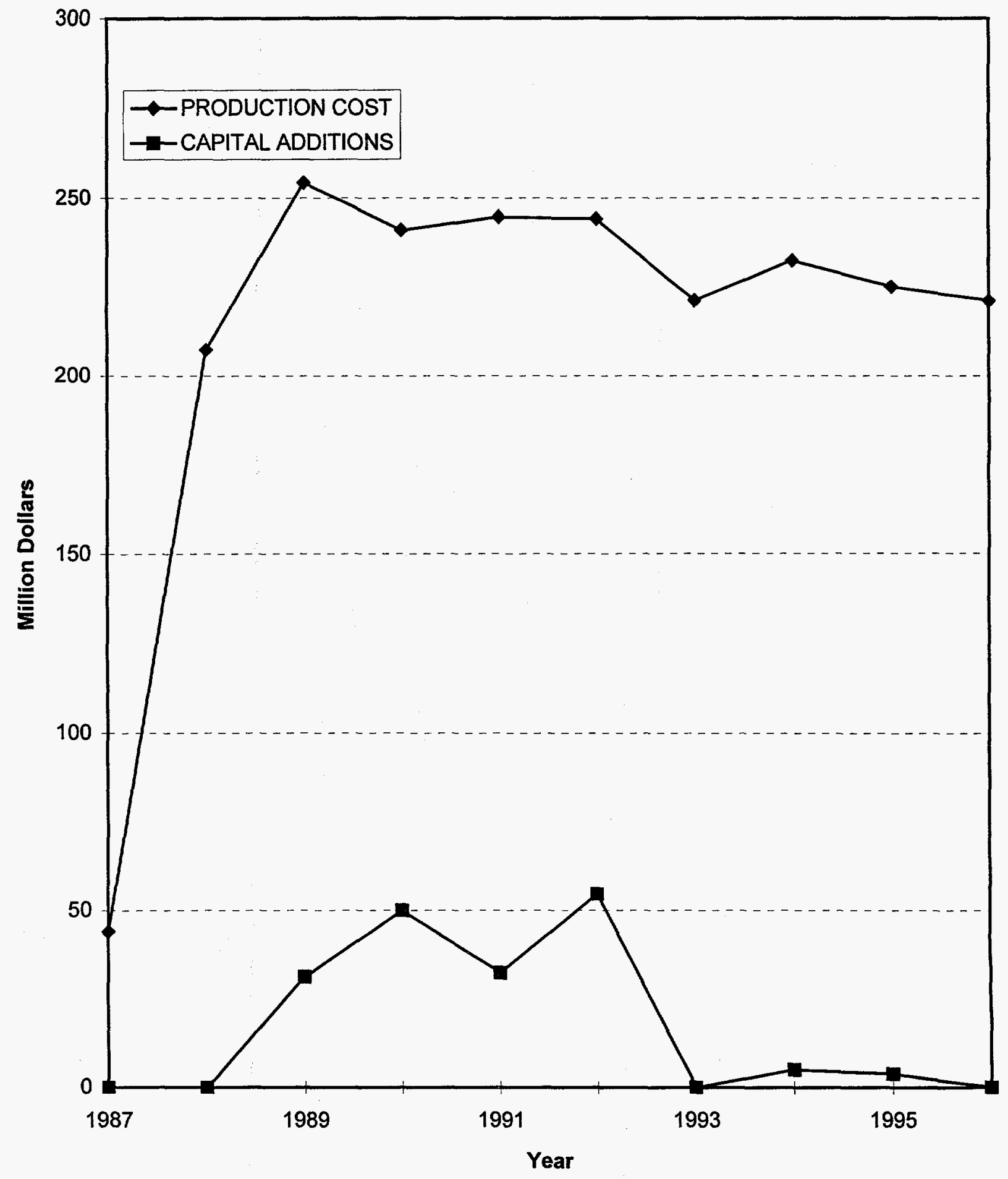




\title{
NUCLEAR POWER PLANT OPERATING EXPERIENCE SUMMARY
}

\author{
Unit data summary through December 1996
}

Unit: BRAIDWOOD 1

Location: WILL COUNTY, ILLINOIS

Owner: COMMONWEALTH EDISON CO.

Type: WESTINGHOUSE PWR

Construction Permit: 12/31/75

Operating License: 07/02/87

Commercial Oper. Date: 07/29/88
Nameplate Rating: 1175 MWe

MDC Net MWe: 1120 MWe

Cumul. Avail. Factor: $\mathbf{7 7 . 5}$

Cumul. Cap. Factor (MDC Net): $\mathbf{7 1 . 0}$

Cumul. Forced Outage Rate: $\mathbf{7 . 6}$

3-Year Avg. Cap. Factor (MDC Net): 73.3

License Expiration: 2026

OPERATING HISTORY (To December 1996)

Date

Jul 1983

Aug 1987

Jan - Mar 1988

Mar 1988

May 1988

Jun 1988

Jan - Feb 1989

Jul 1989

Sep - Dec 1989

Aug 1990

Sep - Oct 1990

\section{Comment}

During construction, the NRC imposed a $\$ 100,000$ fine on the utility for alleged failure to implement an adequate QA program and failure to report a construction deficiency within the required 24 hours.

The unit was shut down following a planned LOSP test. The AFW pump suction problems prolonged the outage for a total of about 20 days.

The unit was shut down for a planned 6-week surveillance outage.

The unit was shut down for an outage of 33 days because of questions concerning EQ of Limitorque valve operator grease. The NRC imposed a $\$ 75,000$ fine for a number of alleged failures to implement $\mathrm{EQ}$ requirements.

The NRC proposed a $\$ 50,000$ fine against the utility for alleged design deficiencies in the control room emergency ventilation system.

The NRC proposed a $\$ 50,000$ fine against the utility for alleged violation of security requirements when two guards were found sleeping at their post.

The unit was shut down for 13 days to repair a leak on the pressurizer manway.

NRC granted the utility request to expand spent fuel storage capacity from 1060 FAs to 2870 FAs.

The first refueling and maintenance outage lasted 105 days. Major work included $100 \%$ inspection of the tubes in all four SGs; stress relief of tubes in all four SGs; replacement of one of three LP turbine rotors; and work on snubber reduction modifications. During startup, a 3-hour plant alert was declared when pressurizer level dropped due to a RHR system valve malfunction.

An 11-day forced outage was caused by a failure of an essential SW discharge check valve.

The unit was shut down after a trip to repair AFW control valves and main steam line supports. Total outage time was about 23 days. 


\section{BRAIDWOOD 1 (Cont'd)}

Dec 1990 - May 1991

Mar 1991

Oct 1991

Nov 1991

Sep - Nov 1992

Nov 1992

Jan 1993

Oct - Nov 1993

Mar - May 1994

Aug 1994

Feb 1995

Apr 1995

Oct - Dec 1995

Mar 1996

Oct 1996
The unit was shut down after a main generator trip and remained down to conduct the second refueling and maintenance outage. Major outage work included main generator inspection and repair, DG 5-year overhaul, human factors modifications, inspection of all four SGs, and main generator stator coil repair. Total outage time was 139 days.

The NRC assessed a $\$ 87,500$ fine against the utility for an incident in October 1990 in which three plant workers were contaminated during testing.

A 4-day outage resulted from a condensate polisher strainer failure, which allowed a small amount of resin to enter the FW system.

A reactor trip followed an FW pump trip due to fatigue failure of an electrohydraulic oil supply line. The outage lasted six days.

The third refueling and maintenance outage lasted 60 days. Maintenance included main turbine-generator overhaul, snubber testing, SG ECT, and DG inspection.

A 5-day outage was needed to balance the main turbine and backflush the generator cooling system.

A reactor trip during RCP under frequency testing was due to a failed logic card. The resulting outage lasted 7 days and included replacing a leaking pressurizer safety valve.

The unit was shut down due to an SG tube leak. Inspection and repairs lasted 18 days.

The fourth refueling and maintenance outage lasted 71 days.

The unit was shut down for 5 days following a reactor scram due to a failed transistor in the RPS.

A 23-day outage was performed to inspect the steam generator tubes.

The unit was shut down for 8 days following a scram due to an inverter failure.

The fifth refueling and maintenance outage lasted 74 days.

A 19-day outage was necessary when one of the batteries was declared inoperable.

A scheduled maintenance outage to perform steam generator tube inspection lasted 53 days. 


\section{NUCLEAR POWER PLANT OPERATING EXPERIENCE SUMMARY}

Unit data summary through December 1996

Unit: BRAIDWOOD 2

Location: WILL COUNTY, ILLINOIS

Owner: COMMONWEALTH EDISON CO.

Type: WESTINGHOUSE PWR

Construction Permit: 12/31/75

Operating License: $\mathbf{0 5 / 2 0 / 8 8}$

Commercial Oper. Date: 10/17/88
Nameplate Rating: 1175 MWe

MDC Net MWe: 1120 MWe

Cumul. Avail. Factor: 83.9

Cumul. Cap. Factor (MDC Net): 76.5

Cumul. Forced Outage Rate: 4.7

3-Year Avg. Cap. Factor (MDC Net): 82.0

License Expiration: 2027

OPERATING HISTORY (To December 1996)

Date

Apr - May 1988

Feb - Mar 1989

Mar - May 1990

May 1991

Sep - Nov 1991

Feb 1992

May 1992

Mar - May 1993

May 1993

Oct 1993

Apr - May 1994

Oct - Nov 1994

Apr 1995

Mar - May 1996

May 1996

\section{Comment}

The unit was shut down for about 50 days during startup testing because of questions concerning EQ of Limitorque valve operator grease.

The unit was shut down for a scheduled maintenance outage that lasted 44 days.

The first refueling and maintenance outage lasted 73 days. Major work included replacement of LP turbine rotors, ATWS modifications, snubber removal, and SG inspection and tube plugging as required in all four SGs.

The unit was shut down for an 8-day outage to repair a containment isolation valve that failed a LLRT.

The second refueling and maintenance outage lasted 75 days. Additional work included control room human factors modifications and the 5-year DG overhaul.

A reactor trip was due to a failed circuit card in the main turbine control system that caused a throttle valve to close. The outage lasted 4 days.

An outage to repair a leaking pressurizer safety valve lasted 10 days. The outage was prolonged due to a failed relay in the controls for the rod control MG sets.

The third refueling and maintenance outage lasted 59 days. Additional work included snubber testing SG ECT and 5-year overhaul of DG B.

The NRC proposed a $\$ 50,000$ fine for allegedly operating the previous cycle without an operable reactor head vent system.

The unit was shut down for 10 days following the failure of a positioner on an FW regulating valve.

The failure of the main transformer required 54 days to correct.

The fourth refueling and maintenance outage lasted 54 days.

The unit was shut down for 1 week to repair a leaking RCS valve.

The fifth refueling and maintenance outage lasted 60 days.

The NRC fined the licensee $\$ 100,000$ for problems with the hydrogen monitoring system. 
BROWNS FERRY

PRODUCTION COST and CAPITAL ADDITIONS

(1996 Dollars)

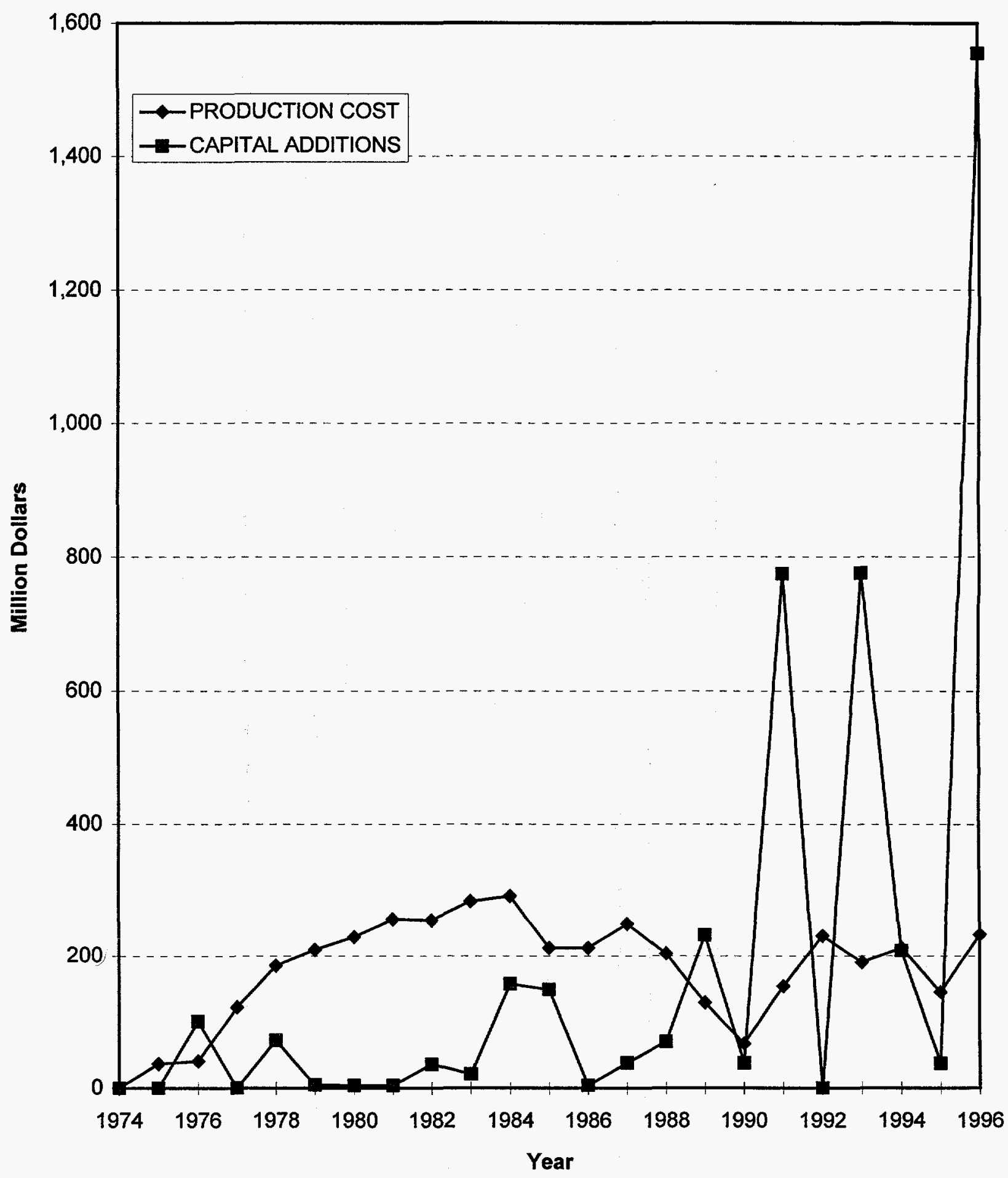




\section{NUCLEAR POWER PLANT OPERATING EXPERIENCE SUMMARY}

Unit data summary through December 1996

\section{Unit: BROWNS FERRY 1}

Location: LIMESTONE COUNTY, ALABAMA

Owner: TENNESSEE VALLEY AUTHORITY

Type: GENERAL ELECTRIC BWR

Construction Permit: 05/10/67

Operating License: $12 / 20 / 73$

Commercial Oper. Date: 08/01/74
Nameplate Rating: 1152 MWe

MDC Net MWe: $1065 \mathrm{MWe}$

Cumul. Avail. Factor: $60.9^{*}$

Cumul. Cap. Factor (MDC Net): $52 . \mathbf{8}^{*}$

Cumul. Forced Outage Rate: $25.6^{*}$

3-Year Avg. Cap. Factor (MDC Net): n/a

License Expiration: 2013

OPERATING HISTORY (To December 1996)

Date

1972

1973

1974

Apr 1974

May 1974

Mar 1975 - Sep 1976

Dec 1976

Jun 1977

Sep 1977 - Jan 1978

Nov 1978 - Jan 1979

\section{Comment}

TVA decided to add mechanical draft cooling towers to plant design at a cost in excess of $\$ 43$ million.

Early startup problems included control rod defects, torus vibration, and fish kills in the circulating water system.

A number of problems occurred with relief valves and the HPCI system during the power escalation and testing program.

Tornados damaged five of seven transmission lines, causing several days of shutdown.

The unit was the first nuclear plant to reach $1000 \mathrm{MWe}$. There was a 3-week shutdown for maintenance on HPCI system and main steam relief valves.

The plant was shut down for an extended outage after a cable fire resulted in a significant amount of damage to the plant; all fuel was unloaded. During the outage, modifications were made to the torus and vent headers, along with LPCI work and installation of additional snubbers.

The unit reached $100 \%$ power after cable fire outage.

Closed-cycle cooling that used cooling towers was initiated.

The first refueling outage was performed. FW spargers were replaced, and CRD return line work was performed. A shoe cover that dropped into the reactor vessel caused an extension of the outage to search for it. It was reported that replacement power for the lost time cost $\$ 2.8$ million.

The second scheduled refueling outage was performed.

"TVA no longer calculates cumulative data for this unit. Cumulative data are through August 1994. 
Jan - Apr 1980

Apr - Oct 1981

Feb 1982

May 1982

Jul - Aug 1982

Jan 1983

Feb 1983

Apr 1983 - Jan 1984

Apr 1984

May 1984

Jun 1984

Aug 1984

Mar 1985

Mar 1985

Jun 1985

Sep 1985

Jan 1986
The third refueling and maintenance outage was performed. Staff replaced cracked HPCI the turbine bearing support pedestal and repaired the damaged RCIC turbine overspeed protection devices. Full power after startup was delayed by FW and recirculation pump maintenance and control rod adjustments.

The fourth refueling outage, including modifications to Mark I torus, lasted 6 months.

NRC assessed a $\$ 50,000$ fine for alleged security violations.

An INPO report praised plant operations in six areas and called for improvements in six other areas.

The unit was shut down for 11 days when secondary containment could not be verified. A displaced relief panel was found in a Unit 1 steam tunnel.

The NRC granted licensee a low-level waste storage license that permitted on-site storage for 5-years from date of waste generation.

TVA paid a $\$ 40,000$ fine to NRC for alleged failure to control access to a protected area and allowing unauthorized entry to the area.

The fifth refueling and extensive maintenance outage lasted 261 days. Major work included TMI-2 and torus modifications; CS sparger and jet pump holddown beam changeout, work on spent fuel pool, and replacement of 100 CRDMs. In May, extensive inspections for IGSC cracks were initiated in several systems after cracks were found in recirculation piping welds. In July, cracks were found in turbine 13th-stage tendon.

NRC assessed TVA a $\$ 40,000$ fine for alleged violation in which a security officer left an entrance to a vital area unattended during a drill in November 1983.

It was determined that cabling for ADS RVs was not adequately separated from non-ADS RV cables. Error was attributed to recovery from 1975 fire and subsequent modifications. Resolution of errors was scheduled for next refueling outage.

TVA paid a $\$ 60,000$ fine to NRC for alleged violations concerning control rod insertion procedures during operation.

TVA paid a $\$ 120,000$ fine to NRC for alleged failures to promptly identify and correct conditions adverse to quality and to make required NRC reports.

The unit was shut down to repair leaking $\mathrm{HPCI}$ and $\mathrm{RCIC}$ valves. The unit remained shut down to begin work to bring plant into compliance with NUREG-0588. It was decided not to restart any of the Browns Ferry units until management was satisfied that the plants could be operated in compliance with all NRC and TVA requirements.

TVA paid a $\$ 100,000$ fine to NRC for alleged violation of primary containment integrity resulting from CS system overpressurizing incident in August 1984.

The fifth refueling and maintenance commenced: work included recirculation piping replacement, hanger and snubber upgrade, and LP turbine rotor maintenance. NRC proposed another \$50,000 fine for alleged security violations that occurred in February 1985.

All eight DGs at the site were declared inoperable because of deficiencies found in DG maintenance and seismic qualification of DG battery racks.

An explosion occurred in the turbine building from a phase-to-phase cable fault; the cause was not determined. 


\section{BROWNS FERRY 1 (Cont'd)}

May 1986

Jul 1986

Sep 1986

Jun 1989

Jul 1989

May 1990

Dec 1996
Fire destroyed one of six cooling towers at the site; the cause was attributed to faulty cable insulation.

An RPS MG set caught fire, resulting in several safety system isolations and actuations. The fire was attributed to dust, high operating temperatures, and degraded electrical insulation.

The NRC proposed a $\$ 150,000$ fine for a number of alleged violations involving design, maintenance, and deficiency reporting.

The plant remained shut down for NUREG-0588 and EQ modifications. NRC retained plant in Category 3 - "Shutdown plants requiring NRC authorization to operate."

The NRC granted TVA's request to extend OL to the year 2013.

The NRC assessed a $\$ 18,750$ fine against TVA for alleged violations concerning control of special nuclear materials.

The unit remained shut down under NRC administrative hold on operation. There is no schedule for restarting the unit. 


\section{NUCLEAR POWER PLANT OPERATING EXPERIENCE SUMMARY}

Unit data summary through December 1996

Unit: BROWNS FERRY 2

Nameplate Rating: $1152 \mathrm{MWe}$

Location: LIMESTONE COUNTY, ALABAMA

MDC Net MWe: $1065 \mathrm{MWe}$

Owner: TENNESSEE VALLEY AUTHORITY

Cumul. Avail. Factor: 69.0

Type: GENERAL ELECTRIC BWR

Cumul. Cap. Factor (MDC Net): 61.8

Construction Permit: 05/10/67

Cumul. Forced Outage Rate: $\mathbf{1 5 . 2}$

Operating License: 08/02/74

3-Year Avg. Cap. Factor (MDC Net): 87.8

Commercial Oper. Date: 03/01/75

License Expiration: 2014

OPERATING HISTORY (To December 1996)

Date

Oct 1974

Mar 1975 - Aug 1976

Dec 1976

Jun 1977

Oct 1977

Mar - Jun 1978

Feb 1980

Jun 1981

Jul 1981

Jul 1982 - Mar 1983

Sep 1984

Dec 1984

Mar 1985

\section{Comment}

The unit was shut down for 10 days because of failure of the main transformer. During shutdown, it was discovered that off-gas HEPA filters had not been installed.

The plant was shut down for an extended outage after a cable fire resulted in a significant amount of damage to the plant; all fuel was unloaded. During the outage, modifications were made to the torus and torus vent headers.

The unit reached $100 \%$ power after cable fire outage.

Closed-cycle cooling that used cooling towers was initiated.

Eight-week outage was performed for turbine maintenance.

A refueling outage and repair of FW spargers was performed.

A 9-day maintenance outage was needed to replace cracked HPCI turbine bearing support pedestal.

A 21-day outage was required for repair of a station service transformer.

A 20-day outage was required to repair another station transformer that had been connected incorrectly.

A refueling and extensive maintenance outage was performed. Major work included TMI-2 and torus modifications, CS sparger and jet pump hold-down beam changeout, relief valve work, and other numerous plant modifications.

A refueling and maintenance outage began. Extensive inspections for IGSC cracks were initiated in several systems after cracks were found in recirculation piping welds. Outage continued through the end of the year.

The NRC assessed a $\$ 50,000$ fine for alleged physical security violations.

The unit remained was shut down to begin work to bring plant into compliance with NUREG-0588. It was decided not to restart any of the Browns Ferry units until management was satisfied that plants could be operated in compliance with all NRC and TVA requirements. A worker was killed when a 25-ton crane hook fell through the roof of an office on the turbine floor. 
Jul 1986

Oct 1986

Nov 1987

Sep 1988

Jan 1989

Feb 1989

Jun 1989

Jul 1989

Jan 1990

Feb 1991

Aug 1991

Dec 1991

Feb 1992

Sep 1992

Jan - Jun 1993

Nov 1993

Apr 1994

Oct - Nov 1994
Cracks were found in all ten recirculation system RPV inlet nozzles; and were believed to be IGSC cracks.

IGSC cracks found in RWCU piping.

A fire occurred in three horizontal cable trays stacked vertically in the drywell. It was determined that the fire was caused by arson because gasoline was found in an electrical pull box and in wood scrap in the area.

TVA reported that the estimated cost of the restart effort for Unit 2 was $\$ 907$ million. TVA settled a lawsuit filed by two engineers who alleged that they had been demoted and harassed for dissenting reports on the scope of the restart effort.

Fuel loading began for eventual restart, but it was delayed by several incidents involving anomalies in core response. The unit was expected to return to service no sooner than August 1989.

Deficiencies were found in seismic design of the emergency cooling water system.

The plant remained shut down for NUREG-0588 and EQ modifications. NRC retained the plant in Category 3, "Shutdown plants requiring NRC authorization to operate."

The NRC granted TVA's request to extend OL to the year 2014.

The unit was defueled to speed replacement of about 275 safety system electrical cables that had been installed without proper documentation. Some pipe supports were modified after a review of the seismic design.

Fuel loading began again for restart.

The plant achieved continuous full power operation.

The NRC proposed a $\$ 75,000$ fine for an alleged breach of primary containment in June 1991. Three employees involved in the event were fired.

The unit completed the year at full power operation with only minor short-term power reductions since August.

The unit was shut down for 8 days due to drywell leakage and to balance the main turbine.

The NRC proposed a $\$ 62,500$ fine for alleged violations involving inoperability of a safety injection pump contrary to Tech Specs.

The unit was shut down for 4 days to correct drywell leakage.

A refueling and maintenance outage lasted 24 days. Major work included main generator rotor and fire protection upgrades, RWCU piping replacement, recirculation pump shaft replacement, and plant computer changeout.

The NRC SALP report gave two Category 1 ratings, operations and plant support, and Category 2 ratings in the remaining two areas.

The unit scrammed when, during maintenance activities on the scram pilot air header, both primary and secondary air pressure regulators were isolated. The unit was shut down for 6 days.

A refueling and maintenance outage lasted 53 days. 


\section{BROWNS FERRY 2 (Cont'd)}

Mar 1996

Mar - Apr 1996

May 1996

Oct 1996
The NRC fined the licensee $\$ 80,000$ for a contractor discriminating against one of its employees.

A refueling and maintenance outage lasted 32 days.

A design error in the feedwater level control system caused a scram that resulted in a 4-day outage.

A main generator malfunction caused a plant shutdown and a 5-day outage. 


\title{
NUCLEAR POWER PLANT OPERATING EXPERIENCE SUMMARY
}

\author{
Unit data summary through December 1996
}

Unit: BROWNS FERRY 3

Location: LIMESTONE COUNTY, ALABAMA

Owner: TENNESSEE VALLEY AUTHORITY

Type: GENERAL ELECTRIC BWR

Construction Permit: 07/31/68

Operating License: 08/18/76

Commercial Oper. Date: 03/01/77
Nameplate Rating: 1152 MWe

MDC Net MWe: 1065 MWe

Cumul. Avail. Factor: 64.5

Cumul. Cap. Factor (MDC Net): 58.6

Cumul. Forced Outage Rate: $\mathbf{1 8 . 8}$

3-Year Avg. Cap. Factor (MDC Net): 54.9

License Expiration: 2016

OPERATING HISTORY (To December 1996)

\section{Date}

Jul 1976

Sep - Nov 1978

Aug - Dec 1979

Jun - Jul 1980

Oct 1981 - May 1982

Jul - Aug 1982

Jan 1983

Sep 1983 - Dec 1984

Aug 1984

Dec 1, 1984

Feb 1985

Mar 1985

\begin{abstract}
Comment
Modifications were required on Unit 3 because the Unit 1 and 2 cable fire delayed initial fuel loading and startup.

A 2-month refueling outage included replacing some FAs and modifying main steam system relief valves and recirculation system trips.

The second refueling outage was performed.

The unit was shut down for about 15 days to resolve problem with CRD SDV draining.

The third refueling outage was extended about 6 weeks because of high turbine vibration. A loose shroud on the LP turbine was repaired.

The unit was shut down for 11 days when the secondary containment could not be verified. A displaced relief panel was found in a Unit 1 steam tunnel. Additional outage time was caused by steam leakage problems.
\end{abstract}

A 20-day outage was needed for false high vibration signals from reactor FW pumps. Shutdown was further prolonged by turbine steam leaks and a leaking RHR heat exchanger, which caused a release to the environment.

Extended outage was needed for refueling and extensive maintenance. Major work included fuel retrofit, TMI-2 and torus modifications, CS sparger and CRD changeout, and replacement of jet pump holddown beams. Extensive inspections for piping and weld cracks were conducted in several systems; only a small crack was found in RHR head spray piping.

Refueling bridge failed, extending core load time by 3 days.

Operation resumed after prolonged outage.

NRC assessed TVA a $\$ 150,000$ fine for alleged violations that occurred during Unit 3 startup in October 1984. TVA paid the fine, but later NRC reduced it by $\$ 37,500$. This amount was then deducted from another fine assessed by NRC for $\$ 150,000$ for alleged violations involving water level instrumentation.

The unit shut down, and NRC placed an administrative hold on operation until management was satisfied that the plants could be operated in compliance with all NRC and TVA requirements. 
Dec 1985

$1986-1995$

July 1989

Nov 1995

May 1996

Jun 1996

Sep 1996
The unit remained shut down and began work to bring the plant into compliance with NUREG-0588.

The plant remained shut down during the period for NUREG-0588 and EQ modifications. NRC retained the plant in Category 3 - "Shutdown plants requiring NRC authorization to operate."

The NRC granted TVA's request to extend OL to the year 2016.

The unit returned to operation and performed restart testing and training.

The unit was shut down for 4 days following a scram due to a low reactor water level.

The unit was taken off the NRC's problem plant list.

The unit was shut down for 6 days for a scheduled maintenance outage. 
This Page Intentionally Left Blank 


\section{BRUNSWICK}

PRODUCTION COST and CAPITAL ADDITIONS

(1996 Dollars)

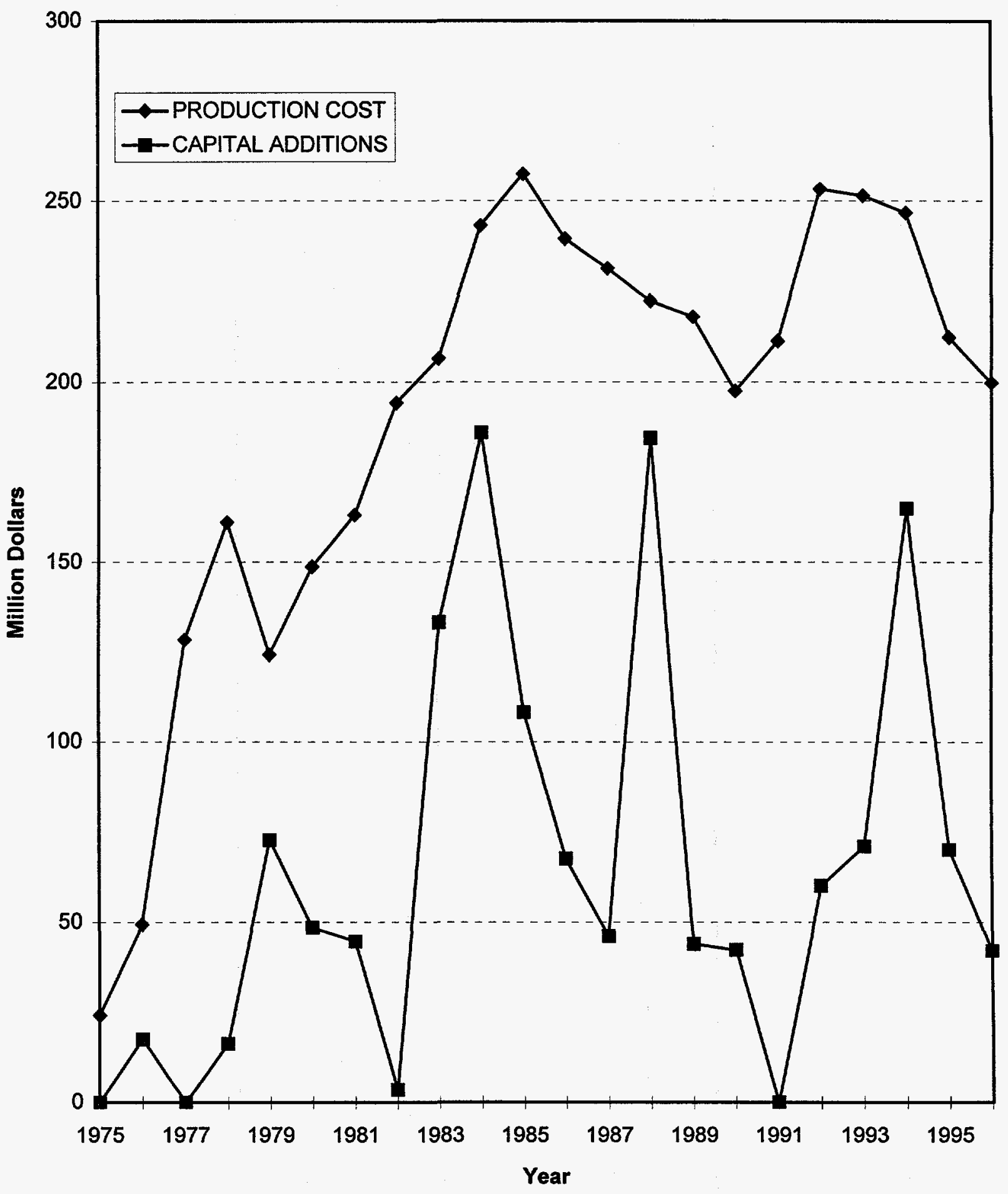




\title{
NUCLEAR POWER PLANT OPERATING EXPERIENCE SUMMARY
}

\author{
Unit data summary through December 1996
}

Unit: BRUNSWICK 1

Nameplate Rating: $867 \mathrm{MWe}$

Location: BRUNSWICK COUNTY, NORTH CAROLINA

MDC Net MWe: $767 \mathrm{MWe}$

Owner: CAROLINA POWER \& LIGHT CO.

Cumul. Avail. Factor: 61.6

TYPe: GENERAL ELECTRIC BWR

Cumul. Cap. Factor (MDC Net): $\mathbf{5 5 . 3}$

Construction Permit: 02/07/70

Cumul. Forced Outage Rate: 13.4

Operating License: 11/12/76

3-Year Avg. Cap. Factor (MDC Net): 86.4

Cómmercial Oper. Date: 03/18/77

License Expiration: 2016

OPERATING HISTORY (To December 1996)

Date

Apr - Jul 1977

Jul - Aug 1977

Nov 1977

Feb 1978

Jan - Apr 1979

May - Jun 1979

Nov 1979

Apr 1980

May - Aug 1980

Mar - Sep 1981

Jul - Oct 1982

Dec 1982 - Aug 1983

Apr 1983

\section{Comment}

An outage was performed for replacement of generator stator and rewinding of field coils damaged from a generator incident.

A 13-day outage for repair of main generator $\mathrm{H}_{2}$ seal leak.

A 14-day shutdown to repair seals on both recirculation pumps.

A 2-week outage to repair several failed seals on recirculation and RWCU pumps and perform other maintenance was conducted.

The first refueling and maintenance outage was performed.

A 16-day outage was required for pipe support inspection and modifications.

Two reactor scrams resulted in an 11-day outage and a 9-day outage. The first was caused by FW flow controller problems; the second was caused by loss of power to two emergency power busses.

The utility was fined $\$ 89,000$ for alleged disposal of contaminated material in a sanitary landfill, some of which had been sold to salvage dealers.

The second refueling outage was extended because of unanticipated maintenance and regulatory problems.

Two outages were caused by MSIV stem/disc separation. Later in April the unit was shut down for removal of oyster shells from the RHR heat exchangers and repair of the main turbine, which had been damaged by failure of the lube oil system.

The unit was shut down for LLRT and ISI. A short-term improvement program was implemented to resolve deficiencies in surveillance and test programs. Long-term program development was continuing.

The third refueling and maintenance outage was performed. Major work included retubing the main condenser with titanium tubes, modification of torus, and installation of advanced off-gas system instrumentation. The NRC-required inspection of recirculation system found IGSC cracks in weld HAZ of 28 -inch diameter piping.

LOSP occurred during switchgear trip testing, and all four DGs started. A fire damaged a $4160-\mathrm{V} / 480-\mathrm{V}$ transformer during the incident. 
Aug 1983

Oct 1983

Feb 1984

Oct - Dec 1984

Mar - Nov 1985

Jul 1985

Feb - Jun 1987

Dec 1987

Jan - Feb 1988

May 1988

Jul 1988

Oct 1988

Nov 1988 - Apr 1989

Feb 1989

Apr 1989

May 1989

Jun 1989

Aug 1989

Sep 1989
The utility paid a record $\$ 600,000$ fine for alleged administrative noncompliance with NRC surveillance requirements that had occurred over several years.

The unit was shut down for maintenance after a number of problems occurred in the rod position indication instrumentation between May and October. The outage lasted 31 days.

The utility paid a $\$ 40,000$ fine for alleged inoperability of both trains of the fire suppression system for the SGTS.

The unit was shut down for LLRT and snubber testing.

The fourth refueling and maintenance outage lasted 224 days. Major items included EQ modifications, torus rework, Appendix R modifications, LP turbine rotor replacement, and major rework of the recirculation system piping to prevent weld cracking.

The reactor building flooded when the CS system actuated while the vessel head and fuel pool gates were removed. The incident was attributed to a number of personnel and procedural errors.

The fifth refueling and maintenance outage lasted 120 days. Major items included piping inspection, RPS modifications to meet ATWS requirements, RWCU system piping replacement, and installation of SPDS.

The two-unit plant had operated continuously for 181 days, which was a new world record for a dual-BWR unit plant.

A 30-day planned maintenance outage was needed for Appendix $R$ modifications and inspection of vital switchgear. A number of failed bolts were found in MCCs at both units; failures were attributed to overtorquing.

The NRC proposed a $\$ 50,000$ fine for alleged deficiencies in EQ of electrical equipment. The penalty was reduced from $\$ 150,000$ because of the utility's prompt reporting and initiation of corrective action.

The NRC sent an AIT to the site to investigate a number of equipment failures associated with a shutdown to replace an HPCI valve.

The NRC placed the unit on its list of eight problem plants.

The sixth refueling and maintenance outage lasted 162 days. The outage entered early after scram from turbine control circuit malfunction. Major maintenance included control rod upgrade, turbine improvements, ATWS modifications, and inspection and repair of IGSC cracks in several systems.

The utility paid a $\$ 75,000$ fine for alleged failure to take prompt action on certain identified equipment deficiencies.

The utility applied to NRC to operate an independent spent fuel storage facility onsite.

The utility paid a $\$ 150,000$ fine for alleged violations of NRC requirements.

The NRC assessed a $\$ 50,000$ fine for alleged violations involving failure to meet $\mathrm{EQ}$ requirements.

A report by the NRC Diagnostic Evaluation Team faulted the utility for failure to correct chronic equipment problems.

The unit was manually shut down because of the warning of Hurricane Hugo. 
Jan 1990

May 1990

Jun 1990

Sep 1990 - Feb 1991

Oct 1990

Mar 1991

May 1991

Dec 1991

Jan 1992

Jan 1992

Mar 1992

Apr 1992 - Feb 1994

Jul 1992

Feb 1993

Jun 1994

Apr - May 1995

Jun 1995
The NRC assessed a $\$ 75,000$ fine for alleged failures to promptly identify and correct deficiencies in operation of the SW system.

Unit 1 was shut down after a number of operators failed requalification tests and all four crews failed group operating tests. NRC issued a confirmatory letter requiring that the plant remain shut down until NRC approval for restart.

The NRC granted approval for restart of both units after four of five operating crews passed NRC examinations.

The seventh refueling and maintenance outage lasted 153 days. Major work included replacement of recirculation piping safe ends, SW piping replacement, RV water level I\&C upgrade, ATWS modifications, and other plant modifications. During the outage, a FA was dropped into the core by a malfunction of the refueling machine.

The NRC assessed a $\$ 62,500$ fine for alleged inadequate work procedures and controls over personnel radiation exposure.

The unit was shut down after the DG was damaged by repairmen working without an approved procedure. Total outage time was 39 days.

The NRC proposed a $\$ 87,500$ fine for alleged violations relating to recurring personnel performance problems involved in the damaged DG during the previous outage.

The unit operated for the balance of the year with only three short-duration shutdowns of less than 8 days each, which totaled 22 days.

The NRC fined the utility $\$ 125,000$ for alleged violations involving inadequate corrective actions for previous violations concerning work control, independent verification, and failure to follow procedures. The fine was increased from the base penalty because previous corrective actions for similar problems had been ineffective.

The NRC SALP review rated two areas, maintenance/surveillance and safety assessment/quality verification, as low Category 3 ratings.

The NRC fined the utility $\$ 100,000$ for alleged violations involving inadequate maintenance of one of the DGs.

The unit was shut down due to the diesel generators being declared inoperable when faulty wall bolts in the diesel generator building were discovered. The unit remained shut down to reduce the backlog of maintenance work and to perform structural inspections. The unit was also refueled during this outage.

The plant was placed on the NRC's problem plant list.

The NRC fined the utility $\$ 225,000$ for alleged violations involving the corrective action program as shown in the response to a faulty wall in the diesel generator building. The fine was increased from the base penalty due to the plant's previous negative enforcement history, duration of problems, and CP\&L's lack of identification of the problems.

The plant was removed from the NRC's problem plant list.

A refueling and maintenance outage lasted 50 days.

The plant received all Category 1 ratings on its NRC SALP report, and the evaluations were lengthened to a 24-month cycle. 


\section{BRUNSWICK 1 (Cont'd)}

Jul 1995

The unit was down for 4 days following a scram due to a malfunction of the main turbine's control system.

Mar 1996

The unit was shut down for 6 days to repair the service water pumps.

Jul 1996

The unit was shut down for 1 week due to Hurricane Bertha.

Sep 1996

The unit was shut down for 5 days due to Hurricane Fran.

Oct - Nov 1996

A refueling and maintenance outage lasted 33 days.

Nov 1996

The NRC fined the licensee $\$ 150,000$ for programmatic EQ issues. 


\section{NUCLEAR POWER PLANT OPERATING EXPERIENCE SUMMARY}

Unit data summary through December 1996

Unit: BRUNSWICK 2

Location: BRUNSWICK COUNTY, NORTH CAROLINA

Owner: CAROLINA POWER \& LIGHT CO.

Type: GENERAL ELECTRIC BWR

Construction Permit: 02/07/70

Operating License: $12 / 27 / 74$

Commercial Oper. Date: 11/03/75
Nameplate Rating: $867 \mathrm{MWe}$

MDC Net MWe: 754 MWe

Cumul. Avail. Factor: $\mathbf{6 2 . 1}$

Cumul. Cap. Factor (MDC Net): $\mathbf{5 3 . 4}$

Cumul. Forced Outage Rate: 10.7

3-Year Avg. Cap. Factor (MDC Net): 81.7

License Expiration: 2014

OPERATING HISTORY (To December 1996)

Date

1975

May 1975

Jun - Jul 1975

Sep 1975

Jan 1976

Nov - Dec 1976

Apr - May 1977

Sep 1977 - Jan 1978

Jun 1978

Sep 1978

Mar - May 1979

May - Jun 1979

Mar - Sep 1980

Mar - Apr 1981

\section{Comment}

The NRC ordered installation of 10 microearthquake stations to detect seismic activity.

Two shutdowns totaling 8 days were required because relief valve $B$ failed open and caused reactor depressurization.

Excess liquid radwaste caused a 30- day shutdown; additional work included recirculation pump repair and drywell cooling modifications.

An RPV pressure transient and consequent scram caused a 17-day shutdown. Recirculation pumps were repaired during the outage.

The utility paid a $\$ 5000$ fine for alleged security violations.

A 1-month outage was required for repair of a recirculation pump seal.

A 3-week outage was required for modifications to recirculation pumps and other maintenance items.

The first refueling and maintenance outage was performed. Major work included CS piping crack repair and FW sparger replacement. Startup was delayed by steam leaks and HPCI problems.

The unit was shut down for 19 days to repair the main generator and recirculation pump.

An 18-day outage was needed for repair of expansion joints and condenser tubes; the outage was extended for recirculation pump nozzle inspection.

The second refueling and maintenance outage was performed. Major work included replacement of CS piping.

Two outages, one for 17 days and one for 4 days, were required for pipe support and snubber inspections and modifications.

The third refueling and maintenance outage lasted 200 days. Major items included Mark I torus modifications and repair of snubber damage caused by a water slug in the SRV discharge line. Unanticipated maintenance and regulatory problems extended the outage.

The unit was shut down for snubber testing outage. Another outage of 4 days was required for replacement of fiber condenser plugs with metal ones because of leaks. 


\section{BRUNSWICK 2 (Cont'd)}

May - Jun 1981

Jul 1981

Apr - Oct 1982

Nov 1982

Feb 1983

Apr - May 1983

Jul - Aug 1983

Nov 1983 - Jan 1984

Mar - Oct 1984

Nov - Dec 1984

Mar 1985

Sep 1985

Nov 1985 - Jun 1986

Oct - Nov 1986

Dec 1987

Jan - Apr 1988

May 1988

Jun 1988

Oct 1988
The unit was shut down for about 1 month to remove marine growth from SW system.

The unit was shut down for 9 days to repair an inboard MSIV. The NRC assessed a $\$ 40,000$ fine for alleged overexposure of a maintenance worker during repair of a RWCU system valve.

The fourth refueling and maintenance outage was performed. Major work included modifications to CRDMs, Mark I containment and SDV valves and instruments. Improved air dryers were installed to reduce moisture in air systems. The outage extended about 10 weeks to complete a short-term improvement program to resolve deficiencies in surveillance and test programs. Long-term program development was continuing.

A TIP maintenance outage was performed.

A 13-day outage was required to repair the recirculation pump seal.

A planned maintenance outage to replace three RWCU heat exchangers occurred. A Unit 1 LOSP and transformer fire caused extension of outage to a total of 31 days.

Indication of leakage in the drywell caused by leaky packing on $\mathrm{HPCI}, \mathrm{RCIC}$, and CS valves caused the unit to shut down. Sea grass on circulating water intakes clogged a condenser filter. The unit was back on line after 12 days.

The unit was shut down for NRC-mandated inspection of recirculation piping. Twenty-four welds were found with IGSC crack indications. The inspection outage lasted 64 days.

The fifth refueling and maintenance outage was performed. Major work included retubing the main condenser, modification of torus, Appendix R modifications, 10-year ISI, recirculation piping inspection, and installation of advanced off-gas system instrumentation.

Several short-duration shutdowns occurred because of steam leaks and high drywell temperatures; a main turbine trip on high MSR level caused 21 days of outage in December.

A 12-day outage was needed for recirculation pump seal replacement, drywell insulation, HVAC repair, and CRD work.

The unit was shut down for a hurricane alert; a steam leak on an RHR valve was repaired. Total outage time was 15 days.

The sixth refueling and maintenance outage lasted 197 days. Major items included EQ and Appendix R modifications, LP turbine rotor replacement, and inspection and repair of recirculation piping welds.

A 15-day outage was performed for surveillance and maintenance.

The 2-unit plant had operated continuously for 181 days, which was a new world record for a dual-BWR unit plant.

The seventh refueling and maintenance outage lasted 116 days. Major items included Appendix R modifications, FW sparger inspection, installation of SPDS, upgrading of SW piping, and repair of RPV head flange seal leak.

A 10-day planned maintenance outage was performed for Appendix $R$ modifications and inspection of vital switchgear bolts. A number of bolt failures were found in MCCs at both units; failures were attributed to static failure caused by overtorquing.

The NRC sent an AIT to the site to investigate a number of equipment failures associated with a shutdown to replace a HPCI injection valve. The unit was shut down for 9 days.

The NRC placed the unit on its list of eight problem plants. 
Jun 1989

Sep 1989 - Mar 1990

May 1990

Jun 1990

Aug 1990

Sep 1990

Oct 1990

Jan 1991

Mar 1991

May 1991

Sep - Dec 1991

Dec 1991 - Jan 1992

Feb 1992

Jul 1992

Apr 1992 - Jun 1994

Jun 1994

Jun 1995

Feb - Mar 1996

Mar 1996

Jul 1996

Sep 1996
The unit lost all off-site power for 10 hours after a repair crew caused a short circuit and loss of the startup auxiliary transformer. Total outage time was 11 days.

The eighth refueling and maintenance outage lasted 188 days. The utility reported that a contract had been awarded to GE to replace recirculation piping during this outage.

Unit 2 was shut down after a number of operators failed requalification tests and all four crews failed group operating tests. The NRC issued a confirmatory letter requiring that the plant remain shut down until NRC approval for restart. Remedial training required a 23-day outage.

The NRC granted approval for restart of both units after four of five operating crews passed NRC examinations.

A reactor scram caused by personnel error resulted in a 15-day outage.

A unit trip occurred due to instability in the main generator voltage regulator, and the unit was down for 5 days.

A reactor scram was caused by a blown fuse in the FW level control system. The unit was shut down for 7 days.

A reactor scram on high water level was due to an FW flow logic calibration error. The outage lasted 6 days.

The unit was shut down after the DG was damaged by repairmen working without an approved procedure. Total outage time was 39 days.

The utility was fined $\$ 50,000$ by the NRC for alleged errors that caused a reactor scram on high water level in January 1991.

The ninth refueling and maintenance outage lasted 98 days. Major work included recirculation piping decontamination, modifications to the control room and service water system, and MOV improvements.

The unit was shut down for 14 days to resolve high temperatures on main turbine bearings.

The unit scrammed during turbine control valve testing due to a EHC system failure. A 12day outage was needed to repair the EHC system.

The plant was placed on the NRC's problem plant list.

The unit was shut down due to the diesel generators being declared inoperable when faulty wall bolts in the diesel generator building were discovered. The unit remained shut down to reduce the backlog of maintenance work and to perform structural inspections. The unit was also refueled during this outage.

The plant was removed from the NRC's problem plant list.

The plant received all Category 1 ratings on its NRC SALP report and the evaluations were lengthened to a 24-month cycle.

The eleventh refueling and maintenance outage lasted 39 days.

The unit was shut down when all service water pumps were declared inoperable.

The unit was shut down for 1 week due to Hurricane Bertha.

The unit was shut down for 9 days due to Hurricane Fran. 


\section{BYRON}

PRODUCTION COST and CAPITAL ADDITIONS (1996 Dollars)

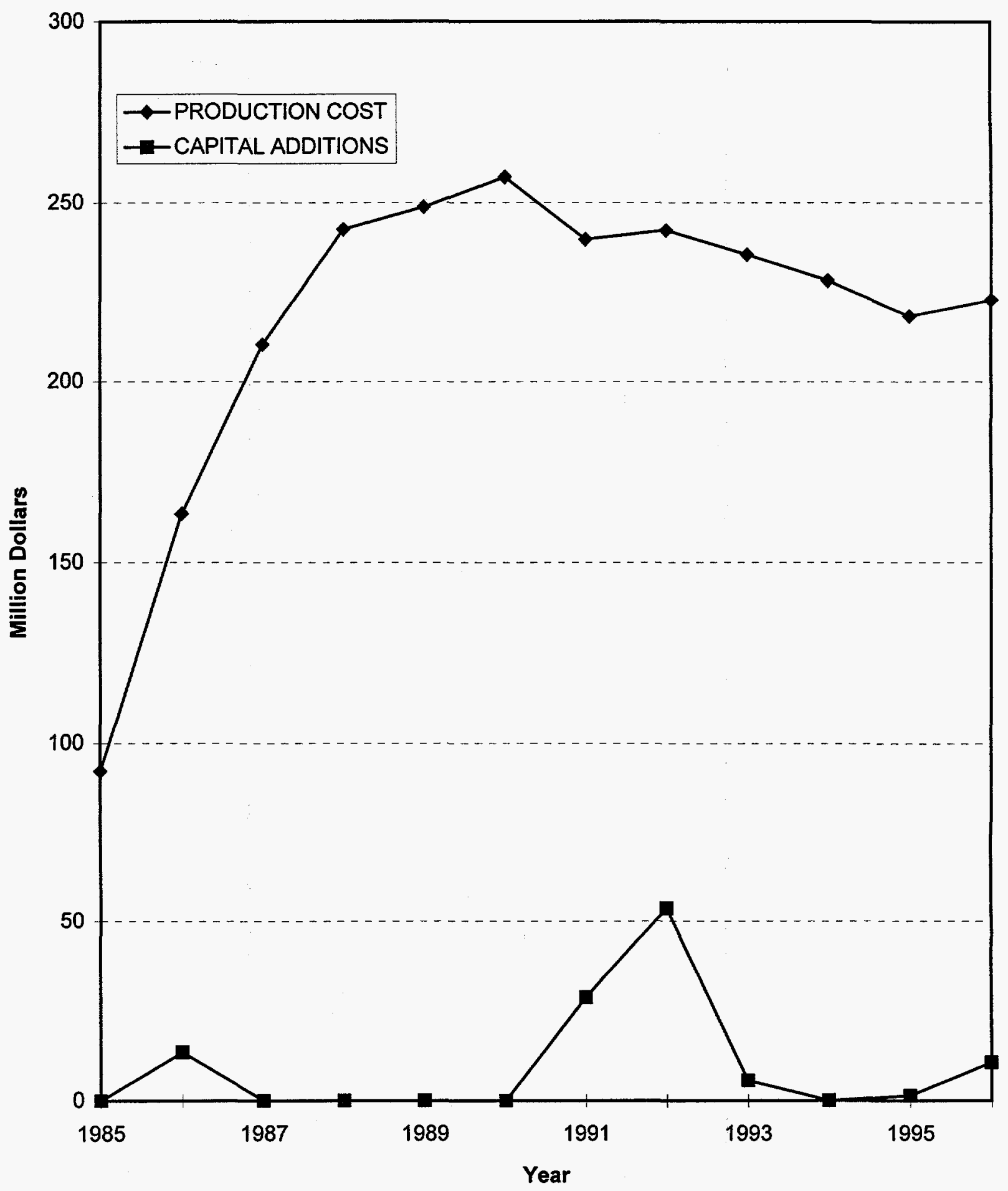




\section{NUCLEAR POWER PLANT OPERATING EXPERIENCE SUMMARY}

Unit data summary through December 1996

\section{Unit: BYRON 1}

Location: OGLE COUNTY, ILLINOIS

Owner: COMMONWEALTH EDISON CO.

Type: WESTINGHOUSE PWR

Construction Permit: 12/31/75

Operating License: 02/14/85

Commercial Oper. Date: 09/16/85
Nameplate Rating: 1175 MWe

MDC Net MWe: 1105 MWe

Cumul. Avail. Factor: 81.9

Cumul. Cap. Factor (MDC Net): 73.0

Cumul. Forced Outage Rate: $\mathbf{2 . 2}$

3-Year Avg. Cap. Factor (MDC Net): 73.4

License Expiration: 2024

OPERATING HISTORY (To December 1996)

Date

Jan - Oct 1984

Dec 1984

Mar 1985

Oct - Dec 1985

Feb - Mar 1986

Mar 1986

Jun 1986

Jul 1986

Nov 1986

Feb - Jun 1987

Apr 1987

May 1987

\section{Comment}

The ASLB questions regarding the utility QA program delayed the fuel load about 9 months.

The NRC proposed a $\$ 40,000$ fine for alleged material false statements made regarding source inspections of safety-related equipment.

The NRC assessed a $\$ 25,000$ fine against the utility for allegedly leaving vital area doors open without compensatory measures in effect.

The unit was shut down for planned SG modifications and EQ work. Total outage time was 53 days. The NRC assessed a $\$ 25,000$ fine for alleged radiation protection procedure deficiencies. The penalty was reduced from $\$ 50,000$ on the basis of extensive utility corrective actions, including retraining about 1250 persons.

The unit was shut down for 15 days for scheduled maintenance.

The NRC proposed a $\$ 50,000$ fine against the utility for alleged breach of a vital area barrier.

The NRC proposed a $\$ 25,000$ fine against the utility for allegedly discharging a subcontractor employee for reporting inadequate inspection procedures to the NRC.

The unit was shut down for $\mathbf{2 1}$ days to resolve a conflict within the plant TS regarding boron dilution protection system.

The NRC proposed a $\$ 25,000$ fine against the utility for four alleged violations of requirements in the installation of code safety valves. The fine was reduced from $\$ 50,000$ because of prompt and effective action by the utility.

The first refueling outage lasted 109 days. Major work included SG inspection and shot-peening, pipe whip restraint removal, and turbine volumetric inspection.

The NRC assessed a $\$ 50,000$ fine against the utility for alleged testing methods for the RHR system that rendered the system inoperable during power operation. The NRC assessed another fine of $\$ 50,000$ for alleged violations involving surveillance procedures and testing.

The utility reported that the unit had produced more electricity than any other nuclear generating unit in the United States in 1986. The unit was available for service more than $88 \%$ of the year. 
Apr 1988

May - Jun 1988

Sep - Nov 1988

Oct 1988

Jan - Mar 1990

Sep - Nov 1991

Feb - Apr 1993

Apr 1993

Sep 1994

Sep 1994

Dec 1994

Oct 1995

Apr - Jul 1996
The unit was shut down for 12 days to repair an SG tube leak and to perform snubber inspections.

The unit was shut down for 14 days to repair SG tube leaks.

The second refueling outage lasted 68 days. Major work included SG inspection, LP turbine rotor A replacement, and extensive plant equipment inspections.

The NRC assessed a $\$ 50,000$ fine for alleged inoperability of shutdown cooling during preparations for refueling.

The third refueling outage lasted 55 days. Major work included SG inspection and tube plugging, LP turbine rotors B and C replacement, and ISI and control room design review modifications.

The fourth refueling outage lasted 64 days. Additional major work included ISI, ECT of the secondary HX, and inspections of the main turbine HP and LP sections.

The fifth refueling and maintenance outage lasted 65 days.

A 4-day outage was needed to repair a pressurizer safety valve.

The sixth refueling and maintenance outage lasted 55 days. The unit had operated a year without any significant outages.

The plant received all Category 1 ratings on its NRC SALP report, and the evaluations were lengthened to a 24-month cycle.

The plant was shut down for 12 days to repair condenser tube leaks.

A scheduled outage to perform SG tube inspection lasted 64 days.

The seventh refueling and maintenance outage lasted 90 days. 


\section{NUCLEAR POWER PLANT OPERATING EXPERIENCE SUMMARY}

Unit data summary through December 1996

Unit: BYRON 2

Location: OGLE COUNTY, ILLINOIS

Owner: COMMONWEALTH EDISON CO.

Type: WESTINGHOUSE PWR

Construction Permit: 12/31/75

Operating License: 01/30/87

Commercial Oper. Date: 08/21/87
Nameplate Rating: 1175 MWe

MDC Net MWe: 1105 MWe

Cumul. Avail. Factor: 86.3

Cumul. Cap. Factor (MDC Net): 76.4

Cumul. Forced Outage Rate: $\mathbf{2 . 5}$

3-Year Avg. Cap. Factor (MDC Net): 87.8

License Expiration: 2026

OPERATING HISTORY (To December 1996)

Date

Feb - Apr 1987

Aug 1987

Nov - Dec 1987

Jan - Mar 1989

May 1989

Nov 1989

Jun 1990

Sep - Nov 1990

Oct 1991

Feb - Apr 1992

Jul 1992

Sep - Oct 1993

Sep 1994

Feb - Mar 1995

May 1996

Aug - Oct 1996

\section{Comment}

The unit experienced a number of shutdowns and short outages because of startup testing and minor equipment problems.

A hydrogen gas leakage in the main generator stator cooling system forced a 9-day outage.

The unit was shut down for a planned surveillance outage. Total outage time was 26 days.

The first refueling outage lasted 55 days. Major maintenance included SG tube U-bend stress relief, SG inspection and tube plugging, and fuel inspection.

$\mathrm{A}_{2}$ leak in the generator stator cooling system required a 7-day outage for repair.

A leaking pressurizer relief valve required an 8-day outage to replace it.

The unit received five Category 1 ratings on NRC SALP review of performance.

The second refueling outage lasted 82 days. Major maintenance included replacement of the main turbine LP section and HP turbine repair and upgrade.

Packing leakage on isolation valves required an 11-day outage for repairs.

The third refueling outage lasted 94 days. Major maintenance included testing and maintenance on the SGs.

A 7-day outage was required to replace hydrogen seals.

The fourth refueling and maintenance outage lasted 53 days.

The plant received all Category 1 ratings on its NRC SALP report, and the evaluations were lengthened to a 24-month cycle.

The fifth refueling and maintenance outage lasted 44 days.

The unit was shut down to repair damage due to water intrusion into the $4-\mathrm{kV}$ system.

Increased primary-to-secondary leakage in one SG caused the unit to be shut down. The sixth refueling outage was entered early. Total outage time was 58 days. 


\section{CALLAWAY}

PRODUCTION COST and CAPITAL ADDITIONS

(1996 Dollars)

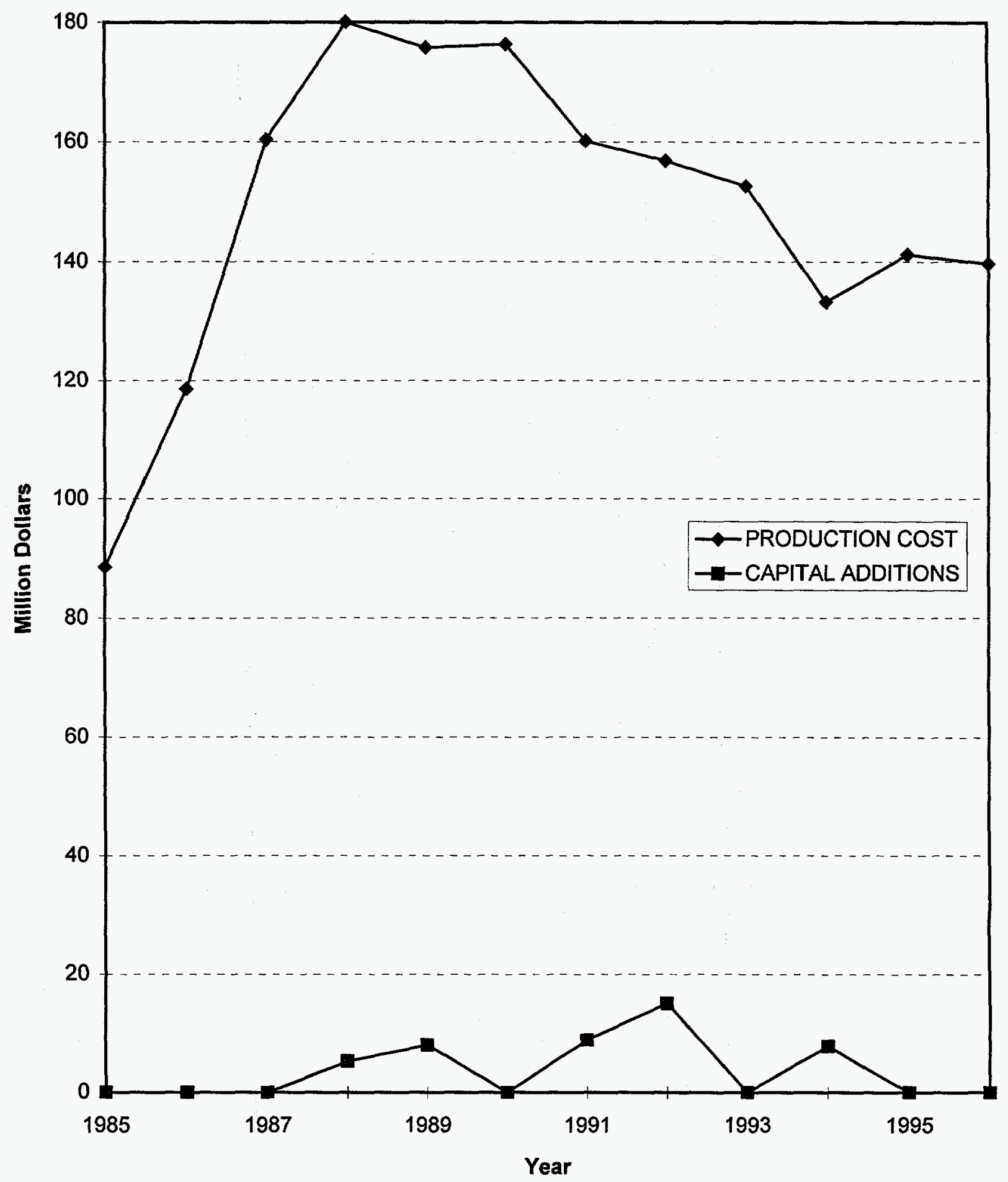




\section{NUCLEAR POWER PLANT OPERATING EXPERIENCE SUMMARY}

Unit data summary through December 1996

Unit: CALLAWAY

Location: CALLAWAY COUNTY, MISSOURI

Owner: UNION ELECTRIC CO.

Type: WESTINGHOUSE PWR

Construction Permit: 04/16/76

Operating License: $\mathbf{1 0 / 1 8 / 8 4}$

Commercial Oper. Date: 12/19/84
Nameplate Rating: 1236 MWe

MDC Net MWe: 1125 MWe

Cumul. Avail. Factor: 86.8

Cumul. Cap. Factor (MDC Net): 84.9

Cumul. Forced Outage Rate: 2.3

3-Year Avg. Cap. Factor (MDC Net): 92.0

License Expiration: 2024

OPERATING HISTORY (To December 1996)

Date

Feb 1985

Mar - Apr 1985

Dec 1985

Feb - Apr 1986

Oct 1986

Dec 1986

Apr - May 1987

Jul 1987

Sep - Nov 1987

Mar 1988

Mar - May 1989

Apr 1990
Comment

The NRC assessed a $\$ 25,000$ fine for alleged operation with containment spray system inoperable for 4 days in August 1984.

The unit was shut down for 12 days to remove startup strainers on MS valves.

The unit led the U.S. LWRs in lowest generating costs for year.

The first refueling outage lasted 49 days. Major work included inspection of two SGs and the main generator, FW pump overhaul, and inspection of RCP seal and MSRs. The unit operating license was amended to use $\underline{\underline{W}}$ optimized FAs.

The NRC assessed a $\$ 25,000$ fine for two alleged violations of safety requirements. One case involved the ECCS; the other was auxiliary FW system.

The unit completed the year as the sixth lowest cost producer of nuclear-generated electricity.

The unit was shut down for a planned maintenance outage of 40 days. Work involved SG sludge lancing and containment isolation leak rate testing.

The NRC assessed a $\$ 50,000$ fine for alleged violation of control room emergency ventilation requirements.

The second refueling outage lasted 65 days. Major work included DG and HP turbine overhaul, seal replacement in two RCPs, and cooling tower repair. Stuck RV head closure bolts and MSIV packing leaks prolonged the outage.

The NRC allowed the utility to increase core thermal power from $3144 \mathrm{MWt}$ to $3565 \mathrm{MWt}$.

The third refueling outage lasted 53 days. Major work included removing stuck RV head rings, LP turbine inspection, replacement of seal on two RCPs, DG inspection, SG cleaning and inspection, ATWS modifications, and FA leak checks.

The unit earned top Category 1 ratings in all functional areas for performance during the NRC SALP period. The unit was also listed by the NRC as a good performer, subject to reduced regulatory inspection and monitoring. 


\section{CALLAWAY (Cont'd)}

Sep - Nov 1990

Mar - May 1992

Jul 1992

Oct - Nov 1993

Mar - May 1995

Jun 1995

Oct 1995

Oct - Nov 1996

Dec 1996
The fourth refueling outage lasted 56 days. Major maintenance work included RCP inspection and seal replacement, RCP motor inspection, SG cleaning and inspection, overhaul of AFW pump turbine, and RTD bypass removal.

The fifth refueling outage lasted 60 days. Major maintenance work included inspection and work on the SGs and DGs.

The unit was again listed by the NRC as a good performer, subject to reduced regulatory inspection and monitoring. This was the sixth consecutive year for this listing, and the unit has been on the list since the NRC began its compilation.

The sixth refueling and maintenance outage lasted 52 days.

The seventh refueling and maintenance outage lasted 48 days.

The plant received all Category 1 ratings on its NRC SALP report, and the evaluations were lengthened to a 24-month cycle.

The plant was shut down for 9 days to repair a leak in the CVCS.

The eighth refueling and maintenance outage lasted 31 days.

A 4-day outage was necessary to repair a feedwater isolation valve. 
This Page Intentionally Left Blank 
CALVERT CLIFFS

PRODUCTION COST and CAPITAL ADDITIONS (1996 Dollars)

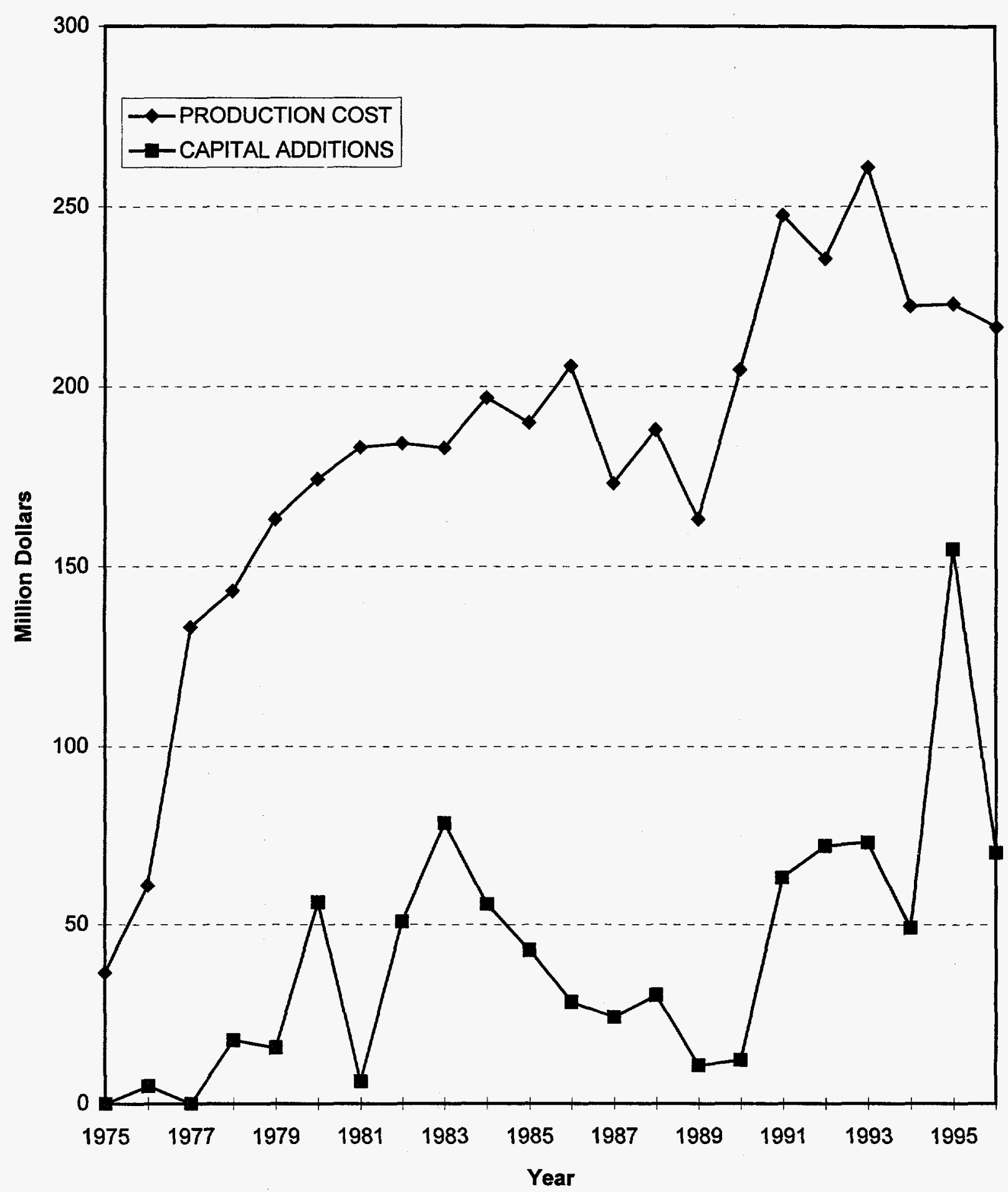




\section{NUCLEAR POWER PLANT OPERATING EXPERIENCE SUMMARY}

Unit data summary through December 1996

Unit: CALVERT CLIFFS 1

Location: CALVERT COUNTY, MARYLAND

Owner: BALTIMORE GAS \& ELECTRIC CO.

Type: COMBUSTION ENGINEERING PWR

Construction Permit: 07/07/69

Operating License: 07/31/74

Commercial Oper. Date: 05/08/75
Nameplate Rating: 918 MWe

MDC Net MWe: 835 MWe

Cumul. Avail. Factor: $\mathbf{7 0 . 9}$

Cumul. Cap. Factor (MDC Net): 69.1

Cumul. Forced Outage Rate: $\mathbf{8 . 7}$

3-Year Avg. Cap. Factor (MDC Net): 75.4

License Expiration: 2014

OPERATING HISTORY (To December 1996)

Date

Nov 1974

Jan 1975 - Feb 1976

Apr 1975

Apr 1976

Dec 1976

Jan - Apr 1977

Jan - Apr 1978

Dec 1978 - Jan 1979

Apr - Jul 1979

Jan - Feb 1980

Oct 1980 - Jan 1981

Jul 1981

Apr - Jul 1982

\section{Comment}

Power ascension testing was delayed for about 2 months by a higher than expected water flow resistance in the RCS because of a thin buildup (about 1 mil thick) of oxides on the core internals.

Power reductions lasting 17 days were caused by condenser tube leaks, which resulted in a loss of about 50,500 MWh.

The unit was shut down for 14 days for planned maintenance.

The unit was shut down for 12 days for leak rate testing of containment pipe penetrations.

During the year, load reductions were required on 19 occasions to plug leaking condenser thibes.

The first refueling and maintenance outage lasted 3 months. Major items included FA inspection, reactor cavity neutron shield installation, and addition of a blowdown recovery system and additional condensate demineralizers.

The second refueling and maintenance outage lasted 3 months. It began early because of RCS leaks. Major items included CEA guide tube repair and RCS leak repairs.

A 1-month shutdown was caused by repairs to the HP turbine that was damaged by blade separation from shroud.

The third refueling and maintenance outage was performed.

The unit was shut down for about $2 \frac{1}{2}$ weeks to make TMI modifications.

The fourth refueling and maintenance outage included TMI modifications and general plant inspections. A turbine thrust bearing failure caused a delay in startup.

The unit was shut down to replace the RCP seal. During the outage, a leak in the main condenser resulted in salt contamination of the secondary system, extending the outage to about 2 weeks.

The fifth refueling and maintenance outage was performed. Major items included retubing the main condenser and conduct general plant inspections. 
Dec 1982

Jan 1983

Oct - Dec 1983

Dec 1983

May 1984

Nov 1984

Dec 1984

Apr - Aug 1985

Sep 1985

Oct 1986 - Jan 1987

Dec 1986

Mar 1987

Apr - May 1987

Jul 1987

Aug 1987

Apr - Jul 1988
Units 1 and 2 combined were rated second in capacity factor (73.7\%) for U.S. multiunit plants for 1980 - 1982.

An INPO report cited 8 good practices and made 42 recommendations for improvements in 27 areas.

The sixth refueling and maintenance outage lasted 15 weeks. During restart, a main turbine bearing failed, and restart was delayed 8 days.

The utility paid a $\$ 60,000$ fine to the NRC for two alleged violations concerning the operability of safety systems.

The unit was shut down for 25 days to repair damage from graphitic corrosion of cast iron components in saltwater systems.

During a plant trip, a worker was burned by steam from an extraction steam line break caused by wet steam erosion.

The unit was shut down for 13 days to repair an MSIV.

The seventh refueling and maintenance outage was performed and was prolonged because of main generator repairs for short circuits and RCP shaft seal replacement. High temperatures in the main generator caused by a blocked stator cooling pipe resulted in an additional outage of 13 days .

The NRC proposed a $\$ 50,000$ fine for alleged violations concerning required plant changes needed to improve radiological measurements during accident conditions.

The eighth refueling and maintenance outage was performed. Major work included a 10-year ISI, installation of a new plant computer and reactor water level system, and changeout of MSR tube bundles, LP turbine rotor, and MSIVs.

The utility announced that the plant had its most productive year with a capacity factor of $88 \%$.

The NRC approved a license amendment extending the limit for Unit 1 operation to July 31,2014 , which is 40 years from the start of operation. This was the first extension of its kind for an operating reactor. The utility announced that fuel cycles would be extended from 18 months to 24 months.

The unit was shut down to repair/replace unqualified electrical splices and connectors because EQ documentation had not been maintained. During the outage, about 4000 gallons of borated water were accidently sprayed into containment, contaminating several workers.

Both units tripped following an LOSP caused by off-site transmission line breaker problems. The unit 1 outage lasted 13 days .

A report by an IAEA OSART team praised plant performance and stated that the plant was above average among those visited by the team.

The ninth refueling and maintenance outage lasted 86 days. Major work included extensive ISI of plant systems; inspection of SGs, HP turbine and main generator; ILRT; RCP motor replacement; and main steam piping replacement. 


\section{CALVERT CLIFFS 1 (Cont'd)}

Sep 1988

Sep 1988

Oct 1988

Oct - Nov 1988

Dec 1988

Mar - Apr 1989

Apr 1989

May 1989 - Apr 1990

Aug 1989

Mar 1990

Apr - Oct 1990

Dec 1990

Dec 1990

Jan 1991

Feb 1991

May - Jul 1991

Dec 1991
A plant worker drowned while attempting to rescue a diver who had become trapped in the condensate storage tank. The diver was rescued by other workers. The utility was fined by the Maryland Occupational Safety and Health Administration for inadequate procedures to address work in confined spaces and for neglecting to provide instructions to employees for such activities.

The NRC proposed a $\$ 150,000$ fine for two alleged violations concerning operability of vital safety systems.

The unit became a candidate for NRC Category 2 list of problem plants.

The unit was shut down for 13 days for scheduled maintenance.

The plant was placed in NRC Category 2 of the problem plant list, performance had improved, but some weaknesses remained.

The unit was shut down for 27 days to replace RCP seal with a new design. Another outage of 25 days was required because of high sulfate levels in the reactor coolant.

The utility paid a $\$ 300,000$ fine to the NRC for alleged violations involving inadequate $\mathrm{EQ}$ of certain types of electrical equipment.

The plant was shut down because a of possible pressurizer heater leakage after evidence was found in Unit 2. The cause of the leakage was thought to be from stress corrosion cracking of Inconel 600 . Total outage time was 345 days.

The NRC assessed a $\$ 75,000$ fine for alleged violations concerning plant configuration control and containment integrity.

The NRC proposed and the utility paid a $\$ 100,000$ fine for alleged violations involving failure to meet all the requirements for low temperature, overpressure protection of the reactor vessels.

The plant was shut down for scheduled SG inspection, RCP seal work, and saltwater system maintenance. Total outage time was 164 days.

The utility received three Category 3 ratings in the NRC SALP report, but the agency noted some improvement in plant operations, maintenance, and surveillance.

The plant was shut down for $\mathbf{2 0}$ days to repair nitrogen leaks on SI tanks.

The utility paid a $\$ 12,500$ fine imposed by the NRC for alleged safeguards violations.

The plant remained on the NRC problem plant list.

The unit was shut down for 17 days for inspection and cleaning of containment sump recirculation suction piping.

The unit was shut down for 51 days for scheduled maintenance and surveillance testing. RCP vibration caused an additional 10 days of outage time. The NRC first-quarter 1991 SALP report indicated that plant performance was continually improving.

The unit was shut down for $\mathbf{8}$ days to repair an SI tank and replace the disk O-ring. 
Mar - Aug 1992

Jul 1992

Aug 1992

Nov 1992

Jun 1993

Jan 1994

Feb - Jun 1994

Jul 1994

Jun 1995

Nov 1995

Jan 1996

Mar - Jun 1996

Jun 1996

Jul 1996
The tenth refueling and maintenance outage lasted 145 days. The unit initially shut down due to failure of the DG load sequencer and then continued for the scheduled refueling. Major work included SG eddy current and MOV testing, LP turbine (2 of 3 ) and DG inspections, and thermal sleeve repairs.

The unit was taken off the NRC problem plant list.

The NRC proposed a $\$ 50,000$ fine for alleged failure to ensure adequate ECCS performance under certain postulated accident conditions. The utility paid the fine the following month.

The NRC issued an extendable 20-year ISFSI license for on-site spent fuel storage. The facility will have a capacity of 2880 fuel assemblies.

The unit was shut down for 5 days to remove boric acid powder buildup in the containment air coolers.

The unit scrammed due to power loss to a vital AC panel after the voltage regulator in the supply inverter failed. The unit was shut down for 9 days.

The eleventh refueling and maintenance outage lasted 109 days. The outage was extended 10 days longer than scheduled to repair a bearing on the main turbine.

The unit scrammed after all four turbine stop valves closed. The unit remained shut down for 9 days.

A malfunction in a feedwater pump caused a reactor scram and a 5-day outage.

Two manual trips occurred due to low steam generator levels. Total downtime was 6 days. The NRC proposed and the licensee paid a $\$ 50,000$ fine for a security violation.

The twelfth refueling and maintenance outage lasted 87 days.

Malfunctions of one of the reactor coolant pumps and its motor required 36 days to correct.

The NRC proposed and the licensee paid a $\$ 50,000$ fine for Appendix $R$ deficiencies with an HVAC system. 


\section{NUCLEAR POWER PLANT OPERATING EXPERIENCE SUMMARY}

Unit data summary through December 1996

Unit: CALVERT CLIFFS 2

Location: CALVERT COUNTY, MARYLAND

Owner: BALTIMORE GAS \& ELEC. CO.

Type: COMBUSTION ENGINEERING PWR

Construction Permit: 07/07/69

Operating License: 11/30/76

Commercial Oper. Date: 04/01/77
Nameplate Rating: 918 MWe

MDC Net MWe: 840 MWe

Cumul. Avail. Factor: $\mathbf{7 4 . 0}$

Cumul. Cap. Factor (MDC Net): 71.6

Cumul. Forced Outage Rate: $\mathbf{5 . 5}$

3-Year Avg. Cap. Factor (MDC Net): 89.4

License Expiration: 2016

\section{OPERATING HISTORY (To December 1996)}

Date

May 1977

Oct 1977

Apr - Jul 1978

Jul 1978

Sep - Oct 1978

Jan 1979

Oct - Dec 1979

Jan 1980

Jan - Mar 1981

Feb 1982

Jul - Oct 1982

Oct 1982 - Jan 1983

Dec 1982

Apr - Jul 1984

Jul - Aug 1984

\section{Comment}

The unit was shut down for a 2-week maintenance outage. Major work included RCP seal repair, MSR rework, and removal of secondary system strainers.

The unit was shut down for a 9-day maintenance outage. Major work included repairs to RCP seal welds, circulating water pumps, and main condenser.

A damaged FW pump turbine limited power to about $70 \%$ until repairs were completed.

Two outages totaling 11 days were forced by RCP seal cooler leaks.

The first refueling and maintenance outage was performed.

Two outages totaling 9 days were forced by cracked RCP seal pressure sensing lines.

The second refueling and maintenance outage was performed. It was extended to replace seals on two RCPs.

The unit was shut down for a 12-day outage to implement TMI-related modifications.

The third refueling and maintenance outage was performed. Major work included TMI modifications and general plant inspections. $C E$ announced a $\$ 6$ million sale of a plant simulator to the utility.

About 2 weeks of outage time were caused by problems with a MSIV, a stuck CEA, and a containment purge valve leak.

The unit operated at about $75 \%$ power during the period because of saltwater leaks in condenser tubes.

The fourth refueling and maintenance outage was performed. The main condenser was retubed using a newly developed seal welding technique.

The unit reported the seventh highest capacity factor (75.6\%) for all U.S. plants for $1980-1982$.

The fifth refueling and maintenance outage was performed.

The unit was shut down on two separate occasions to repair cracks on RCP seal leakoff lines. Total outage time was 14 days. 


\section{CALVERT CLIFFS 2 (Cont'd)}

Apr 1985

Jul 1985

Sep 1985

Oct - Dec 1985

Dec 1986

Mar - Jul 1987

Feb 1, 1988

Feb - Mar 1988

Jan 1989

Mar 1989

Mar 1989 - May 1991

Jan 1990

May 1991

Jun 1991

Oct 1991

Mar 1992

Jun 1992

Jul 1992
The unit was shut down for 11 days because three of four RCP shaft seals failed.

The unit was shut down for 12 days to repair cold reheat piping and the MSIV hydraulic system.

The NRC assessed a $\$ 50,000$ fine for alleged inoperability of PASS since its installation in 1983.

The sixth refueling and maintenance outage lasted 53 days. Major work included SG inspection, RCP motor changeout, RV level I\&C installation, and MSR tube bundle changeout.

The 2-unit plant achieved its most productive year of power generation to date in 1986 and was one of the top 10 lowest cost power producers.

The seventh refueling and maintenance outage lasted 111 days. Major work included 10-year ISI; replacement of RCP motor, MSIVs, and main turbine rotor; and installation of new plant computer. During restart, a flow-shaping device and several bolts came loose and lodged in the impeller in one of the RCPs. The pump was repaired with parts from Millstone 2 . The utility announced plans to switch to a 24-month operating cycle.

An alert was declared because of loss of power to control room annunciators caused by a fire in cable spreading room.

The unit was shut down for a planned 23-day maintenance outage, which was extended for additional work on FW components. Total outage time was 24 days.

The unit was added to the NRC list of problem plants.

The plant became first U.S. PWR to complete a planned 24-month operating cycle.

The eighth refueling and maintenance outage was performed. The outage entered early because of a blowdown pipe leak. ISI of the pressurizer found evidence of coolant leakage from heater penetrations. The unit remained shut down because of cracking of pressurizer heater sleeves.

The NRC held an enforcement conference to discuss alleged multiple omissions, deficiencies, and errors by the utility in ensuring adequate RV low temperature overpressure protection. The plant remained shut down and on the NRC list of problem plants.

The unit started up again after 775 days of shutdown time.

A 12-day outage was caused when both control room HVAC systems were declared inoperable because of a heavy load of noncondensible gases in the system.

The unit was shut down for a 36-day testing and maintenance outage. Major testing included LLRT; RPS, NIS, ESF, DG, and snubber surveillances: maintenance performed was MOV testing and overhaul and turbine bearing repair.

The unit was shut down for 15 days due to a deficiency in the DG load sequencer design.

A 13-day outage was caused by failure of a condenser expansion joint.

The unit was taken off the NRC problem plant list. 


\section{CULVERT CLIFFS 2 (Cont'd)}

Aug 1992

Sep 1992

Nov 1992

Feb - Jun 1993

Jan 1994

May 1994

Sep 1994

Oct 1994

$\operatorname{Jan} 1995$

Mar - May 1995

Feb 1996
The NRC proposed a $\$ 50,000$ fine for allegedly failing to ensure adequate ECCS performance under certain postulated accident conditions. The utility paid the fine the following month.

An MSR relief valve failed open, causing a 4-day outage.

The NRC issued an extendable 20 year ISFSI license for spent fuel at the site. The facility will have a capacity of 2880 fuel assemblies.

The ninth refueling and maintenance outage lasted 113 days. Major maintenance and testing included turbine overhaul, surveillance and eddy current testing, cleaning all 4-kV electrical buses, step down service transformers (1 of 2), saltwater header replacement, and containment air cooler cleaning.

The unit tripped when the service transformer failed during installation of a relay for the supply breaker. The unit was shut down for 1 week.

A planned outage for surveillance testing lasted 6 days.

The unit was shut down for 4 days for a reactor scram on low water pressure. A loose wire on the turbine governor valve caused the valve to open fully.

The unit scrammed after the main generator tripped due to a ground fault. Repairs required 9 days.

Two reactor scrams forced 4 days of downtime.

The tenth refueling and maintenance outage lasted 60 days.

A 6-day outage was required following a scram due to a partial LOSP. A leak in the blowdown line was repaired. 
CATAWBA

PRODUCTION COST and CAPITAL ADDITIONS

(1996 Dollars)

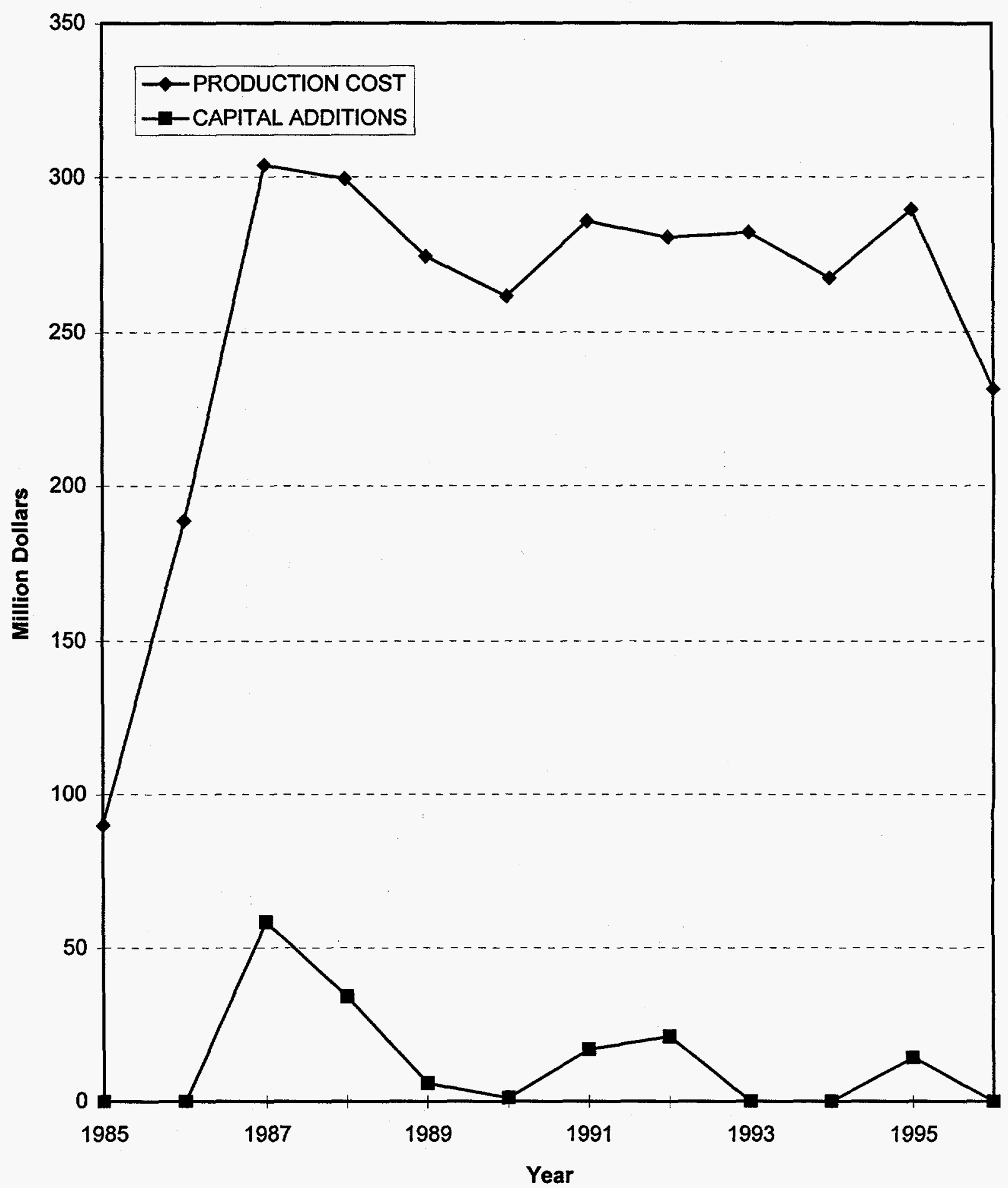




\section{NUCLEAR POWER PLANT OPERATING EXPERIENCE SUMMARY}

Unit data summary through December 1996

Unit: CATAWBA 1

Location: YORK COUNTY, SOUTH CAROLINA

Nameplate Rating: 1305 MWe

Owner: DUKE POWER CO.

MDC Net MWe: $1129 \mathrm{MWe}$

Type: WESTINGHOUSE PWR

Cumul. Avail. Factor: $\mathbf{7 6 . 2}$

Construction Permit: 08/07/75

Cumul. Cap. Factor (MDC Net): 73.0

Operating License: 01/17/85

Cumul. Forced Outage Rate: $\mathbf{7 . 9}$

Commercial Oper. Date: 06/29/85

3-Year Avg. Cap. Factor (MDC Net): 83.6

License Expiration: 2024

OPERATING HISTORY (To December 1996)

Date

Feb 1985

Oct - Nov 1985

Jun 1986

Aug - Nov 1986

Oct - Dec 1987

Jan 1988

Aug 1988

Nov 1988 - Feb 1989

Dec 1988

Dec 1988

Jan - Apr 1990

\section{Comment}

A leak in the condenser circulating water piping caused a 10-day shutdown for repairs.

A number of RCS valve, flange, and fitting leaks forced several shutdowns totaling 32 days.

The utility paid a $\$ 20,000$ fine to the NRC for alleged actions against a welding foreman for raising safety concerns. Two outages totaling 31 days were caused by failed welds on RCS piping.

The first refueling and maintenance outage was performed. Major work included modification of the DGs.

The second refueling and maintenance outage was performed. Major work included SG inspection and replacement of a leaking CRD vent plug.

Another break occurred in the condenser circulating water piping; it forced a 7-day outage.

The unit was shut down to repair a SG tube leak. Outage was extended to repair a RHR pump and a PORV isolation valve and perform a pressure boundary LLRT. Total outage time was 20 days.

The third refueling and maintenance outage lasted 76 days. Major work included SG U-bend heat treatment, inspection and tube plugging; AFW turbine and governor modifications; cooling water HX leak repairs; and LP turbine maintenance.

The utility paid a $\$ 50,000$ fine levied by the NRC for alleged violations involving EQ of RCS components.

The NRC assessed a $\$ 37,500$ fine for alleged problems encountered during a AFW pump test during in July.

The fourth refueling and maintenance outage lasted 65 days. Major work included SG tube inspection and plugging on all four SGs, HP and LP turbine inspection, removal of UHI system from reactor building, and RCP flywheel work. The outage was extended for SG tube inspection and plugging ( 5 days), valve realignment checks ( 7 days), and an RCS leak repair (10 days). 
Mar 1990

Apr 1990

Jun 1990

Aug 1990

Mar - Jun 1991

Jul - Sep 1992

Jun 1993

Oct - Dec 1993

Feb - Mar 1995

Jan 1996

Jun - Oct 1996
The NRC proposed a $\$ 100,000$ fine against the utility for alleged failure to place RCS pressure instrumentation back in service after maintenance, causing an RCS overpressure during filling. The base penalty of $\$ 50,000$ was increased because of ineffective implementation of corrective actions from previous events.

The unit was shut down for a total of 23 days for SG tube plugging, valve alignment checks and testing, repairs resulting from overpressure event in March, and repairs to a RV head Conoseal ${ }^{\oplus}$ leak.

The unit was shut down for a total of 12 days to repair a nuclear SW pump motor bearing and the ice condenser temperature monitoring system.

The NRC assessed a $\$ 50,000$ fine against the utility for numerous alleged violations over a 2-year period concerning plant access control and other security measures at all three utility plant sites.

The fifth refueling and maintenance outage lasted 86 days.

The sixth refueling and maintenance outage lasted 98 days. The outage was extended for SG maintenance, RCS leakage at reactor vessel head Conoseal ${ }^{\oplus}$, and for CRD troubleshooting.

The unit was shut down for 13 days to repair expansion joint leakage.

The seventh refueling and maintenance outage lasted 63 days.

The eighth refueling and maintenance outage lasted 42 days.

The unit was shut down for 4 days when the RTBs failed a surveillance test.

The ninth refueling and maintenance outage lasted 113 days. The steam generators were replaced during this outage, and problems with the SG replacement caused almost 2 weeks of delay. 


\title{
NUCLEAR POWER PLANT OPERATING EXPERIENCE SUMMARY
}

\author{
Unit data summary through December 1996
}

Unit: CATAWBA 2

Location: YORK COUNTY, SOUTH CAROLINA

Owner: DUKE POWER CO.

Type: WESTINGHOUSE PWR

Construction Permit: 08/07/75

Operating License: $\mathbf{0 5 / 1 5 / 8 6}$

Commercial Oper. Date: 08/19/86
Nameplate Rating: 1305 MWe

MDC Net MWe: $1129 \mathrm{MWe}$

Cumul. Avail. Factor: $\mathbf{7 8 . 4}$

Cumul. Cap. Factor (MDC Net): $\mathbf{7 5 . 0}$

Cumul. Forced Outage Rate: $\mathbf{8 . 8}$

3-Year Avg. Cap. Factor (MDC Net): 83.7

License Expiration: 2026

OPERATING HISTORY (To December 1996)

\section{Date}

Sep - Nov 1986

Apr 1987

Aug 1987

Dec 1987 - Mar 1988

Mar - Jun 1989

Feb 1990

Jun - Sep 1990

Jan 1991

Sep 1991

Oct - Dec 1991

Jan - Apr 1993

Apr - Jul 1994

Feb 1995

\section{Comment}

The unit was shut down to repair damage to the main generator stator and rotor caused by a foreign object in the generator. Total outage time was 77 days.

A failed grease seal on the main generator forced a 17-day outage. The NRC assessed a $\$ 50,000$ fine for alleged inadequate control over design modifications during plant startup and testing.

The unit shut was down to repair an inoperable AFW bypass valve and a RCP seal leak. SG inspection was also performed. Total outage time was 26 days.

The first refueling and maintenance outage was performed. Major work included removal of the UHI system, SG inspection and sludge lancing, repair of reactor building crane and turbine-driven AFW pump, and repair of FW bypass control valve. The outage was extended because of lack of assured backup FW caused by infestation of Asiatic clams. Total outage time was 95 days.

The second refueling and maintenance outage lasted 91 days. Major work included SG inspection and extensive plant maintenance. The NRC assessed a $\$ 75,000$ fine for an alleged violation involving corrective action for a design change.

The NRC reported that unit operating history had improved during the current SALP rating period.

The third refueling and maintenance outage was performed. The outage was extended 4 days to resolve various problems.

A 4-day outage was needed for ice condenser U-bolt inspection.

A 10-day outage was needed due to an inoperable diesel generator.

The fourth refueling and maintenance outage lasted 65 days.

The fifth refueling and maintenance outage lasted 62 days.

The sixth refueling and maintenance outage lasted 66 days. The outage was extended 4 days to repair a RCP seal.

The unit was shut down for $\mathbf{8}$ days after an MSIV closed. 
Apr 1995

Oct - Nov 1995

Feb 1996

Aug 1996

Dec 1996
A 4-day outage was caused by a scram on low steam generator level.

The seventh refueling and maintenance outage lasted 51 days. Various equipment problems caused an extra 11 days to be added to the outage.

LOSP caused the unit to be shut down for 12 days.

Following the control room ventilation being declared inoperable, the unit was shut down for 9 days.

The unit was shut down for 1 week to repair an RHR check valve. 
This Page Intentionally Left Blank 


\section{CLINTON}

PRODUCTION COST and CAPITAL ADDITIONS

(1996 Dollars)

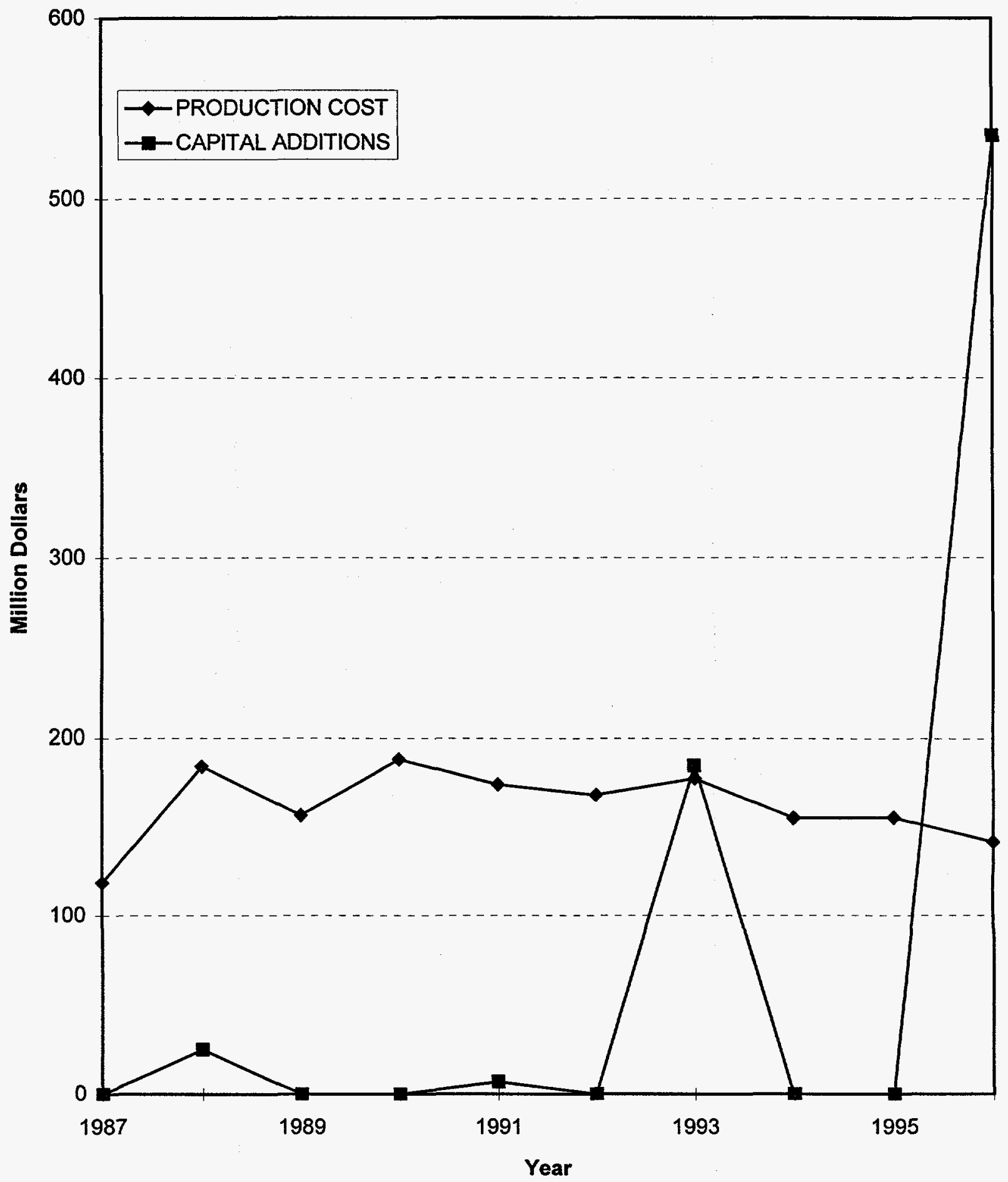




\section{NUCLEAR POWER PLANT OPERATING EXPERIENCE SUMMARY}

Unit data summary through December 1996

Unit: CLINTON

Location: DEWITT COUNTY, ILLINOIS

Owner: ILLINOIS POWER CO.

Type: GENERAL ELECTRIC BWR

Construction Permit: 02/24/76

Operating License: 4/17/87

Commercial Oper. Date: 11/24/87
Nameplate Rating: 985 MWe

MDC Net MWe: 930 MWe

Cumul. Avail. Factor: $\mathbf{7 1 . 9}$

Cumul. Cap. Factor (MDC Net): $\mathbf{6 5 . 6}$

Cumul. Forced Outage Rate: 9.1

3-Year Avg. Cap. Factor (MDC Net): 77.0

License Expiration: 2026

OPERATING HISTORY (To December 1996)

Date

$1982-1986$

Apr 1987

May 1987

Oct 1987

Jan - Feb 1988

Mar - May 1988

Nov 1988

Jan - May 1989

Jun 1989

Jul 1989

\section{Comment}

During construction, the utility was fined by the NRC for numerous alleged violations. One fine for $\$ 90,000$ was assessed for deficient $Q A$ of electrical equipment installation. Another fine of $\$ 50,000$ was assessed for alleged improper firing of a construction contractor foreman.

The NRC assessed a $\$ 75,000$ fine for alleged multiple safety violations concerning safetyrelated MOV electrical installation.

The unit was shut down for 13 days to repair a malfunctioning FW control valve.

After completion of its warranty run, the unit was shut down for 17 days for planned maintenance. The unit was placed in service in November 1987, with declaration of commercial operation made as of November 24, 1987.

A number of power reductions were caused by condenser waterbox repairs and various other plant problems.

The unit was shut down for a scheduled maintenance outage. Major work included condenser tube cleaning, FW heater and MSR maintenance, and surveillance testing. Two MSIVs failed LLRT, prolonging the outage to a total of 21 days.

The NRC assessed a fine of $\$ 75,000$ for alleged EQ violations concerning electrical equipment.

The first refueling and maintenance outage lasted 146 days. Major work included recirculation pump replacement, rebuild of 15 CRDs, and LLRT. Several MSIVs failed LLRT, causing delays.

Failure of a recirculation pump seal and numerous problems on restart forced an outage of 20 days.

A failed turbine expansion joint forced an outage of 12 days. 
Feb - Apr 1990

Apr 1990

May 1990

Jul 1990

Oct 1990 - Mar 1991

Nov 1990

Jan 1991

Dec 1991

Jan 1992

Mar - May 1992

Jun - Jul 1992

Sep - Dec 1993

Dec 1993

Apr 1994

Aug 1994

Oct 1994

Mar - Apr 1995
The unit was shut down for a planned maintenance outage. Major work included repair of electrical penetrations; RWCU pump and valve repairs; fuel handling system repairs; and replacement of ESF instrument transmitters. Total outage time was 49 days.

The NRC assessed a $\$ 25,000$ fine against the utility for alleged deficiencies in procedural compliance training for plant staff. The unit was shut down for 11 days for operating crew training.

An 8-day outage was needed to install expansion joint tie rods on the SW supply and return lines for the DG jacket water heaters.

The unit was shut down for 15 days to repair a reactor recirculation flow control valve and recirculation pump seal leakage.

The second refueling and maintenance outage lasted 146 days. Major work included further work on electrical penetrations, recirculation pump seal replacement, MOV repair and testing, MSIV modifications, and LP turbine rework. The outage was extended to perform LLRTs on previously untested potential leakage paths and to repair RHR suction line pipe hangers.

In November, the NRC assessed and the utility paid, a $\$ 112,500$ fine for alleged violations of safety requirements.

The fuel building basement was flooded with about 100,000 gallons of water when the valve bonnet on a SW valve blew off during maintenance. The valve had been installed backward.

A 5-day outage was necessary to repair and replace reactor recirculation flow control logic components.

The unit tripped due to a fault in one of the main transformers. The outage was extended to clean up a EHC fluid spill and lasted 12 days.

The third refueling and maintenance outage lasted 92 days. Major work included repair and rework of FW valves, DG overhaul, LP turbine disassembly/inspection, and condenser tube cleaning. A fire in the charcoal vessels in the off-gas system caused an unusual event to be declared and extended the outage by 4 days.

The unit was shut down to repair a turbine-driven reactor feed pump and an MSIV that failed to open and to investigate a recirculation pump seal high-temperature alarm. The outage lasted 14 days.

The fourth refueling and maintenance outage lasted 73 days.

A manual scram was performed when condenser vacuum was lost while changing SJAEs. The unit was shut down for 8 days.

The unit was shut down for 10 days to replace a recirculation pump seal and other maintenance.

The unit was shut down for 4 days to replace a recirculation pump seal and other maintenance.

Vibration problems in one of the main turbine's bearings required 8 days to correct.

The fifth refueling and maintenance outage lasted 49 days. 


\section{CLINTON (Cont'd)}

May 1995

Dec 1995

Apr 1996

Sep - Dec 1996
Two manual shutdowns caused a week of downtime for the unit. The first was for a maintenance outage and the second when the recirculation pumps shifted to low speed.

A 1-week maintenance outage was performed to replace a recirculation pump seal and other work.

The unit scrammed after a full MSIV isolation occurred when the reserve auxiliary transformer lost power.

The unit was shut down to replace a recirculation pump seal. The unit remained shut down to correct numerous equipment and performance problems identified by the NRC. The sixth refueling outage was entered early. The unit remained shut down at the end of 1996. 
COMANCHE PEAK

PRODUCTION COST and CAPITAL ADDITIONS (1996 Dollars)

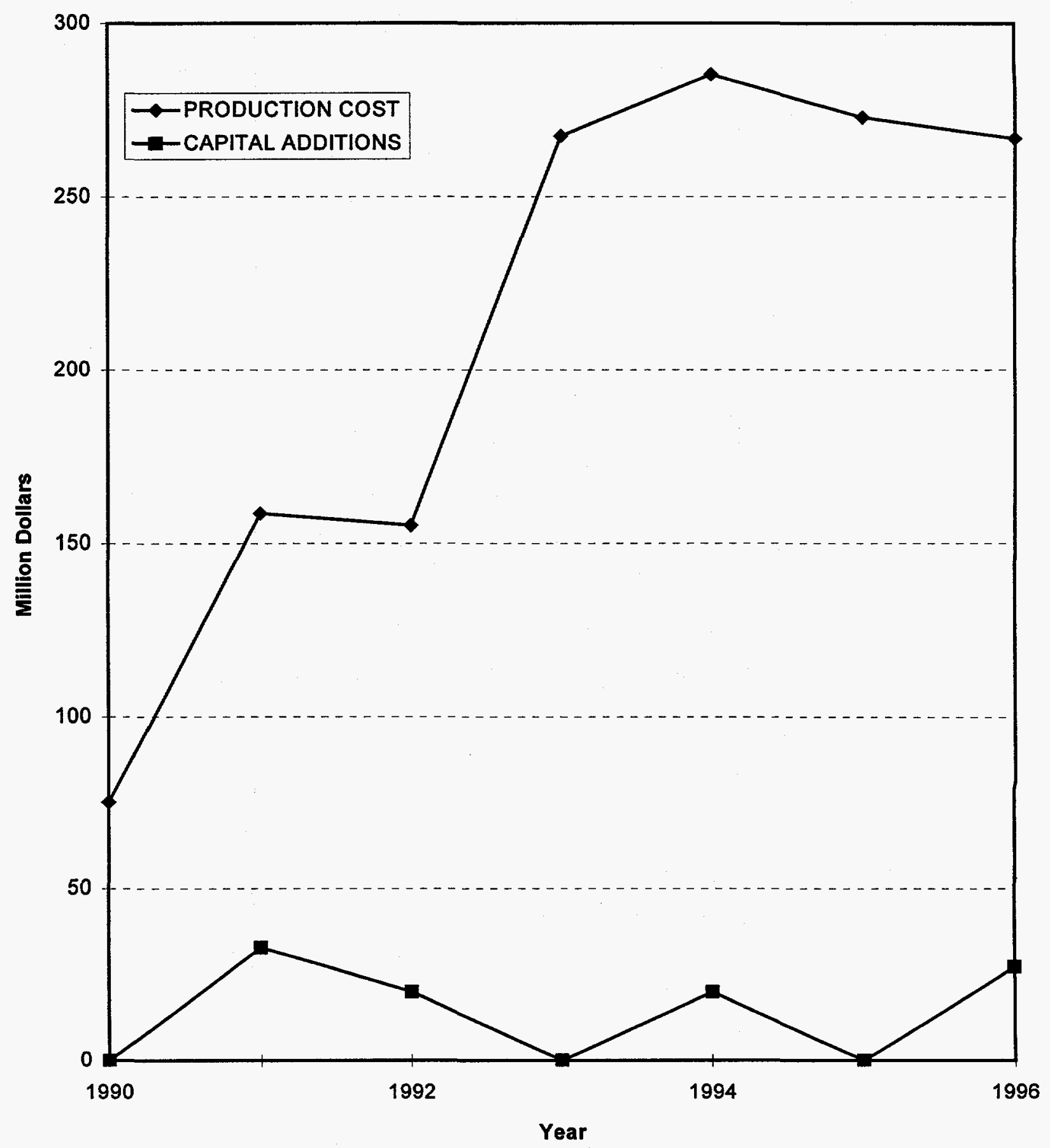




\section{NUCLEAR POWER PLANT OPERATING EXPERIENCE SUMMARY}

Unit data summary through December 1996

Unit: COMANCHE PEAK 1

Location: SOMERVELL COUNTY, TEXAS

Owner: TEXAS UTILITIES ELECTRIC CO.

Nameplate Rating: $1161 \mathrm{MWe}$

Type: WESTINGHOUSE PWR

MDC Net MWe: 1150 MWe

Construction Permit: 12/19/74

Cumul. Avail. Factor: $\mathbf{8 1 . 2}$

Operating License: $4 / 17 / 90$

3-Year Avg. Cap. Factor (MDC Net): 82.4

Commercial Oper. Date: $\mathbf{0 8 / 1 3 / 9 0}$

License Expiration: 2030

OPERATING HISTORY (To December 1996)

Date

Aug - Nov 1990

Nov 1990

Mar - May 1991

Oct - Dec 1991

Mar 1992

Jul 1992

Oct - Dec 1992

Oct - Dec 1993

Mar - Apr 1995

Jun 1995

Jan 1996

Oct - Nov 1996

\section{Comment}

The unit operated with no significant outages or power reductions.

The unit entered a planned outage of 11 days for RCP maintenance and in-core flux thimble cleaning.

The unit was shut down because of condenser tube failure and entered a midcycle outage 2 days later. Major work included RCP seal replacement, DG rework and testing, MOV tests, condenser tube repairs, LP turbine repair, and turbine/generator inspection. Total outage time was $\mathbf{5 7}$ days.

The first refueling outage lasted 68 days. Major work included RCP No. 2 seal replacement, LP turbine and generator overhaul, DG overhaul, snubber inspections, and SG ISI.

The utility paid a $\$ 25,000$ fine to the NRC for allegedly failing to properly align two RHR valves prior to entering Mode 3.

A fine of $\$ 125,000$ was proposed by the NRC for alleged violations concerning a loss of spent fuel pool cooling that occurred in May 1991.

The second refueling and maintenance outage lasted 65 days.

The third refueling and maintenance outage lasted 70 days.

The fourth refueling and maintenance outage lasted 45 days.

An inverter failure caused a loss of feedwater to occur. The plant was shut down for 5 days.

Inverter failures were the cause of two reactor scrams. Total outage time was 16 days.

The fifth refueling and maintenance outage lasted 43 days. 
Unit: COMANCHE PEAK 2

Location: SOMERVELL COUNTY, TEXAS

Owner: TEXAS UTILITIES ELECTRIC CO.

Type: WESTINGHOUSE PWR

Construction Permit: 12/19/74

Operating License: 04/06/93

Commercial Oper. Date: 08/03/93
Nameplate Rating: 1161 MWe

MDC Net MWe: 1150 MWe

Cumul. Avail. Factor: 81.0

Cumul. Cap. Factor (MDC Net): 73.3

Cumul. Forced Outage Rate: $\mathbf{7 . 5}$

3-Year Avg. Cap. Factor (MDC Net): 72.1

License Expiration: 2033

OPERATING HISTORY (To December 1996)

Date

Mar 1993

Jun - Jul 1993

Sep 1993

Mar 1994

Apr - May 1994

Aug 1994

Oct - Nov 1994

May 1995

Feb - May 1996
Comment

Initial criticality was achieved.

Prior to commercial operation, the unit was shut down for 37 days to perform major surveillance testing.

A 13-day outage was required to repair FW leaks in the SG split-flow bypass valve inside containment and the full-flow recirculation valve in the turbine building.

An 8-day outage followed a unit shutdown due to load swings on the main generator.

A scheduled midcycle outage lasted 59 days. The outage was extended almost a month to repair cracks in welds on the containment spray piping.

The unit was shut down twice for a total of 7 days to repair insulator oil leakage on the main transformer and then due to axial flux being out of limits.

The first refueling and maintenance outage lasted $\mathbf{4 8}$ days.

An outage to repair leaks on the charging line check valves required 12 days.

The second refueling and maintenance outage lasted 74 days. The outage was extended by 3 weeks to replace a RCP motor. 
This Page Intentionally Left Blank 


\section{COOK}

PRODUCTION COST and CAPITAL ADDITIONS (1996 Dollars)

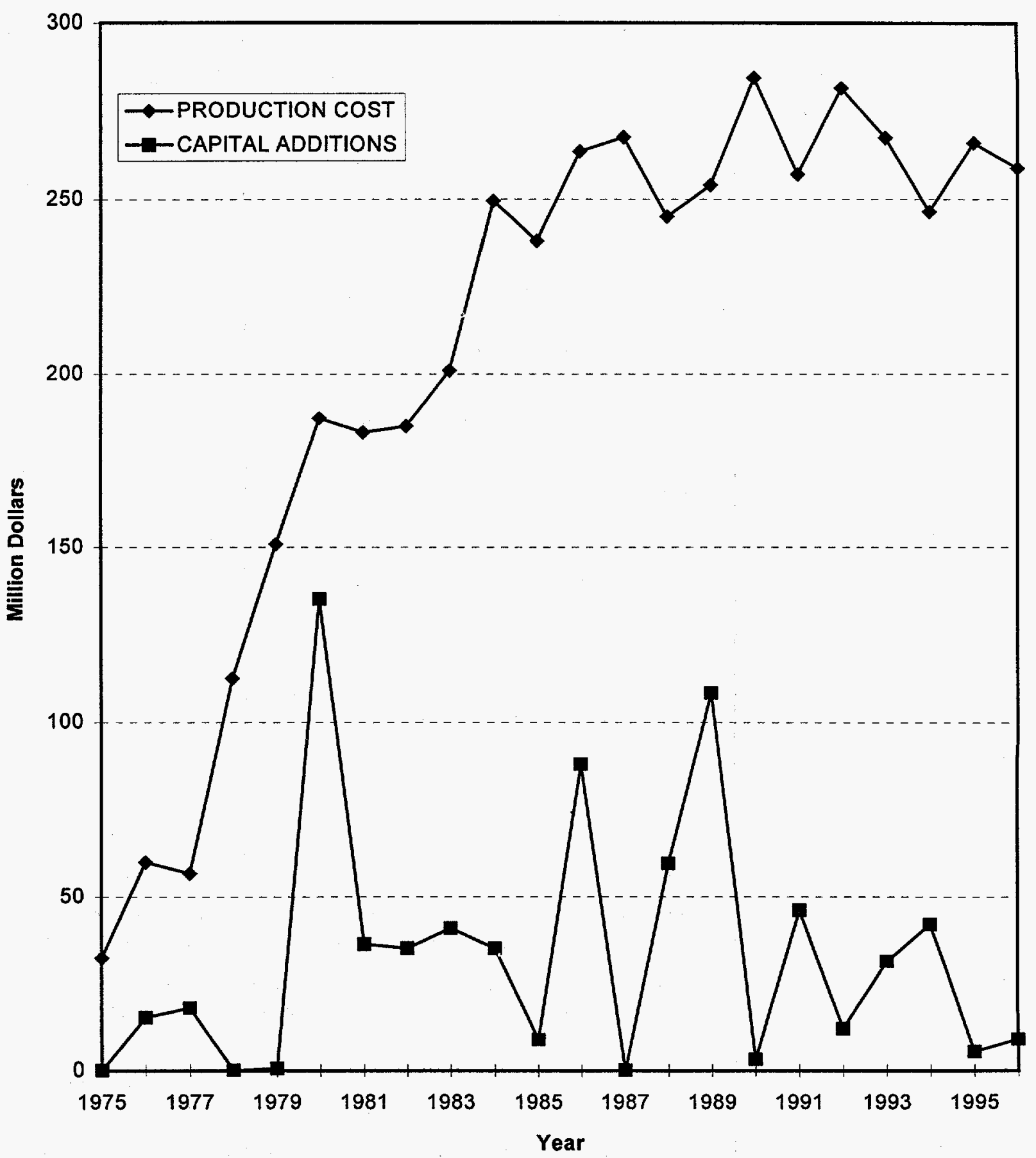




\section{NUCLEAR POWER PLANT OPERATING EXPERIENCE SUMMARY}

Unit data summary through December 1996

\section{Unit: COOK 1}

Location: BERRIEN COUNTY, MICHIGAN

Owner: INDIANA \& MICHIGAN ELECTRIC CO.

TyPe: WESTINGHOUSE PWR

Construction Permit: 03/25/69

Operating License: $10 / 25 / 74$

Commercial Oper. Date: 08/28/75
Nameplate Rating: 1152 MWe

MDC Net MWe: $1000 \mathrm{MWe}$

Cumul. Avail. Factor: $\mathbf{7 4 . 9}$

Cumul. Cap. Factor (MDC Net): 68.8

Cumul. Forced Outage Rate: $\mathbf{5 . 9}$

3-Year Avg. Cap. Factor (MDC Net): $\mathbf{7 4 . 2}$

License Expiration: 2014

OPERATING HISTORY (To December 1996)

$\underline{\text { Date }}$

Nov 1974

Jan 18, 1975

Mar 1975

Jul 1975

Oct - Nov 1975

Mar 1976

Apr - May 1976

Sep 1976

Dec 1976 - Feb 1977

May 1977

Nov - Dec 1977

Apr - Jun 1978

Dec 1978

Apr -Jul 1979

Oct - Nov 1979

\section{Comment}

The containment ice condenser, which was the first one of its type, was loaded.

Incomplete construction of FW restraints and steam line high-energy line break protection delayed initial criticality until this date.

The unit was shut down for a 16-day maintenance outage.

The plant was shut down for 20 days to allow repairs to a main condenser leak, SW system maintenance, steam dump valve modifications, and an RCP seal replacement.

An outage for RCP seal inspection and replacement lasted 14 days.

The NRC issued a license amendment authorizing operation at $90 \%$ power and testing up to $100 \%$.

The SG, turbine, and condenser work was performed during a 28-day outage.

The unit was shut down for a scheduled outage of nine days to inspect the main transformer, change RCP motor oil, and weigh the ice condenser baskets.

The first refueling and maintenance outage included SG tube inspection and main transformer replacement.

The unit operated at reduced power (about $60 \%$ ) to extend the fuel cycle life.

The NRC ordered the plant shut down for replacement of unqualified electrical connectors.

The second refueling and maintenance outage included ISI of RPV welds, containment leak testing, and turbine-generator inspection. A fire occurred in an MCC during the outage.

The unit was shut down for a scheduled outage for snubber inspection, ice condenser inspection, replacement of pressurizer relief tank rupture discs, and repair of a stator cooling water tank. The unit was off-line 6 days.

The third refueling and maintenance outage included testing of concrete expansion anchor bolts and FW piping repairs. Two FAs were replaced due to damage.

A shutdown was performed to repair an inverter and correct high vibration in a RCP due to coupling misalignment. The unit was down for 15 days. 
Dec 1979 - Jan 1980

May - Aug 1980

Dec 1980 -Jan 1981

May - Aug 1981

Nov 1981

Dec 1981 - Jan 1982

Mar 1982

Jul - Sep 1982

Jul -Oct 1983

Nov - Dec 1983

Jul -Aug 1984

Jan 1985

Jan 1985

Apr - Nov 1985

Oct 1985

Nov - Dec 1985

Dec 1985 - Mar 1986

Apr 1986
The unit was shut down due to design deficiencies discovered in the containment $\mathrm{H}_{2}$ skimmer system.

The fourth refueling and maintenance outage included installation of new SG thermal sleeves and elbows. The LP turbines were also examined.

The unit was removed from service to conduct ice condenser surveillance, miscellaneous maintenance, and inspection/plugging of SG tubes. The duration of the outage was 12 days.

The fifth refueling and maintenance outage lasted 66 days.

After a unit scram resulted from a trip of one main feedpump turbine, the outage was extended 12 days to repair a pressurizer spray valve leak and work on design changes.

The unit was shut down 16 days to fix an RCS leak caused by a ruptured bellows in the pressurizer spray control valve.

INPO visited the plant and praised the staff's positive attitude, the shielded frisking booths, and tracking of material deficiencies. Improvements were recommended in management oversight, industrial chemical control, procedural adherence, plant modification program, and control room alarms.

The sixth refueling and maintenance outage lasted 89 days.

The seventh refueling and maintenance outage lasted 100 days. DG inspection and repair and RCP motor modifications were made.

Repairs to a RCP caused an outage lasting 26 days. The pressurizer spray valve was also repaired while the unit was shut down.

Ice condenser surveillance and pressurizer safety valve repair necessitated an outage of 15 days. Leaking pressurizer safety valves were replaced with rebuilt units.

The unit was shut down 18 days for ice condenser surveillance and replacement of all pressurizer safety valves.

The NRC proposed a fine of $\$ 50,000$ for two alleged violations associated with the AFW operating requirements and one alleged violation of the required operating configuration for ventilation exhaust fans. The violations occurred in June and August 1984.

The eighth refueling and maintenance outage lasted 225 days. Major work included a 10-year ISI, SG inspection, control rod guide tube replacement, main condenser retubing, FW pump turbine condenser replacement, and Appendix R design changes. An error in the Exxon Nuclear Fuels computer code affecting peak clad temperature predictions was discovered.

The NRC proposed a $\$ 100,000$ fine for three alleged violations of improperly securing vital areas in May and June 1985.

The unit was shut down 19 days because of a leaking RCP flange.

The utility implemented a $90 \%$ power limit to minimize SG tube degradation.

The NRC proposed a $\$ 100,000$ fine for two alleged violations involving incorrect valve alignment during an ILRT. 


\section{COOK 1 (Cont'd)}

May - Jun 1986

Jul - Aug 1986

Aug - Apr 1987

Apr 1987

Jun - Oct 1987

Sep 1988

Oct 1988

Mar - Jul 1989

Feb 1990

Mar 1990

Oct 1990 - Jan 1991

Mar 1991

Apr 1991

May 1991

Sep 1991

Jun - Oct 1992

Feb - May 1994
After a spurious reactor trip, the unit remained shut down to fix an electrical problem in the main turbine overspeed protection system and repair RCS leaks. RCP seals were repaired using the latest $\underline{W}$ seal materials. The outage lasted 41 days.

After a reactor scram due to personnel error during calibration, the unit remained shut down for 10 days. A pressurizer spray valve leak, a failed SW pump, and an RCP oil leak were repaired during the outage.

The unit operated at $90 \%$ nominal power the remainder of the year to minimize SG tube degradation.

A letdown shutoff valve packing leak caused a TS-required shut down. The unit operated at $90 \%$ power after a 14-day outage for repairs.

The ninth refueling and maintenance outage lasted 102 days. Scheduled maintenance included SG inspection and sludge lancing. Replacement of RCP hatch bolts, BOP circuit panel rework and resolving fuel oil leakage into ECCS pump conduits caused an extension of the outage.

The unit was shut down to resolve an RCS leak due to a broken instrument line for a RCP seal. SG crevice flushing was also conducted during the 12-day outage.

EQ concerns caused a precautionary shutdown. Design changes were implemented for conduits for RPV head vent and pressurizer steam space vent solenoid valves.

The tenth refueling and maintenance outage lasted 108 days.

The NRC proposed a $\$ 75,000$ fine for alleged failure to identify an instrumentation anomaly that could have allowed pump runout in the AFW system.

A unit record for 251 days of continuous operation was set. The unit was shut down for scheduled ice condenser surveillance and snubber replacement.

The eleventh refueling and maintenance outage lasted 99 days. Major work included ECT of all four SGs, SG tube sleeving, MOV testing, RCP seal inspection, and valve leak rate testing.

The NRC proposed a $\$ 150,000$ fine for alleged violations of the fire protection requirements. The fine was paid.

A 16-day outage was made to inspect the main transformer. The inspection revealed arcing had occurred among bolts installed during 1985 .

A reactor trip occurred due to a UV condition on the RCP buses. This was caused by a defective generator overcurrent device and required a 4-day outage to correct.

A 4-day outage was caused by blockage in the BIT recirculation flow path.

The twelfth refueling and maintenance outage lasted 128 days. Major work included $100 \%$ SG ECT, RCP seal inspection, ice condenser basket replacement, erosion/corrosion inspection and repair, turbine inspection, turbine monoblock rotor replacement, SG sludge lancing, and BAST overhaul.

The thirteenth refueling and maintenance outage lasted 106 days. 
Jul - Oct 1995

Oct 1995

$\operatorname{Dec} 1995$

Sep 1996
The reactor scrammed on low condenser vacuum due to a leak on a connecting valve. When the unit was restarted, a main generator transformer was damaged. Due to the extent of the damage, the fourteenth refueling and maintenance outage was entered early. Total outage time was 103 days.

Following startup from the refueling outage, increasing concentrations of sodium in SGs forced a 10-day outage.

The unit was taken offline twice for a total of 6 days for repairs to the main transformer and to the bus ducts.

Following a lightning strike, a 1-week outage was entered to replace two source detectors. 


\title{
NUCLEAR POWER PLANT OPERATING EXPERIENCE SUMMARY
}

\author{
Unit data summary through December 1996
}

Unit: COOK 2

Location: BERRIEN COUNTY, MICHIGAN

Owner: INDIANA \& MICHIGAN ELECTRIC CO.

Type: WESTINGHOUSE PWR

Construction Permit: 03/25/69

Operating License: $12 / 23 / 77$

Commercial Oper. Date: 07/01/78
Nameplate Rating: $1133 \mathrm{MWe}$

MDC Net MWe: $1060 \mathrm{MWe}$

Cumul. Avail. Factor: 67.5

Cumul. Cap. Factor (MDC Net): $\mathbf{6 2 . 2}$

Cumul. Forced Outage Rate: 14.2

3-Year Avg. Cap. Factor (MDC Net): $\mathbf{7 2 . 3}$

License Expiration: 2017

OPERATING HISTORY (To December 1996)

Date

Apr 1978

May - Jun 1978

Jul - Aug 1978

Aug 1978

Nov 1978

May - Jul 1979

Oct 1979 - Jan 1980

Mar 1980

Jun - Jul 1980

Oct - Dec 1980

Mar - May 1981

Jull 1981

Oct 1981

Dec 1981
Comment

After power ascension testing at 50\% power was completed, a 14-day outage for maintenance and modifications was performed.

The unit was shut down for 13 days to troubleshoot unidentified RCS leakage and perform MSR modifications.

The main generator and MSRs were repaired during a 15-day outage.

The unit achieved $100 \%$ power.

MSRs were modified, and a minor fire occurred in the main generator during a 16-day outage.

Cracks discovered in the FW lines of all four SGs caused a forced outage.

The first refueling and maintenance outage was performed. Modifications to safety-related piping systems were made.

Personnel were found to have ingested contaminated demineralized water (in coffee).

An outage for AFW modification was performed.

Main generator and other miscellaneous repairs were required after a generator fault led to a unit trip.

The second refueling and maintenance outage was performed. Work items included new blades and seals on the HP turbine, SG inspections, and installation of thermal sleeves in place of the SG FW elbows.

High temperature inside containment and in an RCP motor caused an outage for cleaning RCP motor coolers and conducting RCS maintenance.

The unit was shut down for SG inspection and tube plugging. Other general maintenance was also conducted for an extended outage of 22 days.

The NRC proposed a fine of $\$ 80,000$ for alleged violations in the fire protection program and containment integrity. 
Mar 1982

Jul - Aug 1982

Nov 1982 - Jan 1983

Jun -Jul 1983

Oct - Nov 1983

Jan - Dec 1984

Mar - Jul 1984

Dec 1984 -Jan 1985

Oct - Nov 1985

Nov 1985

Feb - Jul 1986

Nov 1986

Mar - Apr 1987

Mar 1987

Aug - Oct 1987

Apr 1988 - Mar 1989

Apr 1989

Jun 1989
The plant was shut down to replace seals on an RCP and conduct ice condenser basket weighing. The outage lasted nearly 20 days.

The SG tube leak repair forced a 17-day outage.

The third refueling and maintenance outage lasted 63 days. Major work included plugging of SG tubes, sipping of FAs, and TMI-related design modifications.

After a unit scram caused by vital instrument inverter failure, the unit remained shut down to plug a leaking SG tube and conduct ice condenser surveillance. The outage required nearly 16 days.

The unit was shut down because of increasing primary-to-secondary leakage. A total of eight tubes in three SGs were plugged during the 37-day outage.

Condenser tube leaks required a number of power reductions to about $70 \%$.

The fourth refueling and maintenance outage lasted 124 days. Work included SG inspection and tube plugging, RCP motor modifications, condenser retubing, SG crevice flushing, and Appendix R design changes.

An outage was performed for ice condenser surveillance and replacement of the RTD loop manifold valves. During restart, loose parts (broken control rod guide tube pins) were detected in two SGs.

The unit was shut down 10 days for an investigation of a reactor trip breaker that failed to open on a spurious reactor trip signal.

Power operation was restricted to $80 \%$ to minimize SG tube degradation.

The fifth refueling and maintenance outage was performed. Major activities included EQ and fire protection modifications, SG inspection, LP turbine inspection, and replacement of control rod guide tube split pins, main FW pump turbine condensers, $\mathrm{PCB}$ oil-cooled transformers, and vital instrument bus inverters.

The NRC proposed a fine of $\$ 25,000$ for three alleged violations concerning wiring errors that rendered a portion of the reactor instrumentation inoperable.

The unit was shut down to repair increasing SG tube leakage. A total of 110 SG tubes were plugged. Damaged primary manway bolt holes were repaired, and the studs were replaced. The outage lasted 49 days.

The NRC proposed a fine of $\$ 50,000$ for alleged violations involving the inoperability of ECCS subsystems.

The unit was shut down when it was discovered that the RCP hatch covers had not been installed as designed. The unit returned to service after an outage of 45 days.

The unit was shut down for the sixth refueling and planned replacement of all four SGs. The replacement cost $\$ 112$ million and was completed with low total worker exposure dose (less than 561 person-rem). Other major work included ISI of RPV, RCP seal replacement, ISI hydrostatic testing, DG testing, MOVATS testing and valve repairs, and replacement of all 58 thimble tubes due to thinning from flow-induced vibration.

Several power reductions of short duration were required to repair main condenser tube leaks. One tube was plugged, and 50 were rerolled.

The unit was shut down to inspect containment leakage. The lower containment ventilation unit air and water sides were also inspected. The outage lasted nearly 14 days. 
Aug 1989

$\operatorname{Jan} 1990$

Mar 1990

Mar - Apr 1990

Jun - Nov 1990

Jul 1990

Dec 1990 - Mar 1991

Aug 1991

Feb - Dec 1992

Aug 1993

Jan 1994

Feb - Apr 1994

Sep 1994

Feb 1995

Aug 1995

Sep 1995

Mar - May 1996
Degraded voltage in the control room instrument inverter caused a false loss of RCP signal and a reactor scram. The NRC dispatched an AIT to the plant to review the event.

The unit was shut down for ice condenser surveillance. SG stop valves required modification to increase moisture drainage. The outage required nearly 20 days.

The NRC proposed a $\$ 75,000$ fine for an alleged violation regarding an inoperable AFW pump. The deficiency had been discovered in 1978 but had not been corrected. The fine was paid the following month.

The utility announced improvements that included computerized maintenance management, a contract with CE to replace analog process equipment, and a contract with Nuclear Energy Services to modify and upgrade the fuel transfer systems.

The seventh refueling and maintenance outage lasted 133 days. Surveillance, maintenance, and design change activities were also performed.

An UE was declared due to a 4-kV feeder breaker explosion and fire. One worker was electrocuted and three others injured during the event. The fire was extinguished within 5 minutes, and unit operations were not affected.

The unit experienced three separate trips. Two of the trips were due to spurious FW instrument signals, and the third occurred when an ice storm knocked out $345-\mathrm{kV}$ and 765 $\mathrm{kV}$ lines. All three outages were short in duration.

A unit trip occurred as the result of an electrical problem in a $765-\mathrm{kV}$ system. During the outage, a leak on the reactor vessel head instrument penetration was repaired. The outage interrupted operation 23 days.

The eighth refueling and maintenance outage lasted 130 days. During startup from the refueling outage, the unit was shut down due to high main turbine vibration. The unit was restarted in September, but continued vibration problems led to shutdown after less than 2 weeks of operation. The main generator rotor was the source of the vibration problems. Additional problems with the main turbine/generator required a total of 162 days of outage time.

The unit was shut down for 12 days after the main turbine tripped due to spurious actuation of the turbine exhaust hood high-temperature switches.

A 5-day outage was needed to repair an unisolable leak on a SG blowdown line.

The reactor scrammed when a SG stop valve closed during testing. The unit attempted to startup, but further problems with the main generator prevented operation. The unit was shut down for 62 days.

The ninth refueling and maintenance outage lasted 97 days.

A feedwater controller malfunction caused a reactor scram and resulted in a 5-day outage.

Eleven days of downtime were the result of two reactor scrams. The first due to an MSR drain tank high level trip and the second when both CRD MG sets tripped.

Operator error caused a reactor trip that resulted in a 4-day outage.

The tenth refueling and maintenance outage lasted 47 days. 
COOPER STATION

PRODUCTION COST and CAPITAL ADDITIONS

(1996 Dollars)

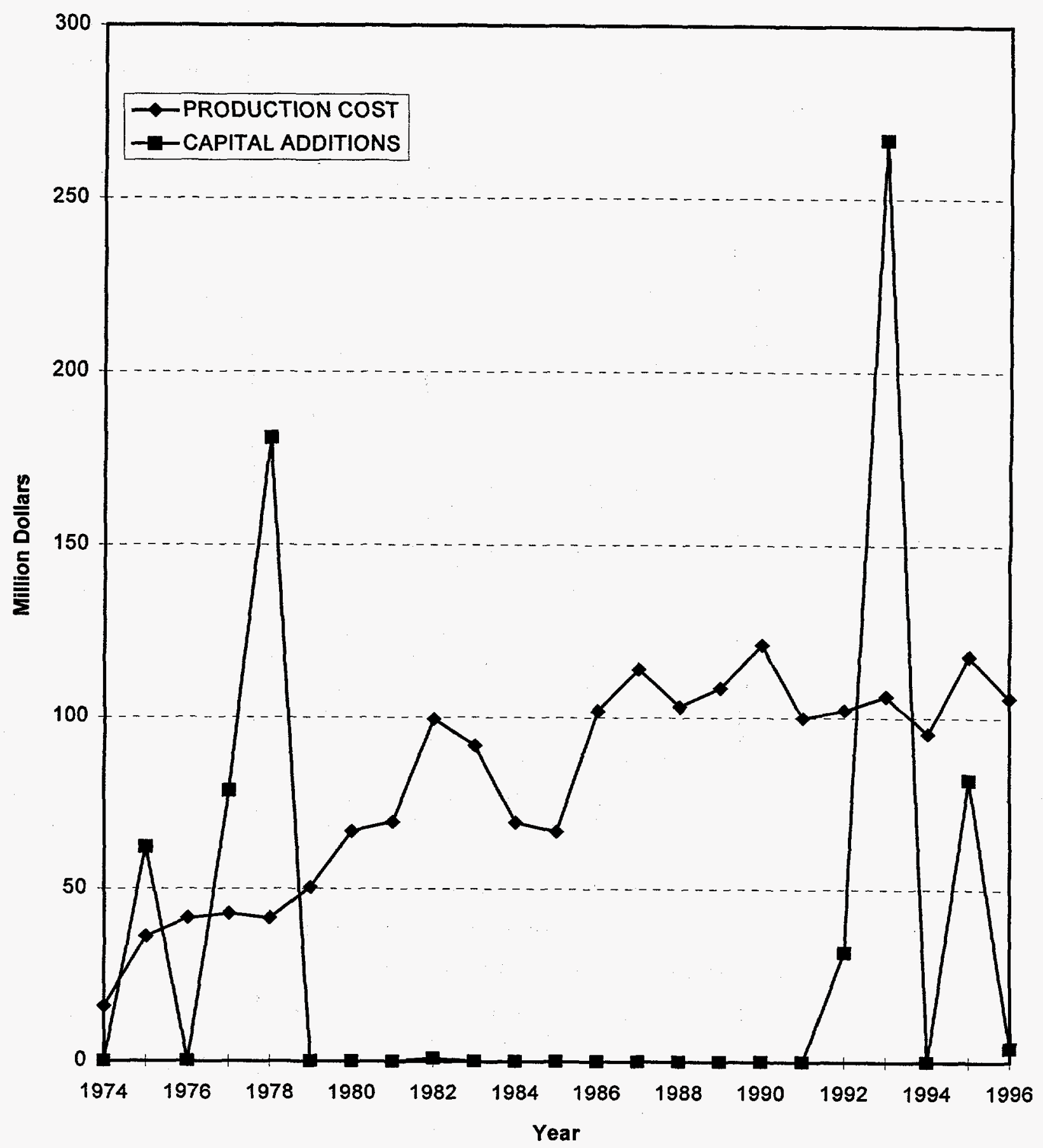




\section{NUCLEAR POWER PLANT OPERATING EXPERIENCE SUMMARY}

Unit data summary through December 1996

Unit: COOPER STATION

Location: NEMAHA COUNTY, NEBRASKA

Owner: NEBRASKA PUBLIC POWER DISTRICT

Type: GENERAL ELECTRIC BWR

Construction Permit: 06/04/68

Operating License: 01/18/74

Commercial Oper. Date: 07/01/74
Nameplate Rating: 836 MWe

MDC Net MWe: 764 MWe

Cumul. Avail. Factor: $\mathbf{7 3 . 7}$

Cumul. Cap. Factor (MDC Net): 63.4

Cumul. Forced Outage Rate: $\mathbf{8 . 0}$

3-Year Avg. Cap. Factor (MDC Net): 63.2

License Expiration: 2014

OPERATING HISTORY (To December 1996)

Date

1974

Apr - Sep 1975

Sep 1975

Jan 1976

May 1976

Sep - Nov 1976

Apr 1977

Sep - Oct 1977

Apr - May 1978

Apr - May 1979

Nov 1979

Mar - Jun 1980

\section{Comment}

After initial criticality was achieved in February, turbine bypass modifications required a 2week shutdown in March. Commercial operation began in July at $50 \%$ power. Relief valve blowdowns and minor turbine problems occurred prior to full-power operation in September. A 2-week maintenance outage was conducted in December.

Power was reduced to $50 \%$ because of possible vibration of in-vessel instrument components that could damage FAs.

The unit was shut down for about 5 weeks for investigation of LPRMs, modifications to core components, and generator inspection.

An off-gas system explosion caused a 12-day outage.

The for 17 days for installation of a permanent generator exciter and torus modifications.

The first refueling and maintenance outage was performed. Major work included installation of new FAs and modifications to FA tie plates to reduce flow-induced vibration of LPRMs. Cracks were found in the FW nozzles and repaired.

The unit was shut down for 10 days for torus inspection, MSIV leak testing, HPCI turbine modifications and CRD changeout.

The second refueling and maintenance outage was performed. Major work included CRD and LPRM replacement, turbine inspection, safety valve testing, and capping of CRD return water nozzles.

The third refueling and maintenance outage was performed.

The fourth refueling and maintenance outage was performed.

Cylinder sleeve damage in one DG forced a 6-day outage.

The fifth refueling and maintenance outage was performed. Major work included RCIC turbine repair (foreign object caused damage) and repair to the LP main turbine. Twelve rows of turbine blades were removed, forcing operation at about $84 \%$ power. 


\section{COOPER STATION (Cont'd)}

Apr - Jun 1981

Sep - Nov 1981

May - Jul 1982

Feb 1983

Mar - Sep 1983

Sep 1984 - Aug 1985

Feb 1985

Oct - Nov 1985

Mar 1986

Apr 1986

Oct 1986 - Jan 1987

Mar - Apr 1987

Dec 1987

Mar - Jun 1988

Apr 1988

Dec 1988

Jan - Feb 1989
The sixth refueling and maintenance outage was entered early because of turbine vibration. Inspection revealed damaged blades in the LP turbine. Other outage work included containment penetration leak testing and turbine modifications. Power was still limited by turbine problems.

The unit was shut down to replace LP turbine rotors and conduct general maintenance.

The seventh refueling and maintenance outage lasted 47 days. Major work items included modifications to SRVs, torus, and RPS; inspection of snubbers, CS spargers and jet pump beams; and replacement of CRD lower mechanisms. Delays were caused by problems with torus and SDV work.

The NRC assessed a $\$ 112,000$ fine for alleged deficiencies in an emergency preparedness system and for alleged material false statements by management. The original amount of $\$ 300,000$ was reduced by $\mathrm{NRC}$ after reconsideration of circumstances of violation.

The eighth refueling and maintenance outage lasted 127 days. Outage time was extended to repair cracks found in recirculation and bypass lines, RWCU, RHR and CS piping.

The ninth refueling and maintenance was performed. All RCS piping susceptible to IGSC cracking was replaced. Other work included Appendix R modifications and EQ of equipment, installation of a SPDS, and major chemical decontamination of systems. Total cost was about $\$ 53.5$ million.

The NRC proposed a $\$ 25,000$ fine for alleged violations concerning inadequate testing of station batteries.

The unit was shut down for 47 days to repair damage to the condenser and the turbine after a shroud came loose.

The NRC assessed a $\$ 50,000$ fine for alleged violations concerning surveillance procedures and failure to detect inoperable equipment.

The NRC proposed a $\$ 50,000$ fine (later reduced to $\$ 25,000$ ) for alleged security violations.

The tenth refueling and maintenance outage was performed. Major work included Appendix R modifications; work on SBGT controls, ATWS modifications and postaccident instrumentation; repair of DG cylinder heads; and repair of RHR and CS pump motors.

The unit operated at $68 \%$ power because of single FW pump operation. The second FW pump was declared inoperable because of high vibration. The FW pump was replaced and unit resumed full-power operation in early April.

The unit completed its most productive year ever with a capacity factor of $77.4 \%$.

The eleventh refueling and maintenance outage lasted 105 days. Major work included replacement of $125-\mathrm{V}$ dc batteries, control room design review, RG 1.97 I\&C replacement, ATWS and MSR modifications, and a review of seismic design of all essential piping.

The NRC assessed a $\$ 25,000$ fine for alleged security violation wherein ammunition was introduced into the protected area.

The NRC assessed a $\$ 150,000$ fine for alleged electrical EQ violations. The fine was increased by $100 \%$ because the utility allegedly failed to identify the condition and take corrective action.

The unit scrammed and was shut down for 12 days for repairs when a MSIV disk separated from its valve stem. 
Apr - Jun 1989

Mar - May 1990

Oct 1990

Oct 1990

Mar 1991

Oct - Dec 1991

Jan 1992

Apr 1992

Mar - Jul 1993

Mar 1993

Oct 1993

Oct 1993

Dec 1993

Jan 1994

Mar 1994
The twelfth refueling and maintenance outage lasted 71 days. Major work included upgrading of control room and control room HVAC, DG controls, and FW pump turbine controls; modifications to piping restraints and other plant systems; and a pipe wall thinning study.

The thirteenth refueling and maintenance outage lasted 64 days. Major work included additional plant upgrading; modifications to the SPDS; and small bore and seismic Category I piping hanger replacement.

The unit was shut down for 13 days to repair damage after $345-\mathrm{kV}$ line was shorted by wind-blown maintenance equipment.

Although the NRC SALP report was awarded a Category 1 rating in operations and found improvements in safety assessment/quality verification, problems with training, especially operators performance at near minimum levels during requalification exams, were identified.

The unit was shut down for 5 days to repair a FW check valve leak.

The fourteenth refueling and maintenance outage lasted 74 days. Major work included recirculation pump and motor refurbishment; LP turbine, HPCI, and FW turbine 5-year inspections; ECT and cleaning of condenser tubes; and an ILRT.

An Unusual Event was declared, and the unit was shut down when the $250-\mathrm{V}$ batteries were declared inoperable due to copper contamination. The unit was shut down for 5 days to replace the batteries.

The unit was shut down for 5 days to replace degraded $250-\mathrm{V}$ batteries.

The fifteenth refueling and maintenance outage lasted 148 days. Major work included replacement of all SRM/IRM dry tubes; installation of hardened containment vent pipe mods; removal of the rod sequence control system; torus inspection and recoating; and DG inspection.

The NRC proposed a $\$ 200,000$ fine for two alleged violations involving (1) failure to provide the NRC complete and accurate information, and (2) failure of the corrective action program to identify and resolve potentially significant safety concerns.

The NRC SALP review reported a decline in performance. Problems were found with equipment, many which were long-standing.

The NRC proposed a $\$ 200,000$ fine for three alleged violations involving (1) breakdowns of corrective actions, (2) nearly 3 years of operation with containment hydrogen and oxygen analyzers inoperable at various times, and (3) failure to include part of the SW and reactor equipment cooling systems in the required ISI program.

The unit was shut down for 7 days after the feedwater level controller failed, causing a reactor trip.

The plant was placed on the NRC's problem plant list.

The reactor tripped after the turbine control system malfunctioned due to failed power supplies. The outage lasted 11 days. Later in the month, the unit was shut down for 8 days to repair an RHR valve. 


\section{COOPER STATION (Cont'd)}

May 1994 - Feb 1995

The unit originally shut down when the diesel generators were declared inoperable due to insufficient UV relay testing. The unit remained shut down to reduce the maintenance backlog and correct other concerns. The shutdown lasted 272 days. The licensee conducted an extensive diagnostic self-assessment that was evaluated by a NRC assessment team. This was in lieu of a NRC Diagnostic Evaluation Team visit.

Jun 1995

The plant was removed from the NRC's problem plant list.

Oct - Dec 1995

The sixteenth refueling and maintenance outage lasted 77 days.

Apr 1996

The NRC proposed and the licensee paid a $\$ 50,000$ fine for alterations of the blowout panels, which created an USQ.

Jun 1996

The plant was shut down for 10 days to replace a leaking fuel assembly. 
This Page Intentionally Left Blank 
CRYSTAL RIVER 3

PRODUCTION COST and CAPITAL ADDITIONS (1996 Dollars)

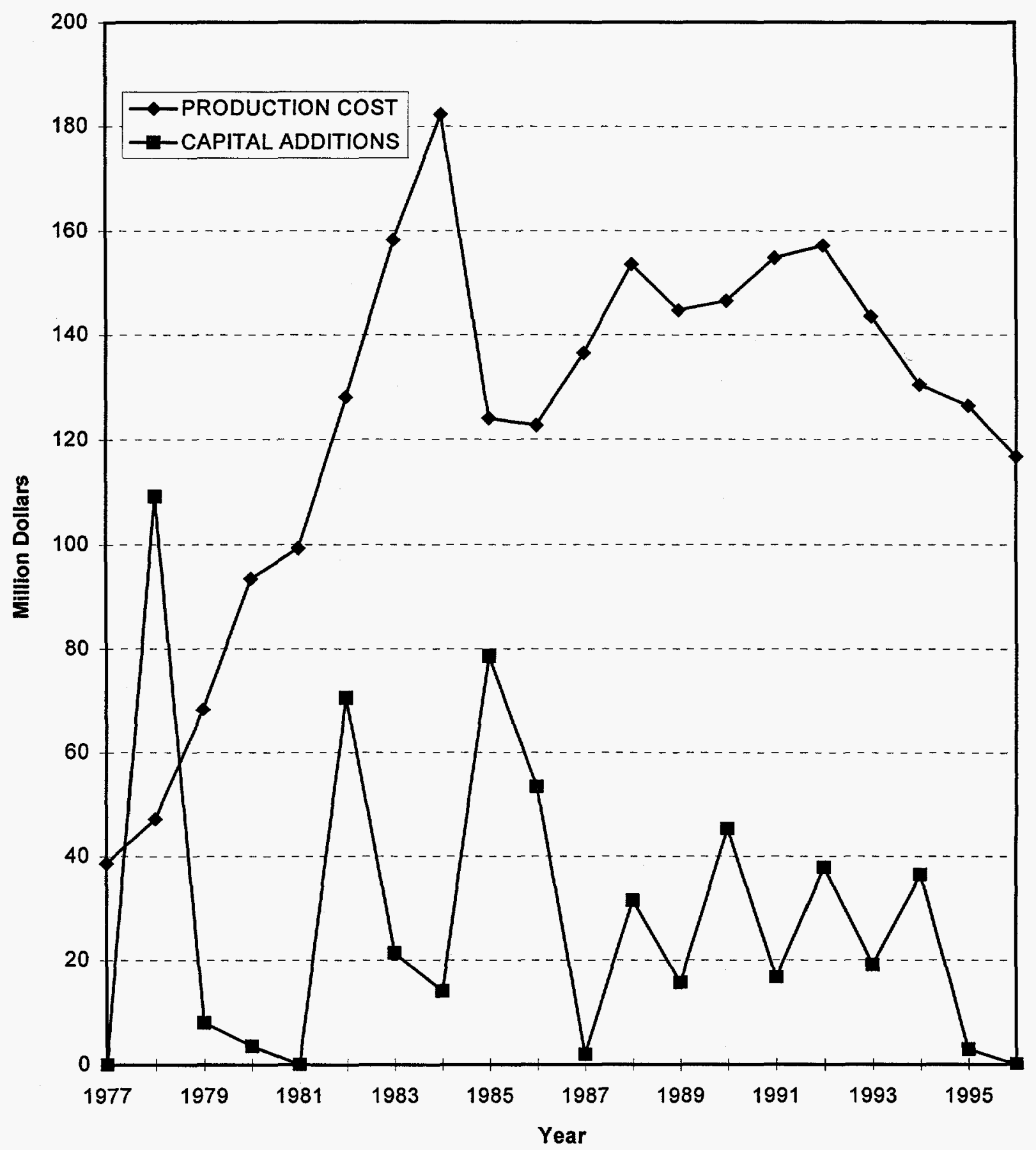




\title{
NUCLEAR POWER PLANT OPERATING EXPERIENCE SUMMARY
}

\author{
Unit data summary through December 1996
}

Unit: CRYSTAL RIVER 3

Nameplate Rating: 890 MWe

Location: CITRUS COUNTY, FLORIDA

MDC Net MWe: 818 MWe

Owner: FLORIDA POWER CORPORATION

Cumul. Avail. Factor: 66.4

Type: BABCOCK \& WILCOX PWR

Cumul. Cap. Factor (MDC Net): 62.3

Construction Permit: 09/25/68

Cumul. Forced Outage Rate: $\mathbf{1 7 . 0}$

Operating License: 01/28/77

3-Year Avg. Cap. Factor (MDC Net): 72.5

Commercial Oper. Date: 03/13/77

License Expiration: 2016

OPERATING HISTORY (To December 1996)

$\underline{\text { Date }}$

$1968-1975$

1976

May 1977

Mar - Sep 1978

Mar 1979

Apr - Jul 1979

Aug - Sep 1979

Feb - Aug 1980

Feb 1981

Jun - Jul 1981

Sep - Dec 1981

Jan 1982

Oct 1982
Comment

The RV was delivered about 1 year late. Due to a lack of funds, construction was halted in late 1974 at about $95 \%$ completion. Construction resumed in summer 1975 after $10 \%$ interest in the plant was sold to a group of local municipal and cooperative electric systems.

Problems with RCPs and containment building concrete separation delayed plant completion.

Cracked governor valve baffles were found during a planned outage. Total outage time was 15 days.

The plant was shut down for an extended outage after loose parts were detected in the RV. A failed burnable poison rod coupling damaged a SG. The reactor had to be defueled for repairs.

The plant shut down for 15 days to repair condenser expansion joints.

The plant was shut down for the first refueling outage. The shutdown was extended to repair RCP seals and conduct NRC-mandated inspection of pipe supports. A man was killed during the outage when he fell into the spent fuel pool.

After several trips, the plant shut down for about 30 days to repair RCP seals and SG tubes.

The plant shut down early for the second refueling after a pressure transient caused by a loss of NNI caused about 43,000 gallons of primary coolant to be released into the containment. Outage work included turbine inspection and TMI modifications.

A 17-day outage was forced by repair to seals on three RCPs.

A planned shutdown of 13 days was used to replace nuclear instrument detectors and repair reactor cavity fans.

The plant was shut down for the third refueling outage. Major work included inspection of thermal shield bolts as a result of Oconee experience. No abnormalities were found.

A crack found on a weld on the RCS loop A nozzle forced a 33-day outage for repairs. Other cracks were found and repaired on RCP seal housings.

The plant entered a 16-day outage to repair the RCS drain tank cooler and replace pressurizer relief valves. 
Nov - Dec 1982

Dec 1982

Mar - Jul 1983

Sep - Oct 1983

Mar - Aug 1985

Aug 1985

Jan - Jun 1986

Apr 1986

Aug - Oct 1986

Oct 1986

Nov 1986

Jan 1987

May 1987

Aug - Sep 1987

Sep 1987 - Jan 1988

Apr 1988

May 1988

Oct 1988
The plant entered a 25-day outage to repair letdown valves and replace both letdown coolers.

The NRC assessed a $\$ 50,000$ fine for alleged failure to provide adequate security for protected and vital areas.

The plant was shut down for the fourth refueling and maintenance outage. During the outage, IGSC cracks were found in RPV bolts. To meet TS fire suppression system requirements, extra personnel had to be hired as continuous fire watches until deficiencies were resolved.

The plant was shut down for 13 days to repair seals on two RCPs.

The plant was shut down for the fifth refueling and maintenance outage. During the outage, it was found that certain control complex HVAC supports were installed with deficient bolts and anchors.

The NRC assessed a $\$ 50,000$ fine for two alleged violations discovered during a routine safeguards inspection in August 1984.

Shaft failure in RCP A caused a reactor trip. During the ensuing shutdown, cracks were found in RCP B and C shafts. The plant remained shut down to replace the shafts in all four RCPs. During the outage, two divers were drowned while working on circulating water intakes. Total outage time was 169 days.

The utility paid a $\$ 50,000$ fine for alleged breach of vital area barrier.

On 14 occasions during the period, power was reduced to repair saltwater leaks in the condenser waterboxes.

The utility paid a $\$ 80,000$ fine for alleged training requirement violations.

The control rod stator repairs and other PM forced a 10-day outage. A 33-day outage was performed to repair both letdown coolers.

The plant was shut down for 21 days to replace all four RCP seal packages after 1 seal became degraded during operation.

The utility paid a $\$ 50,000$ fine for alleged security violations concerning sleeping guards and failure to adequately check security badges.

The unit was shut down to repair a RCP shaft seal. Upon startup, the unit operated at reduced power because only three of four RCPs were in operation and SG flow was limited by fouled tubes.

The sixth refueling and maintenance outage lasted 114 days. Major work included replacement of turbine governor valves, FW flow nozzles, and MSR tube bundles; conduct of ILRT; control room modifications; and SG sludge lancing. A LOSP occurred when contractor personnel contacted a $230-\mathrm{kV}$ line with a metal pole; one person died, and one was severely injured.

The utility paid a $\$ 100,000$ fine for alleged overexposure to an operator. The fine was doubled from $\$ 50,000$ because of previous similar events.

The NRC proposed a $\$ 50,000$ fine for alleged potential DG overloading after it was found that an EFW pump had been inadvertently included in the automatic DG loading sequence from May 1980 to October 1987.

The unit was shut down for scheduled replacement of two leaking check valves and main FW pump balancing. Other maintenance was also accomplished during the 19-day outage. 
Dec 1988 - Jan 1989

Jan - May 1989

Sep - Oct 1989

Feb 1990

Mar - Jun 1990

May 1990

Oct 1990

Oct - Nov 1991

Dec 1991

Mar 1992

Apr - Jul 1992

Mar - Apr 1993

Apr - Jul 1994

Jan 1996

Feb - May 1996

May 1996

Jul 1996

Sep - Dec 1996
The unit went off-line for RCP inspection because of shaft failure concerns. Cracks were found in six of eight gussets in RCP A. The MFW pump and a CRD flange leak were also repaired during the 33-day outage.

The plant shut down to repair RCP A motor shaft. Total outage time was 112 days.

The plant was shut down for 41 days to replace raw water service pumps

A leaking pressurizer SRV required an 8-day outage to replace it.

The seventh refueling and maintenance outage lasted 101 days. Major work included generator stator replacement, DG upgrade, turbine inspection, RCP seal replacement, RV nozzle inspection, LLRT, RCP motor and shaft rework, SG nozzle modification, and CRDM work.

The NRC assessed a $\$ 100,000$ fine for alleged slow response on the part of the utility to resolve EQ problems with electrical equipment.

The plant was shut down for 10 days to repair an RCP motor oil leak and lube oil collection system. The local hospital emergency room and emergency room staff had to be decontaminated after a fatally injured plant worker was brought in for treatment from a fall inside containment.

A midcycle maintenance outage lasted 47 days. Major work performed was raw water pump overhaul, letdown cooler replacement, DG inspection, FW system flange leak repairs, reactor building leak test, RCP seal and control rod drive replacements, and pressurizer spray valve repair.

Two reactor trips occurred during the month, and the resulting outages totaled 16 days.

After a reactor trip, the shutdown was used to replace a DG jacket cooling water pump. The outage lasted 8 days.

The eighth refueling and maintenance outage lasted 78 days. Major work included RCP repairs, eddy current testing, DG inspection, and boron corrosion inspection.

A midcycle maintenance outage lasted 54 days. Major work included rework of the main steam safety valves, one DG, one raw water pump, and selected snubbers; main generator and snubber inspections; condenser water box $\mathrm{D}$ retubing; reactor building tendon surveillances; and LLRT.

The ninth refueling and maintenance outage lasted 57 days.

The unit was shut down for 19 days to repair a large leak in the main condenser.

The tenth refueling and maintenance outage lasted 91 days.

A 6-day outage was needed to repair the main turbine's control oil system.

The NRC proposed and the licensee paid a $\$ 500,000$ fine for the performance of unauthorized tests by operators. Four operators had their licenses terminated by the licensee due to this event.

The unit was shut down to repair a leak in main turbine's lube oil system. Due to utility and NRC concerns, it was decided to remain shut down to resolve a number of design issues, especially with respect to the diesel generators. The unit will remain out-of-service for most, if not all, of 1997. 
DAVIS BESSE

PRODUCTION COST and CAPITAL ADDITIONS

(1996 Dollars)

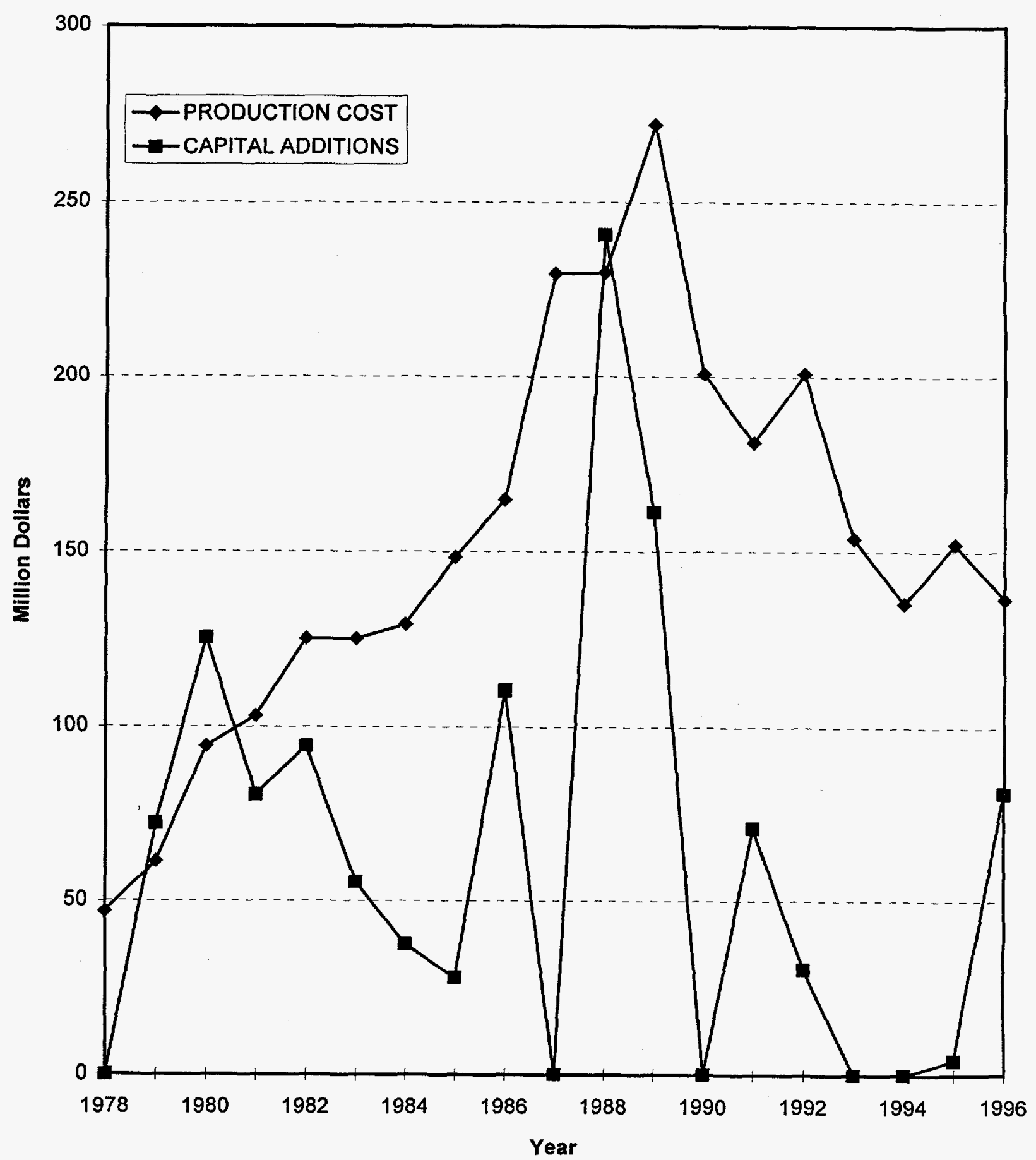




\title{
NUCLEAR POWER PLANT OPERATING EXPERIENCE SUMMARY
}

\author{
Unit data summary through December 1996
}

Unit: DAVIS BESSE

Location: OTTAWA COUNTY, OHIO

Owner: TOLEDO EDISON CO.

Type: BABCOCK \& WILCOX PWR

Construction Permit: 03/24/71

Operating License: 04/22/77

Commercial Oper. Date: 07/31/78
Nameplate Rating: 925 MWe

MDC Net MWe: 873 MWe

Cumul. Avail. Factor: 65.4

Cumul. Cap. Factor (MDC Net): 58.9

Cumul. Forced Outage Rate: 17.2

3-Year Avg. Cap. Factor (MDC Net): 89.6

License Expiration: 2017

OPERATING HISTORY (To December 1996)

Date

Sep 1977

Apr - Jul 1978

Aug 1978

Oct - Nov 1978

Dec 1978

Jan 1979

Mar - Jul 1979

Oct - Nov 1979

Dec 1979 - Jan 1980

Apr - Nov 1980

Jan - Feb 1981

\section{Comment}

During power escalation testing, condenser tube leaks forced a 15 day shutdown. A CRD stator was replaced, and the main steam safety valves were also set during the outage.

The plant was shut down for inspection of core components. The outage was extended to resolve design problems with the emergency load sequencer and conduct work on the cooling tower, condenser, and MSRs.

The plant was shut down for 15 days because two of four nuclear instrument channels were declared inoperable. RCP seals were also changed.

A shutdown of about 1 month was needed for RCP seal and impeller repair, FW pump repair, and repairs to various plant valves. Outage was extended for natural circulation testing and chemistry problems.

A 2-week outage was needed to repair failed extraction steam line expansion joints and broken condenser manway studs.

A 2-week maintenance outage included work on RCP seals, relief and safety valves, and FW heaters.

The unit was shut down for maintenance and to make modifications in response to TMI accident.

Outages totaling 20 days were necessary to repair a pressurizer spray valve, a RCP seal, and a failed circuit board in the ICS.

The unit was shut down for about 5 weeks to investigate RCP oil level alarms and to repair the RPI system.

The first refueling and maintenance outage lasted 207 days. Major work included replacement of all FA holddown springs, TMI modifications, turbine/generator overhaul, and a number of other plant modifications. The outage was prolonged because of construction and office employee labor strikes. The NRC assessed a $\$ 13,000$ fine for alleged overexposure to a technician.

A 4-week outage was necessary for repairs to RCP seals and FW controls. 


\section{DAVIS BESSE (Cont'd)}

Apr 1981

Jun - Jul 1981

Jul - Aug 1981

Nov 1981

Mar - Sep 1982

Jan - Feb 1983

Jul - Sep 1983

Jan 1984

Sep 1984 - Jan 1985

Nov 1984

Mar - Apr 1985

Jun 9, 1985

Jul 1985

Jun 1985 - Dec 1986

Jul 1986

Aug 1986

Dec 22, 1986

Feb 1987
The SG tube leaks caused operation at decreasing power levels until the plant shut down to repair SG. Total outage time was 20 days.

The unit was shut down for about 4 weeks after a reactor scram from CRD power loss. Resolution of CRD power problems prolonged the outage.

A 17-day outage was forced by a failed condenser boot seal.

A 19-day outage was forced by a leaking extraction steam line bellows.

The second refueling and maintenance outage was performed. Major work included SG inspection, repair of FW headers in SGs, and addition of supports to extraction steam lines to prevent damage to bellows.

The plant was shut down for 14 days to repair the NNI power supply and a leaky MSIV.

The third refueling and maintenance outage entered early after a power supply failure in the FW rupture control system. Major outage work included inspection of core support barrel bolts and SG, modifications to DG, and rework of FW header.

A 17-day outage was caused by repairs to nuclear instrumentation systems.

The fourth refueling and maintenance outage was performed. Major work included cooling tower grouting; core barrel and thermal shield bolt inspections; condenser and SG tube inspections; and RCP seal refurbishment.

The NRC assessed a $\$ 90,000$ fine for a number of alleged violations.

The plant was shut down for 23 days to repair failed CRD leaf springs.

The plant suffered a unit trip on high RCS pressure after a main FW pump trip. Numerous equipment failures and personnel errors caused a loss of $\mathrm{FW}$ flow for about 12 minutes. The unit was placed in cold shutdown, and an NRC investigation team was sent to the site.

The NRC proposed a $\$ 100,000$ fine for alleged violations occurring in April 1985 concerning lax operating practices by operators.

The plant underwent extensive equipment modification and inspection in response to the loss of FW event of June 9, 1985. Major items included modification to the PORVs; installation of a motor-driven startup FW pump; extensive adjustment and testing of all safety-related MOVs in the plant; inspection and rework of Raychem ${ }^{\circledR}$ electrical splices; and replacement of all RCP shafts in response to Crystal River experience. In addition, plant management and operator training and maintenance programs were upgraded in response to findings by the NRC.

The utility reported that it had spent in excess of $\$ 100$ million to correct deficiencies uncovered in the loss of FW event.

The utility filed suit against support services contractor, Torrey Pines Technology, blaming the company for the lengthy shutdown after the event.

The plant restarted after a 561-day outage following the loss of FW event of June 1985.

The NRC had proposed a $\$ 900,000$ fine for 10 alleged violations related to the loss of FW event of June 9,1985 . The fine was reduced by $50 \%$ to $\$ 450,000$ by the NRC. 


\section{DAVIS BESSE (Cont'd)}

May - Jun 1987

Dec 1987

Mar - Dec 1988

May 1988

Nov 1988

Apr 1989

Jan - Jul 1990

Aug - Nov 1991

Dec 1991

Mar - Apr 1993

Oct - Nov 1994

Mar 1995

Jul 1995

Apr - Jun 1996

Oct 1996
The plant was shut down for scheduled maintenance. Major work included replacement of pressurizer code safety valves, PORV, RCP seals, and FW pump bearings; repairs to motordriven FW pump and turbine bypass valves; and repair and adjustment of a number of plant valves. Total outage time was 37 days.

The NRC assessed a $\$ 25,000$ fine for alleged violations of security requirements for vital areas.

The fifth refueling and maintenance outage lasted 281 days. Major work included control room modifications, turbine and generator overhaul, cooling tower repair, SG inspection, and DG modification.

The utility announced that a $\$ 4$ million radwaste treatment and storage facility would be added to the plant.

The NRC proposed an $\$ 80,000$ fine for alleged actions of a supervisor who deliberately laid off a QC inspector who raised a safety issue.

The NRC proposed a $\$ 50,000$ fine for several alleged violations identified during a plant startup in December 1988.

The sixth refueling and maintenance outage lasted 160 days. Major work included addition of a portable third DG, refurbishment of MS safety valves, Appendix R modifications, RV and core barrel ISI, SG inspection and tube plugging, control room modifications, and overhaul of RCP motors. Outage was extended for repair to pressurizer PORV block valves and spray valves.

The seventh refueling and maintenance outage lasted 69 days.

The turbine generator was taken off-line for 5 days due to TS limit for DG inoperability being exceeded.

The eighth refueling and maintenance outage lasted 60 days.

The ninth refueling and maintenance outage lasted 46 days.

The plant received all Category 1 ratings on its NRC SALP report, and the evaluations were lengthened to a 24-month cycle.

The plant was recognized as a superior performer by the NRC.

The tenth refueling and maintenance outage lasted 55 days.

The NRC proposed and the licensee paid a $\$ 50,000$ fine for problems with fire protection design issues. 
DIABLO CANYON

PRODUCTION COST and CAPITAL ADDITIONS

(1996 Dollars)

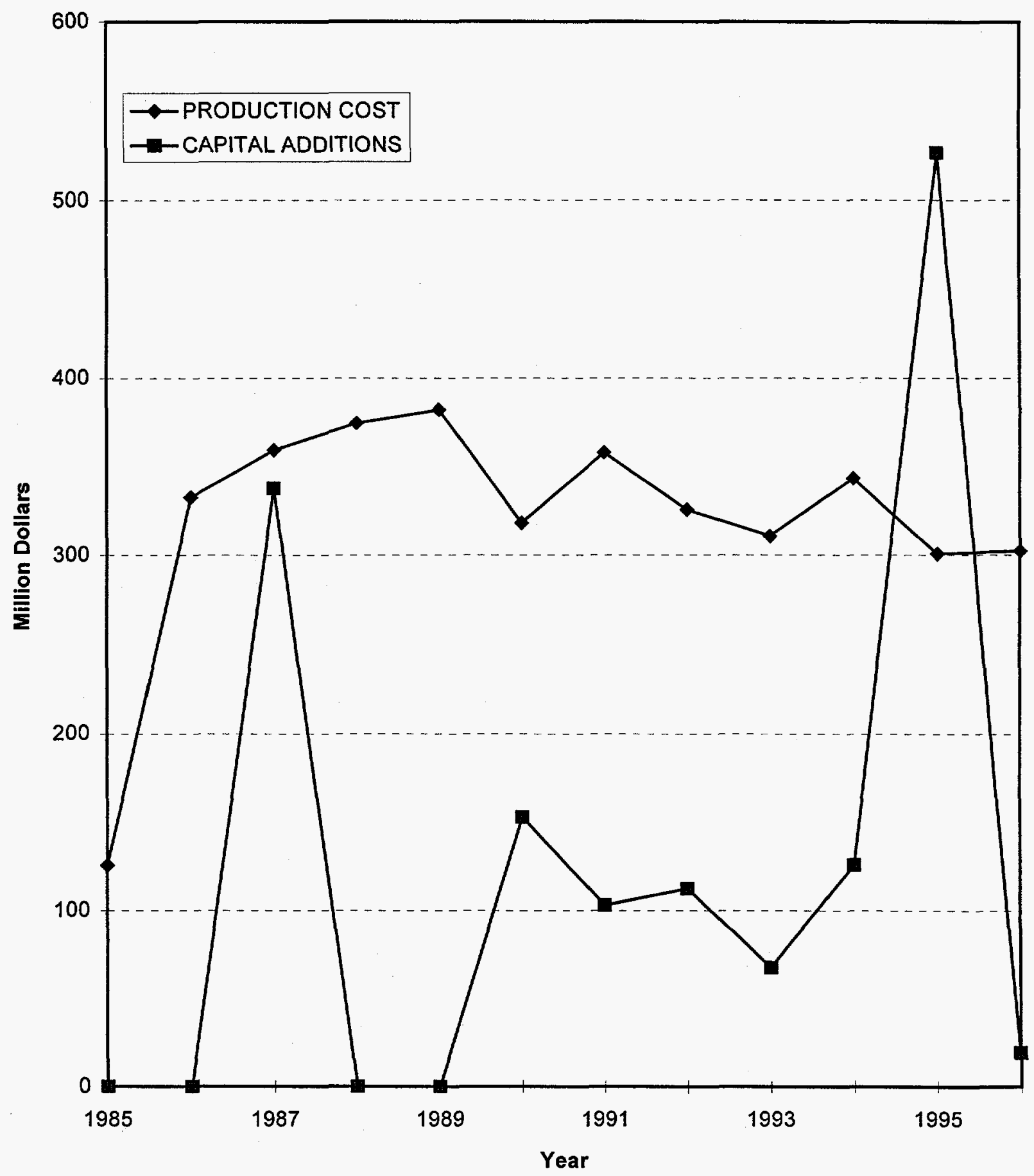




\section{NUCLEAR POWER PLANT OPERATING EXPERIENCE SUMMARY}

Unit data summary through December 1996

\section{Unit: DIABLO CANYON 1}

Location: SAN LUIS OBISPO COUNTY, CALIFORNIA

Owner: PACIFIC GAS \& ELECTRIC CO.

Type: WESTINGHOUSE PWR

Construction Permit: 04/23/68

Operating License: 11/11/84

Commercial Oper. Date: 05/07/85
Nameplate Rating: 1137 MWe

MDC Net MWe: 1073 MWe

Cumul. Avail. Factor: 84.0

Cumul. Cap. Factor (MDC Net): 79.7

Cumul. Forced Outage Rate: 3.4

3-Year Avg. Cap. Factor (MDC Net): 83.6

License Expiration: 2021

OPERATING HISTORY (To December 1996)

Date

Nov 1981

Jan 1984

Jun 1984

Nov 1985

Sep 1986

Oct 1987

Dec 1987

Mar - Jul 1988

Jul 1989

Oct - Dec 1989

\section{Comment}

The NRC revoked the fuel load permit after it was found that plant layout drawings for seismic support installation were inadvertently switched between Unit 1 and Unit 2. An independent design verification was then required, and fuel load was delayed until November 1983.

The utility reported that about 500 major structural changes were needed in response to updated NRC licensing requirements.

The NRC assessed a $\$ 50,000$ fine against the utility for an alleged event where the BIT inlet and outlet valves were inadvertently closed.

The unit was shut down for 12 days for secondary system cleaning after a condenser tube leak.

The first refueling outage was performed. Unit 1 produced 8.3 billion net $\mathrm{kWH}$ it its first year of operation, a new record for a domestic nuclear power plant. The unit also set a world record for a $\underline{W}$ four-loop plant by achieving a capacity factor of $88 \%$ during its first year.

After prolonged hearings for intervenors requests to stop spent fuel storage expansion, the unit was issued a license amendment to increase spent fuel storage from 270 to 1324 FAs.

The unit completed the year with an $88 \%$ availability factor.

A second refueling and maintenance outage lasted 129 days. Major work included SG inspection and sludge lancing, RV and turbine inspection, RCP seal replacement, and major RHR maintenance.

The NRC proposed a $\$ 75,000$ fine for alleged violations involving engineering and design control and failure to take corrective action for identified problems.

The third refueling and maintenance outage lasted 70 days. Major work included SG inspection, RCP seal and LP turbine rotor replacement, and main generator winding rework. One of the largest earthquakes in California history resulted in a base slab acceleration of only $0.0044 \mathrm{~g}$ vs plant design acceleration of $0.67 \mathrm{~g}$. No damage to the unit was reported. The quake epicenter was 145 miles from the plant site. Several large oil-fired units in northern California were incapacitated. 


\section{DIABLO CANYON 1 (Cont'd)}

Feb 1990

Mar 1990

Jun 1990

Dec 1990

Dec 1990

Feb - Apr 1991

Mar 1991

Jun 1991

Sep - Nov 1992

Dec 1993

Mar - May 1994

May 1994

Oct 1994

Dec 1994

Sep - Nov 1995

Dec 1995

Mar 1996

Aug 1996

Nov 1996
The NRC proposed a $\$ 50,000$ fine for alleged violations relating to containment sump operability at both units.

The NRC proposed fines totaling $\$ 75,000$ for various alleged violations involving both units.

The unit was shut down for 6 days following a load rejection due to a grid disturbance offsite.

A reactor trip resulted when a pressurizer spray valve stuck open and caused a rapid primary cooldown. The unit was shut down for 4 days.

The NRC questioned the seismic qualification of over 120 non-load-bearing masonry brick walls. New acceptance criteria would require modification to the walls.

The fourth refueling and maintenance outage lasted 94 days. It was entered early due to a reactor trip on low SG level.

A loss of off-site power occurred due to a crane boom coming near a 500-kV line. The unit was in a refueling outage at the time.

The NRC approved the existing seismic design of the plant.

The fifth refueling and maintenance outage lasted 59 days.

The reactor tripped due to a system disturbance and transducer drift. The unit was shut down for 5 days.

The sixth refueling and maintenance outage lasted 57 days.

The unit was shut down for 12 days to replace a transformer that had an internal fault.

The plant received all Category 1 ratings on its NRC SALP report, and the evaluations were lengthened to a 24-month cycle.

An off-site grid transient caused the plant to shut down for $\mathbf{4}$ days.

The seventh refueling and maintenance outage lasted 57 days.

The unit was off-line for 5 days due to kelp in the seawater cooling system.

The unit was shut down for 4 days to replace a transformer.

An off-site grid disturbance resulted in the plant being shut down for 6 days.

A trip of the auxiliary transformer tripped the main generator and the reactor with the unit being down for 8 days. 


\section{NUCLEAR POWER PLANT OPERATING EXPERIENCE SUMMARY}

Unit data summary through December 1996

Unit: DIABLO CANYON 2

Location: SAN LUIS OBISPO COUNTY, CALIFORNIA

Nameplate Rating: 1164 MWe

Owner: PACIFIC GAS \& ELECTRIC CO.

MDC Net MWe: 1087 MWe

Cumul. Avail. Factor: $\mathbf{8 5 . 2}$

Type: WESTINGHOUSE PWR

Cumul. Cap. Factor (MDC Net): $\mathbf{8 1 . 7}$

Construction Permit: 12/09/70

Cumul. Forced Outage Rate: 3.9

Operating License: 08/26/85

3-Year Avg. Cap. Factor (MDC Net): 86.2

Commercial Oper. Date: 03/13/86

License Expiration: 2025

OPERATING HISTORY (To December 1996)

Date

Aug - Oct 1985

Jan - Feb 1986

Mar 1986

Jan 1987

Feb - Mar 1987

Apr - Jul 1987

Jul - Aug 1988

Sep - Dec 1988

Jul 1989

Oct 17,1989

Mar - May 1990

\section{Comment}

A 6-week delay in the low power testing program was caused by a RCP motor winding failure.

The unit was shut down after a planned trip during startup testing to remove piping system strainers and perform other maintenance. Total outage time was 39 days.

The NRC proposed a $\$ 50,000$ fine for alleged violations involving wiring errors that disabled one MSIV actuation channel.

During its first operating year, the unit had run for 151 consecutive days - the longest uninterrupted operation for a large U.S. plant in its first year of operation. The combined capacity factor for both units was $86.4 \%$, a new U.S. record for multi-unit plants.

Generator stator cooling hydrogen leaks caused two outages for repair totaling 9 days.

The first refueling and maintenance outage lasted 102 days. Major work included replacement of the containment building crane, replacement of FW heater and MSR tube bundles and SG J-tubes, inspection and sludge lancing of the SGs, containment ILRT, and main FW pump and turbine overhaul.

The unit was shut down for 24 days to make repairs to nonsafety-related $12-\mathrm{kV}$ buses that had deteriorated over four years from thermal and electrical cycling.

The second refueling and maintenance outage lasted 84 days. Major work included SG inspection and sludge lancing, inspection of two RCP seals, RPV ISI, main turbine inspection, and inspection/repair of Anchor Darling check valves.

The NRC assessed a $\$ 75,000$ fine for six alleged violations, including Unit 2 operation with two of three FW pumps inoperable for 2 days.

One of the largest earthquakes in California history resulted in a base slab acceleration of only $0.0044 \mathrm{~g}$ vs plant design acceleration of $0.67 \mathrm{~g}$. The unit continued to operate at $100 \%$ power, while several large oil-fired units in northern California were incapacitated. No damage to the unit was reported. The quake epicenter was 145 miles from the plant site.

The third refueling outage lasted 58 days. 
Mar 1990

Mar 1990

Dec 1990

Jun 1991

Aug 1991

Aug - Oct 1991

Mar 1992

Mar - May 1993

Mar 1994

Sep - Oct 1994

Oct 1994

Dec 1994

Sep 1995

Dec 1995

Apr - May 1996

Aug 1996
The utility received three Category 1 ratings and no low marks in the NRC SALP review of unit performance.

The NRC proposed fines totaling $\$ 75,000$ for various alleged violations involving both units.

The NRC questioned the seismic qualification of over 120 non-load-bearing masonry brick walls. New acceptance criteria would require modification to the walls.

The NRC approved the existing seismic design of the plant.

The utility received four Category 1 ratings in the NRC SALP review of unit performance. In August, the unit set a new LWR continuous operation record of 481 days.

The fourth refueling outage lasted 53 days.

The unit was shut down for 6 days to repair a turbine stop valve.

The fifth refueling and maintenance outage lasted 57 days.

The unit was shut down to repair a leak on a vent line weld. The outage lasted 13 days.

The sixth refueling and maintenance outage lasted 34 days.

The plant received all Category 1 ratings on its NRC SALP report, and the evaluations were lengthened to a 24-month cycle.

The unit was shut down for 6 days following a manual scram brought about by circulating water problems due to heavy seas.

Kelp loading in the seawater cooling systems required the plant to shut down for 9 days.

A 4-day outage was initiated by kelp loading.

The seventh refueling and maintenance outage lasted 48 days.

Two separate shutdowns resulted in 7 days of downtime for the unit. The first was due to an EHC leak and the second from an off-site grid disturbance. 
This Page Intentionally Left Blank 
DRESDEN

PRODUCTION COST and CAPITAL ADDITIONS

(1996 Dollars)

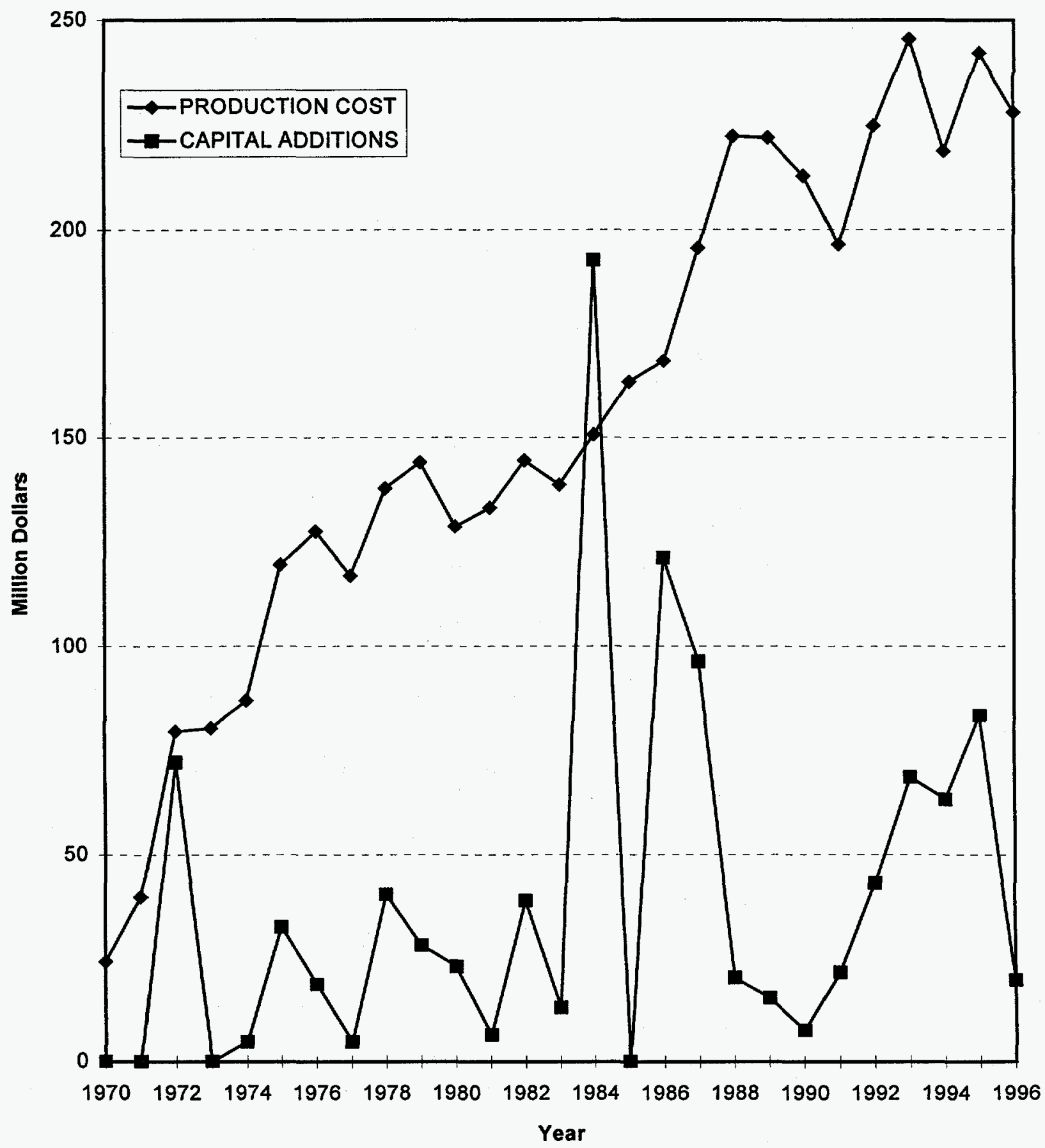




\title{
NUCLEAR POWER PLANT OPERATING EXPERIENCE SUMMARY
}

\author{
Unit data summary through December 1996
}

Unit: DRESDEN 2

Location: GRUNDY COUNTY, ILLINOIS

Owner: COMMONWEALTH EDISON CO.

Type: GENERAL ELECTRIC BWR

Construction Permit: 01/10/66

Operating License: 12/22/69

Commercial Oper. Date: 06/09/70
Nameplate Rating: 840 MWe

MDC Net MWe: 772 MWe

Cumul. Avail. Factor: 68.8

Cumul. Cap. Factor (MDC Net): 55.7

Cumul. Forced Outage Rate: 14.2

3-Year Avg. Cap. Factor (MDC Net): 39.8

License Expiration: 2006

OPERATING HISTORY (To December 1996)

Date

Jun - Aug 1970

1971

Feb 1972

Dec 1973

Sep 1974

Jan - May 1981

Jun 1982

Aug 1982

Jan - Apr 1983

Mar 1984

Nov 1986 - May 1987

\section{Comment}

A primary containment pressure incident occurred. Refueling was required because 29 fuel assemblies failed; problems with Electromatic relief valves and Limitorque motor operators recurred throughout 1970.

The failed fuel assemblies caused restriction to $60 \%$ power for half the year; a new cooling lake was placed in operation.

An 11-week shutdown to replace all 509 FAs and remove core poison curtains was performed (new fuel contained gadolinium).

GE paid \$18 million to settle contract disputes with Commonwealth Edison.

A weld crack in a recirculation valve bypass line caused a 3-week shutdown; AEC directed all BWRs to inspect similar piping.

A refueling outage involved major work on torus modifications plus CRD replacements and turbine overhaul. The NRC assessed an $\$ 80,000$ fine for two incidents involving personnel overexposure.

The licensee was fined $\$ 100,000$ by NRC for administrative deficiencies associated with the use of substandard parts in Electromatic relief valves.

The operating licensee was amended to allow installation of $\mathbf{3 3}$ high-density fuel storage racks.

A refueling and maintenance outage lasted 108 days. The new Exxon fuel assemblies were placed in about one-third of core, CRDs were replaced, the torus was painted, extensive MSIV work was completed.

The NRC imposed a $\$ 50,000$ fine for alleged failure to properly classify vacuum breaker arm shaft seals. The seals allowed excess leakage during ILRT in April.

A refueling and maintenance outage lasted 153 days. Major work included decontamination of recirculation piping and cleaning the torus. The RPV underwent an ASME hydrostatic test. 
Feb 1988

Oct 1988 - Feb 1989

Dec 1989

Dec 1989

Jan 1990

Jan 1990

Jun 1990

Sep 1990 - Feb 1991

Dec 1990

Feb 1991

Feb 1991

Mar 1991

May 1991

Jul 1991

Aug 1991

Oct 1991

Nov 1991 - Mar 1992
The NRC imposed a $\$ 50,000$ fine for allegedly operating with air in the containment atmosphere in excess of allowed time.

The eleventh refueling and maintenance outage lasted 114 days. Cables were found damaged from high temperatures in the upper drywell.

The plant was removed from NRC list of problem plants.

A planned 11-day outage was taken to test the $125-\mathrm{V}$ batteries.

A 5-day outage followed an MSIV isolation and scram during MSL high-flow isolation switch calibration.

An 8-day outage followed a fire in a condensate/condensate booster pump motor and subsequent scram.

Operating power was reduced to $<70 \%$ to prevent exceeding the cooling lake temperature restrictions. The cause was high ambient temperatures and humidity and lack of rain.

The twelfth refueling and maintenance outage lasted 147 days. Major work included RWCU piping replacement, ILRT, CRD replacement, primary system piping ISI, and turbine and RCP repairs.

The NRC proposed a $\$ 37,500$ fine for alleged failure to keep containment adequately sealed against leakage during containment atmosphere sampling.

A full-term operating license was issued effective through January 2006.

The SBLC system was declared inoperable due to cavitation in one of the pumps. Boron solution tank levels and solution temperatures were adjusted to ensure NPSH. The NRC issued Information Notice 91-12 concerning the event.

Two separate outages were performed during the month. A 10-day outage was needed to repair a recirculation sample isolation valve. A 14-day outage was needed to tighten the reactor shroud separator bolts after they were found to be loose.

The NRC proposed a $\$ 100,000$ fine for alleged violations involving a potential leakage path from the reactor containment through a valve connection due to excessive leakage. The leakage was due to improper maintenance performed in February 1989.

A 5-day outage was required to repair leaks from the RCS sample system piping.

A 4-day outage was required following a MSIV isolation on a spurious MSL low-pressure signal after the main turbine tripped.

The unit was shut down after the $250-\mathrm{V}$ battery failed its discharge test. The design calculations were incorrect due to inaccurate information supplied by the vendor. The outage lasted 23 days.

The reactor scrammed when simultaneous IRM spikes occurred. These were caused by EMI mainly from DC valve motor operators. While shutdown, MCC cables were found, which violated separation criteria. Rerouting the cable extended the outage, which lasted a total of 101 days. 
$\operatorname{Jan} 1992$

Feb 1992

Aug 1992

Nov 1992

Nov 1992

Dec 1992

Jan - May 1993

Jul 1993

Sep 1993

Oct 1993

May 1994

Aug - Sep 1994

Mar - Apr 1995

Jun 1995 - Apr 1996

May - Aug 1996

Jun 1996
The NRC proposed and the utility paid $\$ 187,500$ in fines for alleged violations involving operation and maintenance errors. The maintenance error was failing to test a Unit 3 valve following maintenance. There were multiple operations errors including inadequate communications and failure to follow procedures.

The NRC placed Units 2 and 3 back on its problem plant list for lack of attention to detail, failure to follow procedures, lack of supervisory involvement, and station equipment not meeting design requirements.

A 4-day outage was required to replace a recirculation pump seal.

Although the NRC SALP review awarded two Category 1 ratings, continued decline in overall performance was noted, and four areas received a low Category 3 rating.

Four control room operators were fired for covering up an incident involving mispositioning a control rod.

The unit was shut down for $\mathbf{1 0}$ days for maintenance on a recirculation pump.

The thirteenth refueling and maintenance outage lasted 128 days.

The NRC proposed a $\$ 75,000$ fine for alleged violations involving safety review of plant modifications, specifically the inadequate evaluation of reduced flow in one of the safety systems.

The NRC SALP review indicated some improvement, but overall performance was still considered poor. The report gave two Category 1 and two Category 3 ratings. The plant remained on the problem plant list.

The unit was shut down for 34 days for TIP and MSIV repairs.

The NRC proposed a $\$ 75,000$ fine for alleged violations involving failure to adequately correct problems with water level indicator switches.

The unit was shut down due to problems with a HPCI check valve. The unit remained in the outage at the end of September to address other issues.

The unit was shut down for 32 days to perform EDG testing.

The fourteenth refueling and maintenance outage lasted 326 days. The unit performed extensive corrective actions to address plant and personnel problems.

The unit was shut down to correct problems with the feedwater control system and remained shut down to refurbish the 4-kV breakers. The outage lasted 91 days.

The NRC proposed and the licensee paid a $\$ 50,000$ fine for structural steel in the corner rooms not conforming to the licensed plant configuration described in the FSAR due to modifications and errors in the original design. 


\section{NUCLEAR POWER PLANT OPERATING EXPERIENCE SUMMARY}

Unit data summary through December 1996

Unit: DRESDEN 3

Location: GRUNDY COUNTY, ILLINOIS

Nameplate Rating: 840 MWe

Owner: COMMONWEALTH EDISON CO. MDC Net MWe: 773 MWe

Type: GENERAL ELECTRIC BWR

Cumul. Avail. Factor: $\mathbf{6 7 . 2}$

Construction Permit: 10/14/66

Cumul. Cap. Factor (MDC Net): $\mathbf{5 5 . 2}$

Operating License: 03/02/71

Cumul. Forced Outage Rate: 14.9

Commercial Oper. Date: 11/16/71

3-Year Avg. Cap. Factor (MDC Net): 39.5

License Expiration: 2011

OPERATING HISTORY (To December 1996)

Date

1971

1973

Apr - Sep 1975

Mar - May 1978

Dec 1978 - Apr 1979

Jul 1979 - Feb 1980

Jan - May 1982

Jun 1982

Sep 1982

Sep 1983 - Jul 1984

May 1984

\section{Comment}

Startup delays resulted from negotiations with intervenors concerning radioactivity release limits and the need for a cooling lake; a $\$ 3$ million cooling spray system was added.

Failed fuel assemblies and off-gas limitations forced an early refueling outage. A 12-week shutdown to replace defective FAs and remove 200 core poison curtains was performed (new fuel contained gadolinium). A new cooling lake was placed in operation.

A refueling and extensive maintenance outage was performed. Cracks were found in CRDM collet housings and jet pump welds, CRDs were overhauled, recirculation bypass lines were replaced, and cracked FW spargers replaced.

A refueling and major maintenance outage included CRD overhaul, turbine overhaul, CRD nozzle cracks found.

An outage due to fire in main transformer occurred and a replacement was installed. The replacement caught fire in February; it was repaired and returned to operation on April 25.

The unit derated to $75 \%$ power due to high off-gas activity and FA cladding degradation.

The refueling and maintenance outage lasted 122 days. This included turbine maintenance, CRD replacements, and torus modifications.

The licensee was fined $\$ 100,000$ by $\mathrm{NRC}$ for administrative deficiencies associated with use of substandard parts in Electromatic relief valves.

The utility received final approval from NRC for 28 additional high-density spent fuel storage racks.

An extended outage was needed to inspect recirculation piping in accordance with IE Bulletin 83-02. Other work included refueling, HP turbine overhaul, CRD replacement, ISI, chemical cleaning of recirculation piping, and weld overlay repair. A bowed rotor in HP turbine extended outage to July.

The NRC assessed a $\$ 130,000$ fine for alleged security and radiation protection violations. 
Oct 1985 - Sep 1986

Dec 1985

Jan 1986

May 1987

Jun 1987

Mar - Jun 1988

May 1989

Dec 1989

Dec 1989 - Feb 1990

Apr 1990

Jun 1990

Dec 1990

Dec 1990 - Feb 1991

Aug 1991

Sep 1991 - Apr 1992

Sep 1991 - Apr 1992

Dec 1991

Feb 1992
A refueling and extensive maintenance outage was needed to replace portions of core spray piping and cracked nozzles, recoat the torus, and install a new turbine-generator.

The QA inspector fell to his death inside the torus.

A fire occurred in annular space between the containment vessel and shield wall when hot slag from pipe cutting ignited the compressible urethane foam.

The NRC assessed two fines of $\$ 25,000$ each; one for alleged violations concerning primary containment integrity and the other for weakness in control of plant modifications.

The NRC assessed a $\$ 50,000$ fine for alleged security violation found during an NRC inspection.

A refueling and maintenance outage lasted 91 days. It was needed for drywell structural work, cable replacement, and battery replacement.

The NRC imposed a $\$ 150,000$ fine for alleged equipment qualification violations in April 1988.

The plant was removed from the NRC list of problem plants.

The eleventh refueling and maintenance outage lasted 60 days.

The NRC extended the unit operating license to June 12, 2011.

The unit was shut down for 5 days for main turbine thrust bearing and main transformer bushing replacement.

The NRC proposed a $\$ 37,500$ fine for alleged failure to keep containment adequately sealed against leakage during containment air sampling.

The unit operated at reduced power in single-loop mode for about a month due to high vibration on a recirculation pump motor. The unit was shut down for 2 weeks to repair the pump motor, but the outage was extended to repair the main turbine bypass valve pressure regulator and a leaking shaft on a recirculation pump. The total outage time was 26 days.

The unit tripped when a turbine stop valve closure occurred. The fast-acting solenoids for two of the valves were replaced during the 5-day outage.

The twelfth refueling and maintenance outage lasted 231 days. Major work included recirculation system decontamination, LP turbine overhaul, and DG modifications and testing.

During the refueling, fuel handlers erroneously moved a fuel crane while a FA was still attached. The crane, the FA, and two other FAs were damaged when the fuel grapple pulled free. The NRC issued a confirmatory action letter to the utility to prevent further incidents.

The NRC proposed a $\$ 25,000$ fine for alleged violations involving failure to properly control work activities. The fine was paid.

The NRC placed Units 2 and 3 back on its problem plant list for lack of attention to detail, failure to follow procedures, lack of supervisory involvement, and failure of station equipment to meet design requirements. 
May 1992

Oct 1992

Jan 1993

Feb 1993

Jul 1993

Mar - Nov 1994

Jan 1995

May - Sep 1995

Sep - Oct 1995

Oct 1995

May 1996

Jun - Sep 1996

Oct 1996 - Jan 1997
Two outages, totaling 11 days, were performed to repair a steam seal supply valve and a recirculation pump seal.

The unit was shut down for 7 days following a reactor trip. The trip was caused by a condensate/condensate booster pump motor failing due to dirt on the stator.

A 5-day outage followed a shutdown due to loss of instrument air pressure. The backup source of air failed to line up in time.

The unit was manually scrammed due to high reactor pressure. The condition was caused by foreign objects in the HP turbine, which blocked the flow. The resulting outage lasted 33 days.

The unit was shut down for 6 days following a unit trip on low condenser vacuum.

The thirteenth refueling and maintenance outage lasted 240 days. The unit remained in an outage at the end of September to address other equipment and personnel issues.

The unit was shut down for 6 days following a main turbine trip.

The main turbine was damaged, and the repair required an outage of 117 days.

The unit was shut down for $\mathbf{1 6}$ days to inspect the main generator following a load rejection.

Debris on the circulating water inlet screen required a 9-day outage to correct.

A feedwater regulating valve failure caused a loss of feedwater transient. Due to complications following the trip, an unusual event was declared. The NRC sent an AIT to investigate this event. The investigation found that the maintenance backlog had contributed to the event. The subsequent shutdown lasted 28 days.

Refurbishment of all safety related $4-\mathrm{kV}$ breakers and modification of structural steel lasted 94 days.

The unit was shut down to repair a recirculation pump motor. Other outage tasks extended the duration to 96 days. 
This Page Intentionally Left Blank 
DUANE ARNOLD

PRODUCTION COST and CAPITAL ADDITIONS (1996 Dollars)

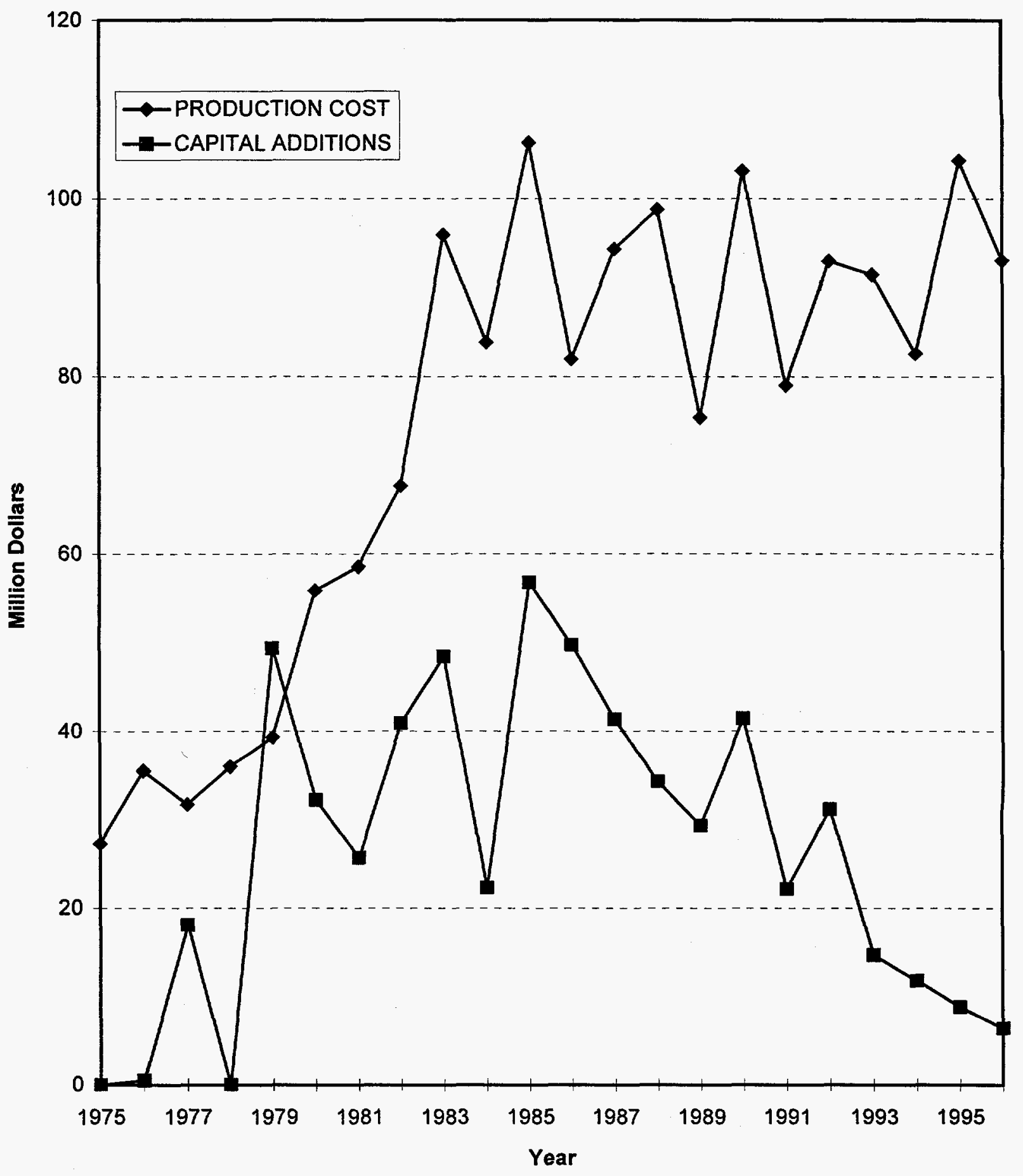




\section{NUCLEAR POWER PLANT OPERATING EXPERIENCE SUMMARY}

Unit data summary through December 1996

Unit: DUANE ARNOLD

Location: LINN COUNTY, IOWA

Owner: IOWA ELECTRIC LIGHT \& POWER CO.

Type: GENERAL ELECTRIC BWR

Construction Permit: 06/22/70

Operating License: 02/22/74

Commercial Oper. Date: 02/01/75
Nameplate Rating: $566 \mathrm{MWe}$

MDC Net MWe: 520 MWe

Cumul. Avail. Factor: 74.4

Cumul. Cap. Factor (MDC Net): 69.6

Cumul. Forced Outage Rate: 10.3

3-Year Avg. Cap. Factor (MDC Net): 86.7

License Expiration: 2014

OPERATING HISTORY (To December 1996)

Date

Aug 1974

Sep 1974

Jun - Jul 1975

Feb - Apr 1976

Mar - May 1977

Mar - Apr 1978

Jun 1978 - Mar 1979

Feb - Apr 1980

Nov 1980

Mar - Jun 1981

Oct 1981

Mar - Apr 1982

Jun - Jul 1982

\section{Comment}

Relief valve leaks caused a 10-day outage.

Additional relief valve leaks caused a 12-day outage.

The plant was shut down to inspect and replace in-core monitors and fuel channels, one FA was dropped during fuel handling.

The first refueling and maintenance outage lasted 9 weeks.

The second refueling and maintenance outage was performed. Major work included replacement of SRVs.

The third refueling and maintenance outage was performed. Major work included the repair of cracks in RWCU system piping and replacement of RV water level indicating system components.

The plant was shut down for extended outage after cracks were found in recirculation riser piping. All FAs were removed from RV to replace all eight recirculation system inlet nozzle safe ends. Startup was delayed due to NRC concern over adequacy of recirculation line repair welds. A lead shielding plug left in a repaired line had to be removed. HPCI turbine damage was repaired.

The fourth refueling and maintenance outage lasted 10 weeks.

The plant was shut down for 9 days to replace a recirculation pump seal and repair a MSRV that stuck open on startup.

The fifth refueling and maintenance outage was performed. Startup was delayed to the end of May because of a leaking MSIV.

The plant was shut down for 25 days for required weld inspections. Restart was delayed for repairs to the RWCU system and FW check valves.

The plant was shut down for 15 days for scheduled maintenance, CRD repair, and RHR system work.

The plant was shut down for 53 days after a pressure transient occurred because an incorrect MSIV actuation sequence was employed during a startup. The hydraulic speed control cylinders were damaged on two of four outboard MSIVs. 
Nov 1982

Dec 1982

Feb - May 1983

Jun 1983

Oct 1983

Apr 1984

May 1984

Aug 1984

Sep - Oct 1984

Oct 1984

Feb - Jul 1985

Oct 1985 - Mar 1986

Mar - Apr 1986

Sep 1986

Dec 1986

Mar - Jun 1987

Oct - Nov 1987

Aug 1988

Sep 1988 - Jan 1989
An 11-day outage was required for repairs to a CS valve and other components.

The NRC decided to reinstate a $\$ 40,000$ fine for alleged improper maintenance and testing of the DGs.

The sixth refueling and maintenance outage lasted 84 days. Major work included loading more highly enriched fuel for 18-month operating cycle, modifications to SRV supports, RPS, and Mark I torus, annual inspections to DGs, CS spargers and jet pump beams, and leak rate testing.

A plant was shutdown to repair a FW check valve was extended when a main turbine bearing was damaged on startup. Total outage time was 26 days.

A 19-day scheduled outage occurred for HFA relay replacement and MSIV actuator repair.

A 17-day outage was required to repair packing leaks on a recirculation bypass valve and its associated vent valve.

Repairs to an inboard MSIV and the main generator caused a 29 day outage.

$\mathrm{NRC}$ assessed a $\$ 20,000$ fine for alleged security violations that occurred in December 1983.

A 26-day scheduled maintenance outage was extended to October 25 for condenser repair.

The NRC proposed a $\$ 25,000$ fine for alleged inoperability of the SBLC system in July 1984.

The seventh refueling and maintenance outage lasted 168 days. Major work included inspection of stainless piping systems and CRDs, repair of cracks found in recirculation system piping, torus inspection and recoating, and hydrostatic testing of several plant systems.

Power was reduced to about $68 \%$ for fuel conservation.

During a scheduled maintenance outage, an MSIV failed to open because of failed internal components. Total outage time was 23 days.

A 13-day outage was required for repairs to a recirculation pump lube oil system.

The plant was shut down for 13 days to replace electrical splices in drywell with environmentally qualified components.

The eighth refueling and maintenance outage lasted 110 days. Major work included inspection of FW heaters, ISI of recirculation piping, LLRT, replacement of one LP turbine rotor, and MOV testing of HPCI and RHR systems. A new process computer was installed. Outage was extended 3 weeks for special logic tests. An additional 8-day outage occurred to repair an outboard MSIV that would not fully open.

The plant was shut down for 17 days to repair leaks in the turbine EHC system.

The unit was forced to derate power about $6 \%$ several times during the summer because of drought conditions and a heat wave that degraded cooling water capacity.

The ninth refueling and maintenance outage lasted 101 days. Major work included inspection of the main generator and replacement of a FW heater, a LP turbine rotor, RHR pumps and condensate pumps, and some CRD piping. 


\section{DUANE ARNOLD (Cont'd)}

Nov 1988

Mar 1989

Sep 1989

Nov 1989

Jan 1990

Feb 1990

Jun - Sep 1990

Sep 1990

Dec 1990

Jan 1991

Feb 1991

Jun 1991

Feb - Apr 1992

Jan 1993

Jul - Oct 1993

Apr 1994

May 1994

Jul 1994

Nov 1994

Feb - Apr 1995

Jun 1995

Oct - Nov 1996
The utility paid a $\$ 50,000$ fine to the NRC for alleged failure to adequately test certain electrical connectors for EQ. The fine was reduced from $\$ 150,000$ because the utility promptly corrected the problem and had a good record of EQ compliance.

The plant was shut down for 11 days to repair MSIVs and a HPCI steam supply valve and to perform other valve maintenance.

The plant was shut down for 39 days for maintenance, MSIV testing, and inspection of various electrical connectors for $\mathrm{EQ}$ compliance.

The plant was shut down for 18 days to repair a HPCI check valve. The outage was extended to repair main steam line relief valves.

The NRC assessed a $\$ 25,000$ fine for alleged violation concerning secondary containment testing.

The utility paid a $\$ 50,000$ fine to the NRC for alleged failure to adequately correct certain identified EQ discrepancies.

The tenth refueling and maintenance outage lasted 73 days.

The reactor tripped when 3 of 4 MSIVs closed during a surveillance test. The unit was shut down for 5 days.

The unit was shut down for $\mathbf{6}$ days for planned maintenance to repair the main generator.

The unit was shut down for 7 days for planned maintenance on extraction steam drain lines.

The main turbine/reactor tripped due to problems with the turbine control system. The trouble was induced electrical noise. The outage lasted 4 days.

The unit was shut down for 6 days to repair leaks in two MSIVs.

The eleventh refueling and maintenance outage lasted 59 days.

A 5-day outage occurred to reconnect a circulating water pump.

The twelfth refueling and maintenance outage lasted 74 days.

The NRC proposed and the licensee paid a $\$ 12,500$ fine for a security violation.

A planned 5-day outage to repair BOP valve packing leaks to improve efficiency occurred.

A 6-day outage to repair a leak in turbine EHC system supply lines and add accumulators to the lines occurred.

The unit was shut down for 15 days to repair drywell leakage and other items.

The thirteenth refueling and maintenance outage lasted 55 days.

Condenser leakage required 5 days to repair.

The fourteenth refueling and maintenance outage lasted 37 days. 


\section{FARLEY}

PRODUCTION COST and CAPITAL ADDITIONS (1996 Dollars)

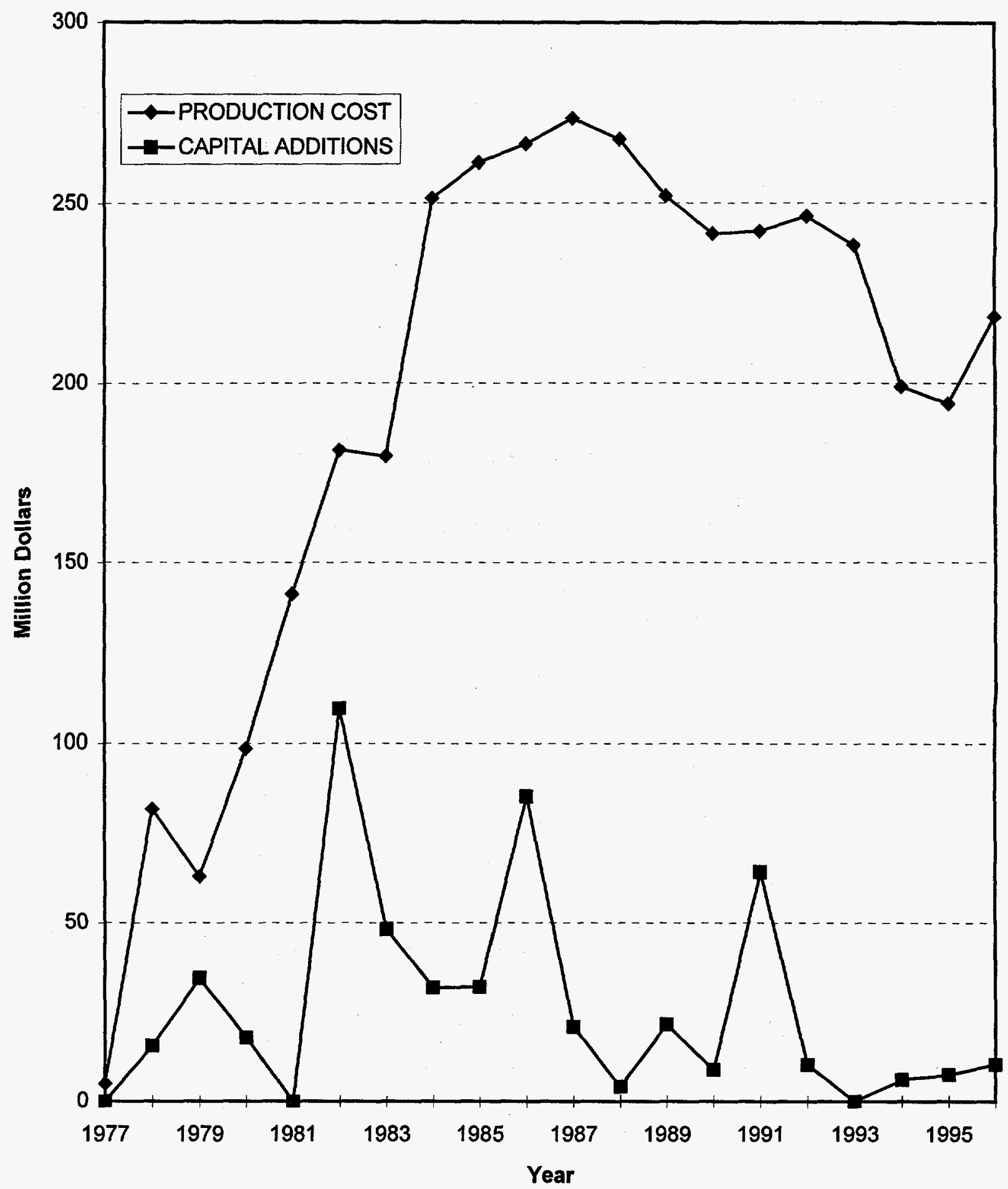




\title{
NUCLEAR POWER PLANT OPERATING EXPERIENCE SUMMARY
}

\author{
Unit data summary through December 1996
}

Unit: FARLEY 1

Location: HOUSTON COUNTY, ALABAMA

Owner: SOUTHERN NUCLEAR OPERATING CO.

Type: WESTINGHOUSE PWR

Construction Permit: 08/16/72

Operating License: 06/25/77

Commercial Oper. Date: 12/01/77
Nameplate Rating: $860 \mathrm{MWe}$

MDC Net MWe: 812 MWe

Cumul. Avail. Factor: 79.7

Cumul. Cap. Factor (MDC Net): $\mathbf{7 7 . 2}$

Cumul. Forced Outage Rate: $\mathbf{5 . 6}$

3-Year Avg. Cap. Factor (MDC Net): 88.7

License Expiration: 2017

OPERATING HISTORY (To December 1996)

\section{Date}

Oct - Nov 1977

Jan 1978

Sep - Oct 1978

Mar - Nov 1979

Jan - Feb 1980

Jun - Jul 1980

Nov 1980 - Mar 1981

Mar - Apr 1981

Sep 1981 - Mar 1982

Jan - Mar 1983

Feb - Apr 1984

\section{Comment}

The unit was shut down due to high vibration in the main turbine. Governor valve repairs were also made during the 22-day outage.

Eight automatically initiated reactor scrams occurred, of which only one resulted in a significant outage (flooding of the river water structure). The outage was extended for a total of 6 days to allow repairs to a pressurizer level transmitter and spray valves.

A scheduled 20-day outage was used for the turbine generator availability improvement program.

The first refueling and maintenance outage was performed. Anchor bolt testing and other problems caused the outage to be extended. After startup, the unit was taken off-line for 13 days to repair RCP seals.

The unit was shut down for 17 days to make TMI-related modifications.

The unit was shut down for 26 days to repair SG tube leaks.

The second refueling and maintenance outage was performed. Design changes associated with IE Bulletins 80-11 and 79-14 were implemented. Startup was delayed 2 months after the discovery of cracks in the LP turbine rotor.

Failure of a FW pump caused a temporary power reduction to $60 \%$ for 12 days and repair outages totaling over 8 days.

The third refueling and maintenance outage was performed. Problems with the generator stator resulted in entering the outage early to begin rewinding the stator. Other work included plugging SG tubes in response to past industry problems with $\underline{W}$ inner row tubes.

The fourth refueling and maintenance outage was performed. Fuel cladding damage on 11 FAs located near baffle joints was discovered. A design modification was made to reverse flow on the baffle exterior from downward to upward.

The fifth refueling and maintenance outage was performed. Control rod guide tube split pins were replaced. 


\section{FARLEY 1 (Cont'd)}

Apr - May 1985

Aug 1986

Oct - Dec 1986

Apr 1987

Aug 1987

Oct 1987

Nov 1987

Dec 1987

Mar - May 1988

Aug 1988

Mar 1989

Mar 1989

May 1989

Sep - Nov 1989

Aug 1990
The sixth refueling and maintenance outage was performed. Major work included SG inspection and anti-vibration bar modifications, RV inspection, and repair of a RCP seal housing O-ring leak. Six containment tendons were replaced as a result of inspection made after Unit 2 anchor head and tendon damage was found earlier.

The NRC announced that the unit would receive fewer inspections and less regulation due to good operational and compliance records.

The seventh refueling and maintenance outage was performed. Six SG tubes were plugged, anti-vibration bars were replaced, a thermal liner was replaced in one SG, CRD electrical penetration modules were replaced, and new RPV flange O-ring seals were installed. Snubber esting, ILRTs, and 10-year ISI were also performed.

The unit was shut down for 10 days to repair various leaks on the RTD bypass manifold, SG A manway, RHR A pump, and both the normal and alternate charging isolation valves.

Power was reduced for 15 days to allow containment access on two separate occasions to inspect and repair splices and cable terminations to meet $\mathrm{EQ}$ requirements on MOVs, solenoid valves, and post-LOCA mixing fans.

Power was reduced for 4 days to repair a pressurizer level transmitter and allow continued equipment $\mathrm{EQ}$ work inside containment.

The NRC proposed a $\$ 50,000$ fine for alleged inadequacy in control and installation of several circuit breakers designed for $480-\mathrm{V}$ use that had been installed in $600-\mathrm{V}$ applications.

The unit was shut down for 10 days to re-terminate cables on RPV head vent valves to satisfy EQ requirements and to replace containment instrumentation splices and connections with EQ splices.

The eighth refueling and maintenance outage lasted 56 days. Work included RPV 10-year ISI, SG inspection and foreign object search, SG J-nozzle inspection, RCP seal and motor inspections, MSR inspections, SG tube plugging, and RTB inspection and repair.

The NRC proposed a $\$ 450,000$ fine for numerous alleged violations of EQ of electrical equipment. Another fine of $\$ 100,000$ was assessed for alleged inadequate engineering analysis associated with ECCS operability.

The NRC proposed a $\$ 75,000$ fine for alleged failure to determine system operability of the high head SI system following discovery of a deficiency.

The NRC reduced the $\$ 100,000$ August 1988 fine to $\$ 75,000$ in recognition of the utility's past performance. The utility contested the fine, and as part of a settlement approved by ASLB, the utility acknowledged violation of QA requirements. No fine was imposed. The utility also modified the subsystem to provide assurance of operation.

The NRC proposed a $\$ 100,000$ fine for alleged operation of the unit without two operable ECCS subsystems.

The ninth refueling and maintenance outage lasted 48 days. Work performed included BOP ISI, SG inspection, tube plugging and cleaning, RCP motor inspection and changeout, HP turbine and turbine valve inspections, MSR inspection, thimble tube inspection, turbinedriven AFW pump overhaul, and FW pump overhaul.

The NRC proposed a $\$ 450,000$ fine for alleged violations involving EQ of electrical equipment. 


\section{FARLEY 1 (Cont'd)}

Sep 1990

Mar - May 1991

Aug 1991

Oct 1991

Dec 1991

Aug 1992

Sep - Dec 1992

Mar 1993

Mar - Apr 1994

Jan 1995

Jun 1995

Sep - Nov 1995

Nov 1995

Dec 1996
The NRC reported that the plant was one of the top one third of performers measured by average SALP scoring between 1987 and 1989.

The tenth refueling and maintenance outage lasted 72 days. Work included RCS midloop level monitor system addition, vital inverter replacement, RTD manifold elimination, control room design upgrade, MOV testing and maintenance, SG cleaning, inspection, tube plugging, and U-bend heat treatment, and ILRT.

The plant was reported to again place in the top one third of U.S. plants according to SALP scores.

The NRC imposed a $\$ 25,000$ fine for alleged startup and operation of the unit with the turbine-driven AFW pump recirculation isolation valve open after time response testing on the pump.

The unit operated the remainder of the year without significant outages or power reductions.

After negotiations and approval by the ASLB, the utility paid $\$ 150,000$ in a settlement over the $\$ 450,000$ fine proposed in August 1990 relating to EQ deficiencies.

The eleventh refueling and maintenance outage lasted 68 days.

A 10-day outage was needed to replace a governor valve on the main turbine.

The twelfth refueling and maintenance outage lasted 51 days.

A DEH system deficiency caused a turbine/reactor trip and a 5-day outage.

Water intrusion into a junction box caused an MSIV closure (6 day outage).

The thirteenth refueling and maintenance outage lasted 49 days.

The unit was off-line for a total of 4 days due to two separate events: (1) a loss of feedwater and (2) to repair instrumentation for the main generator.

The NRC proposed and the licensee paid a $\$ 50,000$ fine for deficiencies in the fire protection program. 


\section{NUCLEAR POWER PLANT OPERATING EXPERIENCE SUMMARY}

Unit data summary through December 1996

Unit: FARLEY 2

Location: HOUSTON COUNTY, ALABAMA

Owner: SOUTHERN NUCLEAR OPERATING CO. Type: WESTINGHOUSE PWR

Construction Permit: 08/16/72

Operating License: 03/31/81

Commercial Oper. Date: 07/30/81
Nameplate Rating: 860 MWe

MDC Net MWe: 822 MWe

Cumul. Avail. Factor: 84.6

Cumul. Cap. Factor (MDC Net): 81.7

Cumul. Forced Outage Rate: 3.7

3-Year Avg. Cap. Factor (MDC Net): 83.2

License Expiration: 2021

OPERATING HISTORY (To December 1996)

Date

Jan - Feb 1982

Oct - Dec 1982

Oct 1982

Nov 1982

Sep - Oct 1983

Aug - Sep 1984

Jan - Mar 1985

Apr - May 1986

Jan 1987

Oct - Dec 1987

\section{Comment}

A RCP seal leak caused a 28-day outage.

The first refueling and maintenance outage lasted 41 days. The spent fuel pool was inspected, SG tube leaks were plugged, and the river water pumps were repaired.

The NRC proposed a fine of $\$ 40,000$ for alleged misalignment of two valves in the containment spray system. The condition had apparently existed since May 1981.

The availability factor for the first 12 months of commercial operation was reported to be $90 \%$. At the time, this rating was the best ever for a U.S. W unit in its first year. Farley Unit 1 was the previous record holder.

The second refueling and maintenance outage lasted 42 days. During the outage, detached valve discs were repaired in three MSIVs, reactor coolant drain tank pumps were overhauled, one RHR pump was repaired, and an auto shunt-trip for the RTBs was installed.

The unit was shut down after inspection data analysis revealed that two SG tubes had significant wall degradation and required plugging. Operation resumed after 15 days.

The third refueling and maintenance outage lasted 75 days, major activities included RPV ISI, SG inspection, and RCP 5-year inspection. Three containment tendons were found to have failed, prompting a check of all tendons at both units. At Unit 2,17 more anchors failed testing and were replaced, while six Unit 1 anchors required replacement.

The fourth refueling and maintenance outage lasted 39 days. Work included inspection of all active $S G$ tubes and modification of SG anti-vibration bars, replacement of FW heaters, modification of the RPV upper internals, and RCP seal inspections. The outage was extended 8 days for a turbine overspeed trip test and other post-refueling maintenance.

An outage of 15 days was needed to repair a SG primary man-way cover leak and to perform a SG flush.

The fifth refueling and maintenance outage lasted 63 days. Activities included repair of two FA grids and a loose thermal sleeve on the core support forging of the lower vessel internals, SG cleaning, inspection, and tube plugging, replacement of non-EQ electrical splices, MOV inspection, DG inspection and maintenance, and ILRTs. 
Dec 1987

Mar - May 1989

May 1989

Jul 1989

Apr 1990

Oct 1990 - Jan 1991

Apr 1991

Mar - May 1992

Feb 1993

Sep - Dec 1993

Dec 1993

Jan 1995

Mar - Apr 1995

May 1995

Jun 1995

Oct - Dec 1996
A shutdown occurred because of a defect found in a welded joint on the RCS cold leg SI line. The failure was attributed to high-cycle fatigue caused by leakage through an isolation valve. The outage lasted 18 days.

The sixth refueling and maintenance outage lasted 72 days. Work included inspection of all SGs and plugging of 27 tubes. Before the outage, the unit had set a world record for continuous power generation among W PWRs. The gross capacity factor for 1988 was reported to be $98.34 \%$.

The NRC granted an adjustment in the license expiration date from 40 years after the commercial operation license date vs the construction permit issuance date. The license expiration was thus shifted from August 2012 to March 2021.

Power was reduced 4 days to repair the inboard bearing on a SG feed pump to eliminate high vibration.

A 12-day outage taken to replace containment coolers.

The seventh refueling and maintenance outage lasted 85 days.

An 8-day outage followed a reactor trip due to a dropped control rod.

The eighth refueling and maintenance outage lasted 66 days.

A 10-day outage was required to replace a pressurizer safety valve.

The ninth refueling and maintenance outage lasted 69 days.

An 8-day outage was required to replace a diaphragm gasket on the inlet flange of one of the LP turbines.

The unit was shut down on for 4 days to modify the DEH control system.

The tenth refueling and maintenance outage lasted 47 days.

The unit was shut down for 10 days to investigate high sodium levels in the secondary system.

The unit was shut down on four separate occasions due to problems with the feedwater pumps and their controls. Total downtime was only 9 days.

The eleventh refueling and maintenance outage lasted 68 days. 
FERMI 2

PRODUCTION COST and CAPITAL ADDITIONS (1996 Dollars)

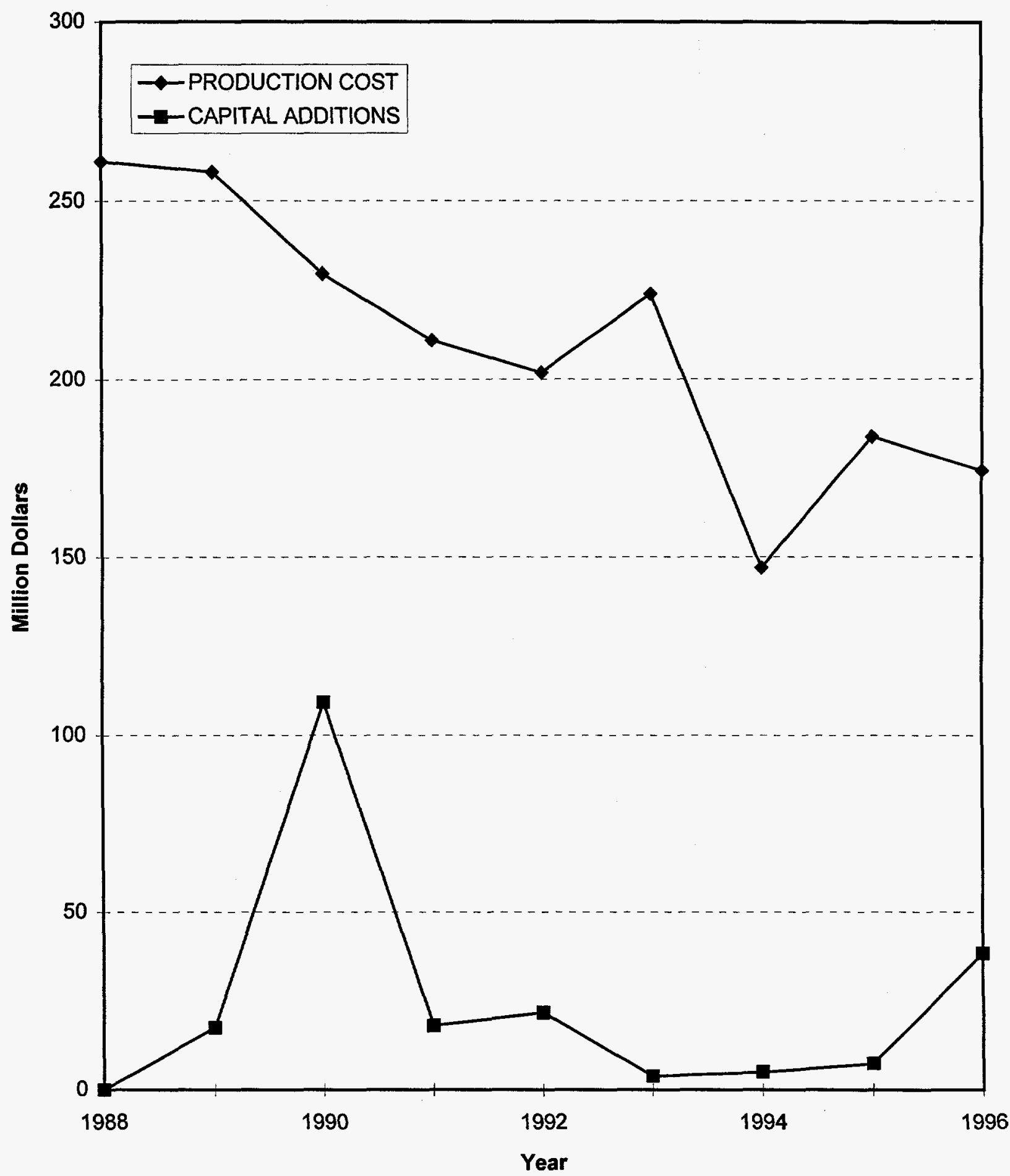




\title{
NUCLEAR POWER PLANT OPERATING EXPERIENCE SUMMARY
}

\author{
Unit data summary through December 1996
}

Unit: FERMI 2

Location: MONROE COUNTY, MICHIGAN

Nameplate Rating: 1179 MWe

Owner: DETROIT EDISON CO.

MDC Net MWe: $1085 \mathrm{MWe}$

Type: GENERAL ELECTRIC BWR

Cumul. Avail. Factor: 65.7

Construction Permit: 09/26/72

Cumul. Cap. Factor (MDC Net): 59.7

Operating License: 07/15/85

Cumul. Forced Outage Rate: $\mathbf{2 1 . 5}$

Commercial Oper. Date: 01/23/88

3-Year Avg. Cap. Factor (MDC Net): 43.1

License Expiration: 2025

OPERATING HISTORY (To December 1996)

Date

$1984-1988$

Jul 1985

Oct 1985 - Aug 1986

Sep 1986

Oct - Dec 1986

Jan 1987

Feb 1987

Mar 1987

Apr - May 1987

May 1987

\section{Comment}

The plant was completed after numerous delays due to construction problems and difficulty in financing. Plant startup lasted more than $2 \frac{1}{2}$ years because of DG repairs, CRDM modifications, and other equipment problems.

Late reporting of a premature criticality incident led the NRC to limit the plant to $5 \%$ power. The NRC also assessed a $\$ 300,000$ fine against the utility for alleged deficient operating practices during reactor startup. The $5 \%$ power restriction was extended because of through-wall cracks found in two main turbine bypass lines.

The plant was shut down to replace the main turbine bypass lines, install EQ modifications, and add an alternate fire protection system. DG problems continued to occur. The NRC would not authorize operation above $5 \%$ power until the utility improved its operations, maintenance, engineering, and security. The outage was extended to resolve problems with structural embedment plates and perform LLRTs. The NRC assessed a $\$ 50,000$ fine for thirteen alleged security violations at the plant. A $\$ 75,000$ fine was assessed by the NRC against the utility for a number of alleged violations of requirements for safety-related equipment. The plant was returned to service on August 4.

The NRC authorized a power increase to $20 \%$, and the unit generated its first power on September 21 . Two days later, the plant was shut down for 25 days to repair condenser tube leaks.

The plant suffered several forced outages from a number of equipment failures. Total outage time during the period was 54 days.

Repair of weld cracks on main steam-line instrument taps forced a 26-day outage.

The NRC authorized an increase in power to $50 \%$.

The plant was shut down to conduct a turbine-generator test and repair a number of plant components. Total outage time was 21 days.

The plant was shut down to again repair weld cracks on main steam-line instrument taps. The taps leaked because of inadequate design and/or fabrication during initial installation in January. Total outage time was $\mathbf{4 8}$ days.

The NRC proposed a $\$ 100,000$ fine against the utility for alleged deficiencies in the surveillance testing program. 
Jul - Oct 1987

Sep 1987

Dec 1987

Jan 1988

Feb 1988

Feb - May 1988

Jun 1988

Jul 1988

Aug - Sep 1988

Apr 1989

Sep - Dec 1989

Feb 1990

Apr 1990

Sep 1990

Oct 1990

Nov - Dec 1990
False turbine-generator vibration signals and a leaking FW check valve forced the unit into two outages totaling 82 days.

The NRC assessed a $\$ 75,000$ fine against the utility for an alleged incident in June where an unsupervised operator trainee allowed RCS temperature to rise to hot shutdown condition. The event caused the NRC to deny a request for $75 \%$ power operation. Plant management was reorganized after the incident.

The NRC authorized $75 \%$ power operation for the plant.

The NRC authorized $100 \%$ power operation for the plant.

The NRC assessed a $\$ 25,000$ fine for alleged design deficiencies that could render the ECCS inoperable. The fine was reduced from $\$ 50,000$ for prompt corrective action by the utility.

The unit was shut down to complete TS testing of the DGs. Other work included LLRT, MSIV modifications, and SRV replacement. Total outage time was 77 days.

Four members of the Canadian parliament petitioned the NRC to revoke the plant's operating license because alleged deficiencies at the plant caused concern for areas of Canada downwind of the plant. The NRC later denied the petition. The NRC assessed a $\$ 175,000$ fine against the utility for alleged violations of safety requirements involving containment radiation monitoring and control room HVAC operability.

The plant was shut down because of unidentified excessive RCS leakage. The event prompted local Canadian parliament members to call for an operational safety review by the IAEA. The outage lasted 16 days.

The plant was shut down to repair an MOV and found a number of other MOVs with improper settings from earlier repair work. The NRC assessed a $\$ 50,000$ fine for the incident. The outage lasted 40 days.

An NRC SALP report indicated improvement in most areas, but management attention was directed to improving maintenance and engineering technical support.

The first refueling and maintenance outage lasted 103 days. Major work included CRD changeout, LP turbine and main generator inspection, DG overhaul, and drywell ILRT.

The NRC issued an order of violation based on the number of violations which occurred between 1984 and 1986 concerning deliberate material false statements and failures to properly evaluate construction deficiencies and provide complete, accurate information to the NRC.

A 5-day outage followed a reactor scram due to MSIV closure that was caused by loss of air following the loss of a RPS MG set.

A scheduled outage to test and repair FW heaters lasted 11 days. The outage was extended when the unit scrammed on low water level. The water level instrumentation reference legs had not been backfilled.

A technician was fatally injured when she fell into a 36 -inch reactor building supply fan during a test.

A unit was shut down to investigate the cause of turbine bearing vibration. During the 5-week outage, damage to the shroud and blades of one LP turbine was found. 
Mar - Jun 1991

Dec 1991

Sep 1992

Sep - Nov 1992

Dec 1992

Dec 1993 - Jan 1995

Jan - Mar 1995

Apr 1995

Jun 1995

Mar - Apr 1996

May 1996

Sep - Dec 1996
The second refueling and maintenance outage lasted 73 days. Major work included replacement of 165 control rod blades, retubing of the main condenser, blade replacement on all three LP turbines, and inspection of the HP turbine.

The unit was shut down for replacement of one of two main generator output transformers. Total outage time was 10 days.

The NRC approved uprating the unit from $3293 \mathrm{MWt}$ to $3430 \mathrm{MWt}$, which will produce an additional $46 \mathrm{MWe}$.

The NRC SALP report awarded Category 1 ratings in four areas, no low Category 3 ratings, and improving trends in two areas.

The third refueling and maintenance outage lasted 56 days. Major work included RPV ISI, SRV and a main unit transformer replacements, HPCI turbine inspection, addition of an eighth condensate demineralizer, erosion/corrosion piping replacement, and installation of a torus hardened vent. The modifications to allow uprating the unit were also performed.

A 9-day outage was needed to repair the FW heater No.4 extraction steam line which had ruptured.

The main turbine tripped after multiple turbine blades failed and resulted in damage to one LP turbine, the main generator, and the main generator excitor. The fourth refueling was conducted during the spring of 1994. Plans were to restart with the main turbine derated due to several rows of blades being removed. After the next cycle, the main turbine would be replaced. The unit was down for 383 days. An NRC AIT was sent due to the turbine damage and suggested that not replacing worn blades during the previous refueling outage was a cause of the event.

The unit was shut down to balance the main turbine and then remained off-line to repair the turbine jacking oil system. Total outage time was 43 days.

The plant was down for 10 days following a reactor scram due to a pressure regulator transient.

The main turbine tripped on overspeed during overspeed trip testing. The unit was shut down for 2 weeks.

The unit was shut down when an essential cooling water system was declared inoperable. During startup, both HPCI and RCIC were declared inoperable and required repairs. The unit was down for a total of 26 days.

The NRC proposed and the licensee paid a $\$ 50,000$ fine for diesel generators being inoperable due to ice blockage in the service water system because of a leaking check valve.

The fifth refueling and maintenance outage was performed. The outage was extended to repair an EDG voltage regulator, relocate an SRV tail pipe pressure switch, repair an SRV solenoid actuator, repair a drywell vacuum breaker, and other items. 
FITZPATRICK

PRODUCTION COST and CAPITAL ADDITIONS

(1996 Dollars)

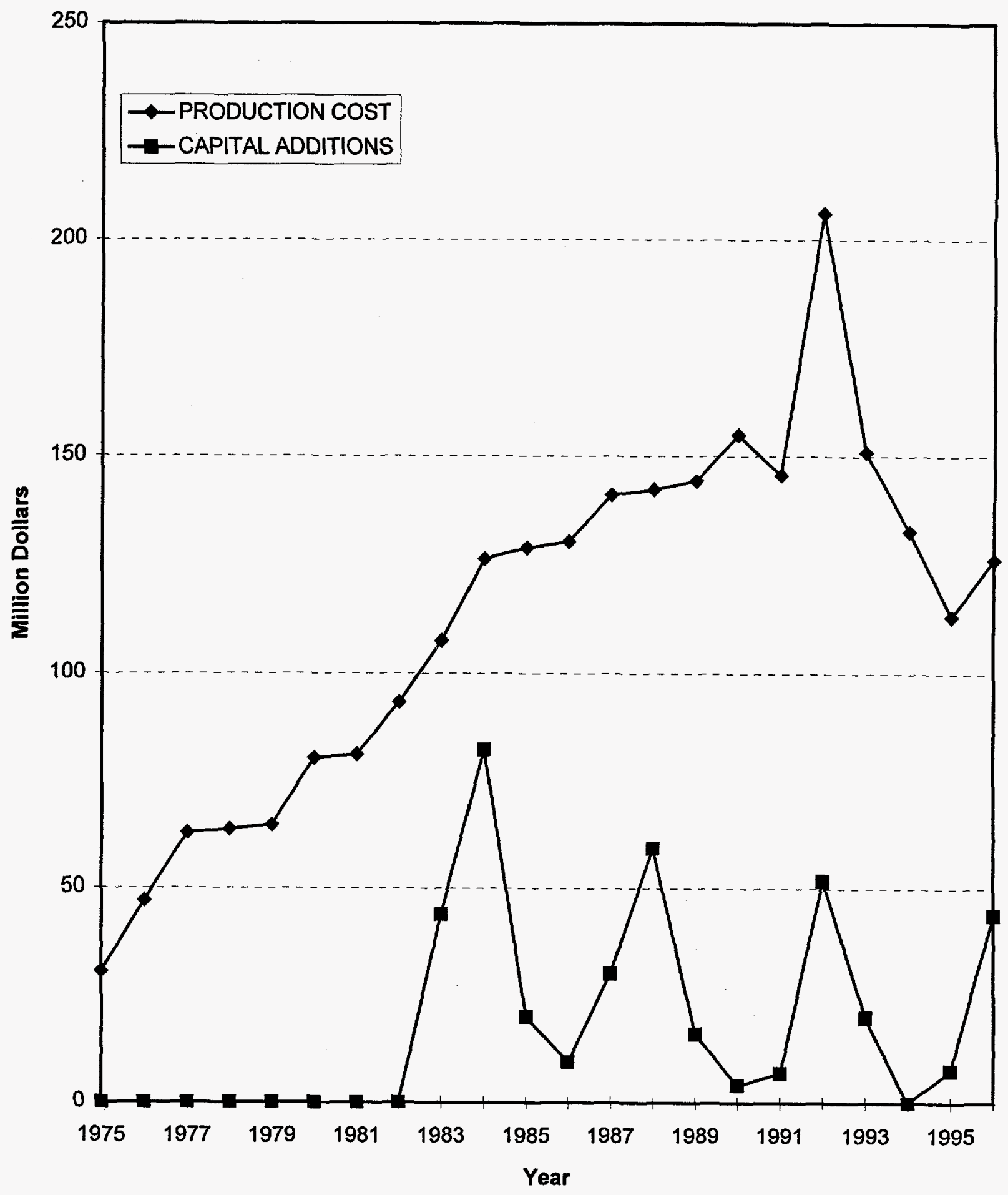




\section{NUCLEAR POWER PLANT OPERATING EXPERIENCE SUMMARY}

Unit data summary through December 1996

Unit: FITZPATRICK

Nameplate Rating: 883 MWe

Location: OSWEGO COUNTY, NEW YORK

MDC Net MWe: $762 \mathrm{MWe}$

Owner: NEW YORK POWER AUTHORITY

Cumul. Avail. Factor: 68.5

Type: GENERAL ELECTRIC BWR

Cumul. Cap. Factor (MDC Net): $\mathbf{6 5 . 0}$

Construction Permit: 05/20/70

Cumul. Forced Outage Rate: 11.7

Operating License: 10/17/74

3-Year Avg. Cap. Factor (MDC Net): 74.3

Commercial Oper. Date: 07/28/75

License Expiration: 2014

OPERATING HISTORY (To December 1996)

Date

Mar 1975

Dec 1975

Jan - Mar 1976

Aug 1976

Jun 1977

Sep - Dec 1978

Mar - Sep 1979

May - Aug 1980

Oct 1981 - Mar 1982

Nov 1981

Oct 1982

Jun - Sep 1983

Sep - Nov 1984

\section{Comment}

Fire in an emergency DG forced a 7-week shutdown for repairs.

Two shutdowns totaling 15 days occurred because of cracks in a turbine building cooling tank and condenser tube leaks.

A 6-week maintenance outage was required for LPCI modifications, in-core tube repair, and leak-rate testing.

$\mathrm{NRC}$ levied an $\$ 18,000$ fine for alleged physical security violations.

The Power Authority of the State of New York (PASNY) assumed operating responsibility from Niagara Mohawk Power Co. The plant had been operated by Niagara until PASNY recruited its own staff.

A refueling and maintenance outage was performed. Torus supports were modified to withstand multiple safety valve actuations. The outage extended 13 days by delays on FW nozzle clad removal and containment leak rate testing.

The plant was shut down to comply with the NRC order to reanalyze seismic pipe stresses and make appropriate modifications.

A refueling and maintenance outage was performed. Torus modifications were made; startup was delayed by CRD system testing.

A refueling and maintenance outage lasted 130 days. Major work included repair of stress cracks found in core spray piping, torus modifications, LLRT testing, turbine generator maintenance, FW heater replacement, and fire protection system modifications.

The NRC assessed a $\$ 40,000$ fine for an alleged valving error that occurred on August 21, 1981.

The unplanned outage resulted from blockage of the steam line by broken MSIV.

A refueling and maintenance outage was performed. Major work included modifications to torus, scram discharge, and accident sampling systems, turbine generator maintenance, and leak rate testing.

A planned maintenance outage for weld inspection and heat treating occurred. Some IGSC cracks were found in recirculation piping. 


\section{FITZPATRICK (Cont'd)}

Feb - Jun 1985

Mar 1986

Jan - Apr 1987

Apr 1987

Jan 1988

Aug - Nov 1988

Mar 1989

Sep 1989

Nov 1989

Mar 1990

Mar 1990

Mar - Jul 1990

Aug 1990

Oct 1990

Mar 1991

Mar 1991

Apr 1991

May - Aug 1991
A refueling and maintenance outage was performed.

A 17-day maintenance outage was required to repair CRDs.

A refueling and maintenance outage lasted 105 days. All four DGs were overhauled, RCP seals and LP turbine rotor were replaced, and Appendix R were modifications performed.

$\mathrm{NRC}$ assessed a $\$ 75,000$ fine for alleged deficiencies in personnel radiation protection measures. A technician received an extremity exposure of 29.6 rems while handling an irradiated instrument dry tube.

A 18-day outage for CRD repair was required.

A refueling and maintenance outage lasted 89 days. Work included LP turbine rotor replacement, recirculation system decontamination, DG overhaul, and RV and piping inspection. Turbine vibration caused an additional 15 days of outage time to resolve.

The NRC assessed a $\$ 75,000$ fine for alleged violations concerning operation of ECCS.

The unit was shut down for 22 days to resolve CRD problems and perform other maintenance.

The unit was shut down for 12 days due to problems with the EHC system and the SRVs.

NRC proposed a $\$ 75,000$ fine for alleged inadvertent overexposure to an employee while conducting water flow tests in piping using a sodium-24 source.

The unit was shut down for 4 days due to a failure in the reactor water level controller.

The ninth refueling and maintenance outage lasted 92 days. Work included inspection and welding on CS and recirculation piping, inspection of RHR and CS pumps, DG modifications, HPCI turbine work, RPV ISI, and LPRM replacement.

The unit was shut down voluntarily for 6 days to re-evaluate the primary containment pressure limit calculations for the drywell vent valves and to upgrade the valves.

A senior reactor operator reportedly tested positive on a drug test.

The NRC proposed a $\$ 137,500$ fine for alleged violations involving unmonitored release of radioactive materials. The leak path was from the steam-heated wastewater concentrator leaking into an auxiliary boiler system then venting to atmosphere at concentrations above the permissible limits.

A maintenance outage lasted 10 days, but was then extended for another 26 days due to unmonitored release of radioactive materials.

The operator requalification program was declared unsatisfactory when less than $75 \%$ of the operators passed and one operating crew failed.

The unit was shut down for 104 days to repair a leaking RHR isolation valve and to inspect and repair 80 other similar valves. 
Sep 1991

Sep 1991

Nov 1991 - Jan 1993

$\operatorname{Jan} 1993$

Feb 1993

Apr 1993

May 1993

Oct - Nov 1993

Jan 1994

Apr - May 1994

Nov 1994 - Mar 1995

May 1995

Sep 1995

Feb 1996

Sep 1996

Oct - Dec 1996

Dec 1996
The NRC proposed a $\$ 500,000$ fine for alleged violations involving (1) inadequate postmodification testing of RPS relays, (2) inadequate corrective actions, (3) fire protection program inadequacies, (4) Appendix R requirements, and (5) the submittal of inaccurate information. In January 1993 , the fine was reduced to $\$ 300,000$ due to the corrective actions implemented.

The NRC proposed a $\$ 100,000$ fine for alleged multiple violations involving the service water system.

The unit initially shut down because the containment isolation valves for both core spray trains were inoperable due to failure to meet TS requirements. The unit remained shut down due to fire protection issues. The refueling outage began on January 11, 1992. The outage was extended for the remainder of the year to inspect and modify, if necessary, electrical cables to meet fire protection requirements, evaluate procedures for maintaining setpoints for key water level control instruments, and to improve control of temporary engineering and modifications. Work performed during the outage included MOV maintenance and testing; and replacement of bottom head drain valves, jet pump beams, analog trip system relays, and shroud head bolts. At the beginning of the outage, the NRC placed the plant on its problem plant list.

During restart after the extended outage, a number of problems were encountered. These included problems with the RCIC and HPCI systems, and condenser tube leaks.

The unit was manually scrammed when ice buildup in the intake structure on Lake Ontario caused an extremely low water level in the intake. The outage was extended to repair a recirculation pump seal and a leak in a chemical decon connection. The outage lasted 27 days.

A 9-day outage was required to repair the speed controller for one of the feedwater pumps.

Two outages totaling 11 days occurred. The first was to repair a HPCI check valve leak and the second followed a reactor trip on a APRM high signal.

A scheduled maintenance outage lasted 31 days.

The plant was removed from the NRC's problem plant list.

A scheduled mid-cycle maintenance outage lasted 32 days.

The eleventh refueling and maintenance outage lasted 116 days.

A 9-day outage was necessary to repair a packing leak on a manual valve for the jet-pump instrumentation.

The unit was shut down for 1 week following a feedwater transient due to personnel error.

The unit was shut down for 2 weeks to replace scram pilot solenoid valve diaphragms and to install flexible tubing in the EHC system.

A 1-week outage followed a scram due to $345-\mathrm{kV}$ breakers opening.

The twelfth refueling and maintenance outage lasted 47 days.

A 4-day outage was needed to replace an EHC leak on a turbine bypass valve. 
FORT CALHOUN 1

PRODUCTION COST and CAPITAL ADDITIONS (1996 Dollars)

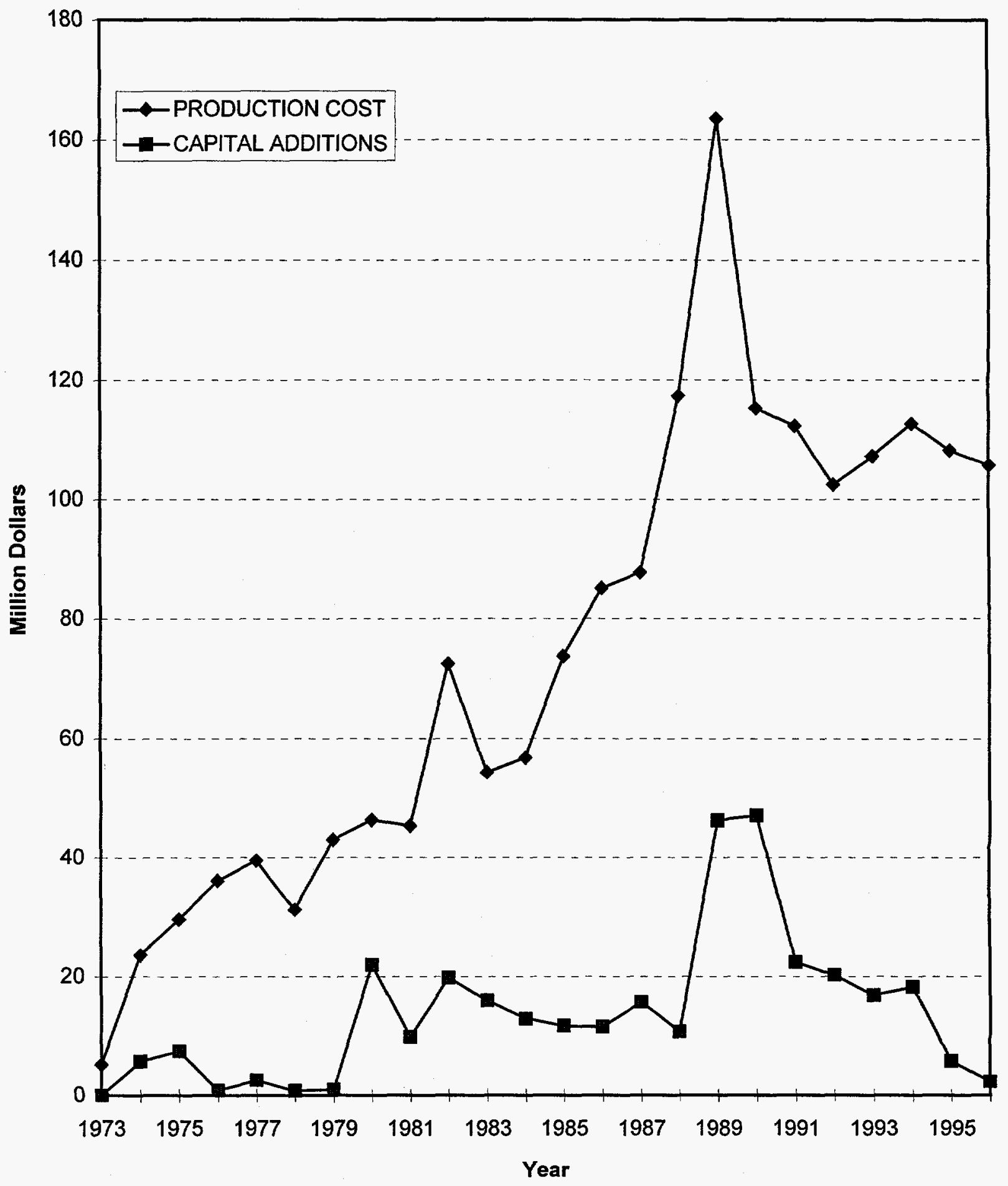




\section{NUCLEAR POWER PLANT OPERATING EXPERIENCE SUMMARY}

Unit data summary through December 1996

Unit: FORT CALHOUN 1

Location: WASHINGTON COUNTY, NEBRASKA

Owner: OMAHA PUBLIC POWER DISTRICT

Type: COMBUSTION ENGINEERING PWR

Construction Permit: 6/7/68

Operating License: $8 / 9 / 73$

Commercial Oper. Date: $9 / 26 / 74$
Nameplate Rating: 502 MWe

MDC Net MWe: 478 MWe

Cumul. Avail. Factor: $\mathbf{7 7 . 9}$

Cumul. Cap. Factor (MDC Net): $\mathbf{7 0 . 9}$

Cumul. Forced Outage Rate: $\mathbf{4 . 0}$

3-Year Avg. Cap. Factor (MDC Net): 84.4

License Expiration: 2013

OPERATING HISTORY (To December 1996)

Date

Sep 1973

Jan - May 1974

Feb - May 1975

Sep - Oct 1975

Feb - Mar 1976

Oct - Dec 1976

Jan 1977

Sep - Dec 1977

May 1978

Jun 1978

Oct - Dec 1978

Nov 1979

Jan - Jun 1980

Sep - Dec 1981

Dec 1982 - Apr 1983

Apr 1983
Comment

Commercial operation began about 2 years behind schedule. Main steam line vibration problems were encountered during power ascension program.

MSIV vibration problems caused several outages during power escalation; plant power level was administratively limited. Initial design power was achieved in May.

The first refueling outage was performed. Power was limited to about $90 \%$ until late July due to numerous failures of incore detectors.

The plant was shut down for rod block circuit modifications and RCP seal repair.

An outage of 34 days was required after the unit tripped from failure of a relay in $151-\mathrm{kV}$ power supply. Incore detectors were replaced during the outage.

The second refueling outage was performed.

About 3360 gallons of water was pumped into the containment building by accidental actuation of containment spray system.

The third refueling outage was performed.

The unit was shut down for 8-day outage to repair SG blowdown valves.

The unit was shut down for 10-day outage to repair RCP seals.

The fourth refueling and maintenance outage was performed.

SG nozzle-to-piping weld test required a 7-day outage.

The fifth refueling and maintenance outage was performed. TMI modifications were performed and several corroded RCP studs were replaced.

The sixth refueling and maintenance outage was performed.

The seventh refueling and maintenance outage lasted 124 days. The unit was shut down about 1 month early for the outage because of turbine vibration caused by broken blades and wiped bearings in HP turbine. Other work included ILRT, HP turbine repair and 10-year RPV ISI.

Several plant areas were contaminated when the refueling water tank overflowed. 
Sep 1983

$\operatorname{Mar}$ 3, 1984

Mar - Jul 1984

May 1984

Jun 1984

Nov - Dec 1984

Feb 1985

Sep 1985 - Jan 1986

Jan 1987

Mar - Jun 1987

Aug 1987

Oct 1987

Apr 1988

May 1988

Apr 5, 1988

Jun 1988

Jun - Sep 1988

Jul 1988

Sep 26, 1988
The NRC granted a license amendment to expand spent fuel storage from 483 FAs to 729 FAs.

The unit completed the longest nonstop duty cycle after 302 days of operation. The utility estimated the unit had saved $\$ 179$ million, exceeding the initial cost of plant of $\$ 178.3$ million.

The eighth refueling and maintenance outage lasted 132 days. Major work included SG leak inspection, sludge lancing, and tube plugging. Startup was delayed when a SG tube ruptured during a hydrostatic test and additional SG inspection had to be performed.

A 4160/480V transformer failed, causing a fire in the switchgear room. A mowing machine threw a downed wire into a $161-\mathrm{kV}$ line feeding the plant, which caused a partial LOSP.

The Missouri River overflowed and flooded the chemical waste lagoon and parking lot.

The unit was shut down for 14 days to repair leaky pressurizer spray valve and perform routine maintenance.

The utility was fined $\$ 21,425$ by the NRC for alleged violations involving plant security requirements and failure to report a facility modification.

The ninth refueling and maintenance outage lasted 110 days. Major work included SG tube inspection, main generator rewinding, control rod assembly replacement, and FW heater and drain cooler replacement.

The utility paid a NRC assessed fine of $\$ 15,000$ for alleged inadequate design and installation of a vital area barrier.

The tenth refueling and maintenance outage lasted 93 days. Major work included SG inspection and tube repairs, rework of welds and nozzles on emergency FW storage tank; MOV testing, ATWS modifications, and numerous other plant modifications and upgrading.

The utility awarded a $\$ 10.2$ million contract to $\underline{W}$ for design and construction of a plant simulator.

The utility paid a NRC assessed fine of $\$ 50,000$ for alleged inadequate safety evaluation of a modification to the AFW system.

The utility paid a NRC assessed fine of $\$ 75,000$ for alleged failures to follow radiation protection regulations.

The utility paid a NRC assessed fine of $\$ 175,000$ for two alleged events in which water from the fire protection system disabled one DG and potentially disabled the other.

The unit completed its longest nonstop duty cycle after 303 days of continuous operation.

The utility paid a $\$ 112,500$ fine to the NRC for alleged failure to lock a door to a very high radiation area.

Power was reduced to $90 \%$ because of poor condenser performance and high river water temperatures. Power was further reduced in August to $80 \%$ to conserve fuel until a upcoming refueling outage.

The plant was placed on the NRC problem plant list, despite high availability, because of lack of depth in technical and engineering personnel.

The plant completed 476 days of continuous operation, a new world record for nuclear power plants of all types. 
Sep 1988 - Jan 1989

Oct 1988

May 1989

Jun 1989

Sep 1989

Feb - May 1990

Apr 1990

Aug 1990

Sep 1990

Dec 1990 - Jan 1991

Sep 1991

Nov 1991

Feb - May 1992

Jul 1992

Aug 1992

Nov 1992

Apr 1993

Sep - Nov 1993

Feb - Apr 1995

May 1995

Mar 1996
The eleventh refueling and maintenance outage lasted 126 days. Major work included RCS hydrostatic testing, EFW storage tank weld inspection, RCP seal replacement, SG inspection and sludge lancing, and rebuilding of both DGs.

NRC assessed a $\$ 50,000$ fine for two separate alleged violations: one for faulty check valves that could degrade a backup air supply system, and one for a missing test cap on a containment test line that could have resulted in significant radiation exposure in case of an accident.

Power was reduced for seven days to repair a check valve leak on the main FW line.

The plant was removed from the NRC list of problem plants.

A 5-day outage was required to replace an RTD on a RCP.

The twelfth refueling and maintenance outage lasted 102 days. Major work included RCP bearing replacement, HP turbine rotor replacement, installation of a third AFW pump, inspection of FW heater and condenser tubes, SG inspection, sludge lancing and tube plugging, plus numerous other plant modifications.

NRC proposed a $\$ 25,000$ fine for alleged inadequate security over documents containing safeguards information.

A rapidly degrading RCP seal forced a shutdown of 10 days for repair.

An outage of 6 days was necessary to correct design basis problems with the raw water, component cooling, and containment spray systems.

An installed spare control element drive mechanism had a through-wall leak that required a 25-day outage to repair.

An outage of 24 days was caused by cracks in the batteries of the $125-\mathrm{Vdc}$ system.

The unit received four Category 1 ratings in its SALP review from the NRC.

The thirteenth refueling and maintenance outage lasted 92 days. Thermal shield and reactor vessel welds were inspected, and all the cells in both station batteries were replaced.

Following a reactor trip, a pressurizer SRV opened and failed to reseat. About 21,000 gallons of reactor coolant were released onto the containment floor. The resulting outage lasted 19 days.

The reactor tripped when the same pressurizer SRV as in the July incident prematurely opened. This outage lasted 15 days.

The utility estimated decommissioning costs would be approximately $\$ 312$ million.

A 1-week scheduled maintenance outage was taken to improve plant thermal performance for the peak summer season.

The fourteenth refueling and maintenance outage lasted 62 days.

The fifteenth refueling and maintenance outage lasted 53 days.

Two manual reactor scrams were initiated due to cooling water leaks in the lower RCP motor coolers. First, these coolers were replaced, and then all four upper motor coolers were replaced.

A maintenance outage of 10 days was taken to repair CEDM seals and perform other items. 


\section{FORT CALHOUN 1 (Cont'd)}

Jun 1996

Oct - Nov 1996
The unit was shut down to replace the anti-reverse rotation device on one of the RCPs. The sixteenth refueling and maintenance outage lasted 53 days. 
This Page Intentionally Left Blank 
GINNA

PRODUCTION COST and CAPITAL ADDITIONS

(1996 Dollars)

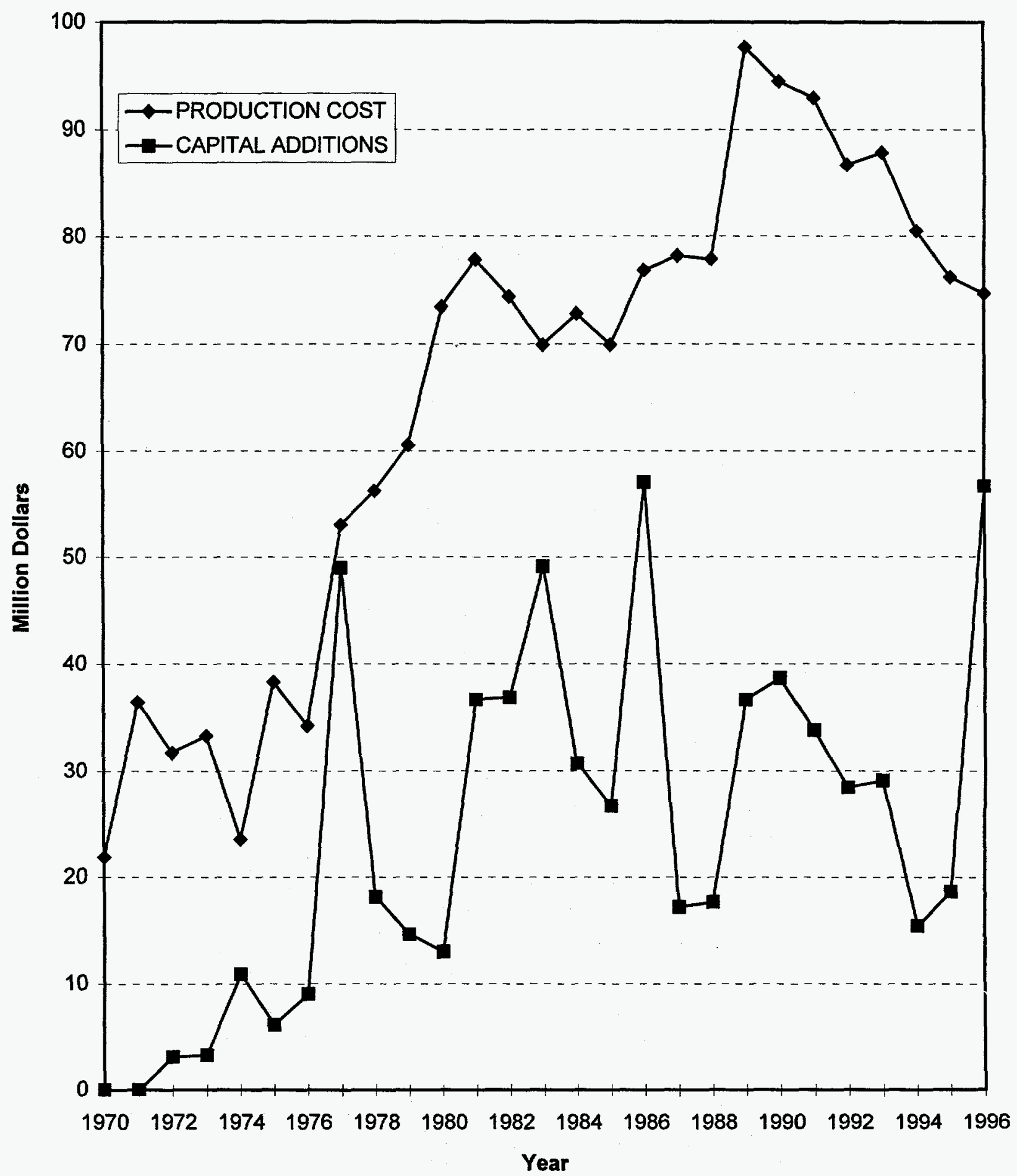




\section{NUCLEAR POWER PLANT OPERATING EXPERIENCE SUMMARY}

Unit data summary through December 1996

Unit: GINNA

Location: WAYNE COUNTY, NEW YORK

Nameplate Rating: 517 MWe

Owner: ROCHESTER GAS \& ELECTRIC CO.

MDC Net MWe: 470 MWe

Type: WESTINGHOUSE PWR

Cumul. Avail. Factor: $\mathbf{7 8 . 7}$

Construction Permit: 04/25/66

Cumul. Cap. Factor (MDC Net): 75.9

Operating License: 09/19/69

Cumul. Forced Outage Rate: 5.7

Commercial Oper. Date: 07/01/70

3-Year Avg. Cap. Factor (MDC Net): 80.2

License Expiration: 2009

OPERATING HISTORY (To December 1996)

Date

May 1970

Feb - Apr 1971

Apr - Jun 1972

Oct - Nov 1972

Jan - Apr 1974

Mar - May 1975

Sep 1975

Jan 1976 - Jul 1977

Nov 1978

Jul - Aug 1979

Jan - May 1982

Mar - Jun 1983

Dec 1984

Feb - Mar 1986

\section{Comment}

A 1-month outage was needed to repair turbine blade damage.

The annual overhaul and partial refueling outage lasted 2.5 months.

A refueling and maintenance outage lasted 71 days, major work included repair of SG and main steam header.

A 34-day shutdown was required to replace unpressurized FAs with pressurized assemblies.

A refueling and maintenance outage was performed. Turbine blade failure caused decision to refuel early. Forty workers received $>3 \mathrm{rem} /$ quarter radiation dose during outage repair activities.

The refueling and maintenance outage was performed. Major work included SG tube plugging.

Fines totaling $\$ 10,000$ were assessed by $\mathrm{NRC}$ for alleged failures to manage personnel radiation protection.

Several outages caused by LP turbine blade failures and leaking tubes in SGs occurred.

$\mathrm{NRC}$ assessed a $\$ 24,000$ fine for alleged noncompliance with radiation protection requirements.

A shutdown was required to inspect SG FW nozzle welds in accordance with NRC requirements; cracks were found in both SGs in FW nozzle-to-pipe welds.

The unit was shut down after SG tube rupture; extensive investigation required by NRC before startup.

A refueling and maintenance outage was performed. Major work included extensive SG tube work. A significant event occurred when an air bubble entered the RHR system causing loss of cooling for several minutes.

NRC issued a full-term operating license to the year 2006.

A refueling and maintenance outage lasted 47 days. Major work included TMI modifications and SG inspection and SG tube sleeving and plugging. 
Feb - Mar 1987

Feb - Mar 1988

May 1988

Mar - May 1989

Mar - May 1990

Nov 1990

Jul 1990

Dec 1990

Mar - May 1991

Mar - May 1992

Dec 1992

Mar - Apr 1993

Nov 1993

Mar - Apr 1994

Aug 1994

Mar - May 1995

Mar 1996

Apr - Jun 1996

Jul 1996

Aug 1996

Sep 1996

Oct - Nov 1996
A refueling and maintenance outage lasted 32 days. Major work included HP turbine overhaul.

A refueling and maintenance outage lasted 35 days, an extension of an additional 10 days was needed for repair of SG tube leaks.

NRC assessed a $\$ 50,000$ fine for alleged failure to include four auxiliary FW check valves in valve test schedule.

A refueling and maintenance outage lasted 66 days. Major work included SG inspection and repair, RPV 10-year ISI, turbine overhaul, and RCP motor replacement.

A refueling and maintenance outage lasted 45 days. Major work included SG inspection and repair, LP turbine rotor changeout, and RCP motor replacement.

NRC SALP results reported a Category 1 rating in emergency preparedness and a Category 2 rating in other areas.

The unit reached the 20-year operating milestone with a capacity factor of about $73 \%$.

A design deficiency in a Foxboro control module required a shutdown lasting 9 days.

A refueling and maintenance outage lasted 50 days. Major work included SG inspection and repairs and main generator inspection and installation of digital FW control system.

A refueling and maintenance outage lasted 46 days. Major work included SG eddy current testing, tube plugging and sleeving, asbestos insulation removal, and weld inspections, periodic maintenance of pumps, valves, motors, and electrical breakers, inservice inspections, and electrical modifications.

A utility announced plans to replace both $\underline{W}$ SGs with Babcock \& Wilcox SGs in 1996 at an estimated cost of $\$ 115$ million.

A refueling and maintenance outage lasted 45 days. Major work included SG eddy current testing and tube sleeving, RCP seal replacement, service water valve rework and replacement, ILRT and MSR relief valve testing, RCP bowl internal inspection, and LP turbine rotor replacement.

The unit was shut down for 5 days to repair a leak in a SG blowdown line.

The refueling and maintenance outage lasted 46 days.

The unit had a 13-day outage to repair a failed pipe weld.

The annual refueling and maintenance outage lasted 39 days.

The unit was shut down for 4 days following a secondary system transient due to a circulating water pump tripping.

The annual refueling and maintenance outage lasted 70 days.

The unit was shut down for 4 days to correct a leaking pressurizer safety valve.

A 6-day outage was taken to perform upgrades to the LPSI valve actuators.

Valve leaks required a 4-day outage to correct.

The main transformer required developed hot spots. Its replacement took 20 days. 


\section{GINNA (Cont'd)}

Dec 1996

The NRC proposed and the licensee paid a $\$ 100,000$ fine for inaccurate design inputs for the RHR system. 


\section{GRAND GULF 1}

PRODUCTION COST and CAPITAL ADDITIONS (1996 Dollars)

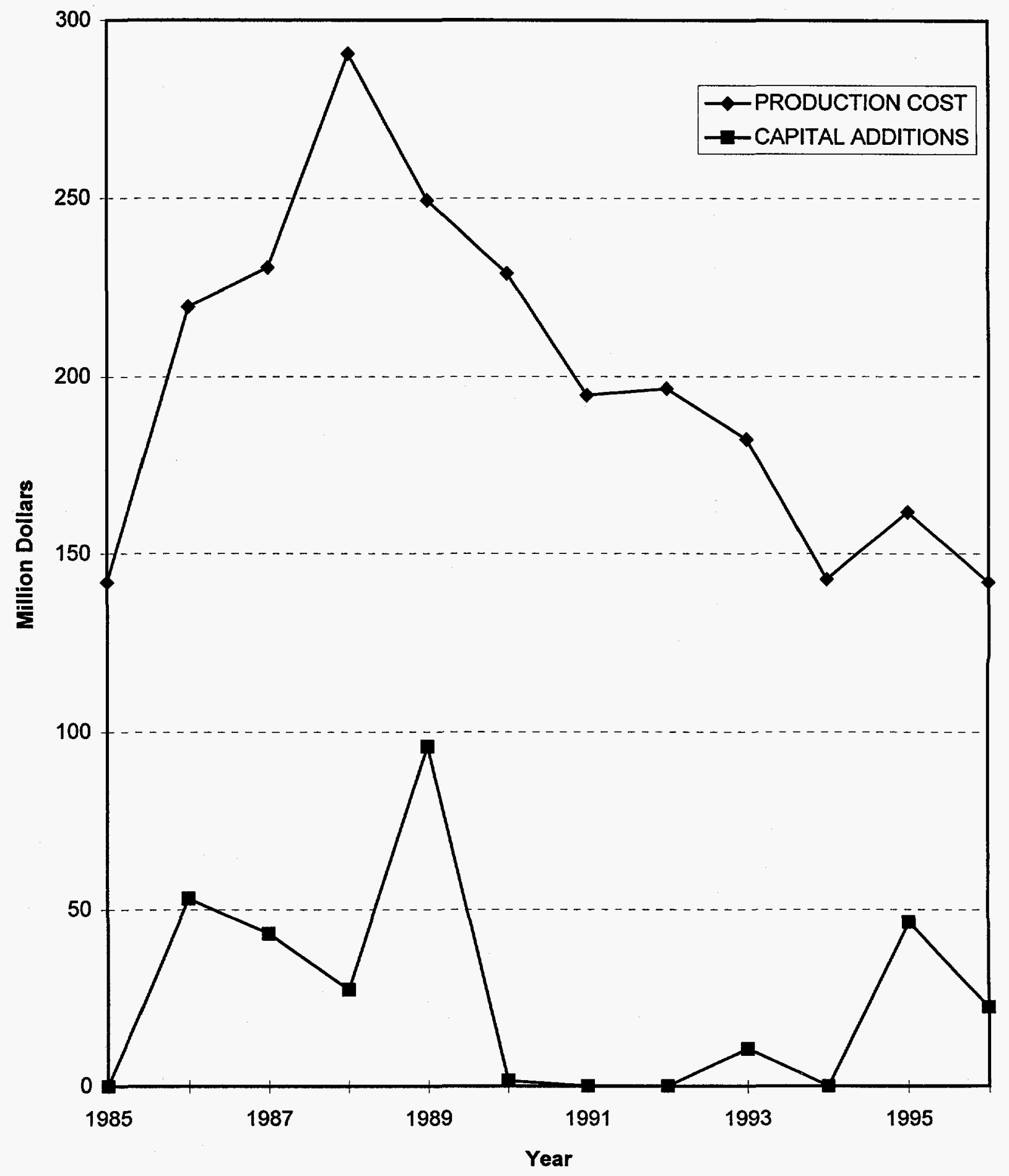




\section{NUCLEAR POWER PLANT OPERATING EXPERIENCE SUMMARY}

Unit data summary through December 1996

Unit: GRAND GULF 1

Location: CLAIBORNE COUNTY, MISSISSIPPI

Owner: ENTERGY OPERATIONS

Type: GENERAL ELECTRIC BWR

Construction Permit: 09/04/74

Operating License: 11/1/84

Commercial Oper. Date: 7/1/85
Nameplate Rating: 1373 MWe

MDC Net MWe: 1179 MWe

Cumul. Avail. Factor: 81.1

Cumul. Cap. Factor (MDC Net): 72.5

Cumul. Forced Outage Rate: 6.3

3-Year Avg. Cap. Factor (MDC Net): 87.7

License Expiration: 2022

OPERATING HISTORY (To December 1996)

Date

Aug 1982 - Sep 1984

Sep 1983

Jan 1984

May 1984

Jun - Sep 1984

Nov 1984

Feb - Mar 1985

Jun 1985

Oct - Dec 1985

Sep 1986 - Jan 1987

Dec 1986

Jun 1987

\section{Comment}

After initial criticality was achieved, the plant was shut down for almost 2 years to correct a number of identified TS deficiencies. Questions concerning the quality of the DGs and additions to the plant makeup system further extended the shutdown.

The NRC assessed a $\$ 20,000$ fine for an alleged violation when a security guard was found asleep at his post.

The NRC assessed a $\$ 12,000$ fine when personnel allegedly failed to follow maintenance procedures on the DGs.

The utility received an order from the NRC to tear down and inspect the DGs in response to problems found with the same type DeLaval DG unit at Shoreham.

The unit was shut down for a total of 118 days to resolve ultimate heat sink and IRM problems. An additional 12 days of outage was attributed to repairing steam leaks.

The unit was shut down for 22 days to correct FW pump test equipment and retrain operators.

The unit was shut down for 44 days to repair condenser and perform other plant maintenance.

The NRC proposed a $\$ 500,000$ fine for alleged material false statements in connection with operator qualification and training. The fine was later reduced to $\$ 200,000$.

The unit was shut down for a scheduled maintenance outage. Major work included LLRT and ILRT, high density fuel storage rack installation, DG repair, and standby service water system modifications. Total outage time was 59 days.

The first refueling and maintenance outage lasted 126 days. Major work included DG and SW pump modifications, remote shutdown panel modifications, and main turbine/generator inspection. Main generator damage during testing extended the outage into January.

NRC issued an amendment to the utility operating license transferring the license to System Energy Resources, Inc., from Mississippi Power and Light Co.

The unit completed 171 days of continuous operation, surpassing the world record of 158 days for a GE BWR in the second fuel cycle. 
Nov 1987 - Jan 1988

Feb 1989

Mar - Apr 1989

May - Jun 1989

Aug 1989

Jun 1990

Jul 1990

Sep - Nov 1990

Dec 1990

May 1991

Jun 1991

Jul 1991

Aug \& Nov 1991

Dec 1991

Apr - Jun 1992

Nov 1992

Sep 1993
The second refueling and maintenance outage lasted 60 days. Major work included 10-year ISI, control room human factors modifications, ATWS modifications, inspection of two DGs, and recertification of all 20 SRVs.

The utility reported that it had signed a three-outage, 5 -year contract with GE to create a joint refueling team to keep refueling outages to less than 45 days.

The third refueling and maintenance outage lasted 43 days. Major work included RV inspection, ILRT, maintenance on all three DGs, emergency SW system chemical cleaning, and MSIV LLRT.

The unit was shut down for 20 days to repair a circumferential crack found in recirculation pump shaft, the first ever found in a U.S. BWR recirculation pump. Shafts on both recirculation pumps were replaced during the outage. The unit had also been shut down for 4 days to replace a faulty FW flow control valve position feedback sensor.

The unit was shut down for 9 days to replace the condenser expansion belts when the failure of one caused a reactor scram.

Operations management of Grand Gulf 1, Waterford 3, and both units of Arkansas Nuclear One were consolidated under a single company - Entergy Operating, Inc.

The unit was cited by the NRC for good performance.

The unit scrammed following failure of the FW pump controller. Repairs required an outage of 6 days.

The fourth refueling and maintenance outage lasted 93 days. Refueling was delayed when the steam dryer became lodged out of position, damaging the guide rods and bolts of the steam separator assembly and preventing immediate removal of the separator. Recirculation pump vibration problems caused additional delays at restart.

The unit was shut down for 13 days to investigate high vibration in one recirculation pump.

Replacement of both recirculation pump seals required a 6-day outage.

Failure of the condensate minimum flow control valve positioner required a 4-day outage to repair.

A 10-day outage followed a reactor scram when the EHC pumps lost power because of an inadvertent Division II LSS load shed. The power source for the BOP optical isolators was changed to prevent recurrence.

Two plant scrams were caused by lighting strikes during August and November.

The plant was shut down for 12 days at the end of December to replace a recirculation pump shaft and a FW system check valve.

The fifth refueling and maintenance outage lasted 52 days. Major work included RCP motor and generator rotor replacement, and decontamination of the recirculation and RWCU systems.

The NRC SALP report awarded Category 1 ratings in six of seven functional areas.

The unit was shut down for 10 days following an inadvertent HPCI actuation. The suspected cause was failure of the No. 10 jet pump. 
Sep - Nov 1993

Mar 1994

Aug 1994

Apr - Jun 1995

Jun 1995

Jul 1995

Oct - Nov 1996
The sixth refueling and maintenance outage lasted 62 days. The outage entered early due to the No. 10 jet pump being declared inoperable. In addition, replacement of jet pumps required the outage to be extended by 10 days.

An excessive number of control rods failed their scram time test, causing an 8-day outage.

The plant received all Category 1 ratings on its NRC SALP report, and the evaluations were lengthened to a 24-month cycle.

The unit was shut down for 9 days after cooling water leaked into the main generator rotor and caused high generator bearing vibration.

The seventh refueling and maintenance outage lasted 57 days. The outage was extended for main generator stator leak repairs.

Two outages totaling 9 days were required to replace the seal on recirculation pump "A."

Three reactor scrams caused a total of 10 days of downtime.

The eighth refueling and maintenance outage lasted 42 days. 
HADDAM NECK (CONNECTICUT YANKEE)

PRODUCTION COST and CAPITAL ADDITIONS (1996 Dollars)

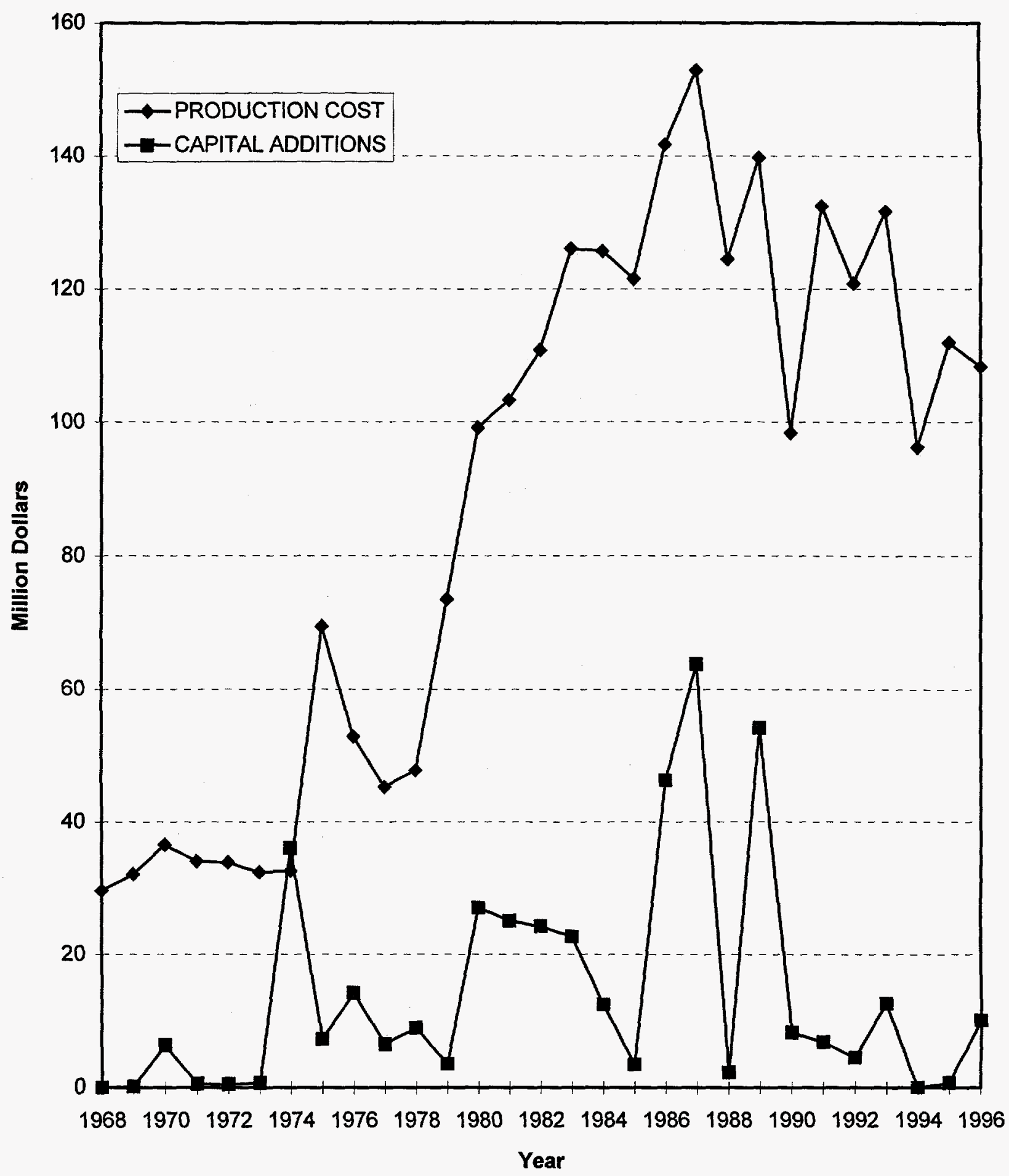




\section{NUCLEAR POWER PLANT OPERATING EXPERIENCE SUMMARY}

Unit data summary through December 1996

Unit: HADDAM NECK 1

Location: MIDDLESEX COUNTY, CONNECTICUT

Owner: CONNECTICUT YANKEE ATOMIC POWER CO.

Type: WESTINGHOUSE PWR

Construction Permit: 05/26/64

Operating License: 6/30/67

Commercial Oper. Date: 01/01/68
Nameplate Rating: 600 MWe

MDC Net MWe: 560 MWe

Cumul. Avail. Factor: $\mathbf{7 6 . 3}$

Cumul. Cap. Factor (MDC Net): 73.4

Cumul. Forced Outage Rate: 6.3

3-Year Avg. Cap. Factor (MDC Net): 69.4

License Expiration: 2007'

OPERATING HISTORY (To December 1996)

Date

Mar 1968

Apr 1970

Jul 1973

Mar 1974

May 1976

May, Sept 1980

1982

Apr 1983

Aug 1984

Jul 1987 - Mar 1988

Sep 1989

Sep 1989 - Aug 1990

Oct 1990

\section{Comment}

A 5-week outage was required for a turbine flange steam leak.

A 10-week shutdown was prolonged for major inspections and modifications. Three original DG units were replaced with two larger units, control rod problems, turbine problems, high reactor coolant activity.

A shutdown occurred early because of recurring turbine problems, both LP turbine rotors were replaced.

A 4-week shutdown was caused by turbine blade problems.

The refueling outage started early because of turbine vibration, two LP turbine rotors were replaced.

Turbine problems occurred.

Several load reductions were needed during the year to plug leaking condenser tubes.

New condenser tubing was installed.

The plant set a new world record for operation -417 consecutive days. During a maintenance and refueling outage, the refueling water cavity seal failed, flooding containment. NRC assessed a $\$ 80,000$ fine for inadequate review of seal design.

The refueling and maintenance outage lasted 252 days. The LP turbine rotor was replaced and the outage was extended because of damage to thermal shield support bolts and dowel pins.

The plant completed a record 461-day run.

The refueling and maintenance outage lasted 347 days. Debris from thermal shield work damaged fuel. Problems occurred with defective fuel rods, the SW system, and pressurizer cracks.

Fouled containment air recirculation fan coolers caused a 19-day outage.

'The unit was permanently shut down in December 1996. The cumulative data are through that date. 
Mar 1991

Oct 1991 - Mar 1992

Mar - Jul 1993

Dec 1993

Feb 1994

Jul 1994

Jan - Apr 1995

Jul 1996

Nov 1996
The unit was shut down due to inadequate testing of containment air recirculation fans occurred. The test method was revised and the fan flow vanes adjusted during the 12-day outage.

The refueling and maintenance outage lasted 150 days.

The seventeenth refueling and maintenance outage lasted 66 days. The NRC ruled against the utility's request for plant-specific alternate plugging/repair criteria for the four SGs. The reason was that it should not be considered until generic criteria are settled.

The plant operated the remainder of 1993 with several short outages to repair leaks.

The unit was shut down for 44 days to replace sections of SWS piping affected by microbiologically influenced corrosion.

A 37-day outage was necessary to repair the RCP oil collection system.

The refueling and maintenance outage lasted 81 days.

The unit was shut down to address design issues related to the containment fans and coolers. The refueling and maintenance outage was entered early due to the number of design issues being raised.

The decision was made to permanently shut down the unit. The cost of upgrading the unit and continuing operation was not justified with the current power available in New England and due to future deregulation of the electric utility industry. 
This Page Intentionally Left Blank 
HARRIS 1

PRODUCTION COST and CAPITAL ADDITIONS (1996 Dollars)

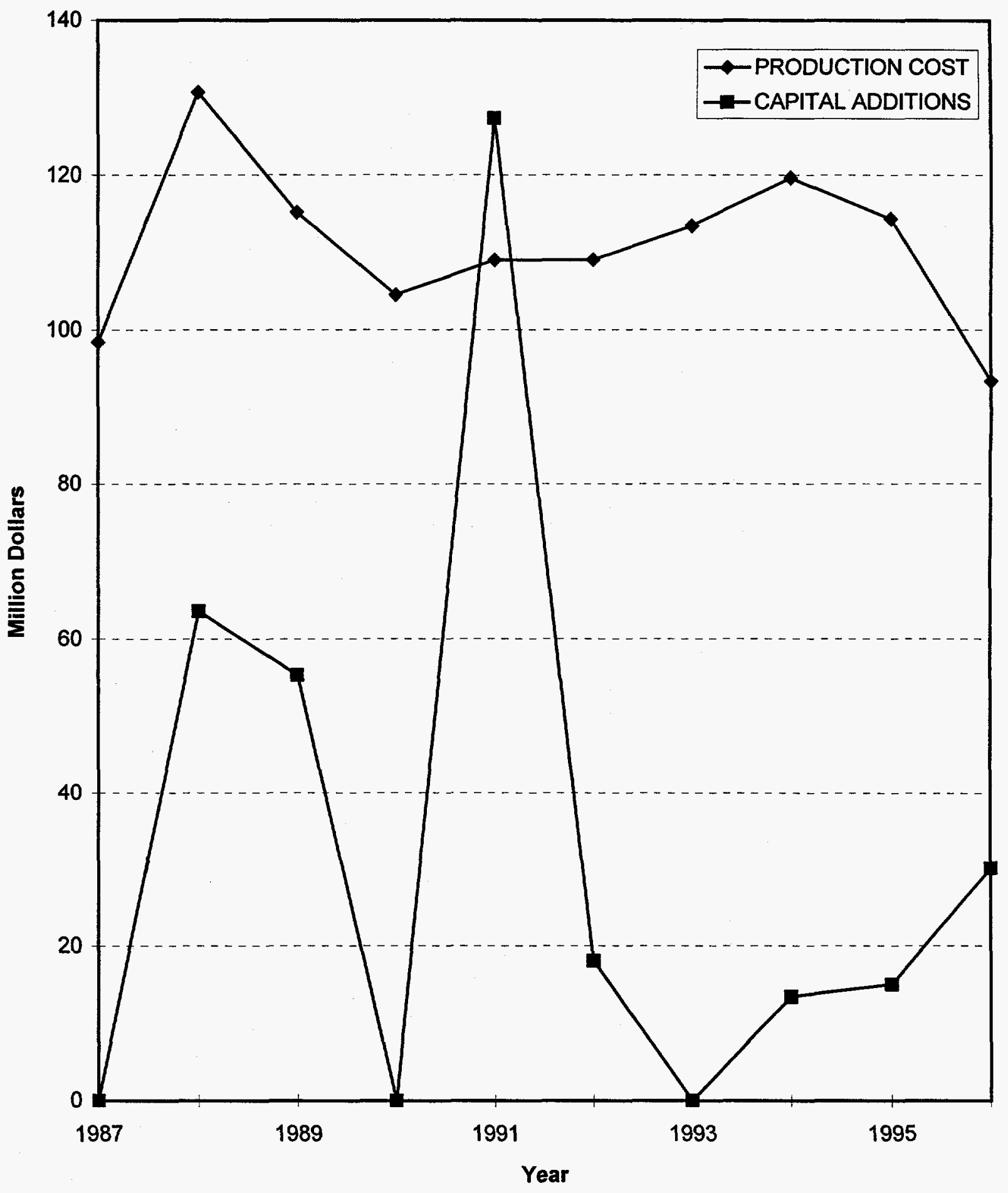




\section{NUCLEAR POWER PLANT OPERATING EXPERIENCE SUMMARY}

Unit data summary through December 1996

Unit: HARRIS 1

Location: WAKE \& CHAPHAM COUNTY, NORTH CAROLINA

Owner: CAROLINA POWER \& LIGHT CO.

Type: WESTINGHOUSE PWR

Construction Permit: 1/27/78

Operating License: 1/12/87

Commercial Oper. Date: 5/2/87
Nameplate Rating: 951 MWe

MDC Net MWe: 860 MWe

Cumul. Avail. Factor: 83.2

Cumul. Cap. Factor (MDC Net): 80.4

Cumul. Forced Outage Rate: $\mathbf{3 . 3}$

3-Year Avg. Cap. Factor (MDC Net): 84.4

License Expiration: 2026

OPERATING HISTORY (To December 1996)

Date

1987

Oct 1987

Jul - Sep 1988

Feb 1989

Oct - Dec 1989

May 1990

Nov 1990

Dec 1990

Mar - May 1991

Jul 1991

Mar 1992

Jul 1992

Sep - Nov 1992

\section{Comment}

The unit experienced several shutdowns and power reductions of 10 days or less after achieving full power in April.

The unit was shut down for a scheduled maintenance outage of 30 days.

The first refueling and maintenance outage lasted 63 days. Major maintenance work performed included SG inspection and sludge lancing, CRD modifications, LLRTs, and maintenance on SG blowdown valves, HP turbine, and main generator. B\&W had performed a variety of the outage work under a turnkey contract. The outage was extended an additional 13 days to complete needed maintenance work.

The NRC assessed a $\$ 25,000$ fine against the utility for alleged failure to provide proper barriers to prevent access to vital plant areas.

The second refueling and maintenance outage lasted 73 days. The unit entered outage early after a main generator hydrogen fire occurred. Major work included main generator repair, SG inspection and sludge lancing, and inspection of LP turbine, snubbers, and DG.

A 12-day outage was forced by repair of leaking condenser tubes and emergency power load sequencer.

A SG tube leak required a 19-day outage to repair.

An outage was required to repair a condenser tube leak caused by the failure of an impingement plate.

The third refueling and maintenance outage lasted 67 days. Major work included service water inspections, control room modifications, and overhaul of a DG.

The NRC proposed a $\$ 50,000$ fine for problems with operability of the reactor trip system.

A 6-day outage was necessary to repair small steam leaks on two RTD bypass manifold isolation valves.

Failure of a LP turbine exhaust boot seal caused loss of condenser vacuum. Replacement of the full boot seal on both LP turbines required 9 days.

The fourth refueling and maintenance outage lasted 80 days. Major work included SG, DG, MOV, and main turbine inspections, DG maintenance, and main turbine overhaul. 


\section{HARRIS 1 (Cont'd)}

Mar - May 1994

May 1994

Oct - Nov 1994

Sep - Oct 1995

Oct 1995

Dec 1995

Mar 1996

Apr 1996

Sep 1996
The fifth refueling and maintenance outage lasted 54 days.

The plant received all Category 1 ratings on its NRC SALP report and the evaluations were lengthened to a 24-month cycle.

A scheduled outage of 11 days was taken to repair valve leakage.

The sixth refueling and maintenance outage lasted 41 days.

The unit was shut down for 2 weeks to repair a leaking feedwater isolation valve.

The unit was shut down for 5 days to repair both No. 4 feedwater heaters. The impingement plates had come loose.

The unit was shut down to complete safety sequencer testing. The unit remained shut down for $\mathbf{8}$ days to repair a condenser tube leak and a main feedwater isolation valve leak.

The plant again received all Category 1 ratings on its NRC SALP report.

The unit was shut down after a service water pump shaft sheared. The unit remained down until FEMA gave restart permission following Hurricane Fran. The unit was down for 6 days. 
This Page Intentionally Left Blank 
HATCH

PRODUCTION COST and CAPITAL ADDITIONS (1996 Dollars)

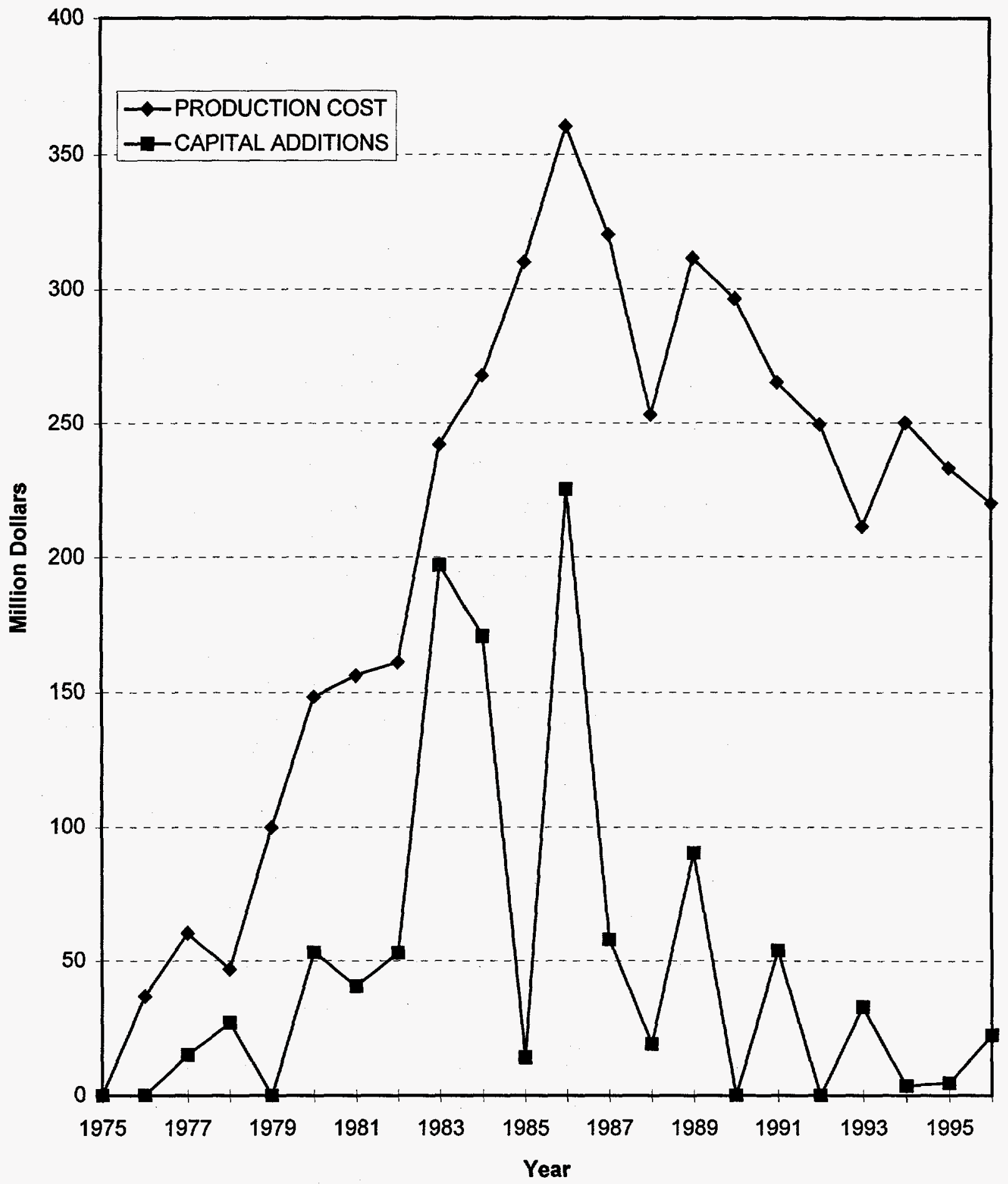




\title{
NUCLEAR POWER PLANT OPERATING EXPERIENCE SUMMARY
}

\author{
Unit data summary through December 1996
}

Unit: HATCH 1

Nameplate Rating: 850 MWe

Location: APPLING COUNTY, GEORGIA

MDC Net MWe: 805 MWe

Owner: GEORGIA POWER CO.

Cumul. Avail. Factor: $\mathbf{7 4 . 4}$

Type: GENERAL ELECTRIC BWR

Cumul. Cap. Factor (MDC Net): 69.0

Construction Permit: 09/30/69

Cumul. Forced Outage Rate: 10.2

Operating License: 10/13/74

3-Year Avg. Cap. Factor (MDC Net): 89.0

Commercial Oper. Date: 12/31/75

License Expiration: 2014

OPERATING HISTORY (To December 1996)

Date

Nov - Dec 1974

Apr 1975

Jun 1975

Nov - Dec 1975

Jan - Mar 1976

Mar - Apr 1976

May 1976

Jan - Feb 1977

Mar - May 1977

Oct 1977

Mar - Apr 1978

May - Jun 1978

Jan - Feb 1979

Apr - Aug 1979

Feb - Jun 1981

Oct - Nov 1981

\section{Comment}

The plant's first electricity was generated on November 11 . Numerous maintenance shutdowns totaling almost 25 days were required during early power ascension program.

A 2-week shutdown was required for turbine repairs.

Power output was limited to $80 \%$ because of a TIP vibration problem.

A 5-week shutdown was required for modifications to the TIP system to prevent vibration and to replace 125 fuel channels.

Power output was restricted to $80 \%$ during the first quarter because of a MSIV leakage that required isolation of one steam line.

The unit was shut down about 1 month for LPCI modifications and MSIV repairs.

An 11-day outage was necessary to replace a burned out recirculation MG set drive motor.

Inadvertent safety/relief valve opening occurred twice causing reactor vessel cooldown rate and torus water temperature limits to be exceeded. Repair required 14 days.

The first refueling and maintenance outage was performed. Major work included loading 92 new 8x8 FAs and replacement of FW spargers. Cracks were found in the CRD return line nozzle.

A safety/relief valve replacement forced an outage of 12 days.

The unit was shut down for a refueling outage.

A 42-day outage was required for repair of a leaking off-gas line.

A 9-day outage was caused by high drywell pressure from a leaking valve.

Upon restart after a refueling outage, RHR SW pump seismic restraints were found to be inadequate and another 4 days for repair was required.

The refueling and maintenance outage was performed. IRM spikes on June 13 resulted in 4 days of additional outage time.

The unit was shut down for a 7-week refueling outage. 
Dec 1981 - Feb 1982

Mar 1982

Apr - Jun 1982

Jul 1982

Oct 1982 - Feb 1983

Jun 1983

Nov - Dec 1983

Feb - Mar 1984

Jul 1984

Sep 1984 - Jan 1985

Jul 1985

Nov 1985 - May 1986

May 1986

Dec 1986

Apr 1987

Apr - Jun 1987

Jun 1987

Dec 1987
The unit was shut down for 44 days for main turbine inspection and plugging of main condenser tubes damaged by turbine parts.

The NRC imposed a $\$ 50,000$ fine for alleged violations involving administrative breakdowns in review and reporting requirements regarding HPCI valve diaphragm failures.

The unit was shut down because of a conductivity excursion caused by FW contamination with trichloroethane organic solvent. Repair of the main generator exciter extended total outage time to 48 days.

The NRC imposed a $\$ 20,000$ fine for alleged violations relating to an inadequate vehicle search prior to entry into a protected area.

The refueling and maintenance outage lasted 136 days. Major work included torus modifications. An NRC-mandated inspection disclosed IGSC cracks on RHR and recirculation piping welds.

The NRC imposed a $\$ 40,000$ fine for alleged failure to maintain adequate administrative and managerial control over cable tray modifications.

The unit was shut down for 37 days for FA reconstitution.

Vibration damage to the LP turbine resulted in a 26-day outage. Another short outage was caused by FW heater problems during restart.

The NRC imposed a $\$ 60,000$ fine for an incident in which an employee allegedly carried a loaded handgun into the protected area without being detected.

The refueling and maintenance outage was performed. During core unloading, a fuel bundle was dropped about 12 feet into its storage rack cell because of grapple hook problems. ISI detected IGSC cracks in several RHR and recirculation pipe welds that were repaired.

A 12-day outage was forced by a malfunctioning MSIV.

The refueling and maintenance outage was performed. Major work included recirculation pipe inspection and repair, EQ and Appendix R fire protection system modifications, and ten-year ISI. During the outage an RHR pump suction line valve opened and caused flooding in an ECCS pump room.

The NRC imposed a $\$ 50,000$ fine for alleged security violations involving failures to properly compensate for the loss of secondary and primary security alarm station annunciators.

About 140,000 gallons of water leaked from the fuel pool when an air supply was isolated from six transfer canal inflatable seals.

The NRC imposed a $\$ 50,000$ fine for alleged noncompliance with requirements concerning the 140,000 gallons of radioactive water that leaked from the spent fuel in December 1986.

The tenth refueling and maintenance outage lasted 65 days. Two turbine rotors were replaced, along with $184 \mathrm{FAs}, 12 \mathrm{CRDs}, 14$ control rod blades, and several hundred valves. Some HFA relays were installed and Appendix $\mathrm{R}$ work was also performed.

The utility reported that it had achieved a $35 \%$ volume reduction in the amount of low-level radwaste shipped during 1986. It was also reported that plant personnel had worked 9 million continuous man-hours without a lost day for an on-the-job accident.

The plant achieved the highest dual-unit availability for the year among GE-supplied BWRs worldwide with a 2-unit availability factor of $88.1 \%$. 


\section{HATCH 1 (Cont'd)}

Apr - May 1988

Sep - Dec 1988

Oct 1988

Jun 1989

Dec 1989

Feb - Jun 1990

Jun 1990

Oct 1990

Feb 1991

Sep - Nov 1991

1992

Mar - May 1993

Jul 1994

Sep - Nov 1994

Jan 1996

Mar - May 1996
After a scram, the unit was taken to cold shutdown to address various INPO concerns. A leaking pipe in the RWCU system was also replaced. Another scram occurred after restart due to an MSIV malfunction. The outage lasted 44 days.

The eleventh refueling and maintenance outage lasted 73 days.

Hatch was identified as one of eight plants that were candidates to be placed on the NRC list of problem plants, with increasing regulatory monitoring.

The plant set a world record for continuous operation of a GE-designed, 2-unit BWR station for more than $180 \frac{1}{2}$ days. In addition, a national industrial safety record of 14 million manhours without an on-the-job accident was achieved.

The unit completed the year with a capacity factor of $97.8 \%$.

The twelfth refueling and maintenance outage lasted 109 days, the main work was to retube the main condenser.

An UE was declared and the unit was shut down when the charcoal in one off-gas charcoal adsorber vessel caught fire. The unit was shut down for eight days.

Two outages totaling 7 days were necessary due to high vibration in the main turbine.

A 10-day outage followed a unit shutdown due to the main turbine tripping on low EHC system hydraulic pressure.

The thirteenth refueling and maintenance outage lasted 73 days. Major work included battery and battery charger replacement, plant process computer replacement, and upgrades to FW control and SW systems and neutron and process RMs.

No outages of 4 days or more occurred, although four reactor scrams (three automatic and one manual) did occur during the year.

The fourteenth refueling and maintenance outage lasted 61 days.

The NRC proposed and the licensee paid a $\$ 25,000$ fine for the fans for the piping penetration area being de-energized.

The fifteenth refueling and maintenance outage lasted 46 days.

The unit was shut down for 4 days following turbine control valve closure due to EHC strainers becoming clogged.

The sixteenth refueling and maintenance outage lasted 40 days. 


\section{NUCLEAR POWER PLANT OPERATING EXPERIENCE SUMMARY}

Unit data summary through December 1996

Unit: HATCH 2

Location: APPLING COUNTY, GEORGIA

Nameplate Rating: $850 \mathrm{MWe}$

Owner: GEORGIA POWER CO.

MDC Net MWe: 809 MWe

Type: GENERAL ELECTRIC CO.

Cumul. Avail. Factor: 76.0

Construction Permit: 12/27/72

Cumul. Cap. Factor (MDC Net): 65.8

Operating License: 6/13/78

Cumul. Forced Outage Rate: 6.5

Commercial Oper. Date: 9/5/79

3-Year Avg. Cap. Factor (MDC Net): 84.2

License Expiration: 2018

OPERATING HISTORY (To December 1996)

Date

Dec 1978 - Feb 1979

Feb - May 1979

Jun 1979

Jun - Jul 1979

Sep - Oct 1979

Mar - Apr 1980

Nov 1980 - Feb 1981

Mar 1981

Jun 1981

Sep - Nov 1981

Feb - May 1982

Jun 1982

Jul - Aug 1982

Aug - Oct 1982

\section{Comment}

The unit was shut down for steam dryer modifications.

Anchor failures during MSIV testing forced an outage.

A booster pump turbine failed and caused a reactor scram on low level. Condenser vacuum problems and testing forced four other outages. Total outage time was 16 days. Initial design power was also reached during June.

The unit was shut down for a planned 2-week outage.

Two separate outages were required to repair MSR steam leaks and repair steam leaks in the drywell for 9 days.

The unit was shut down for periodic tests and vent header deflector maintenance. The outage lasted 53 days.

The first refueling and maintenance outage was performed.

Exciter problems on a recirculation pump caused an 8-day outage.

The NRC imposed a fine of $\$ 40,000$ for an alleged occurrence in which a number of drywell pressure switches were inoperable for 10 days.

FW problems forced reductions in power output throughout most of the month.

Problems with MSIVs caused three outages, including one reactor scram. Repair work on FW heaters accounted for two other outages. Total outage time for all five shutdowns amounted to 14 days.

The second refueling and maintenance outage was performed.

A reactor scram and a 9-day outage resulted from a reactor water level controller problem.

The reactor was scrammed to permit repair of a DG. The unit returned to service after a 9-day outage.

An MSIV failure caused a reactor scram; two other outages occurred for repair of two different MSIVs. Total outage time for all shutdowns was nearly 12 days. 
Jan 1983

Apr - Jul 1983

Jul 1983

Aug 1983

Jan - Sep 1984

Feb 1984

Apr - May 1985

Sep - Dec 1986

May 1987 - Jan 1988

Jan - Mar 1988

Apr - May 1988

Feb 1989

Sep - Dec 1989

1990

Feb 1991

Mar - Jun 1991
Power output was reduced to about $70 \%$ to meet the fuel cycle window. High off-gas activity occurred because of fuel bundle leakage.

The third refueling and maintenance outage lasted 101 days. Recirculation piping weld indications were found on a jet pump riser header end cap. The outage was extended to correct a steam separator that accidently became lodged in the reactor vessel.

Multiple operator and procedural errors led to insertion of control rods out of sequence following a restart attempt after refueling. A management hold on startup was imposed and an outage of nearly 4 days resulted. The NRC imposed a fine of $\$ 100,000$ as a result of the event.

Two shutdowns totaling 12 days occurred. $\mathrm{N}_{2}$ leakage into the drywell caused the first outage. A reactor scram caused by FW pump control signal spiking caused the second outage. Repairs were also made to a TIP tube and drywell airlock door.

The fourth refueling and maintenance outage lasted 234 days. Major work was the recirculation piping replacement.

A circumferential crack was discovered in the containment vent header piping. This event led to shutdowns at other plants for inspections. Further evaluation indicated that the brittle fracture was unique and had been caused by liquid $\mathrm{N}_{2}$ from a malfunctioning line above the header.

The fifth refueling and maintenance outage lasted 49 days.

The sixth refueling and maintenance outage was performed. Major work included turbine inspection, plant modifications, ISI, ILRT, and LLRT.

Power output was administratively limited to a range of $75-90 \%$ to limit off-gas activity caused by fuel leakage problems.

The seventh refueling and maintenance outage lasted 68 days. Major work items included fuel sipping, replacement of $14 \mathrm{CRDs}, 8 \mathrm{LPRMs}$, and 4 control rod blades, reactor vessel ISI, LP turbine inspection, removal and inspection of the generator field, surveillance testing, and performance of plant design modifications.

The reactor tripped because of an APRM regulator card failure. The unit went to cold shutdown to address various INPO concerns and to repair a FW pump discharge valve. Total outage time was 34 days.

The operating license for the unit was extended through June 13, 2018, to recover construction time.

The eighth refueling and maintenance outage was performed. Major work included incore and undervessel work, condenser tube and tube sheet replacement, and LP turbine rotor and RCP seal replacement.

No significant outages or power reductions were reported.

The reactor tripped following a generator trip due to a failed circuit card in the generator field excitation system. The ensuing outage lasted 13 days.

The ninth refueling and maintenance outage lasted 75 days. Major work included battery and battery charger, process computer, FW heater replacements, and upgrades to the FW control, recirculation, and SW systems, neutron and process RMs, and reactor manual controls. 
$\operatorname{Jan} 1992$

Sep - Nov 1992

Dec 1992

$\operatorname{Mar} 1993$

Nov 1993

Mar - Apr 1994

Apr 1995

May 1995

Sep - Nov 1995
The unit was shut down when a recirculation pump discharge isolation valve packing leakoff line separated. The outage lasted 6 days.

The tenth refueling and maintenance outage lasted 67 days. Major work included upgrades to FW control system, SRVs, and seismic qualification, and replacement of battery and battery chargers.

An 8-day outage was necessary to replace the neutral bushing, which was leaking hydrogen, on the main generator.

The unit was shut down for 34 days to identify and remove a leaking FA and to inspect other FAs for possible damage.

The unit was shut down for eight days to repair a leak on the core spray testable check valve.

The eleventh refueling and maintenance outage lasted 45 days.

An 11-day outage followed a reactor scram due to personnel error.

The unit was manually scrammed to repair two of the main turbine's bearings.

The twelfth refueling and maintenance outage lasted 59 days. 
This Page Intentionally Left Blank 
HOPE CREEK

PRODUCTION COST and CAPITAL ADDITIONS

(1996 Dollars)

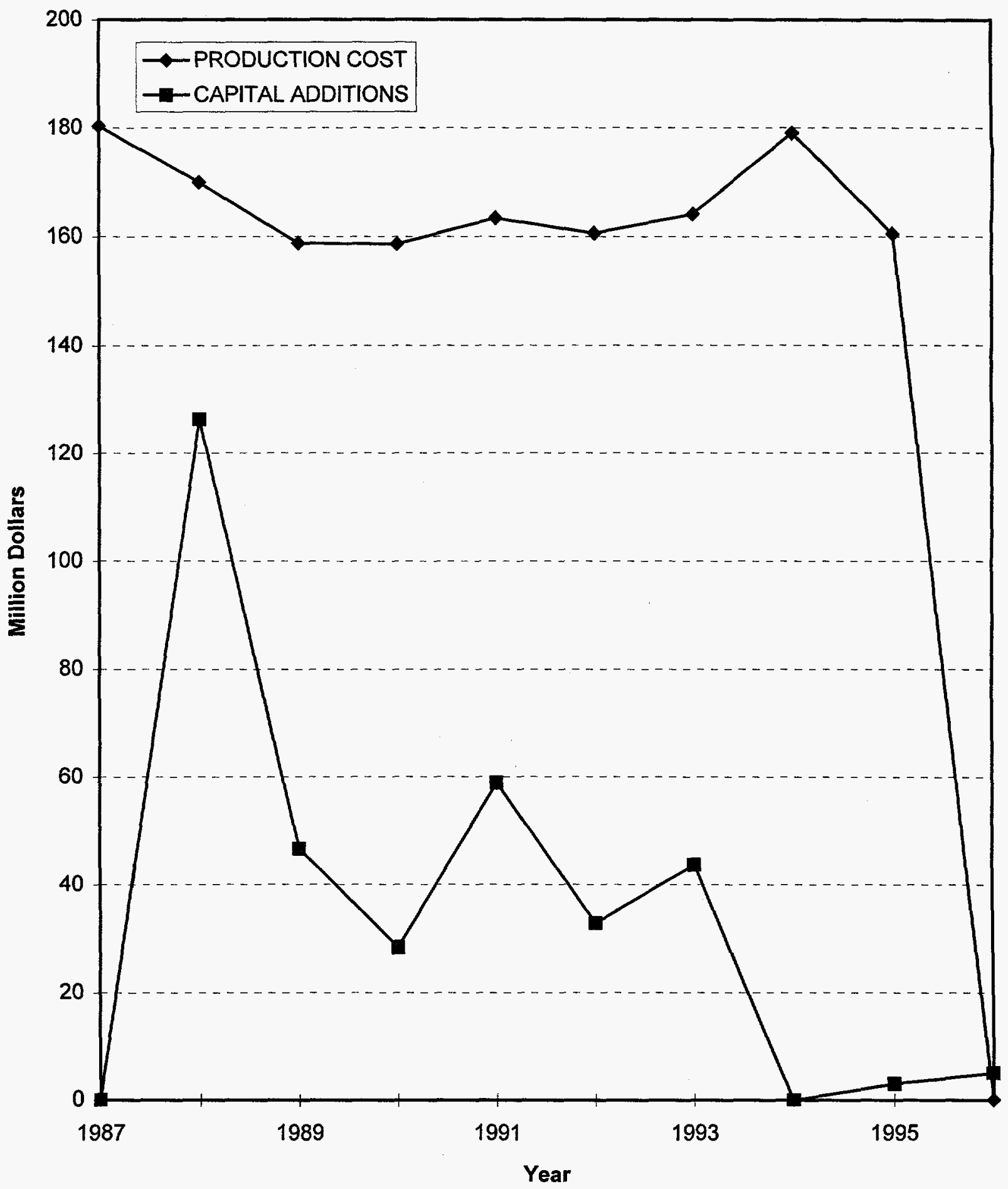




\section{NUCLEAR POWER PLANT OPERATING EXPERIENCE SUMMARY}

Unit data summary through December 1996

Unit: HOPE CREEK

Location: SALEM COUNTY, NEW JERSEY

Nameplate Rating: 1170 MWe

Owner: PUBLIC SERVICE ELECTRIC \& GAS CO.

MDC Net MWe: 1031 MWe

Type: GENERAL ELECTRIC BWR

Cumul. Avail. Factor: 82.5

Construction Permit: 11/4/74

Cumul. Cap. Factor (MDC Net): $\mathbf{8 1 . 0}$

Operating License: 7/25/86

Cumul. Forced Outage Rate: 4.8

Commercial Oper. Date: 12/20/86

3-Year Avg. Cap. Factor (MDC Net): 77.2

License Expiration: 2026

OPERATING HISTORY (To December 1996)

Date

May 1986

Mar 1987

Sep - Oct 1987

Oct - Nov 1987

Feb - Apr 1988

Feb 1989

Mar 1989

Sep - Nov 1989

Jan 1990

Mar 1990

\section{Comment}

During low power testing, a site alert was declared when an improper switchyard breaker lineup caused a LOSP.

One of four $500 \mathrm{kV}$ transmission lines carrying power from Hope Creek and the adjacent Salem nuclear units was destroyed by a drifting oil tanker on the Delaware River. The unit was limited to $90 \%$ power until a new unit trip scheme was installed in late March. The scheme allowed Salem 1 to operate at $100 \%$ and Salem 2 and Hope Creek to operate at $90 \%$ until July, when power was raised to $100 \%$.

The unit was shut down for a planned surveillance outage. Through-wall cracks were found in small piping in the recirculation system. Total outage time was 23 days.

The unit was shut down when a main transformer caught fire, causing an outage of 14 days to replace the transformer.

The first refueling and maintenance outage lasted 64 days. Major work included replacement of main generator retaining rings, one DG overhaul, CRDM modifications, and replacement of 25 control rod blades.

A scheduled mid-cycle maintenance and surveillance outage lasted 17 days. Major work included one DG overhaul, CRD maintenance, SW system piping upgrade, and circulating water system control upgrade.

The plant became first BWR to put into operation a volume reduction and solidification system for radioactive waste.

The second refueling and maintenance outage lasted 64 days. Major work included LP turbine changeout, more SW system piping modifications, one DG overhaul, and CRD overhaul.

A 4-day outage followed a reactor scram/turbine trip due to the MSR level controllers not being tuned properly.

A condensate system trip, caused by a low voltage transient due to the flashover between two power line phases from a marsh fire, resulted in a reactor scram. The unit was shut down for 8 days. 
Jun 1990

Oct 1990

Nov 1990

Dec 1990 - Feb 1991

Feb 1991

May 1991

Mar 1992

Apr 1992

May 1992

Sep - Nov 1992

1993

Mar - Apr 1994

May 1994

Aug 1994

Oct 1994

Mar 1995

Jul 1995

Jan 1996

Nov 1995 - Mar 1996

Jun 1996

Oct 1996

Nov 1996
The plant license was amended to allow new high density spent fuel storage racks to be installed which increased spent fuel capacity from 1290 FAs to more than 4006.

The plant earned Category 1 ratings in six of seven reporting categories in NRC SALP review.

A single MSIV closed due to a failed fitting on the gas supply line to the valve. A reactor scram followed the MSIV closure and the unit was shut down for 11 days.

The third refueling and maintenance outage lasted 55 days. Major work included ISI of recirculation piping. Cracks were found in two recirculation pipe welds and repaired.

The unit was shut down twice for a total outage time of 9 days. The first was due to a level transient during transfer of FW control modes and led to replacement of all Agastat GS relays. The second was to repair a hydrogen leak on the main generator.

A 4-day outage occurred following a reactor scram on low water level when a current source was connected to the wrong transmitter.

A scheduled maintenance outage lasted 10 days.

The NRC SALP report awarded the top Category 1 rating in five of the seven functional areas.

A 5-day outage was necessary to correct excessive suppression chamber-to-drywell-vacuumbreaker leaks.

The fourth refueling and maintenance outage lasted 59 days.

The unit only had two outages of 4 days or more, totaling 10 days of outage.

The fifth refueling and maintenance outage lasted 53 days.

The unit was shut down for 6 days after a scram occurred during testing of the digital feedwater control system.

Two automatic scrams caused the unit to be off-line for 4 days.

The unit was scrammed due to a design error in the digital feedwater control system. The unit also scrammed during restart due to turbine EHC problems. The unit was down for 10 days.

During a surveillance test, both recirculation MG sets tripped. A manual reactor scram was performed because both recirculation pumps were lost.

The unit was shut down for 17 days to correct problems with the control ventilation system.

The plant was placed on the NRC's list of plants with declining trend of performance.

The sixth refueling and maintenance outage lasted 135 days.

The plant was removed from the NRC's declining trend list.

The NRC proposed and the licensee paid a $\$ 150,000$ fine for violations involving lack of planning, corrective actions, and safety evaluations.

Repair of a recirculation pump seal required a 6-day outage. 
This Page Intentionally Left Blank 


\section{INDIAN POINT 2}

PRODUCTION COST and CAPITAL ADDITIONS (1996 Dollars)

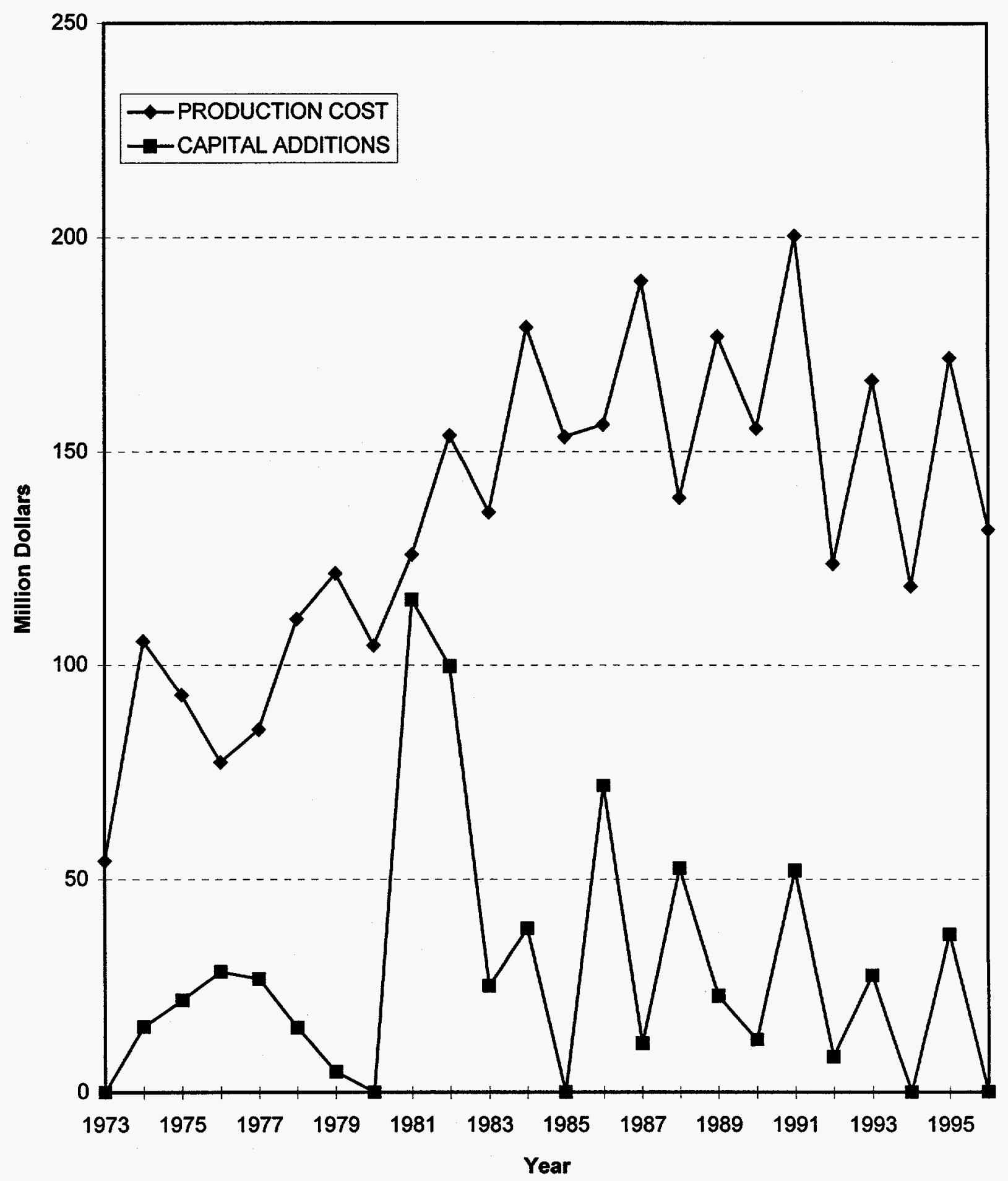




\title{
NUCLEAR POWER PLANT OPERATING EXPERIENCE SUMMARY
}

\author{
Unit data summary through December 1996
}

Unit: INDIAN POINT 2

Location: WESTCHESTER COUNTY, NEW YORK

Owner: CONSOLIDATED EDISON CO. OF N.Y.

Type: WESTINGHOUSE PWR

Construction Permit: 10/14/66

Operating License: $9 / 28 / 73$

Commercial Oper. Date: 8/1/74
Nameplate Rating: 1013 MWe

MDC Net MWe: 951 MWe

Cumul. Avail. Factor: $\mathbf{7 0 . 5}$

Cumul. Cap. Factor (MDC Net): 65.9

Cumul. Forced Outage Rate: 6.1

3-Year Avg. Cap. Factor (MDC Net): 82.0

License Expiration: 2013

OPERATING HISTORY (To December 1996)

Date

Oct 1971

Nov 1971

Feb 1972

Apr - Sep 1972

Oct 1972

Dec 1972 - Sep 1973

Oct 1973 - Jan 1974

Apr 1974

Aug 1, 1974

Mar - Sep 1976

Sep 1976

Dec 1976

Jun - Oct 1979

\section{Comment}

The plant started fuel load about 3 years behind schedule because of construction delays. Fire set by an arsonist cost about $\$ 5$ million and created a three month delay.

Because of fish kill, the state of New York forced suspension of operation of circulating water pumps until modifications were made to intake structure.

Further delays occurred because of sticking control rods, intervenor charges of inadequate RV and SG supports, and fuel collapse problems (see Ginna).

AEC recommended that plant abandon once-through cooling and switch to closed cycle cooling system by 1978 .

Full term licensing hearings occurred. Approval for full power finally was granted in late September 1973.

Several outages occurred because of exciter repair, CRDM problems, and a FW line crack repair. The plant operated for 3 days after last outage before a mild water hammer event occurred, shutdown lasted for about 7 weeks for subsequent tests and analysis.

ASLAB moved the once-through cooling termination date back to May 1979.

The plant was declared commercial.

The first refueling and maintenance outage was performed. NRC assessed $\$ 20,850$ fine for alleged overexposure to an individual during the outage. The utility requested an extension of the termination date for once-through cooling to May 1981. The village Board of Buchanan, N.Y. petitioned for a 10-year delay on construction of cooling towers because of "visual pollution."

Spurious valve closure during startup following an outage caused overpressure of RPV.

A 7-year biological study concluded that the impact on Hudson River fish life would be insignificant if operation continued with once-through cooling.

The refueling and maintenance outage was performed. A loose object was found in the bottom of the RPV; an operator was killed in fork lift accident; another loose object in the $R P V$ was indicated by instrumentation. 
Oct 1980

Jan - May 1981

Dec 1981

Aug 1982

Sep 1982 - Jan 1983

Jun 1983

Jun - Aug 1983

Nov 1983

Jun - Oct 1984

Jan - May 1986

Oct 1987 - Jan 1988

Jan 1,1988

Aug 1988

Nov 1988

Mar - Jul 1989

Oct - Nov 1989

Feb - Jun 1990

Apr 1990

Feb - Jul 1991
The reactor vessel cavity flooded. The plant was shut down to evaluate damage, make some TMI modifications, and refuel.

Loose objects were found in the RPV; FAs were damaged. The source of loose objects was found to be a RCP labyrinth seal; RCP was replaced due to high vibration.

The NRC proposed $\$ 40,000$ fine for alleged deficiencies in radiation exposure records of contractor personnel who worked at the plant.

High density storage racks for spent fuel were installed.

A refueling and maintenance outage lasted 104 days. The NRC proposed fines totaling $\$ 180,000$ for alleged violations in employee radiation protection, physical security, and reactor operations.

The NRC voted to allow units to continue operation after FEMA accepted utility emergency evacuation plans and local governments agreed to complete their own plans.

A strike was held by members of Utility Workers of America. Management personnel operated the plant without incident.

The NRC assessed $\$ 40,0.00$ fine for alleged inoperability of containment spray systems for about 1 month, during which time the reactor was started up five times.

A refueling and maintenance outage was performed. Vessel underwent a 10-year ISI; SGs and turbine were inspected; and ILRT was performed. Flaws were found in RPV by ISI. The unit was allowed to continue operation because the flaw size was less than maximum permitted; however, an augmented ISI program was required.

A refueling and maintenance outage lasted 132 days.

A refueling and maintenance outage lasted 110 days. Major work included RPV ISI, SG inspection and sludge lancing, RCP seal work, HP turbine rotor replacement, electrical splice inspection, plus other maintenance.

SG No. 3 boiled dry, NRC put a hold on startup to investigate. On January 14, startup efforts again were delayed by failure of RHR pump seal.

The plant exceeded SW intake temperature limits because of hot weather and inverse tides that brought Unit 3 discharge into Unit 2 intake; NRC granted a TS change to raise SW limit from $85 \mathrm{~F}$ to $90 \mathrm{~F}$.

The NRC assessed $\$ 75,000$ fine for alleged failure to have documentation of equipment $\mathrm{EQ}$.

A refueling and maintenance outage lasted 88 days. In May, the utility requested permission to operate at full power after 15 years of $90 \%$ capacity.

Repair of an SG inspection port weld leak required a 23-day outage.

SG girth weld problems caused a 119-day outage; crack indications were found in all four SGs. The utility had to submit to NRC an evaluation of SG condition for continued operation prior to restart.

The NRC imposed a $\$ 50,000$ fine for alleged violations in emergency plan revisions; a $\$ 75,000$ fine for alleged inadequacies in record keeping was also assessed.

The tenth refueling and maintenance outage lasted 164 days. Major work included SG ECT, RCP seal and motor replacement, HP turbine and DG upgrades, condenser retubing, SG 10-yr ISI, MOV testing and ILRT. 
Apr 1991

Nov 1991

Sep 1992

Jan - Apr 1993

May 1993

Feb - Jun 1995

Jun 1995

Feb 1996
The NRC proposed a $\$ 62,500$ fine for alleged failure to follow maintenance procedures and falsification of documents.

The unit had a 6-day outage to repair condenser tube leaks.

The unit was shut down for 5 days for condenser repairs.

The eleventh refueling and maintenance outage lasted 82 days.

A 9-day outage to remove a loose part from a SG.

The twelfth refueling and maintenance outage lasted 122 days.

Following restart, the unit required 2 short maintenance outages totaling 5 days.

A scheduled maintenance outage for repairing leaking valves lasted 13 days. 
INDIAN POINT 3

PRODUCTION COST and CAPITAL ADDITIONS (1996 Dollars)

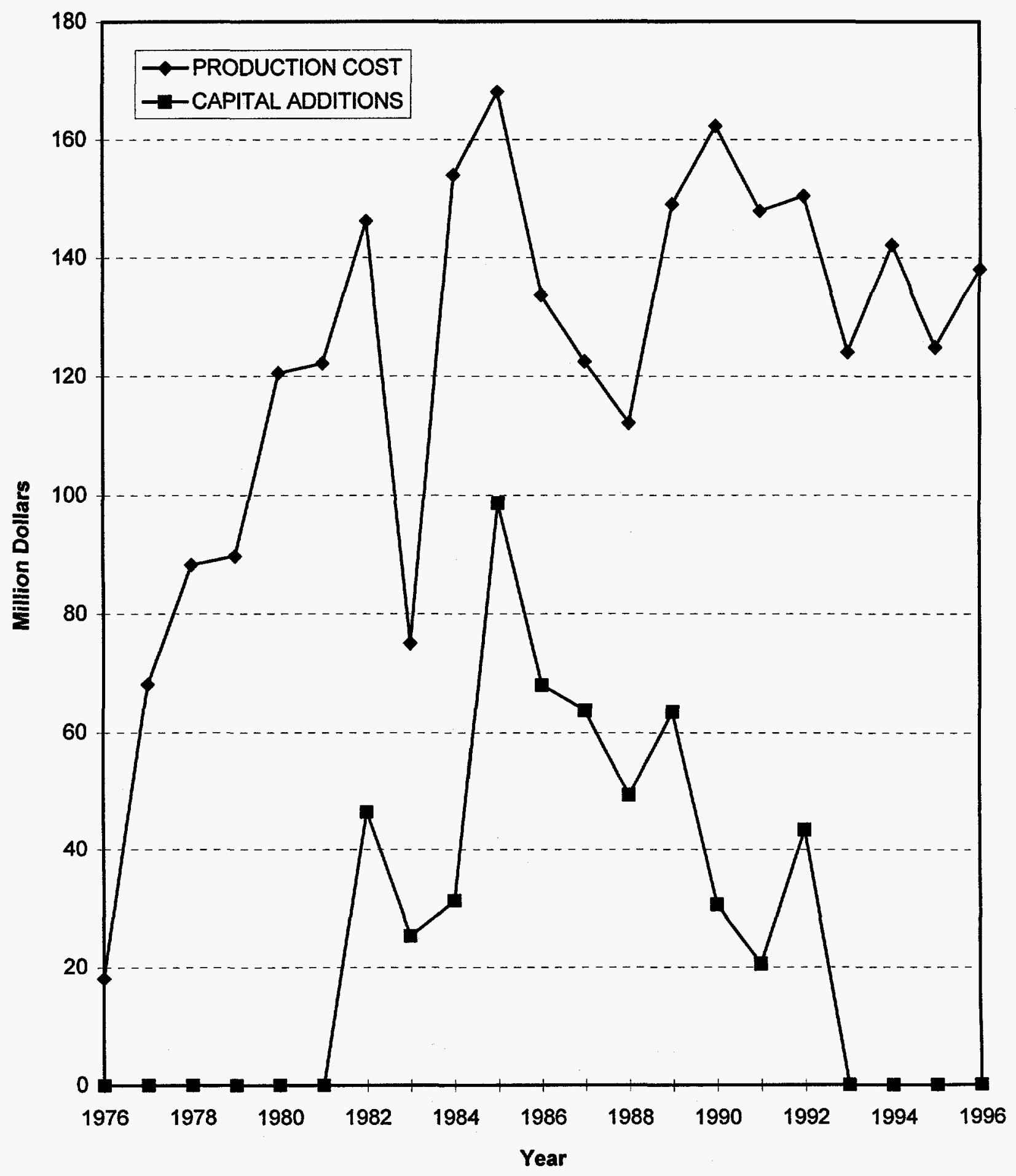


NUCLEAR POWER PLANT OPERATING EXPERIENCE SUMMARY

Unit data summary through December 1996

Unit: INDIAN POINT 3

Location: WESTCHESTER COUNTY, NEW YORK

Owner: NEW YORK POWER AUTHORITY

Type: WESTINGHOUSE PWR

Construction Permit: 8/13/69

Operating License: $4 / 5 / 76$

Commercial Oper. Date: 8/30/76
Nameplate Rating: 1013 MWe

MDC Net MWe: 965 MWe

Cumul. Avail. Factor: $\mathbf{5 4 . 7}$

Cumul. Cap. Factor (MDC Net): 49.7

Cumul. Forced Outage Rate: 29.5

3-Year Avg. Cap. Factor (MDC Net): 28.9

License Expiration: 2015

OPERATING HISTORY (To December 1996)

Date

Jan 1, 1976

Mar 1978

Sep 1979 - Feb 1980

Sep - Dec 1980

Mar 1982 - Jun 1983

Apr - May 1983

Jun 1983 - Jan 1984

Oct - Nov 1984

Jun - Oct 1985

Jul - Sep 1986

Jan 1987

May - Sep 1987

\section{Comment}

The New York Power Authority acquired the unit; Consolidated Edison Co. remained the authorized operator.

The Power Authority of the State of New York assumed operating responsibility for the unit.

The refueling outage was extended to allow work on main turbine. Power was restricted to 917 MWe because two rows of blades on LP turbine had been removed.

A turbine caused an repair outage; TMI modifications and fire system changes were made. Startup was delayed 13 days to replace shorted RCP motor.

A 440-day outage to repair steam generator tubes was necessary. About 2800 of 13,000 SG tubes had pitting to a depth of $40 \%$ of wall thickness. SG girth welds also needed repairing

The utility requested NRC to amend license to double number of SG tubes allowed out of service while operating; the amendment was granted in May.

Melted windings in main generator caused a 227-day outage for repair. A strike occurred from June to August by members of Utility Workers of America; management personnel operated the plant without incident. In June, NRC voted to allow units to continue operation after FEMA accepted utility emergency evacuation plans and local governments agreed to complete their own plans. During final hearings, ASLB recommended that Unit 3 install a loose parts monitoring system.

A mid-cycle outage of 46 days was required for SG inspection.

A refueling and maintenance outage lasted 119 days. Condenser tubes were replaced with tubes made of titanium.

A 61-day outage for LP turbine repair was needed.

The NRC assessed a $\$ 50,000$ fine for a incident in September 1986 in which the plant was taken above $200^{\circ} \mathrm{F}$ with both recirculation pumps and both containment spray pumps inoperable.

A refueling outage and a 10-year ISI of RPV occurred. ISI revealed three indications in vessel longitudinal weld; the utility was to investigate. 
Jul 1988

Sep 1988

Feb - Jun 1989

Aug 1989

Mar 1990

Apr 1990

Sep - Dec 1990

Dec 1990

Mar 1991

May 1991

Oct 1991

Mar 1992

Apr - Aug 1992

May 1992

Sep 1992

Sept 1992

Jun 1993

Feb 1993 - Jun 1995

Sep 1995 - Apr 1996
The NRC gave the unit the highest SALP rating for radiological control.

The NRC assessed a $\$ 75,000$ fine for failure to have documentation of EQ for cable connectors, terminal blocks, and other types of electrical equipment.

A refueling and maintenance outage lasted 140 days. Major work included replacement of all four SGs. SG replacement cost was about $\$ 120$ million; total personnel exposure was $<550$ person-rem, the lowest dose to date for a U.S. SG changeout.

The NRC assessed a $\$ 25,000$ fine for alleged personnel security violations.

A scheduled maintenance outage lasted 37 days.

The NRC assessed a $\$ 50,000$ fine for alleged security violations regarding personnel and package search and degraded security systems.

The seventh refueling and maintenance outage was performed. Two fuel assemblies stuck in the upper internals when the internals were lifted. The guide pins in the upper internals had been bent during the refueling in May 1989 .

The NRC assessed a $\$ 50,000$ fine for alleged operator inattentiveness; two operators had been observed sleeping. Although the utility contested the condition, the NRC imposed the fine, and it was paid in May 1991.

High vibration on the main turbine bearings required a 9-day outage.

A 12-day outage was needed to replace the seal packing on a RCP.

A 16-day outage followed a high dew point indication in the main generator.

The unit was shut down for 5 days to repair primary and secondary boric acid heat trace circuits.

The eighth refueling and maintenance outage lasted 74 days.

The NRC assessed a $\$ 225,000$ fine for multiple violations. The failure to correct a design deficiency in the $480-\mathrm{V}$ electrical buses and inoperability of the boric acid heat trace system. The penalties were both escalated because of past poor performance. The fine was not contested.

The NRC assessed a $\$ 100,000$ fine for SW system leaks that were found by the plant staff but not correctly evaluated and repaired. The fine was doubled because of NRC identification and past poor performance.

The unit was shut down for 27 days after problems developed with the level controller for one of the SGs.

The unit was added to the NRC problem plant list.

The NRC proposed and the utility did not contest a $\$ 300,000$ fine for alleged violations involving (1) the design, installation, and testing of the unit ATWS mitigation system; (2) violations of plant procedures during testing of the RCS level instrumentation; and (3) multiple violations of Tech Specs. The penalties could have been higher, but the NRC did not escalate the amount due to the utility's decision to shut down the plant after the ATWS problem was discovered and to implement a performance improvement program.

The unit was shut down due to a hydrogen leak in the main generator. The unit remained shut down to correct persistent plant performance problems. This outage lasted 200 days. 


\section{INDIAN POINT 3 (Cont'd)}

Apr 1996

Jan 1996
The unit was shut down for 4 days following a manual scram due to high temperature in the main generator.

The NRC proposed and the licensee paid a $\$ 50,000$ fine for performing a reactor mode change with control switches in the wrong position. 


\section{KEWAUNEE}

PRODUCTION COST and CAPITAL ADDITIONS

(1996 Dollars)

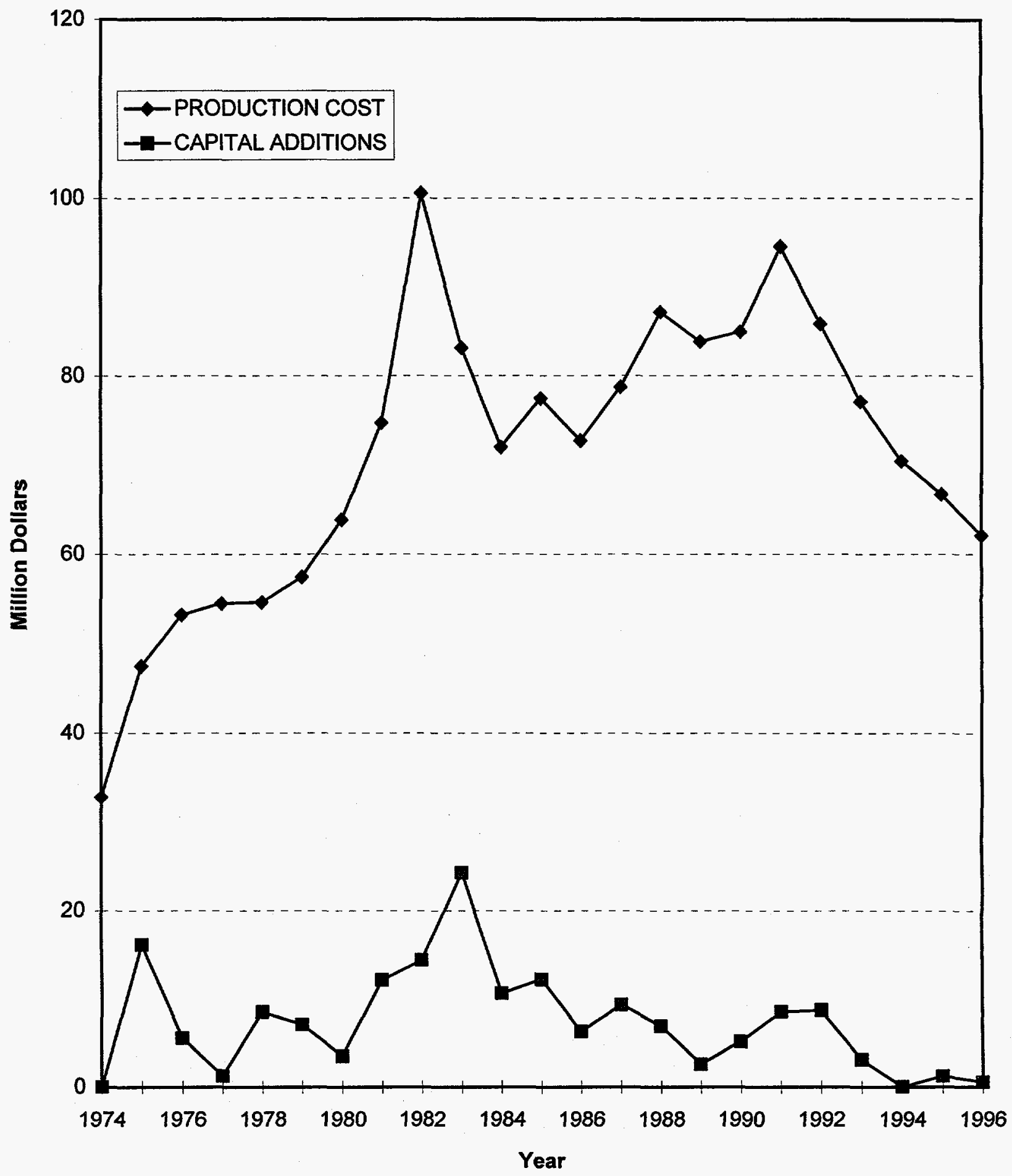




\section{NUCLEAR POWER PLANT OPERATING EXPERIENCE SUMMARY}

Unit data summary through December 1996

Unit: KEWAUNEE

Location: KEWAUNEE COUNTY, WISCONSIN

Owner: WISCONSIN PUBLIC SERVICE CORP.

Type: WESTINGHOUSE PWR

Construction Permit: 8/6/68

Operating License: $12 / 21 / 73$

Commercial Oper. Date: $6 / 16 / 74$
Nameplate Rating: $560 \mathrm{MWe}$

MDC Net MWe: 511 MWe

Cumul. Avail. Factor: 84.4

Cumul. Cap. Factor (MDC Net): 82.6

Cumul. Forced Outage Rate: 2.0

3-Year Avg. Cap. Factor (MDC Net): 81.3

License Expiration: 2013

OPERATING HISTORY (To December 1996)

Date

Mar - Jun 1974

Sep 1974

Oct 1974 - Jul 1975

Feb - Apr 1976

May 1976

Jan - Mar 1977

Apr - May 1978

May - Aug 1979

Jan 1980

May - Jun 1980

Apr - Jun 1981

Apr - May 1982

Mar - May 1983

Apr 1983

Mar - May 1984

\section{Comment}

After initial criticality, FW pump problems and FW heaters caused several outages during power ascension testing.

The unit was shut down for $\mathbf{3 0}$ days to clean and test SGs. The utility changed to an all-volatile secondary water treatment.

FW pump failures limited power to about $75 \%$ from October to February and mid-May to the end of July.

The first refueling and maintenance outage was completed in 8 weeks.

The unit was shut down for 11 days to replace the RPV head seal.

The second refueling outage started about 1 month early because of damage from a thrown LP turbine blade.

The third refueling and maintenance outage was performed. The NRC assessed a $\$ 7000$ fine for an alleged radiation exposure incident during an outage when a shift supervisor received a 2.8 rem dose.

The fourth refueling and maintenance outage was performed. Major work included repairs to LP turbine and generator stator, plus rework of welds on FW piping. A leaky pressurizer relief valve caused additional 7 days of outage 1 week after restart.

An 11-day outage was caused by transformer bushing failure.

The fifth refueling and maintenance outage was performed.

The sixth refueling and maintenance outage was performed.

The seventh refueling and maintenance outage was performed.

The eighth refueling and maintenance outage was performed. Major work included total inspection of SGs and plugging of leaky tubes. Total outage time was 58 days.

The NRC assessed a fine of $\$ 30,000$ for alleged violation involving erroneous capping of all 10 containment pressure sensing lines.

The ninth refueling and maintenance outage lasted 52 days. 


\section{KEWAUNEE (Cont'd)}

Jan 1985

Feb - Apr 1985

Feb - Apr 1986

Mar 1986

Dec 1, 1986

Feb - Apr 1987

Feb - Apr 1988

Feb - Apr 1989

May 1989

Jun 1989

Mar - Apr 1990

Aug 1990

Mar - May 1991

Mar - Apr 1992

Mar - Apr 1993

Jun 1993

Jan 1994

Apr - May 1994

Apr - May 1995

May 1995

Jul 1995
About 2500 gallons of water was introduced into the containment building by accidental actuation of containment spray system.

The tenth refueling and maintenance outage lasted 62 days.

The eleventh refueling and maintenance outage lasted 50 days. Major work included replacing 4 of $10 \mathrm{FW}$ heaters.

The NRC reduced its inspection program at the plant based on continuing superior regulatory performance.

The plant set a U.S. reliability record when it exceeded 200 continuous days of operation for the fifth time. The plant had averaged about 1 day of forced outage time annually during the previous 5 years of operation.

The twelfth refueling and maintenance outage lasted 38 days. Major work included replacing the No. 1 LP turbine rotor.

The thirteenth refueling and maintenance outage lasted 40 days. Major work included SG examination and sleeving, overhaul of HP turbine, and replacement of plant process instrumentation.

The fourteenth refueling and maintenance outage lasted 51 days. The unit was shut down earlier than planned because of SG leakage. Major work included SG inspection, tube sleeving, plugging and sludge lancing, rebuilding of FW pump motor, inspection of turbine and stop valves, replacement of RCS RTDs, and overhaul of incore instrumentation.

The NRC granted the utility's request to defer license expiration date to 2013 from 2008 in order to count plant life from the full power license date.

NRC cited the plant as one of the top nuclear power plant performers.

The fifteenth refueling and maintenance outage lasted 45 days. Major work included SG tube plugging and sludge lancing, battery replacement, MOV testing, SW system chemical cleaning, DG overhaul, ILRT, and replacement of some RCS internals.

The NRC again cited the plant as one of the top nuclear power plant performers.

The sixteenth refueling and maintenance outage lasted 62 days. Major work included SG tube recovery project where previously plugged tubes were returned to service via sleeving. Tube plugging percentage was reduced from $12.2 \%$ to $9.1 \%$.

The seventeenth refueling and maintenance outage lasted 42 days. Major work included plugging and sleeving of SG tubes and replacement of a RCP motor.

The eighteenth refueling and maintenance outage lasted 41 days.

A scheduled 7-day outage was requested to repair leaking SG tubes.

A scheduled 6-day outage was required to repair the pressurizer manway.

The nineteenth refueling and maintenance outage lasted 36 days.

The twentieth refueling and maintenance outage lasted 45 days.

The plant received all Category 1 ratings on its NRC SALP report, and the evaluations were lengthened to a 24-month cycle.

The plant was recognized by the NRC as a superior performer. 
Sep - Dec 1996

The twenty-first refueling and maintenance outage was performed. At the end of the review period, the unit remained shut down. Problems with welding the SG tube sleeves by the contractor, Westinghouse, forced the unit to remain shut down. 


\section{LASALLE}

PRODUCTION COST and CAPITAL ADDITIONS

(1996 Dollars)

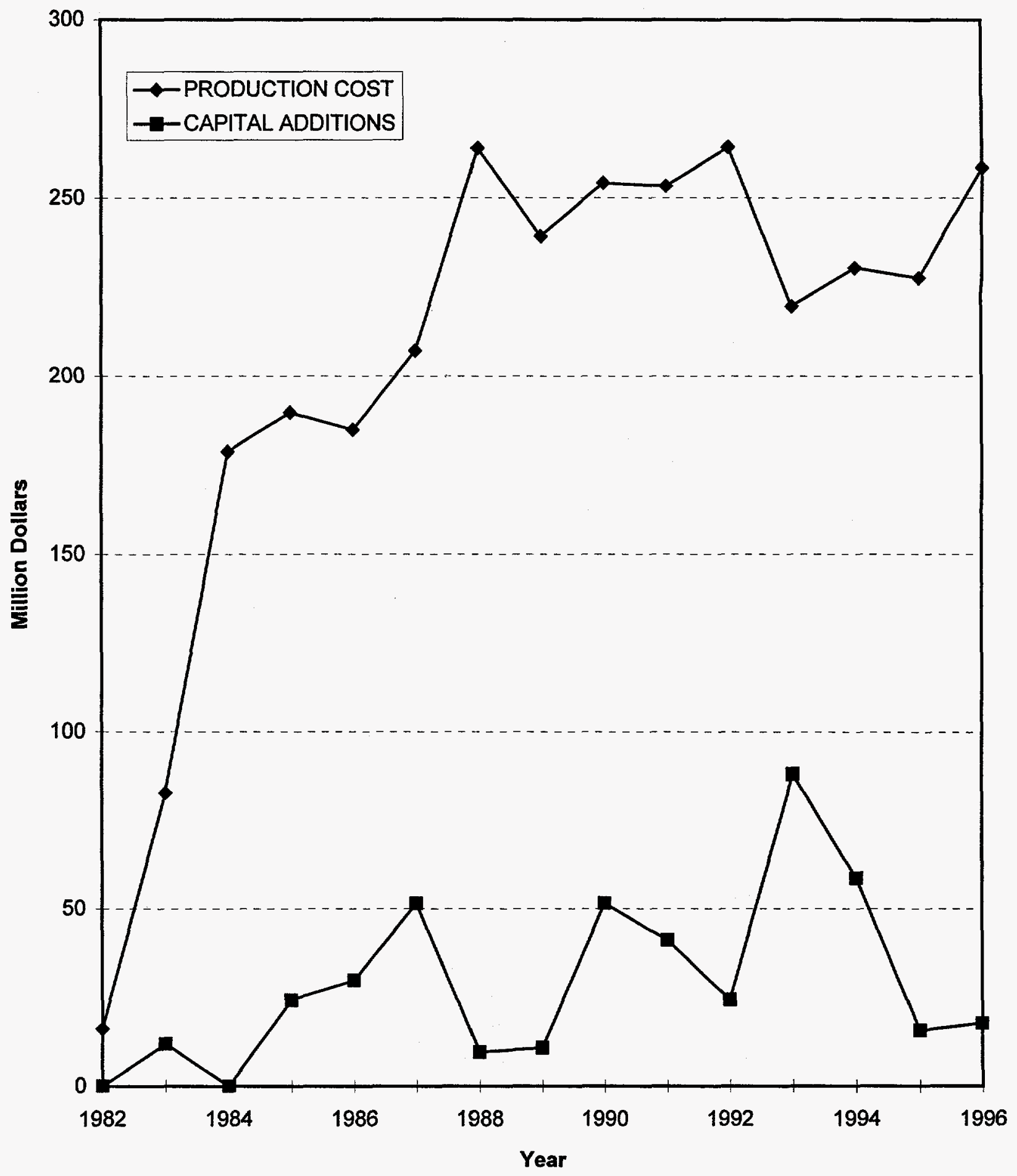




\section{NUCLEAR POWER PLANT OPERATING EXPERIENCE SUMMARY}

Unit data summary through December 1996

Unit: LASALLE 1

Location: LA SALLE COUNTY, ILLINOIS

Nameplate Rating: 1146 MWe

Owner: COMMONWEALTH EDISON CO.

MDC Net MWe: 1036 MWe

Type: GENERAL ELECTRIC BWR

Cumul. Avail. Factor: 67.4

Construction Permit: 9/10/73

Cumul. Cap. Factor (MDC Net): 62.4

Operating License: $\mathbf{8 / 1 3 / 8 2}$

Cumul. Forced Outage Rate: 9.2

Commercial Oper. Date: 1/1/84

3-Year Avg. Cap. Factor (MDC Net): 60.9

License Expiration: 2022

OPERATING HISTORY (To December 1996)

Date

Jul - Dec 1982

Aug 1982

Dec 1982

Dec 1982 - Feb 1983

Feb 1983

Mar - May 1983

Aug - Sep 1983

Nov 1983 - Jan 1984

Dec 1983

Jan 1984

Jan - Mar 1984

Sep - Nov 1984

\section{Comment}

The unit was initially limited to $50 \%$ power by the NRC until an evaluation of reactor building integrity was performed. A subcontractor allegedly drilled through reinforcing steel bars during construction.

The unit was shut down due to seal failure on a recirculation pump.

The reactor building integrity issue was resolved and NRC lifted the $50 \%$ power limitation. Another $50 \%$ limitation was imposed by the NRC because only one recirculation pump was operable.

The unit was shut down for 52 days to repair a sticking RHR valve and a steam leak in RCIC system. Repairs to prevent excessive vibration on an RHR pump further prolonged the outage.

Repair of main steam line leaks forced two outages - one for 4 days and one for 17 days. The cause of both leaks was determined to be cracked welds.

The unit was shut down on three different occasions because of RV level and IRM scrams. Total outage time was 54 days.

The unit was shut down for $\mathbf{3 4}$ days after low RV water level scram.

The unit was shut down for 60 days after problems developed with oil circuit breakers during testing.

NRC assessed a $\$ 60,000$ fine for alleged inoperability of certain vacuum breakers during operation.

The utility paid a $\$ 10,000$ fine to the NRC for allegedly permitting a passageway to exist between Unit 1 and Unit 2 that allowed access to Unit 1 vital areas. The unit entered commercial operation on January 1.

A failed rubber boot on the main condenser caused two outages totaling 33 days. An outage for evaluation of temporary drywell ventilation ductwork forced 12 days of shutdown time.

A planned maintenance outage lasted 58 days. 
Mar 1985

Jul 1985

Oct 1985 - Sep 1986

Nov 1985

Dec 1985

Apr 1986

May - Sep 1987

Mar - Jul 1988

Sep 1989 - Jan 1990

Jun 1990

Feb - May 1991

Mar 1992

Oct 1992 - Jan 1993

Feb - Mar 1993

Oct 1993

Nov 1993

Jan 1994

Jan 1994
The NRC proposed a $\$ 25,000$ fine for alleged inoperability of both SGTS trains during unit operation. The unit was ordered to remain shut down after a scram involving improper installation of RHR vent lines. The utility had to correct the problems before restart. Total outage time was 18 days.

The unit was shut down for 16 days to make corrections to mis-installed RHR flow switches and corresponding design drawings.

The first refueling and maintenance outage was performed (approximately 11 months), major work included EQ modifications and Limitorque valve motor inspections. Numerous failed snubbers were replaced, and RHR piping leaks were repaired. Startup was delayed because of problems found with SOR brand reactor level switches in Unit 2.

The NRC proposed a $\$ 37,500$ fine for alleged violations involving disposal of security system badges.

The NRC proposed a $\$ 125,000$ fine for alleged violations involving the improper installation of RHR piping and level switches at Unit 1 and Unit 2.

The utility paid a $\$ 50,000$ fine to the NRC for alleged inoperability of two divisions of ECCS during operation in October 1985.

The unit was shut down after low RV water level scram and remained down for recirculation pump repairs and scheduled surveillance testing. Total outage time was 110 days.

The second refueling and maintenance outage lasted 117 days. Major work included modifications to drywell cooling and SDVs, work on snubber reduction program and LLRT.

The third refueling and maintenance outage lasted 117 days. Major work included additional modifications to drywell cooling system, installation of a new RPS, and replacement of station batteries.

The unit was shut down due to a turbine stop valve limit switch failure and remained in an outage to plug condenser tubes. Total outage time was 6 days.

The fourth refueling and maintenance outage lasted 85 days. Major work included installation of a new analog reactor trip system, and replacement of two station batteries and the FW control system.

The unit was shut down for 4 days following a reactor scram when the steam seal evaporator condenser level controls failed.

The fifth refueling and maintenance outage lasted 109 days. Major work included installation of digital FW level control system, ILRT, and snubber reduction and testing. The outage was extended by 14 days to replace all three LP turbine rotors.

The unit was shut down three times to repair RCIC system valves. The total outage was 14 days.

The unit was shut down for 23 days after the system auxiliary transformer was lost.

The NRC proposed a $\$ 112,500$ fine for alleged violations involving radiation protection, specifically the contamination of 22 workers while opening the reactor vessel during refueling activities.

A 9-day outage was needed to replace a recirculation pump seal.

The plant was added to the NRC's declining trend list. 


\section{LASALLE 1 (Cont'd)}

Feb - Jun 1994

Apr 1994

May 1994

Jul 1994

Dec 1994

Feb 1995

Jun 1995

Aug 1995

Sep 1995

Jan - May 1996

May 1996

Jun - Jul 1996

Sep 1996
The sixth refueling and maintenance outage lasted 101 days. The unit had been shut down for 28 days prior to starting the refueling outage for repair of a main condenser boot seal.

The NRC proposed a $\$ 75,000$ fine for alleged violations involving lubrication of some circuit breakers and HVAC dampers.

The NRC proposed a $\$ 225,000$ fine for alleged violations involving radiation protection, including two instances of apparent deliberate contamination of workers' clothing with lowlevel radioactive materials.

The unit was shut down for 6 days due to two reactor scrams caused by feedwater level control problems.

The unit was shut down twice for a total of 9 days. The first outage resulted from an MSIV isolation during surveillance testing; the second was due to problems with the rod position indication system.

A 6-day outage was necessary to repair a $\mathrm{RCIC}$ valve.

The plant was removed from the NRC's declining trend list.

A 1-week forced outage was required to replace MSIV solenoids.

A MSIV isolation due to high steam tunnel temperature caused a reactor scram. The high temperatures were caused by loss of the reactor building ventilation system. The unit was off-line for 6 days.

The unit was down for 4 days following a manual scram when one of the main feed pumps tripped during surveillance testing.

The seventh refueling and maintenance outage lasted 103 days.

The unit was shut down for 5 days due to high vibration in one of the main turbine's bearings.

The unit scrammed after an MSIV isolation occurred. The unit remained shut down due to foreign material in the service water systems from maintenance activities. The outage lasted 18 days. An AIT was sent to the site and found poor work control was the cause of the event. The NRC later proposed and the licensee paid a $\$ 650,000$ fine for the incident.

The unit was shut down due to problems with one of the main turbine control valves. Due to numerous engineering concerns, both LaSalle units shut down to upgrade design and resolve personnel problems. Both units are scheduled to remain shut down until the spring of 1998. 


\section{NUCLEAR POWER PLANT OPERATING EXPERIENCE SUMMARY}

Unit data summary through December 1996

Unit: LASALLE 2

Location: LA SALLE COUNTY, ILLINOIS

Nameplate Rating: $1146 \mathrm{MWe}$

Owner: COMMONWEALTH EDISON CO.

MDC Net MWe: $1036 \mathrm{MWe}$

Cumul. Avail. Factor: $\mathbf{7 1 . 0}$

Type: GENERAL ELECTRIC BWR

Cumul. Cap. Factor (MDC Net): 66.8

Construction Permit: 9/10/73

Cumul. Forced Outage Rate: 10.0

Operating License: $\mathbf{3 / 2 3 / 8 4}$

3-Year Avg. Cap. Factor (MDC Net): 73.6

Commercial Oper. Date: 10/19/84

License Expiration: 2023

OPERATING HISTORY (To December 1996)

Date

Aug 1984

Feb - Jul 1985

Oct - Dec 1985

Jun - Aug 1986

Jan - Jun 1987

Mar 1988

Oct 1988 - Feb 1989

Aug - Sep 1989

Mar - Jun 1990

Sep 1990

Dec 1990

Sep 1991

\section{Comment}

A main generator stator winding fault caused a 13-day outage.

The unit was shut down for a 5-month planned maintenance and surveillance outage. A rupture of an underground condensate pipe released about 200,000 gallons of slightly contaminated water near the off-gas filter building.

The unit was shut down for about 2 months to complete unfinished EQ modifications and inspect Limitorque ${ }^{\circledR}$ valve motors.

The unit was shut down following a FW transient in which the RV water level decreased and only one of four SOR brand level switches actuated at the proper setpoint. The NRC ordered the unit to remain shutdown until the problem with level switches was resolved.

The first refueling and maintenance outage lasted 166 days. Major work included Limitorque ${ }^{\otimes}$ valve motor inspections and replacement of numerous failed snubbers.

The unit was scrammed after neutron flux oscillations occurred during a plant instrument functional test. The NRC investigated the event and issued IE Bulletin 88-07 and Supplement 1 plus IE Notice 88-39 in response to their findings.

The second refueling and maintenance outage lasted 118 days. Major work included drywell modifications, snubber reduction, and RHR heat exchanger work.

The unit was shut down to repair a recirculation pump seal. The shutdown was extended to repair the main generator. Total outage time was 50 days.

The third refueling and maintenance outage lasted 88 days. Major work included completion of modifications to drywell cooling system, installation of a new RPS, replacement of station batteries, ILRT, and TMI modifications.

The unit was shut down for 9 days to repair main transformer differential current relay assembly.

A 6-day outage was needed to repair tube leaks in a FW heater.

Two reactor scrams were due to turbine problems. A 5-day outage followed a reactor scram due to turbine ECH fluid leakage. The second was caused by a false overspeed signal and resulted in a 9-day outage. 


\section{LASALLE 2 (Cont'd)}

Jan - Apr 1992

Aug 1992

Sep - Dec 1993

Jan 1994

Jan 1994

Jun, Aug 1994

Oct 1994

Feb - Jun 1995

Sep 1995

Feb 1996

May 1996

Jun 1996

Sep 1996
The fourth refueling and maintenance outage lasted 100 days. Major work included LP turbine rotor replacement, ILRT, and chemical decontamination of the recirculation system.

The reactor scrammed following a turbine trip due to a faulty thrust bearing wear detector signal. After the trip, the unit experienced problems with malfunctioning main FW pumps and RCIC, which led to an NRC inspection team evaluating the various component failures. The unit was shut down for 15 days.

The fifth refueling and maintenance outage lasted 114 days.

The unit was shut down for 12 days to repair a MSIV.

The plant was added to the NRC's declining trend list.

The unit had two reactor scrams, each resulting in a 5-day outage.

The reactor scrammed due to EHC system oscillations and was shut down for 5 days.

The sixth refueling and maintenance outage lasted 113 days.

The unit was shut down for 8 days to repair one of the recirculation FCVs.

The unit was shut down for 6 days for maintenance on the main transformer and one of the turbine control valves.

EHC system problems required 4 days to correct.

The unit was shut down due to the foreign material in the service water systems. This required 17 days to correct.

The seventh refueling and maintenance outage was performed. Due to numerous engineering concerns, both LaSalle units shut down to upgrade design and personnel problems. Both units are scheduled to remain shut down until the spring of 1998. 


\section{LIMERICK \\ PRODUCTION COST and CAPITAL ADDITIONS (1996 Dollars)}

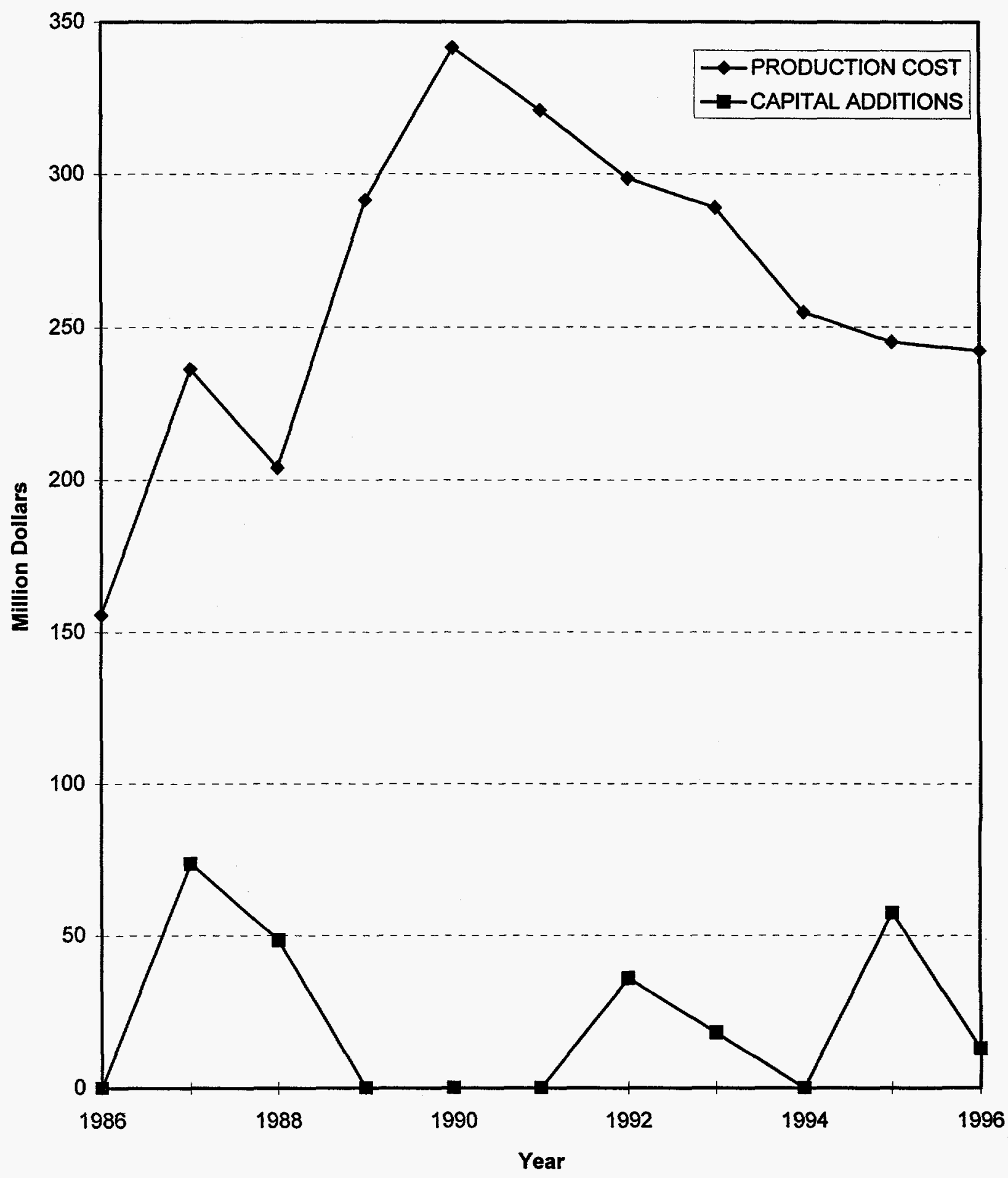




\section{NUCLEAR POWER PLANT OPERATING EXPERIENCE SUMMARY}

Unit data summary through December 1996

Unit: LIMERICK 1

Location: MONTGOMERY COUNTY, PENNSYLVANIA

Nameplate Rating: $1160 \mathrm{MWe}$

Owner: PHILADELPHIA ELECTRIC CO.

MDC Net MWe: 1105 MWe

Type: GENERAL ELECTRIC BWR

Cumul. Avail. Factor: 82.3

Construction Permit: 6/19/74

Cumul. Cap. Factor (MDC Net): 75.9

Operating License: $\mathbf{8 / 8 / 8 5}$

Cumul. Forced Outage Rate: 4.2

Commercial Oper. Date: 2/1/86

3-Year Avg. Cap. Factor (MDC Net): 85.8

License Expiration: 2024

OPERATING HISTORY (To December 1996)

Date

1985

May - Jun 1986

Jan 1987

May - Aug 1987

Mar 1988 - Jan 1989

Jan - May 1989

Aug 1989

Feb 1990

\section{Comment}

All low-power startup testing was completed by April, but full power license was held up until August 8. The Federal Court of Appeals issued a stay to full power license on August 16, and power was limited to $5 \%$. The stay was later lifted on August 21, and the unit proceeded into a full power escalation and testing program. The utility was fined $\$ 75,000$ in May by the NRC for alleged violations concerning physical protection of the plant.

The unit was shut down for a required surveillance and testing outage of 48 days.

The utility announced that unit had set a record of 198 days of continuous first cycle operation for a U.S. BWR larger than 830 MWe. The previous record was 197 days by Oyster Creek.

The first refueling and maintenance outage lasted 107 days. Major work included SGTS rework, inspection of RCS piping, SRM and IRM tubes, RV holddown bolt replacement, LLRTs, and ILRT of containment.

The unit operated at reduced power levels because of crud-induced localized corrosion of fuel pins, believed to be caused by copper fouling from the condenser tubes.

The second refueling and maintenance outage was performed in 128 days. Major work included fuel reconstitution, SGTS and SW system modifications, HPCI turbine overhaul, CRD and LPRM replacement, and numerous other equipment inspections and maintenance.

The NRC assessed a $\$ 75,000$ fine for alleged violations involving the emergency preparedness plan and its implementation. The NRC SALP report for May 1988 to August 1989 awarded the unit Category 1 ratings in all areas except engineering/technical support (Category 2), and emergency preparedness (Category 3).

Five of 14 operators failed an NRC requalification examination; NRC questioned the requalification program. 


\section{LIMERICK 1 (Cont'd)}

Jun 1990

Jun 1990

Sep - Dec 1990

Dec 1990

Apr 1991

Jun 1991

Dec 1991

Mar - Jul 1992

Sep 1993

Feb - Mar 1994

May 1995

May 1995

Jul 1995

Aug 1995

Sep 1995

Feb 1996

Mar 1996

Jul 1996
After 378 days, the longest run ever for the unit, it was shut down to perform some needed maintenance and repair to improve performance and reliability for the remainder of the fuel cycle. Total outage time was 17 days.

Later in the month, the unit was shut down for 9 days to repair a leaking MSIV air solenoid fitting and a leaking condensate demineralizer isolation valve.

The third refueling and maintenance outage lasted 100 days. Major work included LP turbine overhaul, CRD changeout, snubber inspections, LLRTs, ILRT, and CRD HCU overhaul. The outage was extended for 10 days to repair a RHR SW valve.

Repair of the RHR SW HX outlet valve required a 7-day outage.

The unit was shut down for 5 days following a main turbine trip/reactor scram due the failure of the EHC electrical power supply.

The unit was shut down for 11 days to repair a reactor recirculation valve.

HPCI valve problems caused a 13-day outage.

The fourth refueling and maintenance outage lasted 111 days.

A 6-day outage followed a reactor scram on low water level because of complications after the LOSP supply.

The fifth refueling and maintenance outage lasted 35 days. This was the shortest refueling for a domestic BWR to date.

The unit was shut down for 4 days for planned maintenance.

The plant received all Category 1 ratings on its NRC SALP report, and the evaluations were lengthened to a 24-month cycle.

The plant was recognized as a superior performer by the NRC.

The unit was shut down for 11 days to replace a failed fuel bundle. The outage had been extended 4 days due to a leak caused by a misaligned RPV instrument flange connection.

When an SRV failed to open, the plant shut down. The subsequent outage lasted 2 weeks.

The sixth refueling and maintenance outage lasted 24 days.

A 1-week outage was needed to perform SRV and TIP machine maintenance.

Two outages totaling 9 days were taken to repair SJAE leaks and due to an EHC transient. 


\section{NUCLEAR POWER PLANT OPERATING EXPERIENCE SUMMARY}

Unit data summary through December 1996

Unit: LIMERICK 2

Location: MONTGOMERY COUNTY, PENNSYLVANIA

Owner: PHILADELPHIA ELECTRIC CO.

Nameplate Rating: $1162 \mathrm{MWe}$

Type: GENERAL ELECTRIC BWR

MDC Net MWe: 1115 MWe

Cumul. Avail. Factor: 89.8

Construction Permit: 6/19/74

Cumul. Cap. Factor (MDC Net): 85.8

Operating License: $\mathbf{8 / 2 5 / 8 9}$

Cumul. Forced Outage Rate: 3.6

Commercial Oper. Date: 1/8/90

3-Year Avg. Cap. Factor (MDC Net): 90.3

License Expiration: 2029

OPERATING HISTORY (To December 1996)

Date

Jan 1984 - Feb 1986

Jan 1990

Mar 1990

Jun 1990

Jul 1990

Aug 1990

Sep 1990

Mar - Jun 1991

Dec 1992

Jan - Mar 1993

Jan - Feb 1995

Aug 1995

Dec 1996

\section{Comment}

Construction of Unit 2 was halted under a state PUC order until Unit 1 went commercial in 1986. Construction resumed with a PUC-mandated cap of $\$ 3.2$ billion dollars on construction cost. The utility reported that the final unit cost was $\$ 300$ million less than limit.

The unit set a new BWR record of 200 days for elapsed time between granting of fuel load license and start of commercial operation. The unit went from fuel load to full power in 151 days with no unplanned shutdowns.

A 7-day outage followed shutting down the unit after the reactor water conductivity spiked.

The unit was shut down for 21 days to repair a leak in the condensate filter demineralizer system and a RWCU system valve.

The unit was shut down for 9 days after the condenser vacuum was lost.

Two outages totaling 11 days were necessary to repair EHC leaks.

A 5-day outage was performed after a reactor scram during testing.

The first refueling and maintenance outage lasted 75 days. Major work included CRD changeout, snubber inspections, LLRTs, inspection of HP turbine, main generator and FW pump turbine, and installation of deep bed demineralizer connection. The utility claimed a world record low radiation exposure of $\mathbf{3 8 . 6}$ man-rem for BWRs for the outage.

The unit was shut down for eight days after the reactor was manually scrammed when both recirculation pumps tripped during surveillance testing.

The second refueling and maintenance outage lasted 55 days.

The third refueling and maintenance outage lasted 23 days.

Two separate shutdowns required 5 days of downtime. The shutdowns were due to problems with the feedwater control system and then with the EHC system.

Three separate shutdowns lasted a total of three weeks. These were caused by a failed the EHC pressure switch, a cracked main condenser neck seal gasket, and a failed recirculation MG set scoop tube positioner. 
MAINE YANKEE

PRODUCTION COST and CAPITAL ADDITIONS (1996 Dollars)

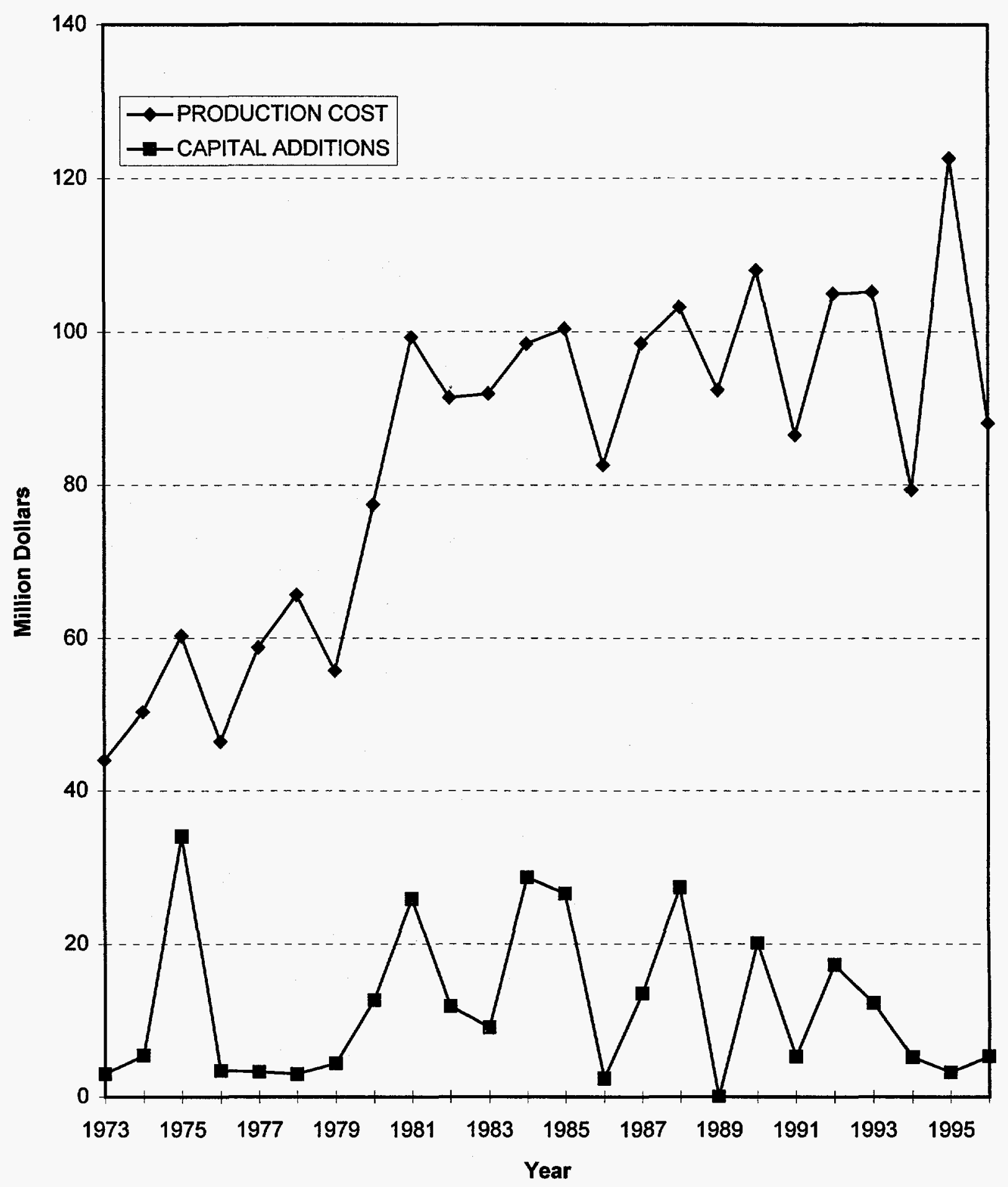

NUREG/CR-6577

186 


\title{
NUCLEAR POWER PLANT OPERATING EXPERIENCE SUMMARY
}

\author{
Unit data summary through December 1996
}

Unit: MAINE YANKEE

Nameplate Rating: 920 MWe

Location: LINCOLN COUNTY, MAINE

MDC Net MWe: $860 \mathrm{MWe}$

Owner: MAINE YANKEE ATOMIC POWER CO.

Cumul. Avail. Factor: $\mathbf{7 5 . 1}$

Type: COMBUSTION ENGINEERING PWR

Cumul. Cap. Factor (MDC Net): 69.7

Construction Permit: 10/21/68

Cumul. Forced Outage Rate: $\mathbf{8 . 5}$

Operating License: 10/20/72

3-Year Avg. Cap. Factor (MDC Net): 52.5

Commercial Oper. Date: $12 / 28 / 72$

License Expiration: 2008

OPERATING HISTORY (To December 1996)

Date

Mar 1973

May - Jul 1973

Jul 1973

Jul - Oct 1974

May - Jun 1975

Sep 1976

Apr - Jun 1977

Jul 1978

Aug - Sep 1978

Jan - Feb 1979

Mar - Jun 1979

Sep 1979

Jan - Mar 1980

Apr 1980

May - Jul 1981

\section{Comment}

A three-week outage was required for turbine and condenser repair, which was damaged by a loose washer.

The plant output was restricted to about $55 \%$ to comply with state restrictions on thermal discharge. A planned discharge diffuser will allow full power during warmer months.

A 1-month shutdown was required for turbine repairs and warranty inspection.

Leaking fuel caused an extended outage ( 15 weeks) for replacement of partial core. The outage extended 3 weeks for repair of a CEA extension shaft bent during head closure.

An eight week refueling outage was required to replace all FAs. A circulating water diffuser was installed to permit full power operation.

A twelve-day outage was required for steam relief valve inspection and seal replacement on all three RCPs.

A refueling and maintenance outage was due to poison pin cracking and hydriding and a SG tube denting. About 2500 condenser tubes were replaced.

The plant ended a continuous run of 392 days without an outage. The plant shut down for about 6 weeks for SG inspection and support plate modifications.

An eleven-day outage was required to repair main transformer windings. The RCP seal was replaced and leaking CRDM vents were repaired.

Numerous load reductions occurred because of condenser tube leaks.

The unit was shut down to comply with the NRC order to re-analyze piping seismic design. The outage was extended to replace RCP seal.

A 29-day outage for $\mathrm{FW}$ piping inspection was required to comply with NRC requirements.

A refueling outage was performed.

Several load reductions and shutdowns were caused by crud deposits on core surfaces. The RCS was chemically cleaned in May.

During a refueling outage, damage to LP turbine was found and the outage was extended to repair the unit. 


\section{MAINE YANKEE (Cont'd)}

Mar 1982

Sep - Dec 1982

Jan - Feb 1983

Jun 1983

Mar - Jun 1984

Apr 1984

Aug - Oct 1985

Feb - Mar 1986

Jun - Jul 1986

Dec 1986

Mar - Jun 1987

Jun - Aug 1987

Nov 1987

Aug 1988

Oct - Dec 1988

Nov 1988

Apr 1989

Apr - Jul 1990

Sep 1990

Oct 1990

Dec 1990 - Jan 1991

Feb 1991
The NRC assessed a $\$ 30,000$ fine for alleged valving failures. A unit outage for 23 days was required for maintenance.

A refueling and maintenance outage was caused by defective SG tubes found during SG ISI. Metal shavings were found in an oil reservoir, sabotage was suspected.

A 1-month outage was required to repair to the FW system damaged by severe water hammer.

The utility paid a $\$ 40,000$ fine assessed by NRC for alleged inoperability of SI subsystems.

A refueling outage was required to repair a burst RWST pipe.

The NRC granted a license amendment to increase spent fuel storage capacity.

The refueling and maintenance outage was performed.

The utility paid an $\$ 80,000$ fine assessed by NRC for alleged mispositioning of nine valves that disabled low SG pressure signals. The unit was shut down for 18 days to repair a $\mathrm{H}_{2}$ leak in the main generator; the outage was extended because of chloride intrusion into the condenser.

A 21-day outage was required for replacement of ruptured discs on excess flow check valve operators and inspection of LP turbine and condenser.

The unit completed the year ranked third in U.S. and seventh in the world in total lifetime net generation of $>69$ million MWh.

A refueling and maintenance outage lasted 82 days. A SG dryer and several heat exchangers were replaced, a main generator inspection was performed, and a main turbine rotor was replaced.

Numerous short outages occurred because of turbine vibration problems. The plant finally shut down and replaced the rotors on turbines.

Maine voters turned down third ballot initiative by $59 \%$ to $41 \%$ to close the plant.

Failed output transformers caused several outages; operation resumed with power restricted to about $76 \%$.

A refueling and maintenance outage lasted 63 days. Both LP turbines were replaced, SGs were inspected, and upgrade of switchgear was accomplished.

A 3.8 Richter scale earthquake occurred about 40 miles southeast of plant; the unit was not effected.

The NRC assessed a $\$ 75,000$ fine for alleged security requirement violations.

A refueling and maintenance outage lasted 85 days. Performed RPV 10-year ISI, SG and core barrel inspection, HP turbine rotor replacement, RCP seals replacement. End cap and $\mathrm{B}_{4} \mathrm{C}$ pellets were found missing on CEA, this appeared to have generic safety implications.

The unit shutdown for 7 days to repair a main turbine oil pump seal.

The unit shutdown for 6 days to correct problems with EQ on SIAS valve limit switches.

The unit was shut down 25 days for SG leakage repair and problems with the containment isolation valve.

A RCS leak from an incore instrument tube required a 5-day outage to repair. 


\section{MAINE YANKEE (Cont'd)}

Apr 1991

Feb - Apr 1992

Jun 1992

Jul 1992

Dec 1992

Jul - Oct 1993

Jun 1994

Jul - Aug 1994

Nov 1994

Jan 1995

Feb 1995 - Jan 1996

Dec 1995

Jul - Sep 1996

Oct 1996

Oct 1996

Dec 1996
The unit was shut down due to failure of the main transformer; a 31-day outage was required to repair.

The twelfth refueling and maintenance outage lasted 64 days.

The unit was shut down for 9 days to repair a leak in the extraction steam system.

A 9-day outage was needed to repair a steam leak on one of the MSR vent pipes.

A 4-day outage was taken to replace a leaking MSR drain line.

The thirteenth refueling and maintenance outage lasted 75 days.

A 5-day outage was taken due to high SG chlorides and cleanup.

The unit was shut down for 30 days due to SG tube leakage and to perform ECT of the SGs.

The unit was shut down for 5 days to repair a steam leak in the turbine building.

A 23-day outage was necessary to repair a ground in the main generator.

The fourteenth refueling and maintenance outage lasted 344 days. The outage was extended to repair the steam generators (i.e., sleeved all steam generator tubes).

Anonymous allegations contended that the 1989 power uprate safety analysis was falsified. Both state and federal regulators investigated. The NRC found the analysis inadequate and the uprate was rescinded.

The unit was shut down to modify containment penetrations of component cooling water lines. The outage was extended to perform safeguards logic testing. Total outage time was 45 days.

The unit scrammed due to an RPS malfunction and was down for 4 days.

The NRC project manager for the plant was placed on administrative leave due to possible improper actions.

The unit was shut down to address cable separation issues and remained down for other design concerns. 


\section{MCGUIRE}

PRODUCTION COST and CAPITAL ADDITIONS

(1996 Dollars)

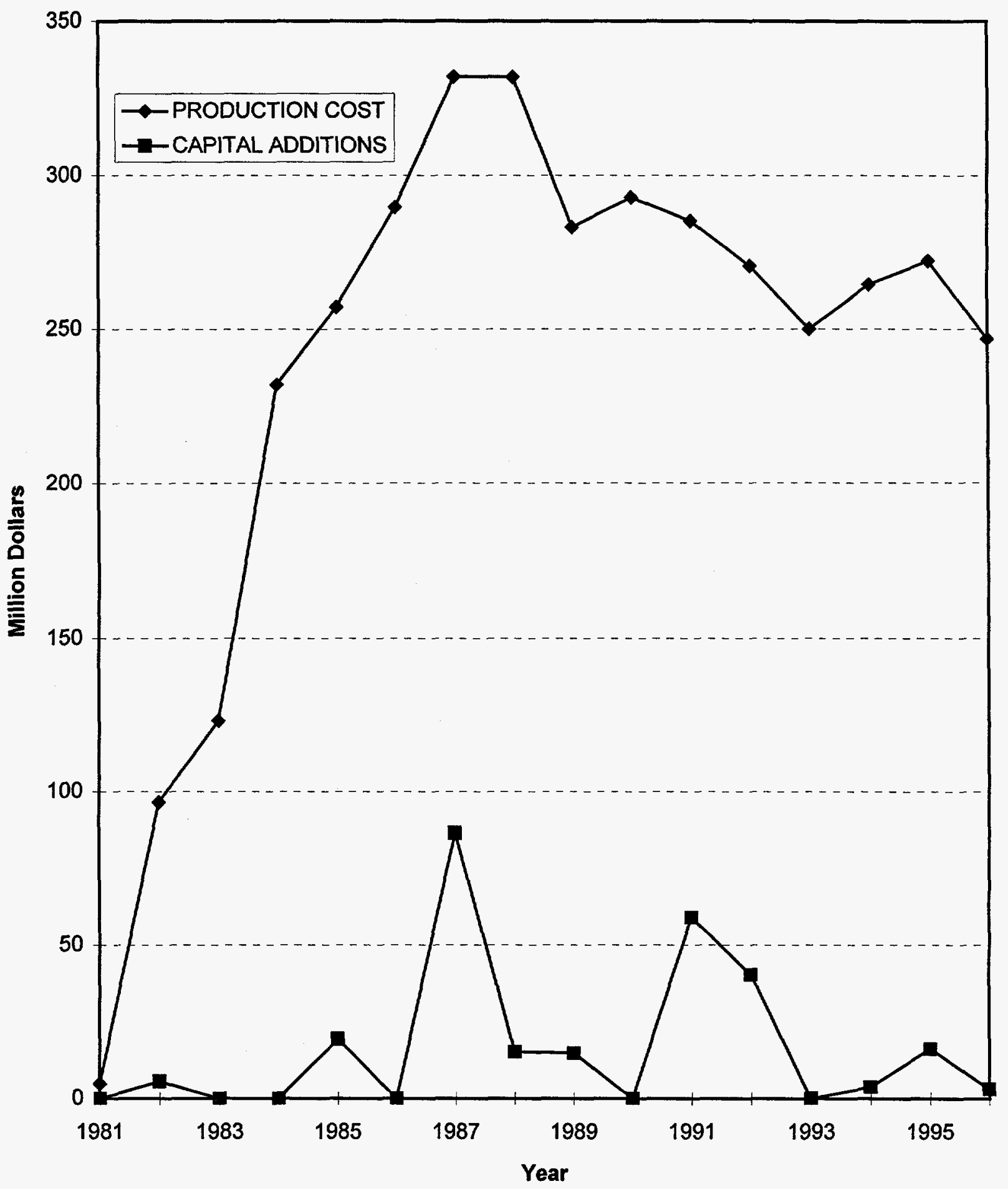




\section{NUCLEAR POWER PLANT OPERATING EXPERIENCE SUMMARY}

Unit data summary through December 1996

Unit: MCGUIRE 1

Location: MECKLENBURG COUNTY, NORTH CAROLINA

Nameplate Rating: 1305 MWe

Owner: DUKE POWER CO.

MDC Net MWe: 1129 MWe

Type: WESTINGHOUSE PWR

Cumul. Avail. Factor: $\mathbf{7 2 . 2}$

Construction Permit: 2/23/73

Cumul. Cap. Factor (MDC Net): 65.2

Operating License: $\mathbf{7 / 8 / 8 1}$

Cumul. Forced Outage Rate: 12.7

Commercial Oper. Date: 12/1/81

3-Year Avg. Cap. Factor (MDC Net): 82.8

License Expiration: 2021

OPERATING HISTORY (To December 1996)

Date

$1975-1981$

Dec 1981

Feb - Mar 1982

Jun - Jul 1982

Nov 1982

Jan - May 1983

Aug 1983

Feb - May 1984

Nov 1984

Apr - Jun 1985

Jul 1985

May - Sep 1986

\section{Comment}

Unanticipated design changes, testing and performance problems, and TMI modifications delayed unit startup for about 6 years.

During a LOSP test, a condensate system malfunction caused ruptures in the main generator hydrogen coolers, admitting water into the generator. The repair outage lasted about 1 month.

SG inspection forced an outage of 20 days.

The unit was shut down for additional inspection of the SG tubes. The outage was extended after discovery of a displaced thermal sleeve nozzle from a RCS accumulator. Total outage time was 23 days.

The unit was shut down for 15 days to perform additional inspection of SG tubes.

The unit was shut down for an extended outage to modify preheater section of each SG. During the outage, the core was off-loaded to search for the missing thermal sleeve. Other work included maintenance and repair of main turbine and generator; ice condenser rework; thermal sleeve removal; and piping weld repairs. Total outage time was 129 days.

The unit was shut down on three separate occasions to repair a leaking RCS RTD cold leg isolation valve. Total outage time was 18 days.

The first refueling outage and maintenance outage lasted 70 days. Startup was delayed because an upper head injection disc ruptured during startup.

The unit was shut down for 32 days for a mid-cycle maintenance outage.

The second refueling and maintenance outage lasted 69 days. Major work included SG inspection.

The NRC assessed a $\$ 50,000$ fine for alleged violations regarding operability of the upper head injection system.

The third refueling and maintenance outage lasted 121 days. Major work included plugging $136 \mathrm{SG}$ tubes, inspection of FAs, and maintenance of main turbine and generator. 
Oct 1986

Mar 1987

Sep - Nov 1987

Jan 1988

Mar 1988

Oct 1988 - Jan 1989

Mar - May 1989

Dec 1989

Jan - May 1990

Oct 1990

Nov 1990

Apr 1991

Sep - Dec 1991

Jan 1992

May 1992

Oct 1992

Mar - Jun 1993

Aug - Sep 1993

Sep - Oct 1993
The unit was shut down for 30 days to inspect MOVs and resolve problems with torque settings on Rotork ${ }^{\circledast}$ valve operators. NRC assessed a $\$ 50,000$ fine for alleged inoperability of two MOVs during a plant startup in November 1985.

The NRC assessed a $\$ 50,000$ fine for alleged violations concerning operability of the nuclear service water system.

The fourth refueling and maintenance outage lasted 71 days. Major work included inspection of DGs and main turbine, SG inspection, removal of upper head injection system, and replacement of cold leg accumulator check valves. Repairs to the main turbine extended the outage an additional 22 days.

The NRC assessed a $\$ 25,000$ fine for alleged inoperability of a containment/shield divider barrier which had existed for more than 4 years.

The NRC assessed a $\$ 100,000$ fine for alleged inoperability of one of two required DGs. The base $\$ 50,000$ fine was increased because of utility's past poor performance.

The fifth refueling and maintenance outage lasted 80 days. Major work included turbine modifications, SG cleaning, inspection and U-bend heat treatment, upgrading of nuclear SW system, and RCP seal rework. Problems with cold leg SI check valves extended the outage an additional 18 days.

A SG tube rupture forced a 63-day outage for repairs.

$\mathrm{NRC}$ assessed a $\$ 50,000$ fine for alleged violations relating to security at all three Duke Power Co. sites.

A sixth refueling and maintenance outage lasted 106 days. The outage was entered 3 months early because of main turbine damage from loss of lubricating oil. Major work during the outage included SG inspection and sleeving, ILRT, and main turbine repairs.

The unit was shut down for 16 days to repair a LP turbine.

The unit was shut down twice for a total of 14 days because of inoperability of control room HVAC and repair of ice condenser ice basket U-bolts.

Repairs on a RCP lower motor bearing and flange required a 19-day outage.

The seventh refueling and maintenance outage lasted 81 days.

The unit was shut down for 34 days to repair a SG tube leak. During the outage, two other leaking SG tubes were found that were overlooked in the previous refueling outage.

The unit was shut down for 44 days to inspect the SG and perfect eddy current testing on all SG tubes.

NRC SALP report gave top ratings in all but two areas and no low marks. The unit ranked in the top 15 most efficient nuclear power plants for 1992.

The eighth refueling and maintenance outage lasted 94 days. Major work included replacing almost all plant snubbers with limit stops. No re-analysis or re-licensing was necessary. The outage extended 10 days for RCP work, cleanup of debris in primary containment, and mechanical penetration work.

The unit was shut down for 35 days due to SG tube leakage.

The unit was shut down for 9 days to repair a CVCS pump seal. 


\section{MCGUIRE 1 (Cont'd)}

Oct 1993

Jan - Feb 1994

Aug - Oct 1994

Jun 1995

Dec 1995 - Jan 1996

Oct - Nov 1996
The unit was shut down for 13 days for SG tube plug repairs.

A 33-day outage was needed to correct SG tube leakage.

The ninth refueling and maintenance outage lasted 69 days.

A 1-week outage was taken when the EDGs were declared inoperable due to problems with their turbochargers.

The tenth refueling and maintenance outage lasted 43 days.

The unit was shut down for 10 days when a vital battery failed a surveillance test. 


\section{NUCLEAR POWER PLANT OPERATING EXPERIENCE SUMMARY}

Unit data summary through December 1996

Unit: MCGUIRE 2

Location: MECKLENBURG COUNTY, NORTH CAROLINA

Owner: DUKE POWER CO.

Nameplate Rating: 1305 MWe

MDC Net MWe: 1129 MWe

Type: WESTINGHOUSE PWR

Cumul. Avail. Factor: 77.6

Construction Permit: 2/23/73

Cumul. Cap. Factor (MDC Net): $\mathbf{7 4 . 8}$

Operating License: $\mathbf{5 / 2 7 / 8 3}$

Cumul. Forced Outage Rate: $\mathbf{7 . 2}$

Commercial Oper. Date: $\mathbf{3 / 1 / 8 4}$

3-Year Avg. Cap. Factor (MDC Net): 84.2

License Expiration: 2023

OPERATING HISTORY (To December 1996)

Date

Jun - Aug 1983

Jul - Aug 1984

Oct 1984

Jan - May 1985

Jul - Aug 1985

Dec 1985

Mar - Jun 1986

Oct - Nov 1986

May - Jul 1987

Dec 1987

May - Jul 1988

Jan 1989

\section{Comment}

The unit was shut down for about 6 weeks to modify the preheater section in each SG.

The unit was shut down for RCP seal replacement for 10 days. Outage was extended another 12 days to repair auxiliary letdown piping welds caused by water hammer.

The NRC assessed a $\$ 40,000$ fine for alleged inoperability of a containment spray valve in September 1983.

The first refueling and maintenance outage lasted 104 days. The outage was extended to repair DG crankshaft and bearing journals, repair cracks in decay heat removal pump crossover piping, and repair leaky SI isolation valve. During the outage, an equipment operator was killed when he attempted to get on a moving manipulator crane bridge and fell.

Main generator problems forced about 3 weeks of outage for repairs.

Main generator tube leaks forced a 13-day outage for repairs.

The second refueling and maintenance outage lasted 107 days. The outage was early because of excessive RCS leakage through CVCS valves. The outage was extended for main generator rotor repair.

The unit was shut down for 20 days to inspect MOVs and resolve problems with torque settings on Rotork ${ }^{\otimes}$ valve operators.

The third refueling and maintenance outage lasted 65 days. Major work included LP turbine rotor replacement, SG tube inspection and peening, main FW pump inspection and ice condenser replacement.

The unit completed the year with an availability factor of $75 \%$.

The fourth refueling and maintenance outage lasted 62 days. Major work included generator modifications, SW piping upgrading, SG U-bend heat treatment, and SG tube inspection and plugging.

NRC proposed a $\$ 37,000$ fine for alleged failure to ensure hydrogen skimmer compartment flow rates. 
Jul - Sep 1989

Sep - Dec 1990

Oct 1991

Jan - Mar 1992

May 1992

Aug 1992

Oct 1992

Jul - Sep 1993

Aug 1993

Oct 1993

Dec 1993

May 1994

Nov 1994 - Jan 1995

Apr 1995

Dec 1995

Apr - May 1996

May - Jun 1996

Oct - Nov 1996
The fifth refueling and maintenance outage lasted 76 days. Major work included SG cleaning, inspection and shot peening, RCP seal inspection, ILRT, and DG lube oil system upgrade. The outage was extended for 10 days to complete planned generator work.

The sixth refueling and maintenance outage lasted 117 days. Major work included ILRT, ESF system testing, SG inspection, tube plugging and hot leg shot peening, RCP seal work, LP turbine rotor replacement, and ice condenser bolt inspection.

A 4-day outage was required to perform leak rate testing of containment spray vacuum check valves.

The seventh refueling and maintenance outage lasted 65 days. Major work included SG eddy current testing and tube plugging, sleeving, and removal, HP turbine and main condenser inspections, and FW heater ECT.

A reactor trip due to FW regulating valve closure initiated a 36-day outage for SG inspection.

A FW regulating valve failed to close and caused a reactor trip and a 4-day outage.

NRC SALP report gave top ratings in all but two areas and no low marks. The unit ranked in the top 15 most efficient nuclear power plants for 1992.

The eighth refueling and maintenance outage lasted 75 days.

In August, a secondary side steam leak occurred due to an incorrectly assembled valve. This pressurized the containment and caused the ice condenser inlet doors to open. The NRC sent an AIT and fined the utility $\$ 25,000$ over the event.

The unit was shut down for 15 days to perform a SG inspection.

A LOSP event occurred when an insulator in the switchyard failed and the turbine did not run back as designed. One of the SGs dried out following the event due to a MSIV not fully closing. An AIT was sent to investigate. The unit was shut down for 10 days following the event.

The NRC proposed a $\$ 100,000$ fine for alleged violations related to the December 1993 event, specifically the MSIV failure.

The ninth refueling and maintenance outage lasted 49 days.

A 6-day outage was needed to repair a leaking RHR valve.

An 8-day outage was needed to repair the pressurizer relief tank.

The tenth refueling and maintenance outage lasted 39 days.

A 43-day outage was needed to repair one of the RCPs. The outage was extended by 4 days to repair an IRM detector.

The unit was shut down for 11 days when a vital battery failed a surveillance test. 
MILLSTONE $1 \& 2$

PRODUCTION COST and CAPITAL ADDITIONS

(1996 Dollars)

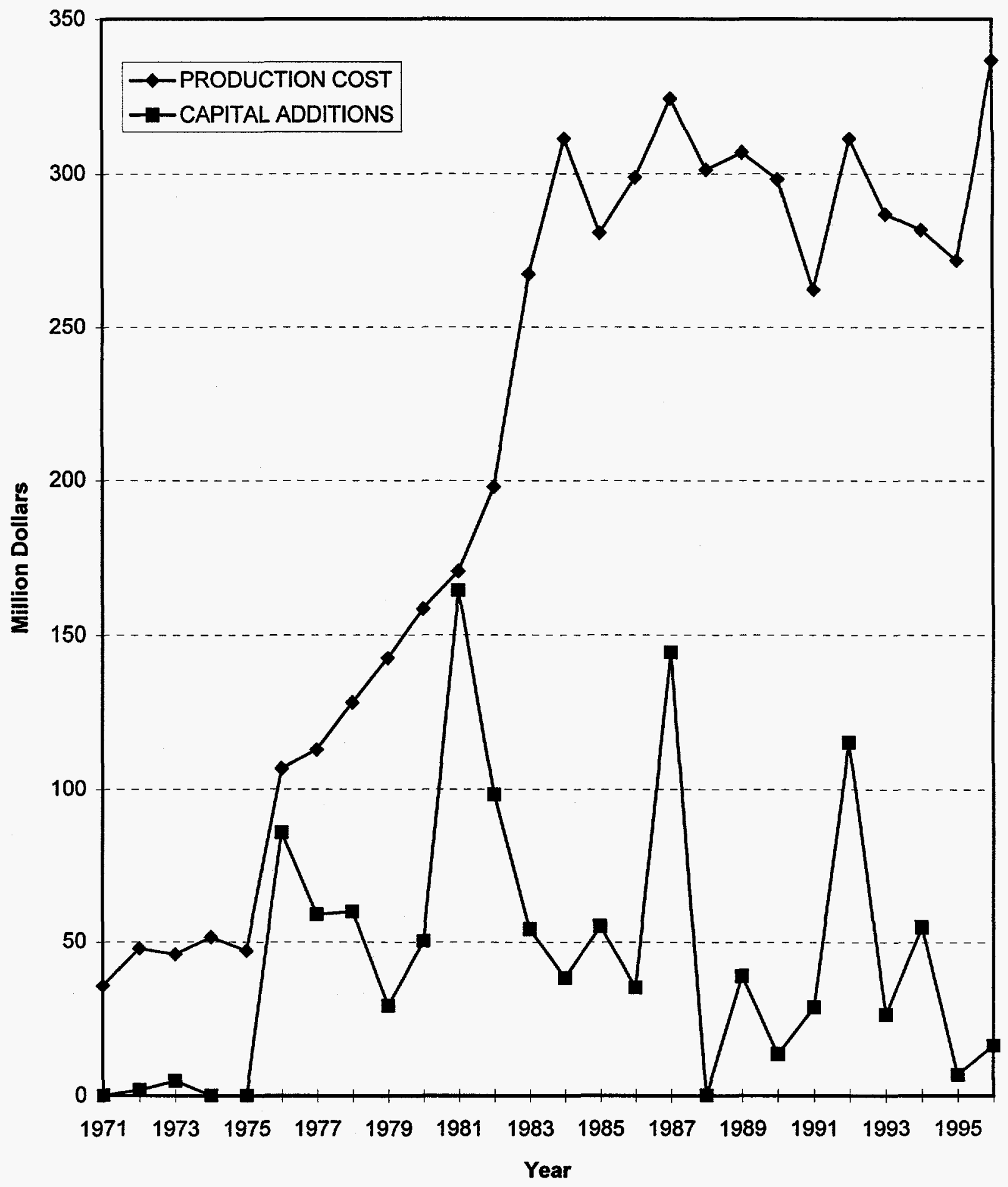




\section{NUCLEAR POWER PLANT OPERATING EXPERIENCE SUMMARY}

Unit data summary through December 1996

Unit: MILLSTONE 1

Location: NEW LONDON COUNTY, CONNECTICUT

Owner: NORTHEAST NUCLEAR ENERGY CO.

Nameplate Rating: 662 MWe

MDC Net MWe: 641 MWe

Type: GENERAL ELECTRIC BWR

Cumul. Avail. Factor: 72.9

Construction Permit: 5/19/66

Cumul. Cap. Factor (MDC Net): 67.8

Operating License: 10/26/70

Cumul. Forced Outage Rate: 15.7

Commercial Oper. Date: 3/1/71

3-Year Avg. Cap. Factor (MDC Net): 45.4

License Expiration: 2010

OPERATING HISTORY (To December 1996)

Date

Oct 1971

Feb 1972

Sep 1972 - Mar 1973

Apr - Aug 1973

Jun 1974

Aug - Nov 1974

Mar 1975

Jul 1975

Sep 1975

Oct - Dec 1976

Dec 1979 - Jan 1980

Oct 1980 - Jun 1981

Apr 1982

\section{Comment}

A 2-week outage was due to relief valve and turbine control failures.

A 2-week outage was due to main steam line venturi problems.

An extended shutdown was due to salt water intrusion from failure of main condenser tubes. This resulted in damage to LPRMs and control rods. FW sparger failures and plating flaking in CRD accumulators were also found. Recovery involved control rod replacement, extensive flushing, condenser retubing, and other system maintenance. The main turbine was overhauled and a number of improvements were made to the gas turbine.

A scheduled shutdown for inspection revealed cracking in four new FW spargers; all four were replaced. An additional 2-week outage was needed to resolve an inverted control rod blade problem. Continued FW sparger vibration limited power to $80 \%$.

GE paid a $\$ 4.2$ million claim to utility for salt water intrusion, and control blade and FW sparger problems.

Refueling and FW sparger replacement caused an outage. Weld cracks were found in the recirculation valve bypass line. Twelve LPRMs and 21 control rod blades were replaced.

Contaminated water from a radwaste system entered the auxiliary boiler system and contaminated portions of the plant. About 1200 construction workers had to be evacuated.

The NRC imposed a $\$ 7,500$ fine for alleged security violations.

A refueling outage started about 1 month early due to failure of the main transformer.

A refueling and maintenance outage was performed.

Water hammer in isolation condenser piping caused some structural damage. Power was limited to $40 \%$ until repairs were made and evaluation was completed.

A 6-month maintenance outage ended in April, but turbine failure, resulting repair, and main condenser repair caused delays into June.

Persistent main condenser tube leakage caused numerous power reductions for leak detection and repair. 
Sep - Nov 1982

Mar 1983

Apr - Jun 1984

Aug 1985

Oct - Dec 1985

Jun 1986

Oct 1986

Dec 1986

Jun - Aug 1987

Dec 1987

Dec 1988

Apr 1989

Aug 1989

Mar 1990

Apr 1990

Sep 1990

Oct 1990

Mar 1991

Apr - Aug 1991

Aug 1991

Oct 1991 - Feb 1992

Mar - Apr 1992
A refueling and maintenance outage was performed. Major work included torus modifications, SDV work, jet pump beam replacement, ISI and inspection for stress corrosion cracking on recirculation piping.

The NRC released the final SEP report for the unit. The report called for equipment modifications or additions in eight areas, plus TS changes and additional changes in other areas of plant operation.

A refueling and maintenance outage was performed. IGSC cracks found in RWCU, CS, and reactor recirculation piping welds. The turbine was overhauled, and station batteries were replaced. Operation resumed 1 month ahead of schedule.

The unit completed 374-day continuous run to set a new U.S. BWR record.

The refueling and maintenance outage lasted 59 days.

ACRS concluded that the unit could be operated up to $2011 \mathrm{MWt}$ without undue risk and that NRC could issue full-term operating license. (The unit had operated under provisional license since October 1970 because of a large number of unresolved safety issues.)

The NRC issued full-term operating license for the unit.

The unit achieved best BWR capacity factor for the year - $90.9 \%$.

The refueling and maintenance outage lasted 74 days. The unit started up 10 days early to alleviate a power shortage in New England due to refueling at other units and prolonged shutdowns at Pilgrim, Seabrook, and Shoreham.

NRC proposed a $\$ 25,000$ fine for alleged violations concerning plant security.

The unit achieved a capacity factor of $95.7 \%$, the highest in the world for any BWR.

The refueling and maintenance outage lasted 50 days. NRC proposed a $\$ 50,000$ fine for alleged $\mathrm{EQ}$ violations.

NRC proposed a $\$ 25,000$ fine for alleged violation of requirements for safe handling of contaminated hydrolazer equipment.

NRC proposed a $\$ 3,750$ fine for alleged violation of shipping requirements for contaminated packages.

The unit was shut down for 5 days to replace service water valves.

An 11-day outage was needed to replace a recirculation pump seal. A 4-day outage was taken after the LPCI HX was declared inoperable due to questionable flow considerations.

The unit was shut down for 14 days to revise procedures and implement design changes for severe weather conditions.

After two LPCI pump motors were declared inoperable, the unit was shut down for 7 days. One pump was replaced with a new one and the other was refurbished.

The refueling and maintenance outage lasted 131 days.

The unit was shut down for 13 days in response to Hurricane Bob.

The unit was shut down for operator training. The outage was extended to perform erosion/corrosion piping inspections and repairs. The outage lasted 152 days.

A 15-day outage was needed to repair steam line drain piping. 


\section{MILLSTONE 1 (Cont'd)}

Jul - Aug 1992

1993

Jan - May 1994

Jul 1994

Nov 1994

Jun 1995

Nov 1995

Jan 1996

Jun 1996

Jun 1996
Repairs to service water piping forced a 42-day outage.

The unit operated with only two outages of 4 days or more, totaling 10 days of downtime.

The fourteenth refueling and maintenance outage lasted 125 days.

The NRC proposed a $\$ 220,000$ fine for alleged violations involving problems with the feedwater coolant injection system, which had been identified in 1989, and also for alleged discrimination against the engineer that had identified the problem. The utility contested the Level 2 severity of the violation but paid the fine.

A 10-day outage was taken to repair leaking SRVs.

The unit was shut down for 2 weeks to correct LOSP logic.

The fifteenth refueling and maintenance outage was started. The unit remained shut down to correct widespread design problems, especially related to design basis issues.

All Millstone units were added to the NRC problem plant list.

All Millstone units were changed to watch list Category 3, which requires Commission approval for restart.

The NRC proposed and the licensee paid a $\$ 100,000$ fine for discrimination against a whistle blower. 


\section{NUCLEAR POWER PLANT OPERATING EXPERIENCE SUMMARY}

Unit data summary through December 1996

Unit: MILLSTONE 2

Nameplate Rating: 909 MWe

Location: NEW LONDON COUNTY, CONNECTICUT

MDC Net MWe: 873 MWe

Owner: NORTHEAST NUCLEAR ENERGY CO.

Cumul. Avail. Factor: 63.5

Type: COMBUSTION ENGINEERING PWR

Construction Permit 12/11/70

Cumul. Cap. Factor (MDC Net) 60.0

Operating License 9/30/75

Cumul. Forced Outage Rate 19.3

Commercial Oper. Date 12/26/75

3-Year Avg. Cap. Factor (MDC Net) 32.2

License Expiration 2015

OPERATING HISTORY (To December 1996)

Date

Dec 1975

Apr - May 1976

Dec 1976 - Jan 1977

May - Jun 1977

Nov 1977 - Apr 1978

Mar - May 1979

Aug 1979

May - Jun 1980

Aug - Oct 1980

May 1981

Dec 1981 - Mar 1982

May 1983 - Jan 1984

Feb - Jul 1985

Sep - Nov 1985

\section{Comment}

Numerous delays were experienced during power ascension program due to condenser tube leaks; the plant was declared commercial in late December.

A total of 17 days of forced outage time occurred due to turbine intercept valve problems and condenser tube leaks.

An outage was required for replacement of DG damaged by a thrown connecting rod.

An outage was required for retubing of the main condenser and SG inspection.

The first refueling and maintenance outage was performed. Early shutdown because of deficiencies found in containment electrical penetrations. Cracks were found in SG support and in several CEA guide tubes. Full flow condensate demineralizers were installed, and corroded SW piping was replaced.

The second refueling and maintenance outage was performed. Five SG tubes were plugged.

The unit was shut down for a 19-day outage for main steam line leak repair. Inspection of SG FW line found cracks in elbow and nozzle welds.

An outage was required for upgrade of pipe supports.

The third refueling and maintenance outage was performed.

An outage was required for inspection and replacement of snubbers.

The fourth refueling and maintenance outage was performed. Major work included plugging 704 SG tubes due to pitting beyond service limits.

The fifth refueling and maintenance outage was performed. A large manufacturing flaw was found in circumferential weld on one SG, ISI of reactor thermal shield found damage (shield later removed), many SG tubes were sleeved or plugged, some FAs were found with damaged hold-down springs.

The sixth refueling and maintenance outage lasted 138 days. Major work included extensive work done on SG tubes, the outage lasted about 1 month longer than planned.

The shutdown for Hurricane Gloria was extended due to damage to the RCP C motor from rotor/stator interference; seals were replaced on RCP A and B. 


\section{MILLSTONE 2 (Cont'd)}

Sep - Dec 1986

Jan - Feb 1987

Jun 1987

Jan - Feb 1988

Sep 1988

Feb - May 1989

Apr 1989

Sep - Nov 1989

Mar 1990

Apr - Jun 1990

Aug 1990

Sep - Nov 1990

Dec 1990 - Jan 1991

Feb 1991

Mar 1991

Apr 1991

May - Jun 1991

Jul 1991

Aug 1991

Aug - Sept 1991

Oct 1991

Nov - Dec 1991

Jan 1992
The seventh refueling and maintenance outage lasted 90 days. Major work included SG inspection, repair and sludge lancing, condenser retubing, and ILRT.

The unit was shut down to repair a SG tube leak; 81 tubes were plugged.

The NRC approved license amendment permitting demonstration of spent fuel consolidation.

The eighth refueling and maintenance outage lasted 52 days, a record time for the unit. Major work included RCP motor replacement, LP turbine overhaul, and SG inspection.

The utility announced that Advanced Nuclear Fuels Corporation (ANF) won the contract to supply the next six fuel loads for the unit.

The ninth refueling and maintenance outage lasted 86 days. Major work included SG inspection, SW piping replacement, ATWS modifications, and replacement of one RCP motor.

The NRC assessed a $\$ 25,000$ fine for alleged violations concerning contamination of equipment.

A 33-day outage was required to inspect SG tubes; 80 tubes were plugged.

The NRC proposed a $\$ 3,750$ fine for alleged violations concerning shipment of contaminated equipment.

The outage for repair of the FW regulating valve was extended to 36 days due to leak testing and SG inspection and repair.

The utility paid NRC-imposed fines totaling $\$ 75,000$ for alleged failure to meet TS LCOs for main steam line setpoints, inadequate surveillance of gas turbine generator, and shipment of irradiated fuel with free-standing liquid in excess of regulatory limits.

The tenth refueling and maintenance outage lasted 56 days.

Repair of four leaking SG manways required a 10-day outage to repair.

The NRC proposed a $\$ 50,000$ fine for alleged failure to maintain containment integrity during refueling. The fine was paid.

The NRC proposed a $\$ 37,500$ fine for alleged operation of the independent service water systems while improperly cross-connected.

The unit had a 20-day outage to repair a leak on a 1-inch steam extraction line.

The unit had a 42-day outage to repair a SG tube leak.

The NRC proposed a $\$ 50,000$ fine for alleged failure to follow written procedures. The four circulating water pumps were not tripped when seaweed buildup occurred and three of the intake screens partially collapsed. The fine was paid in September.

The unit had a 13-day outage to clean the main turbine EHC system.

The unit had a 19-day outage due to inoperability of both DGs.

The unit had a 4-day outage to reanalyze the MSL break.

The unit tripped when an HP FW reheater drain tank ruptured. The repair lasted 52 days.

The unit had a 13-day outage to repair a SG tube leak. 
May 1992

May 1992 - Jan 1993

May 1992

Aug 1993

Sep - Oct 1993

Apr - Jun 1994

Jul - Aug 1994

Aug 1994

May 1995

Jan 1996

Feb 1996 - Present

Jun 1996
The NRC SALP report gave a Category 3 rating in one area, safety assessment/quality verification, and no Category 1 ratings.

The eleventh refueling and maintenance outage lasted 232 days. Major work was the replacement of both steam generators.

The NRC proposed a $\$ 100,000$ fine for two violations: (1) the alleged harassment of a worker for raising potential safety concerns; (2) the timely evaluation and reporting of significant safety hazards.

The unit had a 10-day outage to repair a letdown isolation valve.

The unit was shut down after some MOVs were declared inoperable due to concerns with the motor brakes. The outage lasted 26 days.

A 57-day outage was initiated to repair a RCP seal.

A RCP oil leak required a 38-day outage to repair.

The NRC proposed an $\$ 87,500$ fine for alleged violations involving failure to declare UEs during incidents in April 1994.

The NRC proposed and the licensee paid a $\$ 50,000$ fine for failure to identify and correct a problem with potential pressure locking of containment sump recirculation valves.

All Millstone units were added to the NRC problem plant list.

The unit was shut down to address potential problems with the HPSI valves during the recirculation phase of a LOCA. The outage was then converted into a scheduled maintenance outage. The NRC placed the plant on the problem plant list and ordered the licensee to address design basis issues similar to those found at Millstone 1.

All Millstone units were changed to watch list Category 3, which requires Commission approval for restart. 
This Page Intentionally Left Blank 


\section{MILLSTONE 3}

PRODUCTION COST and CAPITAL ADDITIONS

(1996 Dollars)

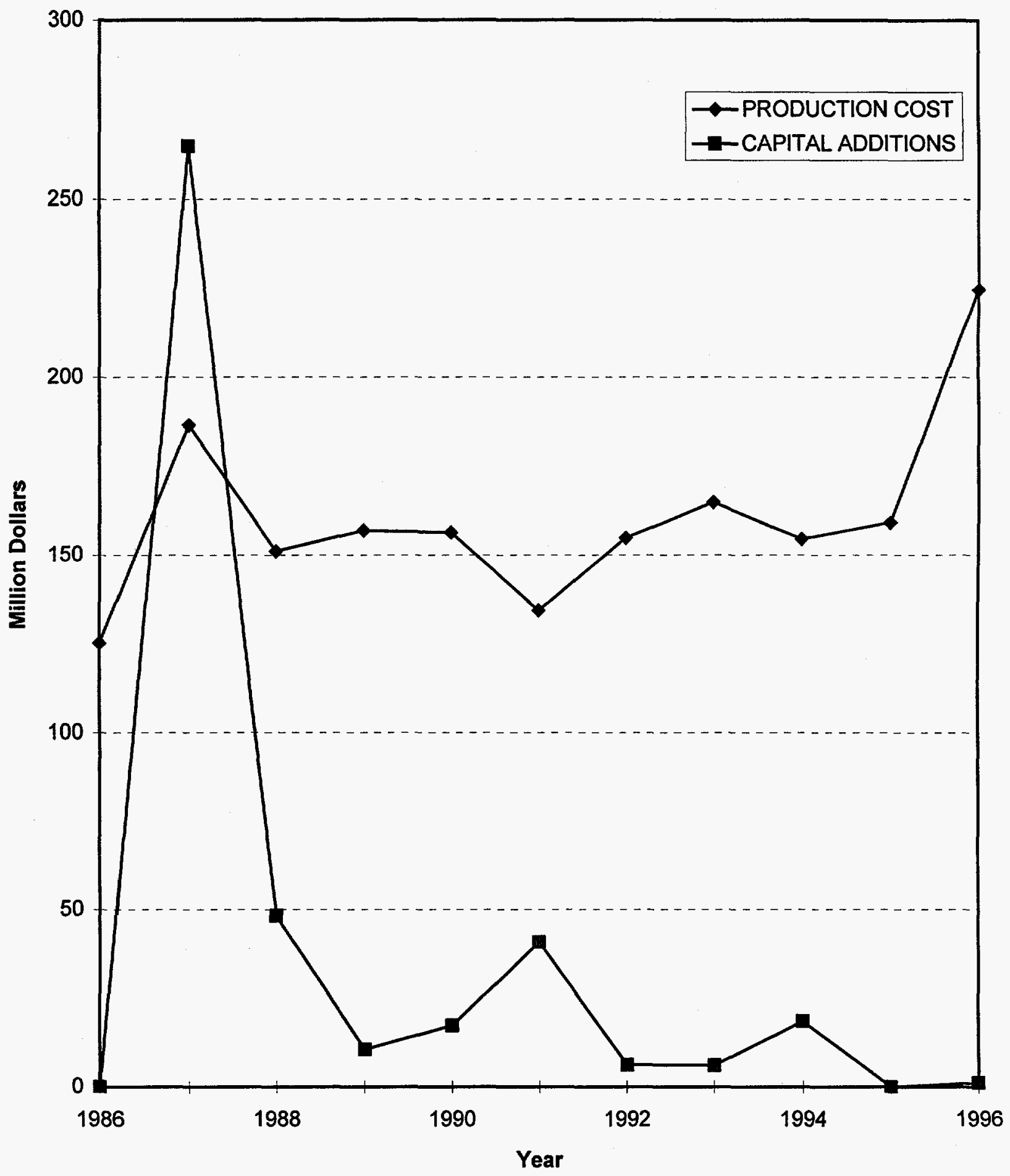




\title{
NUCLEAR POWER PLANT OPERATING EXPERIENCE SUMMARY
}

\author{
Unit data summary through December 1996
}

Unit: MILLSTONE 3

Location: NEW LONDON COUNTY, CONNECTICUT

Owner: NORTHEAST NUCLEAR ENERGY CO.

Type: WESTINGHOUSE PWR

Construction Permit: 8/9/74

Operating License: 1/31/86

Commercial Oper. Date: $\mathbf{4 / 2 3 / 8 6}$
Nameplate Rating: 1253 MWe

MDC Net MWe: 1137 MWe

Cumul. Avail. Factor: $\mathbf{7 0 . 3}$

Cumul. Cap. Factor (MDC Net): 66.8

Cumul. Forced Outage Rate: $\mathbf{2 0 . 5}$

3-Year Avg. Cap. Factor (MDC Net): 66.3

License Expiration: 2025

OPERATING HISTORY (To December 1996)

Date

Apr 1986

May 1986

Mar 1987

Oct 1987 - Feb 1988

Dec 1987

Apr 1988

May - Jun 1989

Mar 1990

May 1990

May 1990

Jul 1990

Dec 1990

\section{Comment}

The commercial operation date was declared about 1 week early due to early successful completion of power ascension testing.

The unit had a 23-day outage for modifications to screen wash system and to repair a main generator stator coolant leak.

The unit had a 29-day outage to perform surveillance on plant systems.

The first refueling and maintenance outage lasted 101 days. Major work included RTD loop bypass removal, SG wet layup recirculation work, FW venturi work, FW heater relief piping modifications, and $\mathrm{SW}$ valve replacement.

The NRC proposed a $\$ 25,000$ fine for alleged failures to meet requirements for physical protection of the plant.

The NRC proposed a $\$ 50,000$ fine for alleged failures to have overpressure protection systems operable at proper times.

The second refueling and maintenance outage lasted 60 days. A fire ignited in containment and burned for about 13 minutes during outage work.

The unit had a 16-day outage for problems resulting from circulating water pumps tripping and low condenser pressure.

The unit received NRC SALP Category 1 ratings in five areas and Category 2 ratings in two areas.

The reactor tripped after storm-induced fouling occurred, and the unit was down for 11 days.

The NRC proposed two fines. The first, for $\$ 25,000$, was for an alleged failure to meet a TS LCO involving an RPS setpoint and for an alleged failure to perform an adequate surveillance test of the gas turbine generator. The second, for $\$ 50,000$, was for shipment of irradiated waste allegedly containing excessive free-standing water. Both fines were paid by the utility.

The secondary MSR drain tank pump discharge pipe failed catastrophically due to erosion/corrosion. Repairs required 8 days. 
Feb - Apr 1991

Apr 1991

Jun 1991

Jul 1991 - Feb 1992

Oct 1991

Apr 1992

May 1992

Sep - Oct 1992

Dec 1992

Mar 1993

May 1993

Jul - Nov 1993

Dec 1993

Sep 1994

Apr - May 1995

Nov - Dec 1995

Jan 1996
The third refueling and maintenance outage lasted 73 days. Major work included LP turbine inspection, ISI, SG sludge lancing, RCP motor replacement, SW system repairs, MOV and eddy current testing, and intake structure improvements.

The utility announced that the unit had achieved about $75 \%$ lifetime capacity factor for the first 5 years of operation.

A 6-day outage followed a turbine/reactor trip due to a broken restraint tab in a switchyard relay.

The unit was shut down when the component cooling water and DG HXs became clogged with mussels. This condition resulted in the NRC proposing a $\$ 50,000$ fine for failure to aggressively determine the cause of the reduction of water flow in the piping affected by the mussels. The extended outage was due to replacing the worn service water piping and completion of the piping erosion/corrosion inspection program. The outage lasted 194 days.

The NRC proposed a $\$ 50,000$ fine for alleged failure to diagnose conditions caused by biofouling of SW system.

The unit tripped when a circulating water pump tripped due to inadequate traveling screens. The unit was shut down for 6 days.

The unit had a 20-day outage to repair safety valves and pressurizer PORVs.

The NRC SALP report gave a Category 3 rating in one area, safety assessment/quality verification, and no Category 1 ratings.

The unit had a 37-day outage due to inoperability of the supplementary leak collection and release system. It was inoperable because of incomplete system design, equipment problems, and inadequate surveillance test procedures.

The NRC proposed a $\$ 62,500$ fine for allegedly operating with inadequate configuration and testing of the auxiliary building filter system and supplementary leak collection and release system. The fine was paid.

A turbine trip occurred after an EHC power supply failed. The outage lasted nine days.

The NRC proposed a $\$ 100,000$ fine for two violations: (1) was the alleged harassment of a worker for raising potential safety concerns and (2) the timely evaluation and reporting of significant safety hazards.

The fourth refueling and maintenance outage lasted 99 days.

The NRC proposed a $\$ 237,500$ fine for alleged violations involving repair of an isolation valve on a reactor coolant pipe.

The unit scrammed after an MSIV closed during testing. The closure was due to a failed pin in a solenoid. The outage to replace solenoids and pins lasted 2 weeks.

The fifth refueling and maintenance outage lasted 54 days.

The unit was shut down for 15 days due to a LPSI check valve leak and to repair an RCS instrument fitting leak.

All Millstone units were added to the NRC problem plant list. 
Mar 1996

The unit originally shut down to correct valve design deficiencies. The NRC ordered the licensee to address design basis issues and employee concerns similar to those found at Millstone 1.

Jun 1996

All Millstone units were changed to watch list Category 3, which requires Commission approval for restart. 


\section{MONTICELLO}

PRODUCTION COST and CAPITAL ADDITIONS (1996 Dollars)

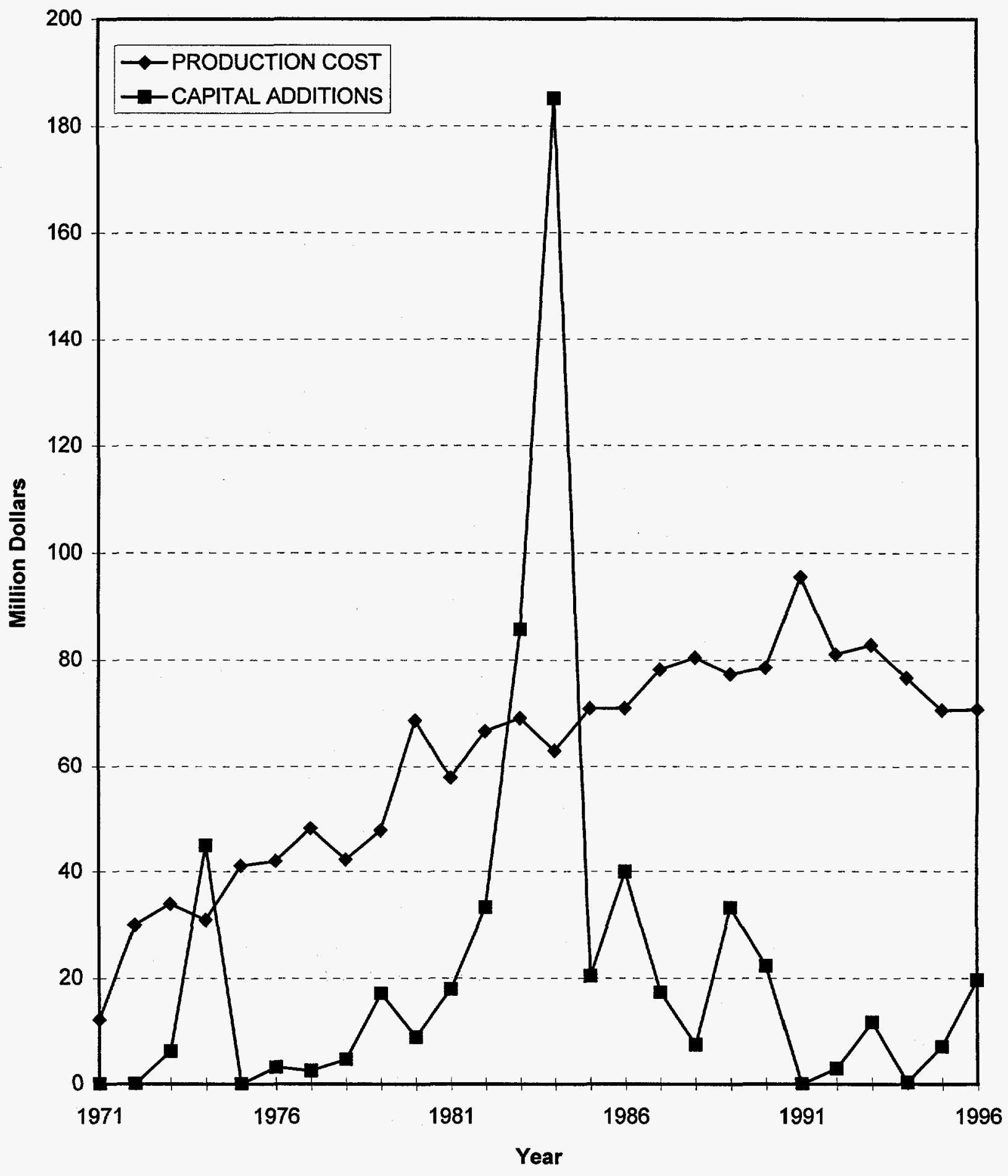




\section{NUCLEAR POWER PLANT OPERATING EXPERIENCE SUMMARY}

Unit data summary through December 1996

Unit: MONTICELLO

Location: WRIGHT COUNTY, MINNESOTA

Owner: NORTHERN STATES POWER CO.

Type: GENERAL ELECTRIC BWR

Construction Permit: 6/19/67

Operating License: $\mathbf{9 / 8 / 7 0}$

Commercial Oper. Date: 6/30/71
Nameplate Rating: 577 MWe

MDC Net MWe: 544 MWe

Cumul. Avail. Factor: 80.6

Cumul. Cap. Factor (MDC Net): 75.6

Cumul. Forced Outage Rate: 3.4 3-Year Avg. Cap. Factor (MDC Net): 89.1

License Expiration: 2010

OPERATING HISTORY (Through December 1996)

Date

1971

Nov 1971

1974

1975

1981

Oct 1981 - Jan 1982

Sep - Dec 1982

Dec 1982 - Jan 1983

Feb 1984 - Jan 1985

Mar 1986

Feb 1988

Oct 1988

Aug - Nov 1989

Jul 1990

Sep 1990

\section{Comment}

Feedwater pump problems occurred throughout the year.

Torus baffle and MSIV repairs required a 2.5 month outage.

The plant experienced several off-gas system explosions. A modified off-gas system was installed.

Several power reductions from high gaseous activity due to failed fuel occurred during the year.

The NRC issued a full-term operating license.

A major modification and refueling outage lasted 86 days. The outage was prolonged by turbine disc cracking problems, piping replacement, and severe cold weather.

The refueling outage was extended because of IGSC cracks in recirculation system piping.

Turbine bearing repair and alignment outages occurred.

A prolonged outage was caused by IGSC cracks found in several systems. All primary recirculation system piping was replaced, a new decontamination method (nitric permanganate) was successfully implemented, the LP turbine spindle was replaced, the condenser was retubed, and a hydrogen gas recombiner was added.

The plant received a high SALP rating; NRC relaxed the inspection program.

The NRC imposed a $\$ 50,000$ fine for Class $1 \mathrm{E}$ breaker replacement miscues.

The unit will be the first BWR to apply for renewal of its 40-year operating license. Monticello is the lead BWR of the DOE license renewal program to extend operating life the past original 40-year license term.

A refueling and maintenance outage lasted 84 days.

Replacing a recirculation pump seal required a 5-day outage.

Repair of a CRD pump required a 5-day outage. 


\section{MONTICELLO (Cont'd)}

Mar - May 1991

Jun 1991

Jun 1991

Apr 1992

Jan - Mar 1992

Aug 1993

Jun 1994

Sep - Oct 1994

Apr - May 1996

Jun 1996
A refueling and maintenance outage lasted 61 days. Major work included in-vessel ISI, recirculation and RWCU system decontamination, and HP turbine work. Three workers were injured during outage work in separate unrelated incidents.

The unit tripped due to a spurious main steam isolation signal and again the following day due to high-high signals from the IRMs. The second event prompted an NRC enforcement conference with plant managers to deal with poor performance of control room operators and supervisors.

The unit marked 20 years of service and had achieved a lifetime capacity factor of about $71 \%$.

The unit was shut down for 7 days to replace rotor pole piece bolts.

A refueling and maintenance outage lasted 54 days. Major work included full core off-load, recirculation system decontamination, ILRT, and human factors modifications of some control room panels.

The NRC SALP report awarded top Category 1 ratings in all functional areas.

The unit was shut down for 5 days after a scram to backfill the reactor water level instrumentation reference legs.

A refueling and maintenance outage lasted 40 days.

A refueling and maintenance outage lasted 47 days. Restart from the outage was delayed by 4 days due to vibration problems with the new turbine.

A 4-day outage followed a scram when both main generator stator cooling water pumps tripped. 
This Page Intentionally Left Blank 
NINE MILE POINT 1

PRODUCTION COST and CAPITAL ADDITIONS

(1996 Dollars)

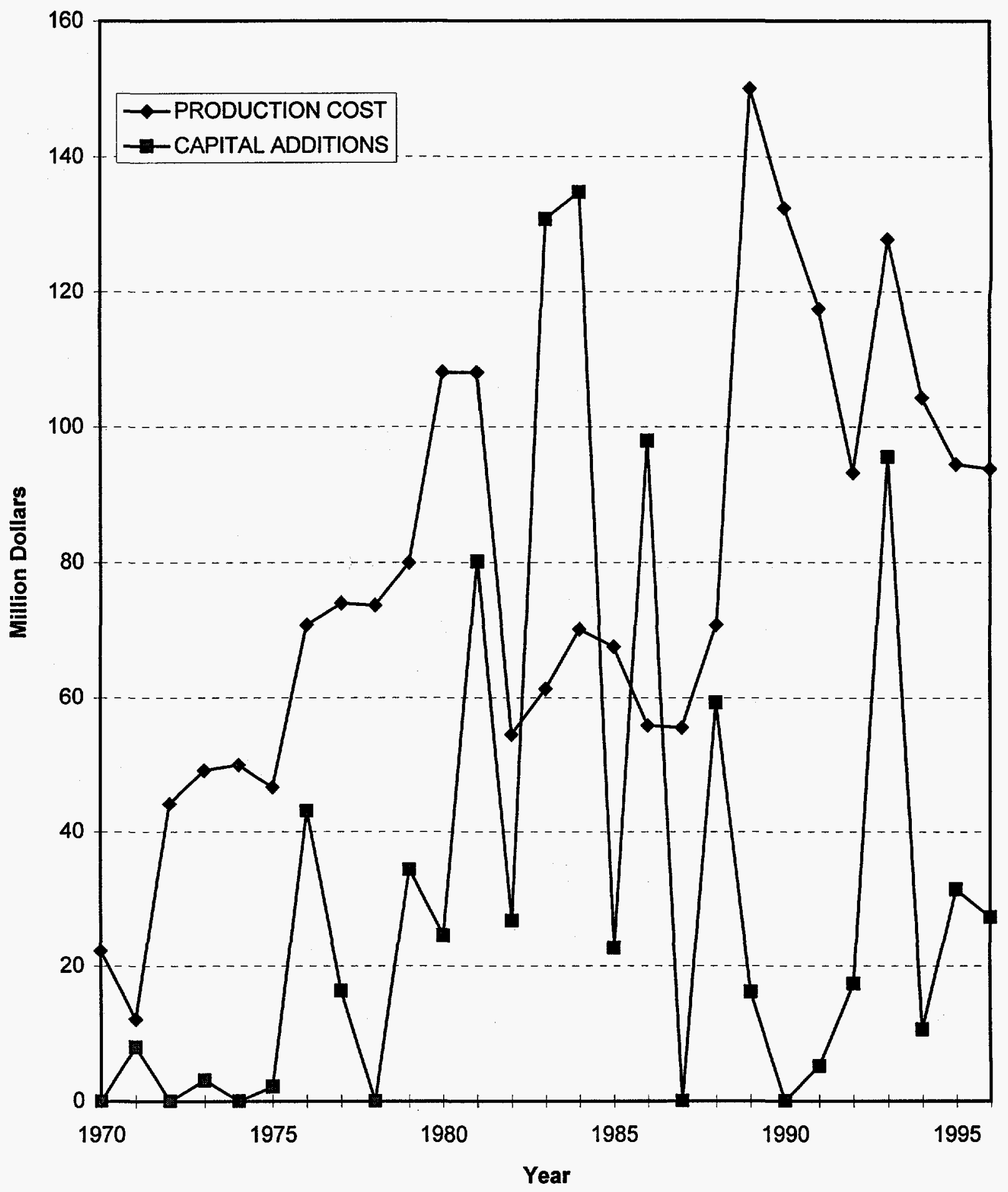




\section{NUCLEAR POWER PLANT OPERATING EXPERIENCE SUMMARY}

Unit data summary through December 1996

Unit: NINE MILE POINT 1

Location: OSWEGO COUNTY, NEW YORK

Nameplate Rating: 642 MWe

OWner: NIAGARA MOHAWK POWER CORP.

MDC Net MWe: 565 MWe

Type: GENERAL ELECTRIC BWR

Cumul. Avail. Factor: $\mathbf{6 6 . 2}$

Construction Permit: 4/12/65

Cumul. Cap. Factor (MDC Net): 60.1

Operating License: $12 / 26 / 74$

Cumul. Forced Outage Rate: $\mathbf{2 2 . 4}$

Commercial Oper. Date: 12/1/69

3-Year Avg. Cap. Factor (MDC Net); 93.5

License Expiration: 2009

OPERATING HISTORY (To December 1996)

Date

1970

Jan - Sep 1971

Apr - May 1971

Apr - Jun 1972

Apr - Jun 1973

Mar - Jun 1974

Dec 1974

Sep - Dec 1975

Mar 1976

Mar - Jul 1977

Mar - Jun 1979

Mar - Jul 1981

Jul 1981

\section{Comment}

A considerable outage time occurred during the year to resolve pipe hanger and restraint problems; cracks found in core spray system piping.

Above normal off-gas activity limited reactor power until new fuel was installed to replace leaking FAs in September; partial refueling poison curtain removed.

A 2-month shutdown was required for LP turbine blade repair and other maintenance.

A 2.5 month outage was required for refueling, removing the remainder of poison curtain, and replacing leaking fuel. Torus baffle damage was found.

A refueling outage was performed. Leaking fuel was removed; cracks were found in steam dryers; and torus baffles were removed.

A refueling outage was required for new fuel, control blade inspection, and CRD filter modifications.

A full-term operating license was issued.

A refueling outage was required for ISI, turbine maintenance, MSIV modifications.

A 23-day outage for RWCU system and turbine repair.

A refueling and maintenance outage was required to replace cracked RWCU pipe elbows and repaired cracked FW nozzles.

A refueling outage was required to make SRV discharge modifications. Bearing and shaft problems on one (of four) RCPs limited power until November when full flow was achieved with three remaining pumps.

A refueling and maintenance outage was performed. Turbine and other equipment problems caused several subsequent short outages.

The NRC proposed a $\$ 50,000$ fine for an alleged violation concerning disabling a safety system. 
Mar 1982 - June 1983

Jul 1983

Aug 1983

Mar - Jun 1984

Aug 1984

Mar - Jun 1986

Dec 1986

Apr 1987

Oct 1987

Dec 1987

Dec 1987 - Jul 1990

Jan 1989

Oct 1990

Oct 1990

Nov 1990

Dec 1990 - Jan 1991

Feb - Mar 1991
A scheduled maintenance outage was extended because of cracks found in HAZ of welds on recirculation piping safe ends; all 10 safe ends were replaced. Further cracks found in recirculation system piping necessitated fuel unload and decontamination. The problem resulted in NRC-mandated testing of all BWRs for IGSC cracking in large diameter recirculation system piping. Cracks were also found in the steam dryer during ISI.

The NRC assessed a $\$ 40,000$ fine for failure to note that MSL radiation monitors were inoperable.

The NRC assessed a $\$ 100,000$ fine for alleged falsification of QA inspection records.

A refueling outage was performed. IGSC cracks were found in CRD housing flanges and core spra' loops. All six MSRVs needed refurbishment before successful startup was accomplished.

The NRC proposed a $\$ 80,000$ fine for alleged violations of containment integrity from June to October 1983 and failure to test closure times on two RCS isolation valves.

A refueling and extensive maintenance outage was required to replace containment spray $\mathrm{HX}$, retube the condenser, and rebuild the CRD. Condenser retube cost was estimated at $\$ 6.5$ million.

The plant produced the lowest cost electric power of all GE BWRs for year.

The NRC assessed a $\$ 50,000$ fine for alleged violations concerning failure to comply with specified requirements in operations, $\mathrm{QA}$, maintenance, and radiation protection.

The plant completed a 415-day run, the longest continuous record for a U.S. BWR.

The unit was lowest cost electricity producer for 1985 through 1987.

An outage for FW valve repair was extended indefinitely because NRC placed the unit on the list of problem plants, which requires NRC approval before restart. Corrosion was found in the torus. Operator requalification problems and a poor performance rating from INPO prolonged the outage. The forced outage lasted 967 days.

The unit was placed on the NRC's problem plant list.

About 7000 gallons of slightly contaminated water was spilled; some flowed into the radwaste building sub-basement that contained high-level radioactive sludge from the July 1981 spill. NRC sent inspection team to investigate after learning of the 1981 incident through press accounts of an INPO study.

An INPO review of plant administration and operations noted many problems such as overdue PM, plant personnel not following procedures, and drawings that did not agree with actual plant configuration.

A 5-day outage followed a reactor scram while MSL high radiation channel test was being performed.

A failure of an MSIV forced a shutdown which lasted 11 days.

The plant entered mid-cycle outage early after turbine control valve oscillations caused operating problems. The outage lasted 39 days. 
Jul 1991

Jul 1991

Sep 1991

Dec 1991

Feb 1992

Apr - Jul 1992

May 1992

Feb - Apr 1993

Apr 1994

Jul 1994

Feb - Apr 1995

Apr 1996

Jun 1996

Jul 1996

Aug 1996

Nov 1996
The NRC removed the plant from the problem list, noting that the plant had received improved scores on a SALP report.

The unit was shut down for 11 days for maintenance to reduce drywell leakage.

A 15-day outage resulted after a scram from a main generator load rejection was caused by failure of a protective relay in a current transformer.

A 5-day outage was caused by failure of the FW control system.

A 15-day outage followed a reactor scram due to a failed TSV.

The reactor scrammed when the electronic pressure regulator failed. During the outage, repairs were made to the emergency condenser valves which required a complete core offload. The outage lasted 102 days.

The NRC proposed a $\$ 200,000$ fine for alleged violations involving isolation of the primary RHR alignment and operation of the plant outside TS.

A refueling and maintenance outage lasted 55 days.

A main generator/reactor trip occurred due to a defective relay on one of the $345-\mathrm{kV}$ lines. The unit was shut down for 8 days.

A 5-day outage followed a reactor scram caused by a failure of an electronic pressure regulator.

A refueling and maintenance outage lasted 55 days. The outage was entered 3 days early when Agastat relays in safety-related systems were found degraded.

The unit was shut down for 5 days to repair leaking feedwater heaters.

The NRC proposed and the licensee paid a $\$ 50,000$ fine for design control and safety evaluation problems with the reactor building's blowout panels.

The unit was shut down for 6 days to repair a feedwater pump.

The unit was shut down for 4 days to complete the repairs to the feedwater pump.

A 1-week outage followed a reactor scram due to the main generator tripping from a ground fault. 
NINE MILE POINT 2

PRODUCTION COST and CAPITAL ADDITIONS (1996 Dollars)

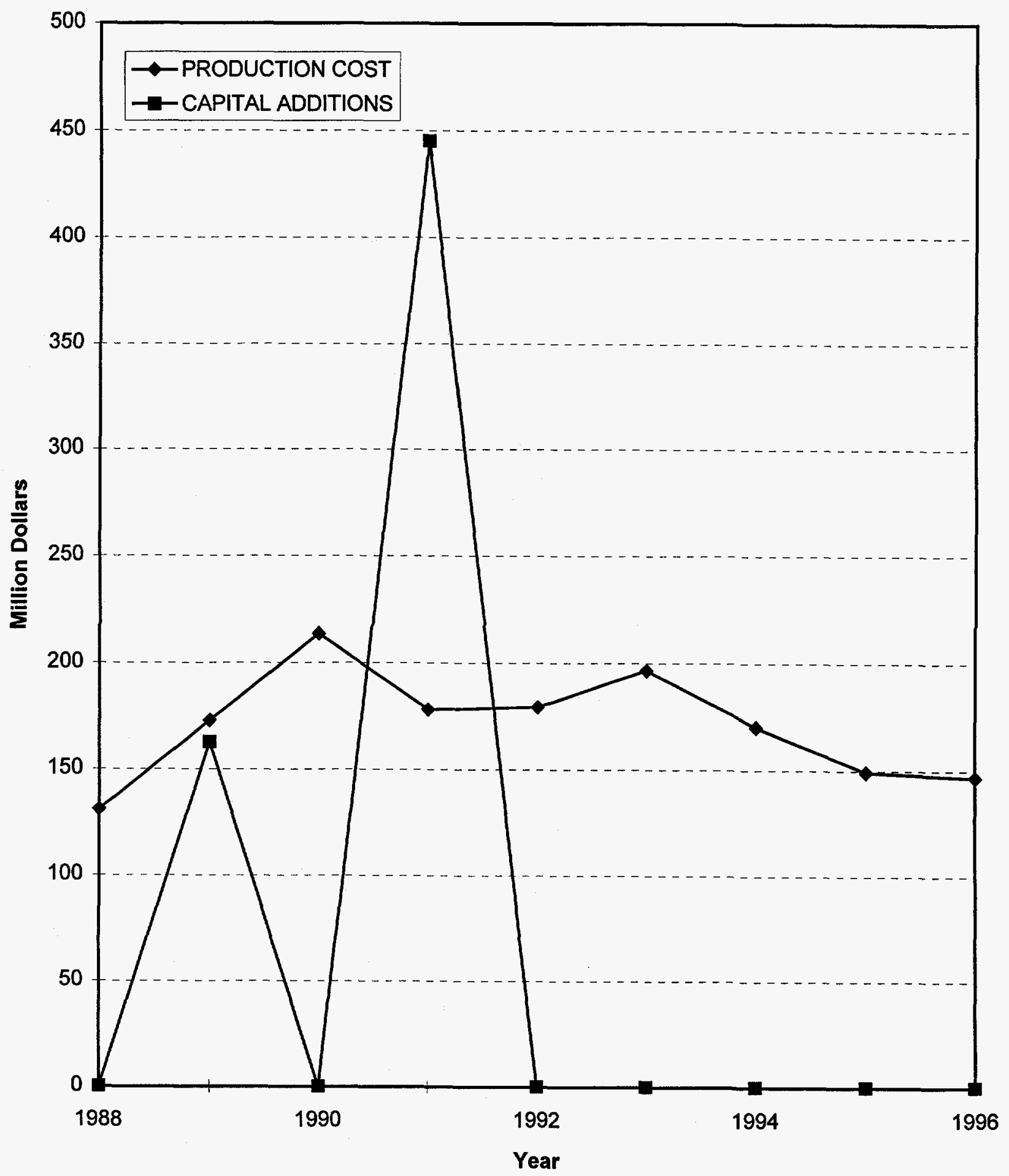




\section{NUCLEAR POWER PLANT OPERATING EXPERIENCE SUMMARY}

Unit data summary through December 1996

Unit: NINE MILE POINT 2

Location: OSWEGO COUNTY, NEW YORK

Owner: NIAGARA MOHAWK POWER CORP.

Type: GENERAL ELECTRIC BWR

Construction Permit: 6/24/74

Operating License: $7 / 2 / 87$

Commercial Oper. Date: 3/11/88
Nameplate Rating: 1214 MWe

MDC Net MWe: 1105 MWe

Cumul. Avail. Factor: 70.6

Cumul. Cap. Factor (MDC Net): $\mathbf{6 7 . 2}$

Cumul. Forced Outage Rate: 13.1

3-Year Avg. Cap. Factor (MDC Net): 87.9

License Expiration: 2027

OPERATING HISTORY (To December 1996)

\section{Date}

$1982-1986$

Sep - Dec 1986

Mar - May 1987

Jul 1, 1987

Nov - Dec 1987

Feb - Mar 1988

Mar 1988

May 1988

Aug 1988

Oct 1988 - Apr 1989

Jan 1989

Apr 1989

Apr 1989

Jul 1989

Sep 1989

\section{Comment}

Plant completion was delayed due to financial problems and construction delays. In August 1984 , NRC proposed a $\$ 100,000$ fine for alleged violations concerning construction and QA documentation.

Excessive leakage in experimental MSIVs (ball type) caused several delays.

The licensee announced plans to replace ball-type MSIVs with conventional Y-pattern globe valves; cost was estimated to be as much as $\$ 500,000,000$ for replacement power and associated plant modifications.

A full-power operating license was approved.

A maintenance outage for correction of FW system problems was prolonged due to rupture of fiberglass CST and consequent spill of about 260,000 gallons of water into the tank storage area and reactor building. The outage lasted 31 days.

The unit reached full power for the first time and began commercial operation.

The NRC proposed a $\$ 2500$ fine for alleged violation involving shipment of contaminated equipment.

A planned 3-week maintenance outage was extended because of a failed recirculation pump seal. The outage lasted 31 days.

The utility filed a lawsuit against $\mathrm{A} / \mathrm{E}$ and others for damages from construction delays caused by misconduct of design and construction work.

A planned 1-month maintenance outage was prolonged by discovery of defects in turbine and generator and flaws found in SW system controls. The outage lasted 155 days.

The unit was placed on the NRC's problem plant list.

The utility settled a lawsuit with GE over Mark II containment issues.

The unit was shut down for 5 days following a main generator trip/reactor scram.

The NRC found the licensee's operator requalification program unsatisfactory; operations continued with augmented shift crews.

The unit was shut down for 16 days for a scheduled maintenance outage. 
Oct - Nov 1989

Dec 1989

Dec 1989 - Feb 1990

May 1990

Sep 1990 - Jan 1991

Oct 1990

Mar 1991

Aug 1991

Jan 1992

Mar - Jun 1992

Aug - Sep 1992

Nov 1992

Oct - Nov 1993

Dec 1993

Mar 1994

Dec 1994

Jan 1995

Apr - Jun 1995

Sep 1995

Jul 1996

Sep - Nov 1996

Dec 1996
Following a reactor scram, acid was inadvertently introduced into the condenser tubes which raised copper limits above limits for the circulating water system. The outage lasted 22 days.

A reactor scram occurred because of troubleshooting the EHC system with inaccurate diagrams. The unit was shut down for 14 days.

The unit was shut down for a total of 43 days to resolve reactor FW pump problems.

The loss of the condenser vacuum because of an instrument air line break caused an outage of 14 days.

A refueling and maintenance outage lasted 147 days. The unit was shut down about 2 days early for the outage because of a generator field ground. Major work during the outage included replacement of nine (of 18) SRVs, turbine maintenance, RCP rework, and snubber testing.

A INPO report noted many problems with plant administration and operation.

The unit was shut down for 13 days after an unisolable leak occurred in the drywell.

The plant was shut down after a reactor scram and five UPSs failed, causing loss of control of room indicators, alarms, lighting and computers. A site area emergency was declared. An NRC investigation team was sent to the site. The outage lasted 45 days.

The unit was shut down for 5 days to repair degraded FW pump seals.

A second refueling and maintenance outage lasted 116 days.

A reactor scram occurred due to an operator error. The outage was extended due to smoke coming from the generator exciter. The outage lasted 16 days.

A 4-day outage followed a reactor scram caused by a RPS relay failing.

The third refueling and maintenance outage lasted 59 days.

A 6-day outage followed a main generator/reactor trip when a stator cooling water flow switch failed.

The unit was shut down for 8 days to investigate increasing drywell pressure.

A 10-day outage was necessary to repair a leaking HPCS valve in the drywell.

The unit was shut down for 5 days to repair an EDG mechanical governor.

The fourth refueling and maintenance outage lasted 55 days.

The unit had two outages for a total of 12 days. One outage was to repair one of the recirculation system FCVs and the other was to replace electrical bus items which had caused a partial LOSP.

The NRC proposed and the licensee paid a $\$ 80,000$ fine for employee discrimination.

A fifth refueling and maintenance outage lasted 36 days.

The unit was shut down for 4 days to inspect and adjust the shoot out steel. 
This Page Intentionally Left Blank 
NORTH ANNA

PRODUCTION COST and CAPITAL ADDITIONS

(1996 Dollars)

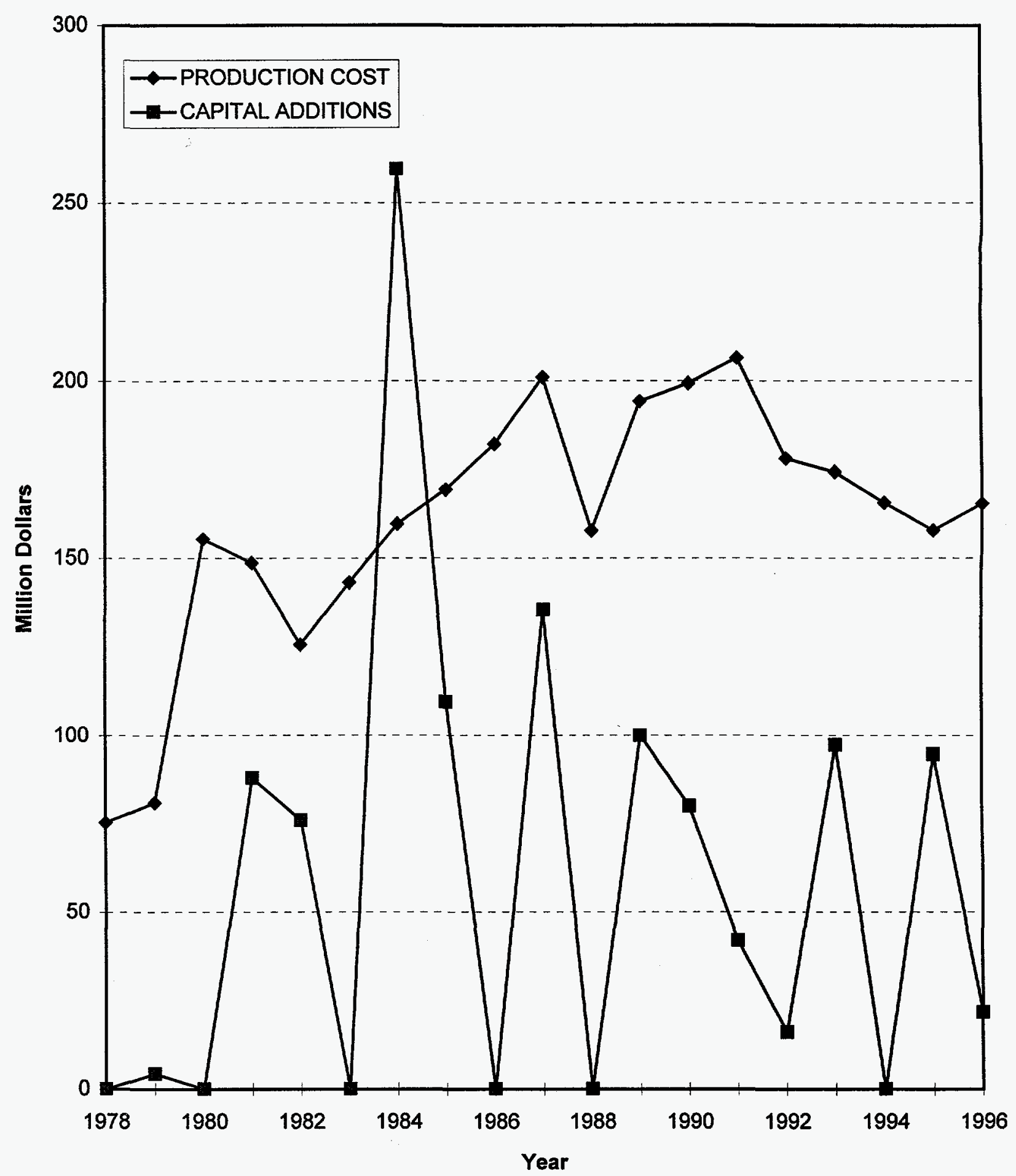




\section{NUCLEAR POWER PLANT OPERATING EXPERIENCE SUMMARY}

Unit data summary through December 1996

Unit: NORTH ANNA 1

Location: LOUISA COUNTY, VIRGINIA

Nameplate Rating: 994 MWe

Owner: VIRGINIA ELECTRIC POWER CO. MDC Net MWe: 900 MWe

Type: WESTINGHOUSE PWR

Cumul. Avail. Factor: $\mathbf{7 5 . 2}$

Construction Permit: 2/19/71

Cumul. Cap. Factor (MDC Net): $\mathbf{7 0 . 3}$

Operating License: $4 / 1 / 78$

Cumul. Forced Outage Rate: $\mathbf{8 . 8}$

Commercial Oper. Date: $6 / 6 / 78$

3-Year Avg. Cap. Factor (MDC Net): 91.6

License Expiration: 2018

OPERATING HISTORY (To December 1996)

Date

Mar - May 1979

Sep 1979 - Jan 1980

May 1980

Dec 1980 - Apr 1981

Oct 1981

May 1982 - Mar 1983

Oct 1983

Jan - Feb 1984

May - Sep 1984

Mar 1985

Aug 1985

Nov - Dec 1985

Dec 1985 - Jan 1986

\section{Comment}

A 33-day outage was forced by repairs and other required plant maintenance after a loss of cooling water to RCP A and the ensuing RCS pressure transient.

The unit was shut down for about 4 months for the first refueling after a RCS

pressure/temperature transient occurred because of a FW heater tube leak and a steam dump valve failed to close.

A 13-day outage was caused by repair to a FW valve.

The second refueling and maintenance outage was performed. major items included TMI modifications, fire protection and generator breaker work, RV ISI, and SG inspection.

The unit was shut down for a planned maintenance outage of 26 days.

The third refueling and maintenance outage lasted 293 days. The unit was shut down early for refueling after a noise occurred in SGs. The problem was later identified as control rod guide tube support pin nuts. The outage was prolonged to repair cracked thermal sleeve welds and to remove an RCS flow splitter. The unit remained shut down after a transformer failure caused extensive damage to the main generator.

The unit was shut down for scheduled fall maintenance.

The unit was shut down for a 31-day outage to repair leaking SG tubes.

The fourth refueling and maintenance outage was performed. The outage was extended to late September to resolve problems with coating on containment ductwork that was found to be unqualified for nuclear installation. The NRC assessed a $\$ 40,000$ fine, later reduced to $\$ 20,000$, for alleged inadequacy in the QC program that led to the coating problem.

The NRC assessed a $\$ 40,000$ fine for alleged material false statements regarding the Unit 2 reactor head vent system and the Unit 1 and 2 RTB maintenance and testing procedures. The action also included a citation for allegedly operating Unit 2 and Surry 1 and 2 with RCS vents inoperable.

The unit was shut down for a 15-day outage to repair leaking SG tubes.

The fifth refueling and maintenance outage lasted 52 days.

Repair of a RV head thermocouple Conoseal ${ }^{\otimes}$ leak caused a 19-day outage. 
Aug 1986

Aug - Sep 1986

Oct 1986

Dec 1986

Apr - Jun 1987

Jul - Oct 1987

Jan - Feb 1988

Dec 1988

Feb - Jul 1989

May 1989

Dec 1989

Jul 1990

Jan - Mar 1991

May 1991

Jul 1991

Dec 1991 - Jan 1992

Jan - Apr 1993

Sep - Oct 1994
The NRC assessed a $\$ 25,000$ fine for alleged noncompliance with NRC security requirements.

The unit was shut down for 28 days to repair main turbine blades.

Core power for both North Anna units was uprated to $2893 \mathrm{MWt}$ from $2775 \mathrm{MWt}$ after operating licenses were amended in August. A higher rating was expected to save $\$ 5$ million per year in fuel costs.

The NRC issued a license amendment allowing a 7-year recovery for full power operation dating 40 years from the date of the operating license.

The sixth refueling and maintenance outage was performed. Major items included SG inspection and cleaning and RCP seal inspection.

The unit experienced a SG tube rupture which resulted in a small release of radiation to the atmosphere. The outage for repair and inspection lasted 90 days. Power was restricted by NRC to $49 \%$ until early November because of SG problems.

The unit was manually shut down for SG cleaning after a trip from high SG levels. SGs had suffered resin intrusion from condensate demineralizers. Total outage time was 27 days

The NRC assessed a $\$ 100,000$ fine for alleged operation with inoperable steam flow channels. The base $\$ 50,000$ penalty was doubled because of previous similar problems.

The seventh refueling and maintenance outage lasted 127 days. The unit originally shut down because of a SG leak caused by a faulty tube plug which broke and punctured a SG tube. The unit remained shut down and entered the refueling outage. Major outage work included SG ECT testing and sludge lancing on all three SGs, 10-yr ISIs, RCP motor, SG secondary side, LP turbine rotor, and secondary pipe thinning inspections, SG tube plug replacements, replacement of 4 of $12 \mathrm{FW}$ heaters, and LLRTs.

The NRC assessed a $\$ 25,000$ fine for alleged failure to correct deficiencies in the control room ventilation and instrument air systems.

A reactor trip due to loss of EHC initiated extensive EHC enhancements which required a 15-day outage to implement.

The unit achieved a world record average burnup for a $\underline{W}$ unit using $17 \times 17$ FA of 58,417 MWd/MT.

The eighth refueling and maintenance outage lasted 57 days: major work included instrument air system upgrade, independent RCS level indicator installation, FW heater and secondary pipe replacement, SG girth weld inspection, primary work, ECT testing and tube plugging, and testing of pressurizer safety and MSSV setpoints.

A RCS pressure boundary leak required a 12-day outage to repair.

Main condenser air inleakage required a 13-day outage to repair.

All three SGs were declared inoperable following review of the SG eddy current testing. The unit was shut down for 73 days for SG inspection and tube plugging.

The ninth refueling and maintenance outage lasted 96 days. The unit replaced its SGs in a world record time of 51 days, 2 weeks ahead of schedule and $\$ 50$ million under budget.

The tenth refueling and maintenance outage lasted 31 days. 


\section{NORTH ANNA 1 (Cont'd)}

Mar 1995

Jul 1995

Feb - Mar 1996
The plant received all Category 1 ratings on its NRC SALP report, and the evaluations were lengthened to a 24-month cycle.

The NRC recognized the plant as a superior performer.

The eleventh refueling and maintenance outage lasted 30 days. 


\section{NUCLEAR POWER PLANT OPERATING EXPERIENCE SUMMARY}

Unit data summary through December 1996

Unit: NORTH ANNA 2

Location: LOUISA COUNTY, VIRGINIA

Nameplate Rating: 979 MWe

Owner: VIRGINIA ELECTRIC POWER CO.

MDC Net MWe: 887 MWe

Type: WESTINGHOUSE PWR

Cumul. Avail. Factor: 82.3

Construction Permit: 2/19/71

Cumul. Cap. Factor (MDC Net): $\mathbf{7 8 . 2}$

Operating License: $\mathbf{8 / 2 1 / 8 0}$

Cumul. Forced Outage Rate: $\mathbf{5 . 6}$

Commercial Oper. Date: $12 / 14 / 80$

3-Year Avg. Cap. Factor (MDC Net): 83.6

License Expiration: 2020

OPERATING HISTORY (To December 1996)

Date

$1979-1980$

May 1981

Jun - Aug 1981

Mar - Jun 1982

Jul 1982

Apr - May 1983

Mar - Apr 1984

Aug - Nov 1984

Feb - Apr 1986

Aug 1986

Oct 1986

Dec 1986

May 1987

Aug - Nov 1987

\section{Comment}

Evaluation of cracks in primary coolant flow splitter delayed startup beyond July 1979 date. A post-TMI licensing pause by NRC further delayed startup to August 1980.

The unit was shut down for a 12-day maintenance outage.

Two main transformer failures and a fire in another main transformer caused the unit to be off-line for almost 8 weeks.

The first refueling and maintenance outage lasted 96 days.

The unit was shut down for $\mathbf{4 5}$ days to repair cracks in SG thermal sleeves.

The second refueling and maintenance outage lasted 57 days.

The unit was shut down for a short planned maintenance outage of 9 days.

The third refueling and maintenance outage lasted 94 days. The unit was shut down 2 weeks early to resolve problems with coating on containment ductwork that was found to be unqualified for nuclear installation. In October, about 81,000 gallons of borated water flooded the containment from recirculation spray pump casing leak.

The fourth refueling and maintenance outage lasted 42 days.

The unit experienced 13 days of outage time to find and repair RCS leaks in valves and RCP seal housing O-rings.

Core power for both North Anna units was uprated to $2893 \mathrm{MWt}$ from $2775 \mathrm{MWt}$ after operating licenses were amended in August. A higher rating was expected to save $\$ 5$ million per year in fuel costs.

NRC issued a license amendment allowing a 9.5 year recovery of construction time for full power operation dating 40 years from the date of the operating license.

The unit was shut down for 9 days to repair leaking RCP seal.

The fifth refueling and maintenance outage lasted 73 days: major work included repair of RCP seals, SG cleaning and inspection, and replacement of a drain cooler and a FW heater. 
Apr 1988

Dec 1988

Feb - May 1989

May 1990

Aug - Oct 1990

Jun 1991

Sep 1991

Feb - Apr 1992

Apr 1993

Sep - Oct 1993

Jun 1994

Mar - May 1995

Mar 1995

Jul 1995

Sep - Oct 1996

Oct 1996

Nov 1996
The utility paid a fine of $\$ 100,000$ to the NRC for alleged operation with two of three MSL flow channels inoperable. The fine was doubled because of past poor performance and lack of prompt corrective action on the part of the licensee.

The unit completed the year with a capacity factor of $98.1 \%$.

The sixth refueling and maintenance outage lasted 78 days: major work included SG cleaning and inspection, replacement of four main FW heaters, inspection of RCPs and LP turbines, LLRT, and containment isolation valve repair.

The unit completed a full year of continuous operation and went on for a new world PWR continuous operation record of 469 days. The net capacity factor during the record run was $96 \%$.

The seventh refueling and maintenance outage lasted 74 days, shutdown occurred 2 days early because of high primary-to-secondary leakage. Major work included SG inspection, cleaning and girth weld inspection, 10-year RPV ISI, RCP refurbishment and turbine inspection.

The unit completed a record 469-day run.

The unit tripped when a main FW regulating valve closed and a steam dump system malfunction caused an SI. The unit was shut down for 7 days for maintenance on a station service transformer.

The eighth refueling and maintenance outage lasted 59 days: major work included SG ECT and tube plugging, RCP motor, DG, HP turbine, and main generator and exciter inspections, and modifications of the fuel transfer system drive and vertical control boards. The pressurizer safety valves and MSSVs failed their setpoint tests due to setpoint drift.

Two 5-day outages occurred. One was caused by a generator voltage regulator malfunction and the other by excessive vibration in the feedwater system.

The refueling and maintenance outage lasted 51 days.

A 1-week outage was necessary to repair leakage from a RCP seal injection line.

The tenth refueling and maintenance outage lasted 68 days. The steam generators were replaced.

The plant received all Category 1 ratings on its NRC SALP report, and the evaluations were lengthened to a 24-month cycle.

The NRC recognized the plant as a superior performer.

The eleventh refueling and maintenance outage lasted 36 days.

Later in the month, the unit was shut down for 4 days to repair a steam leak on the high pressure turbine balance line.

The unit was shut down for 41 days following a generator trip/reactor scram. The stator water cooling flow to the main generator was blocked by foreign material. 
OCONEE

PRODUCTION COST and CAPITAL ADDITIONS (1996 Dollars)

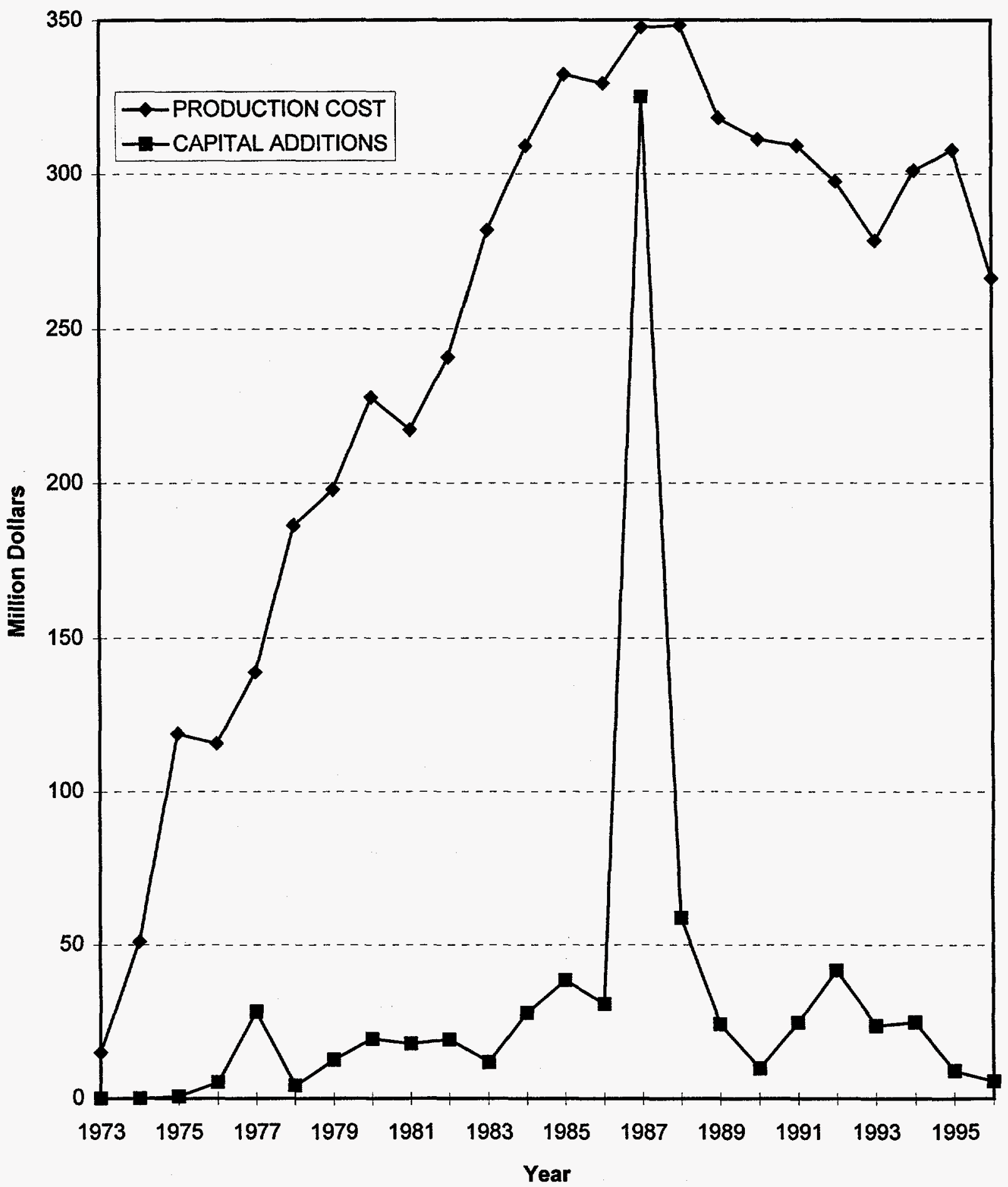




\title{
NUCLEAR POWER PLANT OPERATING EXPERIENCE SUMMARY
}

\author{
Unit data summary through December 1996
}

Unit: OCONEE 1

Nameplate Rating: 934 MWe

Location: OCONEE COUNTY, SOUTH CAROLINA

MDC Net MWe: 846 MWe

Owner: DUKE POWER CO.

Cumul. Avail. Factor: 76.6

Type: BABCOCK \& WILCOX PWR

Cumul. Cap. Factor (MDC Net): $\mathbf{7 2 . 5}$

Construction Permit: 11/6/67

Cumul. Forced Outage Rate: 9.3

Operating License: $2 / 6 / 73$

3-Year Avg. Cap. Factor (MDC Net): 80.9

Commercial Oper. Date: $7 / 15 / 73$

License Expiration: 2013

OPERATING HISTORY (To December 1996)

Date

1971

1972

Feb 1973

Mar 1973

Jul 1973

May 1974

Oct 1974 - Mar 1975

Feb - May 1976

Oct - Nov 1976

Nov - Dec 1976

Jan - Aug 1977

Aug - Oct 1977

Apr - May 1978

Sep - Oct 1978

\section{Comment}

Plant completion delays were attributed to $\mathrm{B} \& \mathrm{~W}$ late delivery of major components, problems with CRDs, and Bingham factory problems with reactor coolant pump (RCP) vibration. W pumps were substituted, but they also suffered vibration problems. The utility underestimated the work force effort to construct the plant.

An instrument nozzle failure during hot functional testing caused an extensive 9-month delay. About 1100 valves had to be replaced because of defects. RCP vibration problems caused a 4-month delay in startup.

A full-term license was issued but the power was limited to $.5 \%$ until RCP vibration tests were evaluated by AEC.

A RCP motor oil fire required about 5 weeks to repair.

The plant was declared commercial at $75 \%$ power.

A 5-week maintenance shutdown occurred.

The first refueling and maintenance outage was performed. The outage was extended because of problems with refueling equipment and RCP motors.

The second refueling and maintenance outage lasted 58 days: an additional shutdown was required to assess surveillance specimen tube damage.

A shutdown for 15 days was required to repair SG tube leaks.

Shut down for 18 days was required for turbine vibration problems, and another 12 days was needed for SG tube repairs.

The unit was shut down on several occasions for SG tube leak repairs, total outage time was more than 46 days.

The third refueling and maintenance outage was performed. Major work included SG repair and RCP seal work. Full power authorization was received in November.

SG tube leaks caused a 32-day outage.

The fourth refueling and maintenance outage lasted 6 weeks. The outage was extended because of SG maintenance and problems with a bad CRDM stator. 
Jun - Jul 1979

Aug - Sep 1979

Nov 1979 - Feb 1980

Jun - Jul 1980

Feb 1981

Jun - Dec 1981

Jan 1982

Feb 1982

Mar 1982

May - Jun 1982

Feb 1983

Jun 1983

Jun - Aug 1983

Oct - Nov 1984

Oct 1985

Feb - May 1986

Feb - May 1986

Oct 1986

Feb 1987

Apr 1987
The unit was shut down to resolve generic implications of TMI-2 event. The outage was extended for NRC-mandated modifications to the AFW system and other modifications.

RCS valve packing leakage problems forced about a 1-month shutdown.

The fifth refueling and maintenance outage was performed. Major work included TMI modifications, SG tube inspections, and SG manway gasket changes. The outage was extended for piping support inspection and modifications.

About a 1-month outage was needed for modifications to emergency power system.

A 23 day outage was attributed to repair SG tube leaks and core flood tank check valves.

The sixth refueling and maintenance outage included 10-year ISI and major maintenance. Major work included NUREG-0737 and Appendix R modifications, installation of remote shutdown system, and replacement of RPV thermal shield fasteners.

Two outages totaling 24 days were attributed to turbine/generator problems and FW heater leaks.

A 17-day outage was required for SG tube repairs.

An 18-day outage was forced for SG tube repairs. NRC levied a $\$ 44,000$ fine for an alleged incident involving an instrument test connection left uncapped for several months.

A 24-day outage was forced for repair of CRDs damaged by inleakage of water. Additional work included FW heater and pressurizer relief valve repair and inspection of reactor building secondary shielding wall tendons.

An INPO report was released that praised unit operations in four areas and called for improvement in four other areas.

A fine of $\$ 180,000$ by the NRC for several alleged violations of containment integrity at Unit 1 and Unit 3 was rescinded by the NRC because of the utility's positive response to findings.

The seventh refueling and maintenance outage was performed. Several FA hold-down springs were found broken.

The eighth refueling and maintenance outage was performed.

The unit was shut down for 11 days to correct SG tube leaks.

The ninth refueling and maintenance outage lasted 81 days: major work included turbine and RPV flange weld inspections.

The NRC assessed a $\$ 25,000$ fine for alleged violations concerning inadequate barriers for a portion of the plant protected area.

All three units shut down because of lack of low pressure service water (LPSW) due to low lake level and arrangement of intake water structure. Unit 1 restarted after 16 days.

A thirteen-day outage was required to replace the main transformer. Power was restricted to about $80 \%$ because the replacement transformer was undersized.

All three units experienced degraded heat transfer capability because of sediment accumulation in Lake Keowee. Unit 1 continued operation at $80 \%$ because of a undersized spare transformer. 
Sep - Nov 1987

Dec 1987

Jan 1989

Jan 1989

Apr 1989

Dec 1989

Jan 1990

Apr - Jun 1990

Aug 1990

Jul 1991

Aug - Sep 1991

Sep 1991

Feb 1992

Apr 1992

May 1992

Dec 1992 - Feb 1993

Apr - Jun 1994
The tenth refueling and maintenance outage lasted 72 days: major work included SG cleaning, RCP seal replacement, generator rewinding and inspection, and FW pump work. Turbine/generator needed rebalancing after initial startup, adding 6 days to the outage time.

A $\$ 25,000$ fine proposed by the NRC for faulty AFW system calculations was withdrawn based on licensee's analysis that showed the system to be adequate.

The eleventh refueling and maintenance outage lasted 42 days. The outage occurred 24 days early because of an electrical fire that interrupted power to all four RCPs. The NRC sent an AIT to investigate the event. Major work during the outage included maintenance on $6900 \mathrm{~V}$ switchgear, SG tube plugging, and component cooling water system upgrading.

The NRC assessed a $\$ 25,000$ fine for alleged failure of licensee to provide adequate procedures for the high pressure SI system.

The NRC assessed a $\$ 25,000$ fine for alleged inoperability of all three reactor building cooling units.

The NRC proposed a $\$ 50,000$ fine for alleged failures in the physical security program at Oconee, Catawba, and McGuire.

The NRC issued the utility a license to locate an independent spent fuel storage facility at the site.

The twelfth refueling and maintenance outage lasted 41 days: major work included SG tube plugs, RCP seal work, and cleaning of heat exchangers.

The NRC proposed a $\$ 25,000$ fine for alleged failure to take prompt action regarding a design error in reactor building penetration room ventilation system.

The unit achieved a record 100 billion- $\mathrm{kWh}$ lifetime power production.

The thirteenth refueling and maintenance outage lasted 60 days: major items included HPSI pump motor replacement, RCP motor work, and nuclear instrument calibration.

The unit was placed under a NRC confirmatory letter after two related events during the refueling outage caused heatup of reactor coolant and loss of RCS inventory. The letter required increased management oversight and an investigation into the events.

The NRC proposed fines of $\$ 125,000$ related to the problems that occurred in September 1991 concerning degraded operation of the decay heat removal system. The fines were paid in March 1992.

An NRC SALP report gave the site top Category 1 ratings in three functional areas and no low Category 3 ratings.

A RCP seal leak required a 14-day outage to repair.

The fourteenth refueling and maintenance outage lasted 32 days: major work included SG ECT and tube plugging/restoration, replacement of one RCP motor, and inspection of a LP turbine and all $4160 / 6900 \mathrm{~V}$ breakers. The outage was extended due to an SG inspection and a core flood check valve problem.

The fifteenth refueling and maintenance outage lasted 59 days. 
Aug 1994

Apr 1995

Nov - Dec 1995

Mar 1996

Oct 1996 - Jan 1997
The NRC proposed a $\$ 15,000$ fine for alleged violations involving failure to identify and independently verify location of FAs during movement of fuel from the spent fuel pool to the reactor core. Although the violation was the lowest severity, level 4 , a fine was proposed because it was the fourth occurrence.

The unit was shut down for 13 days to repair the CRD stators.

The sixteenth refueling and maintenance outage lasted 38 days.

The NRC proposed and the licensee paid a $\$ 50,000$ fine for mispositioning a fuel assembly in the spent fuel pool.

The unit was shut down for 132 days to inspect and repair the MSR drain lines and associated piping. This was in response to the MSR drain line rupture in Oconee 2. 


\section{NUCLEAR POWER PLANT OPERATING EXPERIENCE SUMMARY}

Unit data summary through December 1996

Unit: OCONEE 2

Location: OCONEE COUNTY, SOUTH CAROLINA

Nameplate Rating: 934 MWe

Owner: DUKE POWER CO.

MDC Net MWe: 846 MWe

Type: BABCOCK \& WILCOX PWR

Cumul. Avail. Factor: $\mathbf{7 8 . 2}$

Construction Permit: 11/6/67

Cumul. Cap. Factor (MDC Net): 73.0

Operating License: 10/6/73

Cumul. Forced Outage Rate: 9.6

Commercial Oper. Date: $\mathbf{9 / 9 / 7 4}$

3-Year Avg. Cap. Factor (MDC Net): 78.8

License Expiration: 2013

OPERATING HISTORY (To December 1996)

Date

Jan - May 1974

Jul - Oct 1974

Jan - Mar 1975

Feb 1976

Apr - Jul 1976

Dec 1976

May - Aug 1977

Oct - Nov 1977

Apr 1978

Nov - Dec 1978

May - Jun 1979

Sep - Oct 1979

Mar - Jun 1980

Nov - Dec 1980

Mar 1981

\section{Comment}

An extended outage after a RCP seal line leak resulted in a spill. The fuel was unloaded to retrieve loose objects from RCS.

The plant experienced several CRD stator failures and RCP motor problems.

The plant shut down for RCP motor repairs and valve leakage problems.

An 8-day shutdown was required for RCP seal and CRD stator repairs. The plant operated at reduced power through March because of low oil levels in RCP motors.

The first refueling and maintenance outage was performed. Major work included inspection and repair of reactor internals.

A 21-day outàge was attributed to SG tube leakage problems and repairs to letdown outlet valve.

The second refueling and maintenance outage was performed. Major work included SG tube work.

A total of 29 days of outage time occurred on two occasions because of apparent SG tube leaks; no leaks could be found.

A 19-day outage was required for repair of pressurizer valves and plugging SG tubes.

The third refueling and maintenance outage lasted two months.

The unit was shut down to resolve generic implications of TMI-2 event. The outage extended to repair valves and condenser tube leaks.

The unit was shut down to tie in motor-driven EFW pumps. Startup was delayed because of NRC-required modifications, water chemistry problems, and high silica in SGs.

The fourth refueling and maintenance outage was performed. Major work included inspection and modification to piping and supports.

A 28-day outage was required for plant modifications and other maintenance.

A 13-day outage was required for RCP maintenance. 
Sep - Nov 1981

Dec 1981 - May 1982

Jun - Jul 1982

Sep - Oct 1982

May 1983

Sep - Nov 1983

Nov - Dec 1983

Feb 21, 1985

Feb - Apr 1985

Jun 1985

Feb 1986

Aug - Oct 1986

Mar 1987

Apr 1987

Feb - Apr 1988

Jul 1988

May - Jul 1989

Sep - Oct 1990

Nov 1990

Jul 1991
A 10-day outage was required for low oil levels in RCP motors. A second outage of 13 days was required for SG tube leak repair.

The fifth refueling and maintenance outage was performed. Major items included replacement of RPV thermal shield fasteners and broken holddown springs on FAs, and 10year ISI. Outage was extended for containment secondary shield wall tendon replacement.

Repair of a ruptured 24-inch HP turbine exhaust line elbow caused by steam erosion caused a 14-day outage.

The unit was shut down on two occasions to repair the pressurizer code relief valves and RCP leakage; one outage lasted five days, the other lasted six days.

The unit was shut down twice for a total of 14 days to repair PORV block valves.

The sixth refueling and maintenance outage lasted 74 days: outage was extended for work on neutron source monitor.

\section{A 9-day outage was required for $\mathrm{RCP}$ seal replacement.}

The unit set a new world record of 439 days of continuous operation by an LWR.

The seventh refueling and maintenance outage lasted 60 days: during the outage, a spill of contaminated water occurred from the RCS through a leaky cross-tie valve into another system. The total amount of water lost was about 50 gallons to Lake Keowee.

Three outages occurred SG cleaning, repair of CRDMs, and RCP seals. Total time for the outages was about 25 days.

The NRC proposed a $\$ 25,000$ fine for alleged violations of security requirements.

The eighth refueling and maintenance outage lasted 64 days: major work included SG ECT and inspections. During the outage, a SW test revealed that the system could be disabled under certain conditions. This deficiency applied to all three units.

The NRC proposed a $\$ 25,000$ fine for deficiencies in the emergency FW calculations. The fine was withdrawn in December 1987 because the addition of the motor-driven pumps met the requirements.

An outage of 5-days was necessary for testing the HX cooling of one train of LPSI.

The ninth refueling and maintenance outage lasted 67 days: major work included rewinding main generator rotor, SG chemical cleaning, and RCP work. Main generator Alterrex ${ }^{\circledast}$ coupling leaks and turbine runback problems caused the unit to operate at reduced power for several days.

A 10-day outage was required for SG tube leak repairs.

The tenth refueling and maintenance outage lasted 45 days: major items included ISI on SGs, RV, and pressurizer, work on RCS, MOVs, and PORVs, and LP turbine repair.

The eleventh refueling and maintenance outage lasted 44 days: major items included RCP motor replacement, ILRT, and SG tube plugging.

A SG tube leak caused a 9-day outage for repairs.

The unit operated at reduced power during the month because of problems with heater drain pumps and secondary plant leaks. 
Jan - Mar 1992

Apr 1992

Oct 1992

Apr - Jun 1993

Apr 1994

Jul - Aug 1994

Oct - Nov 1994

May 1995

Mar - May 1996

Sep 1996 - Feb 1997
The twelfth refueling and maintenance outage lasted 58 days: major work included RPV ISI, replacing one RCP motor, RCP motor major PM, inspection of one LP turbine, valve maintenance and testing, and SG ECT, plugging, and restoration.

An NRC SALP report gave the site top Category 1 ratings in three functional areas and no low Category 3 ratings.

A LOSP was caused by battery charger misoperation. The unit was shut down for 7 days.

The thirteenth refueling and maintenance outage lasted 55 days.

The unit was down for 4 days following a reactor scram due to a feedwater pump tripping.

The unit was shut down for 8 days to repair a SG tube leak.

The fourteenth refueling and maintenance outage lasted 43 days.

The unit was shut down for 19 days to repair a leaking expansion joint.

The fifteenth refueling and maintenance outage lasted 39 days.

A second stage MSR drain line ruptured. Seven workers were hospitalized. Repairs and inspections required the unit be shut down for 132 days. An AIT was sent by the NRC. 


\title{
NUCLEAR POWER PLANT OPERATING EXPERIENCE SUMMARY
}

\author{
Unit data summary through December 1996
}

Unit: OCONEE 3

Location: OCONEE COUNTY, SOUTH CAROLINA

Owner: DUKE POWER CO.

Type: BABCOCK \& WILCOX PWR

Construction Permit: 11/6/67

Operating License: $7 / 19 / 74$

Commercial Oper. Date: 12/16/74
Nameplate Rating: 934 MWe

MDC Net MWe: 846 MWe

Cumul. Avail. Factor: 76.7

Cumul. Cap. Factor (MDC Net): 73.6

Cumul. Forced Outage Rate: 9.6

3-Year Avg. Cap. Factor (MDC Net): 79.0

License Expiration: 2014

OPERATING HISTORY (To December 1996)

Date

Dec 1974 - Jan 1975

Apr - May 1975

Jun 1975

Sep - Oct 1975

Feb - Mar 1976

Mar - Apr 1976

Jul 1976

Sep - Nov 1976

Feb 1977

Jun 1977

Jul 1977

Oct - Dec 1977

Jun - Jul 1978

Apr - Oct 1979

Nov 1979

Mar - May 1980

\section{Comment}

A 21-day shutdown was required for planned maintenance and inspection of turbine strainers. Additional inspection was required for excessive condenser air leakage.

RCP seal leakage problems caused a total of 34 days of outage time.

A 13-day outage was required for RCP leakage repair again.

A 12-day shutdown was required for RCP seal repair and main generator repairs.

A 9-day shutdown was required for RCP seal repair.

A 28-day shutdown was required to assess and repair surveillance specimen tube damage.

A 10-day shutdown was required to repair SG tube leaks.

The first refueling outage was performed. Condenser discharge valves failed to open and flooded the turbine building basement.

A 9-day shutdown was required to repair SG tube leaks.

A 16-day shutdown was required to repair SG tube leaks and resolve low RCP motor oil level.

A 12-day shutdown was required to repair SG tube leaks.

The second refueling and maintenance outage lasted about 6 weeks, a control rod was recoupled during a 6-day outage later in December.

The third refueling and maintenance outage was performed .

The unit was shut down to resolve generic implications of TMI-2 event. The outage extended to the fourth refueling and maintenance outage; major work included inspection and repair of pipe hangars and supports.

A significant event occurred in which a temperature transient resulted in a loss of power to the ICS and NNI systems. Operation resumed after 7 days of investigation.

The unit was shut down for NRC-required TMI modifications. 
Jun - Jul 1980

Nov 1980 - Mar 1981

Feb - Mar 1982

Apr - Oct 1982

Sep 1983

Mar - May 1984

Nov 1984

Mar 1985

Aug - Oct 1985

Nov - Dec 1985

Oct 1986

Dec 1986 - Apr 1987

Jul 1987

Jul 1987

Apr 1988

Aug - Sep 1988

Nov - Dec 1989

Aug 1990

Dec 1990

Feb - Mar 1991

Nov 1991
The unit was shut down to repair leaks in SGs and repair several cracked studs on primary manway covers.

The fifth refueling and maintenance outage lasted 77 days.

A 42-day outage was required for repair of SG tube leaks and HPSI nozzles.

The sixth refueling and maintenance outage lasted 63 days. The outage was entered earlier than scheduled because of repairs needed to internal SG AFW headers. Other major work included 10-year ISI, core support bolt replacement, and SG modification. Another outage of 11 days was caused by SG tube leaks and pressurizer code relief valve work.

The NRC granted utility a license amendment to increase spent fuel storage capacity.

The seventh refueling and maintenance outage lasted 79 days.

The unit was shut down for about 2 weeks to repair SG tube leakage.

The unit was shut down for 11 days to repair MSR tube leaks.

The eighth refueling and maintenance outage lasted 61 days.

The unit was forced to shut down on three occasions for repair of main turbine bearings. Total outage time was 29 days.

All three units shut down because of lack of low pressure service water (LPSW) due to low lake level and arrangement of intake water structure. Unit 3 restarted after 21 days.

The ninth refueling and maintenance outage lasted 100 days. The outage was entered early because of continuing RCP problems. Other major work included relocation of motor-driven EFW pump suction piping, SG inspection, ISI of Class 1 and 2 piping, and generator rotor rewinding. Generator bearing vibration problems delayed startup for several weeks. SG tube leaks caused an additional 9 days of outage time.

The utility installed a Smart Auto Signal Selector in Unit 3 in an effort to reduce costly unplanned reactor trips resulting from signal failures.

NRC proposed a $\$ 25,000$ fine for an alleged violation involving a unit startup with valves and breakers mispositioned. The fine was reduced from $\$ 50,000$ because of good performance and prompt, extensive corrective action.

A 13-day shutdown was required to repair SG tube leaks.

The tenth refueling and maintenance outage lasted 43 days; major work included SG nozzle dam installation and a number of plant modifications.

The eleventh refueling and maintenance outage lasted 45 days; major work included SG tube plugging, RV head weld ISI and main turbine maintenance. The outage was extended for several days because of main generator problems.

The NRC proposed a $\$ 25,000$ fine for the alleged failure to take prompt corrective action for a design error in the penetration room ventilation system. The utility paid the fine.

The unit was the top performing U.S. plant for 1990 , with a capacity factor of $97.13 \%$.

The twelfth refueling and maintenance outage lasted 45 days; major work included SG tube plugging, SG plug restoration, and RCP motor replacement.

A reactor coolant leak on an instrument line fitting required 8 days to repair. 
Dec 1991

Apr 1992

Jul - Sep 1992

Oct 1992

Dec 1992

Dec 1993 - Feb 1994

Mar 1994

Jul 1994

Jun - Jul 1995

Nov 1996 - Mar 1997
The unit was shut down to repair a CRD motor. The outage was continued to repair a low pressure injection piping leak. Total outage time was 23 days.

An NRC SALP report gave the site top Category 1 ratings in three functional areas and no low Category 3 ratings.

The thirteenth refueling and maintenance outage lasted 68 days: major work included inspections of a LP turbine, main generator, and all $4160 / 6900 \mathrm{~V}$ breakers, SG ECT and tube plugging, RCP motor replacement, valve maintenance, and CRD system repair and testing.

A 13-day outage was required to repair generator seal oil problems.

The NRC proposed a $\$ 100,000$ fine for alleged violations for failure to take corrective action for a reduced flow condition in the low pressure SW system.

The fourteenth refueling and maintenance outage lasted 61 days.

The unit was shut down for 9 days to repair a SG leak.

A 13-day outage was needed to repair leaks in both letdown coolers.

The fifteenth refueling and maintenance outage lasted 46 days.

The unit was shut down for 117 days to inspect and repair the MSR drain lines and associated piping. This was in response to the MSR drain line rupture in Oconee 2. 
This Page Intentionally Left Blank 
OYSTER CREEK

PRODUCTION COST and CAPITAL ADDITIONS (1996 Dollars)

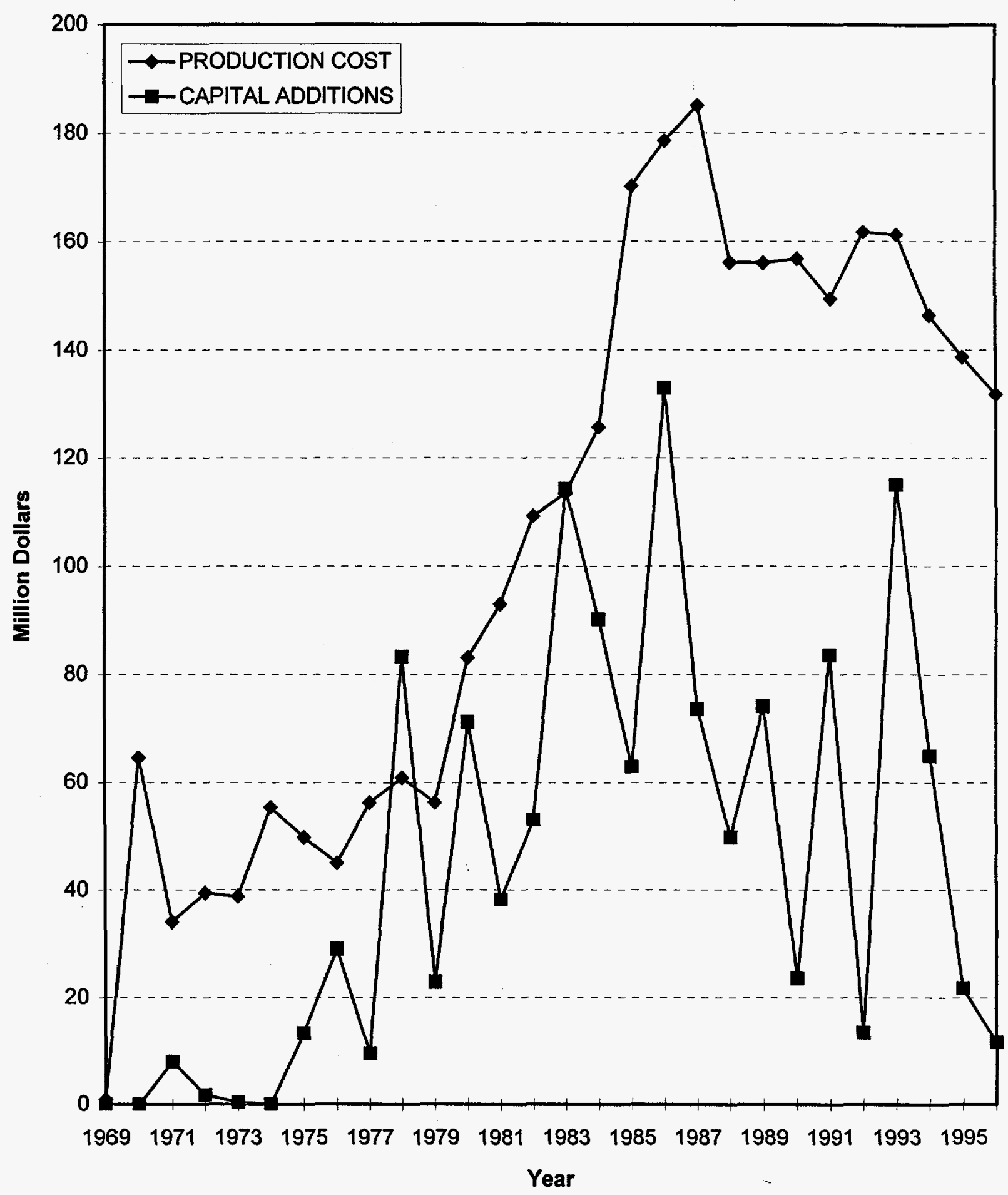




\section{NUCLEAR POWER PLANT OPERATING EXPERIENCE SUMMARY}

Unit data summary through December 1996

Unit: OYSTER CREEK

Location: OCEAN COUNTY, NEW JERSEY

Owner: GPU NUCLEAR CORP.

Type: GENERAL ELECTRIC BWR

Construction Permit: 12/15/64

Operating License: 8/1/69

Commercial Oper. Date: 12/1/69
Nameplate Rating: 550 MWe

MDC Net MWe: 619 MWe

Cumul. Avail. Factor: 67.2

Cumul. Cap. Factor (MDC Net): 60.7

Cumul. Forced Outage Rate: 9.8

3-Year Avg. Cap. Factor (MDC Net): 81.1

License Expiration: 2009

OPERATING HISTORY (To December 1996)

Date

Sept 1967 - Nov 1968

Jan - Aug 1969

Apr 1970

$1970-1971$

1974

Dec 1975 - Mar 1976

Oct 1976 - Apr 1977

Aug 1977

Mar 1978

Jan - Jul 1980

Aug - Oct 1981

Jan 1,1982

Feb 1983 - Nov 1984

Feb 1985

Oct 1985

\section{Comment}

Reactor vessel cracks were found during testing; the cracks were repaired but AEC questions on vessel integrity delayed the fuel load.

Efforts to resolve problems with certain piping and valves caused move delays.

A 1-month shutdown was required to overhaul CRDs.

Major problems with condenser tube leaks occurred.

Numerous load reductions were required throughout the year to effect repairs on condenser tubing.

The condenser was retubed during a maintenance and refueling outage.

The power was limited to about $70 \%$ because of more condenser tube leaks.

An off-gas explosion occurred.

Another off-gas explosion occurred.

A refueling outage occurred because cracks were found in core spray spargers. Four containment spray heat exchangers retubed due to leakage from saltwater corrosion.

The plant shut down for drywell leakage and condenser vacuum problems; shutdown cooling heat exchangers suffered tube failures.

GPU Nuclear Corporation replaced Jersey Central Power and Light Co. as the plant operator.

Refueling and extensive maintenance modifications occurred. The NRC SEP report was released; several fines totaling $\$ 220,000$ were assessed by the NRC; numerous piping corrosion problems were found; fires and explosions occurred in high voltage systems; the utility requested permission to expand spent fuel pool capacity.

A 32-day shutdown was required for CS booster pump logic modifications.

A 30-day shutdown was required for maintenance and environmental qualification modifications. 


\section{OYSTER CREEK (Cont'd)}

Apr - Dec 1986

Apr - May 1987

May 1987

Sep - Nov 1987

Sep 1988 - May 1989

Jan 1989

May - Dec 1989

Jan 1990

Feb 1990

Feb 1990

Apr 1990

Apr 1990

Jun 1990

Feb - Jun 1991

Jul 1991

Oct 1991

Jun 1992

Nov 1992 - Feb 1993

Apr 1994

May 1994

Sep - Dec 1994

Dec 1995

Apr 1996
The 1983 - 1984 outage continued. Extensive modifications and major refurbishment to upgrade unit for 10 additional years of operation occurred. Cost was $\$ 40$ to $\$ 50$ million. Corrosion was found in the sand cushion region of the drywell shell.

A 22-day shutdown was required for replacement of cooling coils in four drywell fan units.

The NRC proposed a $\$ 205,000$ fine for alleged violations involving torus vacuum breakers. (The fine was paid in October 1987.)

A 24-day outage was caused by main flash tank leaks. NRC restart approval was needed because of allegations that five operators sought to cover up safety limit violations.

A major outage occurred for extensive repairs and refueling for more than 208 days before successful startup accomplished. An NRC fine of $\$ 50,000$ was assessed for lack of environmental qualification of selected equipment.

The NRC proposed a $\$ 50,000$ fine for a September 1987 safety limit violation.

The unit suffered a number of power reductions and forced outages, mostly for problems in high voltage systems.

The NRC proposed a fine of $\$ 25,000$ for failure to take corrective action for a misaligned DC control power breaker.

Thickness measurements of the drywell shell indicated that the shell would reach minimum thickness requirements in June 1991 instead of June 1992.

The unit was shut down for 11 days to repair a recirculation pump seal.

Results of requalification exams for plant operators were questioned by NRC.

The unit was shut down for 13 days after the unit substation was lost.

The unit was shut down for 10 days after a reactor scram were caused by low condenser vacuum.

The thirteenth refueling and maintenance outage lasted 132 days.

A leak in a condensate storage tank line required 10 days to repair.

The utility applied to the NRC to change the expiration date of operating license to August 1 , 2009.

A maintenance outage lasted 9 days.

The fourteenth refueling and maintenance outage lasted 80 days.

A main turbine/reactor trip occurred on a high water level signal when part of the feedwater control system circuitry failed. The ensuing outage lasted 8 days.

The unit was shut down for 4 days to repair a CRD check valve.

The fifteenth refueling and maintenance outage lasted 97 days.

The unit was shut down for 10 days following a generator trip due to a stator cooling temperature control valve failing.

The unit was shut down for 5 days after a flapper valve broke and required retrieval from the condensate system. 


\section{OYSTER CREEK (Cont'd)}

Sep - Oct 1996

Oct 1996
The sixteenth refueling and maintenance outage lasted 45 days.

The unit was shut down for 13 days following a manual scram in response to a generator runback. 
PALISADES

PRODUCTION COST and CAPITAL ADDITIONS (1996 Dollars)

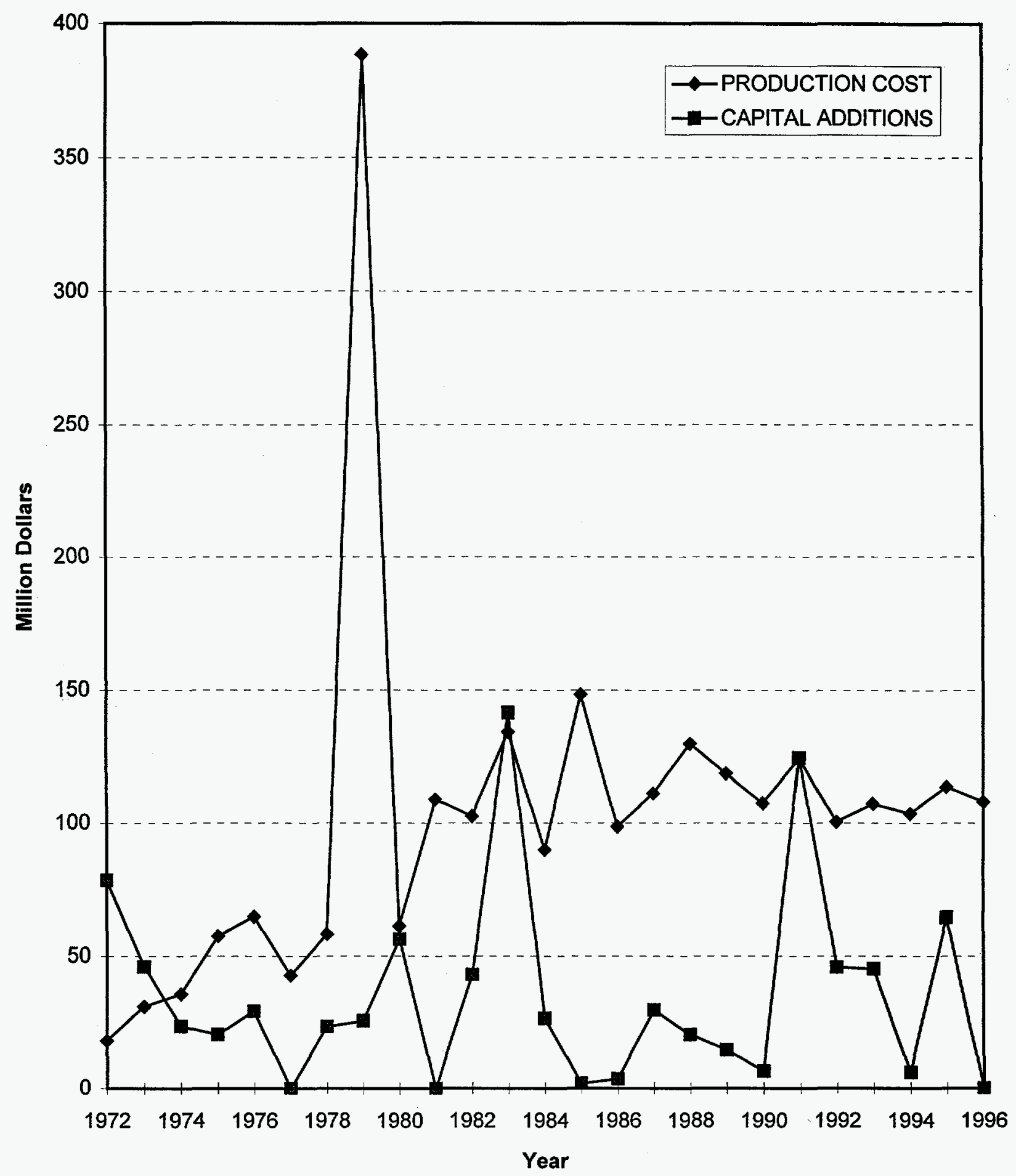




\section{NUCLEAR POWER PLANT OPERATING EXPERIENCE SUMMARY}

Unit data summary through December 1996

Unit: PALISADES

Location: VAN BUREN COUNTY, MICHIGAN

Owner: CONSUMERS POWER CO.

Type: COMBUSTION ENGINEERING PWR

Construction Permit: 3/14/67

Operating License: $10 / 16 / 71$

Commercial Oper. Date: 12/31/71
Nameplate Rating: 812 MWe

MDC Net MWe: 730 MWe

Cumul. Avail. Factor: 56.1

Cumul. Cap. Factor (MDC Net): $\mathbf{5 4 . 3}$

Cumul. Forced Outage Rate: 27.7

3-Year Avg. Cap. Factor (MDC Net): 76.5

License Expiration: 2007

OPERATING HISTORY (To December 1996)

Date

Mar 1971

1972

Jan 1973

Aug 1973 - Apr 1975

Apr - Dec 1975

Dec 1975 - May 1976

Oct 1976

Jun 1977

Jan - Apr 1978

Sep 1979 - May 1980

Nov - Dec 1980

Jul - Aug 1981

\section{Comment}

The fuel load was delayed for more than 1 year by intervenors. The utility committed to adding cooling towers and radwaste modifications totaling almost $\$ 30$ million.

Problems with leaking CRDM seals, condenser tube vibration, and charging system discharge piping modifications caused several outages throughout year. A fuel cladding collapse problem limited power until April 1973.

A 1.5-month shutdown was needed to modify all CRDM clutches and plug SG tubes.

An outage was initially estimated for 3 months to repair SGs. Internal reactor problems and a waste gas release investigation prolonged the outage into 1974 . The new cooling towers were completed and placed in operation and the turbine-generator was overhauled. The Justice Department investigated allegations of criminal activity in regard to waste gas reporting. AEC fined the utility $\$ 19,000$ for alleged violations of AEC requirements. Utility filed a suit against several vendors for startup problems with the condenser, SGs, and core internals. Turbine repairs and condenser retubing extended the outage even further.

The power was limited to about $80 \%$ because of a fuel densification issue.

An extended outage was required for CRDM seal repair and extensive SG tube plugging.

A $\$ 13.5$ million settlement was reached with a vendor in a lawsuit concerning the plant's main condenser.

The utility received an out-of-court settlement with Bechtel Corporation for about $\$ 14$ million in cash and future services.

A refueling and maintenance outage was performed. Major work included SG tube sleeving. CRDM seal problems continued to plague the unit throughout the year.

A refueling and maintenance outage was performed and was extended to perform TMI modifications and pipe support inspections. A $\$ 225,000$ fine was assessed by the NRC for alleged prolonged breach of containment integrity.

A 6-week outage was required for investigation and repair of severe turbine vibration.

A 29-day outage was needed for CRD and RCP seal repairs. 


\section{PALISADES (Cont'd)}

Aug 1981 - Jan 1982

Feb - Mar 1982

Mar - May 1982

Jul - Sep 1982

Nov 1982

Aug 1983

Aug 1983 - Jul 1984

Aug 1984

Sep - Nov 1984

Nov 1985 - Mar 1986

May 1986 - Apr 1987

Oct 1987

Oct 1987 - Jan 1988

Aug - Nov 1988

Dec 1988

Jan - Mar 1989

Mar - Sep 1989

Aug 1989

Sep - Nov 1989

Mar 1990

Apr - May 1990

Jun 1990
Refueling and maintenance outage was performed and was extended into 1982 because of turbine and condenser problems.

Cooling tower pump problems and an $\mathrm{H}_{2}$ explosion in the generator exciter caused a 28-day outage.

A 48-day outage was required for SG tube leakage repair.

Cooling tower pump motor failures caused a 53-day outage.

The NRC released a SEP report for the unit that contained 27 change requirements.

The NRC proposed a $\$ 20,000$ fine for an alleged violation concerning an unbadged person in the protected area.

An extended refueling and maintenance outage was required for SG tube inspection. In January 1984, a loss of off-site power coupled with an EDG trip led to the loss of all power at the plant. A diver received about 4.5 rem exposure while working in the refueling cavity.

A 25-day outage was needed to repair a weld on the primary coolant system instrument line.

A 2-month outage was required to repair the RCP.

A refueling and maintenance outage was performed. High winds and wave action eroded the beach and damaged security fencing.

An outage caused by reactor trip from turbine EHC controls stretched into 1987 when NRC ordered the plant shut down for investigation and review of corrective actions and maintenance. In July 1987, NRC assessed a $\$ 50,000$ fine for alleged violation of leak testing requirements. Total outage was 261 days.

The utility announced an arrangement to sell $56 \%$ interest in the plant to Bechtel Corporation, the plant $\mathrm{A} / \mathrm{E}$; the sale was the first joint venture of a utility and an $\mathrm{A} / \mathrm{E}$.

The plant underwent a scheduled 43-day maintenance outage and a 28-day unscheduled outage to repair a SG tube leak.

The refueling and maintenance outage lasted 113 days: major work included RPV inspection, RCP seal replacement, and SG tube repair.

A SG tube leak forced a 20 -day outage for repair. Utility paid a $\$ 75,000$ fine to NRC for alleged failures to satisfy Appendix $R$ requirements for fire protection, plus a $\$ 150,000$ fine for alleged violations of NRC EQ requirements for electrical equipment.

A 31-day outage was required to repair SG tubes.

The unit operated at reduced power because of SG tube problems. The utility announced plans to replace SGs, the effort would take about 5 months and cost about $\$ 100$ million.

A NRC SALP review reported the highest rating in two areas and the second highest rating in five other areas.

A 25-day outage was required for SG tube repair.

The NRC proposed a $\$ 75,000$ fine for alleged violations with respect to design control for piping and supports.

A 34-day outage was required to prepare for SG replacement.

The unit was shut down for 8 days to replace a pressurizer heater transformer. 


\section{PALISADES (Cont'd)}

Aug 1990

Sep 1990 - Mar 1991

Jul 1991

Nov 1991

Dec 1991

Jan 1992

Feb - Apr 1992

Jun 1992

Sep 1992

Oct 1992

May 1993

Jun - Nov 1993

Feb - Jun 1994

Feb - Jun 1994

May 1994

May - Aug 1995

Jan 1996

Aug 1996

Nov - Dec 1996
The plant provisional operating license in effect since 1971 was converted to a full-term operating license.

The refueling and maintenance outage lasted 180 days: major work during the outage was the replacement of the two SGs. Other major work included ESF and SW upgrades, RCP, FW pump turbine, and LP turbine inspections, ISI, replacement of the HP FW heater and drain cooler, and re-tubing the main condenser with stainless steel tubes.

A plant trip was caused by a several failures in the RPS system, and the ensuing outage lasted 5 days.

The NRC proposed a $\$ 50,000$ fine for allegedly having an inoperable safety system pump inoperable.

A 5-day outage was required after the main generator seal oil pressure decreased.

The NRC proposed a $\$ 100,000$ fine for alleged violations of NRC requirements related to design calculations and specifications for piping and pipe supports associated with the SG replacement.

The refueling and maintenance outage lasted 71 days: the outage was entered early due to concerns about the EQ of the MSIV circuits.

The NRC proposed a $\$ 75,000$ fine for allegedly failing to promptly identify and correct significant $E Q$ problems. The fine was paid.

The unit was shut down for 9 days following the electrocution of a worker.

A 10-day outage was required due to the failure of a UPS in the turbine DEH system.

The utility began loading spent fuel storage casks at the plant following dismissal of a lawsuit challenging the use of the casks.

A 16-day outage was necessary to repair primary coolant leaks.

The refueling and maintenance outage lasted 154 days.

The unit initially shut down to repair an SI check valve. The outage was extended to inspect a cable separation between $1 \mathrm{E}$ and non-1E circuits; and for concerns about the EDG fuel oil system licensing basis. The total outage time was 121 days.

A NRC DET, who was sent due to performance problems, criticized management for poor performance.

The NRC proposed a $\$ 50,000$ fine for alleged failure to take prompt corrective action for problems with equipment cooling systems.

The refueling and maintenance outage lasted 82 days. The outage was entered early after a manual scram occurred due to both main feedwater pumps tripping.

A 2-week outage was taken after a fault occurred in a safeguards $2400 \mathrm{v}$ bus.

The NRC proposed and the licensee paid a $\$ 50,000$ fine for Appendix $R$ violations.

The refueling and maintenance outage lasted 55 days. 


\section{PALO VERDE}

PRODUCTION COST and CAPITAL ADDITIONS (1996 Dollars)

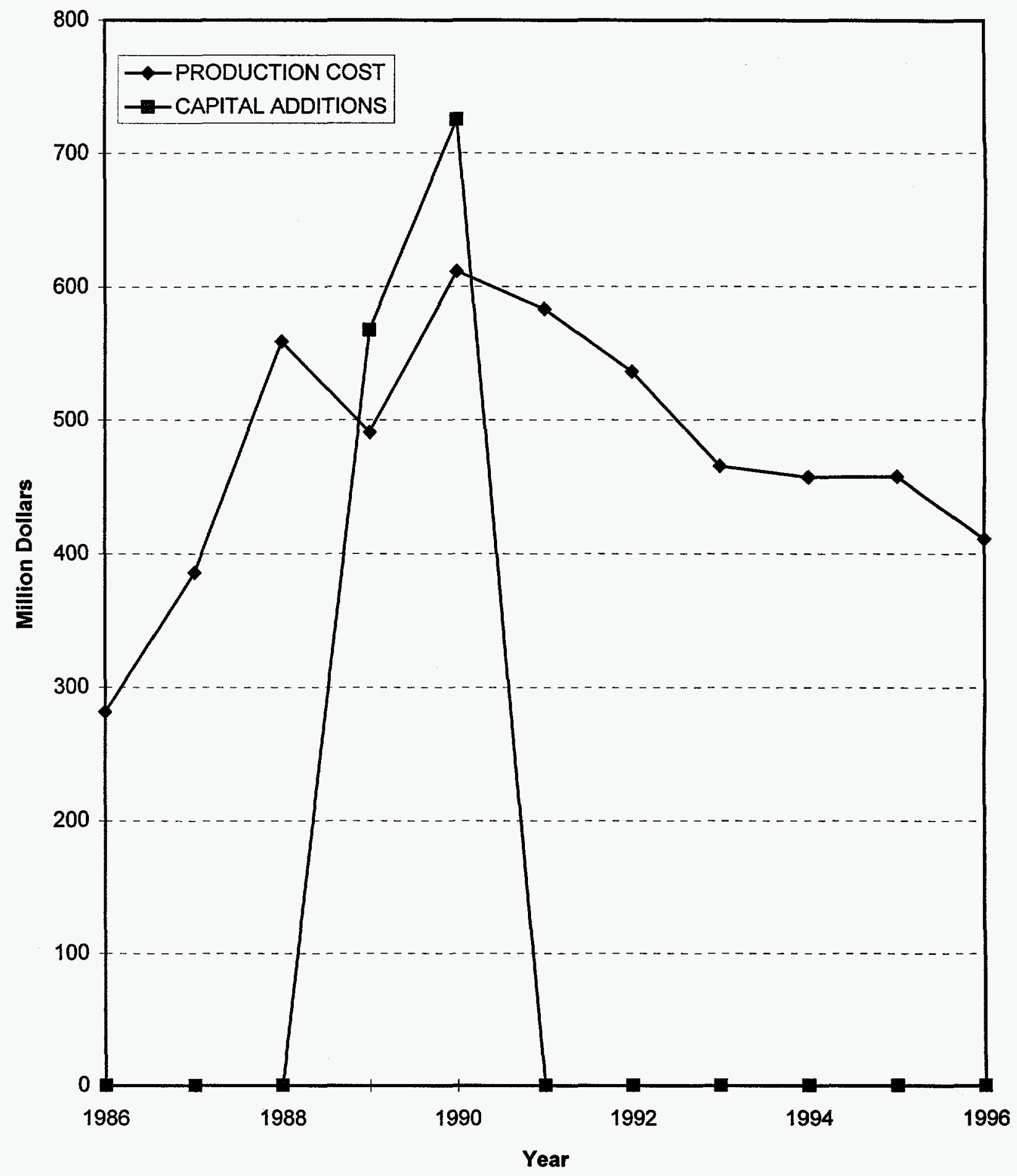




\section{NUCLEAR POWER PLANT OPERATING EXPERIENCE SUMMARY}

Unit data summary through December 1996

Unit: PALO VERDE 1

Location: MARICOPA COUNTY, ARIZONA

Owner: ARIZONA PUBLIC SERVICE CO.

Type: COMBUSTION ENGINEERING PWR

Construction Permit: 5/25/76

Operating License: 6/1/85

Commercial Oper. Date: 1/28/86
Nameplate Rating: 1403 MWe

MDC Net MWe: 1221 MWe

Cumul. Avail. Factor: $\mathbf{6 7 . 0}$

Cumul. Cap. Factor (MDC Net): 64.5

Cumul. Forced Outage Rate: 11.3

3-Year Avg. Cap. Factor (MDC Net): 83.8

License Expiration: 2024

OPERATING HISTORY (To December 1996)

Date

$1983-1984$

May 1983

Mar 1985

Jul - Aug 1985

Nov 1985

Oct - Nov 1985

Dec 1985

Jan 1986

Mar - May 1986

May 1986

Nov 1986

Jan - Mar 1987

Jun 1987

Jun - Jul 1987

Oct 1987 - Mar 1988

\section{Comment}

$\mathrm{RV}$ and RCP damage caused by loose parts caused delays in plant startup. The construction completion date was moved back to December 31, 1984, from the original August 31, 1983 date.

The utility paid a $\$ 20,000$ fine assessed by the NRC for alleged failure to maintain an adequate QA program of systems turned over from construction to startup and operations.

The utility paid a $\$ 40,000$ fine assessed by the NRC for alleged falsification of records.

An outage of 38 days was forced by repairs to a charging pump and repair of condenser tube leaks. The unit also made PASS modifications.

The NRC assessed a $\$ 40,000$ fine for alleged inoperability of the PASS.

The unit was shut down for 37 days for electrical bus repairs and other modifications.

The unit achieved $100 \%$ power for the first time.

Station load transfer problems forced a 10-day outage.

The unit was shut down for a planned surveillance outage of 77 days.

Three of four $500-\mathrm{kV}$ transmission lines to the plant site were sabotaged.

NRC assessed the utility a $\$ 100,000$ fine for alleged security violations.

The unit was shut down for extensive inspection of SG tubes for the source of primary and secondary leakage. Leaking tubes were plugged, and condenser tube leaks were also repaired. Total outage time was 46 days.

The utility filed suit against $\mathrm{CE}$ for alleged delays in construction.

The unit was shut down to repair a ruptured circulating water pipe. During shutdown, both LPSI pumps experienced seal failure. Total outage time for both problems was 32 days.

The first refueling and maintenance outage was performed. Major work included SG, LP, and HP turbine inspection, ISI, and LLRTs. AFW pump degradation caused by an improperly set steam valve limit switch was found. The NRC proposed a $\$ 100,000$ fine for this condition and for other violations. 
Apr 1988

Jul 1988

Feb 1989

Mar 1989

Apr 1989 - Jul 1990

Oct 1989

Aug 1990

Sep 1990

Oct 1990

Nov 1990

Jan 1991

Feb 1991

Sep 1991

Jan 1992

Feb - May 1992

Aug 1992
The NRC proposed a $\$ 100,000$ fine against the utility for a series of alleged violations concerning inoperability of plant equipment, inadequate review and testing of modifications, and poor operator performance at all three units.

Power to all four RCPs was lost due to a fire in an auxiliary transformer. The reactor tripped from $100 \%$ power and relied on natural circulation for decay heat removal. Total outage time for repair was 45 days.

The NRC proposed two fines against the utility: one for $\$ 200,000$ for a number of alleged ongoing violations concerning radiation protection requirements; a second fine of $\$ 50,000$ was assessed for alleged inoperability of the essential water system during May 1988.

After shutting down for $\mathbf{4 8}$ hours because of a circuit breaker fire, startup was delayed because of ADV concerns. The unit remained shut down for 25 days until NRC approval was given for restart.

The second refueling and maintenance outage was performed. The unit was shut down for more than 1 year after the outage because of NRC concerns about management attention to problems. The NRC proposed $\$ 250,000$ in fines for alleged violations concerning corrective action for steam system problems, emergency lighting, and training of plant personnel. The total outage time was about 65 weeks.

The NRC proposed a $\$ 250,000$ fine for three alleged violations: (1) inadequate preventive and corrective actions related to steam system problems; (2) failure to adequately install, inspect, and test the emergency lighting systems; and (3) inadequate training and failure to follow operating procedures. The fine was paid.

A 5-day outage followed the unit being shut down when one main transformer fan became inoperable.

An 11-day outage was necessary due to a leaking pressurizer safety valve.

The NRC imposed a $\$ 75,000$ fine against the site for alleged failure of the utility to notify NRC of licensed operators with potentially incapacitating medical disabilities.

The NRC assessed and the utility paid a fine of $\$ 125,000$ for alleged failure to ensure that emergency lighting systems were adequate and that proper QA was applied to the fire protection system.

The unit was shut down for a 35-day scheduled maintenance outage.

The plant received one top Category 1 rating and no low Category 3 ratings in an NRC SALP report. The NRC said the improved performance resulted from management initiatives to upgrade identified weak areas.

The unit was shut down for 8 days. The initial shutdown occurred when the RPS system caused a reactor scram when a rod dropped. The outage was extended to repair a pressurizer relief valve.

A leak in the pressurizer steam space instrument nozzle required an 11-day outage to repair.

The third refueling and maintenance outage lasted 56 days: major work included the DG 5-year inspection, RCP shaft ultrasonic testing, and SG ECT.

The NRC proposed a $\$ 100,000$ fine for three alleged violations: (1) inadequate work control on a reactor trip breaker; (2) backwards installation of a check valve; and (3) loss of control room annunciators due to improper actions by licensed personnel. 
Sep 1992

Sep - Nov 1993

Apr 1994

Nov 1994

Apr - May 1995

Feb 1996

Mar 1996

Apr 1996

Sep - Oct 1996
The NRC proposed a $\$ 130,000$ fine against the site for alleged cases of discrimination against two employees who raised safety concerns at the plant.

The fourth refueling and maintenance outage lasted 83 days.

The NRC proposed a $\$ 100,000$ fine for two alleged violations involving the security program as implemented by contractors for their workers.

The unit was shut down for 4 days to repair RCS vent lines.

The fifth refueling and maintenance outage lasted 57 days.

Following a reactor scram due to a lightning strike on a main transformer, a 1-week outage was performed.

The NRC proposed and the licensee paid a $\$ 100,000$ fine for discrimination against a contract I\&C technician.

The unit was shut down for two weeks to repair a RCP.

The sixth refueling and maintenance outage lasted 40 days. 


\section{NUCLEAR POWER PLANT OPERATING EXPERIENCE SUMMARY}

Unit data summary through December 1996

Unit: PALO VERDE 2

Location: MARICOPA COUNTY, ARIZONA

Owner: ARIZONA PUBLIC SERVICE CO.

Type: COMBUSTION ENGINEERING PWR

Construction Permit: 5/25/76

Operating License: $\mathbf{4 / 2 4 / 8 6}$

Commercial Oper. Date: 9/19/86
Nameplate Rating: 1403 MWe

MDC Net MWe: 1221 MWe

Cumul. Avail. Factor: 71.6

Cumul. Cap. Factor (MDC Net): $\mathbf{7 0 . 0}$

Cumul. Forced Outage Rate: 4.8

3-Year Avg. Cap. Factor (MDC Net): 77.5

License Expiration: 2025

OPERATING HISTORY (To December 1996)

Date

$1983-1985$

May 1986

Jul 1986

Sep 1986

Jan - Mar 1987

Feb - Jun 1988

Feb 1989

Mar - Jun 1989

Jul 1989

Sep 1989

\section{Comment}

RV and RCP damage caused by loose parts caused delays during plant startup. The fuel load date was moved back to February 1985 from the original August 1984 date. In March 1984, the fuel load date was further set back to late 1985 because of problems with the LPSI system and a backlog of modifications needed to resolve discrepancies found during construction.

Three of four $500-\mathrm{kV}$ transmission lines to the plant site were sabotaged.

High leakage from the RCP seals forced a 21-day outage.

The plant entered commercial operation after successful completion of full power testing.

The first refueling and maintenance outage lasted 59 days: major work included DG and snubber inspections, tests of the shutdown cooling systems, integrated safeguards tests, and RPS calibrations. Condenser tube leaks forced two additional outages of 7 days total for repair.

The second refueling and maintenance outage lasted 120 days: major work included SG, HP turbine, main generator, and RCP shaft inspections, ILRT, LLRTs, and ISI.

The unit was shut down for 13 days after a FW control malfunction caused overcooling of the primary system.

The unit voluntarily shut down because of NRC concerns about equipment problems at Units 1 and 3. NRC approval was required for restart, which was granted June 30 and plant resumed operation. Total outage time was 107 days.

The unit was shut down for 8 days following a reactor trip caused by two of the RCPs tripping. The main FW pump suction piping was overpressurized during the event but no damage occurred.

The unit was shut down for 16 days to test main steam safety valves. 
Oct 1989

Oct 1989

Nov 1989

Feb - Jul 1990

Sep 1990

Oct 1990

Aug 1991

Oct 1991 - Jan 1992

Feb 1992

Mar 1992

Sep 1992

Mar - Aug 1993

Jan - Mar 1994

May 1994

Sep - Oct 1994

Feb - Mar 1995

Mar - May 1996
The unit was shut down for 16 days to replace counterfeit class $1 \mathrm{E}$ breakers and repair a grounded CEA drive motor.

The NRC proposed a $\$ 250,000$ fine against the site for three alleged violations:

(1) inadequate preventive and corrective actions related to steam system problems; (2)

failure to adequately install, inspect, and test the emergency lighting systems; and (3)

inadequate training and failure to follow operating procedures. The fine was paid.

Problems with AFW system forced a 11-day outage.

The third refueling and maintenance outage lasted 145 days: major work included inspection of the SGs, DGs, RCP shafts, and one of four turbines, and replacement of one RCP motor.

The NRC imposed a $\$ 75,000$ fine against the site for alleged failure of the utility to notify NRC of licensed operators with potentially incapacitating medical disabilities. The fine was paid in January 1991.

The NRC assessed a fine of $\$ 125,000$ against the site for alleged failure to ensure that emergency lighting systems were adequate and that proper QA was applied to the fire protection system. The fine was paid the following month.

The unit was shut down for 6 days following a manual reactor trip due to the loss of the CEDM cooling fans.

The third refueling and maintenance outage lasted 56 days: major work included the 5-year DG inspection, changeover of RCP seal packing, RCP shaft ultrasonic testing, SG ECT, major overhaul of the FW pump, extraction steam piping/nozzle replacement, and MOV dynamic testing.

The NRC proposed a $\$ 50,000$ against the unit for violations that occurred during the previous refueling. The fine was paid.

A fault on a startup transformer resulted in power loss to two RCPs, causing a reactor trip. The ensuing outage lasted 6 days.

The NRC proposed a $\$ 130,000$ fine against the site for alleged cases of discrimination against two employees who raised safety concerns at the plant.

The fourth refueling and maintenance outage lasted 171 days; it was entered early when a steam generator tube ruptured.

A planned mid-cycle outage lasted 74 days; main work was SG ECT.

The unit was shut down for 8 days after an RCP tripped due to personnel error.

The unit performed a planned mid-cycle outage that lasted 30 days.

The fifth refueling and maintenance outage lasted 54 days.

The sixth refueling and maintenance outage lasted 49 days. 


\section{NUCLEAR POWER PLANT OPERATING EXPERIENCE SUMMARY}

Unit data summary through December 1996

Unit: PALO VERDE 3

Location: MARICOPA COUNTY, ARIZONA

Nameplate Rating: 1403 MWe

Owner: ARIZONA PUBLIC SERVICE CO.

MDC Net MWe: 1230 MWe

Type: COMBUSTION ENGINEERING PWR

Cumul. Avail. Factor: 77.1

Construction Permit: 5/25/76

Cumul. Cap. Factor (MDC Net): $\mathbf{7 6 . 2}$

Operating License: 11/25/87

Cumul. Forced Outage Rate: 4.7

Commercial Oper. Date: 1/8/88

3-Year Avg. Cap. Factor (MDC Net): 83.6

License Expiration: 2027

OPERATING HISTORY (To December 1996)

Date

Dec 1987

Jul 31, 1988

Dec 1988

Jan 1989

Mar - Dec 1989

Oct 1989

Sep 1990

Oct 1990

Mar - Jun 1991

Oct 1991

Nov 1991

\section{Comment}

The unit experienced a number of trips from high turbine vibration during approach to $100 \%$ power.

The unit tripped and shut down because of a lighting strike to a transformer. Continuous operation for 212 days set a new record for a U.S. nuclear unit in its first cycle. The unit remained shut down for 17 days for AFW pump maintenance.

The unit had a gross capacity factor of $94 \%$ for first year of operation, setting a new U.S. record for gross $\mathrm{MW}$-hr produced in 1 year.

The unit was shut down for 15 days to repair DGs.

The first refueling outage was entered early after failure of the atmospheric dump valves following a trip. NRC sent an AIT and required a complete investigation before restart was allowed in December. One transformer developed a fault during restart and ruptured, delaying restart for several days. Total outage time was 298 days.

The NRC proposed a $\$ 250,000$ fine against the site for three alleged violations:

(1) inadequate preventive and corrective actions related to steam system problems; (2) failure to adequately install, inspect, and test the emergency lighting systems; and (3) inadequate training and failure to follow operating procedures. The fine was paid.

The NRC imposed a $\$ 75,000$ fine for alleged failure of the utility to notify NRC of licensed operators with potentially incapacitating medical disabilities. The fine was paid in January 1991.

The NRC assessed a fine of $\$ 125,000$ for alleged failure to ensure that emergency lighting systems were adequate and that proper QA was applied to the fire protection system. The fine was paid the following month.

The second refueling and maintenance outage lasted 79 days: major work included hot leg nozzle replacement and an ILRT.

The unit tripped following a lightning-induced transient and was shut down for four days.

The unit experienced a partial LOSP when wind blew a crane into a power line and plant operators responded incorrectly. The unit tripped when two of the RCPs lost power. The outage lasted 13 days. 
Feb 1992

May 1992

Aug 1992

Sep 1992

Sep - Nov 1992

Feb 1993

Dec 1993

Mar - Jun 1994

Nov - Dec 1994

Oct - Nov 1995
The NRC proposed a $\$ 112,500$ fine against the unit due to the partial LOSP that occurred in November 1991. The NRC cited four alleged violations that occurred during the event.

The unit was shut down for 8 days to perform additional testing of the annunciator system and the computer system to ensure long term reliability.

The NRC proposed a $\$ 100,000$ fine for three alleged violations: (1) inadequate work control on a reactor trip breaker; (2) backwards installation of a check valve; and (3) loss of control room annunciators due to improper actions by licensed personnel.

The NRC proposed a $\$ 130,000$ fine against the site for alleged cases of discrimination against two employees who raised safety concerns at the plant.

The third refueling and maintenance outage lasted 68 days: major work included replacement of two RCP motors and class $1 \mathrm{E}$ batteries, and inspection/overhaul of the main generator and HP turbine.

The unit was shut down for 4 days after a reactor trip occurred when a FW pump tripped.

A planned mid-cycle outage lasted 26 days: the main work was SG ECT.

The fourth refueling and maintenance outage lasted 93 days.

A 22-day planned mid-cycle outage occurred principally for SG tube inspection.

The fifth refueling and maintenance outage lasted 47 days. 
PEACH BOTTOM

PRODUCTION COST and CAPITAL ADDITIONS (1996 Dollars)

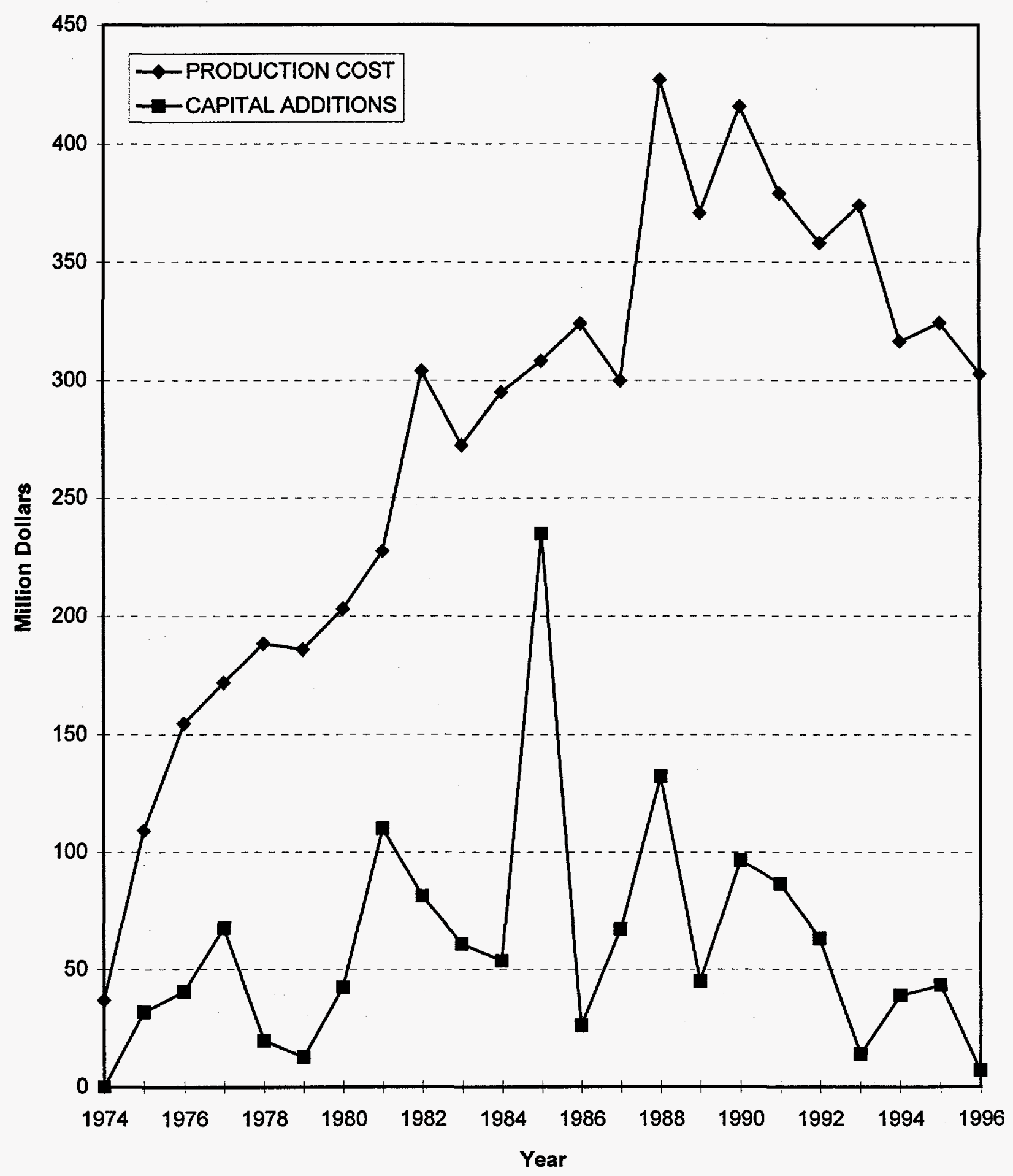




\title{
NUCLEAR POWER PLANT OPERATING EXPERIENCE SUMMARY
}

\author{
Unit data summary through December 1996
}

\section{OPERATING STATUS}

Unit: PEACH BOTTOM 2

Location: YORK \& LANCASTER COUNTY, PENNSYLVANIA

Nameplate Rating: 1221 MWe

Owner: PHILADELPHIA ELECTRIC CO.

MDC Net MWe: 1093 MWe

Type: GENERAL ELECTRIC BWR

Cumul. Avail. Factor: 64.3

Construction Permit: 1/31/68

Cumul. Cap. Factor (MDC Net): $\mathbf{5 7 . 8}$

Operating License: $12 / 14 / 73$

Cumul. Forced Outage Rate: 11.7

Commercial Oper. Date: $\mathbf{7 / 5 / 7 4}$

3-Year Avg. Cap. Factor (MDC Net): 85.1

License Expiration: 2013

OPERATING HISTORY (To December 1996)

Date

Nov 1973

1974

Nov 1975

Mar - Jun 1976

Apr - Sep 1977

Mar - Aug 1980

Apr - Jun 1981

Feb - Jun 1982

Jul - Dec 1983

Apr 1984 - Jun 1985

May 1985

\section{Comment}

A main generator failure caused a 3-month shutdown; Unit 3 stator was swapped for use in Unit 2.

The unit experienced a number of problems with relief valves, the HPCI system, the RCIC system and recombiners during the early power ascension program. The warranty run was completed in early July.

The unit was shut down for the entire month for core plugging and repair of damaged RPV stabilizers.

A refueling outage was required for replacement of leaking fuel elements, repair of FW nozzles and spargers, and replacement of the recirculation pump bypass line.

The second refueling outage was performed. Cracks were found in CS piping, FW nozzles, and a CRD nozzle; three of seven installed neutron sources were found broken.

A refueling outage was required to replace $28 \%$ of fuel, modify torus, and perform other plant modifications. Faulty recombiners caused startup problems.

Several short outages occurred because of equipment problems: a recirculation pump motor failed; a crack occurred in the SW line; one main transformer failed; and problems occurred with reactor $F W$ pump $A$.

A refueling and torus modification outage was performed. A crack was found in the core spray sparger; A startup was delayed due to damage from a dropped fuel bundle.

A shut down was in response to IE Bulletin 83-02 for inspection of the recirculation riser and RHR shutdown cooling pipe welds; 16 of 20 welds repaired by overlay. An on-site storage facility for low-level radwaste was proposed.

A refueling and maintenance outage was required for replacement of primary system piping. Cracks were found in jet pump instrumentation penetration welds and recirculation riser safe ends.

The NRC proposed a $\$ 75,000$ fine for alleged violations related to personnel contamination and exposures at Peach Bottom and physical security violations at Limerick. 
Jun 1986

Feb 1987

Mar 1987 - Apr 1989

Nov 1987

Aug 1988

Oct 1988

Dec 1988

Apr 1989

Jun 1989

Aug 1989

Nov 1989

Feb 1990

Mar - Apr 1990

Jul 1990

Aug 1990

Sep 1990

Nov 1990

Jan - Apr 1991

Mar 1991
The NRC fined the utility $\$ 200,000$ for alleged violations concerning out-of-sequence withdrawal of control rods during earlier startup.

The NRC proposed a $\$ 50,000$ fine for alleged dismissal of a contract Health Physics technician for raising radiological concerns.

A refueling outage began and was extended when NRC ordered both units shut down when operators were found sleeping on duty. A final restart plan included extensive management changes and reorganization to address employee training and attitudes.

Four plant employees and two contract workers were indicted by Federal court for allegedly distributing illegal drugs at the plant.

The NRC fined the utility $\$ 1,250,000$ for alleged failure to deal with inattentive operators and supervisors who condoned actions. This fine was the largest civil penalty ever proposed by NRC against a utility. Individual fines totaling $\$ 21,900$ were levied against 33 individuals. The other three owners of Peach Bottom sued the utility for the cost of replacement power during the prolonged outage.

The plant was placed on the NRC list of Category 3 problem plants.

The NRC proposed a $\$ 50,000$ fine for alleged security violations.

The NRC voted to allow restart; total outage time was 774 days. Extensive maintenance and testing were also accomplished during this time.

The plant upgraded to NRC Category 2 and was allowed to operate under close NRC scrutiny.

The unit returned to full power for the first time in over 3 years.

The unit was shut down for 7 days due to leakage in a RCIC check valve.

Both Peach Bottom units taken off the NRC problem plant list and were promoted to Category 1 because of improved overall performance and a positive safety culture.

During a mid-cycle outage, silting and corrosion were found in emergency SW system, affecting design basis conditions; high vibration in main generator exciter bearings caused startup delays.

The utility was fined $\$ 75,000$ by NRC for alleged violations concerning design and operation of the emergency SW system.

A 6-day outage was needed when a reactor water-level instrument became inoperable.

The utility received SALP Category 1 ratings in emergency preparedness and security and Category 2 in other areas.

The unit was manually shut down when emergency bus voltage relays were found susceptible to noise and tripped below TS limits. A 5-day outage was necessary to install filters on the relays.

The refueling and maintenance outage lasted 79 days: major work included replacing 160 fuel elements and brass condenser tubing with titanium tubing.

The NRC proposed a $\$ 75,000$ fine for alleged violations involving operation of the unit with the ESW system inoperable and changes to the functional description of the system without adequate analyses. 
May 1991

Jun 1991

Oct 1991

Nov 1991

Dec 1991

Feb 1992

Mar 1992

May 1992

Jul 1992

Sep - Dec 1992

Jan 1993

Mar 1993

Aug 1993

Oct 1993

May 1994

Sep - Oct 1994

Nov 1994

Dec 1995

Sep - Oct 1996
The unit was shut down for 17 days to repair emergency auxiliary transformer cables.

The unit was shut down twice for a total of 10 days: once due to high temperature on a recirculation pump and then for low steam flow to the recombiner.

A 6-day outage was necessary to repair a packing leak on a HPCI valve.

The NRC SALP report awarded one Category 1 rating and no low Category 3 ratings.

A 13-day outage was needed to repair RHR valves.

The NRC proposed a $\$ 285,000$ fine for alleged violations involving both units for operating nearly 2 years with incorrectly installed thermal insulation on the ADS SRVs. The fine was paid.

A 10-day outage followed the discovery of reactor level mismatch.

The unit tripped and was down for 8 days following closure of two turbine CIVs.

The main generator/reactor tripped after a lightning strike caused a load imbalance. The resulting outage lasted 9 days.

The ninth refueling and maintenance outage lasted 89 days.

The unit was shut down for 15 days to repair a recirculation pump seal.

A maintenance outage lasted 14 days.

An 8-day outage was taken to modify the reactor water-level instrumentation.

The unit was shut down for 9 days to inspect Walworth ${ }^{\circledR}$ MOVs for yoke cracks.

The unit was shut down for 5 days after a scram on a high flux signal was caused by recirculation pump speed problems.

The tenth refueling and maintenance outage lasted 36 days. A power uprate of $\sim 5 \%$ was implemented during the outage.

The NRC proposed and the licensee paid a $\$ 87,500$ fine for incorrect operation of the ESW for both units.

A 1-week planned maintenance outage was performed.

The eleventh refueling and maintenance outage lasted 19 days. 


\section{NUCLEAR POWER PLANT OPERATING EXPERIENCE SUMMARY}

Unit data summary through December 1996

Unit: PEACH BOTTOM 3

Location: YORK \& LANCASTER COUNTY, PENNSYLVANIA

Owner: PHILADELPHIA ELECTRIC CO.

Nameplate Rating: 1221 MWe

MDC Net MWe: 1093 MWe

Cumul. Avail. Factor: $\mathbf{6 5 . 5}$

Type: GENERAL ELECTRIC BWR

Cumul. Cap. Factor (MDC Net): $\mathbf{5 9 . 5}$

Construction Permit: 1/31/68

Cumul. Forced Outage Rate: $\mathbf{1 0 . 5}$

Operating License: $7 / 2 / 74$

3-Year Avg. Cap. Factor (MDC Net): 91.3

Commercial Oper. Date: 12/23/74

License Expiration: 2008

OPERATING HISTORY (To December 1996)

Date

Jun 1975

Dec 1976 - Apr 1977

Sep - Nov 1979

Mar - Oct 1981

Feb - Oct 1983

Jan 1984

Jul 1984

Jul 1985 - Mar 1986

Mär 1987 - Apr 1989

Jul 1987

Oct 1987

Nov 1987

Jan 1988

\section{Comment}

The unit derated to about $50 \%$ power due to fuel channel wear and TIP vibration.

A refueling and maintenance outage was performed. Cracks were found in both core spray lines, and CRD and FW nozzle cracks were repaired.

Startup from a refueling outage was delayed because of FW pump seal water filter problems, nitrogen system leaks, and RHR pipe hangar modifications.

A refueling outage included modifications to the suppression pool, FW equipment, and piping. Startup was delayed by DG and turbine bearing problems.

A refueling and maintenance outage was performed. IGSC crack indications were found in recirculation and RHR piping and on several jet pump risers. Vacuum pump problems delayed startup.

The condensate pump room became flooded and damaged the pumps; cracks were found in jet pump instrument nozzles.

The NRC assessed a $\$ 30,000$ fine for alleged operating violations.

A refueling and extensive maintenance outage was performed. Piping inspections found crack indications; IRM dry tubes were replaced; steam separator holddown bolts were found cracked; the CST overflowed and flooded plant areas.

The NRC ordered both units shut down when operators were found sleeping on duty. The final restart plan included extensive management changes and reorganization to address employee training and attitudes.

The NRC proposed a $\$ 50,000$ fine for alleged Appendix $\mathrm{R}$ violations regarding cable separation requirements.

Full changeout of recirculation piping commenced.

Four plant employees and two contract workers were indicted by Federal court for allegedly distributing illegal drugs at the plant.

IGSC cracks were found in core shroud support access hole cover welds. 
Aug 1988

Oct 1988

May 1989

Jun 1989

Jan 1990

Feb 1990

Mar 1990

Jul 1990

Sep 1990

Oct - Nov 1990

Jan 1991

May 1991

Jul 1991

Sep 1991 - Jan 92

May 1992

Jul 1992

Oct - Nov 1992

Mar 1993

Jul 1993

Sep - Nov 1993

Dec 1993
The NRC fined the utility $\$ 1,250,000$ for alleged failure to deal with inattentive operators and supervisors who condoned actions. This fine was largest civil penalty ever proposed by $\mathrm{NRC}$ against a utility. Individual fines totaling $\$ 21,900$ were levied against 33 individuals. The other three owners of Peach Bottom sued the utility for cost of replacement power during the prolonged outage.

The plant was placed on the NRC list of Category 3 problem plants.

The NRC voted to allow restart of plant. Extensive maintenance and testing were accomplished during the NRC-enforced outage.

The plant was upgraded to NRC Category 2 and was allowed to operate under close NRC scrutiny.

With Unit 3 resuming full power, it was the first time all six of the nuclear units partially or wholly owned by Philadelphia Electric were operating at $100 \%$ power.

Both Peach Bottom units were taken off the NRC problem plant list and were promoted to Category 1 because of improved overall performance and positive safety culture.

A turbine/reactor trip occurred when the only available stator cooling water pump tripped. A 6-day outage followed, and EQ concerns for the HPCI system were addressed.

Failure of a recombiner cooling water control valve required plant shutdown and a 7-day outage.

The utility received SALP Category 1 ratings in emergency preparedness and security and Category 2 in other areas.

A scheduled mid-cycle outage lasted 28 days.

A 6-day outage was required to repair a transformer cooling fan motor.

The unit was shut down for 26 days to repair emergency auxiliary transformer cables.

A 7-day outage followed a generator trip/reactor scram due to a generator load imbalance caused by a lightning strike.

A refueling and maintenance outage lasted 109 days; major work included replacement of one RHR motor and one LP turbine rotor.

A scheduled maintenance outage lasted 7 days.

One off-site power source was lost due to an explosion. Failure of a 4-kV board to transfer to the remaining source resulted in loss of condenser vacuum and a reactor scram. The unit was shut down for 9 days. On startup from the outage, the SJAE flow controller failed and required an 8 day shutdown to repair.

The reactor tripped upon MSIV closure due to instrumentation being bumped. The unit was shut down for 25 days for work on various safety related valves.

The unit was shut down for 5 days after a reactor trip followed a feedwater pump trip.

A 12-day outage was needed to replace defective FAs.

The nineth refueling and maintenance outage lasted 58 days.

The unit was shut down for 14 days to repair a LPCI MOV. 
Oct 1994

Mar 1995

Sep - Oct 1995

Dec 1995

Jun 1996
A 4-day outage followed a reactor trip caused by feedwater control problems after the loss of an inverter.

A 4-day outage followed a plant trip caused by a low condenser vacuum when the steam supply to the SJAEs was lost.

A tenth refueling and maintenance outage lasted 24 days. A power uprate of $\sim 5 \%$ was implemented during the outage.

A 4-day outage followed an automatic reactor scram.

A 4-day outage was taken to repair a turbine control valve. 
This Page Intentionally Left Blank 
PERRY

PRODUCTION COST and CAPITAL ADDITIONS

(1996 Dollars)

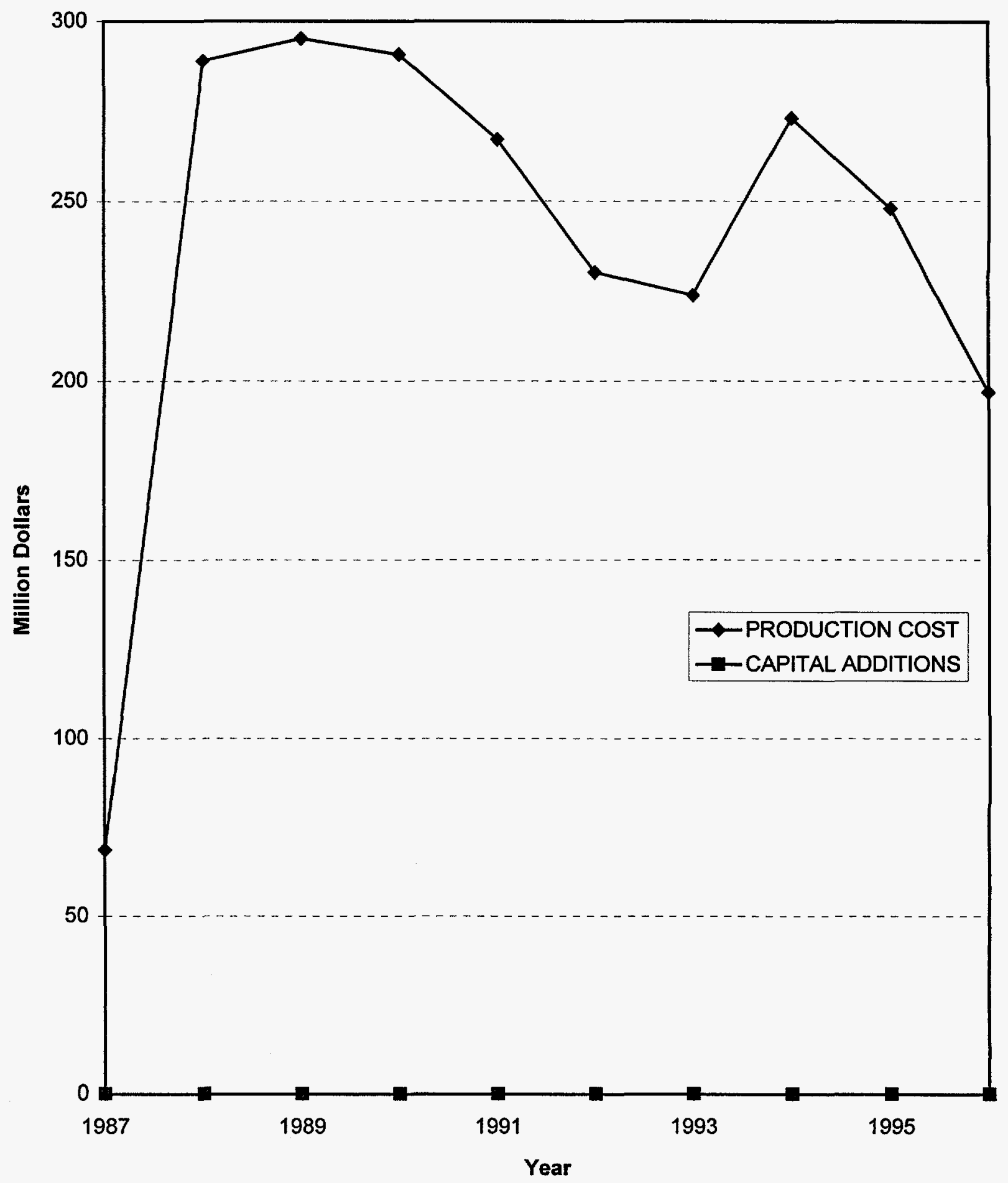




\section{NUCLEAR POWER PLANT OPERATING EXPERIENCE SUMMARY}

Unit data summary through December 1996

Unit: PERRY

Location: LAKE COUNTY, OHIO

Owner: CLEVELAND ELECTRIC ILLUMINATING CO.

Type: GENERAL ELECTRIC BWR

Construction Permit: 5/3/77

Operating License: 11/13/86

Commercial Oper. Date: 11/18/87
Nameplate Rating: 1250 MWe

MDC Net MWe: $1166 \mathrm{MWe}$

Cumul. Avail. Factor: $\mathbf{6 9 . 0}$

Cumul. Cap. Factor (MDC Net): 66.2

Cumul. Forced Outage Rate: 10.0

3-Year Avg. Cap. Factor (MDC Net): 69.2

License Expiration: 2026

OPERATING HISTORY (To December 1996)

Date

Jan 1986

Sep - Dec 1986

Apr 1987

Jul - Aug 1987

Nov - Dec 1987

Jan 1988

Mar 1988

May 1988

Sep 1988

Oct 1988

Feb - Aug 1989

Aug 1989

Jan 1990

Mar 1990

\section{Comment}

An earthquake measuring 5.0 on the Richter scale occurred about 10 miles from the plant. NRC investigation concluded that the event was within the plant design basis and was no impediment to issuance of the low-power operating license.

Intervenors filed a petition to prevent plant operation, delaying issuance of the full power license until December 23.

The unit was shut down for 10 days to repair a ruptured secondary side drain line and others that needed repair.

After achieving full power for the first time, the unit was shut down for 30 days to repair main generator bushings and various valve leaks, and to inspect the DG.

The plant shut down for 11 days to repair the solenoids on the MSIVs.

MSIV repair and reactor FW pump replacement forced a 26-day outage.

The NRC assessed a $\$ 25,000$ fine for alleged violations of testing and maintenance requirements for electrical equipment.

Generator hydrogen seal leaks forced a 12-day outage.

Repair of blockage in the condenser off-gas lines forced a 12-day outage.

The plant shut down for a 13 day scheduled maintenance outage to prepare for the February 1989 refueling outage.

The first refueling and maintenance outage lasted 164 days: major work included removal of temporary RPV vibration instruments; replacement of the main generator rotor; and modification of RPV level instrument sensing lines.

The utility was fined $\$ 37,500$ by the NRC for alleged failure to correct previously identified electrical EQ violations.

A maintenance and surveillance testing outage lasted 7 days.

The NRC assessed a $\$ 100,000$ fine for the alleged failure of two control rods to operate properly during testing in 1989 . 
Sep 1990 - Jan 1991

Apr 1991

Oct 1991

Dec 1991 - Jan 1992

Mar - Jun 1992

Oct 1992

Jan - Mar 1993

Mar - May 1993

May 1993

Jul 1993

Oct - Nov 1993

Dec 1993

Feb - Aug 1994

Apr 1995

Nov 1995

Jan - Apr 1996

May 1996

Oct 1996
The second refueling and maintenance outage lasted 120 days: major work included replacement of all SRVs and recirculation pump shafts, and overhaul of a DG.

The unit was shut down for 16 days due to drywell leakage and failure of a recirculation pump to shift to slow speed.

The NRC proposed a $\$ 100,000$ fine for alleged violations involving inadequacies in the emergency operating procedures. The fine was paid.

The unit was manually shut down when a circulating water elbow ruptured. The repairs took 10 days to complete.

The third refueling and maintenance outage lasted 79 days. The outage was extended to repair a RHR HX bypass valve.

The unit was shut down for 8 days to repair a leak on a condensate system pipe.

A planned maintenance outage lasted 62 days.

The unit was shut down after a service water pipe ruptured. Repairs required 68 days to complete.

The NRC proposed and the utility paid a $\$ 200,000$ fine for alleged violations involving build-up of debris in the suppression pool on the ECCS pump strainers.

The unit was shut down for 18 days after the recirculation pumps inadvertently shifted from fast to slow speed.

A planned reliability maintenance outage lasted 45 days.

A 12-day outage was needed to repair one of the recirculation pump seals.

The fourth refueling and maintenance outage lasted 190 days.

A forced 10-day outage was required to repair an EHC oil leak and to replace a recirculation pump seal.

The unit was shut down for 1 week to replace the lower drywell fans.

The fifth refueling and maintenance outage lasted 74 days.

The unit was shut down for 13 days after an auxiliary transformer fault occurred.

The NRC proposed a $\$ 160,000$ fine for discrimination against five insulators who sued after they were contaminated while working at the plant. 
This Page Intentionally Left Blank 


\section{PILGRIM}

PRODUCTION COST and CAPITAL ADDITIONS (1996 Dollars)

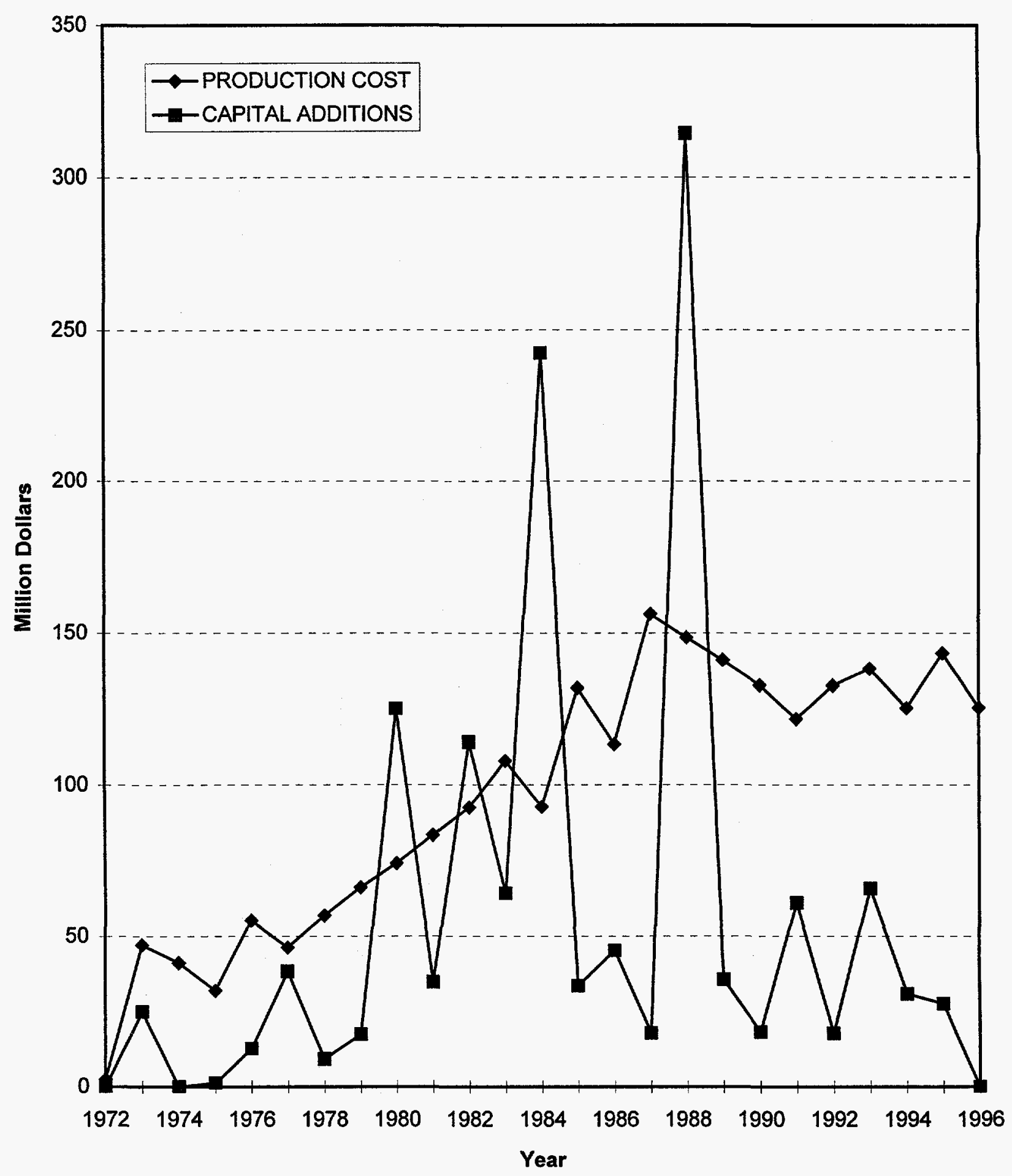




\section{NUCLEAR POWER PLANT OPERATING EXPERIENCE SUMMARY}

Unit data summary through December 1996

Unit: PILGRIM

Location: PLYMOUTH COUNTY, MASSACHUSETTS

Nameplate Rating: $678 \mathrm{MWe}$

Owner: BOSTON EDISON CO.

MDC Net MWe: 670 MWe

Type: GENERAL ELECTRIC BWR

Cumul. Avail. Factor: 61.7

Construction Permit: 8/26/68

Cumul. Cap. Factor (MDC Net): $\mathbf{5 3 . 6}$

Operating License: 9/15/72

Cumul. Forced Outage Rate: 11.5

Commercial Oper. Date: $12 / 1 / 72$

3-Year Avg. Cap. Factor (MDC Net): 77.4

License Expiration: 2012

OPERATING HISTORY (To December 1996)

Date

Oct 1973

Dec 1973 - Jul 1974

Jan 1975

Aug 1975

Sep 1975

Jan - Jun 1976

Aug - Dec 1977

Jan - Feb 1978

Oct 1978

Dec 1979

Jan - May 1980

Sep 1981 - Apr 1982

Mar 1983

\section{Comment}

A 50\% power limit was imposed because of fuel channel problems first discovered at Vermont Yankee.

The AEC ordered the plant shut down for inspection and repair of fuel channels. Refueling and maintenance completed in March, but hearings delayed startup to July.

Two outages occurred for maintenance in January: one for recirculation pump seals and one for piping inspection. High off-gas levels limited power throughout year.

The utility paid a $\$ 12,000$ fine for alleged falsification of ISI records.

A 45-day outage was required for repair of condensers and circulating pump motors.

A refueling and maintenance outage was performed. High off-gas rates still limited power.

A refueling and maintenance outage was performed. All $7 \times 7$ fuel was replaced with $8 \times 8$. array fuel; main condenser tubes were replaced with titanium tubes; CS system piping was replaced. Crud buildup in condensate demineralizers delayed startup; power was limited to about $50 \%$ due to resin trapped in FW heaters.

The plant shut down for about 4 weeks to test and replace questionable electrical connectors.

An outage occurred after a light bulb shorted an auxiliary transformer breaker indicator. A relief valve that was stuck open and other problems prolonged the outage.

Two fuel handling incidents occurred: in one, the crane hooked a spent FA and caused a high radiation alarm; in the other, a new FA was dropped and damaged.

A refueling and maintenance outage was performed. Turbine end wheel problems were found.

A refueling and maintenance outage was performed. Many drywell cables found to need replacement. NRC proposed $\$ 550,000$ fine for alleged violations concerning operating and maintenance documentation. The utility announced a major reorganization of corporate and site management.

An INPO report was released that commended three areas. Improvement efforts after reorganization following the 1982 fines were also praised. 


\section{PILGRIM (Cont'd)}

Dec 1983 - Dec 1984

May 1984

Nov 1984

Feb 1986

Apr 1986 - Dec 1988

May - Jun 1986

Jul 1986

Jun 1987

Aug 1987

Nov 1987

May 1988

Aug 1988

Nov 1988

Dec 1988

Jan 1989

Mar 16, 1989

Apr 1989

Jul 1989

Aug 1989

Oct 1989

Oct - Nov 1989

Mar - Apr 1990

Jul 1990

Sep 1990
A prolonged outage was neccessary for recirculation piping replacement and torus modifications. Most drywell stainless steel piping was also replaced.

The NRC assessed a $\$ 40,000$ fine for alleged violations related to personnel radiation exposure.

The licensee was notified by NRC to undertake an independent assessment of radiological controls and to prepare a radiological controls improvement plan.

The NRC assessed a $\$ 25,000$ fine for alleged violations involving openings found in a barrier designed to prevent entry into a vital area.

The plant shut down to repair MSIV problems. NRC sent an AIT to investigate causes; the plant was ordered to remain shut down until the matter was resolved.

Maintenance work was hampered by labor strikes.

An outage was extended into 1987 to perform Appendix R modifications in addition to other modifications and maintenance. A new management team was appointed in response to NRC findings.

Adverse publicity concerning a GE report on safety and design flaws delayed restart.

A FEMA report found the evacuation plan inadequate.

Maintenance work was halted when two workers were contaminated in separate incidents.

The utility submitted a self-assessment report to the NRC.

The NRC inspection team reported no adverse conditions to prevent approval for restart. However, the plant remained on the NRC list of problem plants.

NRC proposed a $\$ 50,000$ fine for alleged violations concerning inadequate security barriers and a false statement made by a security officer. Massachusetts voters rejected a referendum that would have banned nuclear-generated waste in the state after July 4,1989, effectively shutting down Yankee Row and Pilgrim. About 2300 gallons of contaminated water were spilled at the plant.

The NRC voted to allow restart of plant.

The plant shut down to resolve Generic Letter 88-14 concerns for operability of air-operated containment isolation valves.

The generator was synchronized to a grid; the power was administratively limited to $25 \%$.

The NRC assessed a $\$ 25,000$ fine for a spill of contaminated water due to improperly set circuit breakers.

The NRC authorized a power increase to $50 \%$.

The NRC authorized a power increase to $75 \%$.

The NRC authorized a power increase to $100 \%$.

A scheduled maintenance and testing outage lasted 27 days.

A mid-cycle maintenance outage lasted 48 days.

Problems with one of the recirculation MG sets required an 8-day outage to correct.

Problems with the reactor water-level instrumentation required 22 days to correct. 


\section{PILGRIM (Cont'd)}

May - Aug 1990

Nov 1991

Mar - Apr 1992

Oct - Nov 1992

Dec 1992

Apr - May 1993

Jul 1993

Nov 1993

Feb 1994

Apr 1994

Aug - Nov 1994

Mar - Jun 1995

Apr 1996

Sep 1996
The eighth refueling and maintenance outage lasted 105 days.

A 21-day outage was taken to install improved inverters for both the RCIC and HPCI systems

Failure of a MOV required 18 days to repair.

A planned mid-cycle outage lasted 31 days.

A load rejection in the $345-\mathrm{kV}$ switchyard was caused by flashovers from salt deposits during a coastal storm. The unit was shut down for 5 days.

The ninth refueling and maintenance outage lasted 57 days.

The unit was shut down for 4 days to repair a weld leak on a two inch undervessel drain line.

A 4-day outage was needed to repair a feedwater heater.

The unit was shut down for 6 days to perform MSIV maintenance.

A 6-day outage was taken to perform maintenance on CRD HCU solenoid valves.

The unit tripped from a load rejection and then entered a planned mid-cycle maintenance outage. The outage had to be extended to repair the main generator that had been damaged in the load rejection. The outage lasted 94 days.

The tenth refueling and maintenance outage lasted 73 days.

The unit scrammed on high turbine vibration during the shutdown for a planned maintenance outage. The outage lasted 6 days.

The unit was shut down for 13 days to repair a leaking reactor building component cooling water heat exchanger. 


\section{POINT BEACH}

\section{PRODUCTION COST and CAPITAL ADDITIONS (1996 Dollars)}

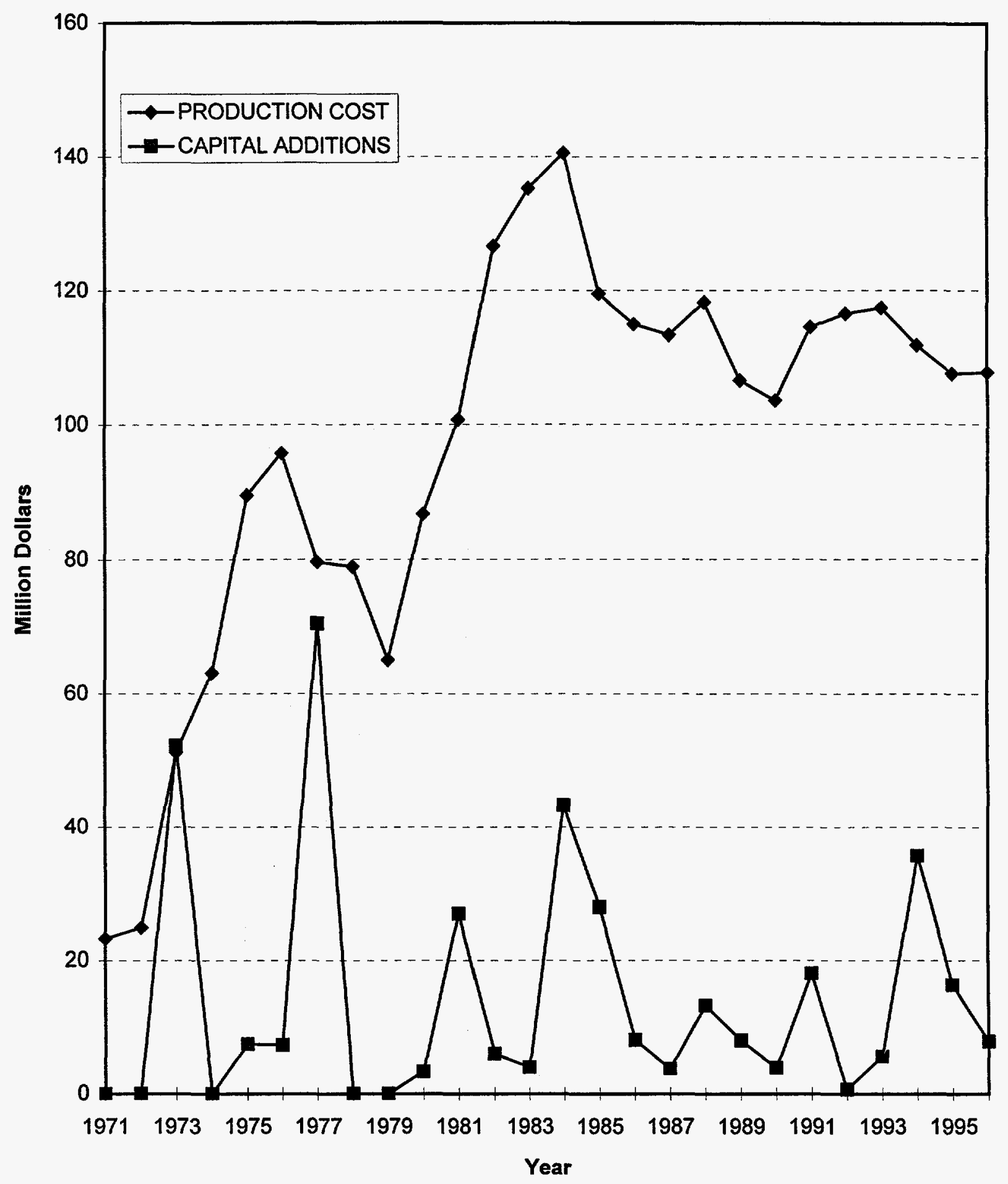




\title{
NUCLEAR POWER PLANT OPERATING EXPERIENCE SUMMARY
}

\author{
Unit data summary through December 1996
}

Unit: POINT BEACH 1

Location: MANITOWOC COUNTY, WISCONSIN

Owner: WISCONSIN ELECTRIC POWER CO.

Type: WESTINGHOUSE PWR

Construction Permit: 7/19/67

Operating License: $10 / 5 / 70$

Commercial Oper. Date: 12/21/70
Nameplate Rating: 524 MWe

MDC Net MWe: 485 MWe

Cumul. Avail. Factor: 83.1

Cumul. Cap. Factor (MDC Net): $\mathbf{7 7 . 8}$

Cumul. Forced Outage Rate: 1.4

3-Year Avg. Cap. Factor (MDC Net): 91.7

License Expiration: 2010

OPERATING HISTORY (To December 1996)

\section{Date}

Sep - Oct 1970

Sep 1972 - Mar 1973

Mar - May 1973

Apr - May 1974

Jan - Feb 1975

Feb - Apr 1975

Nov 1975 - Jan 1976

Oct - Nov 1976

Oct - Nov 1977

Sep - Oct 1978

Oct - Dec 1979

Feb - Apr 1980

Nov - Dec 1980

\section{Comment}

A 1-month delay in fuel load was caused by licensing intervenor. A control rod that was stuck caused a 2-week delay.

The first refueling and maintenance outage was performed. A planned 10-week outage stretched into 6 months because of SG tube defects and cracked blades found in the LP turbine.

Power was limited to $75 \%$ because of fuel densification issue.

The second refueling and maintenance outage was performed. An outage was extended for 10 days due to damaged blades in a turbine from a dropped washer.

An 18-day outage was necessary for SG sludge lancing and RCP seal repair.

A 5-week shutdown occurred after a SG tube ruptured; 157 tubes were plugged.

A third refueling and maintenance outage occurred. This outage occurred 10 days early because of turbine bearing damage. Major work included repair of leaking SG tubes; spent fuel storage capacity was increased.

The fourth refueling and maintenance outage was performed. Major work included SG inspection, RCP seal replacement, and RPV internal inspection. The unit was plagued by condenser tube leaks the rest of the year.

The fifth refueling and maintenance outage lasted 1 month: major work included repairing and/or plugging SG tubes.

The sixth refueling outage started 1 week early because of excessive SG tube leakage.

The seventh refueling and maintenance outage was performed. SG inspection revealed cracks in the tube sheet; 73 additional SG tubes were plugged for a total of $324(10 \%)$; cracks were found in LP turbine discs. Primary-to-secondary leakage caused an additional 11 days of outage.

The unit was taken off line for SG inspection; subsequent operation was limited to about $75 \%$ to inhibit SG tube corrosion.

The eighth refueling and maintenance outage was performed. 
Oct - Dec 1981

Oct - Dec 1982

Oct 1983 - Apr 1984

Apr - Jun 1985

Apr - May 1986

Apr - May 1987

Apr 15, 1987

Oct 1987

Apr - May 1988

Sep 1988

Apr - May 1989

Mar - May 1990

Jul 1990

Apr - May 1991

Jan 1992

Apr - Jun 1992

Aug 1992

Mar - May 1993

Apr 1994

Mar - Apr 1995

Jul 1995

Mar - Apr 1996
The ninth refueling and maintenance outage was performed. Major work included successful 10-year ISI hydrostatic testing on main steam and FW systems, including SGs.

The tenth refueling and maintenance outage lasted 49 days.

The eleventh refueling outage included replacement of SGs. This task was completed 31 days ahead of schedule and with about one-third of estimated man-rem exposure the for project. Other major work included RPV ISI, TMI modifications, ILRT, and extensive BOP repair and modifications.

The twelfth refueling and maintenance outage was performed. Major work included CRD component replacement. Loose parts generated during CRD work caused stuck control rods.

The thirteenth refueling and maintenance outage was performed. Major work included replacing several FW heaters, the plant process computer, and condenser tubes.

The fourteenth refueling and maintenance outage was performed. Major work included 10 -year RPV ISI and core barrel modifications.

The NRC granted an operating license extension to 2010.

The NRC imposed a $\$ 50,000$ fine for alleged violations concerning plant security.

The fifteenth refueling and maintenance outage lasted $\mathbf{4 2}$ days: major work included 5-year main generator inspection.

Six plant workers were fired for alleged violation of utility drug policy.

The sixteenth refueling and maintenance outage lasted 44 days: major work included Appendix J testing, SG inspection and sludge lancing, and main turbine inspection.

The seventeenth refueling and maintenance outage lasted 49 days.

A leak through a weld on a CRDM required a 9-day outage to repair.

The eighteenth refueling and maintenance outage lasted 46 days: major work included SG ECT and inspection, containment service water system cleaning/inspection, and inspection/maintenance of one LP turbine.

The NRC proposed a $\$ 150,000$ fine against the site for alleged violations relating to MSIV testing. The fine was paid the following month.

The nineteenth refueling and maintenance outage lasted 55 days: major work included installation of a full test line in the RHR system, SG ECT, and walkdowns of the RPS and safeguards system for as-built drawings.

The NRC proposed a $\$ 50,000$ fine against the unit for alleged violations during the previous refueling outage. The incident caused the RCS temperature to exceed the limit for temperature change of $100 \mathrm{~F} / \mathrm{hr}$. The fine was paid.

The twentieth refueling and maintenance outage lasted 43 days.

The twenty-first refueling and maintenance outage lasted 28 days.

The twenty-second refueling and maintenance outage lasted 37 days.

The main generator tripped due to moisture condensation in the exciter from the hot weather conditions. The unit was down for 4 days.

The twenty-third refueling and maintenance outage lasted 25 days. 
Sep 1996

A proposed power uprate for both units was deferred to devote resources to improving plant performance.

Dec 1996

The NRC proposed and the licensee paid a $\$ 325,000$ fine for control room inattentiveness, auxiliary feedwater inoperability, inadequate corrective actions, and spent fuel dry casks problems. 


\section{NUCLEAR POWER PLANT OPERATING EXPERIENCE SUMMARY}

Unit data summary through December 1996

Unit: POINT BEACH 2

Nameplate Rating: 524 MWe

Location: MANITOWOC COUNTY, WISCONSIN

MDC Net MWe: $485 \mathrm{MWe}$

Owner: WISCONSIN ELECTRIC POWER CO.

Cumul. Avail. Factor: 85.9

Type: WESTINGHOUSE PWR

Cumul. Cap. Factor (MDC Net): 82.3

Construction Permit: 7/25/68

Cumul. Forced Outage Rate: 0.9

Operating License: 5/25/72

3-Year Avg. Cap. Factor (MDC Net): 79.1

Commercial Oper. Date: 10/1/72

License Expiration: 2013

OPERATING HISTORY (To December 1996)

Date

Nov 1971 - Jul 1972

Mar 1973

$1974-1983$

Mar - Jun 1983

Oct - Nov 1985

1986

Jun 1987

Oct - Nov 1987

Dec 1987

Oct - Nov 1988

Mar 1989

Sep - Nov 1989

Oct - Nov 1990

\section{Comment}

Intervenors' legal maneuvers delayed licensing for about 8 months; a long wet layup caused corrosion product buildup, which had to be flushed from steam and feedwater lines.

A full-power operating license was issued after protracted delays were caused by intervenors.

Mostly routine operation and refueling outages occurred. SG tube problems were beginning to occur more frequently.

A refueling and maintenance outage was performed. The main task was a SG sleeving effort conducted to prolong the lives of SGs.

A refueling and maintenance outage lasted 51 days: major work included SG inspection and tube plugging.

The unit completed the year as one of the top 10 lowest cost power producers for the second year.

The unit operating license was extended to March 2013.

The refueling and maintenance outage lasted 47 days: major work included SG inspection and tube sleeving and plugging.

The utility paid a $\$ 25,000$ fine to the NRC for alleged violations concerning inoperability of MSIVs during the August startup after a trip. The unit completed the year with an energy availability factor of $84.2 \%$.

The refueling and maintenance outage lasted 46 days: Major work included SG inspection: 509 tubes were sleeved and an additional 25 were plugged. The HP turbine was also overhauled.

An actuation of a main transformer deluge system caused a plant trip. The unit was shut down for 4 days.

A refueling and maintenance outage lasted 63 days. Major work included 10-year RPV ISI, LP turbine repair, SG inspection, and tube sleeving and repair.

The sixteenth refueling and maintenance outage lasted 44 days. Major work included SG ECT, crevice flushing, and tube plugging, and ECT of other HXs. 
Sep - Nov 1991

Jan 1992

Sep - Nov 1992

Dec 1992

Sep - Oct 1993

Sep - Oct 1994

Feb 1995

Oct - Dec 1995

Oct 1996 - Present
The seventeenth refueling and maintenance outage lasted 47 days: Major work included SG ECT, installing a full-flow test line in the RHR system, and replacing SI and containment spray pumps.

The NRC proposed a $\$ 150,000$ fine against the site for alleged violations relating to testing of the MSIVs. The fine was paid the following month.

The eighteenth refueling and maintenance outage lasted 53 days. Major work included SG ECT and inspection, SI valve and battery replacement, and MSIV modifications. Check valve leakage testing revealed additional work that extended the outage 5 days.

The NRC proposed a $\$ 75,000$ fine for allegedly operating the unit with a temporary pipe plug in a safety system, rendering a portion of the system inoperable. The fine was paid the following month.

The nineteenth refueling and maintenance outage was performed.

The twentieth refueling and maintenance outage lasted 38 days.

The unit was shut down for nine days due to seal oil leakage into the main generator.

The twenty-first refueling and maintenance outage lasted 57 days.

The twenty-second refueling and maintenance outage was performed. The steam generators were replaced. The outage was extended due to cable separation and other design issues. 
PRAIRIE ISLAND

PRODUCTION COST and CAPITAL ADDITIONS

(1996 Dollars)

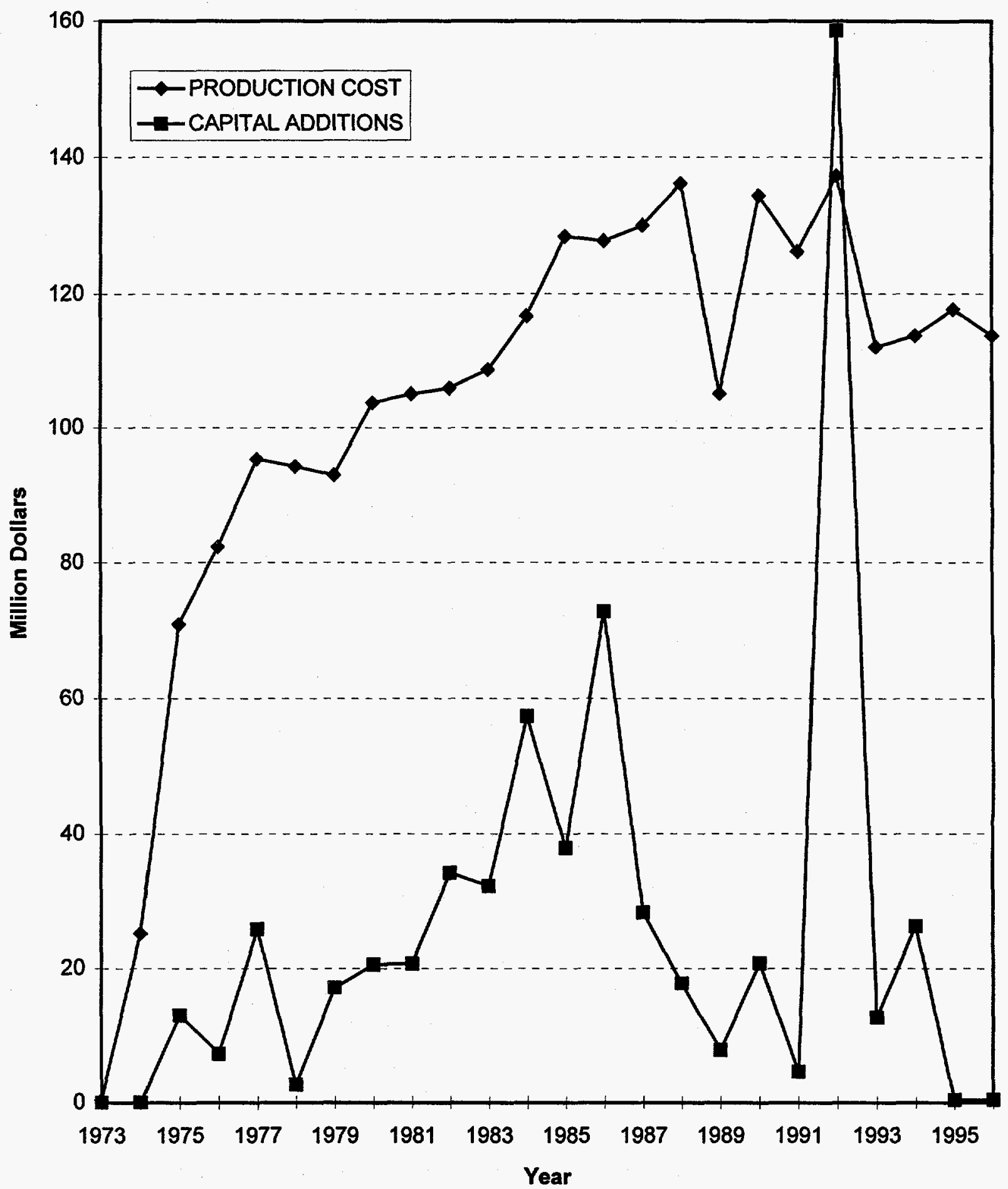




\section{NUCLEAR POWER PLANT OPERATING EXPERIENCE SUMMARY}

Unit data summary through December 1996

\section{OPERATING STATUS}

Unit: PRAIRIE ISLAND 1

Location: GOODHUE COUNTY, MINNESOTA

Owner: NORTHERN STATES POWER CO.

Type: WESTINGHOUSE PWR

Construction Permit: 6/25/68

Operating License: 8/9/73

Commercial Oper. Date: 12/16/73
Nameplate Rating: 593 MWe

MDC Net MWe: 513 MWe

Cumul. Avail. Factor: $\mathbf{8 5 . 2}$

Cumul. Cap. Factor (MDC Net): 83.1

Cumu!. Forced Outage Rate: $\mathbf{4 . 5}$

3-Year Avg. Cap. Factor (MDC Net): 88.8

License Expiration: 2013

OPERATING HISTORY (To December 1996)

Date

Dec 1973

Mar 1974

Apr - Jul 1974

Sep - Oct 1974

Feb - Dec 1974

Jan 1975

Apr - May 1975

Aug 1975

Oct 1975

Mar - May 1976

Sep 1976

Mar - May 1977

Mar - Apr 1978

Apr - May 1979

Jul - Aug 1979

\section{Comment}

A 14-month delay in vessel delivery, labor strikes, and a pipe break controversy delayed plant startup about 1 year. Commercial operation was begun, but a turbine blade failure caused a plant shutdown.

After restart in early February, a second turbine blade failure forced another shutdown.

A full-power license was granted. Another turbine blade failure forced a shutdown that lasted for more than 2 months.

A 7-week shutdown was required for turbine reblading; the unit switched to an all-volatile secondary water treatment.

FW pumps and MSIVs were sources of operational problems throughout the year.

A FW pump failure caused power to be limited to $325 \mathrm{MWe}$ for several weeks.

The unit was shut down for SG tube inspection.

The unit was shut down for 8 days to perform a refueling surveillance.

A brief shutdown occurred because of another FW pump failure.

The first refueling and maintenance outage was performed. Restart was delayed to repair a seal weld on an RPV head penetration.

A 10-day outage was needed to replace leaking RPV head O-rings.

The second refueling and maintenance outage was performed. Major work included SG inspection, LP turbine rotor replacement, and containment leak testing.

The third refueling and maintenance outage was performed. Major work included SG inspection.

The fourth refueling and maintenance outage lasted 2 months.

The unit was shut down because of main turbine vibration and damage to the HP turbine blading. The unit was restarted with four rows of blades removed. 
Oct 1979

Nov 1979

Jul 1980

Aug - Oct 1980

May 1981

Aug 1981

Sep - Oct 1981

Nov 1981

Aug 1982

Sep 1982

Nov - Dec 1982

Jan - Feb 1983

Dec 1983 - Jan 1984

Oct - Nov 1984

Jan - Mar 1985

Mar - Apr 1986

Mar 1986

Sep 1986

Feb - Mar 1987

Apr - May 1987
A 3-week shutdown occurred because of a SG tube rupture.

Two unit trips occurred due to ground faults in both FW pump motors, causing an 11-day outage.

A 3-week shutdown occurred because of a SG tube leak.

The fifth refueling and maintenance outage was performed. Cracked SG support column bolts were found.

The NRC approved installation of high density, borated spent fuel storage racks. The modifications provided storage capacity for $1582 \mathrm{FAs}$; however, pending an evaluation of the heavy load issue, storage was limited to 1120 FAs.

A reactor scram resulted from an EHC system control card fault. The unit had operated continuously since November 11, 1980 (293 days) prior to the scram.

The sixth refueling and maintenance outage was performed.

Power was limited to $90 \%$ during an evaluation of an $\mathrm{I}^{131}$ activity spike.

Two plant surveys conducted by INPO resulted in 19 recommendations in 16 areas. No recommendations were made for 35 areas. Six good practices were highlighted, and only one item from the 1981 INPO visit was still pending.

The reactor scrammed after a FW regulating valve lost control air supply. The event ended 311 days of continuous operation. An iodine spike exceeded the limits following the trip.

The seventh refueling and maintenance outage lasted 6 weeks. The unit returned to service ahead of schedule.

The unit was shut down after extensive corrosion cracks were found in SI piping. The outage for repairs required 15 days.

The eighth refueling and maintenance outage was performed.

The unit was taken off line on two separate occasions to repair SG tube leaks. The combined outage time was 17 days.

The ninth refueling and maintenance outage lasted 58 days. Major work included a 10-year overhaul.

The tenth refueling and maintenance outage lasted 36 days: major work included inspection and sludge lancing of SGs, RCS flushing, and replacement of the RPV upper internals with an improved design.

The NRC announced a reduction in its inspection efforts in recognition of the quality of performance of the plant. The plant status would be reviewed every 3 months.

The NRC authorized the utility to operate both units for 40 years from the date of issuance of their operating license, rather than from the construction permit dates.

The unit was shut down for investigation and repair of a SG tube leak. The outage lasted 11 days.

The eleventh refueling and maintenance outage lasted 50 days: major work included SG inspection, sludge lancing, and crevice flushing, RCP seal replacement, inspection of RCP motors, main generator, and turbine control/stop valve, and modifications to the control room boards. 
Sep 1987

Dec 1987

Aug - Sep 1988

Jun 1989

Jul 1989

Dec 1989

Jan - Feb 1990

Feb - Mar 1990

Apr 1990

Aug 1990

Mar 1991

May - Jun 1991

Aug 1991

Sep 1991

Apr 1992

Aug 1992

Sep 1992

Oct 1991 - Jan 1992

May 1993

May - Jul 1994
The NRC proposed a $\$ 25,000$ fine for an alleged violation in which one of two SI pumps had been inoperable for 25 days because a circuit breaker had not been fully racked in after maintenance. The NRC had reduced the original $\$ 50,000$ amount by $50 \%$ because of prompt corrective action by the utility.

The IAEA announced plans to send a team to visit the plant because of its ranking as one of the world's eight best performing commercial nuclear power plants.

The twelfth refueling and maintenance outage lasted 35 days: major work included FA replacement, SG inspection and sleeve insertion, modification of control boards, RCP motor overhaul, ILRT, MOV testing, and a pipe thinning study.

The NRC cited the plant as one of the top four performers in the industry.

The licensee announced plans to replace Unit 1 SGs in 1998 and recommended that the lower and upper assemblies be refurbished.

The NRC proposed a fine of $\$ 25,000$ for alleged EQ violation.

The thirteenth refueling and maintenance outage was performed. Major work included repairs to the main generator, replacement of FW control valves and controls, ISI and pipe thinning inspections, inspection of SG and condenser tubes, SG sleeving, replacement of an RCP seal, and replacement of SG lateral support bolts.

The unit was shut down for 25 days because of problems with FW regulating valve stems and plugs.

Construction began on building two new DGs to meet the NRC station blackout rule. Estimated project cost was \$57 million and completion was projected for spring 1992.

The NRC cited the plant for good performance. The unit operated without further significant outages the rest of the year.

The utility initiated work on an independent spent fuel storage facility at the plant site. Construction was scheduled to begin in 1992, and spent fuel storage was to begin in early 1993.

The fourteenth refueling and maintenance outage lasted 30 days.

Rod control circuit card problems caused a 4-day outage.

The plant received high marks on the latest SALP reports. A "slight decline" in performance was noted in operations and maintenance/surveillance areas.

The site had the highest capacity in the U.S.: Unit 1 was first with $87.63 \%$ and Unit 2 second with $87.38 \%$. For the first time, two units at a site came in first and second.

The Minnesota PUC issued a certificate of need for an independent spent fuel storage installation (ISFSI).

A 12-day outage was required to repair SG leaks by plugging tubes.

The fifteenth refueling and maintenance outage lasted 79 days: major work included tie-in of the two new DGs, replacement of the HP O-ring, major cooling water piping, and control room control panels, HP turbine and RCP seal inspections, ILRT, and SG ECT.

The NRC SALP report for the site gave five Category 1 ratings and no Category 3 ratings.

The sixteenth refueling and maintenance outage lasted 56 days. 
PRAIRIE ISLAND 1 (Cont'd)

Aug 1994

Jan - Mar 1996
The unit was shut down for 1 week to repair a reactor vessel adapter canopy seal leak. The seventeenth refueling and maintenance outage lasted 58 days. 


\section{NUCLEAR POWER PLANT OPERATING EXPERIENCE SUMMARY}

Unit data summary through December 1996

\section{OPERATING STATUS}

Unit: PRAIRIE ISLAND 2

Location: GOODHUE COUNTY, MINNESOTA

Nameplate Rating: 593 MWe

Owner: NORTHERN STATES POWER CO.

MDC Net MWe: 512 MWe

Type: WESTINGHOUSE PWR

Cumul. Avail. Factor: $\mathbf{8 8 . 0}$

Construction Permit: 6/25/68

Cumul. Cap. Factor (MDC Net): 86.5

Operating License: 10/29/74

Cumul. Forced Outage Rate: 2.4

Commercial Oper. Date: 12/21/74

3-Year Avg. Cap. Factor (MDC Net): 96.6

License Expiration: 2014

OPERATING HISTORY (To December 1996)

Date

Dec 1974

Jun 1975

Jun - Jul 1975

Dec 1975 - Jan 1976

Oct 1976

Nov - Dec 1977

Nov 1978

Jun 1979

Jan - Feb 1980

Sep 1980

Feb - Apr 1981

Jun - Jul 1981

Sep 1981

\section{Comment}

Initial criticality, first power generation, and commercial power status were achieved.

The plant tripped due to a partial closure of an MSIV and remained off-line for 16 days for turbine bearing repair.

A forced outage of 15 days was necessary to repair a fluid leak in the EHC system and a damaged turbine bearing.

The unit was shut down because of turbine blade failure. SG inspection, modification, and sludge lancing were also performed. A $10 \%$ power reduction was necessary because baffles were installed as a temporary fix for the turbine.

The first refueling outage lasted about 8 weeks. Major work included turbine repair.

The second refueling and maintenance outage was performed. Major work included SG inspection and tube plugging, containment leak testing, turbine blade replacement, and installation of a new transformer.

The third refueling and maintenance outage was performed.

The unit tripped because of a failed FW pump; power was restricted to $60 \%$ for 15 days until pump repairs were completed.

The fourth refueling and maintenance outage was performed. Major work included replacement of LP turbine rotor spindles and SG tube inspection and plugging.

Cracked SG support bolts were found during a 9-day outage.

The fifth refueling and maintenance outage was performed. Some SG tubes were found to be degraded.

The unit was shut down to investigate excessive RCP vibration caused by cracked shaft. A replacement pump was acquired from the D.C. Cook site and operation was restored after an outage of 42 days.

A 10-day outage was required to repair SG tube leaks. 
Jun - Jul 1982

Feb - Mar 1983

Apr 1983

Aug - Sep 1983

Sep - Oct 1984

Sep - Nov 1985

Oct - Nov 1986

Sep 1987

Dec 1987

Jan - Feb 1988

Nov 1988

Mar - Apr 1989

Dec 1989

Apr 1990

Jun 1990

Sep - Oct 1990

Dec 1990

Feb - Mar 1992
A sixth refueling and maintenance outage was performed. SG tube inspection showed some degradation, and 27 tubes were plugged.

A 9-day outage was required for RCP seal repairs.

A turbine stop valve failure limited power to $70 \%$ until the unit was shut down to repair the valve.

The seventh refueling and maintenance outage was performed.

The eighth refueling and maintenance outage lasted 40 days.

The ninth refueling and maintenance outage lasted 57 days; major work included the tenyear ISI.

The tenth refueling and maintenance outage lasted 33 days. Major work included inspection and sludge lancing for both SGs, replacement of the reactor vessel upper internals, and RCP inspection.

Unit 2 completed back-to-back continuous run records of $300+$ days; the dual unit plant completed a record run of 240 continuous days.

Unit 2 achieved an energy availability factor of $99.5 \%$ for the year.

The eleventh refueling and maintenance outage started after ending a 406-day continuous run, 33 days short of a world record. Major outage work included RCP retaining ring and seal replacement, SG inspection, and turbine generator stator and rotor inspection.

An outage for FW heater extraction line bellows repair and main condenser tube work ended a 268-day continuous run. The unit was shut down for 90 hours.

The twelfth refueling and maintenance outage lasted 32 days: major work included SG inspection, pipe thinning study, canopy welding over instrument seal welds, and replacement of the reactor vessel head adapter plug.

A reactor scram occurred because of a faulty RPS MG set voltage regulator. Also, the buses supplying RCP power were unavailable because a $345-\mathrm{kV}$ substation breaker failed.

Extremely cold weather was considered to be the cause. A similar event occurred later in the month causing a 15-day outage.

The unit generator was taken off line for repair of the high side disconnects. A failure of the turbine thrust bearing oil seal required additional repairs. Total outage time was 20 days.

The unit was cited for good performance by the NRC.

An outage lasting 29 days began after transformer oil analysis indicated a hot spot in the core steel. The thirteenth refueling and maintenance outage was started ahead of schedule. Major work included SG inspection, LP turbine overhaul, component cooling water HX repair, circulating water pump impeller replacement, station battery replacement, pipe thinning study, and other component inspections.

The reactor tripped due to failure of two circuit cards in the rod control system. The unit was down for 9 days.

The fourteenth refueling and maintenance outage lasted 25 days: major work included MOV and station battery testing, replacement of MSR tube bundles ( 2 of 4), control room control panels, and HP O-rings, modification of the RX head vent, and SG ECT. 
Feb 1992

Apr 1992

Aug 1992

Oct 1992 - Jan 1993

May 1993

Oct - Dec 1993

May - Jun 1995
During the refueling outage, the unit had a loss of shutdown cooling which resulted in a RCS temperature increase of $90^{\circ} \mathrm{F}$. In May 1992, the NRC proposed a $\$ 12,500$ fine for this event. Although the initial base penalty was increased by $100 \%$ due to prior notice via generic documents, the penalty was reduced by $100 \%$ for past good performance and $75 \%$ for the utility's response to the incident. The fine was paid in June.

The site had the highest capacity in the U.S. since Unit 1 was first with $87.63 \%$ and Unit 2 second with $87.38 \%$. For the first time, two units at a site came in first and second.

The Minnesota PUC issued a certificate of need for an independent spent fuel storage installation (ISFSI).

A mid-cycle maintenance outage was taken with the main work being the tie-in of the two new DGs. The outage lasted 80 days.

An NRC SALP report for the site gave five Category 1 ratings and no Category 3 ratings.

The fifteenth refueling and maintenance outage lasted 49 days.

The sixteenth refueling and maintenance outage lasted 46 days. 


\section{QUAD CITIES}

PRODUCTION COST and CAPITAL ADDITIONS (1996 Dollars)

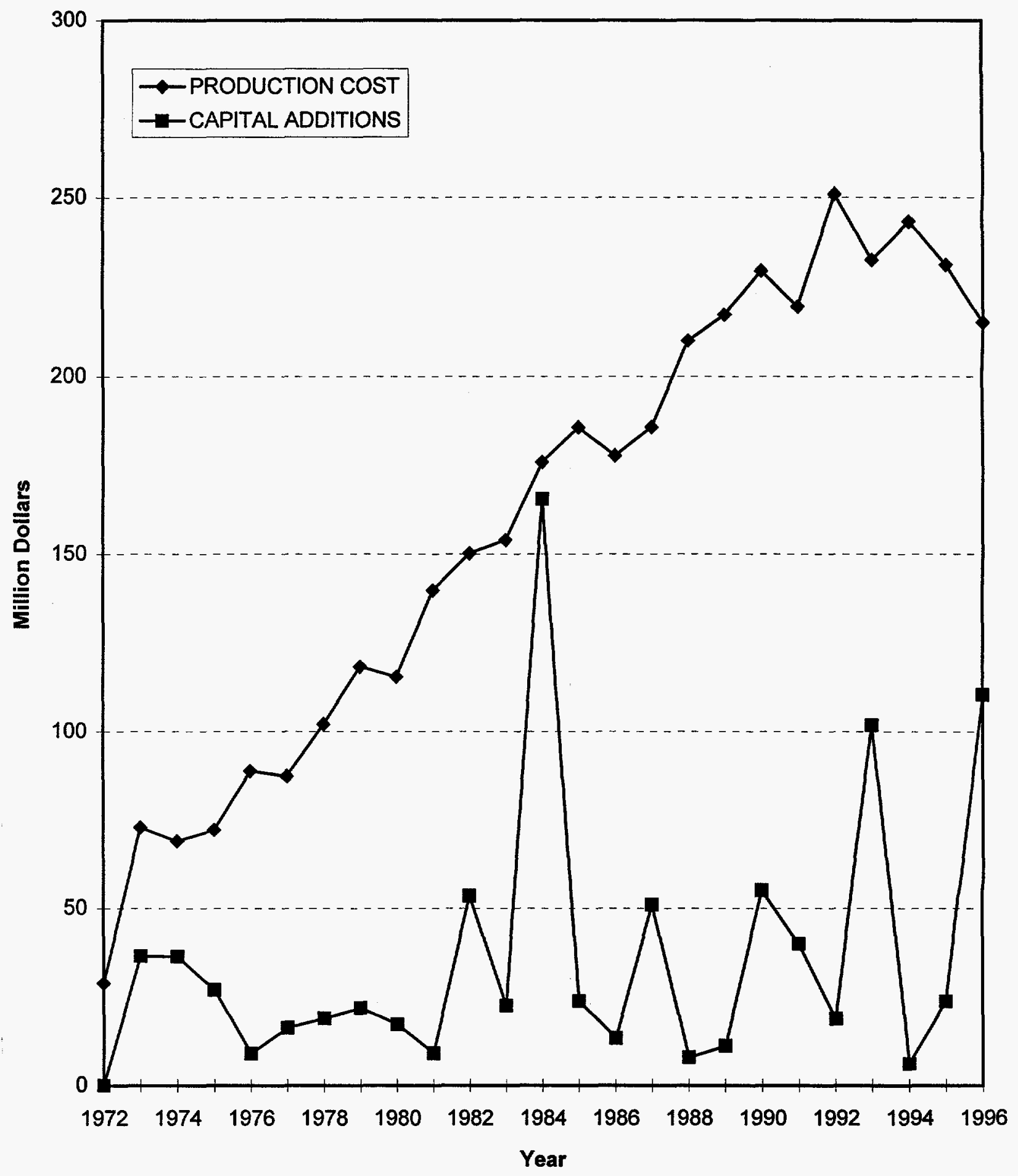




\section{NUCLEAR POWER PLANT OPERATING EXPERIENCE SUMMARY}

Unit data summary through December 1996

Unit: QUAD CITIES 1

Location: ROCK ISLAND COUNTY, ILLINOIS

Nameplate Rating: 828 MWe

Owner: COMMONWEALTH EDISON CO. MDC Net MWe: 769 MWe

Type: GENERAL ELECTRIC BWR

Cumul. Avail. Factor: $\mathbf{7 4 . 0}$

Construction Permit: 2/15/67

Cumul. Cap. Factor (MDC Net): 63.7

Operating License: $12 / 14 / 72$

Cumul. Forced Outage Rate: $\mathbf{7 . 5}$

Commercial Oper. Date: 2/18/73

3-Year Avg. Cap. Factor (MDC Net): $\mathbf{5 0 . 6}$

License Expiration: 2012

OPERATING HISTORY (To December 1996)

Date

Dec 1971

Mar 1972

Jun 1972

Jan 1973

Apr - Jul 1974

Jan - Feb 1975

Jan - Mar 1976

Jun - Jul 1975

Mar - May 1977

Jan - Mar 1979

Aug - Dec 1980

May 1982

Sep - Dec 1982

Feb 1983

Mar 1983

\section{Comment}

Intervenors won an injunction in U.S. District Court preventing AEC from issuing an operating license until a full environmental review performed.

The utility agreed to build a $\$ 30$ million spray cooling canal for plant cooling to replace the originally designed river bottom diffuser system.

A circulating water line expansion bellows ruptured and flooded a considerable amount of equipment.

Full-power testing was completed.

A 16-week refueling outage was performed. Leaks were found in the RHR Service Water system. Jet pump damage and 29 leaking FAs were also found.

The unit was shut down to replace a cracked recirculation valve bypass line.

A refueling outage and turbine overhaul occurred; cracks were repaired in FW nozzles.

A unit was shut down to repair the main generator field ground.

A refueling outage was performed and recirculation line bypass line cracks were repaired.

A refueling outage was performed.

A refueling and major maintenance outage that included turbine inspection, torus modifications, and CS and FW sparger inspections was performed.

An INPO survey praised plant operations in several areas and recommended improvement in five other areas.

A refueling and maintenance outage lasted 108 days; work included torus modifications and recirculation piping inspection per NRC order.

The NRC proposed a $\$ 120,000$ fine for alleged use of substandard parts on pressure relief valves.

The NRC proposed a $\$ 150,000$ fine for alleged procedural deficiencies in the control rod withdrawal sequence during a startup. Also, involved operating personnel and station management were required to meet with NRC officials. 
May 1983

Mar - Aug 1984

Sep 1985

Jan - Apr 1986

Sep - Dec 1987

Nov 1987

Jul - Aug 1988

Apr 1989

Sep - Nov 1989

Aug 1990

Nov 1990 - Apr 1991

Feb 1991

May 1991

May - Jun 1991

Jun 1991

Feb 1992

Aug 1992

Sep - Dec 1992

Jun - Jul 1993

Nov 1993

Dec 1993

Jan 1994

Mar - Aug 1994
$\mathrm{NRC}$ assessed a $\$ 60,000$ fine for alleged disabling of scram circuits.

A refueling and maintenance outage lasted 165 days. Major work included inspection and repair of recirculating piping welds and modifications to containment to restore original design margin.

The NRC assessed the utility a $\$ 50,000$ fine for alleged violation related to an incident in which a Unit 1 operator left his control area unattended while assisting a Unit 2 operator.

The refueling and maintenance outage lasted 89 days.

The refueling and maintenance outage lasted 103 days.

An NRC inspection identified drywell structural steel connections that failed to meet FSAR requirements due to a construction/design error that had existed since November 1986.

The plant initiated several power reductions to maintain EPA restrictions on river water temperature. Hot weather caused record-breaking demands at the same time, but the utility was able to obtain adequate power from other sources.

The unit was shut down for 7 days following the failure of a turbine EHC circuit board.

The tenth refueling and maintenance outage lasted 79 days: major work included control room modifications, recirculation piping welding, battery replacement, and various plant improvements.

The unit was shut down for 5 days to repair an electromatic relief valve.

The eleventh refueling and maintenance outage lasted 169 days: major work included LP turbine inspection and repair.

The NRC extended the unit operating licenses by 5 years to recapture the construction period.

The NRC proposed a $\$ 112,500$ fine for alleged violations concerning an incident in January involving two shutdown cooling system valves. The consequence was the release of 4200 gallons of water to the floor of the reactor building. The utility paid the fine.

The unit was manually scrammed and shut down for 34 days due to problems with the main unit transformer.

The NRC SALP report rated operations a low Category 3.

The reactor scrammed on high steam flow indication. Maintenance was performed on an electromatic relief valve during the 12-day outage.

The NRC SALP report noted improved performance in operations and upgraded the rating to Category 2.

The twelfth refueling and maintenance outage lasted 87 days.

$\mathrm{HPCI}$ repairs required 32 days to complete.

A maintenance outage lasted 25 days.

EHC problems caused a reactor trip. The unit remained shut down for 15 days to work on the EHC system and the MSIVs.

The site was placed on the NRC's declining trend list.

The thirteenth refueling and maintenance outage lasted 168 days. 


\section{QUAD CITIES 1 (Cont'd)}

Oct 1994 - Jan 1995

Jun 1995

Oct 1995

Jan 1996

Feb - Aug 1996

Jun 1996

Sep 1996
A forced outage lasted 102 days to reduce the maintenance backlog.

The site was removed from the NRC's declining trend list.

The unit was shut down for 3 weeks to correct a design deficiency with the scram discharge volume level switches.

The NRC proposed and the licensee paid a $\$ 50,000$ fine for failure to correct problems with circuit breaker settings.

The fourteenth refueling and maintenance outage lasted 204 days.

The NRC proposed and the licensee paid a $\$ 50,000$ fine because the structural steel in the corner rooms did not conform to the licensed plant configuration described in the FSAR due to modifications and errors in the original design.

The unit was shut down for 4 days after an MSIV failed its timing requirements. 


\title{
NUCLEAR POWER PLANT OPERATING EXPERIENCE SUMMARY
}

\author{
Unit data summary through December 1996
}

Unit: QUAD CITIES 2

Nameplate Rating: 828 MWe

Location: ROCK ISLAND COUNTY, ILLINOIS

MDC Net MWe: 769 MWe

Owner: COMMONWEALTH EDISON CO.

Cumul. Avail. Factor: 72.9

Type: GENERAL ELECTRIC BWR

Cumul. Cap. Factor (MDC Net): 62.4

Construction Permit: 2/15/67

Cumul. Forced Outage Rate: 11.2

Operating License: $12 / 14 / 72$

3-Year Avg. Cap. Factor (MDC Net): $\mathbf{5 5 . 3}$

Commercial Oper. Date: 3/10/73

License Expiration: 2012

OPERATING HISTORY (To December 1996)

Date

Aug 1972

Apr 1973

Dec 1974 - Apr 1975

Jul 1975

Aug - Sept 1975

Oct - Nov 1975

Sep - Oct 1976

Feb - Mar 1977

Jul - Sep 1977

Jan - Mar 1978

Nov 1979 - Apr 1980

Sep - Dec 1981

Jan - Feb 1982

Jun 1982

\section{Comment}

A jet pump holddown failure forced a 54-day outage.

The unit was shut down for a 2-week planned outage to make connections to the modified off-gas system and perform other maintenance.

The unit was shut down for a refueling and maintenance outage. Major work included repair of FW sparger weld cracks, replacement of 74 leaking FAs, repair of recirculation bypass line cracks, and repair of jet pump holddown mechanisms.

The NRC assessed a $\$ 25,000$ fine for alleged security violations and a control rod withdrawal incident.

FW piping leaks and FW valve problems forced two outages totaling 15 days.

The unit was shut down for 35 days to perform fuel shuffling and repair I\&C cables damaged by leaking EHC system piping.

The unit was shut down for a 6-week refueling and turbine maintenance outage.

The generator field ground repairs forced a 26-day outage.

The low system power demand allowed three outages totaling 24 days.

The unit was shut down for a 53-day refueling outage.

The unit was shut down for refueling and maintenance outage. Major work included repair of CS injection piping cracks. Total outage time was 147 days.

A refueling and maintenance outage lasted 111 days. Major work included modifications to the RCIC, HPCI, SDV, and DG systems.

Repairs to cracked RWCU piping forced a 44-day outage.

The unit was authorized to expand spent fuel capacity from 2920 FAs to a maximum of 7684 FAs by the use of neutron absorbing fuel storage racks. The NRC proposed a $\$ 100,000$ fine for alleged administrative weaknesses associated with a failure of an electromatic relief valve. 


\section{QUAD CITIES 2 (Cont'd)}

Nov 1982

May 1983

Sep 1983 - Feb 1984

Mar - Jun 1985

Oct 1986 - Jan 1987

Aug - Sep 1987

Oct 1987

Nov 1987

Apr - Aug 1988

Sep 1988

Oct 1988

1989

Jul 1989

Aug 1989

Feb - May 1990

Sep 1990

Jan 1991

Apr 1991

Sep 1991
The plant became the first Commonwealth Edison plant to log over two million consecutive person-hours without a disabling injury to a member of the work force.

The NRC proposed a $\$ 60,000$ fine for an alleged disabling, during maintenance in October 1982, of two scram circuits and allowing the condition to exist for more than 40 hours with an alarm light on in the control room.

A refueling and maintenance outage lasted 167 days. The unit was shut down early in response to NRC Bulletins concerning IGSC cracks in recirculation piping. Major work included repair of crack indications found in RWCU and RHR piping welds.

A refueling and maintenance outage lasted 82 days. The utility announced favorable operation with a new GE barrier fuel design that allowed an increased power rating and improved load following capabilities.

A refueling and maintenance outage lasted 106 days. Major work included repair of several recirculation piping cracks and condenser tube leaks.

A main output transformer failure forced a 36-day outage for repairs.

The unit was shut down after a trip was caused by personnel racking out the wrong circuit breakers. Consequent damage to safety-related electrical equipment forced a 15-day outage.

An NRC inspection identified drywell structural steel connections that failed to meet FSAR requirements due to a construction/design error that had existed since November 1986.

A refueling and maintenance outage lasted 76 days. Power was restricted upon restart because of EPA restrictions on river water temperature. Hot weather caused record-breaking demands at the same time, but utility was able to obtain adequate power from other sources.

The NRC proposed two fines totaling $\$ 125,000$ against the utility. One fine of $\$ 75,000$ for alleged inoperability of a DG; the other for $\$ 50,000$ for alleged lack of written safety evaluations for modifications to the $125 \mathrm{~V}$ battery system.

The NRC proposed a $\$ 150,000$ fine for alleged EQ violations in testing electrical cable connections in safety-related equipment.

The unit operated through August with no significant outages or power reductions.

The NRC fine proposed in October 1988 was reduced to $\$ 75,000$.

A scheduled maintenance outage for replacement of a recirculation pump seal was extended to correct leakage from an RHR SW pipe. The outage lasted seven days.

The tenth refueling and maintenance outage lasted 94 days. Major work included replacement of 2 of $3 \mathrm{LP}$ turbine rotors, RWCU pipe penetration, and containment bellows, and an ILRT.

A 5-day outage was needed to troubleshoot the EHC system.

A planned maintenance outage lasted 4 days.

The unit was shut down when high acetylene gas content was found in the reserve auxiliary transformer. A 16-day outage was necessary to repair that and other transformer problems.

The reactor scrammed when an inboard MSIV failed and a 12-day outage was needed for repairs. 
Mar 1991

Jan - May 1992

Jan 1993

Mar - May 1993

Jun - Jul 1993

Jul 1993

Aug 1993

Jan 1994

Jun - Jul 1994

Aug 1994

Oct - Dec 1994

Mar - Aug 1995

Aug 1995

Oct 1995

May - Aug 1996

Oct 1996
The NRC proposed a $\$ 50,000$ fine for alleged violations involving an October 1990 incident where an operator caused a reactor scram due to improper operation of the controls rods.

The eleventh refueling and maintenance outage lasted 129 days: Major work included decontamination of the recirculation system, replacement of the recirculation pump shafts, and an ILRT.

The unit was shut down for 6 days after a scram was caused by a MSIV closure due to a faulty solenoid.

The twelfth refueling and maintenance outage lasted 82 days.

A main transformer fault caused a reactor trip and required $\mathbf{3 0}$ days to repair.

An eleven-day outage was needed for condensate pipe maintenance.

Feedwater check valve leaks required 13 days to correct.

A forced maintenance outage lasted 26 days.

EHC fluid leaks on one of the turbine control valves required 19 days to repair.

A 4-day shutdown followed a reactor scram caused by a spurious main steam line high flow signal.

A 75-day outage was taken to address equipment problems and personnel performance issues.

The thirteenth refueling and maintenance outage lasted 153 days.

The unit was shut down on two occasions ( 2 weeks total) due to EHC problems.

A 33-day forced outage was caused by a leak on one of the main turbines control valves.

A forced outage was initiated due to tornado damage to the secondary containment building. The outage lasted 87 days.

Two short outages totaled 4 days off-line. 
This Page Intentionally Left Blank 
RANCHO SECO

PRODUCTION COST and CAPITAL ADDITIONS

(1996 Dollars)

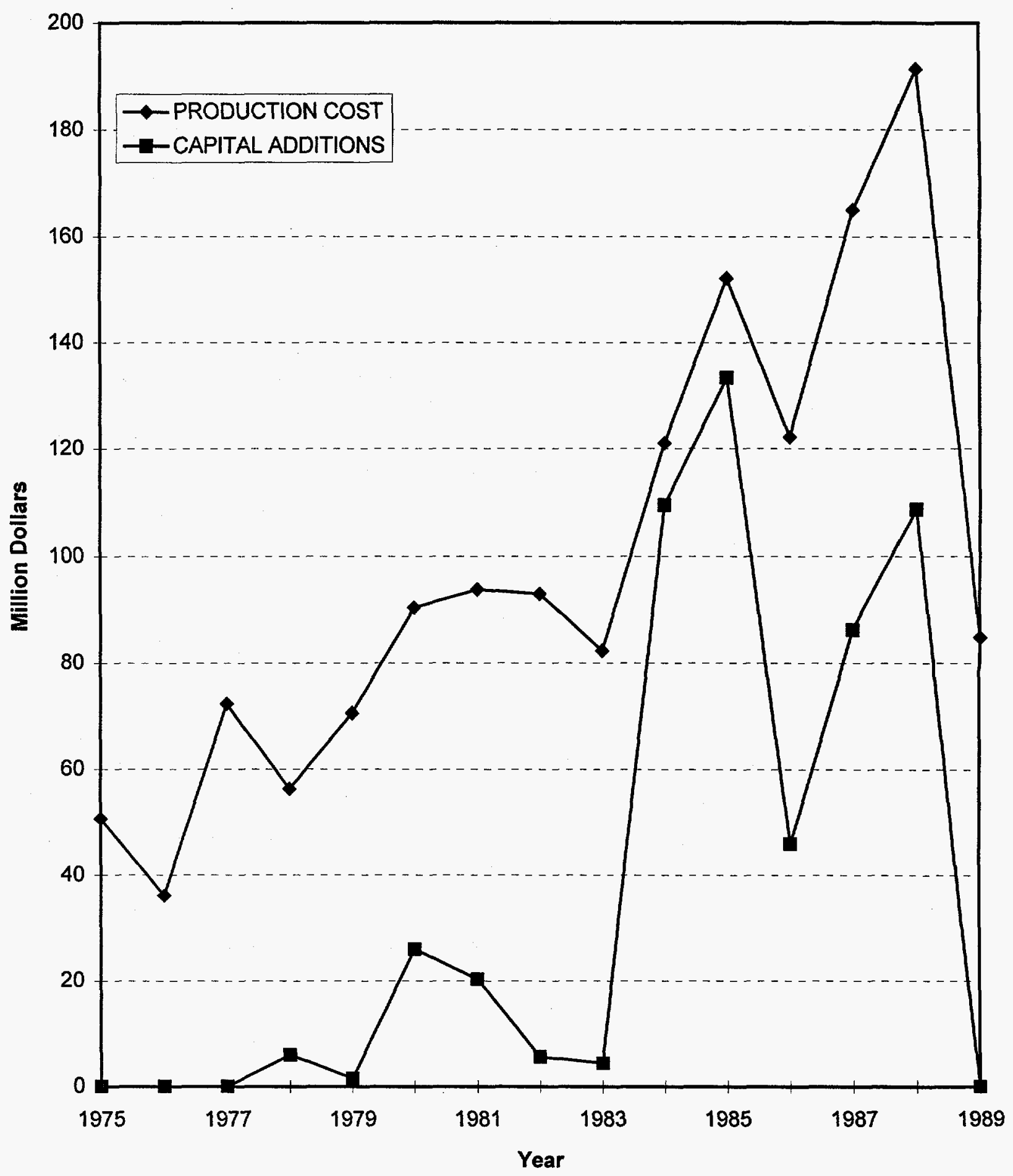




\title{
NUCLEAR POWER PLANT OPERATING EXPERIENCE SUMMARY
}

\author{
Unit data summary through December 1996
}

Unit: RANCHO SECO

Location: SACRAMENTO COUNTY, CALIFORNIA

Owner: SACRAMENTO MUNICIPAL UTILITIES DISTRICT

Type: BABCOCK \& WILCOX PWR

Construction Permit: 10/11/68

Operating License: 8/16/74

Commercial Oper. Date: 4/17/75
Nameplate Rating: 963 MWe

MDC Net MWe: 873 MWe

Cumul. Avail. Factor: $\mathbf{4 7 . 4}$

Cumul. Cap. Factor (MDC Net): $\mathbf{3 7 . 5}$

Cumul. Forced Outage Rate: $\mathbf{4 2 . 7}$

3-Year Avg. Cap. Factor (MDC Net): n/a

License Expiration: $2008^{1}$

OPERATING HISTORY (To December 1996)

Date

1973

Aug 1974

Oct - Nov 1974

Mar - Apr 1975

Jun 1975 - Feb 1976

Apr - Oct 1976

May 1976

Apr 1977

Aug - Nov 1977

Jan 1978

Mar 1978

Jun 1978

\section{Comment}

Plant completion fell 17 months behind schedule because of organizational problems and late delivery of components. A number of MOVs were damaged during initial testing due to lack of correct torque settings from vendors. About 20,000 pounds of iron oxide was removed from plant systems during chemical cleaning.

Fuel loading was delayed about 6 weeks because of labor problems.

A 26-day shutdown was required for condenser tube plugging and main steam pilot valve work.

The plant shut down for 23 days for turbine inspection and removal of steam line screens.

The plant shut down for repair of damage to LP turbine from thrown blades. Loss of stator cooling to CRDs necessitated repair to 69 CRD stators. Damaged winding insulation found in the main generator required repair before startup. The plant reached $100 \%$ power for first time on March 5.

The plant shut down for inspection of specimen holder tubes for potential vibration damage. The main generator stator coils and FW heaters were replaced during the prolonged outage.

To date, the utility had incurred about $\$ 14.2$ million in unforeseen expenses.

Valve leakage in the waste gas compressor room exposed two plant workers to noble gas of about 10,000 times their allowed maximum permissible concentration.

The plant shut down for the first refueling outage. SG tubes were inspected.

The power was reduced to about $70 \%$ because of a main transformer damaged during a storm.

A scram and significant pressure/temperature transient was caused by a short circuit when a light bulb was dropped into an electrical control panel. Outage time for the event was 5 days.

The plant shut down for $\mathbf{1 8}$ days to repair relief and safety valves.

'The unit was permanently shut down in June 1989. Cumulative data are through that date. 


\section{RANCHO SECO (Cont'd)}

Jul 1978

Nov - Dec 1978
Apr - Jun 1979
Jan - May 1980
Aug 1980
Jan - May 1981
May - Jun 1981
Aug - Oct 1981
Nov - Dec 1981
Apr - Aug 1982

Oct 1982

Nov - Dec 1982

Feb - Aug 1983

Sep - Oct 1983

Jan 1984

Mar - Apr 1984

Jun 1984

Jul - Aug 1984

Aug - Oct 1984

Mar - Sep 1985
The transformer damaged in January was replaced and the unit returned to $100 \%$ power operation.

The plant shut down for a refueling outage.

The plant shut down to make TMI modifications and to repair the main generator.

The plant shut down for a refueling outage. The utility was fined $\$ 25,000$ by NRC for alleged valving errors in ECCS operation.

A 3-week outage was required for repair of the main turbine thrust bearing.

A refueling and maintenance outage was performed. Major work included turbine inspection and removal of four stages of blades in the LP turbine.

SG tube leak repairs caused a 4-week outage; the secondary system was decontaminated also.

The plant shut down to replace damaged internal parts on the LP turbine. A new rotor and blading were installed by $\underline{\mathrm{W}}$.

An 11-day outage was required for turbine balancing and repairs.

The unit was shut down for an extended maintenance outage. Major work included inspection and repair of HP injection nozzles, modification of SG AFW ring headers, LP turbine rotor replacement, and SG tube plugging.

The utility was fined $\$ 120,000$ by NRC for alleged inoperability of DGs and HP injection pump because of personnel error.

The unit was shut down for 23 days for repair of SG tube leaks.

The unit was shut down for refueling and extensive maintenance outage. Major work included 10-year ISI, TMI modifications, replacement of core barrel shield bolts, thermal shield bolt replacement, containment ILRT, SG tube plugging, and main steam heater replacement.

The plant shut down for 19 days to repair SG tube leaks.

The utility received permission from NRC to increase spent fuel pool capacity from 579 to 1080 FAs.

A $\mathrm{H}_{2}$ explosion in the main generator exciter enclosure and $\mathrm{H}_{2}$ seal oil problems caused a 1month outage for repairs.

A nonnuclear steam explosion killed two plant workers.

The unit was shut down to repair SG tube leaks and problems with Swagelock $^{\circ}$ fittings on the primary system.

The unit was shut down for 37 days because of SG tube leaks and high iodine levels in RCS. Another tube leak caused an outage of 29 days later in October.

The unit was shut down for a refueling and maintenance outage. Major work included SG tube plugging, RCP modifications, auxiliary boiler replacement, and PASS installation. The outage was extended from June to September because of turbine lube oil system problems and SG high point line leaks. During the extension, the technical support center was completed and several plant modifications were made. 
Jul 1985

Oct 1985

Oct - Nov 1985

$\operatorname{Dec} 1985$

Mar 1986

Nov 1986

Dec 1986

Jan 1987

Jun 1987

Jul 1987

Sep 1987

Feb 1988

Mar 1988

May 1988

Jun 1988

Aug 1988

Oct 1988
Local residents filed a $\$ 1.5$ billion lawsuit against the utility for alleged damage to crops and livestock from radioactive liquid effluent from the plant.

NRC assessed a $\$ 50,000$ fine for alleged violations concerning seismic supports for the $\mathrm{N}_{2}$ supply system.

The plant was shut down for about 30 days after a main FW pump trip and low condenser vacuum caused a plant trip. The unit was not allowed to restart until NRC safety concerns were resolved.

The plant shut down following a loss of ICS power and rapid RCS cooldown. NRC sent an AIT to the site and the plant was to remain shut down until NRC approved return to power.

The utility paid a $\$ 25,000$ fine assessed by the NRC for alleged violations of security requirements for personnel search.

The utility paid a $\$ 375,000$ fine assessed by the NRC for alleged violations that occurred during December 1985 when power was lost to the ICS.

The plant remained in cold shutdown. During the outage, NRC investigation and plant upgrade continued. Major work included SG tube inspection and plugging, MOV maintenance, and EFW system control modifications.

The utility announced a planned restart date on May 1987 after extensive plant modifications and personnel changes in management and operations.

The restart date was rescheduled for January 1988 to accommodate expanded tests and inspections of plant systems.

A local judge ordered the utility to hold a referendum in November on a petition by rate payers to shut down the unit permanently.

Pacific Gas \& Electric Co. and Duke Power Co. discussed a joint purchase of the plant with the utility.

Pacific Gas \& Electric Co. and Duke Power Co. withdrew their proposal to purchase the plant. The utility board agreed with local leaders to allow the unit to operate at least until fuel load was spent and to hold a referendum for Sacramento voters in June 1988 on continued operation of the plant.

The unit began power ascension testing after receiving NRC approval for restart. Utility board approved a measure to operate the plant to the end of fuel load life (about 18 months). During that time, if the unit fell below 50\% capacity for 4 or more consecutive months, it was to be closed permanently unless it was economically necessary for the rate payers. Any further operation was to be decided by another favorable vote by rate payers.

Turbine trips during the power ascension program caused 8 days of shutdown time.

Voters agreed by a narrow margin to continue operation of the plant for another 18 months or to the end of fuel load life, and then hold another referendum to decide on closing the plant permanently. Quadrex Corporation announced a plan to recruit investors to purchase the plant and sell power to the utility.

The plant shut down for 8 days as part of a reactor trip test.

The plant suffered 2 separate reactor trips and outages totaling 8 days. 
Dec 1988

Jan 1989

Jan - Mar 1989

Apr 1989

May 1989

Jun 6, 1989

Jul - Sep 1989

Oct 1989

Dec 1989

Sep 1990
The unit was shut down for $\mathbf{2 5}$ days after two pressure control valves failed and initiated a start of the EFW system. Operators halted emergency core cooling and allowed one SG to boil dry to avoid a recurrence of the overcooling incident of December 1985.

The NRC assessed a $\$ 100,000$ fine for alleged lack of control of radioactive effluent releases.

The unit was shut down for 45 days after a major portion of the AFW system was overpressurized during a test.

The unit was having difficulty meeting the 1988 referendum requirement to operate at $50 \%$ capacity for 4 consecutive months. The plant was at $51.5 \%$ for January and out of service for all of February.

Bechtel Power and $B \& W$ entered into a memorandum of understanding with the utility to improve performance of the unit under an incentive/penalty plan based on plant output.

A majority of $53.4 \%$ of voters in the utility service area voted to shut down operation of the plant by the utility. The unit was brought to cold shutdown the next day and preparations were begun to decommission the unit.

The utility reported negotiations with several entities to purchase and operate the plant; none succeeded.

NRC proposed a $\$ 50,000$ fine for alleged violations of the emergency preparedness program requirements.

The unit completed defueling. Work continued on wet layup of systems, leak repair of spent fuel pool, and preparation of a request for a fuel possession only license and a decommissioning plan.

A 1985 lawsuit filed by 208 nearby plant residents was dismissed by a Superior Court judge after he noted that annual exposure averaged less than 1 millirem and that the EPA limit for annual exposure to the public was 25 millirem. 
This Page Intentionally Left Blank 


\section{RIVER BEND 1}

PRODUCTION COST and CAPITAL ADDITIONS

(1996 Dollars)

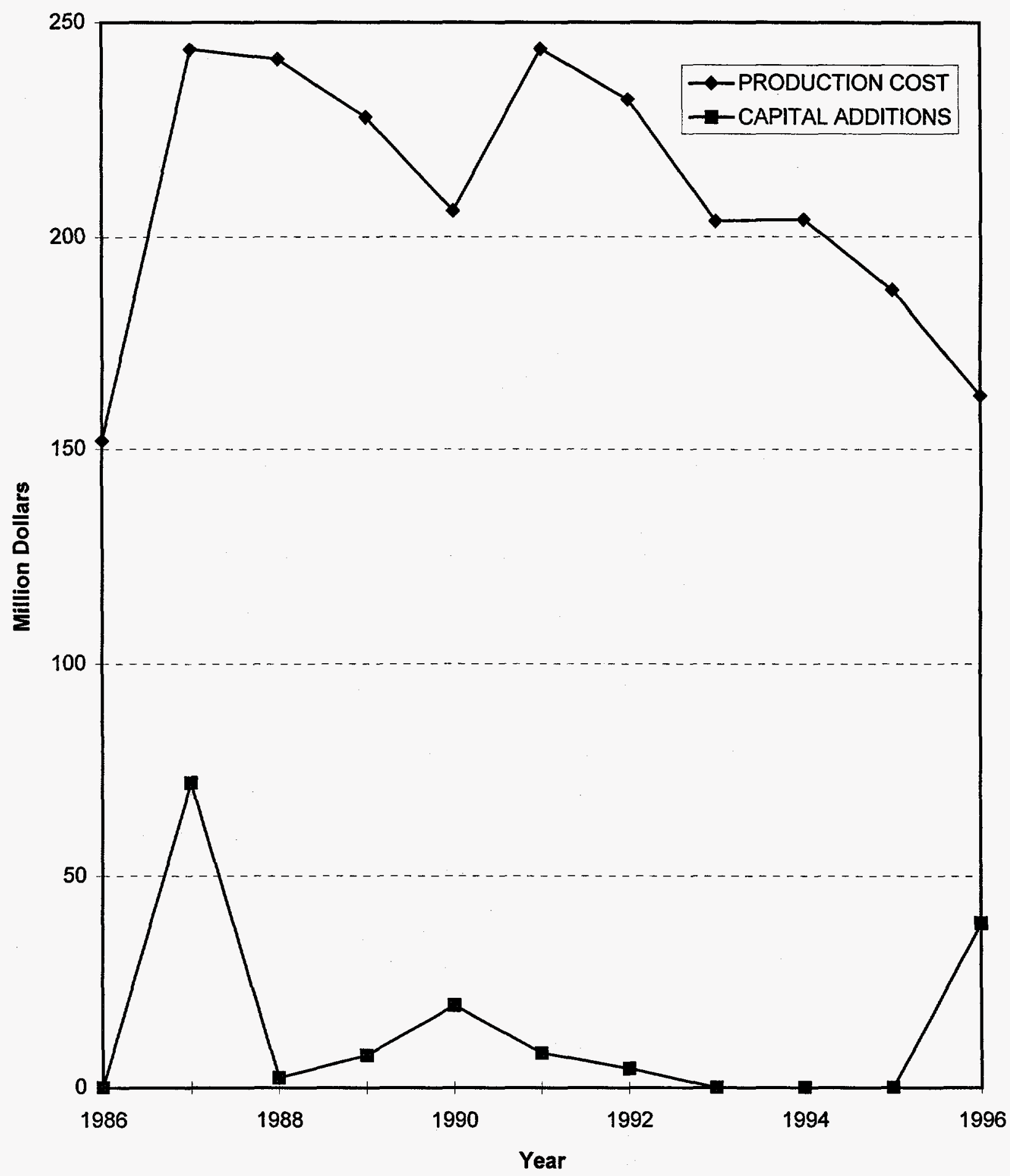




\section{NUCLEAR POWER PLANT OPERATING EXPERIENCE SUMMARY}

Unit data summary through December 1996

Unit: RIVER BEND 1

Location: WEST FELICIANA COUNTY, LOUISIANA

Nameplate Rating: 936 MWe

Owner: ENTERGY OPERATIONS

MDC Net MWe: 936 MWe

Type: GENERAL ELECTRIC BWR

Cumul. Avail. Factor: $\mathbf{7 2 . 6}$

Construction Permit: 3/25/77

Cumul. Cap. Factor (MDC Net): 68.0

Operating License: 11/20/85

Cumul. Forced Outage Rate: 11.8

Commercial Oper. Date: 6/16/86

3-Year Avg. Cap. Factor (MDC Net): 79.9

License Expiration: 2025

OPERATING HISTORY (To December 1996)

Date

Dec 1985

Jan 1986

Feb 1986

Mar - Apr 1986

May 1986

Jun - Jul 1986

Sep 1986

Oct 1986

Jun 1987

Sep - Nov 1987

Nov 1988

Aug 1989

Dec 1989

Mar - Jun 1989

\section{Comment}

As part of the power ascension program, a planned outage and a LOSP test were conducted. Total outage time was 17 days.

A number of plant trips forced outages totaling 14 days.

The unit was shut down for 12 days for maintenance after completing a remote shutdown panel test.

The unit was shut down because of main condenser tube leakage and disintegration of the diffuser screen clips in the cooling towers. The outage was extended to resolve Class IE bus voltage problems. Total outage time was 24 days.

The Unit achieved $100 \%$ power for the first time.

The unit was shut down for 14 days due to an EHC line leak and to complete testing on testable check valves. Restart was delayed by scrams from MSR drain tank leaks and loss of condenser vacuum.

The NRC assessed a $\$ 65,000$ fine against the utility for alleged plant security violations.

The plant shut down for a scheduled outage of 55 days to perform LLRT.

FW control problems and repair of leaks in the drywell forced a 21-day outage.

The first refueling and maintenance outage lasted 96 days.

Plant workers exceeded a record 7.2 million hours without time lost for a disabling injury. The unit also set two BWR-6 records for 151 and 184 continuous days of operation during the first and second operating cycles, respectively.

The unit was shut down for four days to repair a recirculation pump seal leak.

A scheduled maintenance outage lasted 4 days.

The second refueling and maintenance outage lasted 101 days: major work included FW sparger repair, SW system inspection and repair of erosion/corrosion damage, instrument air system upgrade, and inservice testing. The outage was extended for replacement of a $230 \mathrm{kV}$ transformer damaged by fire. 
Sep - Dec 1990

Feb 1991

Jun 1991

Sep 1991

Nov 1991

Dec 1991

Mar - Sep 1992

Sep 1992

Nov 1992

Dec 1992

Dec 1992

Dec 1992

Apr - Jun 1993

May 1993

Jul 1993

Aug 1993

Aug 1993

Oct 1993

Apr - Jul 1994
The third refueling and maintenance outage lasted 67 days. Major work included HP turbine inspection, integrated ECCS testing, LLRTs, and SW heat exchanger maintenance and testing.

Unit was shut down for 8 days to repair various plant pump seals.

The NRC proposed and the utility paid a $\$ 37,5000$ fine for two alleged violations involving the radiological control program.

A planned mid-cycle outage that lasted 17 days, but had been extended due to circulation water piping leakage.

The NRC proposed and the utility paid a $\$ 75,000$ fine for alleged violations involving wiring errors in the primary containment/drywell hydrogen mixing system's control system. These errors had existed since initial startup of the plant.

The unit was shut down for $\mathbf{4 5}$ days to repair a leak in the main generator stator cooler.

The fourth refueling and maintenance outage lasted 180 days. The unit had shut down a week early due to wind damage to the turbine building and a main transformer. Major work included repair of a cracked FW nozzle, conversion of SW to a closed system, chemical decontamination of the RWCU and recirculation systems, ILRT, and overhaul of the DGs.

The unit was manually scrammed and shut down for 4 days after loss of stator winding temperature indication for a recirculation pump.

The unit was shut down for 5 days to correct problems with undervessel sump pumps.

The unit was shut down for 8 days to replace a recirculation pump seal.

An NRC SALP report gave one Category 1 rating in emergency preparedness and no low Category 3 ratings.

The NRC proposed and the utility paid a $\$ 100,000$ fine for alleged violations involving radiation protection requirements.

The unit was shut down to replace both recirculation pump seals and to perform MSIV repairs. On startup, one of the recirculation pump seals failed, and the unit was shut down to replace it again. Total outage time was 59 days.

The NRC proposed a $\$ 50,000$ fine for alleged violations involving inadequacies with control and operation of a containment airlock.

A 19-day outage was needed to repair a leak on a FW MOV.

The NRC proposed a $\$ 100,000$ fine for alleged violations involving operating the unit with one of the MSIVs stuck open.

The unit was shut down for 21 days after a scram was caused by a personnel error during surveillance testing.

The unit was shut down for 5 days after a turbine trip occurred from a spurious signal during turbine testing.

The fifth refueling and maintenance outage lasted 82 days. 
Apr 1994

Sep - Oct 1994

Oct - Nov 1994

Dec 1994

Jan - Feb 1996

Jun 1996

Jul 1996
The NRC proposed a $\$ 212,500$ fine for alleged violations involving fire protection which had apparently existed since plant startup and for violations of physical security requirements.

The reactor tripped on a false high water level signal generated by normal process noise. An UE was declared due to post-trip complications. The NRC sent an AIT. The unit was shut down for $\mathbf{4 3}$ days to replace the Rosemount level transmitters.

The unit was shut down for 6 days to repair recirculation pump seals.

The unit was shut down for 1 week after tripping due to a full MSIV isolation that occurred during surveillance testing.

The sixth refueling and maintenance outage lasted 39 days.

A 9-day outage followed a scram due to a pressure spike caused by a power supply failure.

The unit was shut down for 10 days after failure to perform required testing on a battery. 
ROBINSON 2

PRODUCTION COST and CAPITAL ADDITIONS

(1996 Dollars)

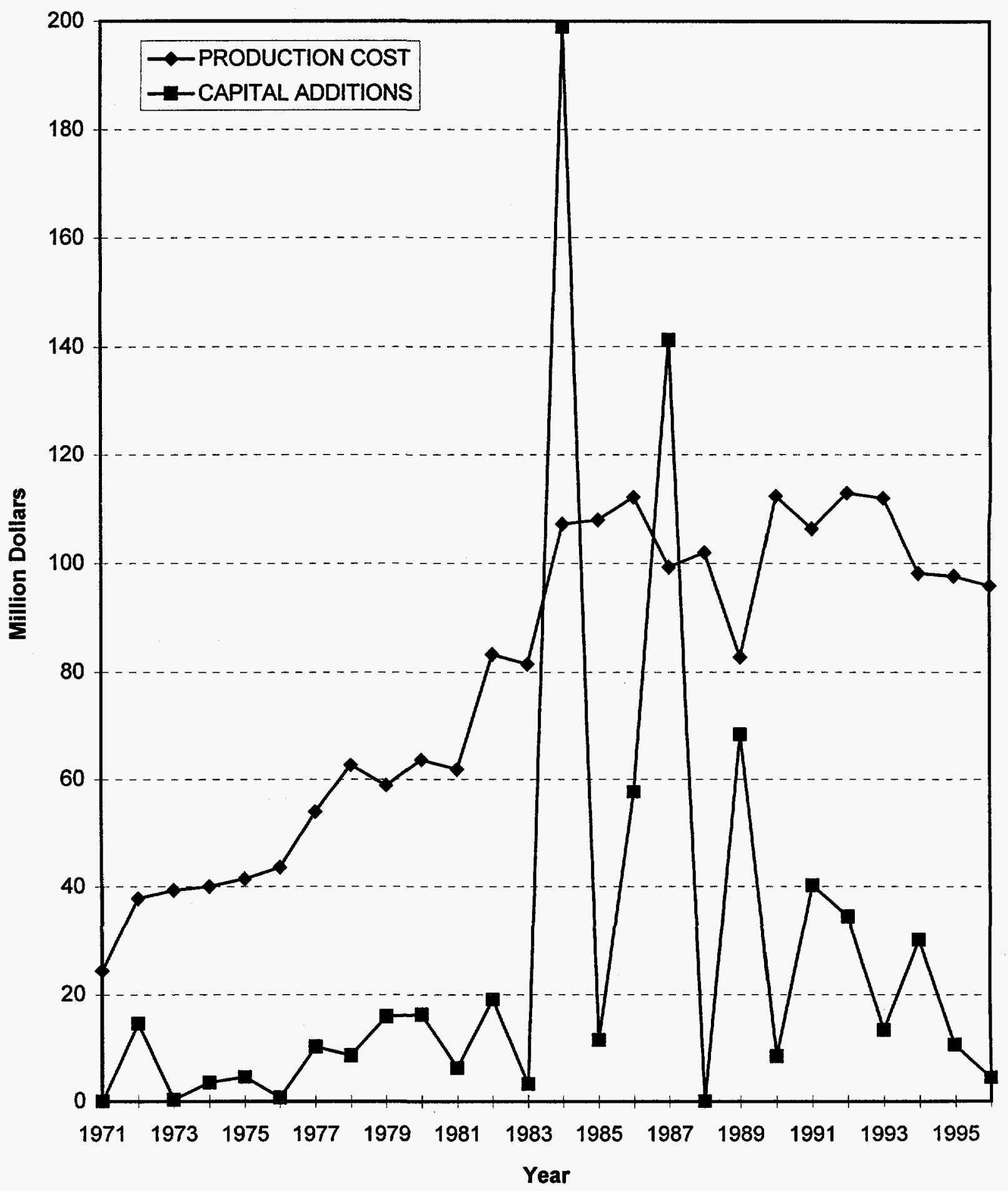




\section{NUCLEAR POWER PLANT OPERATING EXPERIENCE SUMMARY}

Unit data summary through December 1996

OPERATING STATUS

Unit: ROBINSON 2

Nameplate Rating: 739 MWe

Location: DARLINGTON COUNTY, SOUTH CAROLINA

MDC Net MWe: 683 MWe

Owner: CAROLINA POWER \& LIGHT CO.

Cumul. Avail. Factor: $\mathbf{7 0 . 4}$

TyPe: WESTINGHOUSE PWR

Cumul. Cap. Factor (MDC Net): 65.4

Construction Permit: 4/13/67

Cumul. Forced Outage Rate: 14.0

Operating License: $9 / 23 / 70$

3-Year Avg. Cap. Factor (MDC Net): 84.9

Commercial Oper. Date: 3/7/71

License Expiration: 2010

OPERATING HISTORY (To December 1996)

Date

Comment

Mar 1971

Turbine bearing damage caused 12-month outage and required more than 19,000 man-hours.

May - Aug 1971

More turbine problems and SG cladding failure caused a 3-month outage.

Mid 1972

About a 1-month outage was needed for SG tube repair.

$1973-1974$

Recurring SG tube problems caused high man-rem exposures.

Apr - Jun 1975

RCP seals and SG tubes required work.

$1976-1980$

SG tube leakage and RCP seal problems continued to occur.

1981

SG tube problems caused several power reductions and outages.

Feb - Aug 1982

A refueling and maintenance outage lasted 171 days: SG problems continued.

1983

1984

Jan 1985

Aug 1986

Mar - Jun 1987

SG tube problems continued to occur.

The unit was shut down for most of the year for SG replacement; the RCP motors and main turbine and generator were overhauled.

The unit returned to service.

The NRC issued a license for limited dry spent fuel storage.

A refueling and maintenance outage was performed. Major work included replacement of LP turbine rotor.

Sep - Nov 1987

The NRC assessed two $\$ 50,000$ fines for TS violations and failure to establish certain safe shutdown procedures.

Jan - Feb 1988

An unplanned outage lasted 41 days for unanalyzed DC power distribution condition. 
Jun 1988

Jun 1988

Aug 1988

Oct 1988

Nov 1988 - Feb 1989

Mar 1989

Mar 1989

Apr 1989

Aug - Dec 1989

May 1990

Sep 1990 - Mar 1991

Mar - Jun 1992

Aug - Sep 1992

Sep - Nov 1993

Nov 1993 - Feb 1994

Feb 1994

Aug 1994

Apr - Jun 1995

Sep - Oct 1996
The NRC proposed a fine of $\$ 50,000$ for faulty analysis of an SI pump operation; a second fine of $\$ 450,000$ was assessed for violations of $E Q$ requirements for electrical equipment.

The NRC proposed a fine of $\$ 450,000$ for alleged violations of EQ requirements for electrical equipment.

An outage of 19 days was required to correct biofouling of SW piping for four containment fan coolers.

A 4-day outage was required to investigate undersized MCC feeder cables.

A refueling and maintenance outage lasted 105 days: major work included SG ECT, sludge lancing, and tube inspection, ILRT, control room upgrades, SW pipe replacement, and MSR modifications.

The first transfer of spent fuel to the ISFSI was performed.

The NRC assessed a $\$ 50,000$ fine for faulty analysis of the ECCS SI system.

A 13-day outage was needed for loose parts found in primary side of SG.

An outage of 124 days was caused by problems with an auxiliary FW pump NPSH requirements under certain operating conditions. The NRC assessed a $\$ 75,000$ fine for failure to identify and correct problem with inadequate suction supply for the AFW system.

A 10-day outage was taken to perform maintenance on the main and auxiliary transformers.

The thirteenth refueling and maintenance outage lasted 183 days.

The fourteenth refueling and maintenance outage lasted 88 days.

The unit tripped due to loss of the startup transformer. The unit remained shut down for 33 days to repair the transformer and to clean up foreign material in the SI system.

The fifteenth refueling and maintenance outage lasted 64 days.

An 86-day outage was needed to repair a weld leak in the feedwater system and to move FAs that had been misloaded during the previous refueling. The NRC sent an AIT and found that although the FA mispositioning was due to an error by the fuel vendor, the plant personnel should have detected it.

An inoperable EDG forced the unit to shut down and to remain in a 32-day outage to repair the EDG. A loose part in one SG was detected and found to be a welding flag from the SG manufacture in the early 1980 s.

The unit was manually scrammed after all four turbine governor valves shut. The unit was shut down for 5 days.

The sixteenth refueling and maintenance outage lasted 53 days.

The seventeenth refueling and maintenance outage lasted 43 days. 
This Page Intentionally Left Blank 
SALEM

PRODUCTION COST and CAPITAL ADDITIONS (1996 Dollars)

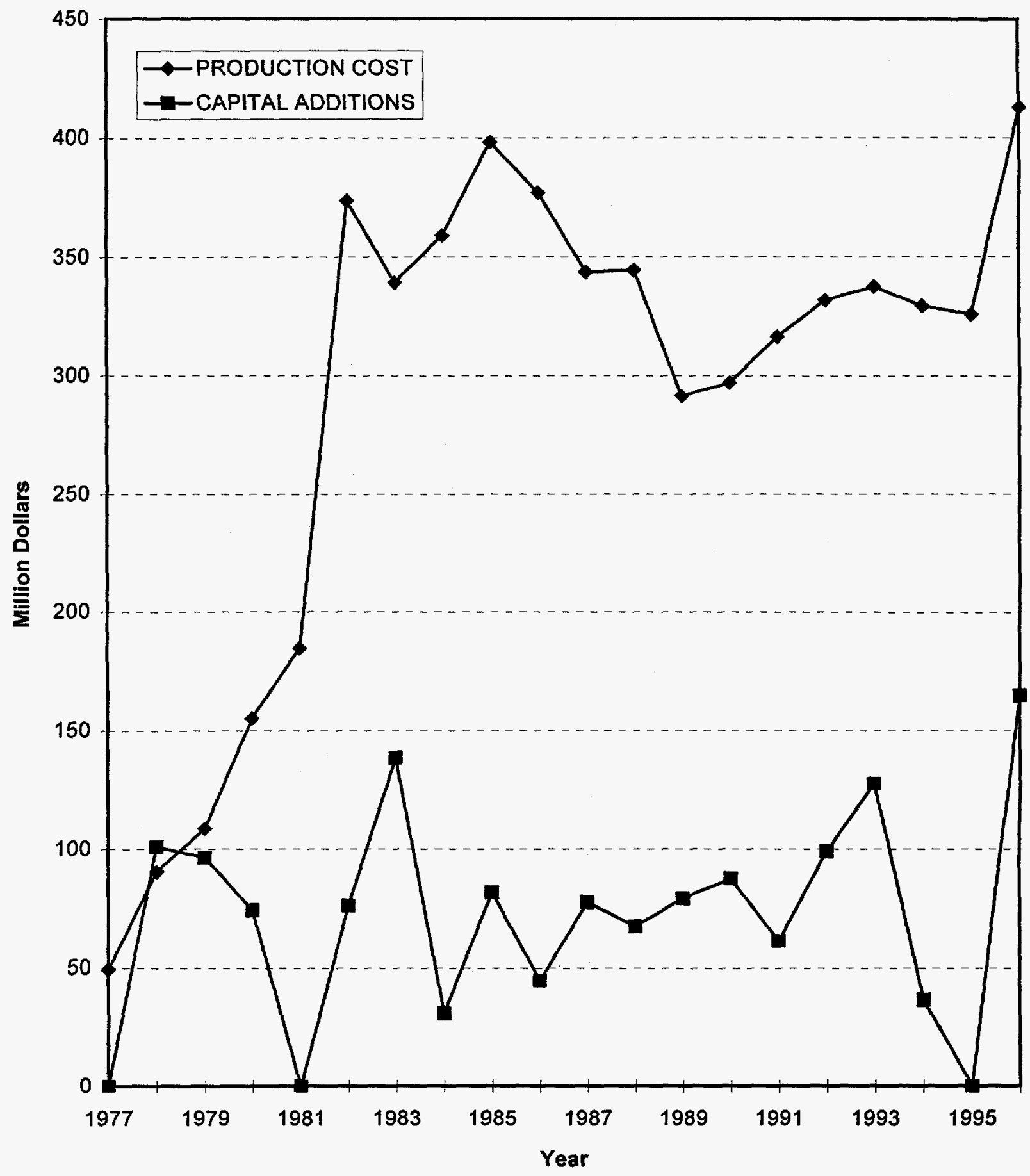




\section{NUCLEAR POWER PLANT OPERATING EXPERIENCE SUMMARY}

Unit data summary through December 1996

Unit: SALEM 1

Location: SALEM COUNTY, NEW JERSEY

Owner: PUBLIC SERVICE ELECTRIC \& GAS CO.

Type: WESTINGHOUSE PWR

Construction Permit: 9/25/68

Operating License: 12/1/76

Commercial Oper. Date: 6/30/77
Nameplate Rating: 1170 MWe

MDC Net MWe: 1106 MWe

Cumul. Avail. Factor: $\mathbf{5 8 . 7}$

Cumul. Cap. Factor (MDC Net): $\mathbf{5 3 . 0}$

Cumul. Forced Outage Rate: $\mathbf{2 6 . 3}$

3-Year Avg. Cap. Factor (MDC Net): 28.4

License Expiration: 2016

OPERATING HISTORY (To December 1996)

\section{Date}

Jan - Feb 1977

Feb - Mar 1977

Jun 1977

Jul - Sep 1977

Sep - Nov 1977

Mar - Jun 1978

Oct - Nov 1978

Apr - Dec 1979

Sep - Dec 1980

Mar - Apr 1981

May - Jun 1981

Jan - Apr 1982

Feb 1982

\section{Comment}

The FW pump trips caused a number of reactor shutdowns during early power ascension testing.

The unit was shut down for 13 days to perform secondary system maintenance.

The failure of a RCP 4-kV cable forced a 14-day shutdown.

About 50 load reductions were necessary to clean condensate and FW pump strainers.

The unit was shut down for about 10 weeks to perform ISI and make modifications to the LP turbine.

The unit was shut down for about 12 weeks to resolve LP turbine problems.

Condenser leaks and secondary system chemistry problems forced a 1-month shutdown.

During restart, a RCP seal failed and spilled about 15,000 gallons of coolant into containment.

The first refueling and maintenance outage was performed. Major work included retubing of the main condenser. Stress corrosion damage to RCCAs was found, and 31 FA grid assemblies were damaged during refueling. Startup was delayed by repairs of FW nozzle cracks, reblading of the main condenser, and modifications to pipe supports.

The second refueling and maintenance outage was performed. The utility was fined $\$ 90,000$ by the NRC for alleged personnel contamination and overexposure during refueling.

The unit was shut down for 30 days to repair LP turbine; the blades had separated from the rotor.

The unit was shut down again for 30 days to repair the same LP turbine.

The third refueling and maintenance outage was performed. Major work included replacement of a component cooling water heat exchanger. The outage was prolonged by overheating of a turbine bearing.

The utility was fined $\$ 40,000$ by the NRC for alleged physical security violations. 
May - Jun 1982

Oct 1982

Oct 1982 - Feb 1983

Feb $22-25,1983$

May 1983

Feb - Oct 1984

Apr 1985

Mar - May 1986

Mar 1, 1987

Oct 1987 - Feb 1988

Mar - Jun 1989

Apr 1989

Dec 1989

Mar - Apr 1990
The unit was operated by management operators during a strike by bargaining unit employees.

The utility was fined $\$ 40,000$ by the NRC for alleged physical security violations.

The fourth refueling and maintenance outage was performed. Major work included overhaul of the main condenser, generator, and turbine. The outage was extended to repair closed cooling water heat exchangers, replace an RCP motor, and repair hydrogen leaks on the main generator.

On two occasions, RTBs failed to close in response to a reactor trip signal, and the unit had to be manually tripped. These events initiated an extensive NRC investigation and resulted in an $\$ 850,000$ fine for alleged failure by plant personnel to recognize that the breakers had failed and to initiate investigation of the cause. The plant remained shut down until late April, but startup was delayed into May to resolve shellfish intrusion into the service water system.

The NRC assessed a $\$ 20,000$ fine for allegedly operating with an inoperable radiation monitor in 1982.

The fifth refueling and maintenance outage was performed. The unit was shut down early after sustaining main generator exciter damage. Extensive maintenance and repair was performed on the main generator and turbine, MSRs, and plant piping systems. New RCP seals and motors were installed; many Limitorque ${ }^{\circledR}$ valve motors were modified; and CFCU piping expansion joints were upgraded.

The NRC assessed a $\$ 50,000$ fine for alleged deficiencies in the emergency preparedness program.

The sixth refueling and maintenance outage lasted 46 days: major work included ILRTs, MSR tube replacement, and RCP motor modifications. The unit returned to service more than 2 weeks ahead of schedule.

One of four 500-kV transmission lines carrying power from the Salem and Hope Creek nuclear units was destroyed by a drifting oil tanker on the Delaware river. Salem 1 was limited to $75 \%$ power until a new unit trip scheme was installed in late March. The scheme allowed Salem 1 to operate at $100 \%$ and Salem 2 and Hope Creek to operate at $90 \%$.

The seventh refueling and maintenance outage lasted 123 days: major work included SG inspection and tube plugging, main turbine repair, and new RV thimble tube installation. The outage was extended in December for major work on the SW system and again extended in January for repairs to CRDM welds.

The eighth refueling and maintenance outage lasted 82 days: major work included feedwater pump and SRV testing, RPI calibration and main transformer repair. Outage was entered early after a burned connector was found in one main transformer.

The NRC assessed a $\$ 50,000$ fine for alleged violations involving documentation for safety-related solenoid valves.

The unit was shut down for 11 days to repair charging pump bearings, SI system check valves, and DG controls.

The unit was shut down for 11 days to repair safeguards equipment cabinet faults and ECCS check valve leaks. 
Apr - Jun 1990

Jul - Aug 1990

Aug 1990

Feb - Apr 1991

Feb 1991

Jun 1991

Jan 1992

Apr - Jun 1992

Jul - Aug 1992

Oct 1992

Jan 1993

Feb 1993

Jun 1993

Jul 1993

Oct 1993 - Feb 1994

Feb 1994

Apr 1994

Apr - May 1994

May 1994

Jun 1994

Jul 1994

Aug 1994

Feb 1995
The unit was shut down for 58 days to repair a feedwater pump and resolve cable separation, RHR, and ECCS problems.

Unit was shut down for 15 days to correct problems with the MSIVs closing.

The unit tripped during a bus swap when a breaker failed. The resulting outage was extended for a RCP motor replacement and AFW modifications. Total outage time was 22 days.

The ninth refueling and maintenance outage lasted 76 days: major work included SG ECT, tube plugging, U-bend heat treatment, and tube plug removal, RCP and main turbine inspection, MSIV and DG overhaul, and SW pipe replacement.

The New Jersey Department of Environmental Protection proposed installation of cooling towers to reduce harm to fish in the Delaware River. The estimated cost was $\$ 2.1$ billion and a shutdown of at least 4 years.

The unit tripped when lightning struck the main transformer and the unit was down for 8 days.

The unit tripped when a circulating water pump lost power. The unit was down for 6 days.

The tenth refueling and maintenance outage lasted 86 days: major work included replacement of piping that had thinned due to erosion/corrosion.

The unit was shut down for 50 days to perform erosion/corrosion inspections and to repair SG and other BOP piping.

Leaks in various systems required a 7-day outage to repair.

A reactor feed pump trip caused a reactor scram. The ensuing outage lasted 8 days.

The unit was shut down for 1 week after scramming during surveillance testing of the RPS system.

The unit was shut down for 11 days because of circulating water problems

The unit was shut down for 9 days after scramming during troubleshooting of the feedwater control system.

The eleventh refueling and maintenance outage lasted 124 days.

A 10-day outage was needed to correct problems in the EHC system.

The NRC proposed a $\$ 50,000$ fine for alleged violations involving control of maintenance and radioactivity.

The unit was shut down for 46 days due to problems with sea grass entering the intake structure. An AIT was sent due to complications in the shut down and found operator error, design deficiencies, and degraded equipment.

A 9-day outage followed a reactor trip during main safety/relief valve testing.

The unit was shut down for 5 days after tripping because a main generator voltage regulator potential transformer failed.

A lightning strike caused the unit to trip. The unit was shut down for 4 days.

Problems with the condensate system piping forced an 8-day outage.

The unit was shut down for 26 days to correct an SSPS design deficiency. 
May 1995 - Present

Oct 1995

Jan 1996

Jun 1996

Dec 1996
The unit was shut down because two containment fans were inoperable. The unit remained shut down to address widespread design, equipment, and personnel deficiencies. The twelfth refueling outage was begun. While shut down, inspection of the SG tubes revealed greater than expected degradation. The SGs from the canceled Seabrook 2 unit were purchased and installed as replacements. The unit is scheduled to resume operation in the summer of 1997.

The NRC proposed and the licensee paid a $\$ 600,000$ fine for multiple hardware and operational problems. These included an inoperable RHR at Salem 2, inoperable switchgear at Salem 1, pressurizer overpressure protection system problems at both units, and valve mispositioning at Salem 1. Programmatic failures included failure to correct condition: adverse to quality.

The site was placed on the NRC's declining trend list.

The site was removed from the NRC's declining trend list.

The NRC proposed and the licensee paid a $\$ 180,000$ fine for alleged violations concerning security and whistleblower discrimination. 


\title{
NUCLEAR POWER PLANT OPERATING EXPERIENCE SUMMARY
}

\author{
Unit data summary through December 1996
}

Unit: SALEM 2

Location: SALEM COUNTY, NEW JERSEY

Owner: PUBLIC SERVICE ELECTRIC \& GAS CO.

Nameplate Rating: $1170 \mathrm{MWe}$

Type: WESTINGHOUSE PWR

MDC Net MWe: $1106 \mathrm{MWe}$

Construction Permit: 9/25/68

Cumul. Avail. Factor: 56.4

Operating License: $5 / 20 / 81$

Commercial Oper. Date: 10/13/81

3-Year Avg. Cap. Factor (MDC Net): 26.2

License Expiration: 2020

OPERATING HISTORY (To December 1996)

\section{Date}

Sep - Oct 1981

Feb - May 1982

May - Jun 1982

Jan 1983

Jan - Jul 1983

Aug 1983 - Mar 1984

Apr - May 1984

Jul 1984

Oct 1984 - Apr 1985

Apr 1985

\section{Comment}

Full-power testing was delayed because of indications of excessive carryover occurring in one SG. Steam flow instrumentation problems persisted through January 1982. The problem was eventually traced to a nonlinear instrumentation signal for steam flow.

The power was reduced several times because of sea grass accumulation on traveling screens.

The unit was operated by management during a strike by bargaining unit employees.

A RTB failed to open on a trip signal. The utility failure to act sufficiently on the incident was a major factor in the $\$ 850,000$ fine by NRC for Unit 1 RTB failure.

The first refueling outage included major condenser overhaul. Return to operation was delayed by problems with the SW system, RHR pump motor, RCP seals, and a FW regulating valve. Additional delay was incurred by response to NRC concerns following Unit 1 RTB failure. The unit returned to service $2 \frac{1}{2}$ months later than scheduled.

A 5-week shutdown was forced to repair a hydrogen gas leak in the main generator stator. After restart, more leaks were found, and the unit was shut down again to make repairs. Leaking SI check valves and faulty SG safety valves delayed startup.

A severe water hammer that occurred during testing caused about a 1-month outage to resolve FW control problems.

The unit was shut down for 19 days to repair a charging pump suction line leak. Another shutdown of 14 days duration was caused by failure of a pressurizer safety valve and a block valve.

The unit was shut down because of a fault in the main generator that led to extensive damage. The utility decided to replace the generator and perform second refueling and maintenance during the outage. Major items included turbine and condenser overhaul, SG inspection, RCP seal replacement and component cooling water heat exchanger retubing. Total outage time was 191 days.

The NRC assessed a $\$ 50,000$ fine for alleged deficiencies in the emergency preparedness program. 
Dec 1985 - Jan 1986

Dec 1985

Sep 1986

Oct - Dec 1986

Mar 1, 1987

Jun - Jul 1987

Aug 1987

Oct - Dec 1987

May 1988

Sep - Dec 1988

Dec 1988 - Jan 1989

Mar 1989

Apr 1989

Oct - Nov 1989

Jan 1990

Mar 1990

Mar - June 1990

Jun - Aug 1990

May 1991
The unit was shut down for 25 days to repair steam leaks and an RCP seal. Another outage of $\mathbf{1 5}$ days was forced to repair another RCP seal leak.

The utility filed suit against $\underline{W}$ for its alleged failure to warn of incorrect RTB maintenance and for alleged failure to repair the Unit 2 main generator properly in 1983 1984.

The unit was shut down for 16 days to replace two failed power transformers.

The third refueling and maintenance outage lasted 82 days: major work included 10-year RV ISI, RCP motor modifications, SG inspection, containment ILRT, and SW system repairs.

One of four $500-\mathrm{kV}$ transmission lines carrying power from the Salem and Hope Creek nuclear units was destroyed by a drifting oil tanker on the Delaware River. Salem 2 was limited to $75 \%$ power until a new unit trip scheme was installed in late March. The scheme allowed Salem 2 and Hope Creek to continue to operate at $90 \%$ power.

The unit was shut down on two occasions to investigate noise and high vibration in the LP turbine and MSR. Total time for the two outages was 14 days.

The unit was shut down for an 11-day outage to replace failing main transformer and repair RV head leaks.

The unit was shut down for 54 days to resolve breaker coordination problems with DG loading sequence.

The NRC assessed a $\$ 50,000$ fine for alleged failure to meet fire protection requirements.

The fourth refueling and maintenance outage lasted 89 days: major work included reactor core FA rearrangement, main generator inspection and turbine rotor replacement.

The unit was shut down for $\mathbf{1 7}$ days to replace a failing main transformer. Another outage of 13 days was forced by problems with the gland seal system on the main turbine.

Repairs to the auxiliary building ventilation system required a 7-day outage.

The NRC proposed a $\$ 50,000$ fine for alleged violation of EQ requirements.

The unit was shut down for 22 days to replace another failing main transformer and repair MSIV controls.

Weld repair on an ECCS injection line and other maintenance required a 7-day outage.

A solar magnetic disturbance alert caused several minor load reductions.

A fifth refueling and maintenance outage was performed. Utility reported that the total cost of replacing the $S W$ piping could reach $\$ 75$ million.

The reactor tripped after a transformer failed. During the shutdown, it was discovered that the MSIVs were inoperable due to improper switch calibration and/or poor maintenance on valve components. The outage totaled 53 days.

A scheduled maintenance outage lasted 10 days. 
Nov 1991

Nov 1991

Jun - Jul 1992

Mar - Jun 1993

Jun 1993

Dec 1993 - Jan 1994

Jun - Jul 1994

Sep 1994

Oct - Feb 1995

Feb - Mar 1995

Jun 1995 - Present

Jan 1996

Jun 1996
During monthly turbine testing, the main turbine oversped and some turbine rotor blades were ejected from the turbine. Inadequate maintenance and personnel error were the causes.

The sixth refueling and maintenance outage lasted 174 days: the outage entered early due to the turbine blade ejection incident.

Inspections revealed that 11 components in the nonnuclear piping had thinned excessively due to erosion/corrosion. The unit was shut down for 12 days for SG piping repairs and testing of piping wall thickness.

The seventh refueling and maintenance outage lasted 86 days.

The unit was shut down for 20 days to repair problems with the control rod instrumentation.

A 32-day outage was needed to repair an EDG with a failed cylinder liner.

Intake grating fouling and feedwater pump problems caused a 17-day outage.

Repairs to one of the charging pumps required a 1-week outage.

The eighth refueling and maintenance outage lasted 113 days.

Following startup, the unit had to shut down twice: once to address a SSPS design inadequacy, and the other to repair a RCP seal. Total downtime was 30 days.

The unit was shut down due to a $500-\mathrm{kV}$ breaker failing. The unit remained shut down to address widespread design, equipment, and personnel deficiencies. The twelfth refueling outage was begun. The unit is scheduled to resume operation in the summer of 1997.

The site was placed on the NRC's declining trend list.

The site was removed from the NRC's declining trend list. 


\section{SAN ONOFRE}

PRODUCTION COST and CAPITAL ADDITIONS

(1996 Dollars)

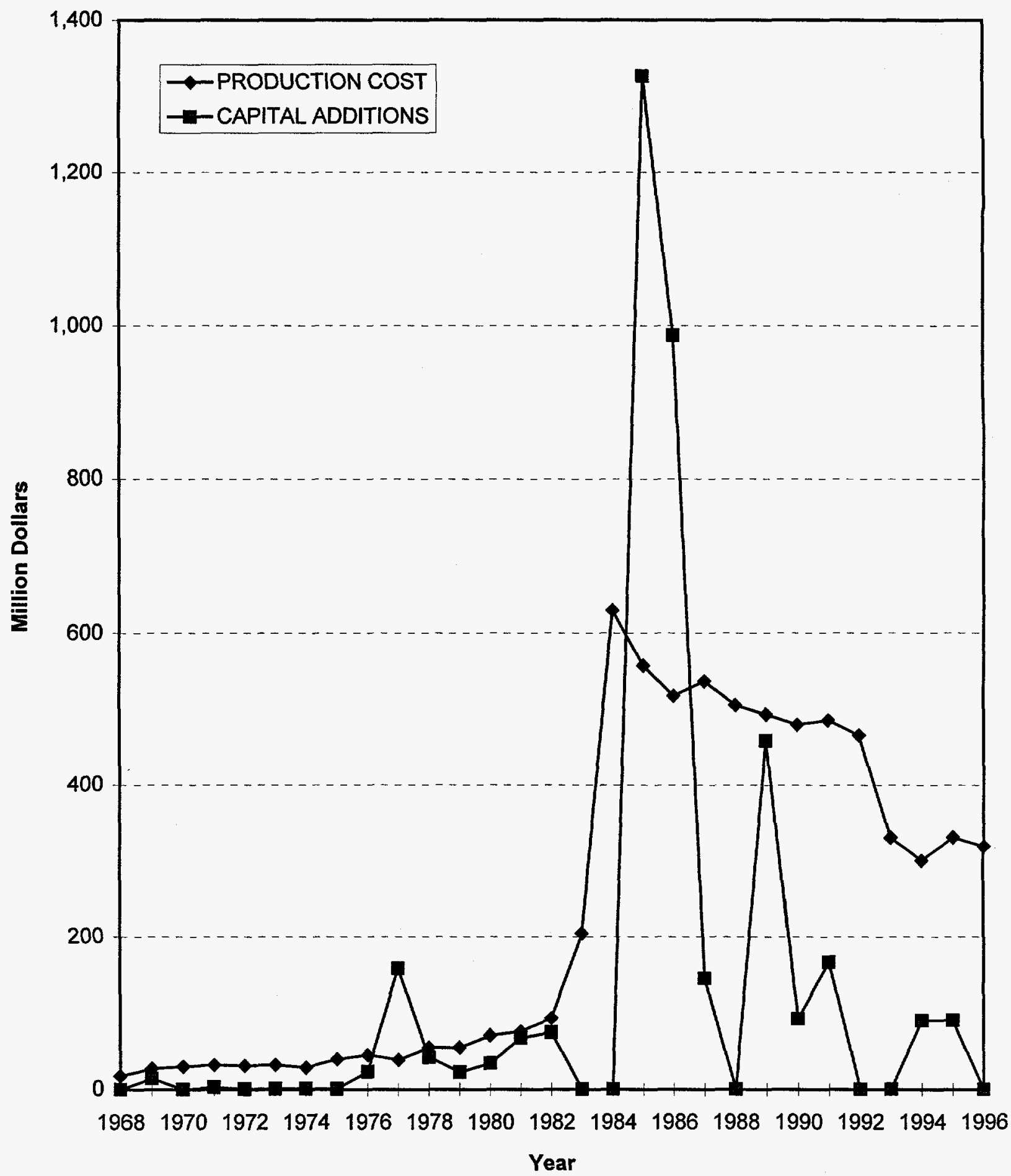




\section{NUCLEAR POWER PLANT OPERATING EXPERIENCE SUMMARY}

Unit data summary through December 1996

Unit: SAN ONOFRE 1

Location: SAN DIEGO COUNTY, CALIFORNIA

Owner: SOUTHERN CALIFORNIA EDISON CO.

Type: WESTINGHOUSE PWR

Construction Permit: 3/2/64

Operating License: $3 / 27 / 67$

Commercial Oper. Date: 1/1/68
Nameplate Rating: $456 \mathrm{MWe}$

MDC Net MWe: $436 \mathrm{MWe}$

Cumul. Avail. Factor: $\mathbf{5 7 . 7}$

Cumul. Cap. Factor (MDC Net): $\mathbf{5 2 . 4}$

Cumul. Forced Outage Rate: 17.9

3-Year Avg. Cap. Factor (MDC Net): n/a

License Expiration: $2007^{1}$

OPERATING HISTORY (To December 1996)

$\underline{\text { Date }}$

Feb - Sep 1968

1969

Oct-Nov 1970

Feb 1971

Jan - Feb 1972

Jun - Jul 1973

Oct 1973 - Jan 1974

Mar 1975

Sep 1976 - Apr 1977

Apr 1977

\section{Comment}

Two major outages occurred because of cable tray fires; extensive electrical modifications were made.

Safety valve leakage, turbine and generator inspections, SG moisture separator modifications, and tsunami gate problems resulted in a significant amount of unavailability during the year.

A 48-day outage occurred for refueling, ISI, maintenance, and switchyard relocation for San Onofre Units 2 and 3. Several uranium-plutonium oxide Zircaloy clad FAs were loaded into core for testing.

An earthquake occurred about 75 miles from the plant; no damage was found at the plant. Site acceleration was $0.01-0.018 \mathrm{~g}$. (Plant design is $0.25 \mathrm{~g}$.)

During a 61-day refueling outage, 21 turbine blades were discovered missing.

Refueling outage and extensive maintenance on SG and turbine were necessary; condenser and reheater tubes were replaced.

An outage was forced by turbine blade failure and SI water hammer damage.

A refueling outage lasted 40 days: condenser water boxes were retubed, ISI was performed, and 52 new FAs were added.

The refueling and maintenance outage was performed. Major work included a containment sphere enclosure project and addition of two $6000-\mathrm{kW}$ diesel generators. SG inspection showed some tube thinning; stress corrosion cracks were found in containment spray piping.

The unit electrical capacity increased to $456 \mathrm{MWe}$ (gross) based on reevaluation of the turbine generator.

${ }^{1}$ The unit was permanently shut down in November 1992 . The cumulative data are through that date. 
Apr 1980 - Jun 1981

Jul 1981

Sep - Nov 1981

Feb 1982 - Nov 1984

Jun 1982

May 1983

Nov 1984

Nov 1985 - July 1986

Dec 1985

Aug 1986

Dec 1987

Feb - Aug 1988

Nov 1988 - May 1989

Dec 1988

Apr 1990

Jun 1990 - Mar 1991

Apr - May 1991

Sep 1991

Jan 1992
A refueling and maintenance outage occurred because of extensive SG tube repair. Sixty-six workers were overexposed during SG work, and the utility was fined $\$ 150,000$ by NRC.

The DG oil line fire caused a 30-day outage.

A 2-month outage occurred for replacement of SI valves.

The unit was shut down for extensive seismic backfitting. SG tube leakage problems resulted in a prolonged outage; the SG inspection program was reevaluated.

The NRC proposed a $\$ 60,000$ fine for alleged violations concerning the plant security program.

The NRC levied a $\$ 120,000$ fine for alleged TS violations involving containment coolers.

The plant restarted after almost 2 years of seismic backfit modifications. Remaining seismic backfit work was to be done during subsequent outages.

The plant entered refueling and maintenance outage early because of secondary system water hammer damage incurred during recovery from loss of power to a safety bus. The NRC sent a team to evaluate problem. Seismic backfit work continued.

The NRC assessed a $\$ 50,000$ fine for alleged violation involving unauthorized and undocumented repair to an auxiliary FW pump.

The NRC proposed a $\$ 25,000$ fine for alleged failure to meet NRC requirements for security for vital areas.

The NRC proposed a $\$ 100,000$ civil penalty for alleged incidents involving detection and control of radioactive particles.

A planned PM outage was extended for several months because of extensive equipment upgrades needed to comply with EQ requirements for safety-related electrical equipment. The NRC assessed a $\$ 150,000$ civil penalty against the utility for noncompliance with EQ requirements. Total outage time was $\mathbf{1 7 5}$ days.

The refueling outage was extended because of structural problems with sleeved SG tubes. Cracked bolts were found on the thermal shield; NRC prohibited operation until questions concerning thermal shield integrity had been resolved.

OL was amended to allow Unit 1 spent fuel to be stored in the Unit 2 and 3 spent fuel pool.

The unit received higher ratings in three functional areas in a positive NRC SALP report.

The refueling and major maintenance outage lasted 262 days: the thermal shield support was replaced.

A 30-day outage was forced for repair of SG tube leaks.

A full-term operating license was issued by NRC. (The plant has operated since startup under a provisional operating license.)

The utility announced that the unit would be permanently shut down at the end of the current fuel cycle. The utility concluded that it was not cost-effective to implement the $\$ 125$ million upgrade that the NRC required for continued operation. 
Feb 1992

Nov 30, 1992
The NRC proposed and the utility paid a $\$ 50,000$ fine for alleged violations involving failure to maintain operability of the Halon fire protection system in the 4160-V switchgear room.

The unit was permanently shut down after a year of continuous operation. A possessiononly license had been granted the previous month, effective after the unit was shut down and defueled. Decommissioning work is planned to begin around 2013 and projected to cost $\$ 260$ million in 1992 dollars. 


\section{NUCLEAR POWER PLANT OPERATING EXPERIENCE SUMMARY}

Unit data summary through December 1996

Unit: SAN ONOFRE 2

Location: SAN DIEGO COUNTY, CALIFORNIA

Owner: SOUTHERN CALIFORNIA EDISON CO.

Type: COMBUSTION ENGINEERING PWR

Construction Permit: 10/18/73

Operating License: $9 / 7 / 82$

Commercial Oper. Date: $\mathbf{8 / 8 / 8 3}$
Nameplate Rating: 1127 MWe

MDC Net MWe: $1070 \mathrm{MWe}$

Cumul. Avail. Factor: 76.6

Cumul. Cap. Factor (MDC Net): 75.4

Cumul. Forced Outage Rate: $\mathbf{4 . 8}$

3-Year Avg. Cap. Factor (MDC Net): 86.5

License Expiration: 2013

OPERATING HISTORY (To December 1996)

Date

Feb - May 1983

Mar 1983

Dec 1983

Oct 1984 - Apr 1985

Mar - June 1986

Aug - Dec 1987

May - Jun 1989

Sep - Dec 1989

May 1990

Jul - Aug 1990

Nov 1991

\section{Comment}

An outage to repair damage on a steam bypass line was extended for work on RTBs and the postaccident sampling system (PASS).

The NRC proposed three $\$ 40,000$ fines for alleged violations concerning containment system inoperability and administrative failures in notifying NRC of deficiencies in PASS testing.

The NRC proposed a $\$ 40,000$ fine for an alleged valving error that caused both charging pumps to be isolated.

The first refueling and maintenance outage was performed. RV horizontal sealing ring failure, binding of a FA in stand, and RCP seal failure contributed to outage extension.

The second refueling and maintenance outage lasted 89 days: major work included SG inspection and sludge lancing and minor plant modifications. Calibration error caused loss of both shutdown cooling trains on March 26.

The third refueling and maintenance outage lasted 106 days: major work included ILRT, fuel alignment plate modifications, and a plant monitor computer replaced; personnel contamination problems occurred.

The unit was shut down to inspect all SG tubes; cracks were repaired in three welded tube plugs.

The fourth refueling and maintenance outage lasted 97 days: the plant reported that a 2-year reliability centered maintenance ( $\mathrm{RCM}$ ) program improved reliability of some systems.

Plans to expand the spent fuel pool were announced; new high-density fuel storage racks would provide reserve storage capacity through cycle 11 in 2001.

A 32-day outage occurred for SG inspection and repair based on indications found in Unit 3 SGs.

A 5-day outage was required due to degraded CRD MG set output resistance. 
Jan 1991

Apr 1991

Aug - Nov 1991

Dec 1991

Feb 1.992

Mar 1992

Jun - Aug 1993

Feb - May 1995

Jun 1995

Dec 1996
The NRC proposed and the utility paid a $\$ 150,000$ fine for several alleged violations involving inoperability of the AFW pump at Unit 2 and the containment spray system at Unit 3.

The unit was shut down for 28 days because of problems with RCP bleedoff and baffle on RCP shaft.

The fifth refueling and maintenance outage lasted 96 days: major work included SG inspection, sludge lancing, and tube plugging, cooling water system maintenance, main generator overhaul, AFW check valve rework, and MOV testing.

The California Coastal Commission recommended that, instead of building closed-circuit cooling towers (as demanded by environmentalists), the utility should restore wetlands, install fish deterrents around intakes, build artificial reefs, and closely monitor marine life in the plant vicinity.

The NRC proposed a $\$ 50,000$ fine against the site for allegedly failing to maintain the Halon fire protection system in the $4160 \mathrm{~V}$ switchgear room and providing the NRC with an inadequate LER describing the situation.

Inadequate ECCS and containment check valves required a 20-day outage to correct.

The sixth refueling and maintenance outage lasted 64 days: major work included a 10-year RV ISI, SG ECT and tube plugging, LPCI pump seal replacement, HP and first-stage turbine overhaul, and pressurizer nozzle replacement.

The seventh refueling and maintenance outage lasted 102 days.

The turbine was taken off-line for 4 days to repair a crack in a gland steam pipe flange.

The eighth refueling and maintenance outage started. 
Unit: SAN ONOFRE 3

Location: SAN DIEGO COUNTY, CALIFORNIA

Owner: SOUTHERN CALIFORNIA EDISON CO.

Type: COMBUSTION ENGINEERING PWR

Construction Permit: 10/18/73

Operating License: 11/15/82

Commercial Oper. Date: 04/01/84
Nameplate Rating: 1127 MWe

MDC Net MWe: $1080 \mathrm{MWe}$

Cumul. Avail. Factor: 79.2

Cumul. Cap. Factor (MDC Net): $7 \mathbf{7 6 . 0}$

Cumul. Forced Outage Rate: 4.7

3-Year Avg. Cap. Factor (MDC Net): 89.8

License Expiration: 2013

OPERATING HISTORY (To December 1996)

Date

Dec 1983

May 1984

Jun - Jul 1984

Oct - Dec 1984

Sep 1985 - Jan 1986

Sep 1986

Jan - Mar 1987

Jul 1987

Apr - Aug 1988

Oct 1988

Feb 1990

Apr - Jul 1990

May 1991

\section{Comment}

The NRC proposed a $\$ 40,000$ fine for alleged personnel errors involving valve positioning.

The NRC assessed a $\$ 125,000$ fine for alleged violations involving valve alignment checkoff in the containment spray system.

The unit was shut down for a 26-day outage for CEA calculator circuit board replacement and RCP seal work, plus an additional 21-day outage for SG tube leak repairs.

Another outage was required for SG tube leak repair and RCP seal replacement. Fuel inspection and reconstitution were performed. Work was done on the waste gas system and emergency chillers.

The first refueling and maintenance outage was performed. Major work included NRCmandated modifications; outage was extended to replace RCP thrust bearings.

The NRC assessed a $\$ 25,000$ fine for alleged security violations; a 20 -day outage was needed to replace RCP seals.

The second refueling and maintenance outage lasted 68 days.

The NRC assessed a $\$ 100,000$ fine for alleged violations involving inadequate control of radioactive material and personnel overexposure.

The second refueling and maintenance outage lasted 113 days: major work included ILRT, Appendix R modifications, and fuel inspection and replacement performed.

The NRC assessed a $\$ 150,000$ fine for alleged violations involving EQ of electrical equipment.

The reactor tripped after a main steam isolation signal was generated during relay testing. The outage lasted 5 days.

The third refueling and maintenance outage lasted 100 days: major work included LP and HP turbine overhaul, SG inspection, in-core instrumentation replacement, and shutdown cooling system maintenance.

A leak of hydrogen into the main generator stator water system required 25 days to repair. 


\section{SAN ONOFRE 3 (Cont'd)}

Jan - Mar 1992

Apr 1992

May 1992

Oct - Dec 1993

Jul - Sep 1995

Sep 1996
The fourth refueling and maintenance outage lasted 66 days: major work included RCP alignment and seal replacement (2 each), LP turbine, main generator, and one DG overhaul, ILRT, and SG ECT.

A 6-day outage was needed for turbine balancing. The RCP seal failure required a 16-day outage to repair.

The plant tripped when a RCP tripped due to a motor surge capacitor failure and was shut down for 4 days.

The fifth refueling and maintenance outage lasted 82 days.

The sixth refueling and maintenance outage lasted 66 days.

The unit was shut down for 18 days to repair a failed RCS thermowell. 


\section{SEABROOK}

PRODUCTION COST and CAPITAL ADDITIONS

(1996 Dollars)

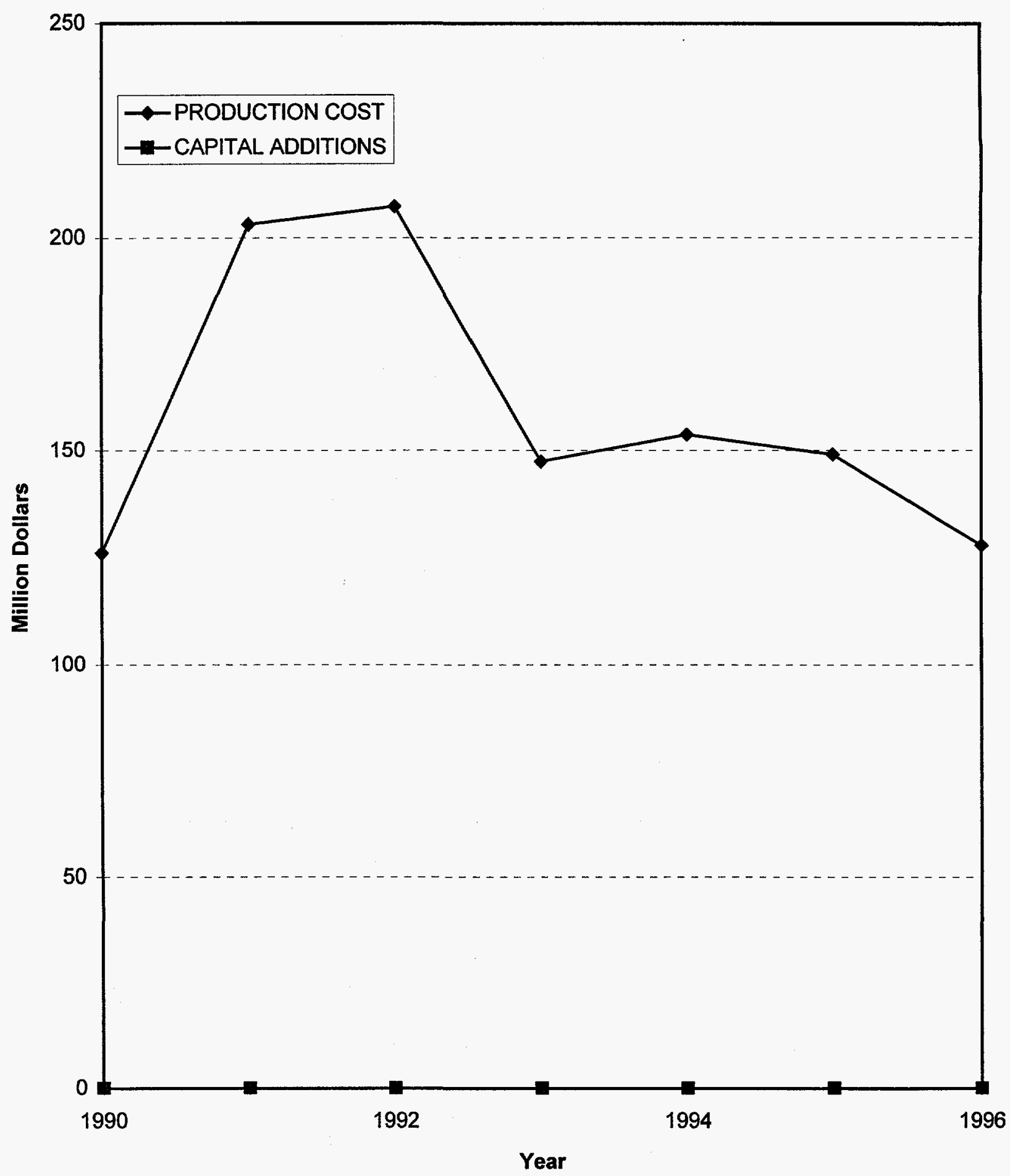




\section{NUCLEAR POWER PLANT OPERATING EXPERIENCE SUMMARY}

Unit data summary through December 1996

Unit: SEABROOK 1

Location: ROCKINGHAM COUNTY, NEW HAMPSHIRE

Owner: NORTHEAST UTILITIES

Type: WESTINGHOUSE PWR

Construction Permit: 7/7/76

Operating License: $\mathbf{5 / 2 6 / 8 9}$

Commercial Oper. Date: 8/19/90
Nameplate Rating: 1197 MWe

MDC Net MWe: $1158 \mathrm{MWe}$

Cumul. Avail. Factor: 82.3

Cumul. Cap. Factor (MDC Net): 79.7

Cumul. Forced Outage Rate: 5.5

3-Year Avg. Cap. Factor (MDC Net): 80.5

License Expiration: 2026

OPERATING HISTORY (To December 1996)

Date

$1976-1986$

$1987-1990$

Mar 1990

Apr - May 1990

Jul 19, 1990

Nov 1990

Mar 1991

May 1991

Jul - Oct 1991

Nov 1991

Mar 1992

Sep - Nov 1992

\section{Comment}

Construction of the plant was continually interrupted by political and financial problems. Major elements included disagreement with the state of Massachusetts over approval of emergency plans, a New Hampshire ban on charging ratepayers before operation of the plant, and a number of court and regulatory interventions by groups opposed to the plant. At the time, plant cost had risen to $\$ 4.2$ billion.

Continued opposition by intervenors delayed plant startup. In 1988, the Public Service Co. of New Hampshire declared bankruptcy, the first U.S. utility to do so since the 1930s, and Unit 2 was canceled. Plant costs increased another $\$ 2.2$ billion to a total of $\$ 6.4$ billion.

The plant started a power ascension program.

The plant shut down for about 6 weeks to make turbine modifications to reduce vibration.

The plant achieved $100 \%$ power for the first time.

The unit tripped when a FW regulating valve air supply failed. Relocating the air booster relays for the four valves required an outage of 14 days.

A transformer fault resulted in a manual trip, and the ensuing outage lasted 5 days.

Northeast Utilities completed a takeover of the Public Service Co. of New Hampshire. The plant continued to be operated by New Hampshire Yankee, a consortium of utilities with ownership shares of the plant.

The first refueling and maintenance outage lasted 68 days: major work included retubing two primary component cooling heat exchangers, HP and LP turbine inspection, and SG eddy current testing.

The NRC proposed a $\$ 100,000$ fine for alleged failures concerning radiographs during construction.

The utility suspended 9 auxiliary operators, and 4 more resigned or were terminated following investigation of improper entries in nonsafety-related surveillance logs. Some of the entries had been falsified.

The second refueling and maintenance outage lasted 68 days. 
Jan 1993

Sep - Oct 1993

Jan - Feb 1994

Apr - Jun 1994

Jun 1995

Nov - Dec 1995
The unit was shut down for 6 days following a main generator/reactor trip caused by a ground voltage signal.

The reactor tripped when a RCP tripped on an undervoltage signal due to arcing of the exciter field brushes. Repairs required a 15-day outage.

The reactor tripped after an MSIV fully closed, rather than partially, during a test. The unit was shut down for 23 days.

The third refueling and maintenance outage lasted 114 days.

The unit was shut down for 16 days following a reactor scram due to both EHC oil pumps tripping.

The fourth refueling and maintenance outage lasted 38 days. 
This Page Intentionally Left Blank 


\section{SEQUOYAH}

PRODUCTION COST and CAPITAL ADDITIONS

(1996 Dollars)

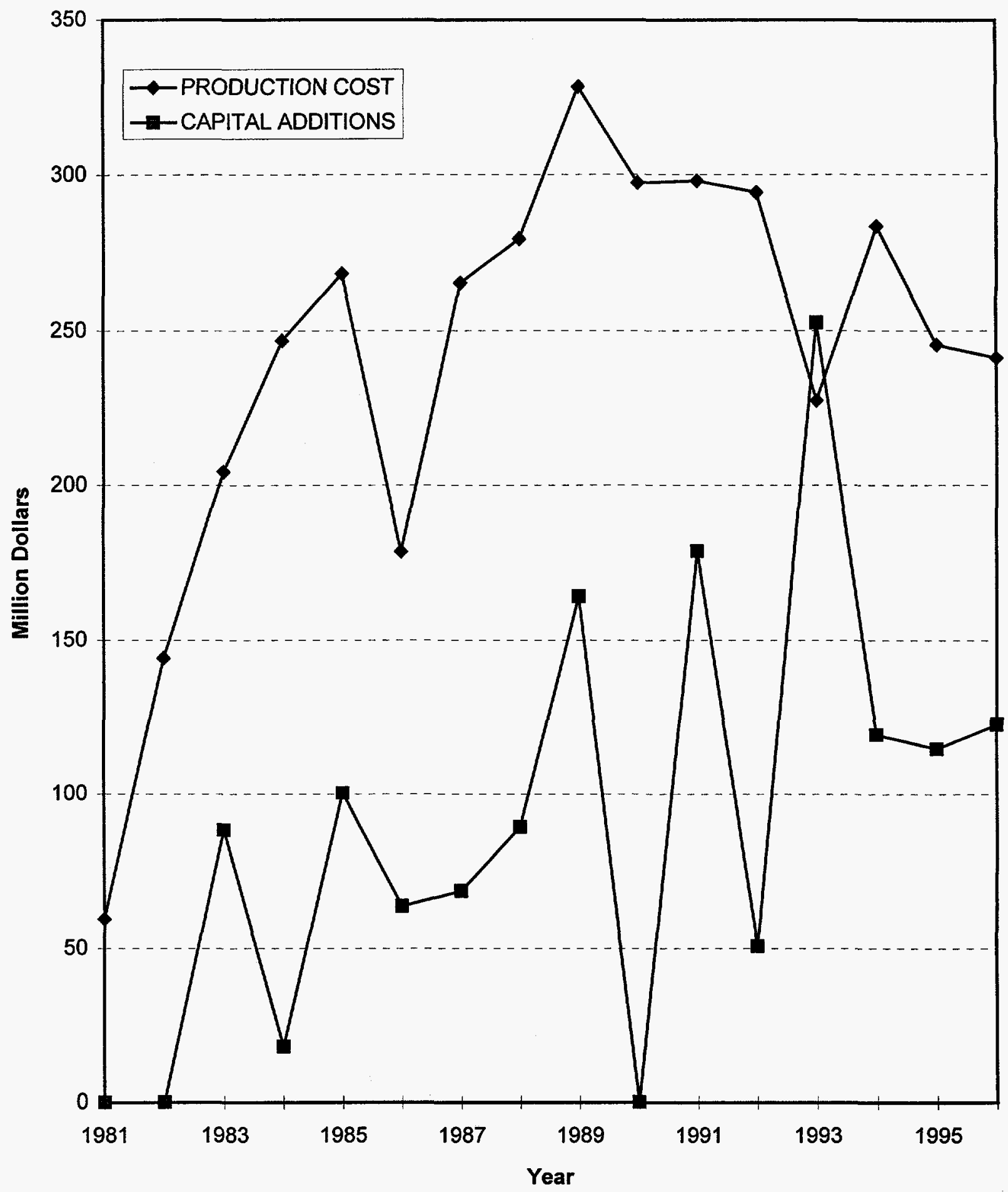




\section{NUCLEAR POWER PLANT OPERATING EXPERIENCE SUMMARY}

Unit data summary through December 1996

Unit: SEQUOYAH 1

Nameplate Rating: $1221 \mathrm{MWe}$

Location: HAMILTON COUNTY, TENNESSEE

MDC Net MWe: $1117 \mathrm{MWe}$

Owner: TENNESSEE VALLEY AUTHORITY

Cumul. Avail. Factor: 55.6

Type: WESTINGHOUSE PWR

Cumul. Cap. Factor (MDC Net): $\mathbf{5 2 . 9}$

Construction Permit: 5/27/70

Cumul. Forced Outage Rate: 32.1

Operating License: $\mathbf{9 / 1 7 / 8 0}$

3-Year Avg. Cap. Factor (MDC Net): 75.8

Commercial Oper. Date: 7/1/81

License Expiration: 2020

OPERATING HISTORY (To December 1996)

Date

Feb - Mar 1981

May 1981

Jul - Aug 1981

Sep - Oct 1981

Jan 1982

Feb 1982

Sep 1982 - Jan 1983

Aug 1983

Nov 1983 - Jan 1984

Feb - Apr 1984

Apr - May 1984

Apr - Jun 1985

\section{Comment}

The unit was shut down to resolve excessive generator vibration. The outage was extended to early March to repair a steam dump valve.

The repair of leaking SG manways required an 11-day outage. The unit was derated about $20 \%$ because the turbine would not meet design specifications.

Six outages, totaling 19 days, were forced by various equipment failures and repairs of steam leaks.

The unit was shut down for 48 days for ice weighing and general maintenance.

The unit was shut down for 20 days because of a transformer explosion and to perform ice weighing.

The unit was shut down for 29 days to correct excessive turbine vibration and to replace a RCP motor.

The first refueling and maintenance outage lasted 150 days: during the shutdown, a LOCA occurred that rendered the RHR system inoperable. Another RCP motor was replaced.

SG water chemistry problems and malfunctions of the condensate demineralizer system forced two outages totaling 17 days.

Repairs to the main generator after a stator core short circuit forced a 48-day outage.

The second refueling and maintenance outage lasted 57 days.

The unit was shut down for about 3 weeks after personnel inadvertently drilled through a seal table thimble, and 15,000 gallons of radioactive water was spilled. The NRC imposed a $\$ 112,500$ fine for the incident because the procedure allegedly should not have been used during operation.

The unit was shut down for about 2 months to repair a main generator hydrogen leak and a RCP seal leak. Various other repairs to plant equipment were also performed. 
Aug 26, 1985

$1986-1987$

Jun 1988

Nov 1988

Jul 1989

Sep 1989

Jan 1990

Mar - Jun 1990

Sep 1990

Oct 1990

Feb 1991

May 1991

Oct - Dec 1991

Mar 1992

Jul 1992
All TVA nuclear units were shut down because of NRC questions about EQ of plant equipment and overall TVA management of nuclear plant construction, design, and operation.

The third refueling was performed during the extended shutdown.

The unit remained shut down throughout the years. Utility efforts were concentrated on restart of Sequoyah Unit 2. In July, the NRC proposed a $\$ 150,000$ fine for alleged discrimination against three employees who raised concerns about the QA program and one who supported another employee in a discrimination proceeding before the Department of Labor. The unit was placed on the NRC problem list.

The utility assured the NRC that the TVA reorganization plan would not affect progress toward restart. The plan included layoff of about 3600 employees.

The NRC agreed to schedule for restart after more than 3 years of being shutdown. An electrical fault in the main generator forced a 13-day outage.

Units 1 and 2 were removed from the NRC problem plant list.

The utility paid NRC a $\$ 50,000$ fine for alleged inadequacy of a post-trip review.

The NRC proposed an $\$ 87,000$ fine for a number of alleged violations including failure to perform safety evaluations of off-normal operation, failure to obtain NRC approval before reducing the safety margin on an ECCS system, and failure to take adequate corrective action to preclude the use of deficient procedures.

The fourth refueling and maintenance outage lasted 77 days.

The NRC assessed a $\$ 75,000$ fine for alleged failure to evaluate and correct a design deficiency described in NRC IE Bulletin 88-04 concerning RHR pump deadheading during minimum flow conditions.

The unit was shut down to investigate the cause of disc separation from valve arm in three MSL check valves. The outage lasted 14 days.

The unit was shut down for 6 days due to problems with the centrifugal charging pump.

The NRC proposed a $\$ 75,000$ fine against the site for alleged violations concerning a DG air start accumulator low pressure and operator failure to respond to alarms about the condition. The fine was escalated due to poor past performance and was paid by the utility.

The fifth refueling and maintenance outage lasted 86 days: major work included FW heater and RCP seal replacements, ice condenser inspection/inventory restoration, SG ECT, sludge lancing, and internals inspection, and turbine-to-condenser seal replacement.

The unit was shut down to correct problems with ice condenser doors binding due to water seeping under the door and refreezing. The condition was discovered at Unit 2 during its refueling outage. The outage was extended to repair a feedwater leak. The outage lasted 30 days.

The NRC proposed a $\$ 75,000$ fine against the site for alleged violations relating to the Cable Test Program. The fine was escalated because the NRC found the condition. The fine was paid by the utility. 
Sep 1992

Oct 1992

Nov 1992

Mar 1993

Mar 93 - Apr 94

May 1994

Nov 1994

Feb 1995

Sep - Nov 1995

Nov 1995

Dec 1995

May 1996

Nov 1996

Dec 1996
The NRC proposed a $\$ 62,500$ fine against the unit for alleged violations involving an inoperable SI pump. The fine was paid.

The unit was shut down for 5 days following a plant trip due to a FW regulating valve opening when the controller was placed in manual.

The NRC SALP gave the site two category 1 ratings and none of the lowest category 3 ratings.

The NRC proposed a $\$ 2250,000$ fine for three alleged violations involving mispositioned throttle valves, failure to maintain RWST temperature, and loss of RCP seal injection during recovery from a dual unit trip.

The unit was shut down to resolve secondary-side erosion/corrosion problems. The shutdown was prompted by a pipe rupture in Unit 2. In April, the unit entered the sixth refueling outage. Both the NRC and the utility stated that deficiencies identified during the outage were partially due to prematurely restarting after the 1985-1988 extended outage.

The unit was down for 5 days following a reactor scram. The scram was due to loss of one of the main feedwater pumps from personnel error.

The unit was down for 1 week after an automatic turbine trip/reactor scram. This was due to the loss of both EHC power sources from an incorrect set point.

The unit was shut down for nine days to repair a leaking RCS instrument fitting.

The seventh refueling and maintenance outage lasted 64 days.

The unit was shut down twice for a total of five days due to secondary plant transients.

The unit was shut down twice for a total of 10 days. One event required the replacement of the main generator's exciter.

Replacement of the motor and seal for a RCP lasted 12 days.

The NRC proposed and the licensee paid a $\$ 50,000$ fine for deficiencies in the fire protection program.

The NRC proposed and the licensee paid a $\$ 100,000$ fine for complications following a reactor trip. 


\section{NUCLEAR POWER PLANT OPERATING EXPERIENCE SUMMARY}

Unit data summary through December 1996

Unit: SEQUOYAH 2

Location: HAMILTON COUNTY, TENNESSEE

Owner: TENNESSEE VALLEY AUTHORITY

Type: WESTINGHOUSE PWR

Construction Permit: 5/27/70

Operating License: 9/15/81

Commercial Oper. Date: 6/1/82
Nameplate Rating: 1221 MWe

MDC Net MWe: 1117 MWe

Cumul. Avail. Factor: 60.7

Cumul. Cap. Factor (MDC Net): 56.5

Cumul. Forced Outage Rate: 31.3

3-Year Avg. Cap. Factor (MDC Net): 76.7

License Expiration: 2021

OPERATING HISTORY (To December 1996)

Date

Sep 1981

Jan 1982

Mar 1982

Nov - Dec 1982

Jul - Oct 1983

Nov 1983

Sep - Dec 1984

Aug 22, 1985

$1986-1987$

Feb - May 1988

May - June 1988

Jun 1988

Jan 1989

\section{Comment}

The NRC proposed a $\$ 40,000$ fine for alleged mispositioning of three valves in the containment spray system.

The unit experienced two trips on high SG level on two separate occasions, causing outages totaling 18 days.

The NRC proposed a $\$ 50,000$ fine for alleged violations involving TS LCOs, staff retraining, and procedure implementation.

The unit was shut down for 20 days to conduct ice weighing. Another 29-day outage was caused by repairs to a fan in the hydrogen cooling system.

The first refueling and maintenance outage lasted 88 days: a faulty FW pump and a small SG leak caused unit to shut down early.

High vibration in three RCPs caused several outages, totaling 9 days, during the month.

The second refueling and maintenance outage lasted 90 days.

All TVA nuclear units were shut down because of NRC questions about EQ of plant equipment and overall TVA management of nuclear plant construction, design and operation.

The unit remained shut down throughout the years. Utility efforts were concentrated on restart of Unit 2. TVA and NRC efforts were directed at assuring EQ of components, integrity of cables, and resolving safety concerns raised by employees. TVA management was restructured.

The unit restart efforts were hampered by pressurizer safety valve problems and SG tube leaks. The unit reached 100\% power for the first time in almost 3 years on May 31, 1988.

The unit suffered a number of trips from the FW system. The unit was shut down for a 14-day outage to investigate and resolve problems with $\mathrm{FW}$ valves and controls.

The NRC proposed a $\$ 50,000$ fine for alleged failure to maintain the required number of charging pumps operable during operation.

The unit established a new utility record of over 209 days of continuous operation. 
Jan - Apr 1989

Jul 1989

Sep 1989

Nov 1989

Sep - Nov 1990

Dec 1990

Nov 1991

Mar - May 1992

Jan 1993

Mar 93 - Oct 93

Oct 1993

Nov 1993

Dec 1993

Jan 1994

Jul - Nov 1994

Apr 1995

Apr - Jun 1996

Oct 1996
The third refueling and maintenance outage lasted 86 days.

Unit 1 and 2 were removed from the NRC problem plant list.

The unit was down for 4 days following a trip due to a dropped control rod.

The utility paid a $\$ 50,000$ fine to the NRC for alleged inadequate post-trip reviews and insufficient corrective actions.

A 7-day outage was necessary to work on the head vent valves.

The fourth refueling and maintenance outage lasted 75 days: major work included replacement of analog protection system with a digital one, FW heater replacement, ATWS mitigation system installation, and removal of the upper-head injection system.

The NRC proposed a $\$ 30,000$ fine for alleged violations relating to the amount of overtime hours worked by personnel performing safety-related activities. The fine was paid.

The unit was shut down for 10 days following a plant trip caused by an inadvertent MSIV closure. During the outage, it was discovered that various $480-\mathrm{V}$ electrical boards did not have selective coordination between the feeder and load breakers.

The fifth refueling and maintenance outage lasted 64 days: major work included FW heater and SG nozzle replacement, ILRT, ice condenser inspection/inventory restoration, SG ECT and shot peening, and HP turbine and main generator inspection. During the outage, it was found that over half the ice condenser inlet doors were binding.

The unit was shut down for 9 days after a trip due to a fault in the $500-\mathrm{kV}$ switchgear.

The unit tripped after an extraction steam pipe ruptured due to pipe thinning from erosion/corrosion. The unit remained shut down to inspect other piping for this condition and to improve overall plant conditions and performance. The outage lasted a total of 234 days.

The unit was shut down for 5 days after a letdown valve malfunctioned because of incorrect reassembly of the valve following maintenance.

The unit was shut down for 7 days to correct stuck-open thermal barrier check valves. The repairs required 6 days to correct.

The unit was shut down for 12 days after main turbine generator problems caused a trip.

Repairs to a charging pump could not be completed within TS allowable time limits. The unit was shut down for $\mathbf{5}$ days to complete the repairs.

The sixth refueling and maintenance outage lasted 134 days.

A water hammer event in the feedwater heater system occurred and caused valve damage. Repairs lasted 18 days.

The seventh refueling and maintenance outage lasted 51 days.

A 25-day outage followed a manual scram when the turbine load was lost due to corroded pressure switches. Other outage maintenance included RCP seals and auxiliary feedwater pump work. 
SOUTH TEXAS

PRODUCTION COST and CAPITAL ADDITIONS

(1996 Dollars)

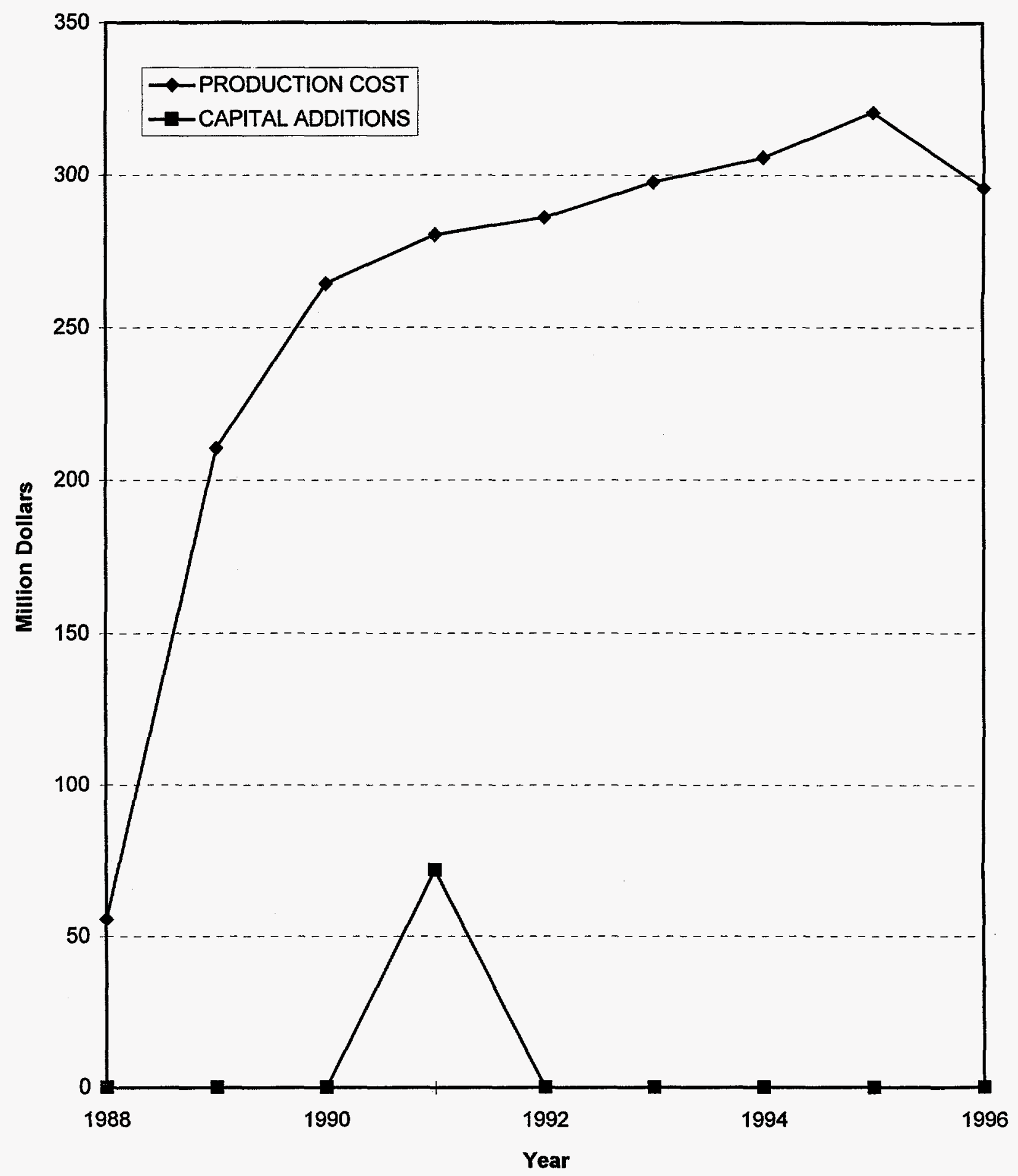




\section{NUCLEAR POWER PLANT OPERATING EXPERIENCE SUMMARY}

Unit data summary through December 1996

Unit: SOUTH TEXAS 1

Location: MATAGORDA COUNTY, TEXAS

Nameplate Rating: 1311 MWe

Owner: HOUSTON LIGHTING \& POWER CO.

MDC Net MWe: $1251 \mathrm{MWe}$

Type: WESTINGHOUSE PWR

Cumul. Avail. Factor: 67.0

Construction Permit: 12/22/75

Cumul. Cap. Factor (MDC Net): 64.0

Operating License: $\mathbf{3 / 2 2 / 8 8}$

Cumul. Forced Outage Rate: 22.9

Commercial Oper. Date: $\mathbf{8 / 2 5 / 8 8}$

3-Year Avg. Cap. Factor (MDC Net): 84.4

License Expiration: 2027

OPERATING HISTORY (To December 1996)

$\underline{\text { Date }}$

$1980-1985$

Feb 1988

Mar 1988

May 1988

Nov 1988

Jan - Mar 1989

Aug - Sep 1989

Sep 1990
Comment

The NRC proposed a $\$ 100,000$ fine against the utility for alleged inadequacies in QA and gave the utility 90 days to show cause why the construction permit should not be terminated. All safety-related construction was halted following an NRC report on substantial QA deficiencies attributed to the $\mathrm{A} / \mathrm{E}$. The original $\mathrm{A} / \mathrm{E}$ and constructor, Brown \& Root, was replaced by Bechtel Power and Ebasco Services in 1981. The plant owners agreed to fund a $\$ 250,000$ study on conversion of the plant to coal generation. Units 1 and 2 were about $50 \%$ and $25 \%$ completed at the time. The utility received an out-of-court settlement of $\$ 750$ million for mismanagement from Brown \& Root in 1985. Plant cost was estimated to be $\$ 5.495$ billion at the time.

The NRC assessed a $\$ 75,000$ fine against the utility for alleged violations concerning a disabled ECCS train in October and November 1987.

The NRC granted the unit a full power license. Also in March, a $\$ 50,000$ fine was assessed by the NRC for alleged violations concerning plant physical security.

During an LOSP test, a SG main feed pump failed. Scattered debris damaged 15 condenser tubes. A 19-day outage was required to repair the damage.

The NRC approved a license amendment for expanding spent fuel storage from 196 FAs to 1969 FAs.

The unit was shut down after a fire occurred in the turbine/generator. The subsequent outage was extended for thimble tube inspections that had been rescheduled to take place concurrently with the turbine/generator repairs. Total outage time was $\mathbf{4 2}$ days.

The first refueling and maintenance outage lasted 55 days. Major work included thimble tube replacement; SG inspection, sludge lancing, and U-bend heat annealing; RCP seal changeout; MOV testing; LLRTs; overhaul of all DGs; and replacement of LP turbine rotor.

The unit was shut down for 12 days after a FW isolation valve closure occurred from a misapplied control circuit jumper. 
Nov 1990 - Apr 1991

Jul 1991

Aug 1991

Oct 1991

Dec 1991

Apr 1992

Sep - Dec 1992

Jan 1993

Feb 1993 - Feb 1994

Feb 1993 - Feb 1994

Jun 1993

June 1993

Mar 1994

Oct 1994

Feb 1995

Mar - Apr 1995

Dec 1995
The unit was shut down after main generator stator cooling was lost because of a failed water inlet header box. The generator rotor was removed for repair, and outage was extended through April 1991 to accomplish a second refueling. Maintenance during the outage included ILRT, SG eddy current testing and sludge lancing, snubber testing, and other modifications. Total outage time was 114 days.

The NRC proposed a $\$ 75,000$ fine against the utility for alleged violations involving ATWS system inoperability on Unit 1 and Unit 2.

The unit received three top Category 1 ratings in an NRC SALP review. However, the NRC noted declining performance in areas of operations, maintenance, and surveillance that were attributable to lack of management involvement.

Two trips due to personnel error resulted in 11 days of downtime.

The NRC proposed a $\$ 50,000$ fine against the utility for alleged safety violations committed by a contractor employee.

A scheduled maintenance outage lasted 8 days.

The third refueling and maintenance outage lasted 103 days. Major work included 10-year ISI RCP and DG motor maintenance reactor head vent piping modifications, CS additive tank removal, and pressurizer safety valve maintenance.

A 6-day outage was needed to correct the lead-lag controller calibration for the low steam line pressure and high negative steam line pressure channels.

The unit was shut down due to multiple problems with the turbine-driven AFW pump. The site was subject to broad-based NRC evaluations due to management and other deficiencies. The outage was extended for both units to correct these conditions.

In April, the NRC proposed and the utility paid a fine of $\$ 175,000$ for three alleged violations: (1) failure of management to promptly inform the NRC of a possible condition that could have affected operations; (2) personnel errors involving work on the wrong unit or system; and (3) the failure to repair an inoperable MOV in a Unit 2 safety system and not declaring the system inoperable.

The site was added to the NRC problem plant list.

The NRC proposed and the utility paid a $\$ 325,000$ fine for alleged violations involving inoperability of the turbine-driven auxiliary feedwater pump and the emergency diesel generators.

The unit tripped on low water level caused by a malfunctioning main feedwater regulating valve. Repairs required 22 days.

The NRC proposed a $\$ 100,000$ fine for alleged discrimination against a contractor employee engaged in protected activity, (i.e., whistle-blowing). The Department of Labor had ruled in 1992 in favor of the employee. In May 1995, the NRC withdrew the proposed fine based on evidence presented by the licensee.

The site was removed from the NRC's problem plant list.

The fourth refueling and maintenance outage lasted 42 days.

A turbine trip/reactor scram caused a 4-day outage. 


\section{SOUTH TEXAS 1 (Cont'd)}

May - Jun 1996

Sep 1996
The fifth refueling and maintenance outage lasted 23 days.

The NRC proposed and the licensee paid a $\$ 200,000$ fine for two separate whistle-blower infractions committed by two different contractors. 


\section{NUCLEAR POWER PLANT OPERATING EXPERIENCE SUMMARY}

Unit data summary through December 1996

Unit: SOUTH TEXAS 2

Location: MATAGORDA COUNTY, TEXAS

Nameplate Rating: 1311 MWe

Owner: HOUSTON LIGHTING \& POWER CO. MDC Net MWe: $1251 \mathrm{MWe}$

Type: WESTINGHOUSE PWR

Cumul. Avail. Factor: 68.4

Construction Permit: 12/22/75

Cumul. Cap. Factor (MDC Net): 65.5

Operating License: $3 / 28 / 89$

Cumul. Forced Outage Rate: $\mathbf{2 2 . 3}$

Commercial Oper. Date: 6/19/89

3-Year Avg. Cap. Factor (MDC Net): 80.1

License Expiration: 2028

OPERATING HISTORY (To December 1996)

Date

$1980-1985$

May 1989

Nov 1989 - Jan 1990

May 1990

Jul 1990

Sep - Dec 1990

Sep - Dec 1991

Jan 1992

Feb 1993 - May 1994

Jun 1994

\section{Comment}

The NRC proposed a $\$ 100,000$ fine against the utility for alleged inadequacies in QA and gave the utility 90 days to show cause why the construction permit should not be terminated. All safety-related construction was halted following an NRC report on substantial QA deficiencies attributed to the $\mathrm{A} / \mathrm{E}$. The original $\mathrm{A} / \mathrm{E}$ and constructor, Brown \& Root, was replaced by Bechtel Power and Ebasco Services in 1981. The plant owners agreed to fund a $\$ 250,000$ study on conversion of the plant to coal generation. Units 1 and 2 were about $50 \%$ and $25 \%$ completed at the time. The utility received an out-of-court settlement of $\$ 750$ million for mismanagement from Brown \& Root in 1985. Plant cost was estimated to be $\$ 5.495$ billion at the time.

The unit was shut down for 15 days to investigate an abnormal noise in a bearing between the LP turbine and the main generator.

The unit was shut down for inspection of in-core instrumentation and main turbine. During a test, a DG was damaged, and the outage was extended into January 1990. Total outage time was 75 days.

The unit received four top Category 1 ratings, including the areas of operations and maintenance in an NRC SALP review. The unit was shut down for a 15-day outage to repair a pipe crack near the SG C drain valve.

The unit was shut down for 191 hours to repair a main turbine bearing.

The first refueling and maintenance outage lasted 73 days. Major work included LP turbine rotor replacement SG inspection and sludge lancing, LLRT, and snubber testing.

The second refueling and maintenance outage lasted 74 days. Major work included modifications to the turbine/generator, SG inspection, MOV testing, replacement of two RCP seals, 5-year DG inspection, and LLRT and ILRT.

The unit was shut down for 6 days to repair a SG handhole gasket leak.

The unit was shut down due to multiple problems with the turbine-driven AFW pump. The site was subject to broad-based NRC evaluations due to management and other deficiencies. The third refueling was performed during this outage.

The unit was shut down for 4 days following a main generator/reactor trip due to the failure of a pilot wire relay in the main transformer protection system. 


\section{SOUTH TEXAS 2 (Cont'd)}

Oct - Nov 1995

Jan 1996
The fourth refueling and maintenance outage lasted 27 days.

The unit was shut down for 15 days for main generator inspection and repairs. 


\section{ST LUCIE}

PRODUCTION COST and CAPITAL ADDITIONS

(1996 Dollars)

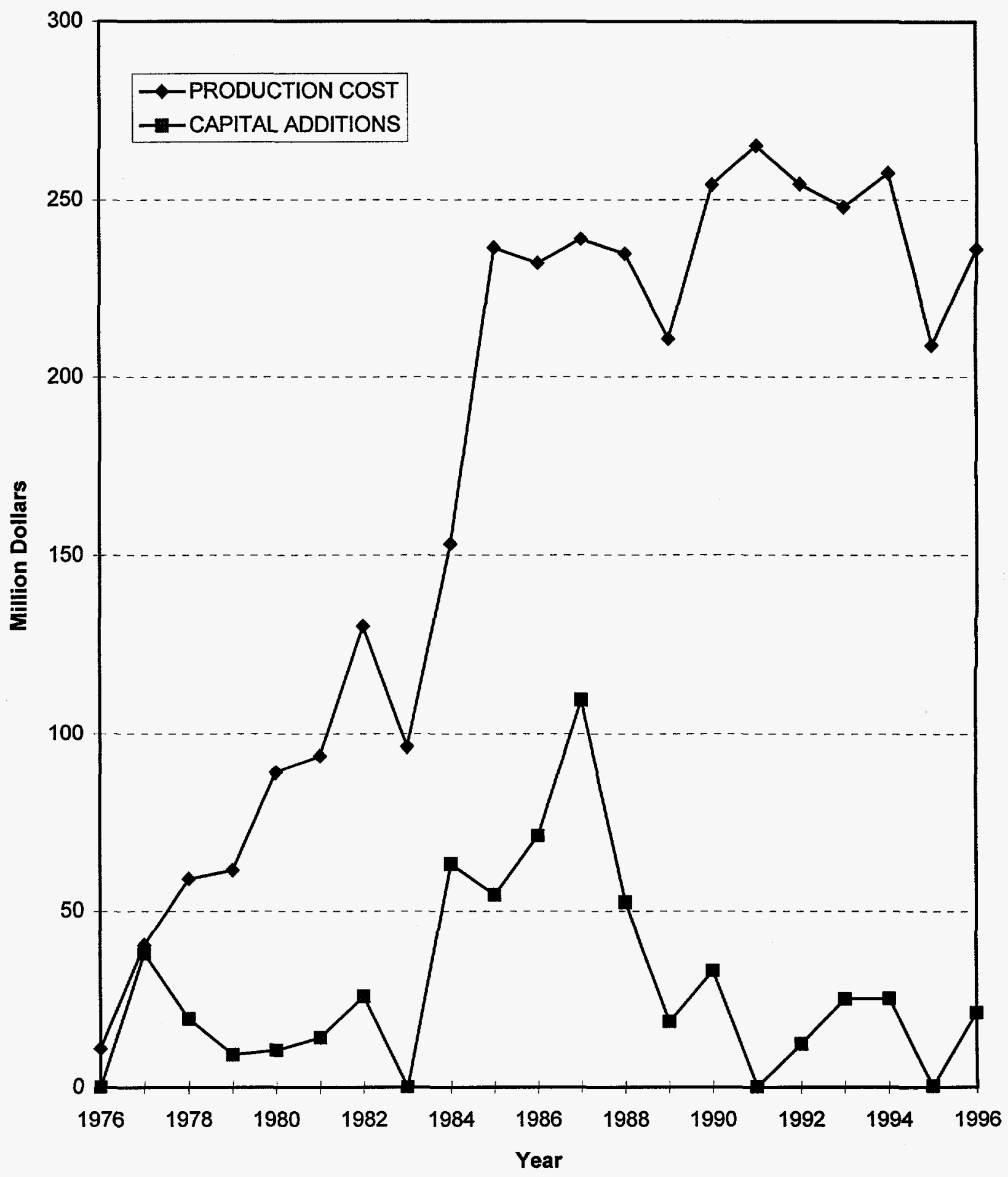




\section{NUCLEAR POWER PLANT OPERATING EXPERIENCE SUMMARY}

Unit data summary through December 1996

\section{Unit: ST LUCIE 1}

Location: ST LUCIE COUNTY, FLORIDA

Owner: FLORIDA POWER \& LIGHT CO.

Type: COMBUSTION ENGINEERING PWR

Construction Permit: 7/1/70

Operating License: $3 / 1 / 76$

Commercial Oper. Date: 12/21/76
Nameplate Rating: 850 MWe

MDC Net MWe: 839 MWe

Cumul. Avail. Factor: $\mathbf{7 7 . 0}$

Cumul. Cap. Factor (MDC Net): 74.1

Cumul. Forced Outage Rate: 5.1

3-Year Avg. Cap. Factor (MDC Net): 76.6

License Expiration: 2016

OPERATING HISTORY (To December 1996)

Date

Jul 1976

Apr 1977

Sep - Oct 1977

Mar - Jun 1978

Oct - Nov 1978

Apr - Jun 1979

Sep 1979

Mar - May 1980

Sep - Dec 1981

May 1982

Dec 30, 1982

\section{Comment}

The unit was shut down during power ascension testing to investigate power distribution anomalies; degradation of burnable poison pin cladding was found.

An 8-day shutdown was forced by a hydrogen fire in the main generator. A 13-day outage was forced by a loss of containment air. SG tube thinning was also found.

The unit was shut down for 16 days for maintenance.

The first refueling and maintenance outage was performed. The SG inspection revealed tube denting found in $22 \%$ to $36 \%$ of the tubes examined.

The unit was shut down for $S G$ inspection. Some personnel received minor contamination from a 2000-gallon spill of contaminated water in the containment.

The second refueling and maintenance outage was performed.

While the unit was shut down for a hurricane, an adjacent construction tower crane was blown down, and a cable fell over lines to the startup transformer.

The third refueling and maintenance outage was performed. Major work included TMI modifications.

The fourth refueling and maintenance outage was performed. Major work included SG inspection - 30 tubes in one SG and 46 in the other were plugged. In addition, 27 tubes in one SG were mistakenly plugged due to an out-of-position template.

The unit was shut down for SG inspection and RCP seal work. Total outage time was 19 days.

The unit scrammed during RPS logic testing. Crystal River 3 then tripped from an off-site power disturbance, and the resulting brownout affected about 400,000 people for about $1 / 2$ hour. 
Feb 1983 - May 1984

Aug - Sep 1984

Oct - Dec 1985

Jun 1986

Aug 1986

Sep 1986

Dec 1986

Feb - Apr 1987

Oct 1987

Jul 1988

Jun 1989

Jan - Apr 1990

May 1990

Jul - Aug 1990

Aug 1990

Jan 1991

Oct - Dec 1991

Jan 1992
The fifth refueling and maintenance outage was performed. Major work included replacement of mechanical seals on HP and LP SI pumps and replacement of the charging pump accumulator. The RV was defueled to search for thermal shield bolt pieces. Core internals were removed, and the thermal shield was eliminated from the vessel because it was no longer needed. Repairs to core support barrel prolonged outage into 1984. The unit went critical in late April, but SG tube leaks forced an additional 3 weeks of outage time. Total time for the 14-month prolonged shutdown was 445 days.

A large mass of jellyfish clogged seawater intakes and forced intermittent shutdowns, costing \$11 million in replacement power.

The sixth refueling and maintenance outage lasted 66 days. Major work included core support barrel inspection and nozzle dam installation.

The unit was shut down for SG tube repair. Twenty-three tubes were plugged, and a failed HPSI valve was repaired.

The NRC announced a reduction in inspection efforts at the site because of an overall record of good performance.

The NRC assessed a $\$ 25,000$ fine for alleged violations of security requirements. The fine was reduced by $50 \%$ because of prompt corrective action by the utility.

The unit was ranked eighth among U.S. lowest cost nuclear electricity producers for the year and thirteenth for the 1984-1986 period.

The seventh refueling and maintenance outage lasted 81 days. Major work included 10-year ISI, DG air start piping work, SG tube inspection, and secondary system chemical cleaning.

While the unit was shut down to repair an RCS leak, adjustments to criticality calculations extended the outage to a total of 11 days

The eighth refueling and maintenance outage lasted 52 days.

The unit was shut down in response to NRC IE Bulletin 89-01 to repair or replace W SG tube plugs that were susceptible to stress corrosion cracking. Startup was delayed for minor repairs. Total outage time was 19 days.

The ninth refueling and maintenance outage lasted 92 days. The unit was shut down early for outage after a SG tube leak was detected. Major work included incore component replacement, ILRT, RV ISI, SG inspection and repair, and containment building cooler replacement. The unit remained shut down to inspect CEAs for damage from high radiation exposure.

A 5-day outage was necessary to repair PORV block valves.

A 36-day outage was needed to repair a seal leak on a RCP.

The NRC named the plant one of eight good performers.

The NRC SALP report rated the plant Category 1 in 6 of the 7 functional areas.

The tenth refueling and maintenance outage lasted 64 days. Major work included SG ECT and sludge lancing, RCP seal replacement, and HP turbine overhaul.

The plant received all Category 1 ratings on its NRC SALP report, and the evaluations were lengthened to a 24-month cycle. 


\section{ST LUCIE 1 (Cont'd)}

Sep 1992

Mar - Jun 1993

Sep 1993

Feb 1994

Mar 1994

Jun 1994

Oct - Nov 1994

Feb 1995

Aug - Oct 1995

Mar 1996

Apr - Jul 1996

Aug 1996
The unit had two outages totaling 13 days to repair a safety valve and a blown capacitor in the main turbine digital control system, which had caused a main turbine trip/reactor trip.

The eleventh refueling and maintenance outage lasted 81 days.

The unit was manually shut down after two circulating pumps were lost. The ensuing outage lasted 4 days.

The plant received all Category 1 ratings on its NRC SALP report.

A main generator trip occurred due to a personnel error causing a loss of generator field. The outage lasted 5 days to repair a shut down cooling valve.

The unit was shut down for 5 days after bad weather caused a main generator trip.

The twelfth refueling and maintenance outage lasted 35 days. The outage was entered 4 days early when a main generator trip/reactor scram occurred during severe weather.

The unit was shut down for 9 days to repair a quench tank leak.

The unit was shut down to replace an RCP seal. Additional downtime was needed due to PORV problems, a containment spray actuation, EDG repairs, and safety system valve repairs. The outage ended after 71 days.

The NRC proposed and the licensee paid a $\$ 50,000$ fine for an operator improperly leaving the controls.

The thirteenth refueling and maintenance outage lasted 88 days.

The unit was shut down for 4 days to repair the main transformer. 


\section{NUCLEAR POWER PLANT OPERATING EXPERIENCE SUMMARY}

Unit data summary through December 1996

Unit: ST LUCIE 2

Nameplate Rating: 850 MWe

Location: ST LUCIE COUNTY, FLORIDA

MDC Net MWe: 839 MWe

Owner: FLORIDA POWER \& LIGHT CO.

Cumul. Avail. Factor: 83.3

Type: COMBUSTION ENGINEERING PWR

Cumul. Cap. Factor (MDC Net): 80.9

Construction Permit: 5/2/77

Cumul. Forced Outage Rate: 6.3

Operating License: $6 / 10 / 83$

3-Year Avg. Cap. Factor (MDC Net): 81.0

Commercial Oper. Date: $\mathbf{8 / 8 / 8 3}$

License Expiration: 2023

OPERATING HISTORY (To December 1996)

Date

Jul 1982

Jun 1983

Sep 1983

Aug - Sep 1984

Oct 1984

Mar 1985

Aug 1985

Sep 1985

Apr 1986

Oct - Nov 1987

Jan - Apr 1989

Sep 1989

Jan 1990

\section{Comment}

The unit was the first to pass an NRC equipment qualification audit.

The first power was generated on June 2. The unit was completed in less than 6 years, about 3.5 years less than many current plants. The unit was shut down for 20 days to repair RCP seal injection and clean condensate pump strainers.

A unit was shut down for 13 days to repair a main FW pump and correct FW chemistry.

A large mass of jellyfish clogged seawater intakes and forced intermittent shutdowns, costing $\$ 11$ million in replacement power.

The first refueling and maintenance outage lasted 38 days. The unit set a company record for shortest refueling outage. During the first 365 days of operation, the unit achieved a $92.5 \%$ capacity factor, exceeding the expected $89 \%$.

The NRC issued an operating license amendment authorizing an increase in thermal power from $2560 \mathrm{MWt}$ to $2700 \mathrm{MWt}$. The unit was shut down for 10 days to inspect leak indications in SG tubes.

The unit was shut down after a trip from ESF actuation due to an incorrectly installed fuse. RCP seal problems forced the outage time to 15 days. On startup, a RCP bearing failure and oil fire caused another 11 days of outage time.

The unit was shut down for 11 days to repair the same RCP seal and damaged RCP motor.

The second refueling and maintenance outage lasted 60 days. Major work included LP turbine inspection and maintenance, ILRT, and SG inspection.

The third refueling and maintenance outage lasted 52 days. Major work included SG inspection, repair, and cleaning; upgrade of generator exciter; HP turbine shell replacement; ILRT; and extraction piping inspection.

The fourth refueling and maintenance outage lasted 87 days. Major work included replacement of selected pressurizer instrument nozzles because of possible IGSC cracking.

A 4-day outage followed a unit trip when 5 control rods dropped.

The unit was shut down for 10 days to repair minor leaks on 2 valves. 
Aug 1990

Sep - Dec 1990

Jul 1991

Apr - Jun 1992

Nov - Dec 1992

Jan - Feb 1993

Mar 1993

May 1993

Feb - Apr 1994

Oct 1995 - Jan 1996

Jun 1996
Two outages, totaling 18 days, were needed to repair the permanent motor generator exciter and to correct vibration in a bearing in the main turbine.

The fifth refueling and maintenance outage lasted 64 days. Major work included SG, ECT, and sludge lancing; LP turbine, turbine valve, and secondary pipe inspections; and ATWS module replacement.

The NRC proposed a $\$ 37,500$ fine against the unit for allegedly operating with a disabled containment spray system. The fine was paid the following month.

The sixth refueling and maintenance outage lasted 66 days. The unit broke the record for continuous operation with a run of 492 days.

The unit was shut down to repair a pressurizer safety valve. The outage was extended to repair reactor coolant vent valves. The outage lasted 13 days.

High vibration on one of the RCPs required 47 days to repair.

The unit was shut down for 30 days to repair pressurizer instrument nozzle leaks.

The unit was shut down for 5 days after the reactor tripped when several control rods dropped.

The seventh refueling and maintenance outage lasted 68 days.

The unit tripped during restart testing due to an RPS wiring error. The unit was down for 5 days and also addressed problems with the turbine steam bypass system.

The eighth refueling and maintenance outage lasted 88 days.

The unit was shut down twice for repairs. The repairs were to the generator hydrogen cooling system and an auxiliary feedwater pump. Downtime totaled 1 week. 


\section{SUMMER}

PRODUCTION COST and CAPITAL ADDITIONS

(1996 Dollars)

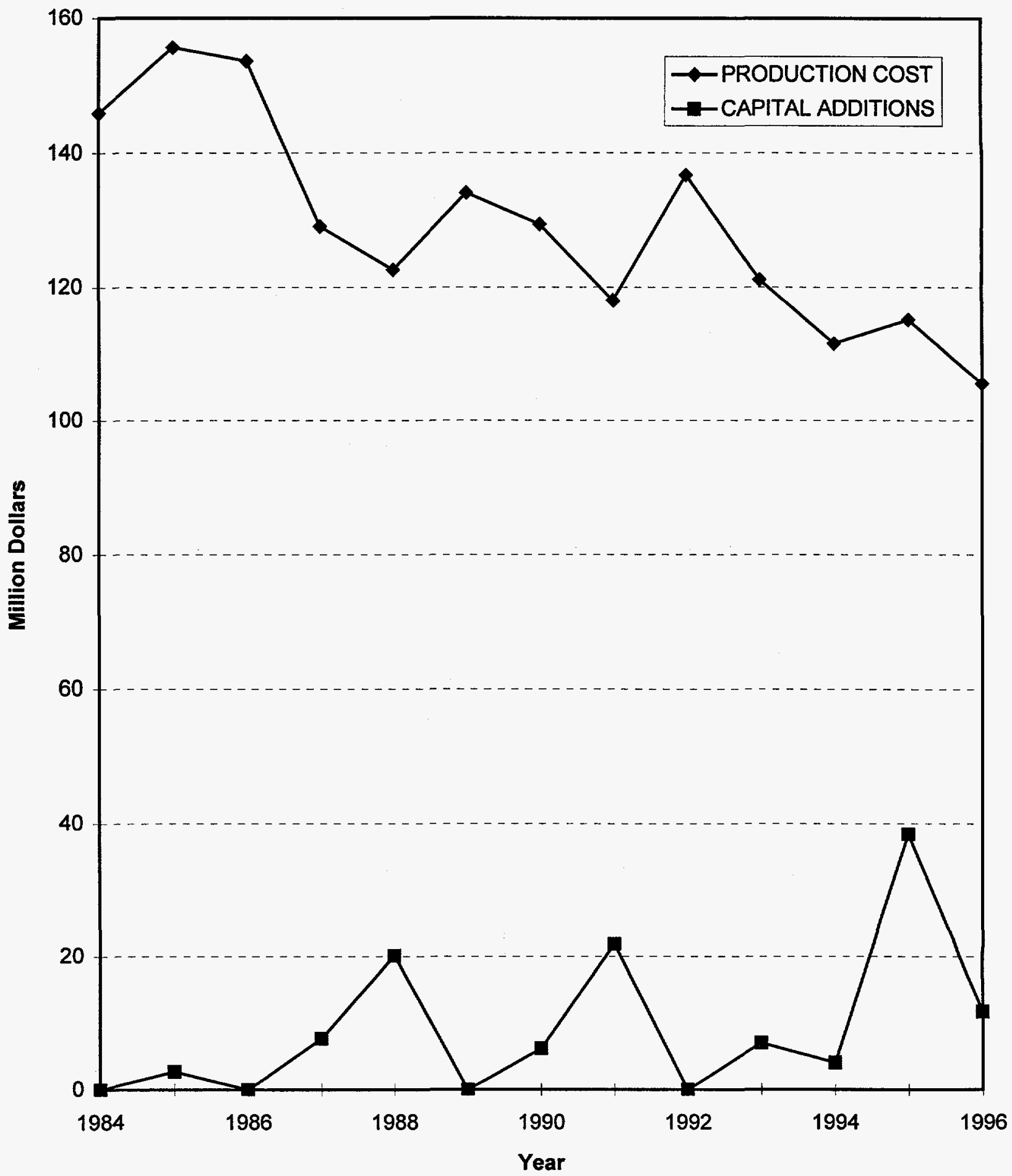




\section{NUCLEAR POWER PLANT OPERATING EXPERIENCE SUMMARY}

Unit data summary through December 1996

Unit: SUMMER

Location: FAIRFIELD COUNTY, SOUTH CAROLINA

Nameplate Rating: $900 \mathrm{MWe}$

Owner: SOUTH CAROLINA ELECTRIC \& GAS CO.

MDC Net MWe: $\mathbf{8 8 5}$ MWe

Type: WESTINGHOUSE PWR

Cumul. Avail. Factor: 80.4

Construction Permit: $3 / 21 / 73$

Cumul. Cap. Factor (MDC Net): 78.1

Operating License: 11/12/82

Cumul. Forced Outage Rate: $\mathbf{4 . 2}$

Commercial Oper. Date: 1/1/84

3-Year Avg. Cap. Factor (MDC Net): 80.9

License Expiration: 2022

OPERATING HISTORY (To December 1996)

Date

Nov 1982

Mar 1983

Nov - Dec 1983

Mar - Apr 1984

Jul 1984

Sep - Dec 1984

Apr - May 1985

Oct - Dec 1985

Feb 1986

Oct 1986

Mar - Jun 1987

Sep 1987

Sep - Dec 1988

\section{Comment}

The amended the plant operating license to allow operation up to $50 \%$ power and to start power ascension testing.

After experiencing SG tube vibration problems that prevented power operation over $50 \%$, the unit was shut down to modify all SGs. The outage duration was 67 days.

The unit was shut down for $\mathbf{2 1}$ days to perform additional testing prior to power ascension.

The unit was shut down for a planned maintenance outage for RCP seal repair, snubber inspections, and leak rate testing. Total outage time was 31 days.

The unit was shut down for 13 days for SG tube repairs.

The first refueling and maintenance outage lasted 83 days.

The unit was shut down for 13 days for SG tube repairs.

The second refueling and maintenance outage lasted 73 days. Major work included plugging 166 SG tubes.

The utility paid a $\$ 50,000$ fine to NRC for two alleged violations. One involved disabling part of the ECCS, and the other was for nonconservative set points existing since 1982.

The utility paid two $\$ 50,000$ fines assessed by the NRC. One involved alleged inoperability of one of two component cooling and service water systems; the other involved alleged inoperability of charging pumps in the event of a LOSP followed by a SI signal.

The third refueling and maintenance outage lasted 95 days. Major work included ISI, RCP seal and motor inspections, and DG surveillance. The SG underwent inspection, and 260 tubes were plugged. The SG U-bends were heat treated to prevent IGSC cracking.

The repair of main generator stator cooling leaks and main condenser boot seal forced an 11-day outage.

The fourth refueling and maintenance outage lasted 104 days. SG inspection revealed indications of primary-side SCC in about 588 tubes. 
Mar 1989

Apr 1989

May - Jun 1989

Aug 1989

Sep - Oct 1989

Mar - May 1990

Apr 1991

Jul 1991

Sep - Nov 1991

May 1992

Jan 1993

Mar - May 1993

Mar 1994

Sep - Nov 1994

May 1995

Apr - May 1996
The unit experienced problems with secondary water chemistry and resin intrusion into the secondary system since January. The unit was shut down for 20 days to clean SGs and the secondary system.

The licensee was assessed a $\$ 62,500$ fine by the NRC for alleged violations involving several failures to control access to protected areas of the plant.

The unit was shut down for 14 days to replace a RCS pressurizer safety valve that malfunctioned.

The NRC proposed a $\$ 25,000$ fine for alleged inadequate management controls that allowed an unqualified senior reactor operator to assume duties of a control room operator.

The unit was shut down on two occasions for a total of 16 days for condenser tube leaks and malfunctioning MSIVs.

The fifth refueling and maintenance outage lasted 61 days. Major work included SG inspection and tube plugging, RTD manifold removal, LP turbine and RCP seal inspection, ISI, and secondary-side erosion/corrosion inspections.

The unit was shut down for 8 days for work on the MSRs and main generator voltage regulator.

The utility announced a decision to replace trouble-plagued SGs with new units.

The sixth refueling and maintenance outage lasted 61 days. Major work included turbine inspection, SG tube inspection and plugging, DG inspection and more secondary-side erosion/corrosion inspections. Startup was delayed by FW isolation valve testing.

A 10-day outage was needed to repair a SG manway steam leak.

The unit was shut down for 4 days after a plant trip caused by a main transformer breaker opening.

The seventh refueling and maintenance outage lasted 58 days.

A hydrogen leak in the main generator required 17 days to repair.

The eighth refueling and maintenance outage lasted 97 days.

The unit was shut down for 12 days to replace a RCP seal.

The ninth refueling and maintenance outage lasted $\mathbf{4 0}$ days. 
This Page Intentionally Left Blank 


\section{SURRY}

PRODUCTION COST and CAPITAL ADDITIONS (1996 Dollars)

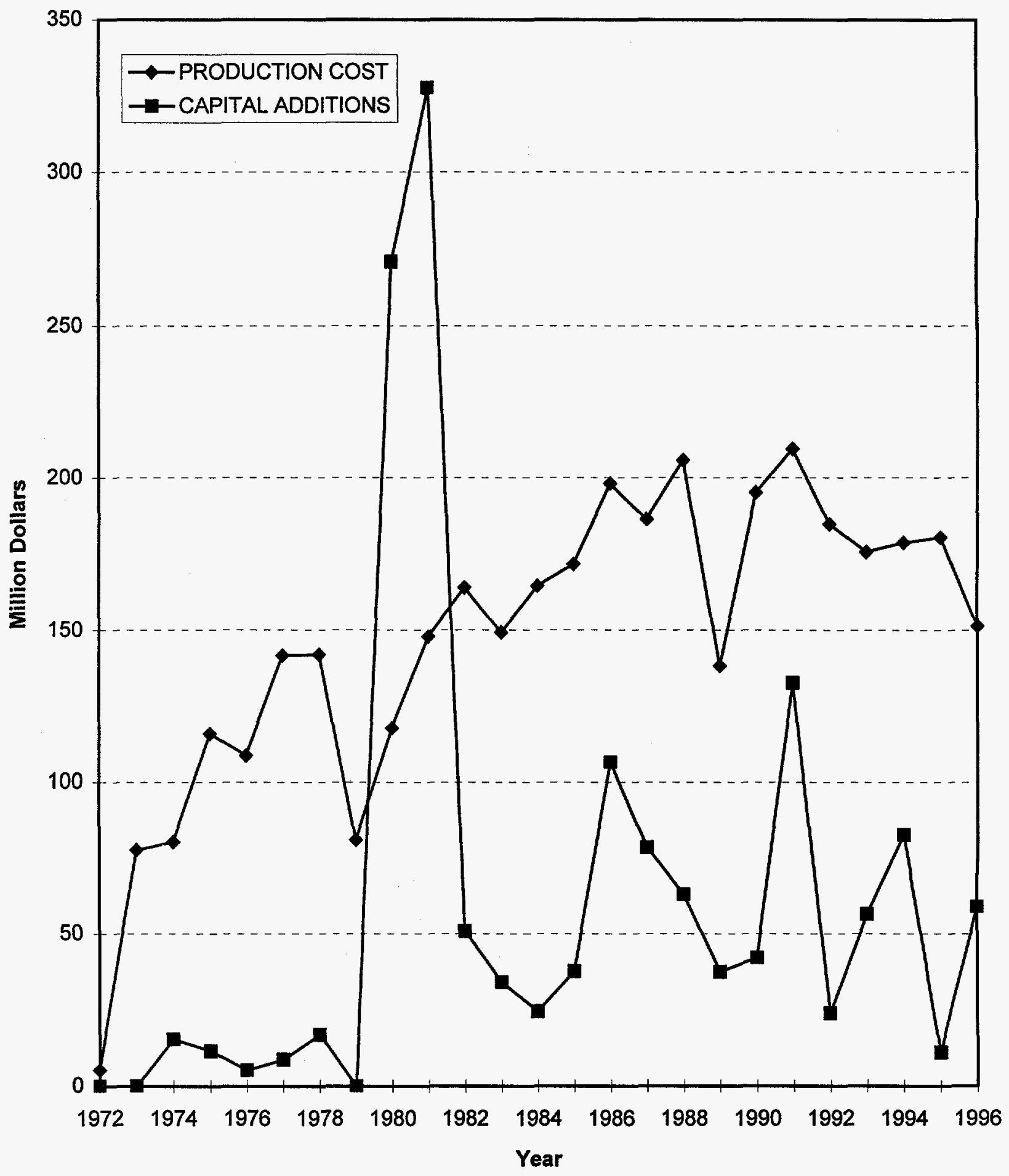




\title{
NUCLEAR POWER PLANT OPERATING EXPERIENCE SUMMARY
}

\author{
Unit data summary through December 1996
}

Unit: SURRY 1

Location: SURRY COUNTY, VIRGINIA

Owner: VIRGINIA ELECTRIC POWER CO.

Type: WESTINGHOUSE PWR

Construction Permit: 6/25/68

Operating License: 5/25/72

Commercial Oper. Date: 12/22/72
Nameplate Rating: 848 MWe

MDC Net MWe: 781 MWe

Cumul. Avail. Factor: $\mathbf{7 0 . 4}$

Cumul. Cap. Factor (MDC Net): 64.5

Cumul. Forced Outage Rate: 15.2

3-Year Avg. Cap. Factor (MDC Net): 85.5

License Expiration: 2012

OPERATING HISTORY (To December 1996)

Date

Jul 1972

Jul - Aug 1972

Oct 1972

Nov 1972

Dec 1972

Jan 1973

Mar 1973

May 1973

May - Jun 1973

Aug 1973

Sep - Oct 1973

Nov 1973 - Mar 1974

Oct 1974 - Feb 1975

Spring 1975

Sep - Dec 1975

\section{Comment}

While investigating a valve malfunction, two men died from burns sustained when a steam dump valve suddenly opened and the exhaust pipe backed out of the vent sleeve in the roof.

The plant shut down for about 1 month for maintenance. The AEC imposed a $75 \%$ power limit because of fuel densification problem.

The unit was shut down for 2 months following failure of a FW check valve gasket that resulted in a SG blowdown.

The unit experienced a small-break LOCA when a hot leg RTD blew out.

Commercial operation began with power still limited to $75 \%$.

A problem with an oil pump caused a 3-week shutdown .

The power limit was raised to $92 \%$.

The AEC assessed a $\$ 38,000$ fine for alleged failures to comply with regulations in station operation and management.

A 3-week shutdown was required to repair loop bypass valves and replace a RCP motor.

The AEC granted approval to operate at $100 \%$ power.

One 2-week outage and one 3-week outage were required to rework main steam trip valves.

A main coolant pump shaft failed during a plant cooldown.

A refueling and maintenance outage was performed. Major work included inspection of SG restraints. SG tubes were plugged, and the plant switched to all-volatile water treatment for secondary water chemistry.

The utility paid a $\$ 10,000$ fine for alleged security violations.

A refueling and maintenance outage was performed. Major work included SG tube inspection and repair. One SG tube inadvertently pulled apart, and a CRD shaft was damaged during the shutdown. Another 6-day outage was required for SG tube plugging soon after startup. 
Mar - Sep 1976

Oct 1976 - Jan 1977

Apr - May 1977

Nov - Dec 1977

Apr - Jul 1978

Dec 1978 - Jan 1979

Mar - Oct 1979

Feb - May 1980

Aug 1980

Sep 1980 - Jul 1981

Feb 1982

May 1982

Oct 1982

Feb - Jun 1983

Mar 1983

May 1983

Jun 1983

Sep 1983

Oct 1983

Feb - May 1984

Sep 1984
The unit was shut down on 6 separate occasions totaling 39 days, due to leaking SG tubes and secondary water chemistry problems.

A refueling and maintenance outage was performed. Major work included replacement of a cracked recirculation spray system piping. Numerous cracked SG support studs were found. Condenser tube leakage was reported to be a major problem during 1976.

A 4-week outage was needed for SG inspection. The utility announced that SG tube bundles would be replaced on both units.

A 26-day outage was needed to plug leaky SG tubes. The tube plugging limit increased to $25 \%$.

A refueling and maintenance outage was performed. Major work included turbine and SG repairs.

A 22-day outage was performed for plugging five leaking SG tubes.

The unit was shut down in response to an NRC order because of an error in seismic analysis of piping systems. SG inspection resulted in plugging $24.6 \%$ of tubes.

The unit was shut down for piping restraint modifications and turbine inspection.

A 10-day shutdown was performed for SG tube leakage.

The unit underwent an 11-month shutdown to replace all three SGs. Condensers were also retubed with titanium tubes.

A 13-day outage was needed for secondary containment maintenance and repair of EHC control system problems that arose during shutdown.

The NRC assessed a $\$ 50,000$ fine for alleged procedural violation in which an LCO was exceeded.

A 2-week outage was needed for scheduled maintenance.

A refueling and maintenance outage lasted 130 days: fuel cladding failures found during the outage required an extensive fuel examination program.

The NRC assessed a $\$ 20,000$ fine for alleged operation with an incorrect valve lineup in containment spray system.

The NRC proposed a $\$ 40,000$ fine for alleged violations of personnel radiation protection requirements.

A turbine bearing was wiped during unit startup after the outage, prolonging shut down an additional 17 days for repair.

The unit was shut down for 14 days to repair inoperable snubbers on MSL and SGs.

A worker was fatally injured by steam and hot water spraying from a ruptured expansion joint on the secondary side HP drain pump.

The unit was shut down on three different occasions for inspection, repair, and replacement of snubbers. The total time for the three outages was 41 days.

The NRC fined the utility $\$ 40,000$ for alleged noncompliance with requirements for snubber maintenance. 
Sep - Oct 1984

Dec 1984

Mar 1985

Apr - May 1985

Aug 1985

Jan - Feb 1986

May - Jul 1986

Jul 1986

Dec 1986 - Feb 1987

May 1987

Jun 1987

Apr - Jul 1988

May 1988

Jul 1988

Sep 1988 - Jul 1989

Oct 1988

Dec 1988

Jun 1989

May 1990
A refueling and maintenance outage was performed. B\&W began replacing control rod guide tubes and support pins.

A DG crankcase explosion and turbocharger fire were caused by a fuel leak into lube oil.

The NRC assessed a $\$ 40,000$ fine for alleged failure to ensure that the reactor vessel vent system was operable during a startup, and for violations at North Anna 1 and 2.

A 14-day outage occurred for repairs to a MOV and snubber inspection and replacement.

A 17-day outage occurred after reactor trip from an inadvertent low RCS flow signal when an operator struck a sensing line. The unit remained shut down to repair a SI valve leak.

A 15-day outage occurred for repair of bus duct and snubber inspection and replacement.

A refueling and maintenance outage lasted 69 days. Major work included SG inspection and sludge lancing, repairs to heat exchangers, and repairs to main generator and turbine.

The utility was issued a 20-year license by NRC to store spent fuel in an independent spent fuel storage facility on-site using dry metal casks. The plant became the first in the United States to begin ơry spent fuel storage.

The unit was shut down for snubber maintenance and piping inspection following an FW pipe break at Surry 2 . The utility will develop testing and inspection program for nonnuclear piping at both Surry units. Total outage time was $\mathbf{7 5}$ days

A 14-day outage was caused by hot leg loop stop valve failure.

A 14-day outage was caused by an inoperable recirculation spray pump.

A refueling and maintenance outage lasted 100 days. Major work included RCP seal and motor work, SG inspection and cleaning, FW heater tube bundle replacement, and secondary piping inspection.

About 30,000 gallons of water leaked from the refueling cavity through the cavity floor seal because of loss of air pressure and failure of the nitrogen backup system.

The NRC proposed a $\$ 50,000$ fine for alleged violation involving the failure to properly test boric acid piping heat trace circuits.

The unit was shut down because of DG operability concerns. Total outage time was 296 days.

The inspection of secondary piping at both Surry units revealed substantial thinning of piping that had been replaced after the 1986 pipe rupture event. The NRC placed the unit on its list of problem plants.

The NRC assessed a $\$ 50,000$ fine for an alleged violation involving failure to maintain cleanliness of critical plant areas.

The utility paid a $\$ 500,000$ fine for about 20 alleged violations involving a broad range of plant system failures and procedural inadequacies. The NRC included the unit on its list of problem plants to assure that licensee followed through with corrective actions.

An 11-day outage occurred because of a turbine and reactor trip from a generator differential lockout caused by an inadvertent actuation of transformer deluge system. 
Jun 1990

Oct - Dec 1990

Feb 1991

Oct 1991

Jan 1992

Feb - May 1992

Jul 1992

Aug 1993

Jan - Mar 1994

Nov - Dec 1994

Jan 1995

Sep - Oct 1995
Both Surry units were removed from the NRC list of problem plants. The utility earned improved ratings in 4 of 7 areas in SALP by NRC.

A refueling and maintenance outage lasted 77 days. Major work included SG girth weld inspections and moisture separator upgrades, control room design review change package, reactor cavity seal replacement, and RCS level indication design change.

The NRC proposed a $\$ 50,000$ fine for alleged violations involving inoperability of two recirculation spray $\mathrm{HXs}$ due to inadequate $\mathrm{SW}$ flow.

The NRC proposed a $\$ 125,000$ fine for two alleged violations. The first was the inoperability of the common diesel generator due to improper maintenance and postmaintenance testing. The second was the operation of the charging system in an electrical configuration, which would require manual actions in some accident scenarios.

The unit was down for 7 days following a manual trip due to dropped control rods.

A refueling and maintenance outage lasted 63 days. Major work included SG ECT, RCP motor and seal work, and HP turbine inspection, and ILRT.

The NRC proposed a $\$ 50,000$ fine for alleged violations involving operating the unit with improperly configured charging/HHSI pumps due to an inadequate procedure change.

A 10-day outage was needed to repair a SG channel head drain line.

A refueling and maintenance outage lasted 63 days.

A 27-day maintenance outage was needed principally for SG chemical cleaning.

The unit was shut down for 1 week after a main feedwater pump tripped when a lube oil coupling failed.

A refueling and maintenance outage lasted 43 days. 


\section{NUCLEAR POWER PLANT OPERATING EXPERIENCE SUMMARY}

Unit data summary through December 1996

Unit: SURRY 2

Location: SURRY COUNTY, VIRGINIA

Owner: VIRGINIA ELECTRIC POWER CO.

Type: WESTINGHOUSE PWR

Construction Permit: 6/25/68

Operating License: $1 / 29 / 73$

Commercial Oper. Date: 5/1/73
Nameplate Rating: $848 \mathrm{MWe}$

MDC Net MWe: 781 MWe

Cumul. Avail. Factor: 68.0

Cumul. Cap. Factor (MDC Net): 63.7

Cumul. Forced Outage Rate: 12.5

3-Year Avg. Cap. Factor (MDC Net): 86.0

License Expiration: 2013

OPERATING HISTORY (To December 1996)

\section{Date}

May 1973

Oct - Nov 1973

Dec 1973

Apr - Jun 1974

Sep 1974 - Jan 1975

Apr - Jun 1975

Jan - Sep 1976

Sep - Dec 1976

Feb - Sep 1977

Sep - Oct 1977

Mar - Apr 1978

Jul 1978

Feb 1979 - Aug 1980

Apr 1981

\section{Comment}

Commercial operation began with power limited to $92 \%$ because of a fuel densification issue. SG modifications required a 3-week shutdown.

A 3-week shutdown was required for repair to main steam trip valves.

An operator was injured when an airlock emergency hatch failed.

A maintenance outage was needed for repair of turbine blades and RCPs and plugging of SG tubes.

An outage for turbine repair was extended to resolve the seismic restraint problem with SGs.

A refueling and maintenance outage lasted 50 days. Major work included SG tube plugging.

The unit was shut down on several occasions, totaling over 25 days, due to leaking SG tubes and secondary water chemistry problems. SG tube denting and support plate distortion were found during a mid-April refueling outage. Condenser tube leakage was a major problem during year.

Extensive SG tube leaks forced a major shutdown. Numerous cracked SG support studs were found. Piping in the recirculation spray system was also replaced.

The SG tube leaks forced almost 3 months total outage time over the period.

A refueling outage and more SG tube plugging were needed. A spray valve failure and leaky SG tubes forced a 9-day outage in November.

A 3-week shutdown was required to plug more leaky SG tubes.

A shut down for about 3 weeks was required for ECCS pump modifications.

The unit underwent an 18-month shutdown to replace all three SGs. Condensers were retubed with titanium tubes, and seismic analysis of plant piping systems was performed.

The unit was shut down for 10 days for snubber inspections and TMI modifications. 
Nov 1981 - Jan 1982

May - Jun 1982

Dec 1982

Jun - Sep 1983

Mar - Apr 1984

Oct - Nov 1984

Mar 1985

Oct 1985

Feb 1986

Jun - Jul 1986

Oct - Dec 1986

Dec 1986

Dec 1987

May - Jun 1988

Jul 1988

Sep 1988 - Sep 1989

Jun 1989

Oct - Nov 1989
A refueling outage was entered early because of FW heater tube rupture. The outage was prolonged by main condenser leaks and FW heater level problems.

A scheduled outage for maintenance lasted 13 days.

A unit was shut down for a 16-day maintenance outage.

During a planned refueling outage, erosion/corrosion holes were found in several SG feed ring J-tubes.

A grounded RCP motor lead caused trip and outage. The unit remained shut down for snubber inspection and maintenance.

The unit was shut down for 26 days after a trip from the load shed signal during transfer bus testing.

A refueling and maintenance outage lasted 101 days. Major work included inspection of the SG girth welds in all three SGs.

The unit was shut down for 13 days for a planned snubber inspection outage.

The unit was shut down for 9 days for another snubber inspection outage.

The SW system leakage in containment caused two outages for diagnosis and repair - one for 15 days and one for 4 days. SG tube leaks were also plugged.

A refueling and maintenance outage lasted 60 days. Major work included SG inspection and sludge lancing, Appendix R modifications, SW heat exchanger inspection and repair, and recirculation spray HX maintenance.

Four plant workers were killed, and several were injured when a FW line ruptured due to pipe thinning caused by erosion/corrosion. The unit remained shut down for piping inspection and further event analysis. The unit restarted in March 1987 after a 101-day shutdown.

The unit was shut down for a 16-day scheduled maintenance outage for snubber and secondary piping inspections.

The unit was shut down from spurious EHC signal. Debris found in containment sumps and recirculation piping in both units extended outage time to 35 days.

The utility paid a $\$ 100,000$ fine to NRC for several alleged violations at Unit 2 involving overexposure of personnel during work on in-core detectors. The base penalty was increased $100 \%$ because of alleged past poor performance.

The unit was shut down for refueling. The outage was extended because of an adverse report on a safety system functional inspection by NRC. Inspection of secondary piping at both Surry units revealed substantial thinning of piping that had been replaced after the 1986 pipe rupture event. The NRC identified the unit as a candidate for inclusion on its list of problem plants. Total outage time was 374 days

The NRC included this unit on its list of problem plants to assure that the licensee followed through with corrective actions.

The unit was shut down for 43 days because of pressurizer safety valve set point calibration problems. 


\section{SURRY 2 (Cont'd)}

Jun 1990

Oct - Nov 1990

Mar - Jun 1991

Jun - Jul 1991

Aug 1991

Sep 1991

Oct 1991

Dec 1991

Jul 1992

Mar - May 1993

Aug 1993

Nov 1993

Jun 1994

Feb - Mar 1995

May 1995

Nov 1995

Feb 1996

May - Jun 1996

Dec 1996
Both Surry units were removed from the NRC list of problem plants. The utility earned improved ratings in 4 of 7 areas in SALP by NRC.

Concerns about low service water flow through the recirculation spray HX required a 26-day outage to resolve.

A refueling and maintenance outage lasted 70 days. Major work included control room design review changes and ILRT.

The unit was shut down when it was discovered that one of the control rods had disconnected from its driveshaft. During the outage, 22 of the other 47 rods were found to have related defects. The outage lasted 23 days.

The unit was shut down for 4 days following a plant trip due to a combination of two false signals.

A 9-day outage was needed to replace a coil stack on a control rod.

A leaking expansion joint on a HP heater drain pump required 6 days to replace.

The unit was shut down for 7 days to repair a leak on a RCS valve.

The unit was shut down for 13 days to repair a leaking pressurizer safety valve.

A refueling and maintenance outage lasted 61 days.

Two outages totaling 22 days were taken. The first was to repair seat leakage through a pressurizer safety valve, and the second was to replace a SI system relay.

A SG maintenance outage lasted 14 days.

Chemical cleaning of the SG secondary sides required a 21-day outage.

A refueling and maintenance outage lasted 46 days.

Two separate manual scrams were necessary when control rods dropped into the core. The downtime was 6 days.

The unit was shut down for 15 days after one of the RCPs tripped.

The unit was shut down for 4 days to repair leaking RHR piping.

A refueling and maintenance outage lasted 36 days.

A scheduled maintenance outage to repair the CVCS letdown line lasted 10 days. 
SUSQUEHANNA

PRODUCTION COST and CAPITAL ADDITIONS (1996 Dollars)

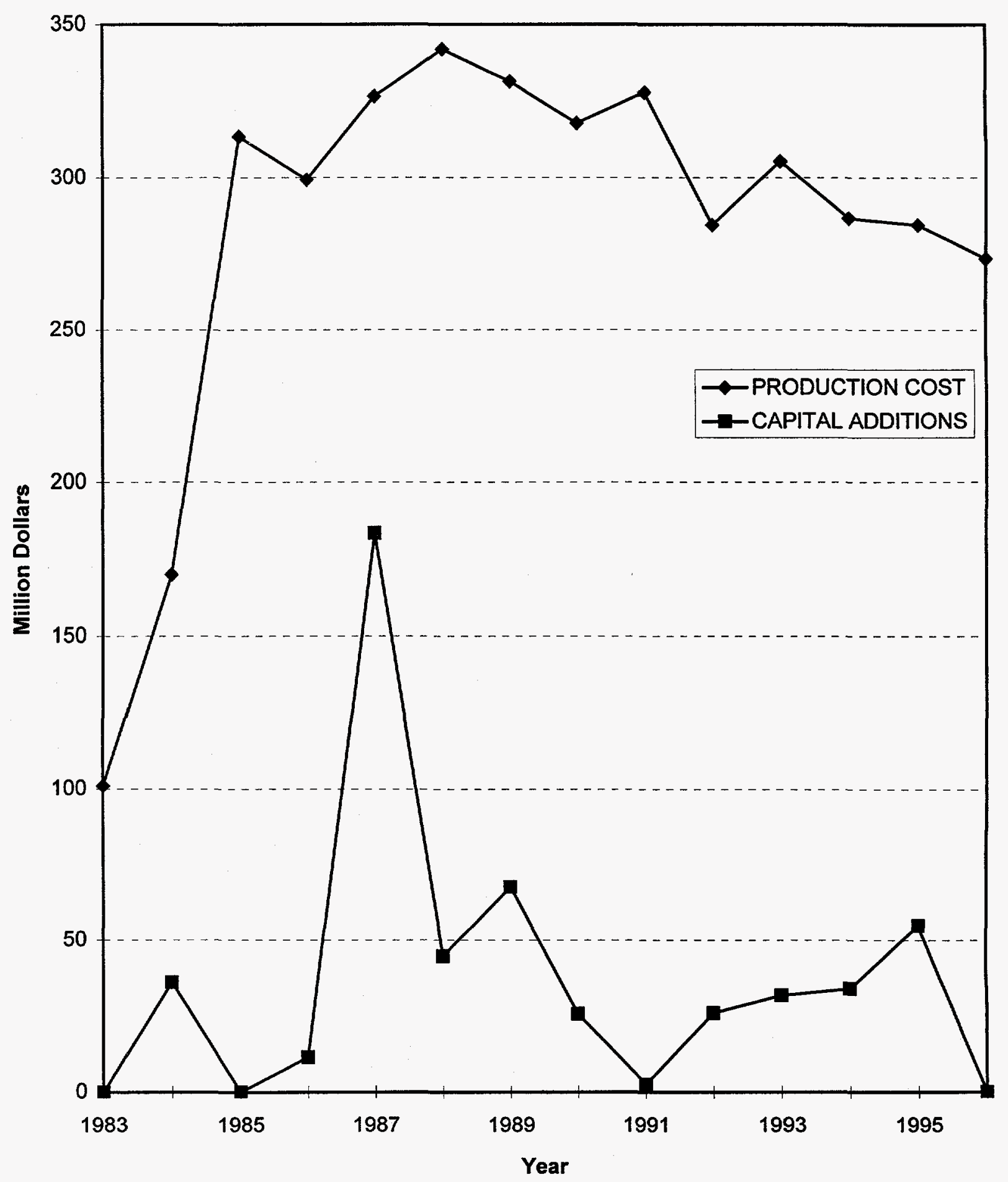




\section{NUCLEAR POWER PLANT OPERATING EXPERIENCE SUMMARY}

Unit data summary through December 1996

Unit: SUSQUEHANNA 1

Location: LUZERNE COUNTY, PENNSYLVANIA

Owner: PENNSYLVANIA POWER \& LIGHT CO.

Type: GENERAL ELECTRIC BWR

Construction Permit: 11/2/73

Operating License: 11/12/82

Commercial Oper. Date: $6 / 8 / 83$
Nameplate Rating: $1165 \mathrm{MWe}$

MDC Net MWe: 1090 MWe

Cumul. Avail. Factor: 77.6

Cumul. Cap. Factor (MDC Net): 74.0

Cumul. Forced Outage Rate: 6.7

3-Year Avg. Cap. Factor (MDC Net): 84.1

License Expiration: 2022

OPERATING HISTORY (To December 1996)

Date

Feb 1983

Apr - May 1983

Dec 1983 - Feb 1984

Mar 1984

Jul 1984

Aug 1984

Feb - Jun 1985

Feb - Apr 1986

May - Jun 1986

Sep 1986

Sep - Nov 1987

Dec 1987

\section{Comment}

The plant shut down for a 13-day outage to investigate and resolve problems with an LPCI injection valve vibration.

The unit was shut down for about 7 weeks for inspection and testing.

The unit was shut down for about 8 weeks for Unit 1 to Unit 2 tie-in work.

The unit was shut down for 20 days after a turbine bearing thrust wear detector circuit relay failed. Startup was delayed to replace the stem on recirculation pump discharge valve.

The utility reported that it had purchased the Zimmer plant initial fuel load.

The NRC proposed a $\$ 75,000$ fine for alleged violations that occurred at both units.

The first refueling and maintenance outage lasted 111 days. Major work during the outage included repair to steam dryers and installation of instrumentation to monitor steam dryer condition.

The second refueling and maintenance outage lasted 67 days. Major work during the outage included replacement of $48 \mathrm{CRDs}, 8 \mathrm{LPRMs}$, and LP turbine rotors; upgrading of HPCI, RHR, RCIC, and other system valves; and ATWS modifications. Operation resumed 17 days ahead of schedule.

Severe erosion found in both emergency SW pumps forced a 25-day shutdown.

The unit was shut down for a 10-day maintenance outage for repair of RWCU valve, MSRV cable work, and drywell sump system repairs.

The third refueling and maintenance outage lasted 77 days. Major work included replacement of jet pump beams; ISI of RV internals; CRD replacement; condenser rework; and modifications for LOSP, ATWS, and Appendix R requirements.

The unit was shut down on three occasions to repair condenser tube leaks and condenser manway gasket leaks. Total outage time was 11 days. 
Jun 1988

Oct 1988

Mar - Jun 1989

May 1989

Feb 1990

Jun 1990

Sep - Nov 1990

Dec 1990

Dec 1990

Feb 1991

Aug 1991

Aug 1991

Mar - May 1992

Jun 1992

Jul 1992

Jul - Aug 1993

Sep 1993 - Jan 1994

Mar - May 1995
The unit was shut down for 11 days after a ground fault occurred on a $500-\mathrm{kV}$ transmission line.

The NRC assessed a $\$ 50,000$ fine for alleged violations involving the use of electrical equipment that did not meet $\mathrm{EQ}$ requirements.

The fourth refueling and maintenance outage lasted 43 days. The plant shut down early after a circulating water expansion joint failed. Major work during the outage included replacement of RHR control room panel, ILRT, CRD replacement, turbine inspection, $125-\mathrm{V}$ battery replacement, and circulating water expansion joint replacement.

The utility announced a $\$ 100$ million contract awarded to Advanced Nuclear Fuels, Inc., to supply 9 fuel reloads for Units 1 and 2.

The unit was shut down to repair a leak in the turbine EHC system. During restart, decay heat removal was lost, and the RCS hot shutdown temperature limit was exceeded when an RPS output breaker malfunctioned. Similar breakers were replaced. Total outage time was 10 days.

The unit was shut down to correct common mode failure concerns of the RHR pump motor oil coolers. The unit was shut down for 10 days.

The fifth refueling and maintenance outage lasted 66 days. Major work included LPRM, heat exchanger, and control rod blade replacement; and LP turbine and erosion/corrosion piping inspections.

A planned maintenance of 5 days was needed for EHC leak and recirculation pump seal repairs.

The NRC proposed a $\$ 25,000$ fine for alleged violations involving EQ of equipment. The fine was mitigated due to the utility corrective actions and good past performance. The fine was paid.

An NRC SALP report awarded five Category 1 ratings and no low Category 3 ratings.

The utility agreed to an $\$ 80$ million settlement with GE over problems with the Mark II containment vessel design.

The unit scrammed, and a failed relay caused a partial MSIV isolation. The unit remained shut down for a scheduled maintenance outage of 9 days.

The sixth refueling and maintenance outage lasted 71 days. Major work included ILRT; RWCU pump replacement; and LP turbine, main generator, and erosion/corrosion piping inspections.

The unit was shut down to repair a reactor feed pump isolation valve. During startup from the outage, the unit was manually scrammed due to a charcoal fire in the off-gas guard bed. Total outage time was 18 days.

An NRC SALP gave Category 1 ratings in all functional areas but one, radiological controls.

The plant tripped when two turbine buckets on a LP rotor failed. Repairs lasted 49 days.

The seventh refueling and maintenance outage lasted 119 days.

The eighth refueling and maintenance outage lasted 43 days. 
Oct 1995

Nov - Dec 1995

Feb 1996

Aug 1996

Sep - Oct 1996

Oct 1996
The plant received all Category 1 ratings on its NRC SALP report, and the evaluations were lengthened to a 24-month cycle.

The unit was shut down to repair a hydrogen leak into the stator cooling water system. Other main generator damage extended the outage, which lasted 25 days.

The NRC proposed and the licensee paid a $\$ 100,000$ fine for employee discrimination. A spurious main turbine trip caused a 4-day outage.

The ninth refueling and maintenance outage lasted 46 days.

Following restart, the unit was shut down for 5 days for alignment of one of the recirculation pumps and balancing the main turbine. 


\section{NUCLEAR POWER PLANT OPERATING EXPERIENCE SUMMARY}

Unit data summary through December 1996

Unit: SUSQUEHANNA 2

Nameplate Rating: $1168 \mathrm{MWe}$

Location: LUZERNE COUNTY, PENNSYLVANIA

MDC Net MWe: 1094 MWe

Owner: PENNSYLVANIA POWER \& LIGHT CO.

Cumul. Avail. Factor: 83.3

Type: GENERAL ELECTRIC BWR

Cumul. Cap. Factor (MDC Net): 80.6

Construction Permit: 11/2/73

Cumul. Forced Outage Rate: $\mathbf{5 . 0}$

Operating License: 6/27/84

3-Year Avg. Cap. Factor (MDC Net): 84.4

Commercial Oper. Date: 2/12/85

License Expiration: 2024

OPERATING HISTORY (To December 1996)

Date

Jan 1985

Mar - Apr 1985

May 1986

Aug - Oct 1986

1987

Mar - Jun 1988

Oct 1988

Sep - Nov 1989

Feb 1990

May - Jun 1990

Dec 1990

\section{Comment}

The NRC assessed a $\$ 50,000$ fine because a worker allegedly opened several switches by mistake and disabled power to several ECCSs.

Generator stator cooling water leaks and a condensate system leak forced two outages totaling 11 days.

Severe erosion found in both emergency SW pumps forced a 26-day shutdown.

The first refueling and maintenance outage lasted 82 days. Major work included RHR throttle valve replacement, RPS modification, replacement of 24 CRDMs, ATWS modifications, replacement of four LPRMs, and other scheduled surveillances.

The unit completed the year with a capacity factor of $93.5 \%$ - the highest of any GE-supplied BWR in the world.

The second refueling and maintenance outage lasted 112 days. Major work included replacement of all three LP turbine rotors; replacement of 24 CRDs; and modifications for LOSP, ATWS, and Appendix R requirements.

The NRC assessed a $\$ 50,000$ fine for alleged violations involving the use of electrical components that were not EQ.

The third refueling and maintenance outage lasted 75 days. Major work included replacement of 20 LPRMs replacement of two RHR control panels; turbine and generator inspection; LOSP, Appendix R, and drywell cooling modifications; replacement of both $125 V$ DC batteries; and FW piping alignment.

Following a generator trip/reactor scram, the unit was shut down to correct the RPS breaker problem found on Unit 1. The outage lasted 7 days.

The reactor scrammed due to a reactor water level instrument failure. The unit was shut down for $\mathbf{1 7}$ days to replace the lube oil coolers on all RHR motors due to potential common mode failure concerns.

NRC assessed a $\$ 25,000$ fine for alleged violations involving EQ of electrical equipment and failing to correct deficiencies that were found. 
Jan 1991

Mar - May 1991

Aug 1991

Mar 1992

Sep - Nov 1992

Feb 1993

Dec 1993

Mar - Jun 1994

Apr 1995

Sep - Oct 1995

Jul 1996
The unit was shut down for 5 days to correct problems with the lube oil system for one recirculation pump.

The fourth refueling and maintenance outage lasted 61 days: Major work included replacement of control rod blades, CRDs, emergency SW valves, and a SW heat exchanger; inspections of HP turbine, snubbers, and SW heat exchangers; and replacement of piping suffering erosion/corrosion damage.

The unit was shut down for 1 week to replace a main transformer.

When a DG relay failed, a safety-related bus lost power and the inboard MSIVs were at risk of closing. The plant was manually scrammed and shut down for 1 week.

The fifth refueling and maintenance outage lasted 71 days. Major work included ILRT, RWCU replacement, and erosion/corrosion inspection.

A 1-week outage was needed to repair a generator exciter field ground.

The unit was shut down for 20 days due to high drywell leakage. The source of the leakage was closed cooling water to one of the recirculation pumps.

The sixth refueling and maintenance outage lasted 89 days.

A load reject caused a 6-day outage. A recirculation pump seal and main transformer bushing were replaced.

The seventh refueling and maintenance outage lasted 38 days.

The reactor scrammed due to a loss of feedwater incident when two condensate pumps tripped due to a bus de-energizing. The ensuing outage lasted 17 days. 
THREE MILE ISLAND

PRODUCTION COST and CAPITAL ADDITIONS

(1996 Dollars)

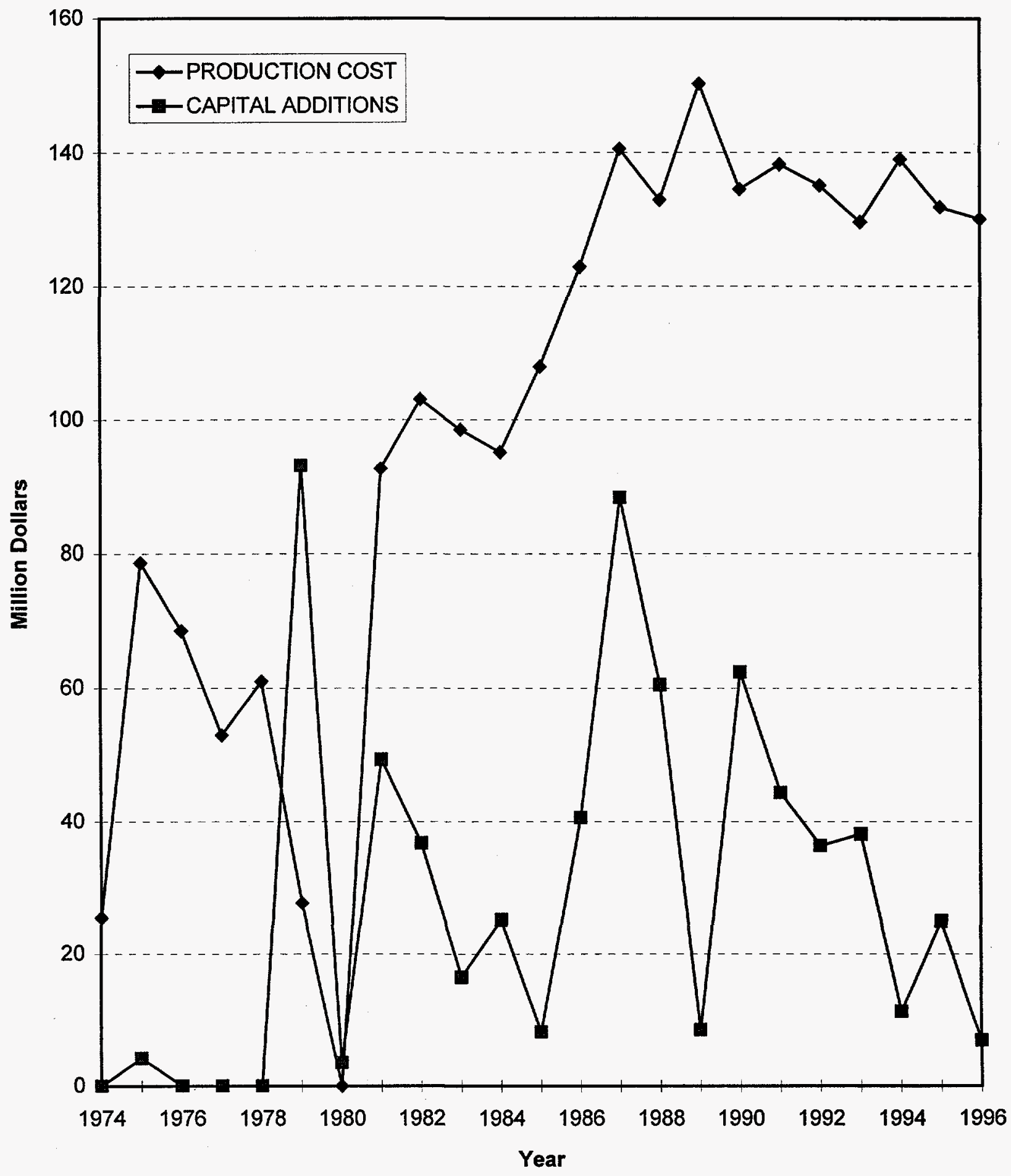




\section{NUCLEAR POWER PLANT OPERATING EXPERIENCE SUMMARY}

Unit data summary through December 1996

Unit: THREE MILE ISLAND 1

Location: DAUPHIN COUNTY, PENNSYLVANIA

Nameplate Rating: 872 MWe

Owner: GPU NUCLEAR CORP.

MDC Net MWe: 786 MWe

Type: BABCOCK \& WILCOX PWR

Cumul. Avail. Factor: 59.8

Construction Permit: 5/18/68

Cumul. Cap. Factor (MDC Net): 59.2

Operating License: 4/19/74

Cumul. Forced Outage Rate: 34.1

Commercial Oper. Date: 9/2/74

3-Year Avg. Cap. Factor (MDC Net): 97.1

License Expiration: 2014

OPERATING HISTORY (To December 1996)

Date

Apr 1974

Aug 1974

Sep 1974

Oct 1974

Apr 1975

Sep - Oct 1975

Nov 1975

Feb - Apr 1976

May 1976

Nov - Dec 1976

Mar - May 1977

Sep 1977

Mar - May 1978

Feb 17, 1979

1980

\section{Comment}

A full-power operating license was issued, but a temporary limit of $19 \%$ power was imposed until both containment spray additive tanks (sodium thiosulfate) were operable.

The plant shut down for 10 days for required maintenance.

The utility was fined $\$ 3500$ by NRC for alleged security violations.

Leaky pressurizer relief valves caused a 10-day shutdown to effect repairs.

A dropped control rod and an inoperable rod drive caused a 9-day shutdown.

The unit was shut down for 11 days to repair a RCP.

CRD stator and turbine control valve repairs forced a 13-day shutdown for repairs.

The first refueling outage was extended from 9 to 13 weeks to accommodate specimen tube removal from the RPV.

The utility was fined $\$ 8000$ by the NRC for alleged physical security violations.

The plant shut down for about 1 month to repair cracked concrete river water discharge pipes.

The second refueling and maintenance outage was performed. During the outage, a circulating water pump casing fractured and flooded the circulating water pump house. SG inspection was performed during the outage.

The plant shut down for 11 days because of high FW conductivity, a malfunctioning RCP, and a main generator ground.

A third refueling and maintenance outage was performed. Major work included inspection of SG tubes.

The unit was shut down for the fourth refueling outage. The plant remained shut down because of an accident at TMI-2 on March 28.

The plant remained shut down throughout the year; restart modification work continued. 
Nov 1981

1982

Jul 1983

Feb 1984

Apr 1984

Jun 1984

Apr 1985

Jun 1985

Oct 1985

Jan 6, 1986

Mar - Apr 1986

Oct 1986 - Mar 1987

Jun 1987

Jun - Aug 1988

Sep 1988

Dec 1988

Aug 9, 1989

Dec 1989

Jan - Mar 1990

Mar 1990
During preparations for restart, tube leaks appeared in both SGs. Inspection revealed tube sheet crevice area cracking.

The unit remained shut down while hearings concerning restart continued throughout the year.

The NRC proposed a $\$ 140,000$ fine for alleged cheating by certain operators on requalification examinations.

The NRC proposed a $\$ 40,000$ fine for numerous alleged TS violations.

The NRC issued a license amendment to allow pre-critical, nonnuclear hot functional testing to test repaired SGs and other plant modifications. The unit returned to cold shutdown after testing was completed.

Leakage was detected in one SG because of incorrectly plugged tubes. The restart vote by NRC was delayed by several factors: SG leakage, emergency drill problems, improper leak rate practices, and utility training program deficiencies. The unit remained in cold shutdown for the balance of year.

The NRC assessed a $\$ 100,000$ fine for alleged material false statements made in 1979 regarding utility training and requalification program.

The NRC authorized restart of the unit, but U.S. Court of Appeals barred restart until petitions for rehearing were decided.

The unit synchronized to grid on October 9 after the Supreme Court refused to block the unit restart.

The unit achieved full power for the first time in 7 years.

The unit was shut down for 33 days for SG inspection.

The fifth refueling and maintenance outage was performed. Major work included Appendix R modifications, RV level instrumentation installation, and EFW system upgrade.

The unit entered a scheduled shutdown to replace two letdown heat exchangers. Total outage time was 14 days.

The sixth refueling and maintenance outage lasted 60 days. Major work included SG inspection, fuel handling bridge upgrade, RCP seal inspection, main turbine overhaul, and cooling tower repairs.

The unit was shut down for 9 days to repair a RCP seal leak.

The unit was shut down for 13 days to repair a RCP seal leak.

The unit completed 163 days of continuous operation, a new record for the unit.

The unit completed the year with a gross capacity factor of $100.3 \%$, the highest among nuclear power plants in 22 countries.

The seventh refueling and maintenance outage lasted 56 days. Major work included FA leak testing, FW nozzle and turbine valve replacement, snubber maintenance and testing, and pressurizer safety valve replacement.

The unit was shut down for 10 days to repair SG tube leak. 
Aug 1990

Jul 22, 1991

Sep - Nov 1991

Sep - Oct 1993

Nov 1993

Mar 1994

Jun 1994

Sep - Oct 1995
The plant received all top ratings in NRC SALP report for 17-month period ending May $15,1990$.

The unit exceeded world the record of 477 days for continuous operation for a LWR.

The eighth refueling and maintenance outage lasted 49 days. Major work included a 10-year ISI of RPV, SG cleaning, RCP seal replacement, turbine overhaul, and in-core detector replacement.

The ninth refueling and maintenance outage lasted 36 days.

The unit was shut down for 5 days for a scheduled maintenance outage to replace a pressurizer safety valve.

The unit was shut down for 9 days to repair a pressurizer safety valve and to perform control rod testing.

The unit was shut down to perform scheduled control rod testing. The thermal barriers for four rods needed to be replaced. The outage lasted 8 days.

The tenth refueling and maintenance outage lasted 35 days. 


\section{NUCLEAR POWER PLANT OPERATING EXPERIENCE SUMMARY}

Unit data summary through December 1996

Unit: THREE MILE ISLAND 2

Location: DAUPHIN COUNTY, PENNSYLVANIA

Owner: GPU NUCLEAR CORP.

Type: BABCOCK \& WILCOX PWR

Construction Permit: 11/4/69

Operating License: $\mathbf{2 / 8 / 7 8}$

Commercial Oper. Date: $12 / 30 / 78$
Nameplate Rating: 871 MWe

MDC Net MWe: 808 MWe

Cumul. Avail. Factor: n/a

Cumul. Cap. Factor (MDC Net): n/a

Cumul. Forced Outage Rate: $\mathbf{n} / \mathbf{a}$

3-Year Avg. Cap. Factor (MDC Net): n/a

Original License Expiration: 2009

OPERATING HISTORY (To December 1996)

Date

Dec 1978

Jan 1979

$\operatorname{Mar} 28,1979$

1980 - present

\section{Comment}

Commercial operation was delayed by main steam safety valve modifications and operational problems.

A 2-week outage was necessary after bellows ruptured on two MS safety valve relief pipes.

The unit experienced the most serious accident in the history of nuclear power plants in the United States. Through a series of equipment malfunctions and personnel errors, core damage occurred and highly contaminated reactor coolant was discharged into containment and then pumped to auxiliary building tanks. The tanks overflowed and multiple off-site releases of radioactivity occurred and a partial evacuation of the general public was implemented. Media panic and local government indecision caused much public confusion and fear. The plant remained shut down pending investigation of the event.

The plant is permanently shut down. Over the years, plant cleanup efforts included removal of damaged fuel from RPV, treatment and disposal of hundreds of thousands of gallons of contaminated water resulting from the accident, and general cleanup of contaminated areas of the unit to allow easier personnel access during (planned) indefinite plant layup. The accident and its aftermath initiated significant changes to domestic nuclear power plant design and operating practices. 
This Page Intentionally Left Blank 
TROJAN

PRODUCTION COST and CAPITAL ADDITIONS

(1996 Dollars)

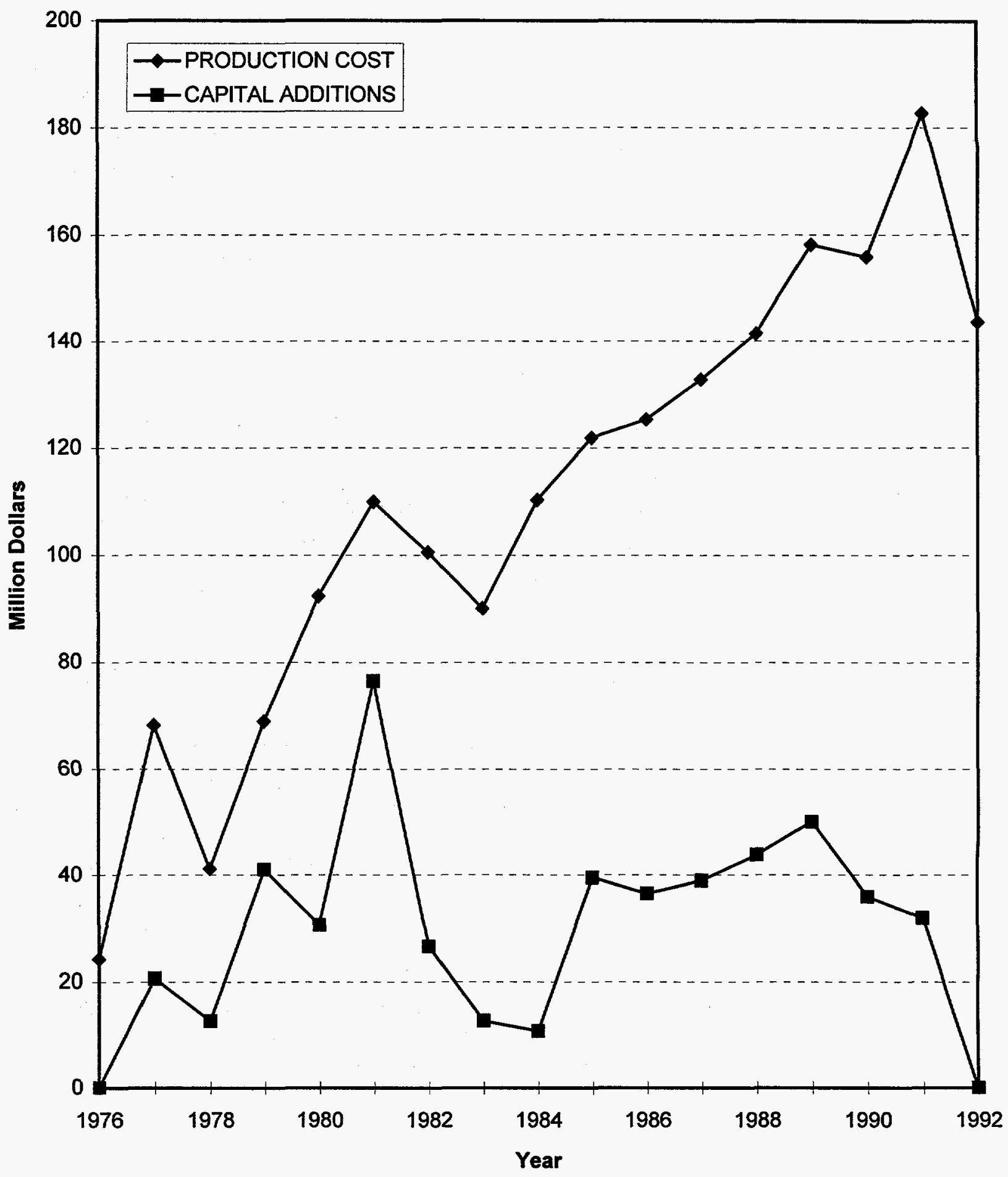




\section{NUCLEAR POWER PLANT OPERATING EXPERIENCE SUMMARY}

Unit data summary through December 1996

Unit: TROJAN

Location: COLUMBIA COUNTY, OREGON

Owner: PORTLAND GENERAL ELECTRIC CO.

Type: WESTINGHOUSE PWR

Construction Permit: 2/8/71

Operating License: 11/21/75

Commercial Oper. Date: 5/20/76
Nameplate Rating: $1216 \mathrm{MWe}$

MDC Net MWe: $1095 \mathrm{MWe}$

Cumul. Avail. Factor: 61.2

Cumul. Cap. Factor (MDC Net): $\mathbf{5 4 . 2}$

Cumul. Forced Outage Rate: 13.7

3-Year Avg. Cap. Factor (MDC Net): n/a

License Expiration: 2011 ${ }^{1}$

OPERATING HISTORY (To December 1996)

Date

1975

Feb - Apr 1976

May - Sep 1976

Oct - Nov 1976

Mar - Apr 1977

Apr - Jun 1977

Mar 1978 - Jan 1979

Jan 1979

Apr - Jul 1979

Oct - Dec 1979

\section{Comment}

Plant completion was delayed about 1 year because of late component delivery, changes in plant design, and shortages in critical construction crafts.

The unit was shut down for about 1 month after $50 \%$ power testing because of AFW pump problems.

After achieving $100 \%$ power and completing a warranty run, the plant shut down to complete minor construction items and make plant modifications. The unit remained shut down for the period because of an abundance of hydroelectric power available in service area.

After returning to power in September, the plant shut down for about 3 weeks to correct a ground on the main generator rotor.

The unit was shut down for 11 days to repair condenser tube leaks, one AFW pump, and the rod control system.

The plant entered a scheduled outage for an 18-month inspection and surveillance testing.

The plant entered a scheduled refueling outage. Startup was delayed to resolve deficiencies in seismic qualification of the control building. In September, a small aircraft crashed into three $230-\mathrm{kV}$ supply lines near the plant, causing a partial loss of off-site power.

Operation resumed after a license amendment granted by NRC authorized interim operation while control building seismic modifications were implemented.

The plant shut down for a 10-week maintenance outage.

The plant shut down for NRC-required hangar and restraint inspections. SG tube leaks were also repaired. ASLB ordered the plant to remain shut down for about 1 month until resolution of concerns about concrete block wall and pipe support seismic designs.

\footnotetext{
${ }^{1}$ The unit was permanently shut down in January 1993. The cumulative data are through that date.
} 
Apr - Jul 1980

Dec 1980

Jan - Feb 1981

Apr - Jul 1981

Mar - Aug 1982

Jan - Jul 1983

Jan 1984

Apr - Sep 1984

May - Jul 1985

Dec 1985

Apr 1986

Apr - Jun 1986

May 1986

Oct 1986

Nov 1986

Dec 1986
The plant shut down for refueling and SG tube repairs. Modifications to an auxiliary building were also made during the outage.

At end of year, tube leakage in two SGs had reached almost 60 gallons per day.

The unit was shut down for 12 days to plug leaky tubes in the SGs. Leak rate was about 300 gallons per day.

The unit was shut down for refueling and SG tube repair and plugging. The core baffle plate was peened to inhibit fuel damage as a result of water jetting.

The plant entered a refueling outage about 5 weeks ahead of schedule due to abundance of hydroelectric power. Severe fuel damage caused by water jet impingement was found. The NRC proposed a $\$ 50,000$ fine for alleged inoperability of EDGs and failure to perform required surveillance tests. The outage was extended because of damage to a charging pump and discovery of damaged thermal sleeves in RCS piping.

The plant entered a refueling outage about 5 weeks ahead of schedule due to abundance of hydroelectric power. On restart, the plant operated at $50 \%$ because of condensate pump problems.

The utility paid a $\$ 50,000$ fine to the NRC for alleged violations concerning fire protection requirements.

The plant shut down for a refueling and maintenance outage. Major work included modification to RV internals, SG inspection, main condenser repair, diesel AFW pump installation, and snubber inspections. The MSL check valves were modified to prevent recurring problems with their sticking open because of tight packing. A failed Swagelock ${ }^{\circ}$ fitting discharged about 15,000 gallons of reactor coolant into containment.

A refueling and maintenance outage lasted 66 days. Major work included 10-year ISI, SG inspection, FW heater replacement, snubber inspections, EQ modifications, and FW pump control work.

Possible sabotage was suspected when a hammer was found inside a DG valve cover; the NRC and the FBI conducted an investigation. The unit finished the year among the 10 lowest cost nuclear-generated electricity producers.

The NRC assessed a $\$ 50,000$ fine for alleged failure to perform certain QA inspections in 1984 and 1985.

A refueling and maintenance outage lasted 64 days. Major work included SG and RCS snubber inspections, SG internal inspection, ILRT, and a number of other system inspections.

The NRC assessed an $\$ 80,000$ fine for alleged failure to maintain operability of control room emergency ventilation.

The NRC proposed a $\$ 50,000$ fine for alleged violations involving invalid QA signoffs and misrepresentation of TS requirements for RHR operability.

An Oregon ballot initiative that called for closure of the plant was defeated.

The unit finished the year as the ninth lowest cost nuclear-generated electricity producer. 
Apr - Aug 1987

Dec 1987

Apr - Jul 1988

Nov 1988

Feb 1989

Apr 1989

Apr - Aug 1989

Sep 1989

Oct 1989

Mar - Jul 1990

Sep - Oct 1990

Nov 1990

Feb 1991

Mar 1991 - Feb 1992
The plant shut down for a refueling and maintenance outage. Major work included main condenser replacement, MSR heat exchanger tube replacement and SG inspection. The utility was fined $\$ 50,000$ by NRC for alleged failure to maintain proper radiation protection program for workers. Restart was delayed when inspections done in response to IE Bulletin 87-01 found secondary piping damaged by erosion/corrosion, and because of concerns about inadequate pipe supports. Total outage time was 146 days. Plant modifications allowed the unit to generate about $30 \mathrm{MW}$ additional.

The unit was shut down for 18 days to repair turbine controls and valves and to resolve various administrative concerns.

The unit was shut down for a planned refueling outage.

A plant shutdown was forced by a failed FW regulating valve controller. Recovery was extended to repair RCP flange leak. Total outage time was 18 days.

The utility paid an NRC-imposed fine of $\$ 75,000$ for alleged violations involving access control to vital plant areas.

The NRC proposed a $\$ 75,000$ fine for alleged failure to adequately ensure the quality of the safety-related equipment.

The plant was shut down for refueling. The outage was extended for replacement of 82 potentially defective SG tube plugs and inspection of all tubes in all three SGs. Flaws found in one SG caused all hot leg tubes to be tested. The utility announced plans to replace all 82 tube plugs at the next refueling outage. Total outage time was 121 days.

A plant shutdown of 18 days was forced by a leaky pressurizer safety valve.

NRC proposed a $\$ 280,000$ fine for alleged inoperability of containment sumps since the 1988 refueling outage and possibly since 1975 because debris screens were missing or damaged.

The plant shut down for a refueling and maintenance outage. In June, the NRC awarded the utility a top Category 1 SALP rating for plant operations. Maintenance and surveillance were given a low Category 3 rating.

Condenser tube repairs and turbine generator inspection forced a 12-day outage.

Oregon voters rejected a ballot initiative that would have shut down the plant if

(1) the federal government did not provide a permanent high level waste repository, (2) the plant was not cost-effective, or (3) the plant was unable to withstand a major earthquake.

The NRC proposed a $\$ 50,000$ fine for alleged violations involving licensed operator medical record requirements.

The unit was shut down for repair of a vital instrument power inverter. While shut down, cable splices for two containment penetrations were replaced. The plant remained shut down and entered refueling outage early because of uncertainty found in a ECCS pump flow rate analysis by the NSSS vendor. During the outage, expanded SG inspection revealed IGSC cracking on the outside diameter of SG tubes. A $100 \%$ inspection of the tubes in all four SGs was initiated. Extensive maintenance on other plant systems was carried out during the prolonged outage. The outage lasted 332 days. 
Feb 1992

Feb 1992

Apr - Jun 1992

Aug 1992

Nov 1992

Jan 1993

Jan 1996
The NRC granted a license change that relaxed the repair limits for SG tubes, but decreased the allowable primary-to-secondary leak rate. This change allowed the licensee to postpone action on 428 SG tubes.

Also, the NRC proposed a $\$ 100,000$ fine for alleged violations of failing to take adequate corrective actions concerning valve maintenance, radiation protection, and fire protection. The fine was paid.

The unit was shut down for 51 days due to excess hydroelectric power in the region.

The utility announced that the unit would be permanently shut down in 1996 to save $\$ 100$ 200 million in costs, principally SG replacement. The licensee would have expired in 2011.

Oregon voters again rejected a measure to shut down the plant.

The unit was shut down to repair a leak in a SG tube which had been sleeved, but not properly cured.

The utility announced that the unit would not be restarted from the current outage. The permanent shutdown was effective on January 4, 1993.

The NRC proposed and the licensee paid a $\$ 50,000$ fine for inaccurate information in an LER concerning electrical penetration assembly seals. 
This Page Intentionally Left Blank 


\section{TURKEY POINT \\ PRODUCTION COST and CAPITAL ADDITIONS \\ (1996 Dollars)}

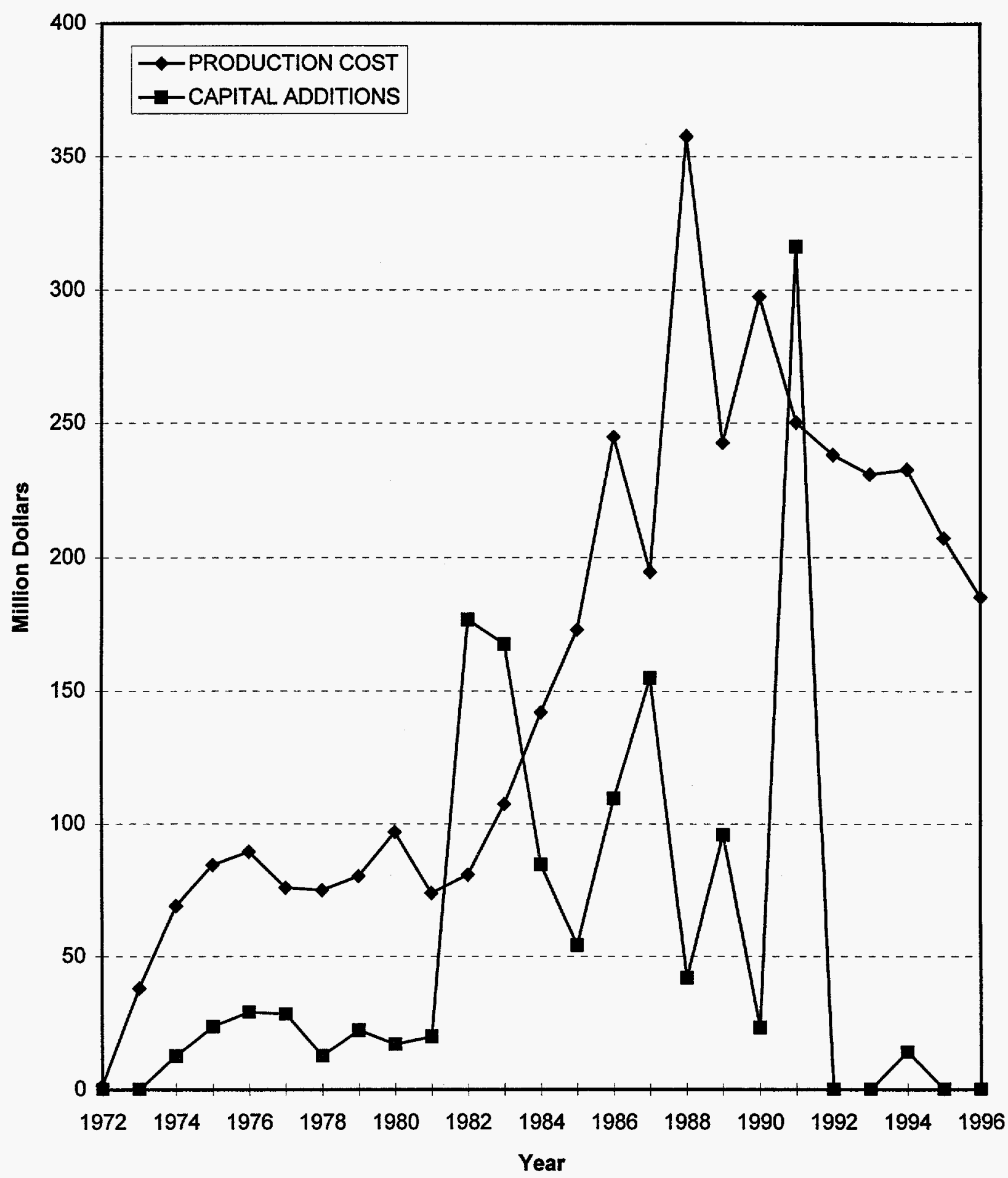




\section{NUCLEAR POWER PLANT OPERATING EXPERIENCE SUMMARY}

Unit data summary through December 1996

Unit: TURKEY POINT 3

Location: DADE COUNTY, FLORIDA

Owner: FLORIDA POWER \& LIGHT CO.

Type: WESTINGHOUSE PWR

Construction Permit: 04/27/67

Operating License: 07/19/72

Commercial Oper. Date: $12 / 14 / 72$
Nameplate Rating: $760 \mathrm{MWe}$

MDC Net MWe: $666 \mathrm{MWe}$

Cumul. Avail. Factor: 68.0

Cumul. Cap. Factor (MDC Net): 62.4

Cumul. Forced Outage Rate: $\mathbf{1 0 . 3}$

3-Year Avg. Cap. Factor (MDC Net): 89.5

License Expiration: 2012

OPERATING HISTORY (To December 1996)

Date

Sep 1972

Dec 1972

Apr 1973

Apr - Jun 1973

Dec 1973

Dec 1973

Mar 1974

Oct - Dec 1974

Oct - Dec 1975

Feb - Sep 1976

Nov - Dec 1976

Jan - Dec 1976

May 1977

Noy 1977 - Feb 1978

Jan - Apr 1979

Jun - Jul 1979

Dec 1979 - Feb 1980
A 75\% power limit was imposed due to the fuel densification issue.

Power escalation was held at $50 \%$ due to four inoperable steam-dump-to-condenser valves.

A $93 \%$ power limit was imposed. A faulty inverter and fossil plant problems resulted in a massive blackout of the southeast Florida coast.

Vibration of the main steam lines limited operation to about $80 \%$ power.

The unit completed steam line modifications. A TS change allowed power operation at $98 \%$.

The canal cooling system was virtually completed.

The unit attained $100 \%$ power $(2200 \mathrm{MWt})$.

An outage was required for refueling, turbine overhaul, and SG tube inspections.

An outage was required for refueling.

Separate outages totaling 32 days were required to effect repairs for SG tube leaks.

A refueling and maintenance outage was performed. SG "hourglassing" was discovered; row 1 tubes in SG B when plugged.

A total of 49 outage days were attributed to SG denting inspections and tube removals.

After a reactor trip, subsequent load sharing efforts by other power plants, and resultant grid instabilities caused a major blackout in SE Florida.

A refueling outage and SG tube inspections were conducted.

An outage was required for refueling, maintenance, SG inspections, and RCP seal repair.

The unit was shut down for SG work. A total of $17.5 \%$ of SG tubes were plugged. SG replacement preparations were made, and RCP mechanical seals were repaired.

An outage was required for refueling and maintenance. 
Oct - Nov 1980

Jan 1981

Feb 1981 - Apr 1982

Jul - Aug 1982

May 1983

Aug 1983

Oct 1983 - Jan 1984

Feb 1984

Apr 1984

Jul 1984

Nov 1984

Dec 1984 - Jan 1985

Feb 1985

Mar - Jul 1985

Aug 1985

Oct - Nov 1985

Jan 1986

Mar 1986

Jun 1986

Jul - Aug 1986
The unit was shut down for SG tests, and to repair leaking SG plugs.

A fine of $\$ 40,000$ was assessed by the NRC for alleged operation without a licensed operator at the control panel.

A refueling, maintenance, and inspection outage was performed. At startup, the generator stator core failed, and the outage was extended 352 days to allow RV ISI and SG replacement.

RCP motor replacement required a 17-day outage.

A fine of $\$ 40,000$ was assessed by the NRC for alleged failure to properly monitor employees during SG maintenance.

A fine of $\$ 100,000$ was assessed by the NRC for alleged operation in April 1983 with valves in the AFW system improperly closed.

The unit was shut down for a refueling and maintenance outage for 3 months.

The NRC proposed a fine of $\$ 40,000$ for allegedly allowing two workers to enter a locked high radiation area without a radiation work permit in October 1983.

The unit was shut down for 16 days for safeguards tests, snubber inspections, and SG FW nozzle inspections.

The NRC proposed a fine of $\$ 150,000$ for allegedly failing to recognize that 2 out of 3 AFW pumps were out of service during plant operation.

The NRC issued a license amendment allowing expansion of the spent fuel pool from 621 FAs to 1,404 FAs.

A main generator exciter shorted to ground requiring a 21-day outage for exciter replacement.

The NRC proposed a $\$ 25,000$ fine for allegedly operating for more than 5 days in August 1984 without the intake cooling system being fully operational.

The unit was shut down for refueling and maintenance for about 3.5 months.

A fine of $\$ 100,000$ was proposed by the NRC for allegedly operating the spent fuel pool prior to September 1984 after making changes for which no review had been conducted.

The unit was shut down for 17 days to replace the condenser boot seal and align RCP motors.

A fine of $\$ 100,000$ was proposed by the NRC for allegedly operating the spent fuel pool for 8 months with two cooling loop isolation valves open instead of closed.

The unit was placed in cold shutdown due to a potential concern with component cooling flow through RHR heat exchangers. During the 36-day outage, an AFW pump, a $\mathrm{N}_{2}$ accumulator leak, and several MOVs were also repaired.

A fine of $\$ 50,000$ was proposed by the NRC for allegedly misrepresenting the operability of a new neutron flux instrumentation system.

The unit was shut down for electrical modifications to correct a potential emergency DG overload under LOSP and SI conditions. The outage was extended a total of 21 days to repair a main generator $\mathrm{H}_{2}$ leak and AFW. 
Aug 1986

Oct 1986

Dec 1986

Dec 1986 - Jan 1987

Mar - Sep 1987

Apr 1987

Apr 1987

Jul 1987

Sep - Dec 1987

Oct 1987

Jan 1988

Mar 1988

Aug 1988
A fine of $\$ 300,000$ was proposed by the NRC for alleged violations concerning AFW operations.

$\mathrm{NRC}$ reduced a proposed $\$ 50,000$ fine in April to $\$ 25,000$ for an alleged incident that involved an unplanned exposure of a worker during TIP maintenance.

The utility reported plans to procure additional DGs for safety-related power distribution systems.

The unit was shut down following loss of control oil pressure for the main turbine governor valve. The shutdown was extended to allow repairs to a leaking FW bypass valve, resolve an RCP oil level alarm and lift pump problems, repair a SG blowdown valve, and a FW pump discharge MOV.

The unit was shut down for 185 days for refueling and maintenance. Outage activities included Appendix R modifications and alternate shutdown system component work, replacement of three LP turbine rotors, upgrade of the tubing in all four MSRs, and EQ of electrical devices.

The NRC proposed a $\$ 75,000$ fine for alleged violations concerning security requirements.

A number of deficiencies were identified in the load sequencing for the emergency power system, including jumpers and lifted leads that could have affected some safety-related power loads.

The NRC proposed a $\$ 75,000$ fine for alleged security violations. The utility failed to adequately control access to both containment buildings and to adequately search packages and personnel entering the plant by vehicle.

The unit was shut down to investigate high RCP vibration. The outage continued for 91 days to allow repairs to RHR cabling and RCP seals, charging line discharge flow check valve bonnet leakage, and seal table leakage. A pressurizer safety valve was replaced and work on RHR recirculation loop was performed in response to NRC Information Notice 87-59.

The NRC proposed a $\$ 225,000$ fine for alleged violations involving overall management of both units. The base penalty was increased by $50 \%$ to reflect past poor performance.

The unit was shut down because of a turbine runback which was due to a dropped control rod. Two additional rods dropped during the subsequent controlled shutdown, resulting in a subcritical manual reactor trip. Investigation attributed the event to a missing gripper coil pin that had been removed. The outage lasted 42 days

The unit was shut down to investigate excessive MSR noise. During unit restart a shutdown occurred after reaching $30 \%$ power because of high secondary condensate conductivity due to a condenser tube leak. Total outage time was approximately 13 days for both events.

The utility submitted a performance improvement plan to the NRC which committed the utility to change the plant and corporate headquarters organizations and create a separate nuclear engineering staff. 
Oct 1988 - Feb 1989

Mar - May 1989

Apr 1989

May - Jun 1989

Jun 1989

Jun 1989

Feb - May 1990

Feb 1990

Jun 1990

Oct 1990

Oct 1990

Dec 1990 - Sep 1991

Apr 1992

Aug 1992
The unit was initially shut down to replace an RHR pump seal, but the outage was extended for pressurizer heater repairs. The outage was further extended to repair main turbine rotor damage using the Unit 4 turbine generator. The NRC delayed startup to allow revision of procedures and drawings. Thimble tube leakage repairs and DG PM was also performed before the unit resumed power operations.

A voluntary shutdown was performed after 11 of 24 licensed operators failed their requalification exams. A plan to improve the plant requalification training program was to be submitted by May 1,1989 , to the NRC in order to prevent any restart delays.

The NRC proposed a $\$ 100,000$ fine for alleged violations of security regarding a degraded vital area barrier. The base civil penalty was doubled based on the utility's past security problems.

The March outage was extended to allow repairs to containment pressure switches, RHR pumps, and SI MOVs. The outage extension lasted 52 days.

Extensive drug screening efforts were initiated after the arrest of a nonnuclear plant employee for drug distribution. The utility initiated mandatory random drug testing.

The NRC notified the utility that it would order a shutdown of the plant if performance did not improve significantly in the next 6 months. Both units had been on the problem plant list since its inception in 1986 . The utility submitted a performance improvement plan that included personnel changes and training enhancements.

The unit was shut down for 120 days for refueling and overhaul. Maintenance items included repacking 600 valves, SG ET, SG J-nozzle changeout, cleaning and inspection of flux map thimbles, RCP seal and motor overhaul, RHR pump seal changeout, and other items. About 2,000 gallons of spent fuel pool water entered the auxiliary building via a leaky pump seal during the outage.

The NRC removed both units from its problem plant list. The NRC staff indicated that long-standing concern about management indifference was reduced after management changes were made.

The unit was shut down for 5 days to repair two feedwater heater valves.

An NRC SALP report showed the best marks in years. No Category 3 ratings were given and one top rating in safety assessment/quality verification was given.

Problems with the seal water system and the boric acid transfer pumps at the plant were reviewed for potential generic implications. Other plants reported using a single mechanical seal rather than a double seal design as used at Turkey Point.

The unit began an extended outage for installation of two additional 2.8 MWe DGs. During the dual unit outage, a new electronic security system was installed. The changes cost about $\$ 237$ million. The unit returned to service on October 1 and operated through the end of 1991 .

The unit was shut down for 15 days to replace a RCP seal.

The unit was shut down before Hurricane Andrew hit the site. Winds of up to $165 \mathrm{mph}$ caused some physical destruction and a LOSP, but no significant radiation releases. 


\section{TURKEY POINT 3 (Cont'd)}

Aug - Dec 1992

Jan 1993

Sep 1993

Apr - May 1994

May 1994

Oct 1994

Sep - Oct 1995

Feb 1996

Jun 1996

Sep 1996

Oct 1996
A refueling and maintenance outage lasted 103 days. Major work included SG ECT and replacement of RCP and FW pumps. The unit had been shut down with the approach of Hurricane Andrew.

A small leak in an unused pressurizer spray valve bypass line required 5 days to repair.

A leak on the pressurizer manway cover required 6 days to repair.

A refueling and maintenance outage lasted 45 days.

The unit's license was extended by 7 years to recapture the construction period.

The plant received all Category 1 ratings on its NRC SALP report, and the evaluations were lengthened to a 24-month cycle.

A refueling and maintenance outage lasted 34 days.

A number of minor problems caused several outages which totaled 1 week of downtime.

The NRC proposed and the licensee paid a $\$ 100,000$ fine for actions against an employee who refused to take a psychological test. The fine was based on a ruling by the Secretary of Labor.

The unit was shut down for 4 days after 2 control rods dropped due to control circuit cards failing.

The plant again received all Category 1 ratings on its NRC SALP report. 


\section{NUCLEAR POWER PLANT OPERATING EXPERIENCE SUMMARY}

Unit data summary through December 1996

Unit: TURKEY POINT 4

Location: DADE COUNTY, FLORIDA

Owner: FLORIDA POWER \& LIGHT CO.

Type: WESTINGHOUSE PWR

Construction Permit: 4/27/67

Operating License: $\mathbf{4 / 1 0 / 7 3}$

Commercial Oper. Date: $9 / 7 / 73$
Nameplate Rating: $760 \mathrm{MWe}$

MDC Net MWe: $666 \mathrm{MWe}$

Cumul. Avail. Factor: 67.3

Cumul. Cap. Factor (MDC Net): $\mathbf{6 2 . 1}$

Cumul. Forced Outage Rate: 9.9

3-Year Avg. Cap. Factor (MDC Net): 89.1

License Expiration: 2013

OPERATING HISTORY (To December 1996)

Date

Apr 1973

Aug 1973

Nov 1973

Jan 1974

Mar 1974

Aug - Oct 1974

Mar - Jun 1975

Aug - Sep 1975

Jan - Dec 1976

Apr 1976

Jan - Nov 1977

May - Aug 1977

Feb - Mar 1978

Jul 1978

Dec 1978

\section{Comment}

A full-term, full-power license was issued with a $93 \%$ power limit because of the fuel densification issue.

Steam line vibrations, similar to Unit 3, were encountered as power was increased to $75 \%$. Power was then limited to $80 \%$.

Seismic restraints were inspected and repaired during a 2-week shutdown.

The unit was shut down nearly a month for maintenance and steam line modifications. The RCS operating pressure was reduced to 1885 psia.

The unit attained $100 \%$ power $(2200 \mathrm{MWt})$.

Tube repairs on SGs and main condenser required 27 days of shutdown on 2 separate occasions.

The unit was shut down 11 weeks for refueling and maintenance. One FA was damaged and SG tubes were inspected during the outage.

Two outages totaling 17 days were necessary for SG tube repairs.

Numerous shutdowns were performed throughout the year for SG tube inspections and repairs for leaks and denting problems. About 140 outage days were attributed to SG problems.

A shutdown of about 7 weeks was initiated to retube the main condenser.

Several unscheduled shutdowns were required to permit SG tube plugging and leak repairs which lasted more than 38 cumulative days.

The unit was shut down for a refueling and maintenance outage. An additional $6.2 \%$ of the SG tubes were plugged during the outage.

A SG tube inspection and repair outage lasted 23 days.

Power was reduced to about $50 \%$ during operating periods to extend cycle 5-core life.

A 9-day outage was necessary for repair of a RCP seal assembly. 


\section{TURKEY POINT 4 (Cont'd)}

Apr - Jun 1979

Apr - Jun 1980

Nov - Dec 1980

Oct - Dec 1981

Jul 1982

Oct 1982 - May 1983

Aug 1983

Nov 1983

Mar - May 1984

Sep - Oct 1984

Oct - Nov 1984

Jan - Feb 1985

Aug 1985

Nov - Dec 1985

Jan - Aug 1986

Mar 1986

Mar - Jul 1987

Oct - Dec 1987

Feb 1988

Apr - May 1988
The unit was shut down for a refueling and maintenance outage.

The unit was shut down for SG tube inspections, LP turbine rotor replacement, and repair of cracks in SG FW nozzle reducers.

The unit was shut down for refueling.

The unit was shut down for refueling.

An outage of 19 days was required for retrieval of foreign objects from a SG and for tube plugging and other maintenance activities.

The unit was shut down for SG replacement work. The lower assemblies, including the tube bundles were installed into the steam generator cavities.

A unit outage of 14 days was necessary for primary and secondary system repairs.

The unit was shut down to repair an RCP seal leak. The outage was extended for PORV block valve repair.

The unit was shut down for a refueling and maintenance outage. Crack indications were found during inspection of SG FW nozzle-to-reducer weld areas.

A 10-day outage was required for repair of the pressurizer relief tank.

Replacement of a leaking RCP seal and modifications to correct slow closure times of MSIVs required an outage of 18 days.

A 8-day outage was required for DG breaker and cubicle repairs.

After a second control rod dropped during turbine runback, a reactor trip occurred. An outage of 8 days was necessary for repairs.

The unit was shut down for MOV grease inspections and to ensure that MOVs were in compliance with tested configuration.

The unit was shut down for a maintenance and refueling outage. During the outage, one RCP motor was replaced, RCP seals were replaced, the main turbine generator was inspected, control rod guide tube split pins were replaced, and the alternate shutdown system was installed. Appendix R modifications were also made, and DG overload design deficiencies were corrected.

Nine of thirteen licensed operators failed requalification examinations.

The unit was shut down after discovery of boric acid corrosion on the reactor vessel head and CRDM exhaust cooling ducts. The outage was extended to 117 days to replace Raychem electrical splices, conduct associated instrumentation checks, replace postaccident $\mathrm{H}_{2}$ monitoring system piping, and other maintenance items.

The unit was shut down as a precaution because of a hurricane warning. The outage was extended to 53 days to make repairs in a number of systems.

A manual shutdown was performed because of damage to 2 circuit cards and a gate filter in a battery charger during a surveillance test. The outage lasted 17 days.

The unit was shut down because of a leaking pressurizer spray control valve. A total outage time of 30 days was necessary for repairs of containment purge isolation valve stroke times and binding problems on RHR suction isolation valves. 
Sep 1988 - Jun 1989

Sep - Oct 1989

Jan - Feb 1990

Apr 1990

May 1990

Jul - Aug 1990

Nov 1990 - Oct 1991

Dec 1991

Jan 1992

Aug - Oct 1992

Apr - May 1993

Jun 1993

Aug 1993

Mar 1994

May 1994

Oct 1994

Oct - Nov 1994

Mar 1995

Mar - Apr 1996
A refueling and maintenance outage lasted 256 days. Major work included installation of a high response generator exciter and LP turbine rotor, 5-year inspection of the HP turbine rotor, fuel inspection, intake structure repair, SG and RCP inspection, CRD and FW control work, and turbine generator rotor replacement due to Unit 3 rotor failure in October.

A 30-day outage was necessary after a manual reactor trip followed a turbine stop valve closure to make repairs to the valve and other components that failed during the trip.

An outage of 14 days was necessary to repair a RCP.

The unit was shut down for 9 days after an RCP under-frequency relay failed.

A 10-day outage was necessary to replace an auxiliary oil pump.

The unit was shut down for 19 days to repair a pressurizer spray valve leak and a leak in the pressurizer upper manway. Total outage time was 19 days.

A refueling and maintenance outage lasted 338 days. Major work included addition of a two more DGs to the site and installation of an additional security system. Other major work included SG plug removal and inspection, transformer changeout, ATWS modifications, RTD bypass elimination, vital area barrier modification, high energy pipe inspection, and atmospheric dump valve replacement. The extended outage was completed on budget and ahead of schedule.

The unit was shut down when a load sequencer circuit card failed. The unit remained down to repair a Conoseal leak. The outage lasted 8 days.

The unit was shut down for 5 days to repair a flow transmitter weld joint.

The unit was shut down before Hurricane Andrew hit the site. Winds of up to $165 \mathrm{mph}$ caused some physical destruction and a LOSP, but no significant radiation releases. The outage was extended partially due to FEMA's concern of off-site emergency preparedness. The unit was down for 61 days.

A refueling and maintenance outage lasted 47 days. Major work included RCP motor replacement, SG ECT, and RV Conoseal ${ }^{\circ}$ and in-core instrument seal table connector upgrades.

A total of 9 days of downtime were needed on two separate occasions to repair a main steam check valve packing leak following failure of the main turbine to relatch following testing.

A 4-day outage was needed to repair a leak on a pressurizer spray valve.

The unit was shut down for $\mathbf{8}$ days to repair a movable in-core guide tube.

The unit's license was extended by 7 years to recapture the construction period.

The plant received all Category 1 ratings on its NRC SALP, and the evaluations were lengthened to a 24-month cycle.

A refueling and maintenance outage lasted 43 days.

A 5-day outage was taken to repair a letdown valve.

A refueling and maintenance outage lasted 36 days. 
This Page Intentionally Left Blank 
VERMONT YANKEE

PRODUCTION COST and CAPITAL ADDITIONS

(1996 Dollars)

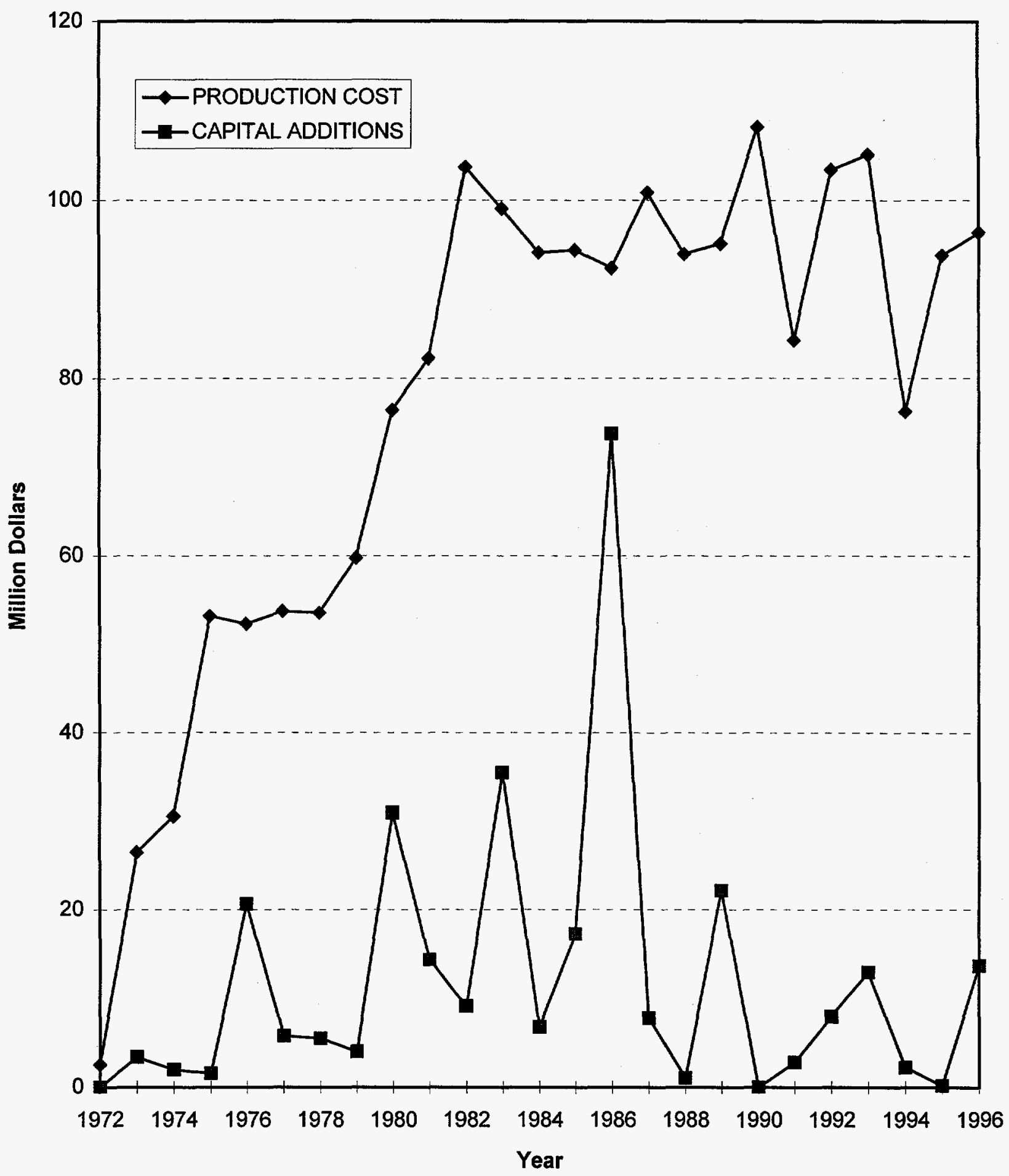




\section{NUCLEAR POWER PLANT OPERATING EXPERIENCE SUMMARY}

Unit data summary through December 1996

Unit: VERMONT YANKEE

Location: WINDHAM COUNTY, VERMONT

Owner: VERMONT YANKEE NUCLEAR POWER CORP. Type: GENERAL ELECTRIC BWR

Construction Permit: 12/11/67

Operating License: $\mathbf{2 / 2 8 / 7 2}$

Commercial Oper. Date: 11/30/72
Nameplate Rating: $540 \mathrm{MWe}$

MDC Net MWe: 510 MWe

Cumul. Avail. Factor: 81.3

Cumul. Cap. Factor (MDC Net): 76.0

Cumul. Forced Outage Rate: 4.8

3-Year Avg. Cap. Factor (MDC Net): 89.6

License Expiration: 2012

OPERATING HISTORY (To December 1996)

Date

Mar 1972

Sep 1972

Nov 1972

Jan - Mar 1973

Aug 1973

Sep - Nov 1973

Dec 1973

Dec 1973

Jan 1974

Mar - Jun 1974

Mar - Apr 1974

Sep - Nov 1974
Comment

A provisional operating license for $1 \%$ power was issued and initial criticality was achieved on March 24.

A $20 \%$ license was issued and the first electricity was produced.

Power levels were severely limited because of high off-gas activity from failed fuel.

The unit was shut down for fuel sipping and reconstitution. After fuel reconstitution, power was limited to $75 \%$ for surveillance of fuel performance.

Special shutdown margin tests and an investigation of $\mathrm{FW}$ vibrations required a 1.5-week outage. Power was restricted to $80 \%$ due to a fuel densification issue. A number of offgas system explosions were experienced during mid-year causing a total of about 1 week of shutdown time.

A 6-week shutdown occurred for fuel reconstitution and connection of a new off-gas system. After fuel damage was discovered, fuel channels were repaired and bypass hole plugs were installed. The AEC permitted startup with a $75 \%$ power limit.

The AEC imposed a fine of $\$ 15,000$ for an inadvertent criticality that occurred in November 1973.

The new off-gas system was placed in service.

The AEC power level restrictions were removed.

Licensing hearings were conducted regarding the necessity for inerting containment. The regulatory staff and the ACRS decided that the containment should be inerted with nitrogen.

High off-gas levels due to leaks in the remaining original fuel assemblies became an issue of concern. An $80 \%$ power limit was imposed, and the state expressed concern over the release rate.

The ASLAB overruled the regulatory staff on the containment inerting issue. The AEC Commissioners then reversed the ASLAB ruling and ordered a formal rule-making proceeding to resolve this issue for all BWRs. The unit was not required to inert in the meantime. 
Oct - Dec 1974

May 1975

Jun 1975

Aug 1975

Jan - Feb 1976

Jun - Jul 1976

Jul 1976

Aug - Oct 1977

Jul - Aug 1978

Sep - Oct 1978

Oct - Nov 1978

Mar - Apr 1979

Sep - Nov 1979

1980

Sep - Dec 1980

Jan 1981

Oct - Dec 1981

Apr 1982

Jul - Aug 1982

Mar - Jun 1983
A refueling shutdown included a main turbine overhaul.

Power was limited to $80 \%$ because of the BWR in-core detector problem.

A 10-day shutdown resulted from a startup transformer failure.

A 23-day shutdown was required to plug core plate holes and eliminate an in-core instrument vibration problem.

A concern about the adequacy of torus hold-downs resulted in a 2.5 -week outage.

The unit was shut down for a refueling and maintenance outage. The FW spargers and recirculation bypass lines were replaced.

Three relief valves were found inoperable due to degraded valve diaphragms caused by improperly installed insulation. All operating U.S. plants were notified of the problem.

The third refueling and maintenance outage occurred. The replacement of cracked core spray piping extended the outage.

Cracks found in the torus support column welds required a shutdown of about $\mathbf{4 5}$ days for repairs.

The unit was shut down for a refueling and maintenance outage. Six leaking FAs were found during refueling operations.

An outage due to turbine bearing problems required a 10-day shutdown.

Refueling and fuel sipping identified 24 leaking FAs.

During a refueling outage, evidence of lower end plug wear was discovered on the water rods; these required modification.

The NRC directed the utility to install recirculation pump automatic shutdown equipment to mitigate the possible effects of an ATWS.

During a refueling outage, the entire core was removed and the RCS drained to replace RWCU piping. Signs of IGSC cracks were detected at several weld points.

The utility hired an independent consultant to investigate and identify problems associated with pipe cracks.

A refueling outage was conducted and jet pump beams were also replaced.

The NRC proposed a fine of $\$ 440,000$ for incorrect operator response during a reactor scram on low-level indication and an ECCS automatic start due to a failure in the FW control system.

The unit operated for a 2-week period with computer-aided circulating water control based on ambient temperature and flow to maximize turbine efficiency and to minimize ecological impact. About $7900 \mathrm{MWh}$ of electricity were saved, and the plan was to be extended.

The unit was shut down for refueling and maintenance. Recirculation piping and welds were inspected per IE Bulletins 82-03 and 83-02. Several crack indications were found and repaired. 
May 1983

Jun - Aug 1984

Sep 1984

Sep - Dec 1985

Oct 1985

Jan - Jul 1986

Sep 1986

Dec 1986

May - Jun 1987

Aug - Oct 1987

Sep 1987

Dec 1987

May 1988

Jun - Aug 1988

Oct 1988

Feb - Apr 1989

Mar 1989

Mar 1990
The NRC proposed a fine of $\$ 40,000$ for alleged failure to maintain secondary containment during spent fuel movement. In August, the NRC withdrew the fine after considering the licensee response to the proposed fine and the corrective actions taken.

A refueling and maintenance outage lasted 54 days.

The unit was shut down to investigate a power-to-flow mismatch. The holddown bolts for the moisture separator were found loose. Reinstallation of the separator was necessary.

The unit was shut down for refueling and recirculation piping replacement.

The NRC proposed a $\$ 50,000$ fine for an alleged personnel overexposure due to inadequate radiological instructions.

The 1985 refueling outage was extended to repair CS nozzle weld IGSC cracks.

A study conducted by the utility and consultant engineers estimated a 7\% probability of containment failure under LOSP and/or overpressure conditions. The study also identified several procedural and hardware modifications that would enhance safety.

The utility submitted a license amendment request to increase spent fuel storage capacity from 2000 to 2870 FAs.

Off-gas activity from the SJAE increased during a 6-week period. One or more fuel pin cladding failures were suspected.

The unit was shut down for a refueling and maintenance outage after completing its best operating cycle. The capacity factor was $95 \%$, and the availability factor was $99 \%$. The core was scheduled to receive 136 new FAs during the outage.

The utility announced plans to pursue a direct torus venting system. The system involves directing steam and gases from the drywell through the torus water before venting to atmosphere.

The unit achieved a yearly capacity factor of $80 \%$ including the refueling outage, equaling its previous best for a refueling year. The unit average capacity factor since initial operation was $70.7 \%$, the highest in the United States for that type unit.

The NRC amended the operating license to allow installation of new spent fuel racks that would accommodate 2870 FAs. However, the number of FAs that could be stored was limited to 2000 pending further NRC review.

Operation was interrupted intermittently due to reactor scrams from main turbine bearing vibration and turbine pressure control. Shutdowns were also necessary to repair steam leaks and RHR valve packing leakage. Total outage time was 13 days.

The unit experienced a $15 \%$ to $18 \%$ power oscillation while at $53 \%$ power. Because the operators were trained to look for such conditions, they were able to recover from the event quickly. This was the third such occurrence at a United States BWR.

The unit was shut down for a refueling and maintenance outage. Major items included control rod blade and LP turbine rotor replacement.

An UE was declared following partial RPV draining caused by an RHR pump testing error.

The unit was manually shut down for a scheduled PM and a control rod exchange which lasted 5 days. 
Aug - Oct 1990

Jan 1991

Mar 1991

Apr 1991

Jul 1991

Aug 1991

Sep 1991

Mar - Apr 1992

Apr 1993

Aug - Oct 1993

Nov 1993

Jan 1994

Oct 1994

Mar - May 1995

Aug 1996

Sep - Oct 1996
A refueling and maintenance outage lasted 45 days. Major work included replacing an UPS and two FW check valves, installation of vibration monitors, and overhaul of one LP turbine rotor.

The NRC extended the operating license almost 5 years to recapture the construction period.

A 4-day outage followed a generator trip/reactor scram due to a main switchyard ground.

Another generator trip was caused by maintenance on the plant's switchyard batteries and resulted in a 5-day shutdown.

The NRC amended the operating license to allow spent-fuel storage up to 2870 FAs.

The NRC proposed and the utility paid a $\$ 75,000$ fine for alleged violations involving safeguards requirements.

The unit was shut down for 6 days to replace both recirculation pump seals.

The Vermont Low-Level Radioactive Waste Authority voted to terminate site characterization at the plant site for a low-level waste facility.

A refueling and maintenance outage lasted 45 days. Major work included invessel ISI; replacing two FW check valves, two FW heaters, three station service transformers, the main transformer, and the drywell cooling units; overhaul of the HP turbine; and installation of a hardened containment vent.

The unit shut down for 10 days to repair a feedwater discharge header leak.

A refueling and maintenance outage lasted 59 days.

A 5-day outage was necessary to replace a leaking expansion joint on one of the condensers.

The NRC proposed a $\$ 187,000$ fine for alleged procedure violations during the September 1993 refueling and for deficiencies in the service water system.

Two short maintenance outages lasted a total of 4 days.

A refueling and maintenance outage lasted 47 days.

The NRC proposed and the licensee paid a $\$ 50,000$ fine for inadequate single failure analysis of ECCS equipment.

A refueling and maintenance outage lasted 55 days. 
This Page Intentionally Left Blank 
VOGTLE

PRODUCTION COST and CAPITAL ADDITIONS (1996 Dollars)

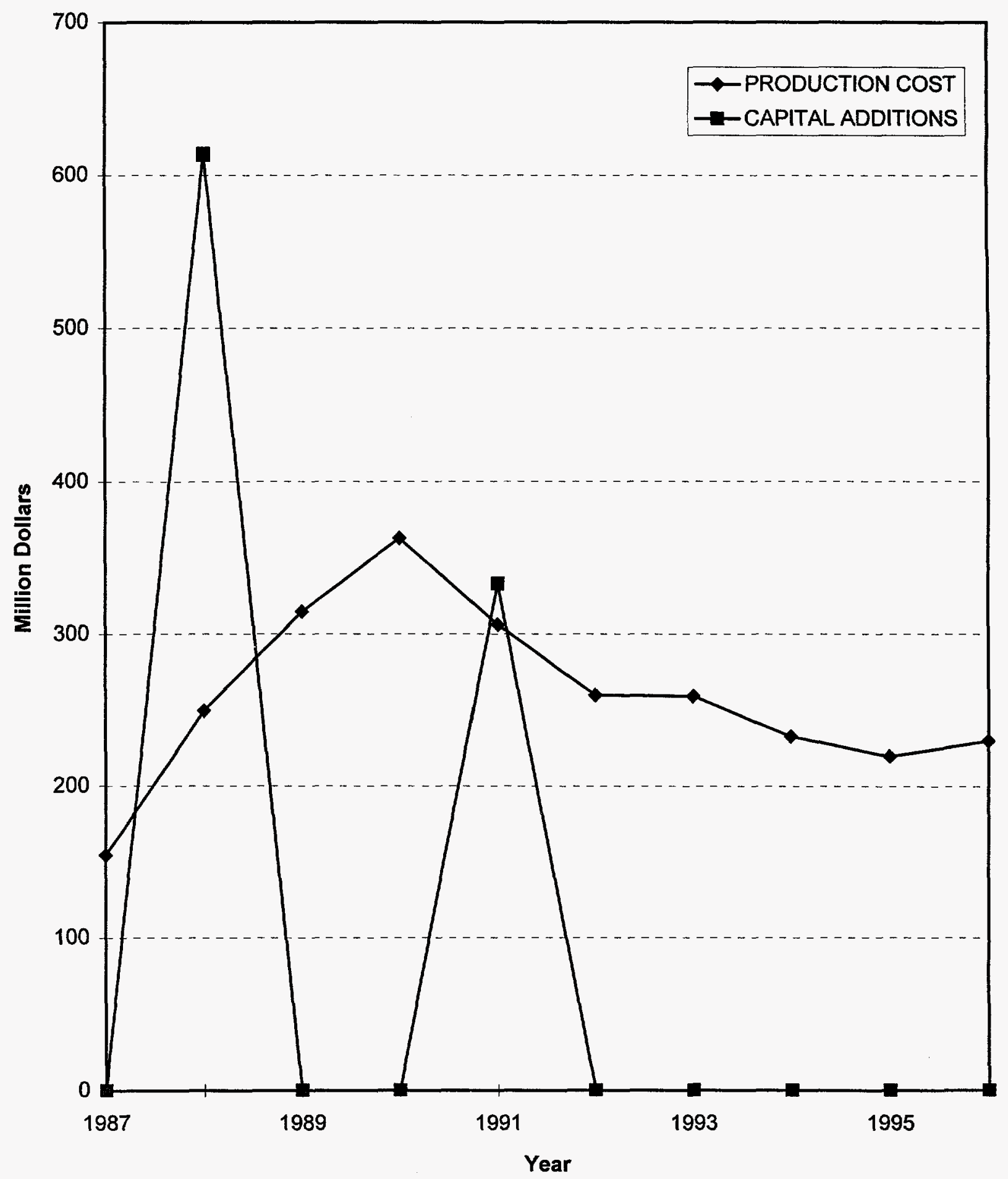




\title{
NUCLEAR POWER PLANT OPERATING EXPERIENCE SUMMARY
}

\author{
Unit data summary through December 1996
}

Unit: VOGTLE 1

Location: BURKE COUNTY, GEORGIA

Owner: GEORGIA POWER CO.

Type: WESTINGHOUSE PWR

Construction Permit: 6/28/74

Operating License: $\mathbf{3 / 1 6 / 8 7}$

Commercial Oper. Date: 6/01/87
Nameplate Rating: 1215 MWe

MDC Net MWe: 1162 MWe

Cumul. Avail. Factor: 86.3

Cumul. Cap. Factor (MDC Net): 84.3

Cumul. Forced Outage Rate: 4.5

3-Year Avg. Cap. Factor (MDC Net): 88.0

License Expiration: 2027

OPERATING HISTORY (To December 1996)

Date

May 1987

Jun - Jul 1987

Sep 1987

Oct - Nov 1987

Jan 1988

May 1988

Oct - Nov 1988

Jan 1990

Feb 1990

Feb - Apr 1990

Mar 20, 1990

\section{Comment}

The unit was shut down for repair of pressurizer spray valves and a PORV. A turbine bearing that exhibited excessive vibration was also inspected. Total outage time was 10 days.

The unit experienced four forced outages for various unrelated problems. Total outage time was 18 days.

The NRC proposed two fines totaling $\$ 250,000$ against the utility. The first, for $\$ 200,000$, was assessed for various alleged security violations. The second, for $\$ 50,000$, was assessed for two alleged operating violations concerning RHR degraded flow conditions and RTB inoperability.

The unit was shut down for an 11-day outage for snubber inspection followed by a 12-day outage to replace a failed $\mathrm{RCP}$ motor.

The unit was shut down for 18 days because of a RCS leak.

The unit completed its first year of commercial operation with a capacity factor of $73 \%$.

The first refueling and maintenance outage lasted 53 days. Major work included turbine, generator, and RCP seal inspections; SG inspection; RHR maintenance; and flux mapping.

An NRC SALP assessment cited two concerns in plant performance: (1) the need to improve the security program, and (2) the need to improve plant staff attention to detail.

The NRC assessed a $\$ 7500$ fine for alleged violations concerning document control of safeguards information.

The second refueling and maintenance outage lasted 56 days. Major work included DG system rework; SG inspection, tube plugging and sludge lancing; ILRT; RHR pump rework; LP turbine, turbine-driven FW pump, and auxiliary turbine inspection; and ISI as required.

During the refueling outage, a site area emergency (SAE) was declared when a fuel truck struck a support pole for incoming power and caused a LOSP. The DG started but tripped; approximately 33 minutes elapsed before power could be restored. The NRC sent an Incident Investigation Team to the plant to investigate the event. The SAE was the second ever declared in the United States; the first was at Ginna in 1982 when a SG tube ruptured. 
Aug 1990

Nov 1990

Dec 1990

Feb 1991

Apr 1991

Sep - Nov 1991

Oct 1991

Jan 1992

May 1992

Sep 1992

Jan 1993

Mar 1993

Mar - Apr 1993

May 1994

Jul 1994

Sep - Oct 1994

Mar - Apr 1996

May 1996
The NRC assessed a $\$ 50,000$ fine for alleged failure to protect safeguards information.

The NRC assessed a $\$ 40,000$ fine against the utility for alleged regulatory violations incurred during the March 20, 1990, LOSP event.

The unit had a scheduled l-week outage to identify and repair the source of RCS leakage.

The NRC proposed a $\$ 50,000$ fine against the utility for alleged continued violations of safeguards information security requirements.

The NRC proposed a $\$ 40,000$ fine for the alleged failure to make timely notification of emergency conditions during the March 1990 LOSP event.

The third refueling and maintenance outage lasted 71 days. Major work included SG ECT, sludge lancing, and level tap modification; RTD bypass modifications; RCP motor inspections; and a 5-year DG inspection.

During the October outage, the reactor vessel water level was lowered too far due to false level readings, and a $17 \mathrm{~F}$ degree increase was the result. The NRC sent an inspection team to the site.

The NRC proposed a $\$ 100,000$ fine for alleged violations involving intentionally opening valves to the RWST in violation of TSs for the purpose of cleaning. The base fine was doubled because the NRC found the violation and lack of response by the utility.

An 8-day outage was needed to repair a leak in a weld on a drain valve in the SI system.

Georgia Power applied to transfer the plant license to Southern Nuclear Operating Company, Inc.

The Justice Department planned to investigate Southern Nuclear about allegations that the company had falsified DG test results submitted to the NRC following the March 1990 LOSP event.

The NRC SALP report gave the plant top Category 1 ratings in 5 categories and no Category 3 ratings.

The fourth refueling and maintenance outage lasted 45 days.

The NRC proposed a $\$ 200,000$ fine for allegedly providing inaccurate information to the NRC about the reliability of the emergency diesel generators. Additional action against six Georgia Power officials for their involvement in this issue was also being considered by the NRC.

The NRC proposed a $\$ 25,000$ fine for alleged violations involving inoperable exhaust dampers for the piping penetration area filter and exhaust system. The base penalty was reduced due to the immediate corrections taken once the deficiency was identified.

The fifth refueling and maintenance outage lasted 36 days.

The sixth refueling and maintenance outage lasted 49 days.

The plant shut down for $\mathbf{1 5}$ days to retrieve loose parts from one of the steam generators. 


\section{NUCLEAR POWER PLANT OPERATING EXPERIENCE SUMMARY}

Unit data summary through December 1996

Unit: VOGTLE 2

Location: BURKE COUNTY, GEORGIA

OWner: GEORGIA POWER CO.

Type: WESTINGHOUSE PWR

Construction Permit: 6/28/74

Operating License: 2/9/89

Commercial Oper. Date: 5/20/89
Nameplate Rating: 1215 MWe

MDC Net MWe: $1162 \mathrm{MWe}$

Cumul. Avail. Factor: 88.9

Cumul. Cap. Factor (MDC Net): 86.4

Cumul. Forced Outage Rate: 1.8

3-Year Avg. Cap. Factor (MDC Net): 89.9

License Expiration: 2029

OPERATING HISTORY (To December 1996)

Date

Jan 1990

Sep - Nov 1990

Feb 1991

Mar 1991

Mar - May 1992

Dec 1992

Sep - Oct 1993

Jun 1994

Jul 1994

Feb - Mar 1995

Sep - Oct 1996

\section{Comment}

An NRC SALP assessment cited two concerns in plant performance: (1) the need to improve the security program, and (2) the need to improve plant staff attention to detail. The report noted that Unit 2 startup had been more efficient due to integration of lessons learned from Unit 1 startup.

The first refueling and maintenance outage lasted 60 days. Major work included SG sludge lancing and cooling tower modifications.

The NRC proposed a $\$ 50,000$ fine against the utility for alleged continued violations of safeguards information security requirements.

The unit was shut down for 7 days to repair a SG secondary side handhole leak.

A second refueling and maintenance outage lasted 59 days. Major work included installation of a new volume control system water level control system, SG ECT, and RCP maintenance.

A 6-day outage was needed to correct increasing RCS and main generator hydrogen leakage.

The third refueling and maintenance outage lasted 41 days.

The unit was shut down to repair a SI check valve leak and remained in the outage to investigate vibration problems on one of the RCPs. Total outage time was 15 days.

The unit was shut down for $\mathbf{8}$ days to repair a leak on a RCS drain line isolation valve.

The fourth refueling and maintenance outage lasted 34 days.

The fifth refueling and maintenance outage lasted 35 days. 
WASHINGTON NUCLEAR 2

PRODUCTION COST and CAPITAL ADDITIONS (1996 Dollars)

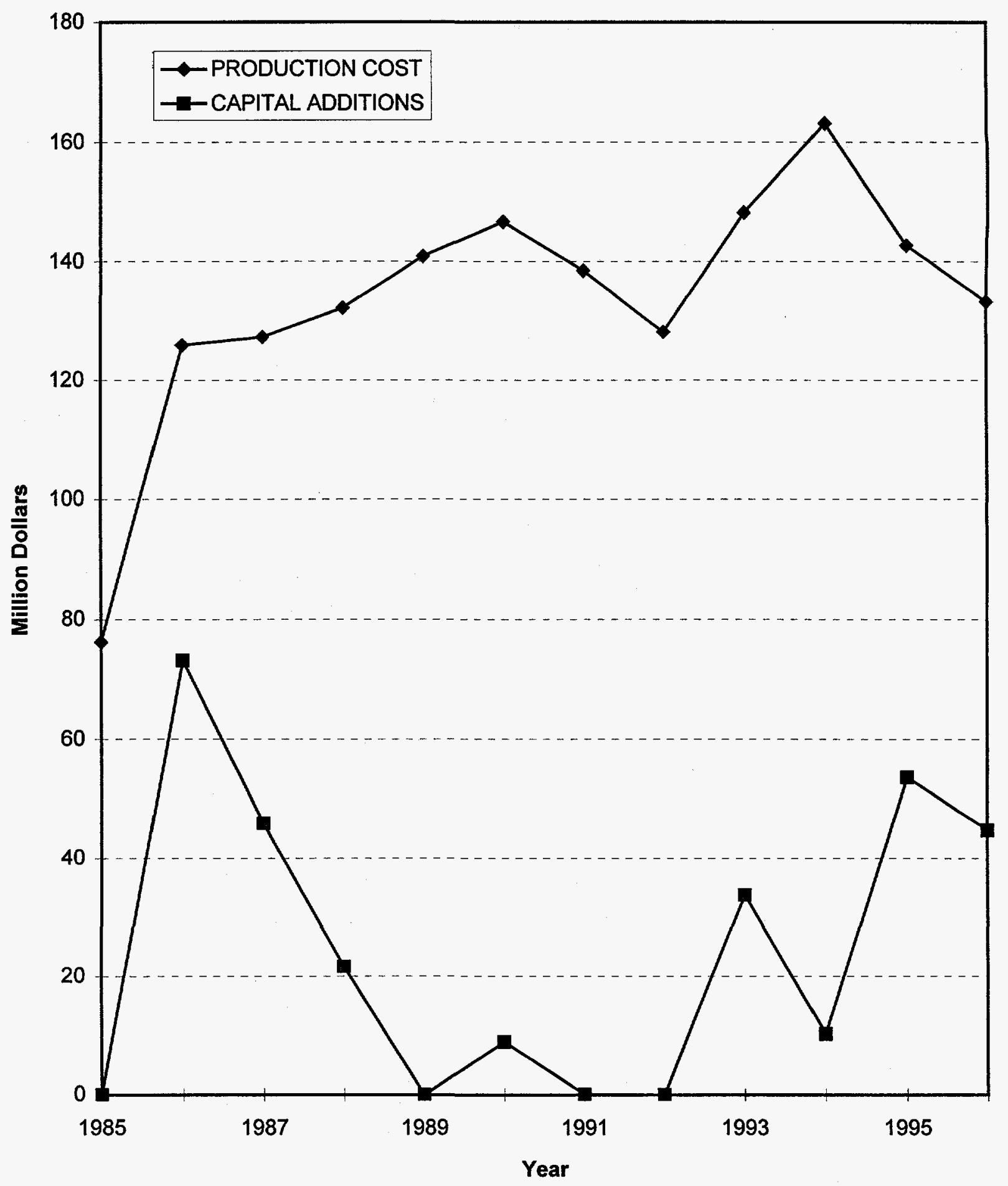




\section{NUCLEAR POWER PLANT OPERATING EXPERIENCE SUMMARY}

Unit data summary through December 1996

Unit: WASHINGTON NUCLEAR 2

Location: BENTON COUNTY, WASHINGTON

Owner: WASHINGTON PUBLIC POWER SUPPLY SYSTEM

Type: GENERAL ELECTRIC BWR

Construction Permit: 3/19/73

Operating License: 4/13/84

Commercial Oper. Date: $12 / 13 / 84$
Nameplate Rating: 1199 MWe

MDC Net MWe: 1107 MWe

Cumul. Avail. Factor: $\mathbf{7 1 . 0}$

Cumul. Cap. Factor (MDC Net): 60.9

Cumul. Forced Outage Rate: 10.4

3-Year Avg. Cap. Factor (MDC Net): 65.4

License Expiration: 2023

OPERATING HISTORY (To December 1996)

\section{Date}

May - Jun 1985

Mar - Jun 1986

Apr - Jun 1987

Jul 1987

Feb 1988

Apr - Jun 1988

Apr - Jun 1989

Aug 1989

Sep 1989

Dec 1989

\section{Comment}

A mid-cycle maintenance outage included turbine shaft alignment, recirculation pump bearing replacement, FW heater maintenance, circulating water and SW system modifications, and repairs to several plant systems. A fire occurred in a FW pump at the end of outage.

The unit was shut down for 87 days because of oversupply of power in region. During the outage, the LP turbine was inspected and rotating assembly on one recirculation pump was replaced.

A refueling and maintenance outage lasted 76 days. Major work included LP turbine refurbishment, MSR tube bundles replacement and installation of a new computer system installed to assist operators in assessing plant conditions.

The plant suffered several unplanned shutdowns to correct various electrical problems and verify operability of a number of valves.

A shut down occurred for work on the main condenser system. During shutdown, inadvertent start of reactor building supply fans overpressurized reactor building and caused rupture of building sheet metal roof. The unit was shut down for 18 days.

A refueling and maintenance outage lasted 55 days.

A refueling and maintenance outage lasted 56 days.

The unit was shut down for 5 days to resolve electrical fuse coordination and electrical separation concerns on low voltage MCCs.

The unit was shut down due to condenser tube leakage. During the 8-day outage, two tubes were plugged and two steam extraction line expansion bellows and a condenser baffle were repaired.

The NRC proposed a $\$ 55,000$ fine for alleged violations involving the use of commercial grade components in safety-related applications. The fine was withdrawn since this appeared to be an industry-wide problem and addressing individual cases was inappropriate. 
Jan 1990

Apr - Aug 1990

Sep 1990

Nov 1990

Apr - Jun 1991

Jun - Sep 1991

Nov 1991

Dec 1991

Feb 1992

Feb 1992

Mar 1992

Apr - Jul 1992

Aug 1992

Jan 1993

Feb 1993

May - Jun 1993

Aug 1993

May - Jul 1994

Feb 1995
The utility's lawsuit against GE for $\$ 1$ billion for containment design deficiencies was scheduled to go to trial.

A refueling and maintenance outage lasted 108 days. Major work included replacing four MSIVs, repairing 35 CRDs, and replacing part of extraction steam piping. The outage was extended to repair a failed diesel generator.

A 5-day outage was necessary to correct a low DEH control system pressure condition.

A crack in the drain line off the HPCS injection header and testing of similar drains required a 9-day outage.

The annual refueling outage was extended to avoid conflict with Bonneville Power Administration plans for flood control and fish protection on the Columbia and Snake rivers.

The unit was shut down for 106 days to upgrade emergency procedures and to provide additional operator training.

Two outages totaling 10 days were caused by condenser in-leakage and a blown fuse in the FW level controller.

A 5-day outage was required to correct condenser tube in-leakage.

An NRC SALP report rated plant operations and safety assessment/quality verification a low Category 3, down from Category 1 in the previous report.

A 22-day outage was taken to perform containment recombiner drain pipe modifications.

The NRC proposed and the utility paid a $\$ 25,000$ fine for violations involving incorrect component installation in both trains of the hydrogen recombiner that had rendered the system inoperable since startup in 1984.

The seventh refueling and maintenance outage lasted 93 days. Major work included replacement of all three LP turbine rotors, recirculation pipe decontamination, and 10-year ISI of the hydraulics.

Power oscillations occurred due to design and operator errors. The unit was shut down for 17 days. In December, the NRC proposed a $\$ 75,000$ fine for alleged violations involving the maintaining reactor core stability as evidenced by the power oscillations.

The unit scrammed on low reactor water level after a FW pump tripped followed an inadvertent actuation of the fire protection deluge system. The outage was extended to repair a main steam leak and lasted 11 days.

Two plant shutdowns resulted in total outage time of another 11 days. The first was due to excessive turbine vibration and containment isolation valve problems. The second was due to FW control problems.

The eighth annual refueling and maintenance outage lasted 52 days.

The unit scrammed when an MSIV closed. The 9-day outage was needed to repair the MSIV pilot valve which had been recently rebuilt.

The ninth annual refueling and maintenance outage lasted 91 days.

The plant was shut down for 5 days following a turbine trip due to operator error. 
Apr 1995

Apr - Jun 1995

Apr - Jun 1995

Mar - Apr 1996

Apr - Jun 1996

Jun 1996

Nov 1996
The plant was shut down for 5 days following a turbine trip due to a relay failing.

The tenth annual refueling and maintenance outage lasted 53 days. After performing postrefueling testing, the unit shut down for 19 days due to low power demand.

An NRC AIT was sent to the plant due to violations of operating procedures during the restart following the outage.

The unit was shut down for 42 days at BPA's request due to low power demand.

The eleventh annual refueling and maintenance outage lasted 69 days.

A software error in the digital feedwater controller caused a reactor scram. The plant was down for 5 days.

The NRC proposed and the licensee paid a $\$ 100,000$ fine for the control room HVAC being inoperable during plant startups. 
WATERFORD 3

PRODUCTION COST and CAPITAL ADDITIONS (1996 Dollars)

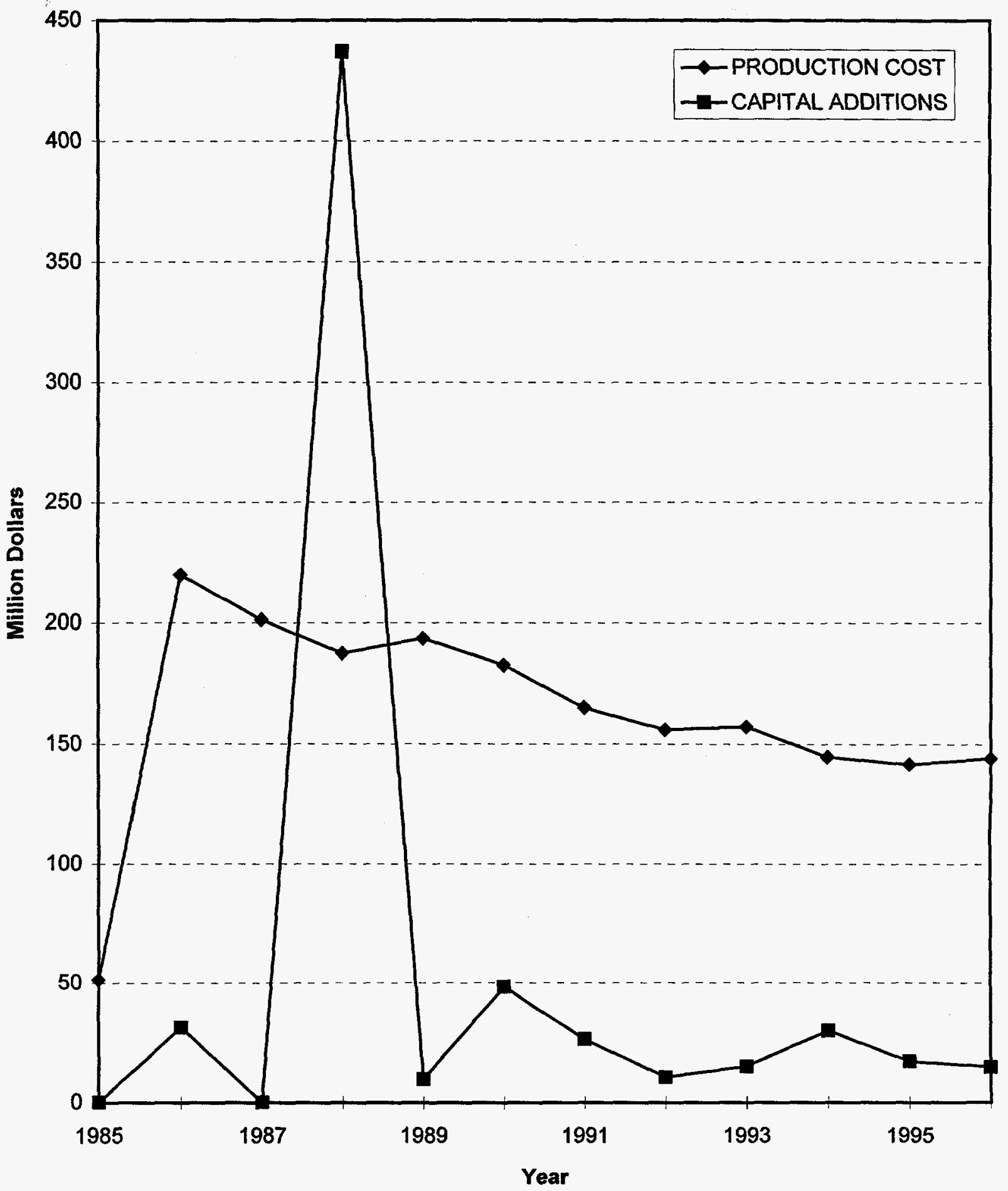




\section{NUCLEAR POWER PLANT OPERATING EXPERIENCE SUMMARY}

Unit data summary through December 1996

Unit: WATERFORD 3

Location: ST CHARLES COUNTY, LOUISIANA

Owner: ENTERGY OPERATIONS

Type: COMBUSTION ENGINEERING PWR

Construction Permit: 11/14/74

Operating License: $3 / 16 / 85$

Commercial Oper. Date: 9/24/85
Nameplate Rating: $1200 \mathrm{MWe}$

MDC Net MWe: $1075 \mathrm{MWe}$

Cumul. Avail. Factor: 84.3

Cumul. Cap. Factor (MDC Net): 82.8

Cumul. Forced Outage Rate: $\mathbf{3 . 7}$

3-Year Avg. Cap. Factor (MDC Net): 87.0

License Expiration: 2024

OPERATING HISTORY (To December 1996)

Date

1983

May 1985

Jul 1985

Dec 1985

Mar 1986

Aug 1986

Nov 1986 - Feb 1987

Sep 1987 - Apr 1988

Apr - May 1988

May 1988

Oct 1988

May 1989
Comment

In April, the utility paid a $\$ 20,000$ fine to the NRC for QA deficiencies found in ECCS systems. The utility requested an extension of the construction permit from October 30 , 1983, to September 30, 1984.

The NRC proposed a $\$ 130,000$ fine for alleged violations of QA requirements. The fine was later reduced to $\$ 110,000$ because of the utility commitment to corrective actions.

The unit was shut down for 68 days to repair a damaged turbine-generator.

The unit was forced to shut down for 12 days because of an incorrect value entered in the core protection calculator. A RTD and the RCP seals were also replaced during the outage.

The unit was shut down for a 23-day planned maintenance outage.

The NRC assessed a $\$ 50,000$ fine for allegedly changing operating modes in December 1985 with one train of containment spray inoperable.

The first refueling and maintenance outage lasted 73 days. Major work included RCP seal replacement, SG inspection and tube plug rework, RCP lube oil system rework, snubber inspection, DG inspection, LLRTs, and Appendix R and EQ modifications.

The unit suffered several short outages from RCP bearing high temperatures caused by clogging of lube oil strainers. The problem was traced to a precipitate in the lube oil that clogged the filters.

The second refueling and maintenance outage lasted 60 days. Major work included RCP seal replacement; SG inspection; snubber inspection; LLRTs; ISI of RV, primary, secondary, and BOP piping; and MSIV repair.

The NRC assessed a $\$ 50,000$ fine for an alleged violation involving lack of corrective action applied after a loss of RCS water level event in 1986 that was repeated in May 1988.

The unit was shut down for 25 days to retrieve FW check valve parts from secondary side SG piping and to repair RCP seals.

The NRC assessed a $\$ 50,000$ fine for alleged EQ violations in HPSI system. 


\section{WATERFORD 3}

Sep - Nov 1989

Jan 1990

Jun 1990

Oct 1990

Mar 1991

Mar - May 1991

Feb 1992

Sep - Nov 1992

Nov 1992

Mar - Apr 1994

Sep 1994

Jun 1995

Sep - Nov 1995

Mar 1996

Jul 1996

Dec 1996
The third refueling and maintenance outage lasted 59 days. Major work included RCP seal replacement, SG inspection, fuel alignment plate modification, LP turbine and generator rotor inspection, erosion/corrosion inspection, and ISI.

The unit was shut down for planned 12-day general system maintenance outage.

Operations management of Grand Gulf 1, Waterford 3, and both units of Arkansas Nuclear One was consolidated under a single company - Entergy Operations, Inc.

A 9-day outage was performed to replace a leaking pressurizer SRV. During the outage, a leak through a RCP flange was found. The NRC allowed the unit to operate with the leak until the next refueling outage.

The NRC proposed a $\$ 37,500$ fine for alleged violations involving maintaining system integrity to protect control room personnel from outside hazardous releases. The fine was paid the following month.

A fourth refueling and maintenance outage lasted 74 days. Major work included SG ECT, ILRT, LP and HP turbine and erosion/corrosion piping inspection, and piping ISI.

A scheduled outage to repair SG manway leaks lasted 8 days.

A fifth refueling and maintenance outage lasted 52 days. Major work included LP turbine disassembly/inspection, SG ECT, and main condenser and DG inspections.

The NRC SALP report gave the Unit 5, Category 1 ratings and no Category 3 ratings.

The sixth refueling and maintenance outage lasted 50 days.

The NRC proposed a $\$ 112,500$ fine for alleged violations involving electrical problems in 3 safety-related ventilation and filtration systems.

The unit tripped after a turbine trip due to a grid fault. The subsequent outage lasted 19 days.

The seventh refueling and maintenance outage lasted 44 days.

The NRC proposed and the licensee paid a $\$ 50,000$ fine for failure to correct a known deficiency in the auxiliary component cooling water system.

Bolt failure caused the baffle to rub against a RCP seal heat exchanger. Replacement of the seal, $\mathrm{HX}$, and baffle took 20 days.

The NRC proposed and the licensee paid a $\$ 50,000$ fine for failure to test valves in the IST program. 
This Page Intentionally Left Blank 
WATTS BAR

PRODUCTION COST and CAPITAL ADDITIONS

(1996 Dollars)

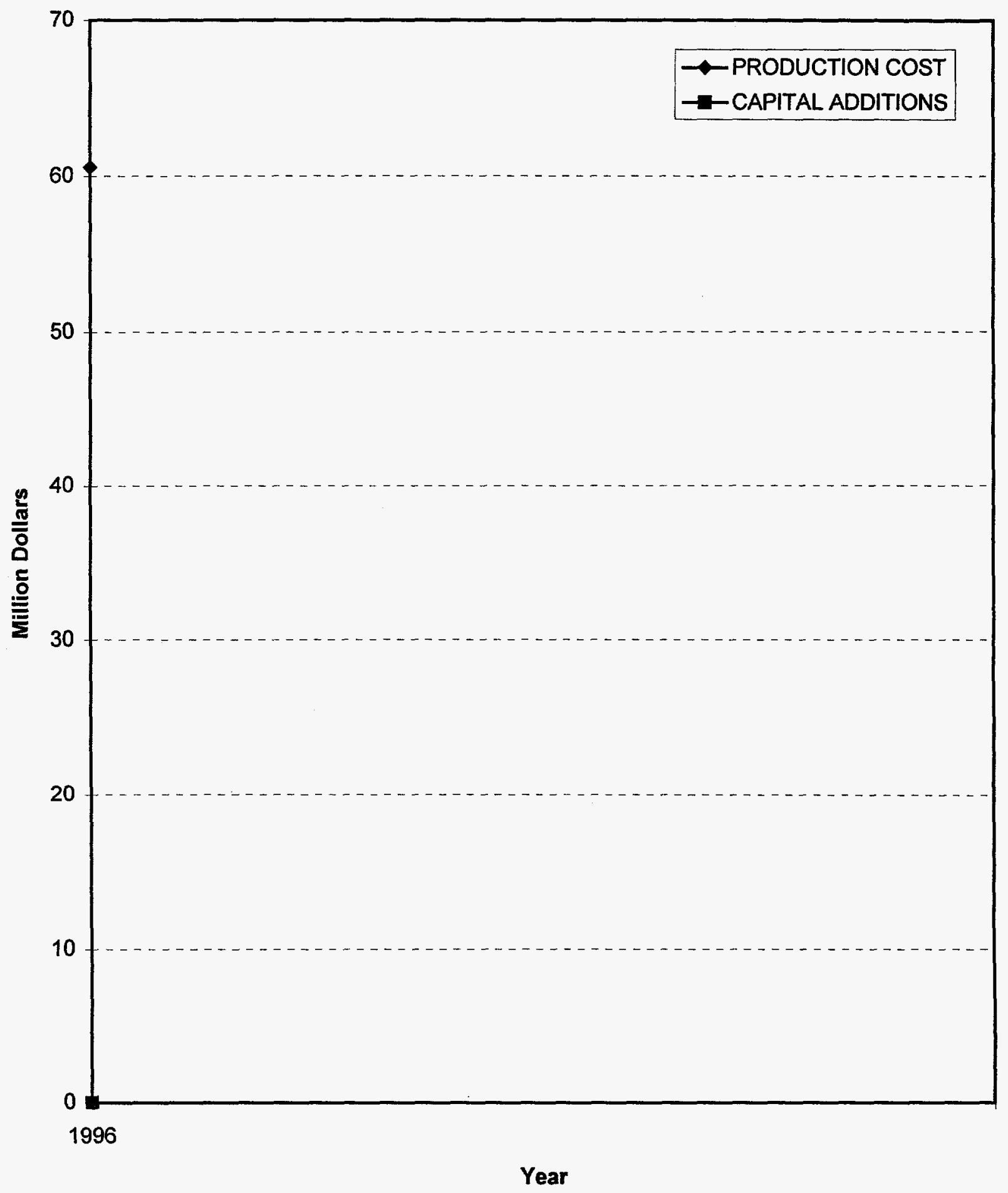




\section{NUCLEAR POWER PLANT OPERATING EXPERIENCE SUMMARY}

Unit data summary through December 1996

Unit: WATTS BAR 1

Location: RHEA COUNTY, TENNESSEE

Owner: TENNESSEE VALLEY AUTHORITY

Type: WESTINGHOUSE PWR

Construction Permit: 1/23/73

Operating License: 2/7/96

Commercial Oper. Date: 5/27/96
Nameplate Rating: 1275 MWe

MDC Net MWe: $1117 \mathrm{MWe}$

Cumul. Avail. Factor: 91.4

Cumul. Cap. Factor (MDC Net): 89.1

Cumul. Forced Outage Rate: $\mathbf{0 . 2}$

3-Year Avg. Cap. Factor (MDC Net): n/a

License Expiration: 2035

OPERATING HISTORY (To December 1996)

Date

Comment

1985

The plant had fuel on-site and was almost ready to load fuel when TVA shut down all of its operating nuclear plants and performed an extensive evaluation of its entire nuclear power program. The review and rework of Watts Bar took a decade with resolution of employee concerns being one of the principal causes.

Nov 9, 1995

The plant received its low-power license, and fuel loading began.

Feb 1996

A 16-day forced outage followed a manual turbine trip due to loss of feedwater.

Mar 1996

Two separate 4-day outages were taken. The first followed a manual turbine trip due to secondary side transients. The second followed the planned LOSP test.

Apr 1996

The plant was shut down for 10 days. The two forced outages were due to a load rejection and a loss of feedwater.

May 1996

The plant was shut down twice for a total of 7 days. Both outages followed planned plant trips as part of the power ascension test program.

Sep 1996

A manual scram occurred during a load reduction test. The plant was shut down for 18 days for surveillance testing. 


\section{WOLF CREEK}

PRODUCTION COST and CAPITAL ADDITIONS (1996 Dollars)

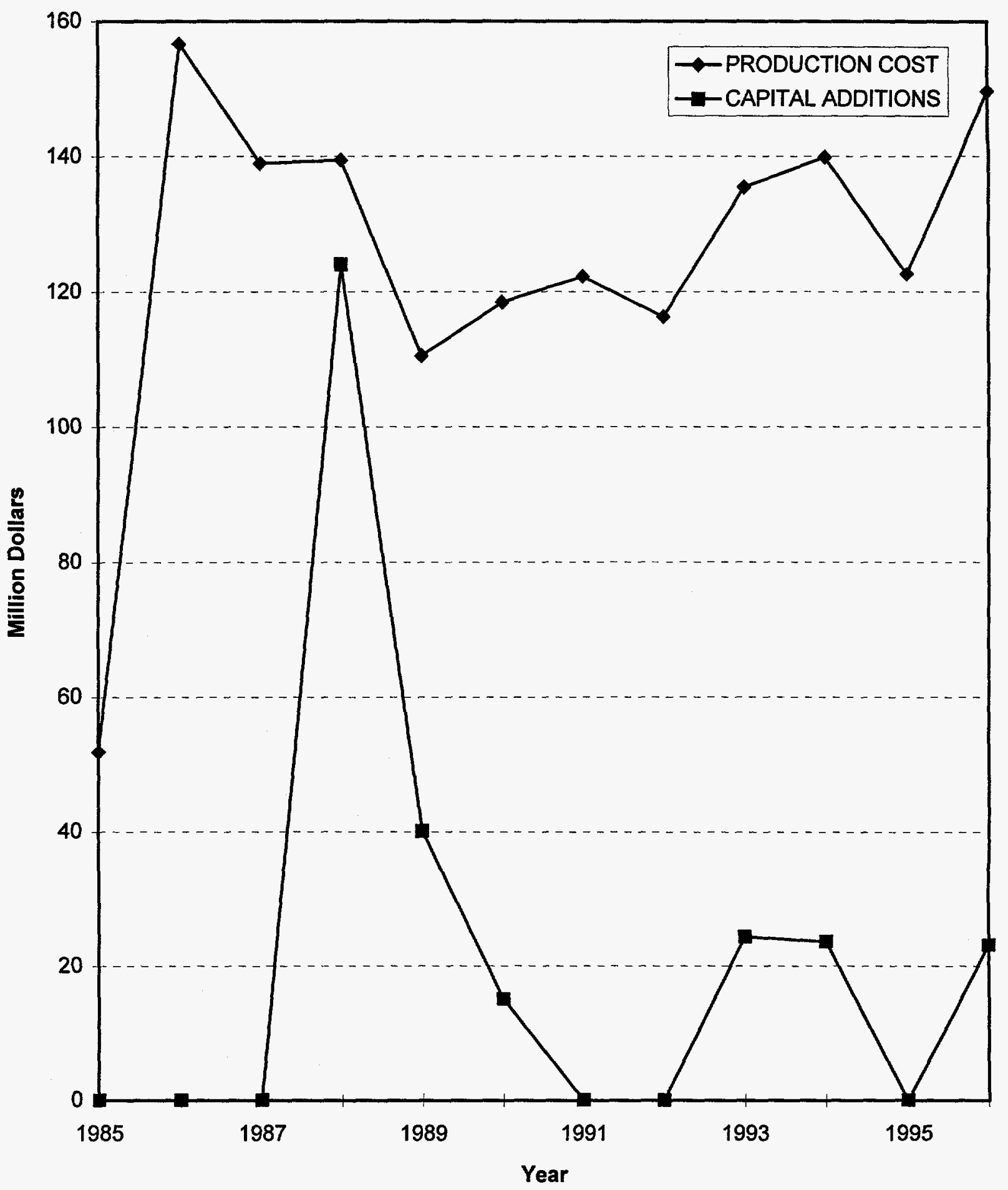




\section{NUCLEAR POWER PLANT OPERATING EXPERIENCE SUMMARY}

Unit data summary through December 1996

Unit: WOLF CREEK 1

Location: COFFEY COUNTY, KANSAS

Nameplate Rating: $1236 \mathrm{MWe}$

Owner: WOLF CREEK NUCLEAR OPER. CORP. MDC Net MWe: $1163 \mathrm{MWe}$

Type: WESTINGHOUSE PWR

Cumul. Avail. Factor: 81.4

Construction Permit: 5/31/77

Cumul. Cap. Factor (MDC Net): 79.3

Operating License: $6 / 4 / 85$

Cumul. Forced Outage Rate: 3.8

Commercial Oper. Date: $\mathbf{9 / 3 / 8 5}$

3-Year Avg. Cap. Factor (MDC Net): 87.8

License Expiration: 2025

OPERATING HISTORY (To December 1996)

Date

Mar 1983 - May 1985

Aug 1984 - Mar 1985

Sep 1985

Apr 1986

Jul 1986

Aug 1986

Oct - Dec 1986

Jan - Feb 1987

Sep 1987 - Jan 1988

\section{Comment}

Prior to initial criticality, fines totaling $\$ 140,000$ were proposed by the NRC for alleged violations involving acceptance of plant systems from the construction contractor without ensuring completion, a breakdown in the inspection and correction program for safetyrelated structural steel welds, and violations in the preoperational testing program.

Delays in meeting the scheduled fuel loading resulted in costs to the utility of about $\$ 27,000,000$.

A fine of $\$ 64,000$ was proposed by the NRC for allegedly firing an employee for expressing his beliefs about safety problems in plant electrical hardware.

After a reactor trip due to a switchyard testing error, the shutdown was extended a total of 17 days to accomplish maintenance, surveillance, and repacking of 14 RCS and 4 CVCS valves.

The NRC proposed a fine of $\$ 40,000$ for alleged violations involving uncontrolled access to protected areas.

The plant set a new performance record of 8.922 billion $\mathrm{KWh}$ for first full year of operation for domestic plants. (The old record set by Diablo Canyon 1 was 8.3 billion KWh).

The first refueling and maintenance outage lasted 66 days.

Power levels were reduced and operations were interrupted due to turbine vibration problems and several attempts to correct the problem.

The second refueling and maintenance outage lasted 101 days. The outage began 4 days early due to a reactor scram when a personnel error caused a control rod bank to drop. Refueling was temporarily suspended until an analysis was performed to determine if four other serious events were related. The events included a worker being fatally electrocuted, an $\mathrm{H}_{2}$ burn within the pressurizer, lake water being accidentally pumped into all four SGs, and a spill of radioactive resin which contaminated two workers. 
Oct 1987

Jan 1988

Oct 1988 - Jan 1989

Feb 1989

Dec 1989

Mar - May 1990

Oct 1990

Feb 1991

Sep 20, 1991

Sep 1991 - Jan 1992

Oct - Nov 1991

Feb 1992

Feb 1992

Dec 1992

Dec 1992

Mar - May 1993
A fine of $\$ 100,000$ was proposed by the NRC for the four events occurring during the outage and a separate incident involving the release of radioactive material to a municipal landfill. The base penalty was doubled because of alleged failure to take prompt corrective action for the events.

An unscheduled shutdown of 26 days was necessary to allow repairs of the reactor vessel $\mathrm{O}$-ring and for main generator exciter ground problems.

The third refueling and maintenance outage lasted 90 days. Major work included replacing 53 Westinghouse hafnium RCCAs due to swelling.

A fine of $\$ 50,000$ was proposed by NRC for alleged operation without declaring one of two essen al SW systems inoperable due to pipe erosion and reduced wall thickness - in some places $<40 \%$ of ASME minimum allowable thickness.

According to the Federal Energy Research Council, Wolf Creek operated at a capacity factor of $97.65 \%$ and incurred very low maintenance costs for 1989 , making it the most efficient plant for the year.

The fourth refueling and maintenance outage lasted 67 days. Major work included fuel inspection and reconstitution, SG ECT, an RCP seal and SW system piping replacement, and containment cooler repairs.

Kansas Gas and Electric Co. (KG\&E), a co-owner of Wolf Creek Nuclear Corporation, and Kansas Power and Light Co. (KPL) agreed to a merger. KG\&E was to become a wholly-owned subsidiary of KPL. The arrangement was to be reevaluated in 3 years.

The NRC proposed a $\$ 25,000$ fine for alleged violations for failing to ensure the operability of the SI pumps. The base penalty was reduced due to the utility's good response after discovering the condition.

The fifth refueling outage commenced after the unit accumulated 487 days of continuous operation and experienced no reactor trips during 1991.

The fifth refueling and maintenance outage lasted 73 days. Major work included RCS RTD bypass manifold removal, maintenance on DGs, SG inspection and cleaning, replacement of one RCP motor and other maintenance items. Startup was delayed by MOV testing issues.

A total of 8 out of 22 reactor operators failed requalification examination and were not allowed to return to control room watch activities.

The unit tripped on SG low-low level when an inverter supplying power to the main FW pump controllers failed. During the outage, minor leakage on three reactor vessel penetrations was found and repaired. The outage lasted 37 days.

The NRC proposed a $\$ 150,000$ fine for alleged violations involving deficiencies related to safety-related MOVs and their test program.

The NRC SALP report awarded two Category 1 ratings and one Category 3 rating, the latter in safety assessment/quality verification.

The NRC proposed a $\$ 50,000$ fine for alleged violations involving the work control program, specifically on the essential SW system.

The sixth refueling and maintenance outage lasted 73 days. 
Jan 1994

Sep - Oct 1994

Mar 1995

Jan 1996

Jan 1996

Feb - Apr 1996
Two separate outages to repair a containment cooling fan and the rod control system required only 4 days downtime.

The seventh refueling and maintenance outage lasted 46 days.

The plant was shut down for 5 days after a reactor scram occurred during testing.

The plant was shut down due to ice accumulation in the circulating water and service water intake bays. An unusual event was declared due to complications in recovery. The unit was shut down for 5 days.

An NRC AIT was sent and noted that an alert should have been declared for the event. The NRC proposed and the licensee paid a $\$ 300,000$ fine for this event which included 10 violations.

The eighth refueling and maintenance outage lasted 64 days. 
YANKEE ROWE

PRODUCTION COST and CAPITAL ADDITIONS

(1996 Dollars)

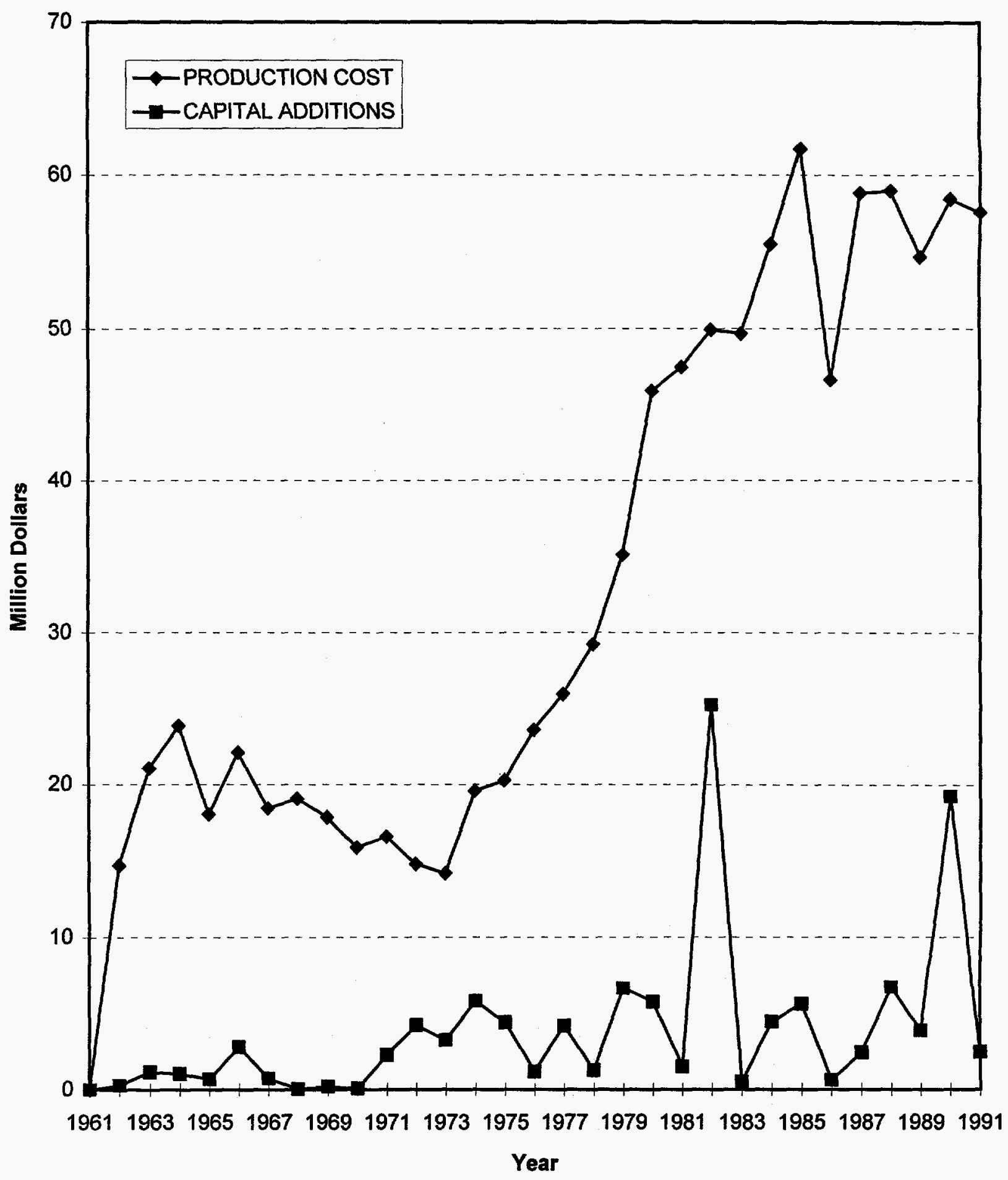




\section{NUCLEAR POWER PLANT OPERATING EXPERIENCE SUMMARY}

Unit data summary through December 1996

Unit: YANKEE ROWE

Location: FRANKLIN COUNTY, MASSACHUSETTS

Owner: YANKEE ATOMIC ELECTRIC COMPANY

Type: WESTINGHOUSE PWR

Construction Permit: 11/4/57

Operating License: 6/23/61

Commercial Oper. Date: 7/1/61
Nameplate Rating: $185 \mathrm{MWe}$

MDC Net MWe: 167 MWe

Cumul. Avail. Factor: 77.7

Cumul. Cap. Factor (MDC Net): 73.7

Cumul. Forced Outage Rate: 4.9

3-Year Avg. Cap. Factor (MDC Net): n/a

License Expiration: 2000 ${ }^{1}$

OPERATING HISTORY (To December 1996)

\section{Date}

Jan 1961

Jan 1961 - May 1962

May - Sep 1962

Sep - Nov 1963

Aug - Nov 1965

$1966-1971$

Feb 1972 - Apr 1973

May - Aug 1974

Aug 1976

Jan - Oct 1980

Sep - Dec 1982

Oct - Dec 1985

\section{Comment}

A 2-week shutdown was required to solve turbine vibration problems.

During the first core, the plant was required to shut down every 2000 full-power hours for extensive physics testing; each shutdown required about 1 week. Yankee was one of first plants to demonstrate feasibility of using boric acid (chemical shim) as an additional means of control during power operation.

The first refueling required 125 days. Radioactive silver from control rod plating contaminated the refueling cavity liner; all control rods were replaced.

The second refueling required 71 days. Control rods were replaced with hafnium; some damage occurred to in-vessel components from flow-induced vibration.

The fourth refueling, which lasted 93 days, involved complete removal of reactor internals for inspection and repair; cracks were found in pressurizer cladding.

SG tubes were piugged during several outages.

The ninth refueling outage was extended to repair the main generator, install new ECCS, replace all control rods, and install new control rod shroud structure.

A refueling outage occurred. New in-core instrumentation was installed, generator and turbine overhauled.

The NRC ordered a change in operating temperature limits related to fuel heat generation; the plant derated about $2 \%$.

The unit was shut down for TMI-2 modifications; damage found in LP turbine rotors prolonged the outage. Power was limited to about $150 \mathrm{MWe}$ because of turbine problems.

A Core 16 refueling outage was performed. A new LP turbine rotor was installed to allow full power operation, NRC granted a request for expansion of spent fuel storage to 721 FAs, the utility awarded $\$ 9$ million contract to $\mathrm{CE}$ for six batches of all-Zircalloy fuel.

During a refueling outage, a SG inspection revealed sparger weld cracks.

\footnotetext{
${ }^{1}$ The unit was permanently shutdown in February 1992 . The cumulative data are through that date.
} 
Aug 1987

Jan 1988

Oct 1988

Dec 1988

Jun - Oct 1990

Apr 1991

May 1991

Jun 1991

Oct 1991

Feb 26, 1992
The NRC assessed a $\$ 25,000$ fine for alleged violations concerning plant physical protection.

The NRC proposed a $\$ 25,000$ fine for alleged violations of plant security for safeguards information.

The unit will be the first PWR to apply for renewal of its 40-year operating license. Yankee Rowe is the lead PWR for DOE license renewal program to extend operating life past the original 40-year license term.

Massachusetts voters rejected an anti-nuclear initiative in referendum to close two nuclear power plants in the state, including Yankee Rowe.

A refueling and maintenance outage was performed. During the outage, the DGs were replaced. NRC raised concerns about pressure vessel embrittlement in light of the application for license renewal.

The plant received four top Category 1 ratings in NRC SALP report.

The NRC proposed $\$ 50,000$ fine for alleged violations concerning training of contractor craft personnel who installed electrical connections during DG changeout.

A lightning strike caused LOSP and declaration of an unusual event, which was later upgraded to alert status because of loss of communications.

The unit was shut down until the reactor vessel embrittlement question resolved.

The utility decided to permanently shut down the unit due to the uncertainty pertaining to the issue of reactor vessel embrittlement. 
This Page Intentionally Left Blank 


\section{ZION}

PRODUCTION COST and CAPITAL ADDITIONS

(1996 Dollars)

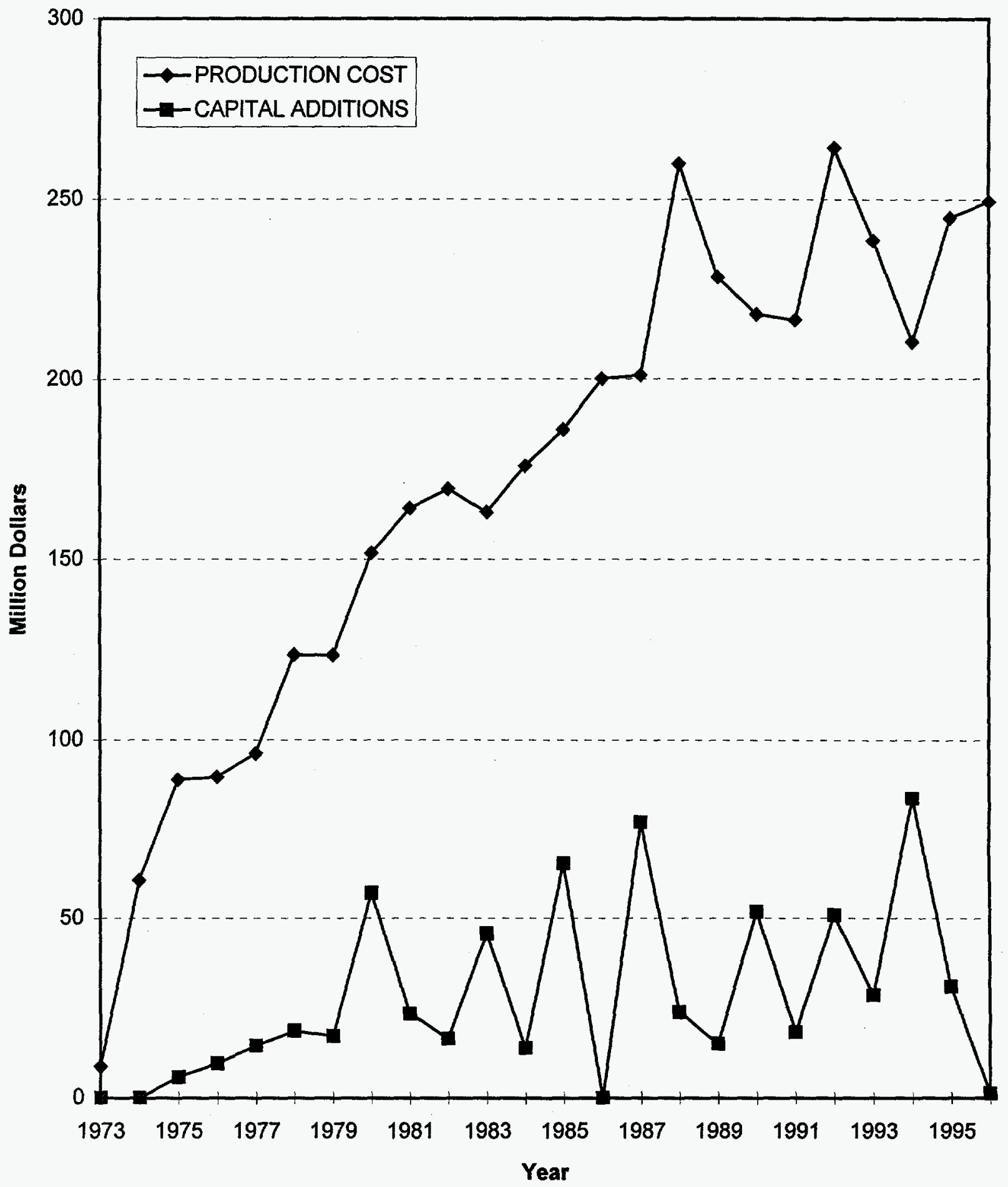




\title{
NUCLEAR POWER PLANT OPERATING EXPERIENCE SUMMARY
}

\author{
Unit data summary through December 1996
}

Unit: ZION 1

Location: LAKE COUNTY, ILLINOIS

Owner: COMMONWEALTH EDISON CO.

Nameplate Rating: 1085 MWe

Type: WESTINGHOUSE PWR

MDC Net MWe: 1040 MWe

Construction Permit: 12/26/68

Cumul. Avail. Factor: 66.2

Operating License: 10/19/73

Commercial Oper. Date: 12/31/73

License Expiration: 2008

OPERATING HISTORY (To December 1996)

Date

1973

Jul 1974

Feb - Mar 1975

May - Jul 1975

Mar - Jun 1976

Sep - Oct 1976

Sep - Dec 1977

Sep - Oct 1977

Oct 1979 - Feb 1980

Jan - Apr 1981

Feb 13, 1982

\section{Comment}

Early startup problems occurred with main steam isolation check valves, boron system heat tracing, and boron removal system. Main generator short circuits extended the outage into April 1974.

Power ascension testing was completed, but power was limited to $85 \%$ because of fuel densification issue.

Several shutdowns were required for various repairs; the last shutdown was to convert to allvolatile secondary water chemistry treatment and to perform fuel surveillance.

A maintenance outage was extended because of a spill incident and RCP problems.

The first refueling outage was performed. The utility was assessed a $\$ 13,000$ fine for alleged failure to follow radiation protection procedures which caused an individual to receive an 8 rem exposure. The plant received approval to operate at $100 \%$ power.

A 27-day shut down was necessary to replace damaged FW pipe hangars and repair pressurizer spray valve.

The second refueling and maintenance outage was performed.

The third refueling and maintenance outage was performed.

The fourth refueling and maintenance outage was performed. The outage was extended because of LP turbine problems, repairs to FW nozzles, and work on RCP seals and charging pump isolation valve seals. NRC ordered plant staff augmentation because of proximity of plant to populated areas.

The fifth refueling and maintenance outage lasted 98 days. Major work included BIT tank replacement; turbine bearing replacement; SG ISI, tube plugging and modifications; and TMI-2 modifications.

The unit operated continuously for 259 days, a site record. On this date, the unit was forced off-line to repair a steam leak on the HP turbine exhaust line. The unit remained shut down to enter the refueling outage. 
Feb - Jul 1982

Aug 1983

Sep 1983 - Feb 1984

Jul - Aug 1984

Sep - Oct 1984

Jan - Jun 1985

Sep 1985

Sep 1986 - Mar 1987

Jun 1987

Feb - May 1988

Oct 1988

Feb 1989

Sep 1989 - Jan 1990

Nov 1989

Jan 1990

Mar - Jun 1990

Mar 1990

Jun 1990
The sixth refueling and maintenance outage was performed. Damage from a loose nozzle cover was found in one SG. The utility was assessed a $\$ 100,000$ fine for overexposure of a shift engineer. The outage was extended because of SG and RCS "loose parts" repairs, RCP motor failure, and SI pump shaft failure.

The utility paid a $\$ 10,000$ fine for alleged failure to control access by unauthorized persons. An additional $\$ 40,000$ fine was proposed by $\mathrm{NRC}$ for allowing a contractor employee unescorted access through vital plant areas.

The seventh refueling and maintenance outage was performed and was extended because of reactor coolant leak problems at the seal table.

The NRC ordered unit shut down because the 1983 containment ILRT was found to be faulty. A new test had to be performed.

SG tube leak required 25 days outage for repair.

The eighth refueling and maintenance outage lasted 139 days.

The utility announced that stack monitors were to be installed to meet new state requirements; the cost reported to be $\$ 1.7$ million.

The ninth refueling and maintenance outage lasted 183 days. Major work included SG inspection and main generator seal replacement. Startup was hampered by problems with DGs and main turbine lube oil system. Generator vibration problems caused an additional 10 days of outage.

The utility paid a $\$ 100,000$ fine to NRC for alleged violation of requirements involving testing check valves at both Zion 1 and 2 .

The tenth refueling and maintenance outage lasted 69 days. Major work included RHR pump and valve maintenance and SG sleeving and plugging.

The NRC proposed a $\$ 50,000$ fine for alleged design deficiencies in a control room ventilation system. The unit was down for 10 days to correct deficiencies in pump start logic under LOSP conditions.

The unit was shut down for 25 days to replace heater drain tank rupture disk and repair SG leaks.

The eleventh refueling and maintenance outage lasted 131 days. Major work included SG inspection and sleeving, SG girth weld repair and auxiliary FW system valve modifications. Restart was hampered by RCS leakage and auxiliary FW pump and valve problems.

NRC proposed a $\$ 75,000$ fine for alleged failure to maintain barriers to prevent entry to a vital building.

$\mathrm{NRC}$ proposed a $\$ 100,000$ fine for alleged deficiencies in the DG ventilation system and for failing to properly evaluate a change to the system.

A total outage time of 106 days was attributed to DG inoperability and MSIV stroke time problems.

The NRC assessed a $\$ 50,000$ fine for alleged lack of management oversight of the licensed operator training program.

An NRC Diagnostic Evaluation Team found deficiencies in the MOV testing program and other operational areas. 
Nov 1990

Dec 1990 - May 1991

Jan 1991

Nov 1991 - Jan 1992

Feb - Aug 1992

Mar 1992

Mar 1992

Sep 1992

Oct 1993 - Apr 1994

Apr - Jun 1994

Jul 1994

Nov 1994

Sep - Nov 1995

Feb - Mar 1996

Mar 1996

Mar 1996

Apr 1996

Aug 1996

Aug - Sep 1996
The unit was shut down for 6 days when two DGs were inoperable and to repair a leak in an SI accumulator check valve.

The unit entered an unplanned outage to repair a RHR valve leak. An RCP bearing failed on startup, extending the outage into 1991. March restart was delayed by investigation of a FP system unplanned actuation in Unit 2. The outage was further extended to modify DGs and auxiliary transformers. The 5-month outage ended May 14, 1991.

The plant was placed on the NRC problem plant list due to deficiencies in corporate management, engineering support, teamwork, staffing, financial commitment, and safety controls.

Power was reduced to $50 \%$ for 10 days due to a hydrogen leak; the unit then shut down to repair the leak. The outage was extended to repair several valves and a SG manway leak. Total outage time was 36 days.

The twelfth refueling and maintenance outage lasted 170 days. Major work included an ILRT, SG ECT and sludge lancing, and AFW MOV and boric acid concentration modifications. The outage was extended to repair DGs, replace two RCP seals, and Conoseal ${ }^{\otimes}$ repairs.

The plant was removed from the NRC problem plant list.

Improved plant performance was reported in a SALP report which awarded two areas a Category 1 rating and no Category 3 ratings.

A 13-day outage was necessary to restore AFW operability due to debris in the system.

A refueling and maintenance outage lasted 164 days. During this period, both units were shut down to upgrade the service water and component cooling systems.

The unit was shut down due to a main generator/reactor trip. A fire occurred at the main generator bus duct, and repairs required 72 days to complete.

Another main generator trip occurred along with a fire under the bus ducts. Repairs took 2 weeks to complete.

The plant shut down for 9 days to repair a ground on the main generator.

A refueling and maintenance outage lasted 100 days.

The unit was shut down for 27 days due to loose parts in a steam generator.

A 5-day outage was initiated by a reactor scram on high SG level.

The NRC proposed and the licensee paid a $\$ 50,000$ fine for failure to replace emergency lighting batteries.

The unit scrammed because of false signals in one of the RCS loop's flow instruments due to gas entrapment. The unit was shut down for 10 days.

The NRC proposed and the licensee paid a $\$ 50,000$ fine for multiple procedure violations by operations personnel.

The unit was shut down for 22 days to repair a PORV block valve. 


\section{NUCLEAR POWER PLANT OPERATING EXPERIENCE SUMMARY}

Unit data summary through December 1996

Unit: ZION 2

Location: LAKE COUNTY, ILLINOIS

Nameplate Rating: 1085 MWe

Owner: COMMONWEALTH EDISON CO.

MDC Net MWe: 1040 MWe

Type: WESTINGHOUSE PWR

Cumul. Avail. Factor: 69.2

Construction Permit: 12/26/68

Cumul. Cap. Factor (MDC Net): 61.1

Operating License: $11 / 14 / 73$

Cumul. Forced Outage Rate: 13.2

Commercial Oper. Date: 9/17/74

3-Year Avg. Cap. Factor (MDC Net): 64.6

License Expiration: 2008

OPERATING HISTORY (To December 1996)

Date

May 1973

Apr 1974

Oct 1974

Nov - Dec 1974

Feb - Apr 1975

Aug - Sep 1975

Jan - Feb 1976

Apr - May 1976

Jun 1976

Sep - Oct 1976

Jan - Mar 1977

Feb - Apr 1978

Mar - Apr 1979

Oct 1979 - Jan 1980

May - Jul 1980
Comment

A 1-day shutdown was caused by generator failure due to overheating.

A 4-month outage was caused by phase-to-phase fault in the main generator. The main steam line check valves were replaced during outage.

A scheduled turbine trip and an unplanned reactor coolant pump trip caused a 17-day outage.

Power ascension testing was completed, but power was limited to $85 \%$ because of a fuel densification issue. The unit was shut down for 16 days to convert to all-volatile secondary water chemistry treatment. An additional 10 days of outage time, extending into 1975, was attributed to repair of $\mathrm{FW}$ regulating valve.

Almost 29 days of outage time was caused by repairs of recurring condenser tube leaks.

A 23-day outage was performed for repair of RCS components.

A 1-month outage was required for SG tube inspection and RCP repair.

A 5-week outage was necessary to repair turbine bearings.

The plant received approval to operate at $100 \%$ power. The unit was shut down for 10 days to repair RCP seals.

Operator error in switching caused loss of DC power and a DG fire due to overload.

The first refueling and maintenance outage was performed.

The second refueling and maintenance outage was performed.

The third refueling and maintenance outage was performed.

The unit was shut down in response to an NRC request to inspect FW nozzles. The NRC ordered plant staff augmentation because of the proximity of the plant to populated areas.

The fourth refueling and maintenance outage was performed. Major work included LP turbine spindle replacement, SG snubber modification, and seismic rework. 
Sep - Dec 1981

Feb - Mar 1982

Sep - Oct 1982

Feb - May 1983

Mar - Jul 1984

Sep 1985 - Feb 1986

Dec 1986

Mar - Aug 1987

Aug 1988

Oct - Dec 1988

Jan - Feb 1989

Mar - Aug 1990

Sep.- Oct 1990

Jan 1991

Mar - Jun 1991

Sep - Nov 1991

Apr - Jun 1991

Nov 1992 - Jan 1993

Oct 1993 - Apr 1994

Jan - Apr 1995

Jan 1996
The fifth refueling and maintenance outage was performed. The outage was entered early because of a trip from SG low-low level caused by steam dump valves not working properly. Generator $\mathrm{H}_{2}$ cooler leaks caused problems at startup.

A repair outage of 43 days was caused by turbine vibration problems.

A LP turbine blade failure caused a 40-day outage. A rod withdrawal failure and subsequent replacement of gripper coils added 11 days to outage.

The sixth refueling and maintenance outage was performed. A broken RTD manifold valve required an additional 16 days to repair.

The seventh refueling and maintenance outage was performed. The outage was extended for CFCU leaks and EQ modifications.

The eighth refueling and maintenance outage lasted 152 days. The utility announced that stack monitors were to be installed to meet new state requirements.

The unit completed the year as one of the top 10 lowest cost power producers.

The ninth refueling and maintenance outage lasted 135 days. Major work included station battery replacement, SG inspection, and RCP motor overhaul. CRD split pins were also replaced.

Unit 2 became the first U.S. nuclear power plant to generate 80 million MWh of electricity.

The tenth refueling and maintenance outage lasted 76 days.

A total of nineteen days of outage time was performed because of SG leakage and spray valve packing leakage.

The eleventh refueling and maintenance outage lasted 181 days. Major outage work included auxiliary FW piping rerouting, BIT removal, and SG inspection and tube sleeving. The outage was entered 20 days early due to one DG inoperable.

The unit was shut down due to a condenser tube failure. During startup, following the outage, a main transformer exploded and burned. Total outage time was 47 days.

The unit was shut down for 7 days when the SI pumps were declared inoperable due to low recirculation flow.

The unit experienced a trip and LOSP when the system auxiliary transformer experienced an inadvertent fire protection deluge actuation. The outage work included SAT and DG maintenance and lasted 82 days.

The unit had a 46-day scheduled surveillance outage.

The unit was shut down to replace the system auxiliary transformer. The outage was extended 77 days to repair two DGs.

The twelfth refueling and maintenance outage lasted $\mathbf{5 0}$ days. Major work included an ILRT, AFW MOV replacement, boric injection tank removal, and boric acid system modifications.

During this period, both units were shut down to upgrade the service water and component cooling systems. Unit 2 was shut down for 193 days.

The thirteenth refueling and maintenance outage lasted 103 days.

The plant was shut down for 19 days to repair condenser tubes. 
ZION 2 (Cont'd)

Sep 1996 - Present

The fourteenth refueling and maintenance outage is underway. 